SPECIAL ISSUE

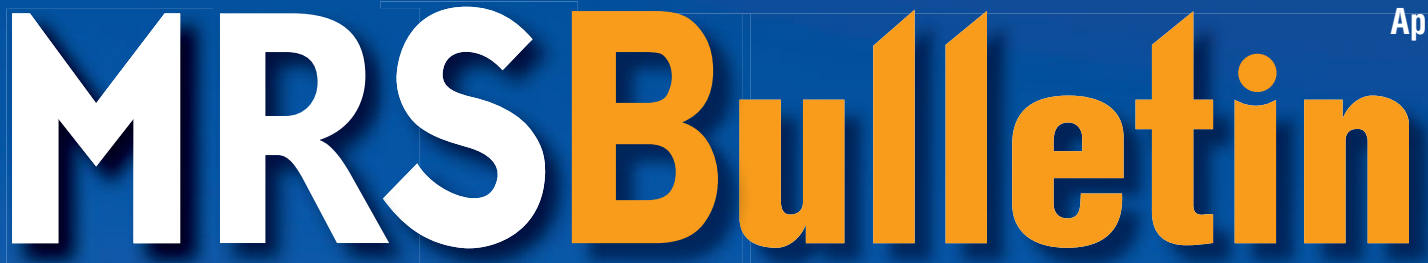

April 2012 Vol. 37 No. 4

www.mrs.org/bulletin

MRS MATERIALS RESEARCH SOCIETY

\title{
Materials for sustainable development
}

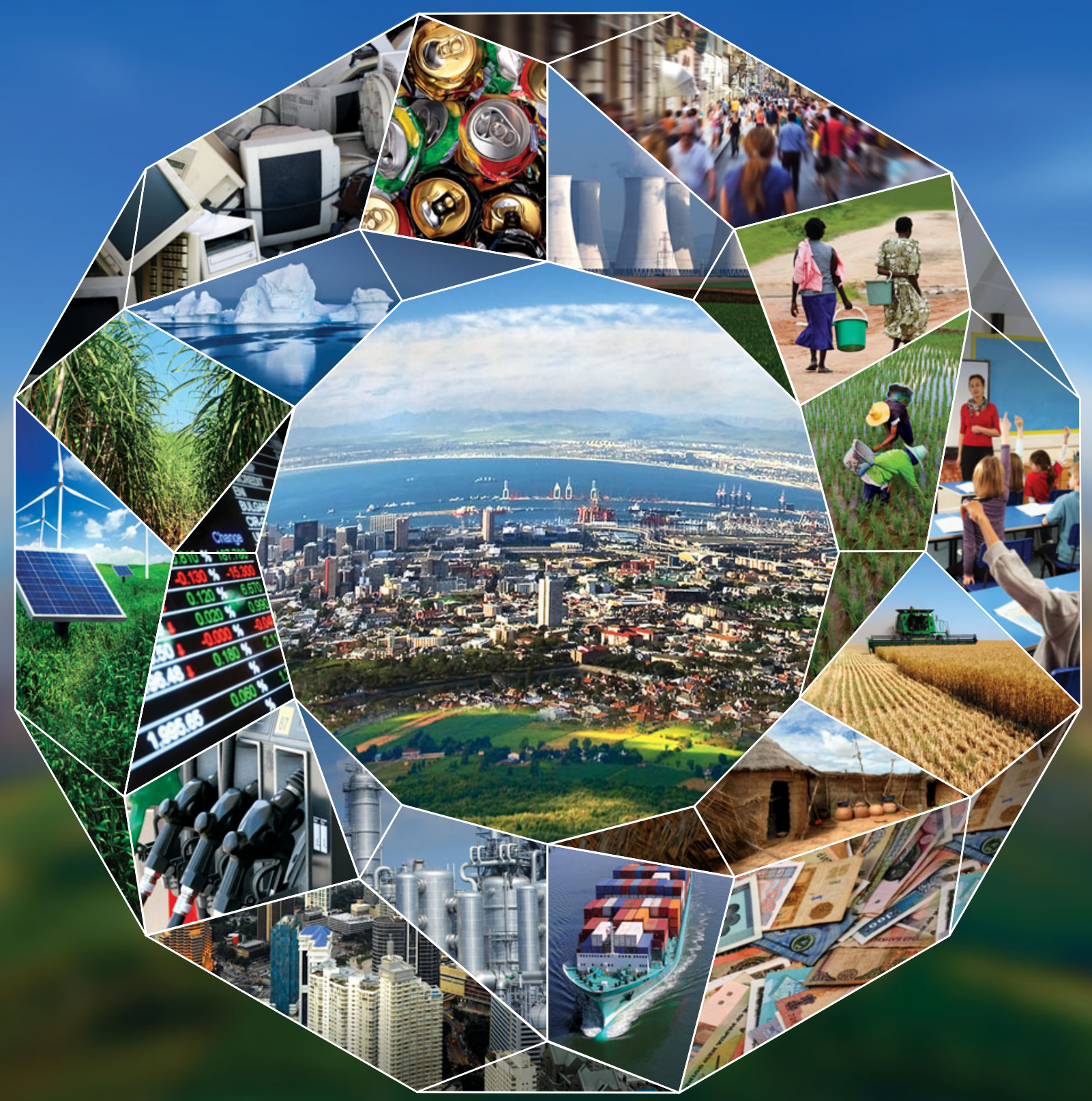

CAMBRIDGE 


\section{CUSTOMIZED PRODUCTION ION IMPLANTERS}

Beam energies from $10 \mathrm{keV}$ up to several $10 \mathrm{~s}$ of MeV

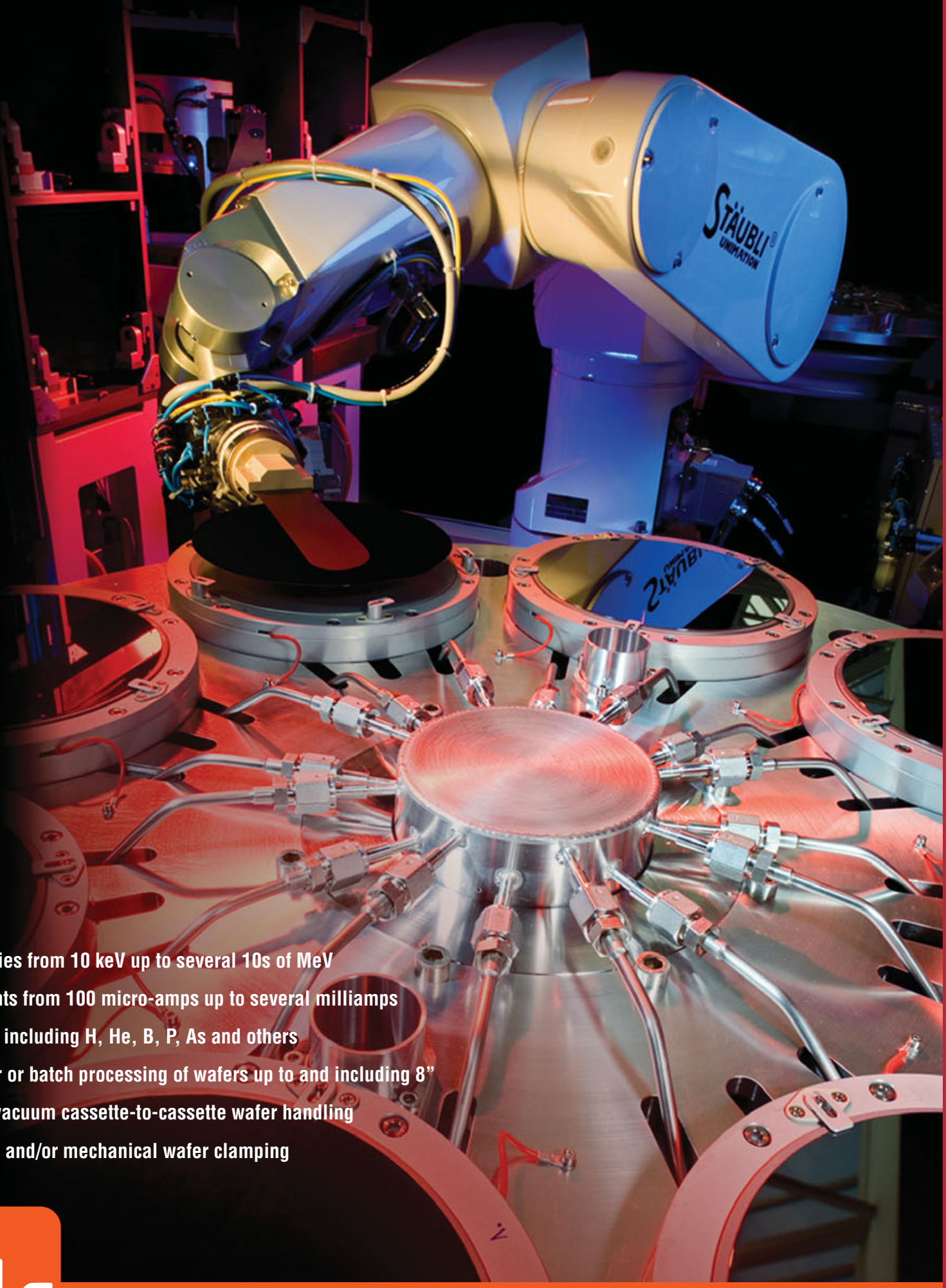

- Beam currents from 100 micro-amps up to several milliamps

- Ion species, including H, He, B, P, As and others

- Single wafer or batch processing of wafers up to and including 8"

- In-air or in-vacuum cassette-to-cassette wafer handling

- Electrostatic and/or mechanical wafer clamping

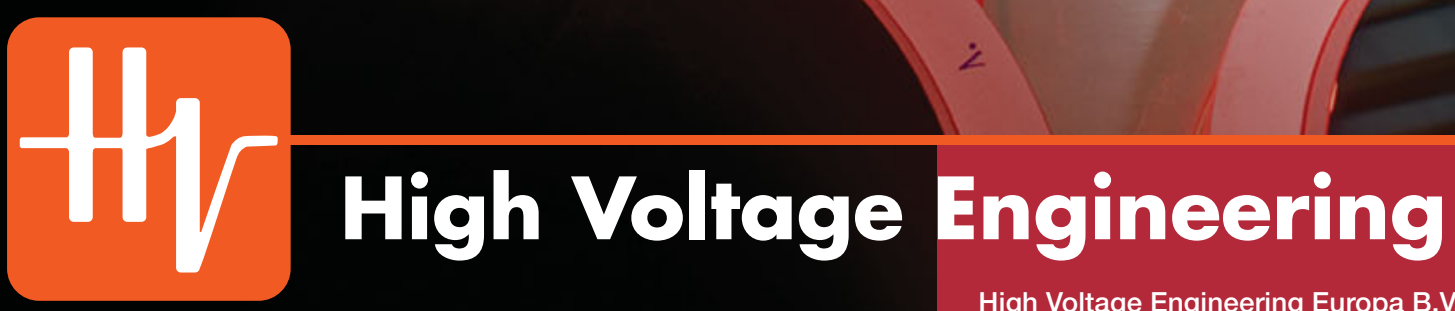

High Voltage Engineering Europa B.V.

P.O. Box 99, 3800 AB Amersfoort, The Netherlands

Tel: $31334619741 \cdot$ info@highvolteng.com

www.highvolteng.com 


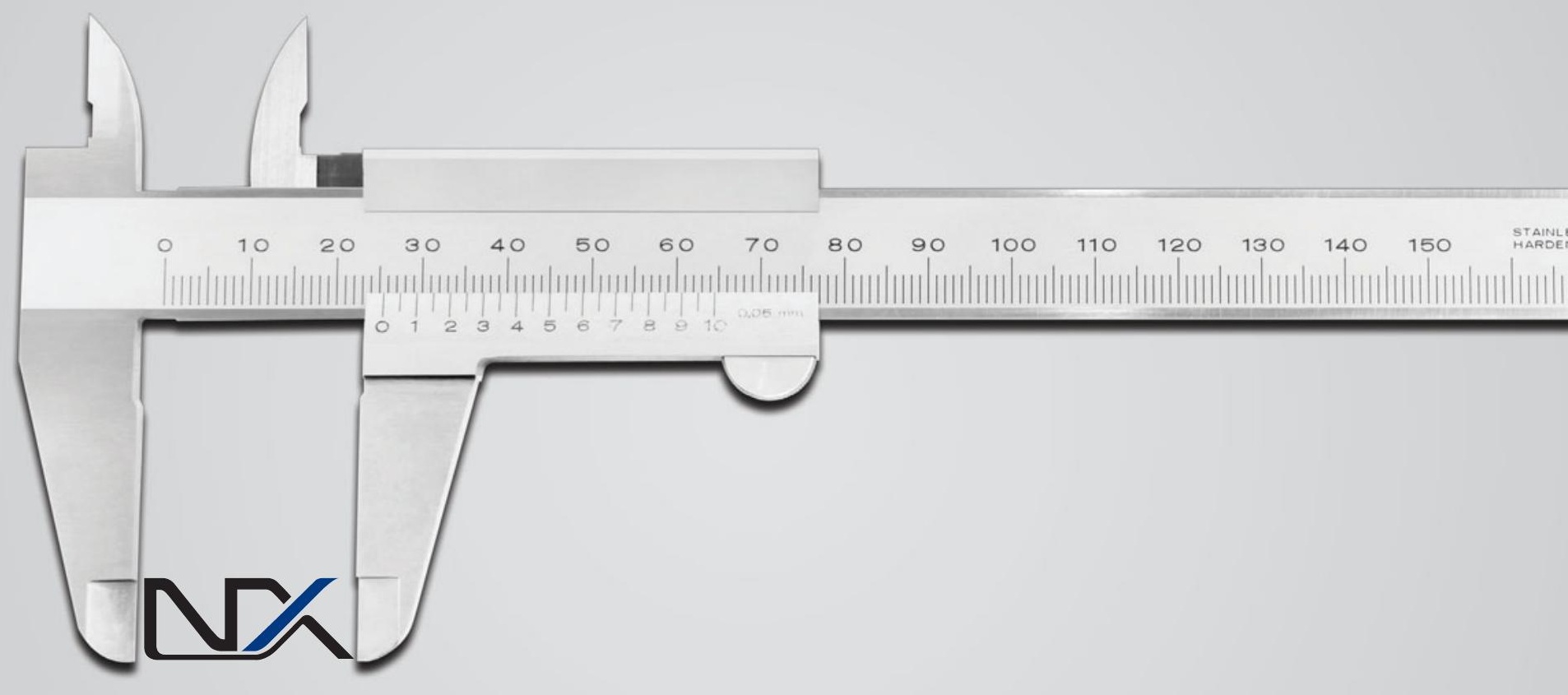

\section{The World's Most}

\section{Accurate AFM}

Data accuracy is of paramount importance to nanotechnology researchers as the credibility of their research depends upon accurate results. The NX10, the world's most accurate AFM, is the flagship AFM of Park Systems' new product line. The NX10 brings unparalleled imaging accuracy, scan speeds, and tip life to the next generation of researchers, all at an affordable price The NX platform builds on Park Systems' 28 years of technology leadership in AFM data accuracy, and its reputation as the leading nanotechnology solutions partner to research and industry.

Come and visit us at www.parkAFM.com/nx and learn about what makes the NX10 a long-awaited and game-changing product from Park Systems. The NX10 is the world's premium research-grade True Non-Contact AFM, featuring industry-leading Z-servo speed, XYZ scanner linearity, closed-loop detector noise, and minimized thermal drift. As Park Systems' most user-friendly AFM, the NX10 makes AFM convenient and intuitive for new and experienced users alike.

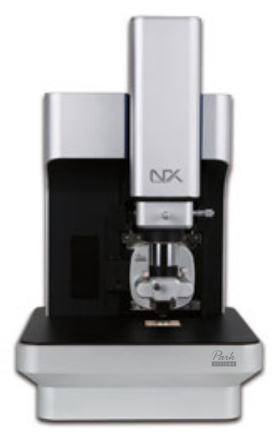




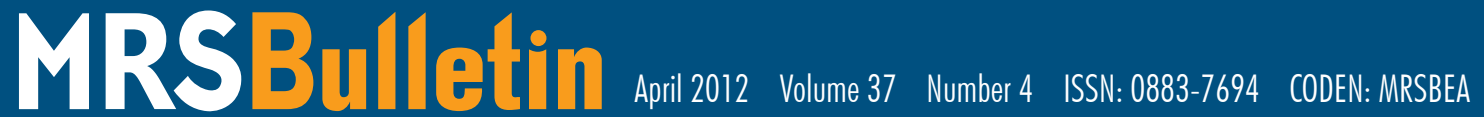
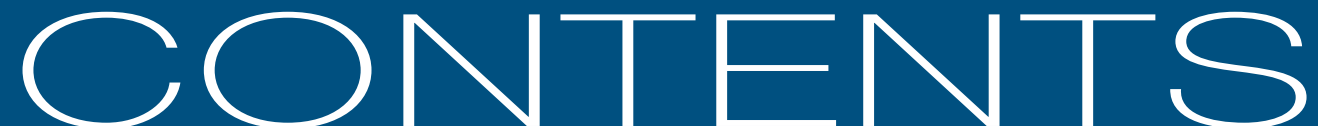

\section{LANDSCAPE}

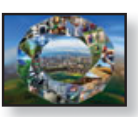

303 Introduction

Materials for sustainable development

Martin L. Green, Laura Espinal, Enrico Traversa,

and Eric J. Amis

\section{Meet Our Authors}

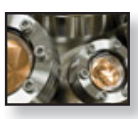

\section{Materials Opportunities}

Materials science and engineering's pivotal role in sustainable development for the 21st century

Diran Apelian

\section{MANUFACTURING}

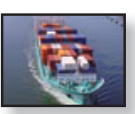

325 Materials Supply Chain

Will metal scarcity impede routine industrial use?

T.E. Graedel and Lorenz Erdmann

\section{Recycling}

To recycle, or not to recycle, that is the question: Insights from life-cycle analysis Linda Gaines

\section{Recycling}

Opportunities and limits of recycling:

A dynamic-model-based analysis

Markus Reuter and Antoinette van Schaik

\section{Metrology \& Standards}

Measurements, standards, and data in support of the sustainable use of materials

Dianne L. Poster, Michael J. Fasolka,

Richard R. Cavanagh, and Ellyn S. Beary

\section{Human Health Concerns}

Human health and ecotoxicological considerations in materials selection for sustainable product development Oladele A. Ogunseitan and Julie M. Schoenung

\section{TRANSPORTATION}

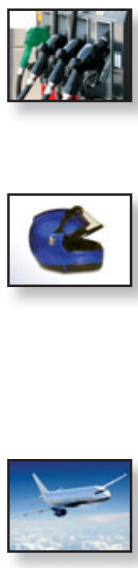

\section{Automobiles}

Materials challenges and opportunities for enhancing the sustainability of automobiles Gregory A. Keoleian and John L. Sullivan

\section{Composites}

Do fiber-reinforced polymer composites provide environmentally benign alternatives? A life-cycle-assessment-based study Joost R. Duflou, Yelin Deng, Karel Van Acker, and Wim Dewulf

\section{Aviation}

Materials for sustainable turbine engine development

Doug Konitzer, Steve Duclos, and Todd Rockstroh

\section{INFRASTRUCTURE}

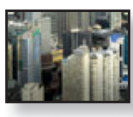

389 Construction Materials

Sustainable development and physical

infrastructure materials

Robert Heard, Chris Hendrickson, and Francis C. McMichael

\section{Construction Materials}

Set in stone? A perspective on the concrete sustainability challenge

Krystyn Van Vliet, Roland Pellenq, Markus J. Buehler, Jeffrey C. Grossman, Hamlin Jennings,

Franz-Josef UIm, and Sidney Yip

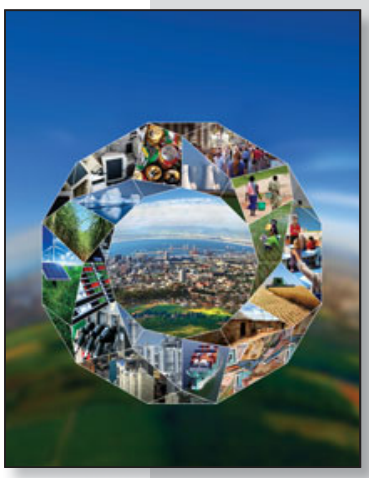
ON THE COVER

Materials for sustainable development. This issue of MRS Bulletin discusses the critical role that materials science plays in sustainable development. The cover depicts an artist's rendition of how a focused sustainable future can be achieved through the lens of materials research, as symbolized by the threefold intertwined ring of society, economy, and environment. See the expanded theme topic that begins on p. 303 


\section{ENERGY \& WATER}

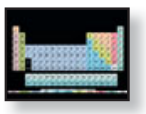

405 Critical Elements

Energy-critical elements

for sustainable development

Alan J. Hurd, Ronald L. Kelley, Roderick G. Eggert, and Min-Ha Lee

\section{Materials \& Energy}

Energy limitations on materials availability Igor Lubomirsky and David Cahen

\section{Nuclear Fission}

Is nuclear fission a sustainable source of energy?

Matthias Englert, Lindsay Krall, and Rodney C. Ewing

\section{Photovoltaics}

Sustainability metrics for extending thin-film photovoltaics to terawatt levels

Vasilis Fthenakis

\section{Carbon Mitigation}

Materials challenges in carbon-

mitigation technologies

Laura Espinal and Bryan D. Morreale

\section{Water}

The energy-water nexus: Water use trends in sustainable energy and opportunities for materials research and development Anthony Y. Ku and Andrew P. Shapiro

\section{ADVERTISERS IN THIS ISSUE}

Aldrich Materials Science 302

American Elements .. Outside back cover

Annual Reviews 332

Bruker ...................................................... 301

Bruker Nano Surfaces Division............................. 404

GlobalFoundries ................................................ 403

Goodfellow Corporation........................................ 373

High Voltage Engineering .............. Inside front cover Hysitron, Inc. ................................................... 388

International Centre .............................................. 448

for Diffraction Data (ICDD)

J.A. Woollam Company, Inc. .................................. 364

Janis Research Company, Inc. ............................... 387

JEOL USA, Inc. ......................................... 317

Kurt J. Lesker Company ......................................... 324

Lake Shore Cryotronics, Inc. ............................. 363

MMR Technologies, Inc. ..................................... 331

National Electrostatics Corp. ............................... 355

Park Systems, Inc. ............................................ 297

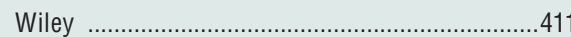

\section{Education}

Teaching sustainable development in materials science and engineering

R. LeSar, K.C. Chen, and D. Apelian

\section{CAREER CENTRAL}




\section{About the Materials Research Society}

The Materials Research Society (MRS), a not-for-profit scientific association founded in 1973, promotes interdisciplinary goal-oriented basic research on materials of technological importance. Membership in the Society includes almost 16,000 scientists, engineers, and research managers from industrial, government, and university research laboratories in the United States and over 80 countries.

The Society's interdisciplinary approach differs from that of single-discipline professional societies because it promotes information exchange across the many technical fields touching materials development. MRS sponsors three major international annual meetings encompassing approximately 125 topical symposia, and also sponsors numerous single-topic scientific meetings. The Society recognizes professional and technical excellence and fosters technical interaction in local geographic regions through Sections and University Chapters.

MRS participates in the international arena of materials research through the International Union of Materials Research Societies (IUMRS). MRS is a member of the Alliance for Science \& Technology Research in America and is an affiliate of the American Institute of Physics.

MRS publishes The MRS Online Proceedings Library, MRS Bulletin, Journal of Materials Research, MRS Communications, and other publications related to current research activities.

\section{MRS BOARD OF DIRECTORS}

President Bruce M. Clemens, Stanford University, USA

Immediate Past President James J. De Yoreo, Lawrence Berkeley Nationa Laboratory, USA

Vice President and President-Elect Orlando Auciello, Argonne Nationa Laboratory, USA

Secretary Sean J. Hearne, Sandia National Laboratories, USA

Treasurer Michael R. Fitzsimmons, Los Alamos National Laboratory, USA

Executive Director Todd M. Osman, Materials Research Society, USA

Wade Adams, Rice University, USA

Ana Claudia Arias, University of California-Berkeley, USA

Shenda Baker, Synedgen, Inc./Harvey Mudd College, USA

Tia Benson Tolle, U.S. Air Force Research Laboratory, USA

Duane B. Dimos, Sandia National Laboratories, USA

Chang-Beom Eom, University of Wisconsin-Madison, USA

Eric Garfunkel, Rutgers University, USA

J. Murray Gibson, Argonne National Laboratory, USA

Oliver Kraft, Karlsruhe Institute of Technology, Germany

Hideki Matsumura, Japan Advanced Institute of Science and Technology, Japan

Ainissa Gweneth Ramirez, Yale University, USA

Stephen K. Streiffer, Argonne National Laboratory, USA

Susan E. Trolier-McKinstry, The Pennsylvania State University, USA

Pierre Wiltzius, University of California-Santa Barbara, USA

\section{MRS OPERATING COMMITTEE CHAIRS}

Academic Affairs M. Stanley Whittingham, SUNY-Binghamton, USA Awards Julia R. Weertman, Northwestern University, USA

Government Affairs Nabil Bassim, U.S. Naval Research Laboratory, USA

Meetings Committee David S. Ginley, National Renewable Energy

$$
\text { Laboratory, USA }
$$

Membership Yves Chabal, The University of Texas at Dallas, USA

Public Outreach Aditi Risbud, Lawrence Berkeley National Laboratory, USA

Publications Paul McIntyre, Stanford University, USA

MRS OFFICE OF PUBLIC AFFAIRS

Ron Kelley, 499 South Capitol St. SW, Suite 600, Washington, DC 20003
Editor

Gopal R. Rao, rao@mrs.org

Managing Editor

Judy Meiksin, meiksin@mrs.org

Technical Editor

Lori A. Wilson, Iwilson@mrs.org

Editorial Assistants

Ben Moriarty, moriarty@mrs.org

Mary Wilmoth

Science Editor

Don Monroe

Associate Technical Editor

Erica Ellison

Art Director

Kasia M. Bruniany

Production/Design

Andrea Pekelnicky, Christopher R. Roberts,

and TNQ

Production Editor

Catherine Paduani

Science News Editor

Tim Palucka

\section{Director of Communication} Eileen Kiley Novak

Principal Development Editor Elizabeth L. Fleischer

\section{Energy Quarterly}

Steve M. Yalisove (Chair),

V.S. Arunachalam, Anshu Bharadwaj,

David Cahen, Russell R. Chianelli,

George Crabtree, Abdelilah Slaoui,

Guillermo Solórzano,

and M. Stanley Whittingham

Advertising/Sponsorship

Mary E. Kaufold, kaufold@mrs.org

Donna L. Watterson, watterson@mrs.org

Member Subscriptions

Michelle Judt, judt@mrs.org

Non-Member Subscriptions

subscriptions_newyork@cambridge.org
MATERIALS FOR SUSTAINABLE DEVELOPMENT ORGANIZING COMMITTEE

Martin L. Green (Chair), National Institute of Standards and Technology, USA

Eric J. Amis, United Technologies Research Center, USA

Joseph J. Berry, National Renewable Energy Laboratory, USA

David Cahen, Weizmann Institute of Science, Israel

Laura Espinal, National Institute of Standards and Technology, USA

Rodney C. Ewing, University of Michigan, USA

Thomas E. Graedel, Yale University, USA

Igor Lubomirsky, Weizmann Institute of Science, Israe

Christina Meskers, Umicore Precious Metal Refining, Belgium

Enrico Traversa, Xi'an Jiaotong University, China; University of Rome, Italy

\section{EDITORIAL BOARD}

Paul S. Drzaic (Chair), Apple, Inc., USA

V.S. Arunachalam, Center for Study of Science, Technology \& Policy, India

Marie-Isabelle Baraton, University of Limoges, France

Robert C. Cammarata, Johns Hopkins University, USA

Laura Fornaro, University of Uruguay, Uruguay

Hanns-Ulrich Habermeier, Max Planck Institute for Solid State Research, Germany

Fiona C. Meldrum, University of Leeds, UK

Amit Misra, Los Alamos National Laboratory, USA

Julie A. Nucci, Cornell University, USA

Linda J. Olafsen, Baylor University, USA

David N. Seidman, Northwestern University, USA

Carol Trager-Cowan, University of Strathclyde, UK

Julia R. Weertman, Northwestern University, USA

Eric Werwa, Washington, DC, USA

Steve M. Yalisove, University of Michigan, USA

\section{VOLUME ORGANIZERS}

2013 Mark T. Lusk, Colorado School of Mines, USA

Eva Olsson, Chalmers University of Technology, Sweden

Birgit Schwenzer, Pacific Northwest National Laboratory, USA

James W. Stasiak, Hewlett-Packard Co., USA

2012 Lei Jiang, Chinese Academy of Sciences, China Sergei V. Kalinin, Oak Ridge National Laboratory, USA

Stéphanie P. Lacour, EPFL, Switzerland

Steven C. Moss, Aerospace Corporation, USA

2011 Kyoung-Shin Choi, Purdue University, USA Reuben T. Collins, Colorado School of Mines, USA Sean E. Shaheen, University of Denver, USA

MRS Bulletin (ISSN: 0883-7694, print; ISSN 1938-1425, online) is published 12 times a year by the Materials Research Society, 506 Keystone Drive, Warrendale, PA 15086-7573. Copyright $\odot$ 2012, Materials Research Society. Permission required to reproduce content. Periodical postage paid at New York, NY, and at additional mailing offices. POSTMASTER: Sen address changes to MRS Bulletin in care of the Journals Department, Cambridge University Press, 100 Brook Hill Drive, West Nyack, NY 10994-2113, USA. Printed in the U.S.A

Membership in MRS is $\$ 115$ annually for regular members, $\$ 30$ for students. Dues include an allocation of $\$ 29$ ( $\$ 17$ for students) to a subscription to MRS Bulletin. Individual member subscriptions are for personal use only. Non-member subscription rates are $\$ 363$ for one calendar year (12 issues) within North America and $\$ 436$ elsewhere. Requests from subscribers for missing journal issues will be honored without charge only if received within six months of the issue's actual date of publication.

MRS Bulletin is included in Current Contents ${ }^{\circledast / E n g i n e e r i n g, ~ C o m p u t i n g, ~ a n d ~ T e c h n o l o g y ; ~ C u r r e n t ~ C o n t e n t s ~} \circledast /$ Physical, Chemical, and Earth Sciences, the SciSearch $\circledast$ online data-

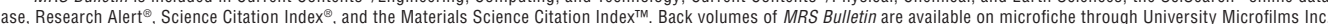
300 North Zeeb Road, Ann Arbor, MI 48106, USA. 


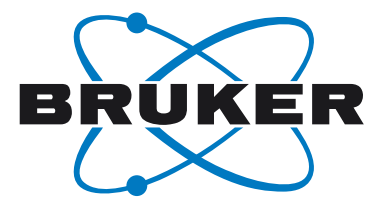

\section{When speed, accuracy $\&$ intensity count the most.}
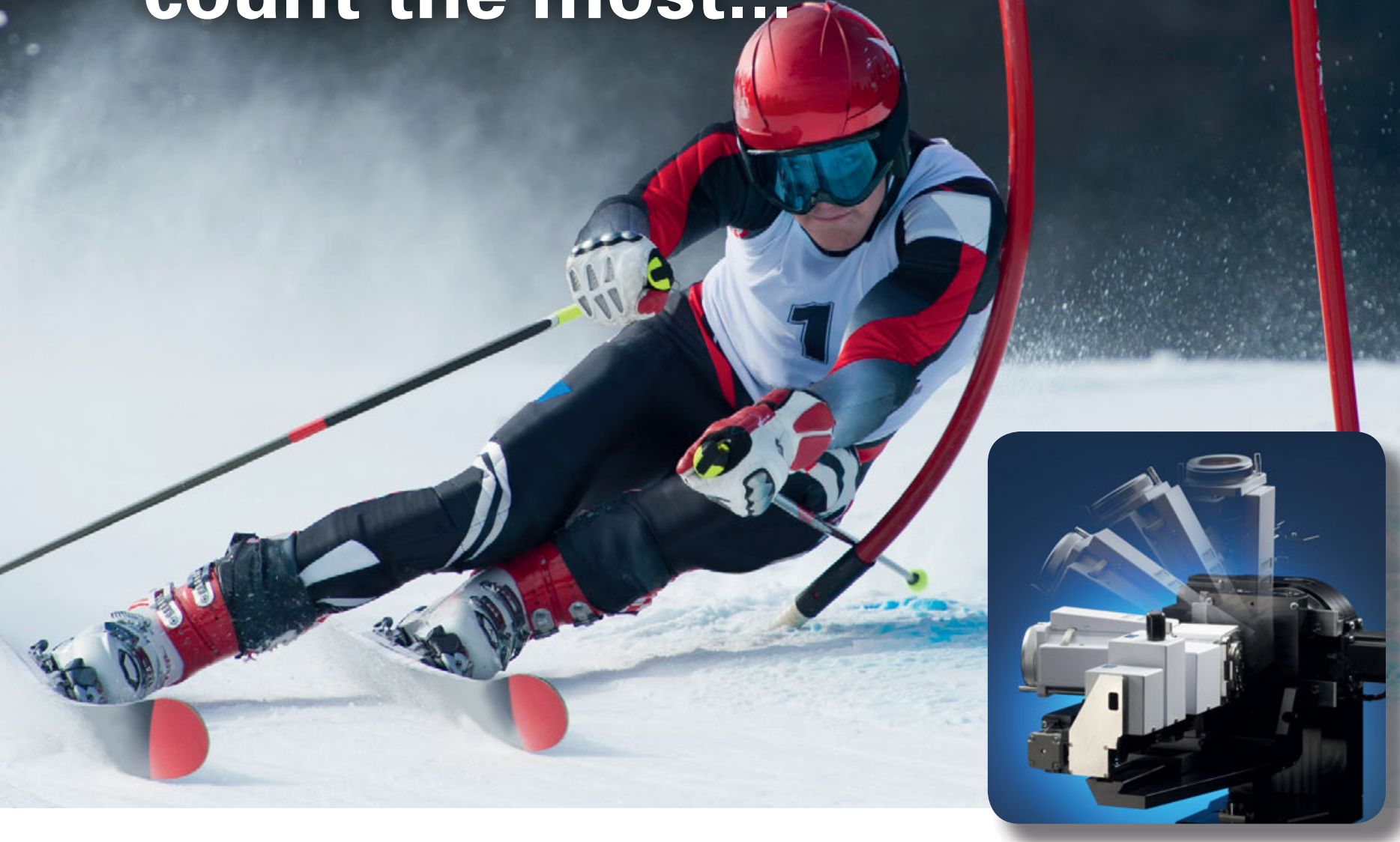

\section{D8 DISCOVER with DAVINCI ULTRA GID: The ultimate thin film characterization system.}

In-plane characterization of ultra-thin films is as fast as pushing a button using the D8 DISCOVER with DAVINCI and ULTRA GID. In-plane grazing incidence diffraction (IP-GID) is a highly surface sensitive scattering technique in which the scattering vector is kept in the plane of the film. The ULTRA GID configuration allows IP-GID while using the full line-focus beam, which results in scattering intensity that can be 100 times higher than traditional laboratory setups. ULTRA GID means push-button, motorized switching of the primary beam orientation between parallel and perpendicular to the scattering plane which gives access to the full range of thin film XRD applications without losing goniometer accuracy.

Contact us for more details and a system demonstration! www.bruker.com/d8discover 



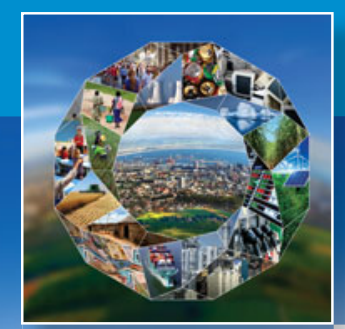

\title{
Materials for sustainable development
}

\author{
Martin L. Green, Laura Espinal, Enrico Traversa, and Eric J. Amis \\ Many technologies in the materials, manufacturing, energy, and water sectors that currently \\ provide important benefits to humanity cannot continue indefinitely and must be directed \\ toward a more sustainable path. In this article, we introduce the concept of sustainable \\ development, discuss the critical roles that materials science plays in this field, and \\ summarize the contents of the articles in this special issue of MRS Bulletin.
}

A society grows great when old men plant trees whose shade they know they shall never sit in.

-Greek proverb

This maxim demonstrates that sustainable development is not a new concept, at least according to its most popular definition: "Sustainable development is development that meets the needs of the present without compromising the ability of future generations to meet their own needs" (from the so-called Brundtland Commission Report, published in 1987). *,1 Why then has sustainable development come so much to the fore in the

\footnotetext{
* In speaking of "sustainable development," the Brundtland report referred to sustainable economic development. In this issue, we take a much broader view of sustainable development, including a range of activities that reflect the spirit of this famous pronouncement. Further, we understand the noun "sustainability" to be the asymptotically approachable, but ultimately unachievable, result of continual sustainable development. More on the Brundtland definition: It does not define sustainable development scientifically and requires that we know, or at least accurately estimate, what the needs of future generations will be. Had our Paleolithic ancestors taken Brundtland to heart, they might have carefully monitored their use of obsidian and flint and stockpiled such stones for future generations. Of course, the Stone Age did not end because humans ran out of stones, but because they found a better substitute, as our species always has.
}

past few decades? Perhaps it is the new buzzword due to growing concerns about the scale of the human impact on the planet. Indeed, the dramatic increases in global population that have occurred ever since the Industrial Revolution are expected to continue, and through the burning of fossil fuels to support the energy needs of this growing population, humankind has liberated a quantity of carbon (as carbon dioxide) in the past two hundred and fifty years that it took our planet about two hundred and fifty million years to sequester. That factor of a million - the price humankind unwittingly paid for the massive industrialization that enabled the advanced civilization many of us now enjoy — has shifted Earth's biosphere to a new equilibrium.

Every human endeavor is affected by the ramifications of sustainable development, because none of our material resources are infinite and only a few sources of energy (solar, wind, hydro, tidal, and geothermal) are sustainable. Sustainable development is a huge field that captures the concepts of environmental stewardship, materials management, green manufacturing, renewable and clean energy technologies, and water and air management under one tent. It is the process by which policies for continual improvements of the economy, environment, and society (the "triple bottom line"2) are guided by scientific analysis. The threefold nature of sustainable development is illustrated in Figure 1. Because the three components of the triple bottom line overlap, it is the nature of sustainable 


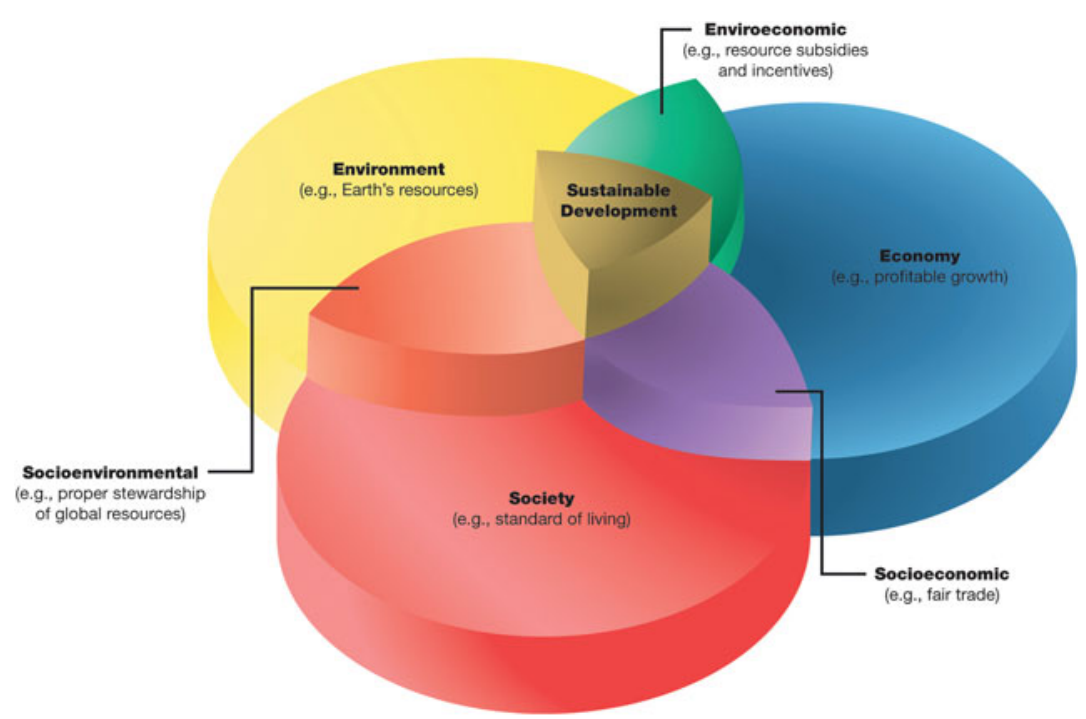

Figure 1. Sustainable development's "triple bottom line," which includes social, economic, and environmental aspects. Sustainable development exists when all three overlap.

development issues to be highly interconnected. Often, a benefit to one part of the bottom line is a deficit to another; a typical example is the marketing of fresh out-of-season produce. ${ }^{3}$ (See the sidebar for another perspective on the triple bottom line.) Sustainable development is thus ideally implemented through the development of scientific tools for full life-cycle assessment (measurements, standards, models, and data). Only quantitative analysis can determine whether the introduction of a change in a product or process represents a sustainable development.
It is important to view sustainable development as a process, a global kaizen (Japanese concept of the process of continuous improvement). Thus, although mentioning clean-coal technology in the context of sustainable development might seem contradictory, the process of reducing the environmental effects of burning fossil fuels, on which society will depend for at least the near future, while developing alternative sustainable energy sources to gradually replace them is bona fide sustainable development.

This special issue of MRS Bulletin explores the intersection of sustainable development and materials science. Materials have always been technology enablers; there would be no information age without silicon, no mobile phones without functional ceramics, no commercial aviation industry without high-strength aluminum alloys, and no skyscrapers without steel girders. Materials will continue to play the same role in sustainable development. Would it be possible to take advantage of the direct conversion of solar power to electricity if photovoltaic materials did not exist and were not efficient and manufacturable? In fact, sustainable development will not be possible without the full involvement of the materials community. This special issue of MRS Bulletin thus provides a materials-centric view of sustainable development, highlighting those areas in which materials science is expected to play a major role. Such areas include manufacturing of materials and products, transportation, infrastructure, energy and water resources, and education.

\section{The Kaya Identity}

One interesting way to look at the triple bottom line of sustainable development is through the Kaya identity. ${ }^{12,13}$ The Kaya analysis is a particularly apt framework for discussing sustainable development, as it is based on carbon dioxide emissions, a convenient figure of merit of human activity. ${ }^{\dagger}$ The Kaya identity is expressed as

$$
F=P\left(\frac{G}{P}\right)\left(\frac{E}{G}\right)\left(\frac{F}{E}\right)
$$

where $F$ is global carbon dioxide emissions, $P$ is global population, $G$ is the sum of global gross domestic products, and $E$ is global energy usage. Thus, $G / P$ is the global gross domestic product per capita, which can be thought of as "economic development or standard of living" and exists in the socioeconomic region of Figure $1 ; E / G$ is the energy intensity of the global gross domestic product, which can be thought of as "energy and resource efficiency" and exists in the enviroeconomic region of Figure $1 ; F / E$ is the carbon intensity of the global energy, which can be thought of as "sophistication of energy production" and exists in the socioenvironmental region of Figure 1. The Kaya analysis indicates that, to sustainably develop energy resources (i.e., lower carbon dioxide emissions), one can minimize $P$ (this is a political and social issue, outside the realm of science and technology) or reduce $G / P$ (this means a reversal of economic growth, which is anathema to the concept of sustainability). Therefore, the only paths forward are to reduce $E / G$ through demand reduction or to reduce $F / E$ through energy supply substitution.

† You can have lots of fun with the Kaya equation at www.wired.com/wired/st_formula.html. 
The links between sustainable development and materials are so obvious and basic that, paradoxically, they are often invisible to the users of advanced technologies. As technology enablers, materials are often in the background and are not perceived by end users as critical. When driving a modern automobile, for example, the owner enjoys its improved fuel economy but is often oblivious to the materials technologies (lightweight composites and alloys, electronic controls, high-density batteries, and so on) that made that improvement possible. Figure 2 shows some examples of such materials applications for sustainable development. This special issue is intended to bring the critical role of materials in sustainable development to the forefront, so that technologists, policy planners, and captains of industry can use this knowledge to define and plan the future roles of advanced materials in the sustainable-development arena.

Materials researchers

It is important to view sustainable development as a process, a global kaizen. and engineers have myriad opportunities to incorporate sustainable development into their work, and many already have. The immediate and direct connections between sustainable development and materials science include efficient use of materials (conservation, substitution, reuse, repurposing, recycling), materials life-cycle assessment (LCA) (see Figure 3), replacement materials (scarcity, resource availability, materials economics), energy (materials to support alternative energy technologies, to mitigate problems with fossil-fuel technologies, and to increase energy efficiency), mitigation of undesirable environmental impacts from technology and economic growth (corrosion, pollution, toxic waste), and water purification. Readers of this issue will no doubt find more topics to add to this list. Future MRS Bulletin issues and articles are anticipated to continue to address the individual topics represented in this issue, such as recycling or LCA methodology. This special issue follows an earlier one that dealt entirely with energy and energy-related materials. ${ }^{4}$

While putting this special issue together, we were struck by the fact that many of our contributors are not part of the materials community at large and do not typically attend the conferences that serve the materials community. Some are working at the periphery of the materials community as, for example, industrial ecologists and economists. ${ }^{5-7}$ Only when such experts and their outstanding work are integrated into the materials community, through enhanced collaboration, will this community be able to fully realize its role in sustainable development.

The greatest challenge to sustainable development might well be that of changing human behavior. Technology alone will not be the answer; governments, policy makers, and technologists will have to develop national and global policies, as discussed by Apelian in the first article in this issue. Further, he contrasts the closed loop of the natural ecosystem, where there is no "waste," with the open-loop nature of human society. As
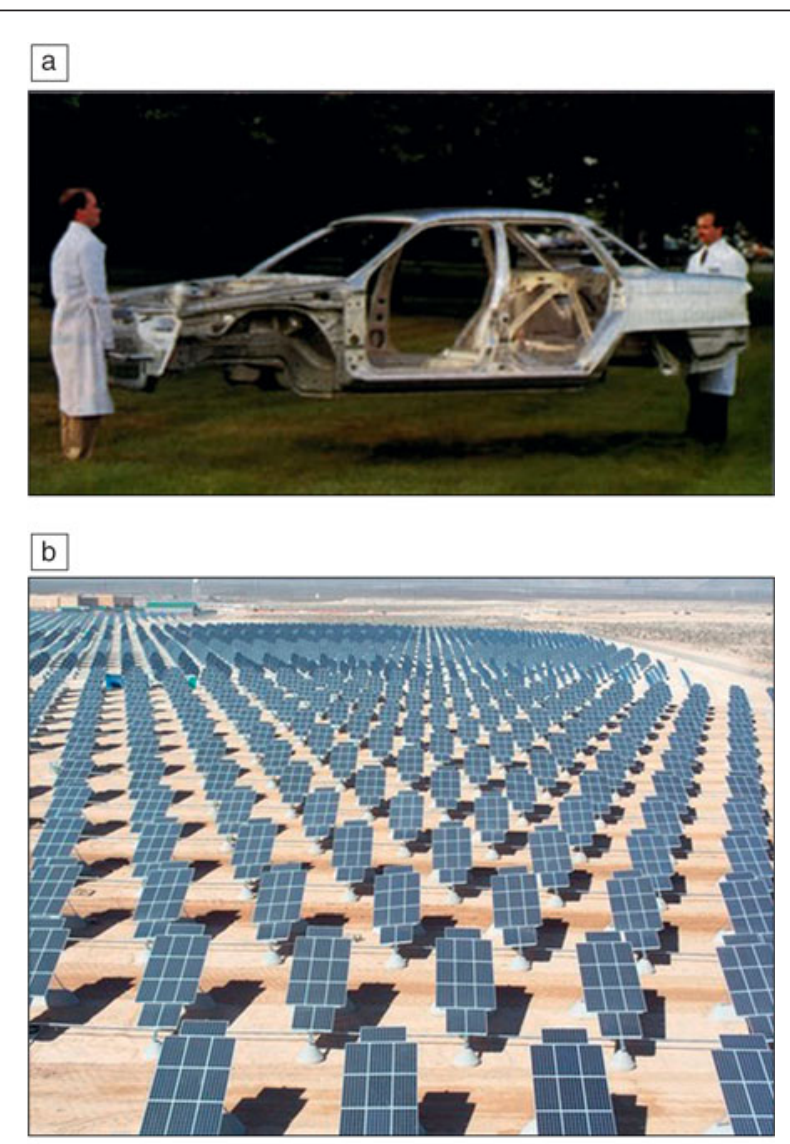

c

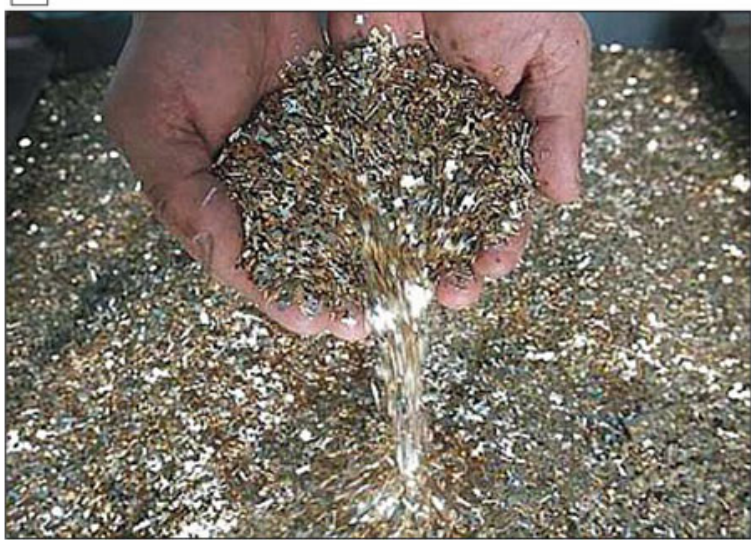

Figure 2. Sustainable developments in materials: (a) Lightweighting is an obvious strategy for all forms of transportation. (Image courtesy of the National Institute of Standards and Technology.) (b) Photovoltaic materials have the potential to be deployed on a large scale for the economical and sustainable generation of electrical power. (Image courtesy of New Energy Nexus.) (c) The recyclate stream from electronic waste, a component of "urban mining," can be richer in strategic elements than an actual mine. (Image courtesy of Star Publications.)

global population grows, the most important question might be not how many people Earth can support, but how many people Earth can support sustainably with an adequate standard of living. 


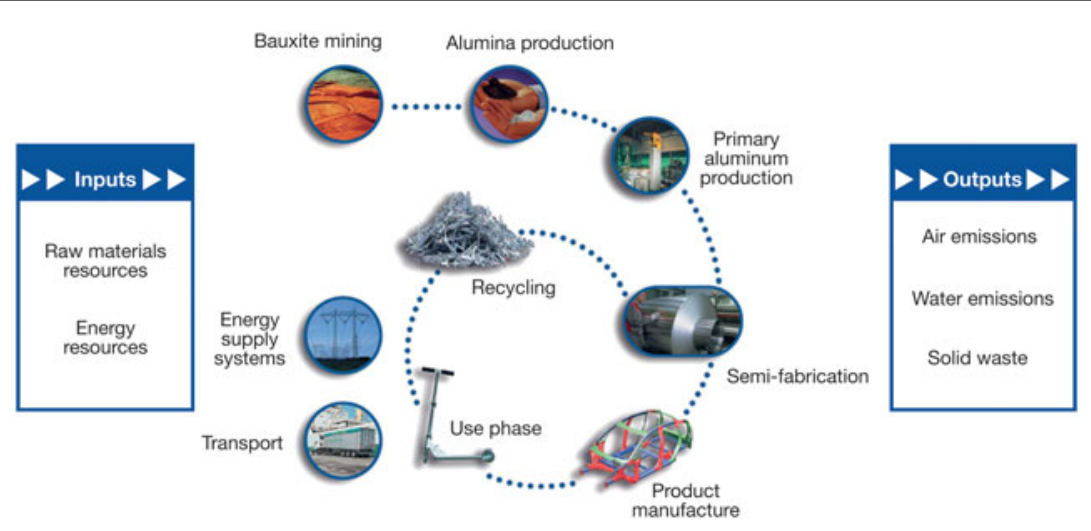

Figure 3. Life-cycle assessment methodology, as applied to aluminum products. In life-cycle assessment, all input and output energy and materials resources are taken into account for a given product or process, once its boundaries have been specified. (Image courtesy of the International Aluminium Institute.)

materials in products to be recycled, as pointed out in the article by Reuter and van Schaik. Thus, such models will incorrectly predict the recycling costs. For example, the recyclate streams will be very different for a car (large pieces of compressed metal) and a computer (fine particulates containing metals). Further, knowledge of the relative ease of "liberation" of the metals of interest in a given product can be used as feedback to design products that are more "recycle-friendly."

Industry is increasingly aware that sustainable development is not only a business opportunity but also a challenge; there is growing market demand for sustainable products, but regulatory standards can make these products difficult to develop economically. Poster et al. discuss how measurements, standards, and data can help industry meet the challenges of developing and intro-

Materials researchers now employ essentially the entire periodic table to enable the benefits of modern technology. However, reports of shortages of metals, for example, rare earths, are rife and have even been featured in the general press. Thus, as Graedel and Erdmann point out, it is reasonable to wonder about elemental resources, because material supply-chain analysis is key to sustainable manufacturing. However, supply assessment is not trivial, as data are often sparse. Graedel and Erdmann stress that materials scientists and corporate and government leaders must understand the complex issue of resource supply and create policies to deal with shortages; government-supported materials research programs for identifying substitutes for key elements is one example. Several other articles in this issue address specific materials resource issues, such as those by Konitzer et al. (turbine engine development), Hurd et al. (energy-critical elements), Englert et al. (nuclear materials), and Fthenakis (photovoltaic materials).

Whereas most grade-school students understand the value of recycling, applying a "one-size-fits-all” recycling strategy will not lead to optimal results, as discussed in the article by Gaines. If a material or product is reused, the direct environmental impact of its production might be reduced; however, the energy resources used to restore the item to a usable condition must also be taken into account. For example, recycling office paper reduces the cutting of timber but does not save fossil fuel, whereas combustion of this paper (a very clean fuel) can displace coal in power plants. Such determinations can be made using the LCA method, which is at the core of sustainable development and can assess the comprehensive carbon, material, and energy footprints of a product.

However, LCAs of durable, multimaterial goods such as batteries become much more complicated very quickly. Although many LCA models and corresponding codes exist, most do not take into account such complexities as the mechanical properties of ducing sustainable materials such as bio-based polymers and lead-free solders. An excellent example of the need for a standard is in bio-based feedstocks for the manufacture of chemicals. The polymer industry requires reliable measures of the true bio-based content in feedstocks, which can also contain petroleum-derived constituents. Because the ${ }^{14} \mathrm{C}$ content in ancient petroleum is much lower than that in feedstocks derived from recently living organisms, standards based on ${ }^{14} \mathrm{C}$ content have been developed to validate claims about bio-based products.

In the process of selecting materials for a new product design, industry has traditionally focused on cost, performance, and more recently carbon footprint. However, Ogunseitan and Schoenung point out that chemical toxicity is another important factor affecting sustainable development. Thus, they argue for a stronger integration of toxicity metrics in materials informatics databases. Without such data, product evolution can solve some problems but create others. The replacement of cathode ray tubes (CRTs) by liquid-crystal displays (LCDs) or plasma flatpanel displays (PDs) is a case in point. LCDs and PDs contain less lead than CRTs and, therefore, decrease the human-health toxicity potential. However, the presence of mercury in LCDs and copper in PDs significantly increases their ecological toxicity potentials at the end of the product lifetimes.

The transportation sector offers many opportunities for sustainable development, as the most energy-efficient means of travel depends on many factors and varies for different situations. In the United States, automobiles are predominant, although vehicle ownership is expected to expand greatly in China, India, and other developing countries in the near future. To support sustainable development of the transportation sector, automobiles must become more sustainable through lightweighting (see Figure 2a), enhanced fuel efficiency, and longer service use, and as Keoleian and Sullivan report, such trends are already underway. Ultimately, they conclude that sustainable mobility for a growing population of 7 billion people requires dramatic innovations by the materials and automotive industries, international commitments and policies for addressing 
greenhouse-gas emissions, and a more informed consumer base that understands basic sustainability concepts.

In all transportation sectors, lightweighting is an obvious path to reduce energy consumption in the use phase of the life cycle. However, as discussed by Duflou et al., the manufacturing and end-of-life phases of the product life cycle must also be taken into account when analyzing the total environmental impact. For example, a detailed LCA study of substituting carbon-fiberreinforced polymer (CFRP) for steel and aluminum structures in cars and airplanes found that CFRP has greater environmental impacts during manufacturing and end of life than the metals. However, the lighter-weight CFRP has a lower impact during use that accrues with each mile traveled. Thus, the sustainable impact is dependent on the lifetime of the vehicle, and there exists a "breakeven mileage" point beyond which use of CFRP has a lower overall impact than use of steel or aluminum.

Jet engines are subject to much more demanding performance standards than automotive engines. The list of materials available to aircraft engine designers 50 years ago was relatively limited compared to what it is today, and further, the jet engine market has continuously demanded increased efficiency. Konitzer et al. explain that efforts to increase engine efficiency through high-temperature operation have resulted in the use of elements that are, in general, scarcer than those for which they are being substituted (otherwise, they probably would have been used in the first place). Their article discusses the methodologies used to maintain a sustainable supply of one such element, rhenium. They conclude that the four-pronged approach of "reduce, revert, recover, and recycle" can conserve this element for use in achieving further efficiency improvements.

Materials demands for

[S] ustainable mobility for a growing population of 7 billion people requires dramatic innovations... our infrastructure, that is, the buildings, roads, pipelines, bridges, power lines, communications, canals, and waterways that people use on a daily basis without much thought, are substantial, as pointed out in the article by Heard et al. In addition to the large volume of material resources required (for example, each year the equivalent of $1 \mathrm{~m}^{3}$ of concrete is poured for every person on Earth), infrastructure construction and operation require large energy inputs and generate large pollution and waste flows. Improving the sustainability of infrastructure will require using materials, including recyclates and byproducts, more efficiently and designing and building for longer life.

With more than half of the world's growing population living in cities, a sustainable physical infrastructure is central to improving and maintaining a high quality of life. Concrete is the most important infrastructure material and, in fact, the most widely used manufactured material on the planet. Further, concrete is the most carbon-intensive material to process. Yet, even though forms of concrete were used in ancient Rome, questions are still being asked about the fundamental mechanisms of concrete formation and processing. The article by Van Vliet et al. provides an up-to-date perspective on the sustainability science of this miraculous "liquid stone." Their multiscale approach speaks to the belief that a more fundamental understanding of concrete will facilitate its optimization at several different length scales.

Energy production enjoys a central position under the sustainability tent. Thus, energy-related materials are essential to sustainable development, and the subject is discussed in a variety of articles in this issue. Hurd et al. make the case for energy-critical elements and isotopes, that is, those required for emerging sustainable energy sources that might encounter supply disruptions. Although rare-earth elements are often held up as the epitome of such critical materials, uranium and tellurium are also examples. An earlier article in this issue, that by Graedel and Erdmann, discusses possible supply limitations of a broader spectrum of elements for manufacturing technologies and explains that the existence of a natural resource does not guarantee that an element or material derived from it is readily obtainable.

Indeed, in their article on the complex relationship between materials and energy, Lubomirsky and Cahen point out that the availability of any material is determined not only by its crustal abundance but also by the amount of energy necessary for its recovery from ores. The vast majority of the energy produced on Earth is consumed in applications vital to ongoing societal needs, leaving perhaps only a few percent available in the short term for new materials technologies. Thus, production of new energy-critical materials cannot be increased rapidly, imposing severe restrictions on the rate of energy technology change.

The proper place for nuclear power in the energy mix has often been contentious and will likely continue to be so for the foreseeable future. Global opinions about the wisdom of expanding nuclear power generation vary widely; for example, Germany plans to phase out nuclear power, whereas neighboring France gets about $75 \%$ of its electricity from nuclear plants (in the United States, the number is about 20\%, and in Japan, before the Fukushima nuclear accident in March 2011, it was about $30 \%$ ). Issues of plant safety, weapons proliferation, and waste storage problems are important, but Englert et al. raise the more basic question of the sustainability of fissile nuclear energy by considering uranium and thorium resources in relation to different fuel cycles. They report that current identified resources can sustain only a two- to three-fold increase in nuclear capacity through the end of this century; further demands would necessarily involve the use of thorium and advanced fuel cycle technologies. Advanced (closed) fuel cycles generate large amounts of fissile materials and are thus problematic because of possible diversion for nuclear weapons (a nuclear device can be made with less than $10 \mathrm{~kg}$ of ${ }^{239} \mathrm{Pu}$ ).

Photovoltaic solar energy is touted as an important part of a global fix for increasing energy demand, although it still represents a very tiny fraction of the whole energy infrastructure, providing less than $1 \%$ of the electricity in the United States in 2010, for example. ${ }^{8}$ An important aspect of the photovoltaic power industry, the need for sustainable growth at much higher energy production levels, is discussed in great 
detail in the article by Fthenakis, who reports that photovoltaics are following a path of cost reduction and market growth that should enable this technology to become a major player in global energy markets, providing terawatts of renewable energy. However, at the very highest levels of market penetration, the sustainability of the industry hinges on concerns about cost, resource availability, and potential environmental impacts. Interestingly, although photovoltaic electricity grid parity is currently attainable only with subsidies, Fthenakis points out that the nuclear, oil, and gas sectors were subsidized to much larger extents during their development. As an example of the tangled web that often emerges from sustainable-development analysis, Fthenakis suggests that, if the high external health costs associated with the use of coal are taken into account, photovoltaic technology is already economically competitive with fossil-fuel power generation. Such debates will continue - it is the nature of the interconnectivity of the sustainable development field.

Coal is destined to remain a crucial power source for at least the next 50 (or maybe 100?) years, ${ }^{9}$ until sustainable sources of energy become a larger part of the global energy portfo-

lio. About $45 \%$ of electricity in the United States is generated in coal-fired power plants, ${ }^{8}$ because of the local abundance of coal and extensive experience with the technology. In addition, the two most populous countries, India and China, have been building new coal-fired power plants every year at an astounding rate. ${ }^{10}$ The article by Espinal and Morreale addresses one aspect of clean coal technology, namely, carbon mitigation. The major challenge in carbon mitigation, which includes capture, transport, and sequestration of carbon dioxide, is the development of cost-effective, technologically compatible, and efficient carbon dioxide capture and storage technologies. Several opportunities are available for leveraging the field of materials science to manage carbon dioxide, most notably the development of advanced solid-state sorbent media for capture. Carbon mitigation is a thorny political issue not only because carbon dioxide is a greenhouse gas implicated in global warming, but also because its implementation will necessarily raise the cost of electricity.

Finally, water is a major sustainability issue not least because of the key role that water plays in energy production. Specifically, thermal modes of power generation (for example, fossil fuel, nuclear, biomass), in which electricity is generated from heat through a thermodynamic cycle, account for almost $80 \%$ of total generating capacity. In each of these processes, lowgrade waste heat is rejected to the environment, most effectively by use of water-based methods. Thus, the article by $\mathrm{Ku}$ and Shapiro speaks to the demand for cooling water in the energy community. Increasing the thermal efficiency of power plants is one way to reduce their water demand, and materials advances can play a large role in this arena. For example, the key materials challenges for improved gas turbine efficiency are lower-cost superalloys and robust thermal barrier coatings that can allow operation under extremely hot operating conditions (typically $>1300^{\circ} \mathrm{C}$ ). Further, solid-oxide fuel cells can be combined with gas turbines or other engines to achieve even higher thermal efficiencies, further reducing the cooling water requirements.

Revised curricula for materials science and engineering education are critical, because, as fittingly stated by one of this issue's authors, materials scientists and engineers can "make a world of difference by making our world different."11 The article by LeSar et al. emphasizes that sustainable development is a relatively new topic in university engineering curricula, and educators are only in the early stages of teaching this broader view of engineering. Going forward, materials researchers must be taught to think beyond the current definition of what constitutes the "best" material for a given application; their decisions will need to be informed by the topics represented in this special issue: resources, life-cycle assessment, energy and carbon footprints, toxicity, and more.

These brief descriptions of the articles in this special issue are meant to whet the reader's appetite for the in-depth versions that follow. It should be clear that there is something in this issue for every materials professional and interested citizen-scientist, given the breadth of the space at the intersection of materials science and sustainable development. Please contribute - our planet needs lasting solutions.

\section{References}

1. Report of the World Commission on Environment and Development: Our Common Future (Annex to Document A/42/427, Oxford University Press, Oxford, UK, 1987).

2. J. Elkington, Cannibals with Forks: the Triple Bottom Line of 21st Century Business (Capstone Publishing, North Mankato, MN, 1997).

3. S. Sim, M. Barry, R. Clift, S.J. Cowell, Int. J. Life Cycle Assess. 12 (6), 422 (2007).

4. MRS Bull. 33 (4) (2008).

5. T. Dietz, E. Ostrom, P.C. Stern, Science 302 (5652), 1907 (2003).

6. D. Richards, G. Pearson, Eds., The Ecology of Industry: Sectors and Linkages (National Academies Press, Washington, DC, 1998).

7. P. Collier, C.M. Alles, Science 330 (6006), 919 (2010).

8. "Electricity Explained: Electricity in the United States" (U.S. Energy Information Administration, Washington, DC, 2011), www.eia.gov/energyexplained/index. cfm?page=electricity_in_the_united_states (accessed February 2012).

9. S. Ansolabehere, J. Beer, J. Deutch, A.D. Ellerman, S.J. Friedman, H. Herzog, H.D. Jacoby, P.L. Joskow, G. McRae, R. Lester, E. Moniz, E. Steinfield, J. Katzer, The Future of Coal: An Interdisciplinary MIT Study (Massachusetts Institute of Technology, Cambridge, MA, 2007).

10. L. Friedman, "China, India Could "Lock" World in a High-Carbon Energy System, IEA Warns," Scientific American (10 November 2011), www.scientificamerican. com/article.cfm?id=china-india-could-lock-wo (accessed February 2012).

11. D. Apelian, JOM 62 (4), 8 (2010).

12. R.M.K. Yamaji, Y. Nagata, Y. Kaya, in Workshop on $\mathrm{CO}_{2}$ Reduction and Removal: Measures for the Next Century (International Institute for Applied Systems Analysis, Laxenburg, Austria, 1991).

13. M.R. Raupach, G. Marland, P. Ciais, C. Le Quere, J.G. Canadell, G. Klepper, C.B. Field, Proc. Natl. Acad. Sci. U.S.A. 104 (24), 10288 (2007). 
Materials for sustainable development is a scientific concept that globally balances use of the Earth's materials and energy resources, a profitable industrial economy, and availability of affordable materials and products to raise the standard of living.
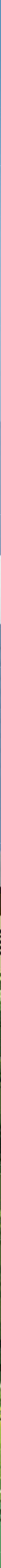


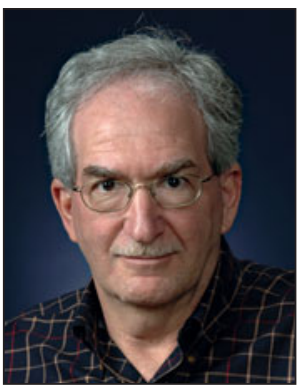

Martin L. Green

Chair of the organizing committee

for this issue of MRS Bulletin

National Institute of Standards and Technology, Gaithersburg, MD 20899, USA; tel. 301-9758496; and email martin.green@nist.gov.

Green is a group leader in the Material Measurement Laboratory at the National Institute of Standards and Technology (NIST). Projects in his group involve measurement science and fundamental properties of functional materials as well as materials for sustainable development applications. He has BS (1970) and MS (1972) degrees from the Polytechnic Institute of Brooklyn, and a PhD (1978) degree in materials science from MIT. Green served as president of the Materials Research Society in 2001 and is an MRS Fellow.

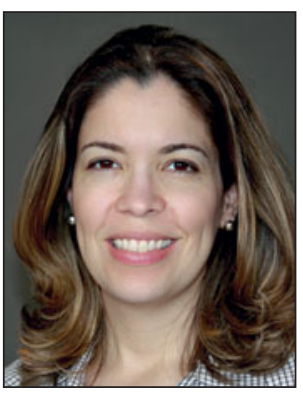

Laura Espinal

Member of the organizing committee

for this issue of MRS Bulletin

Material Measurement Laboratory, National Institute of Standards and Technology, Gaithersburg, MD 20899-8520, USA; tel. 301975-8979; and email laura.espinal@nist.gov.

Espinal is a materials scientist at the National Institute of Standards and Technology (NIST) in Gaithersburg, MD. Her research involves the development of sorbent properties and in situ structural diagnostic tools to enable the rational design of carbon capture materials. Espinal received her $\mathrm{PhD}$ in materials science in 2005 from the University of Connecticut. Before joining NIST, she was a postdoctoral research scientist in the carbon sequestration group at Schlumberger-Doll Research and participated in a crosscareer training program in petrophysics at Schlumberger Carbon Services.

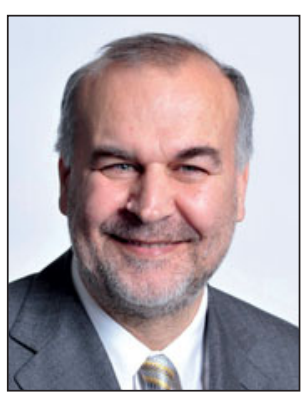

\section{Enrico Traversa}

Member of the organizing committee

for this issue of MRS Bulletin

Xi'an Jiaotong University, China;

tel. +86-29-82668767; and email

traversa@mail.xjtu.edu.cn.

Traversa is the director of the Department of Fuel Cell Research at the International Center for Renewable Energy, Xi'an Jiaotong University, China. He joined the University of Rome Tor Vergata in 1988, where he is a professor of Materials Science and Technology. From January 2009 to March 2012, he was a principal investigator at the International Research Center for Materials Nanoarchitectonics at the National Institute for Materials Science (NIMS), Tsukuba, Japan, leading a unit on sustainability materials. He earned his Laurea (Italian doctoral degree) in 1986 in chemical engineering from the University of Rome La Sapienza. His research interests are in nanostructured materials for environment, energy, and healthcare, with special attention to sustainable development. He is an author of more than 480 scientific papers (more than 300 of them published in refereed international journals) and 15 patents. He is the 2011 recipient of the Ross Coffin Purdy Award of the American Ceramic Society. He is currently an associate editor for the Journal of Nanoparticle Research.

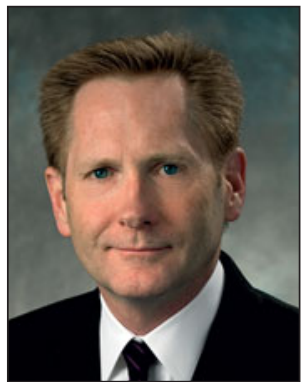

Eric J. Amis

Member of the organizing committee for this issue of MRS Bulletin

United Technologies Research Center, East Hartford, CT 06108, USA; tel. 860-610-7661; and email AmisEJ@utrc.utc.com.

Amis is the director of physical sciences at United Technologies Research Center (UTRC) Prior to UTRC, he spent 15 years in leadership roles at the National Institute of Standards and Technology (NIST) in the Materials Science and Engineering Laboratory, including 10 years in the Polymers Division. He earned a PhD degree in chemistry from the University of Wisconsin-Madison. At UTRC, he is responsible for research and development in materials science, chemistry, chemical engineering, structural integrity, applied physics, and measurement science. He is a Fellow of the Materials Research Society, the American Physical Society (APS), and the Polymeric Materials: Science and Engineering Division of the American Chemical Society (ACS). His research specialties are combinatorial and high-throughput methods for advanced materials, nanomaterial characterization, and soft matter physics. He has 150 peer-reviewed publications.

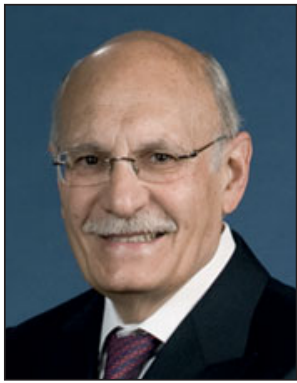

Diran Apelian

Metal Processing Institute, Worcester

Polytechnic Institute, Worcester

MA 01609, USA; tel. 508-831-5992;

and email dapelian@wpi.edu.

Apelian is the Howmet Professor of Engineering and director of the Metal Processing Institute at the Worcester Polytechnic Institute. He received his BS degree from Drexel University and his ScD from MIT. During 2008/2009, he served as president of TMS. Apelian is a Fellow of TMS, ASM, and APMI; he is a member of the National Academy of Engineering (NAE) and the Armenian

Academy of Sciences.

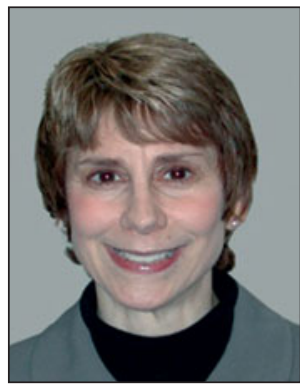

Ellyn S. Beary

Montgomery Village, MD, 20886-4923

USA; tel. 301-529-4518; and

email esbeary@yahoo.com.

Beary retired from the National Institute of Standards and Technology in 2007 as senior scientific advisor in chemical science and technology. Since her retirement, she has remained active in the areas of biofuels and sustainability. She served on the steering committee of the International Congress on Sustainability Science and Engineering (2009 and 2011), chairing sessions on standards and protocols and their relationship to sustainable development. She is a charter member of AIChE's Institute for Sustainability and served on the governing board from 2007-2011 as co-chair of their youth council.

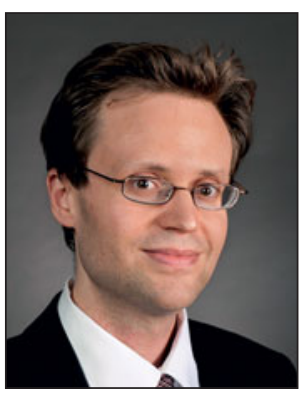

Markus J. Buehler

Massachusetts Institute of Technology, Cambridge, MA 02139, USA; tel. 617-452-

2750; and email mbuehler@mit.edu.

Buehler is an associate professor in the Department of Civil and Environmental Engineering at the Massachusetts Institute of Technology. Buehler's research focuses on bottom-up modeling and simulation of structural and mechanical properties of biological and synthetic materials, with a specific focus on materials failure from a molecular perspective. One of his principal interests is the design of materials that, while being manufactured with low energy use and from abundant and intrinsically poor building blocks, achieve superior engineering properties. 


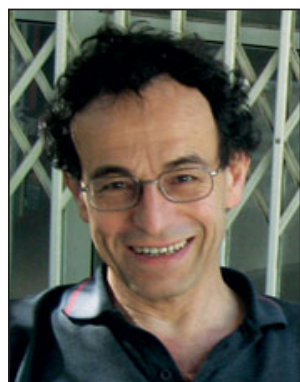

David Cahen

Weizmann Institute of Science, Israel;

email david.cahen@weizmann.ac.il.

Cahen earned his BSc degree in chemistry and physics from the Hebrew University of Jerusalem (HUJ) and his PhD degree in materials chemistry from Northwestern University. His postdoc studies were on photosynthesis at HUJ and the Weizmann Institute of Science. Other studies focus on understanding electronic transport across hybrid molecular/non-molecular, (bio) organic/inorganic materials, including proteins, and on alternative sustainable energy resources, especially on solar cells and combinations of these fields (in terms of possible novel science). Cahen heads the Weizmann Institute's Alternative Sustainable Energy Research Initiative.

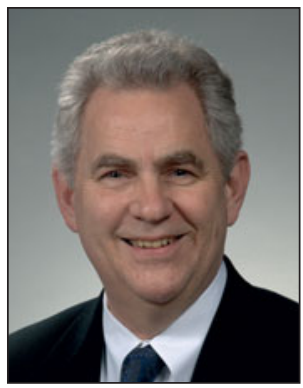

Richard R. Cavanagh

Material Measurement Laboratory,

National Institute of Standards and

Technology, Gaithersburg, MD 20899-

8300, USA; tel. 301-975-8300; and

email Richard.Cavanagh@NIST.gov.

Cavanagh is the acting director of the Material Measurement Laboratory at the National Institute of Standards and Technology. He is responsible for measurement science and standards spanning biology, chemistry, and materials science. He joined NIST in 1979 after obtaining his $\mathrm{PhD}$ degree in physical chemistry from Harvard University. He pursued an active research career in surface science, using stateselected and time-resolved laser diagnostics to examine the surface dynamics of small molecules. He is a Fellow of APS and AVS, has received the Department of Commerce Silver and Gold medals, and currently chairs VAMAS.

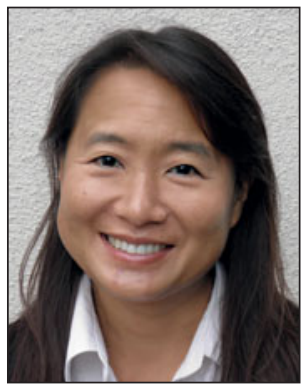

\section{K.C. Chen}

Materials Engineering Department,

Cal Poly, SLO; tel. 805-756-6634;

and email kcchen@calpoly.edu.

Chen has been teaching in the Materials Engineering Department at Cal Poly, SLO, for over a decade. She teaches many different courses in materials engineering, as well as interdisciplinary, project-based classes. Her research interests include engineering education, K-12 outreach, and informal learning. Chen earned her BS degree in materials science and engineering from Michigan State University and her $\mathrm{PhD}$ degree in materials science from the Massachusetts Institute of Technology. She is a member of MRS, the American Society of Engineering Education, ASM, and TMS

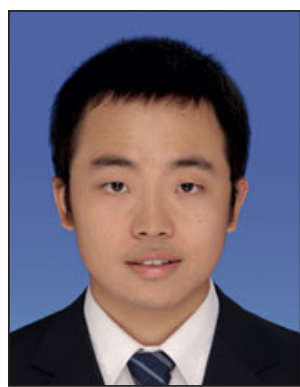

\section{Y. Deng}

Celestijnenlaan, 3001 Heverlee,

Belgium; tel. +32 16 322499; and

email yelin.deng@cib.kuleuven.be.

Deng is a doctoral student in the Centre for Industrial Management at KU Leuven. His research interests include bio-based materials, composite materials, and life-cycle engineering. He holds B.Eng and M.Sc degrees in electrical engineering both from Xi'an Jiaotong University, China.

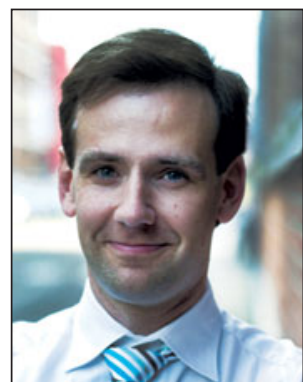

W. Dewulf

Leuven Engineering College, KU Leuven

Association, Belgium; tel. +32 16301074

and email wim.dewulf@groept.be.

Dewulf received his master's and $\mathrm{PhD}$ degrees in mechanical engineering from KU Leuven in 1996 and 2003, respectively. He currently holds the positions of assistant professor in Group T-International University College Leuven and associate professor at KU Leuven-Mechanical Engineering Department. He serves as head of the research groups' manufacturing and control and sustainable engineering, leading research in the fields of life-cycle assessment, sustainable transportation and manufacturing, and quality control.

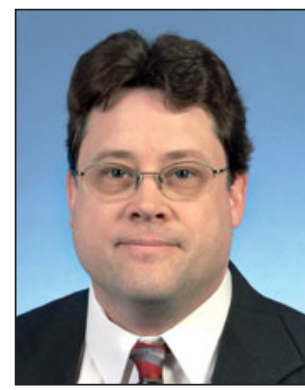

Steven Duclos

GE Global Research Center, Niskayuna, NY

Duclos is a chief scientist at the GE Global Research Center in Niskayuna, NY. He manages GE's Material Sustainability Initiative, addressing the sustainability of the company's raw material supply. Duclos has testified to both U.S. Senate and House committees on the impact of materials constraints on U.S. manufacturing capability. He holds 34 U.S. patents and has authored 30 technical papers. $\mathrm{He}$ received his BS in physics in 1984 from Washington University in St. Louis, and a PhD degree in physics from Cornell University in 1990.

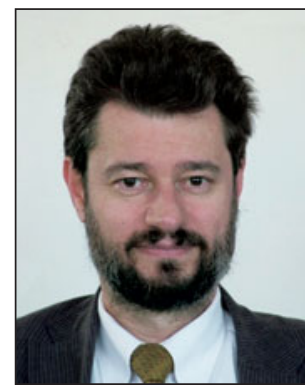

Joost R. Duflou

Celestijnenlaan, 3001 Heverlee, Belgium;

tel. +32 16 322845; and email

joost.duflou@mech.kuleuven.be.

Duflou holds master degrees in architectural and electromechanical engineering and $\mathrm{a} P \mathrm{Ph}$ degree in engineering from KU Leuven, Belgium. After a number of years of industrial experience in different international companies, he has been active as a faculty member in the Mechanical Engineering Department of KU Leuven since 1997. He became a tenured professor in 2006. His principal research activities are in the field of design support methods and methodologies, with special attention to systematic innovation, ecodesign, and life-cycle engineering. He is a member of CIRP and has published over 200 international publications.

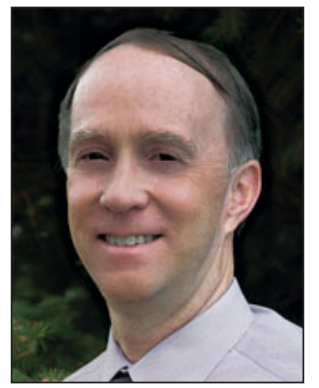

Roderick G. Eggert

Division of Economics and Business, Colorado School of Mines, Golden, CO 80401-1887, USA; tel. 303-273-3981; and email reggert@mines.edu.

Eggert has a BA degree in earth sciences from Dartmouth College, a MS in geochemistry and mineralogy from Penn State University, and a $\mathrm{PhD}$ degree in mineral economics also from Penn State. He is a professor and director of the Division of Economics and Business at the Colorado School of Mines, where he has taught since 1986. His research and teaching have focused on various aspects of mineral economics and public policy, including mineral exploration, metal demand, mining and sustainable development, mineral and metal markets, and critical minerals and materials. He received the 2010 Mineral Economics Award of the American Institute of Mining, Metallurgical, and Petroleum Engineers. He chaired the National Research Council committee and served on the study committee that prepared the 2011 report Energy Critical Elements: Securing Materials for Emerging Technologies. 


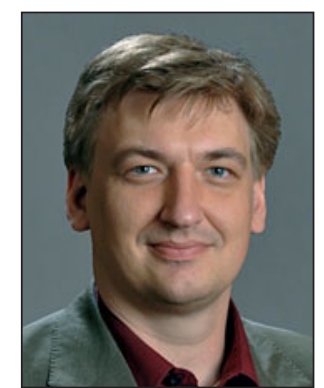

Matthias Englert

Darmstadt University of Technology, Germany; email Englert@ianus.tu-darmstadt.de.

Englert is a research fellow at the Interdisciplinary Research Group in Science Technology and Security (IANUS) at Darmstadt University of Technology. He has a PhD degree in physics from Darmstadt University of Technology and spent two years as a postdoc fellow at the Center for International Security and Cooperation (CISAC) at Stanford University. Englert's current research focuses on the nuclear fuel cycle, especially on enrichment technologies and uranium resources. He is also an expert on nuclear weapons proliferation, fissile materials, civil nuclear energy, and neutron transport simulation.

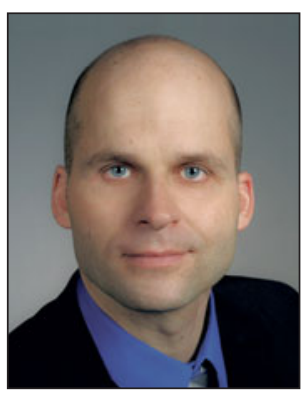

\section{Lorenz Erdmann}

Institute for Future Studies and

Technology Assessment, Berlin,

Germany; email I.erdmann@izt.de.

Erdmann is a senior researcher at the Institute for Futures Studies and Technology Assessment (IZT) in Berlin, Germany. He graduated with a degree in environmental engineering from the Technical University of Berlin. His major research subjects include resource criticality, technology assessment, foresight, and industria ecology. He has been instrumental in establishing research on emerging material issues such as the future impact of RFID tags on waste management and raw material demand for emerging technologies.

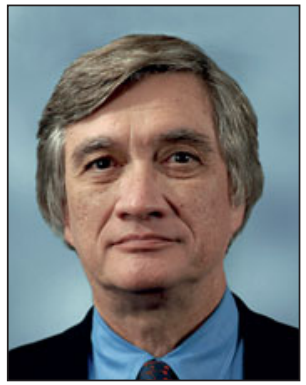

Rod Ewing

Department of Geological Sciences,

University of Michigan; tel. 734-763-9295;

and email rodewing@engin.umich.edu.

Ewing is the Edward $\mathrm{H}$. Kraus University Professor in the Department of Geological Sciences at the University of Michigan. He is also a professor in the Departments of Nuclear Engineering and Radiological Sciences and Materials Science and Engineering. During 2010 to 2011, he was a visiting professor at the Center for International Security and Cooperation (CISAC) at Stanford University. Ewing's research interests focus on radiation effects in minerals, ion beam modification of materials, the crystal-chemistry of actinide minerals and compounds, and the "back-end" of the nuclear fuel cycle. He is the past president of the International Union of Materials Research Societies. Ewing has written extensively on issues related to nuclear waste management. He has received the Dana Medal of the Mineralogical Society of America and the Lomonosov Gold Medal of the Russian Academy of Sciences.

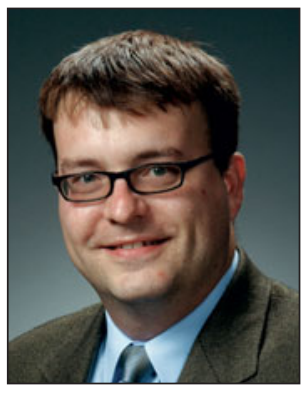

Michael J. Fasolka

Material Measurement Laboratory, National Institute of Standards and Technology, Gaithersburg, MD 20899-8300, USA; tel. 301-975-8526; and email mfasolka@nist.gov. Fasolka is senior scientific advisor to the director of the Material Measurement Laboratory at the National Institute of Standards and Technology, where he supports scientific program development, strategic planning, and stakeholder communications. He completed his doctorate in polymer physics at MIT. At NIST since 2000, he has researched advanced scanning probe microscopy and polymer self-assembly in thin films. He was director of the NIST Combinatorial Methods Center, which developed high-throughput techniques for polymer materials, and which garnered a Department of Commerce Silver Medal for service to industry. He is an author of more than 50 scientific publications and a recipient of a PECASE award in 2005.

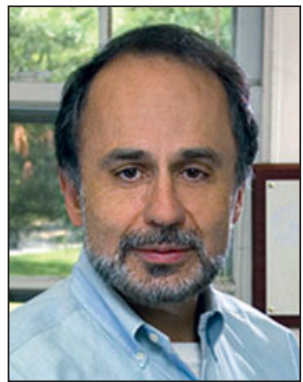

Vasilis Fthenakis

Brookhaven National Lab, Upton,

NY 11973, USA; tel. 631-344-2830;

and email: vmf@bnl.gov.

Fthenakis is a tenured senior chemical engineer at Brookhaven National Laboratory and professor of environmental engineering at Columbia University. He is a Fellow of the American Institute of Chemical Engineers and a Fellow of the International Energy Foundation. He earned his BS from the University of Athens, MS from Columbia University, and PhD degree from New York University. Fthenakis directs the National Photovoltaic Environmental Research Center at BNL and also directs the Center for Life Cycle Analysis at Columbia, which he founded in 2006. Fthenakis is the author or co-author of four books and 300 articles and reports on energy and sustainability topics.

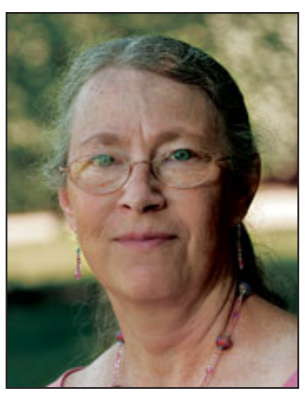

Linda L. Gaines

Center for Transportation Research at

Argonne National Laboratory, Illinois

60439, USA; email Igaines@anl.gov.

Gaines is a systems analyst at the Center for Transportation Research at Argonne National Laboratory. She holds a BA in chemistry and physics from Harvard and a PhD degree in physics from Columbia. Her primary interest is problem solving, applied to efficient use of resources. She began her $30+$ years at Argonne by writing a series of handbooks of energy and material flows in petroleum refining, organic chemicals, and copper industries that provided background for studies of technical and institutional issues involved in recycling discarded tires, packaging, and other energy-intensive materials. Her most recent work has involved studying ways to reduce petroleum use and other impacts from transport by recycling of batteries and also by reducing vehicle idling.

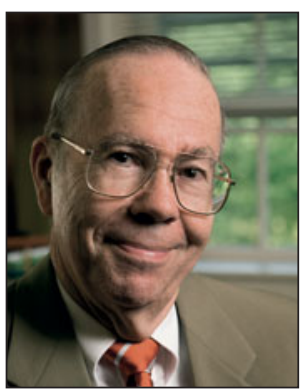

Thomas E. Graedel

Yale School of Forestry and

Environmental Studies, New Haven, CT

06511. USA; tel. 203-432-9733; and

email thomas.graedel@yale.edu.

Graedel joined Yale University in 1997 after

27 years at AT\&T Bell Laboratories. One of the founders of the emerging field of industrial ecology, he co-authored the first textbook in that specialty. His characterizations of the cycles of industrially used metals explore aspects of resource availability, potential environmenta impacts, opportunities for recycling and reuse, and resources policy initiatives. He was elected to the U.S. National Academy of Engineering in 2002 and chairs the Committee on Linkages of Sustainability in the Federal Government for the U.S. National Research Council.

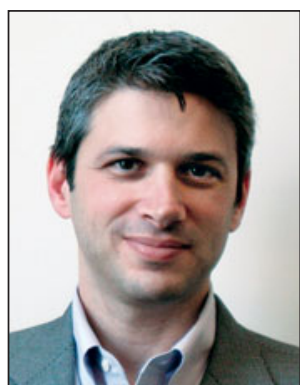

Jeffrey C. Grossman

Massachusetts Institute of

Technology, Cambridge, MA 02139,

USA; email jcg@mit.edu.

Grossman is an associate professor in the Department of Materials Science and Engineering at the Massachusetts Institute of Technology. He received his $\mathrm{PhD}$ degree in theoretical physics from the University of Illinois, performed postdoctoral work at U.C. Berkeley, and was a Lawrence Fellow at the Lawrence Livermore National Laboratory. Grossman's research uses theory and simulation to gain fundamental understanding of, and then uses such insights to design new materials for, energy conversion and storage with improved properties. 


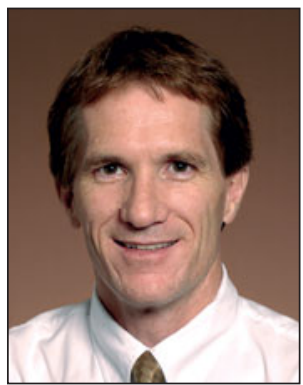

Robert Heard

Department of Materials Science and

Engineering, Carnegie Mellon University, Pittsburgh, PA 15213, USA; tel. 412-2682705; and email rheard@andrew.cmu.edu. Heard is an associate teaching faculty member in the Materials Science and Engineering Department at Carnegie Mellon University and serves as CEO of PowerMetal Technologies, Carlsbad California, and president of Integran Technologies USA. Past work includes activities as a technology consultant and vice president positions in several international engineering companies. Heard has served on the Board of Directors of AIST, as president for the CMU Chapter of Sigma Xi for several terms, and as a member of AIST, ASM, TMS, MRS, and ASEE. He has authored multiple technical papers on engineering education, material applications, materials processing, casting, plasma and alternate iron technologies, and authored a book, Horizontal Continuous Casting. His current activities and interests include global issues in engineering education specific to materials and the commercialization dynamics of materials.

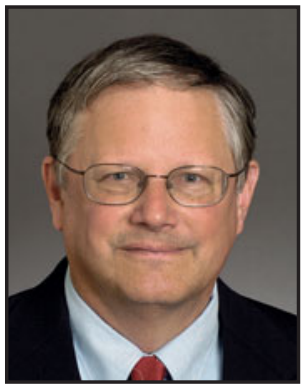

Chris Hendrickson

Green Design Institute, Carnegie Mellon University, Pittsburgh, PA 15213, USA; tel. 412-268-1066; and email cth@cmu.edu. Hendrickson is the Duquesne Light Company Professor of Engineering and co-director of the Green Design Institute at Carnegie Mellon University. His research, teaching, and consulting are in the general area of engineering planning and management, including design for the environment, project management, transportation systems, finance, and computer applications. Current research projects include life-cycle assessment methods, assessment of alternative construction materials, economic and environmental implications of Ecommerce, product take back planning, and infrastructure for alternative fuels. He has co-authored three textbooks and two monographs. Hendrickson is a member of the National Academy of Engineering, a Distinguished Member of the American Society of Civil Engineering, an Emeritus Member of the Transportation Research Board, and a Fellow of the American Association for the Advancement of Science.

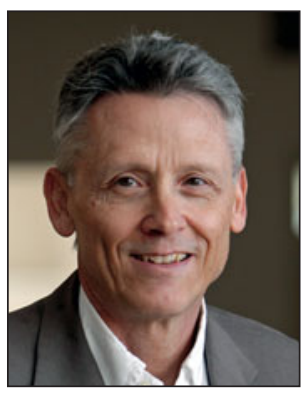

\section{Alan J. Hurd}

Santa Fe Institute and Los Alamos National Laboratory, Los Alamos, NM 87545, USA; tel. 505-946-2723; and email ajhurd@lanl.gov. On sabbatical in 2011-2012 at the Santa Fe Institute where he is working on energy critical elements, Hurd served from 2001 to 2011 as director of the Lujan Neutron Scattering Center at LANSCE at Los Alamos National Laboratory. He has degrees in physics from the Colorado School of Mines and the University of Colorado. Hurd studied light scattering from colloidal crystals at CU as an NSF Fellow, recognized with the university's Outstanding Graduate Research Award. His research interests include neutron scattering, fractal materials, biomembranes, complex fluids, and sol-gel ceramics. Hurd was the president of the Materials Research Society in 2007. He received the 1999 MRS Woody Award, the 2004 MRS Special Recognition Award, the DoD Patriot Award in 2008, and a Citation from the CIA in 2004. He recently served as the chair of the MRS Government Affairs Committee and is a member of the American Physical Society's Committee on International Scientific Affairs.

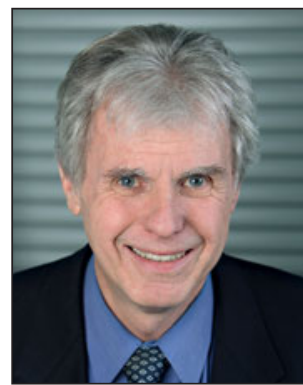

Hamlin Jennings

Massachusetts Institute of

Technology, Cambridge, MA 02139,

USA; email hmj@mit.edu.

Jennings is the executive director of the Concrete Sustainability Hub at MIT. From 1987 to 2010, he was a professor in civil and environmental engineering (a term as chair) and materials science and engineering at Northwestern University. He received a BSc degree in physics from Tufts University and a PhD degree in materials science from Brown University, after which he spent a decade at the University of Cape Town and then at Imperial College London, followed by five years at NIST.

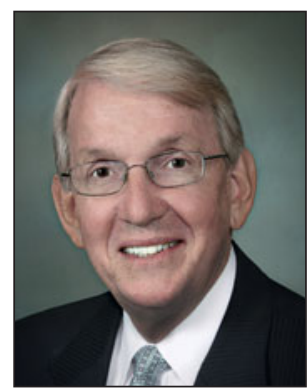

Ronald L. Kelley

MRS Washington Office, Washington

DC; tel. 202-289-9881; and email

rkelley@livingstongroupdc.com.

Kelley specializes in government affairs, lobbying, and strategic alliances for corporations, professional societies, universities, and trade associations. Kelley is president of Strategic Partners, Inc., founded in 1986, and he is also the director of The Livingston Group's Science, Technology, and Telecommunications practice area and has been associated with The Livingston Group since 2000. His consulting experience includes a wide range of high technology industries focused on research and development programs. Prior to his consulting career, he was an employee for 17 years with Dow Corning Corporation. For 20 years he has represented the Materials Research Society (MRS) in Washington, DC advocacy and interacts with federal agencies regarding their research \& development programs. Kelley graduated from the University of Illinois in 1968 with a bachelor of science in chemistry.

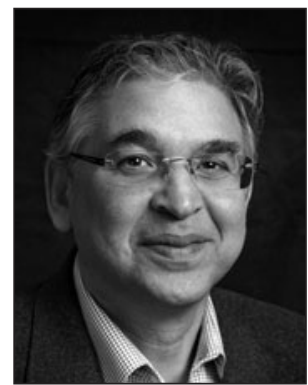

Gregory A. Keoleian

University of Michigan, Ann Arbor, MI 48109-1041, USA; tel. 734-764-3194

and email gregak@umich.edu.

Keoleian is the Peter M. Wege Endowed Professor of Sustainable Systems at the University of Michigan with appointments in the School of Natural Resources and Environment and Civil and Environmental Engineering. He also serves as the director of the Center for Sustainable Systems. He earned a PhD degree in chemical engineering at the University of Michigan in 1987. His research focuses on the development and application of life-cycle models and sustainability metrics to guide the design and improvement of products and technology. In 2011, he began a two-year term as president of the International Society for Industrial Ecology.

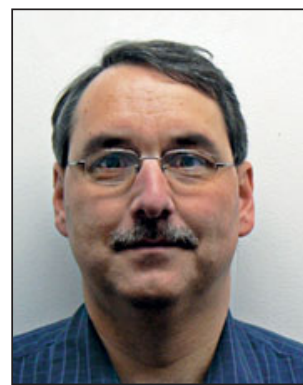

Doug Konitzer

Airfoil Materials, GE Aviation,

Cincinnati, OH, USA.

Konitzer is section manager for Airfoil Materials at GE Aviation. He manages efforts in development and application of $\mathrm{Ni}$ and $\mathrm{Ti}$ alloys to airfoils in aircraft engines. He has authored 35 technical papers and has 10 U.S. patents and applications. Konitzer received his BS degree in 1979, his MS degree in 1981, and PhD degree in 1984 in metallurgical engineering from the University of Illinois. 


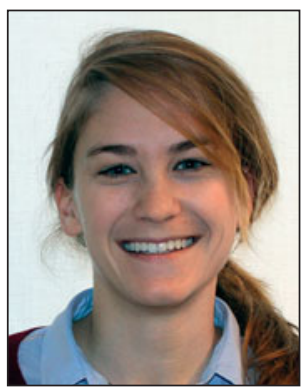

Lindsay Krall

Swedish Nuclear Fuel and Waste

Management Company, Stockholm.

Krall is an intern at Swedish Nuclear Fuel and Waste Management Company (SKB). She has a BSE degree in industrial and operations engineering from the University of Michigan. Krall's current research focuses on energy minerals, particularly those bearing thorium and rareearth element resources, and on organizational and geological approaches to the management of nuclear materials.

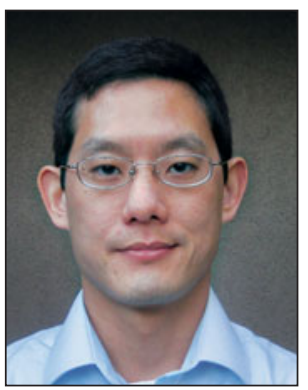

Anthony Ku

GE Global Research, Niskayuna, NY

12309, USA; tel. 518-387-4628; and

emailkua@research.ge.com.

$\mathrm{Ku}$ is a senior engineer in the Manufacturing and Materials Technology Organization at GE Global Research in Niskayuna, NY. He received his $\mathrm{PhD}$ degree in chemical engineering from Princeton University and his MS degree in chemical engineering practice from MIT in 2004 and 1997, respectively. Since joining GE, he has worked on several projects related to nanostructured ceramic materials, in support of GE's energy and water businesses. He currently leads an effort aimed at developing next-generation technologies for gas and liquid separations.

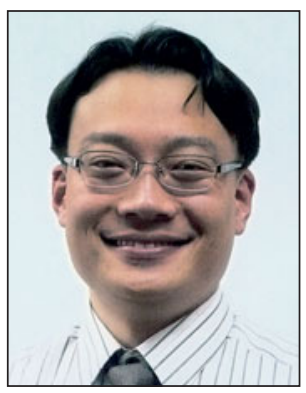

Min-Ha Lee

Korea Institute for Rare Metals, KITECH,

Incheon, 406-840, South Korea; tel. +82-328500-424; and email mhlee1@kitech.re.kr.

Lee has been the principal researcher of the Korea Institute for Rare Metals (KIRAM) at the Korea Institute of Industrial Technology (KITECH) since 2010. He joined KITECH as a senior researcher in 2008. Lee graduated from Yonsei University in 2004 with a PhD degree in metallurgical engineering. His research interests include rapid solidification, mechanical alloying, powder consolidation, and thermoplastic deformation. Currently he focuses on rare metals-related issues such as recycling, replacement, reduction, and substitution of critical elements. Lee is a member of TMS and the German Materials Science Association (DGM). He received the 2009 Korea Materials \& Components Industry Agency President's Award. Lee serves as a member of the Korean government policy advisory board on International Affairs of Rare Metals and is a member of the Korean Powder Metallurgy Institute's Committee on scientific publication affairs.

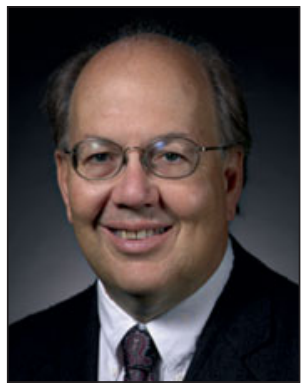

Richard LeSar

Department of Materials Science and

Engineering, lowa State University; tel.

515-294-1841; and email lesar@iastate.edu.

LeSar is the Lynn Gleason Professor and Chair of the Department of Materials Science and Engineering at lowa State University. His work is centered on the use of modeling and simulation of materials, with a recent focus on dislocation-based plasticity. He has been the co-founder of three courses on sustainability at lowa State, including one course taught in Africa, and is a co-leader of the creation of a

new sustainability minor.

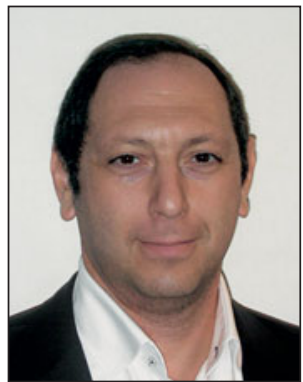

Igor Lubomirsky

Department of Materials and Interfaces,

Weizmann Institute of Science, Rehovot

76100, Israel; tel. 972-8-9342142; and

email igor.lubomirsky@weizmann.ac.il.

Lubomirsky is an associate professor in the Department of Materials and Interfaces at the Weizmann Institute of Science. He earned his BSc degree in chemical engineering from Kharkov Polytechnic Institute (Ukraine) and his PhD degree in solid-state chemistry from the Weizmann Institute of Science. His postdoc work was in electrical engineering at UCLA and the Max Planck Institute for Solid State Research (Stuttgart, Germany). He studies systems in which elasticity modifies chemical and physical properties of solids. This includes three main topics: quasi-amorphous materials, inelastic effect in oxygen ion conductors, and polycrystalline macro-domains in ferroelectric films. He also works on materials-energy sustainability and energy storage technology based on $\mathrm{CO}_{2}$ to $\mathrm{CO}$ conversion.

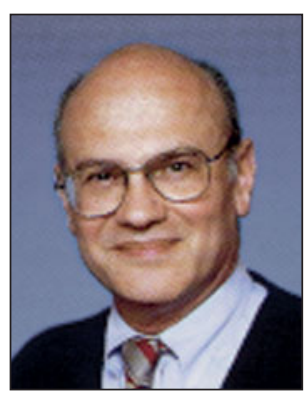

Francis C. McIlichael

Carnegie Mellon University, Pittsburgh, PA 15213, USA; email fm2a@andrew.cmu.edu. McMichael is Professor Emeritus at Carnegie Mellon University (CMU) and a member of the faculty of the Department of Civil and Environmental Engineering and the Department of Engineering and Public Policy at CMU. His research and teaching address environmental engineering, planning and management, and engineering cost analysis, including pollution prevention, life-cycle analysis, full cost accounting, design for the environment, and technology design and assessment for integrated waste management. Recent work has combined engineering process flow modeling with economic inputoutput analysis.

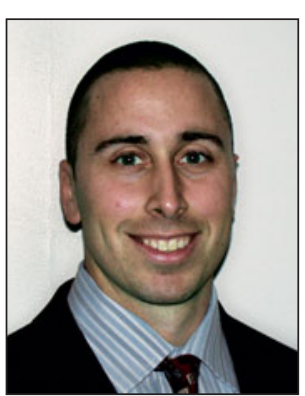

Bryan D. Morreale

Office of Research \& Development, National

Energy Technology Laboratory, Pittsburgh,

PA 15236, USA; tel. 412-386-5929; and

email bryan.morreale@netl.doe.gov.

Morreale is the acting Materials Science and Engineering Focus Area Lead within the Office of Research and Development at the U.S. DOE's National Energy Technology Laboratory. He currently leads activities across a diverse research portfolio related to both structural and functional materials for advanced energy conversion applications, specifically focused on an integrated computational and experimental approach to accelerated materials development. Morreale earned his PhD degree from the University of Pittsburgh with a research focus on the development of materials for hydrogen separation. His research focuses on numerous energy conversion and conservation technologies, specifically gasification, gas separations, membrane reactors, synthesis gas conversion, liquefaction, and carbon utilization.

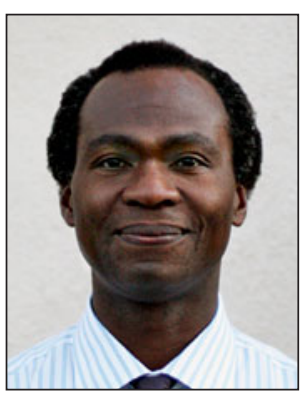

Oladele Ogunseitan

Department of Population Health and Disease

Prevention, University of California, Irvine, CA 92697-3597, USA; tel. 949-824-0611; and email Oladele.Ogunseitan@uci.edu. Ogunseitan is professor and chair of Population Health \& Disease Prevention at UC Irvine, where he directs the Green Materials Research and Education initiative. He is general editor of Green Health, part of the SAGE series on "Green Society: Toward a Sustainable Future." He was a faculty fellow in the Environment and Natural Resources Program at Harvard. He serves on the steering committee of the UC Irvine Environment Institute and on the State of California's Green Ribbon Science Panel. 


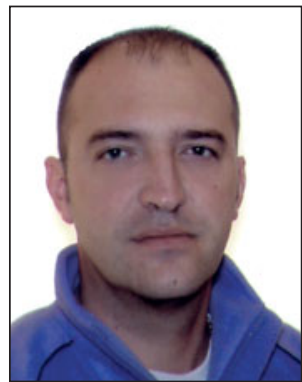

Roland J.-M. Pellenq

Massachusetts Institute of

Technology, Cambridge, MA 02139,

USA; email pellenq@mit.edu.

Pelleng is a computational materials scientist with a strong interest in the physics and mechanics of porous materials and confined fluids applied to a large variety of critical problems in energy and environment. He graduated in 1994 with a PhD degree in chemical physics from Imperial College and is a CNRS Research Director at the CINaM Laboratory (Aix-Marseille University). Since 2010, he has been the senior research scientist at MIT and one of the co-founders of the MIT Concrete Sustainability Hub.

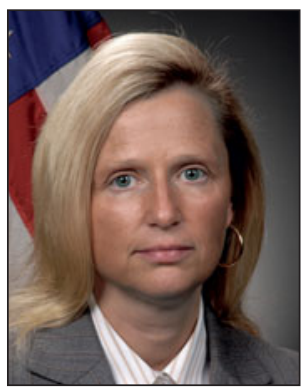

Dianne L. Poster

National Institute of Standards and Technology; tel. 301-975-8941; and e-mail poster@nist.gov. Poster is the special assistant to the NIST deputy director. She holds a PhD degree in chemistry from the University of Maryland and is frequently an invited speaker and panelist on environmental health issues, both nationally and internationally. In a prior assignment, as deputy associate director for technology and environmental policy at the White House Council on Environmental Quality, Poster administered the environmental federal regulatory portfolio and advised on policy and strategy issues related to protecting the environment.

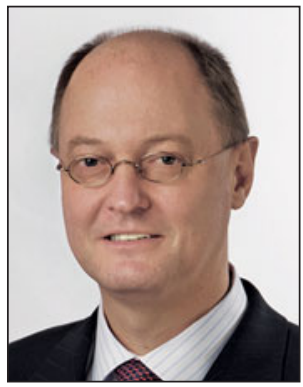

Markus A. Reuter

Outotec Oyj, Espoo 02201, Finland;

email markus.reuter@outotec.com.

Reuter is a director of Technology Management at Outotec Finland. He was a professor at TU Delft (Netherlands), and now is a professorial fellow at the University of Melbourne. He has a D.Eng. degree from Stellenbosch University, a Dr. habil. degree from RWTH Aachen University (Germany), and a PhD degree from the University of Stellenbosch. He also worked for Mintek and Anglo American Corporation in industry. Reuter has over 370 publications and is a co-author of Metrics of Material and Metal Ecology. He is the lead author of a second report on recycling for UNEP and co-editor of the Handbook of Recycling.

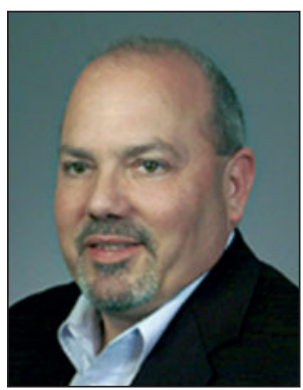

Todd Rockstroh

GE Aviation, Cincinnati, OH, USA.

Rockstroh is the supply chain consulting engineer for Laser and Advanced Manufacturing Processes at General Electric. His primary programs include intelligent, additive, and sustainable manufacturing technologies, establishing roadmaps for the GE Aviation supply chain. Rockstroh completed his bachelor's (1978) and master's (1980) degrees at Purdue University. He received his PhD (1986) degree in mechanical engineering from the University of Illinois and was previously employed by Bell Labs.

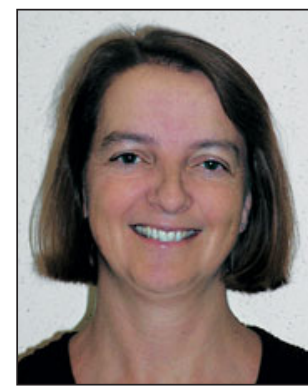

Julie M. Schoenung

Department of Chemical Engineering and Materials Science, University of California Davis, CA 95616, USA; tel. 530-752-5840; and email jmschoenung@ucdavis.edu.

Schoenung is a professor of chemical engineering and materials science at the University of California, Davis. Her research interests include green engineering and design, materials selection, industrial ecology, processing and characterization of nanostructured materials for structural applications, and mechanistic interpretation of material behavior. Schoenung serves on the State of California Green Ribbon Science Panel and is a member of the Eco-Design Executive Committee (Japan), the Green Screen Technical Advisory Committee, and UC Berkeley's Green Chemistry Extension Program Advisory Board.

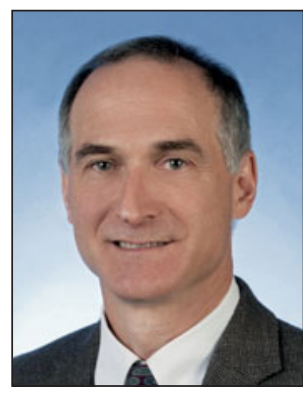

Andrew Shapiro

GE Global Research, Niskayuna, NY

12309, USA; tel. 518-387-4735

and email Shapiro@ge.com.

Shapiro is a principal engineer in the Thermal Systems Organization at GE Global Research in Niskayuna, NY. He received his PhD degree in mechanical engineering from MIT in the area of physicochemical hydrodynamics in 1990. His thesis was on using electro-osmosis for soil remediation. At GE he has worked on many projects related to energy and environmental technologies and has more than 25 patents. Currently his research interests include both thermally driven water purification and electrochemical energy conversion systems.

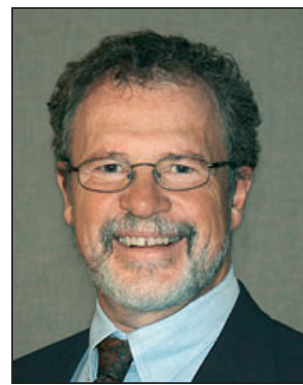

John L. Sullivan

Energy Systems Division, Argonne National Laboratory, Argonne, IL 60439-4815, USA; tel. 630-252-3786; and email jsullivan@anl.gov. Sullivan is an environmental scientist at Argonne National Laboratory. Previously, he spent two years at the University of Michigan Transportation Research Institute, and 30 years at the Scientific Research Laboratory at Ford Motor Company. He received a PhD degree in physical chemistry from the State University of New York College of Environmental Science and Forestry. Sullivan has conducted and led research projects in advanced materials, experimental structural analysis techniques, recycling of automotive materials, life-cycle assessment, advanced vehicle safety, alternative fuels, and transportation sustainability. He has 20 years of experience in life-cycle assessment.

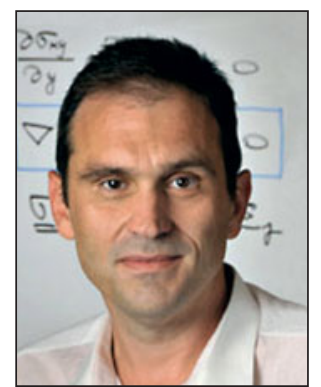

Franz-Josef UIm

Massachusetts Institute of

Technology, Cambridge, MA 02139,

USA; email ulm@mit.edu.

Ulm is the George Macomber Professor of Civil and Environmental Engineering at the Massachusetts Institute of Technology. His research focuses on the nano- and micromechanics of porous materials, such as concrete, rocks, and bones; in the durability mechanics of engineering materials and structures; and in computational mechanics of high-performance composite materials. Ulm was one of the cofounders of the MIT Concrete Sustainability Hub and is its current director. 


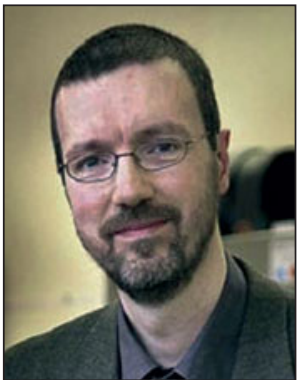

Karel Van Acker

Kasteelpark Arenberg 44 bus 2450, BE-3001, Heverku, Belgium; tel. +32 16 321271; and email karel.vanacker@Ird.kuleuven.be.

Van Acker is a senior lecturer in sustainable materials and processes and coordinator of the Leuven Materials Research Centre at KU Leuven. He chairs the Flemish Transition Network on Sustainable Materials Management and is involved in numerous projects on sustainability assessments of material life cycles, ranging from CFRP to bio-based plastics, and on landfill mining and the valorization of residues. He earned a M.Sc. degree in materials engineering and obtained a PhD degree in materials science, both from KU Leuven. He worked for several years in industry as manager of a materials and mechanical testing laboratory and at the Flemish Institute for Technological Research. He joined KU Leuven at the end of 2005.

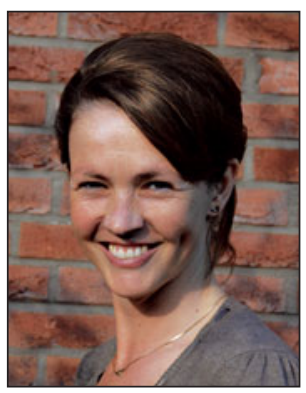

Antoinette van Schaik

Material Recycling and Sustainability, The Netherlands; tel. +31 6 53836042; and email A.vanSchaik@marasustainability.nl. Van Schaik owns and operates Material Recycling and Sustainability (since 2005), a technological consultancy company on recycling and sustainability. She has worked at Delft University of Technology (NL) (PhD in 2004) and for Auto Recycling Nederland (1997). She has worked with automotive OEM's, metallurgical (waste) water, and recycling industries. She book Metrics of Material and Metal Ecology.

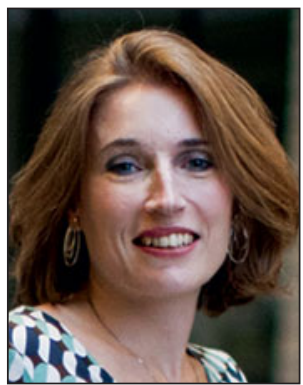

Krystyn J. Van Vliet

Massachusetts Institute of

Technology, Cambridge, MA 02139,

USA; email krystyn@mit.edu.

Van Vliet is an associate professor of materials science and engineering and biological engineering at the Massachusetts Institute of Technology. She earned her ScB degree at Brown University, her $\mathrm{PhD}$ degree at MIT, and completed postdoctoral research at Children's Hospital Boston. Her group studies coupling between chemistry and mechanics at complex material interfaces-ranging from cell-matrix interfaces to those in engineered nanocomposites-through both molecularscale experiments and computational simulations. She is a co-founder of the MIT Concrete Sustainability Hub.

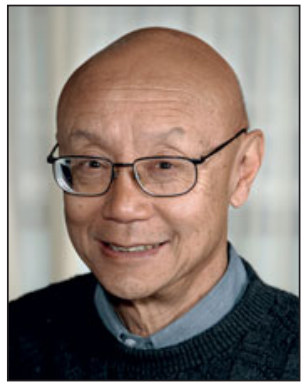

Sidney Yip

Massachusetts Institute of

Technology, Cambridge, MA 02139,

USA; email syip@mit.ediu.

Yip is professor emeritus (since 2009) at the Massachusetts Institute of Technology, where he was a member of the Department of Nuclear Science Engineering (1995-2009) and the Department of Materials Science and Engineering (2002-2009). He is interested in modeling materials phenomena with characteristic multistage kinetics-thermal and irradiation creep, corrosion in extreme environments, and hardening of cement paste-through molecular simulations that can reach time scales from seconds to years.

\section{8 NDNC

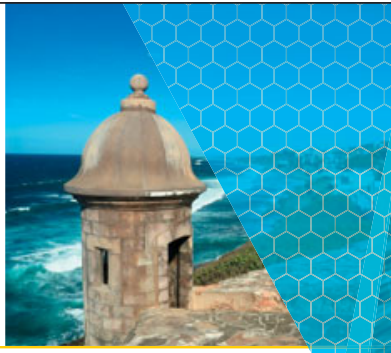

\section{SAVE THE DATE}

Join us for the fourth international New Diamond and Nano Carbons Conference (NDNC 2012). Hosted in beautiful San Juan, Puerto Rico, the conference will present high-impact scientific and technological advances, along with critical developments to enable the application of diamond, carbon nanostructures and related materials in a diverse range of products. This year's conference will feature plenary sessions, parallel topical sessions, poster sessions and an industrial exhibition. Mark your calendars today and plan to attend NDNC 2012!

\section{SCIENTIFIC PROGRAM}

The five-day conference will feature oral and poster presentations covering:

- Science and Technology of Diamond

- Synthesis and Characterization of Graphenes

- Synthesis and Characterization of Nano Carbons

- C-based Coatings and Tribological Applications

- Interfaces and Heterojunctions of C-based Materials with Other Materials

- Electronic, Optical and Acoustic Applications of C-based Materials

www.mrs.org/ndnc-2012
- Electrochemical Applications of C-based Materials

- Sensor Applications of C-based Materials

- Biological Applications of C-based Materials

- Spintronics of C-based Materials

- Business Opportunities and Commercialization 


\section{Untraled Ens for TEM}

$0.98 \mathrm{sr} 100 \mathrm{~mm}^{2}$

- Exponentially enhances elemental mapping for nano-area analysis TEM

- Automatic retractable design
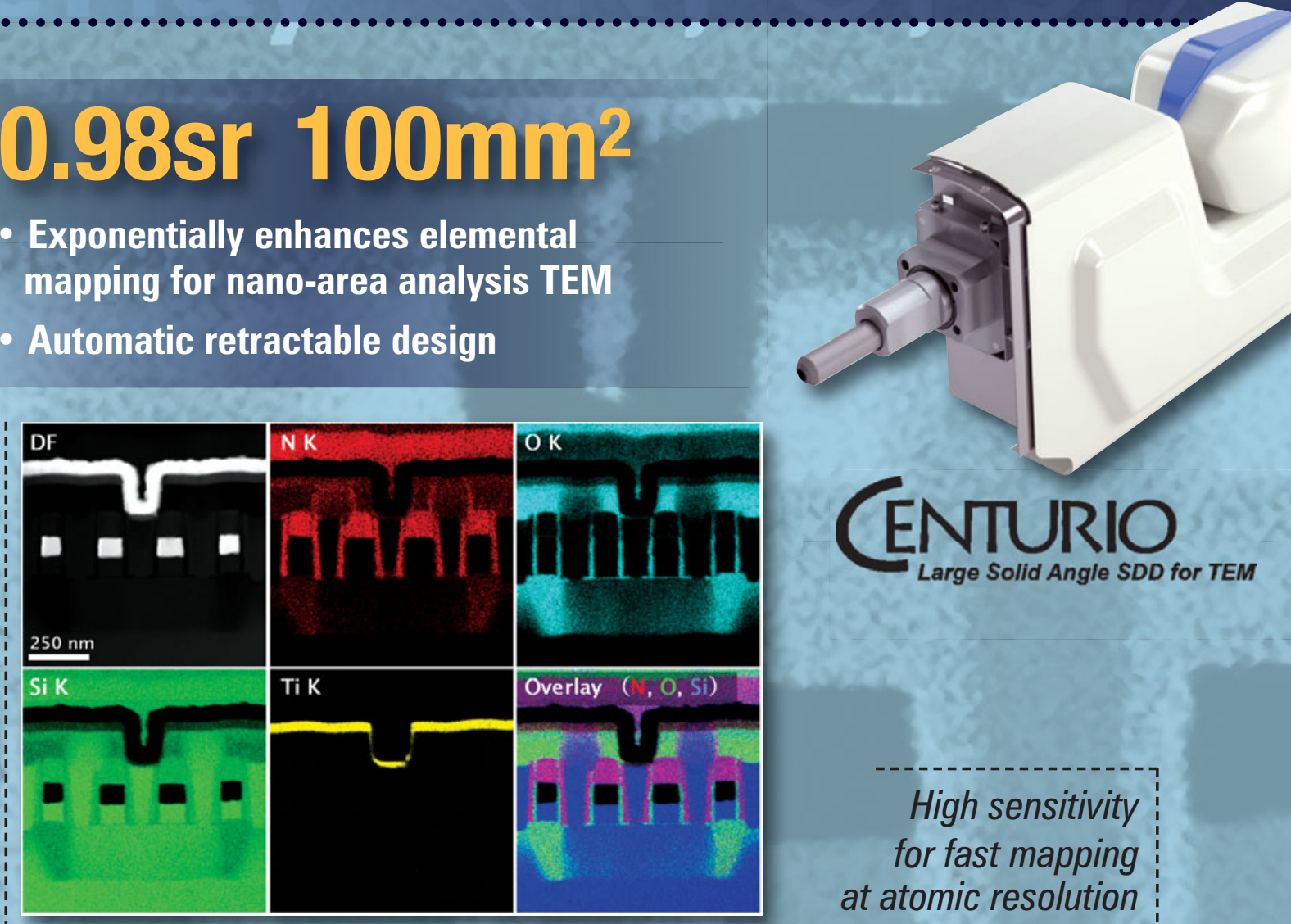

Seamless chemical mapping and data collection for S/TEM-TEM-

SEM-EDS. $(256 \times 256$ pixels.

Total acquisition time: $1 \mathrm{~min} .13 \mathrm{sec}$.)

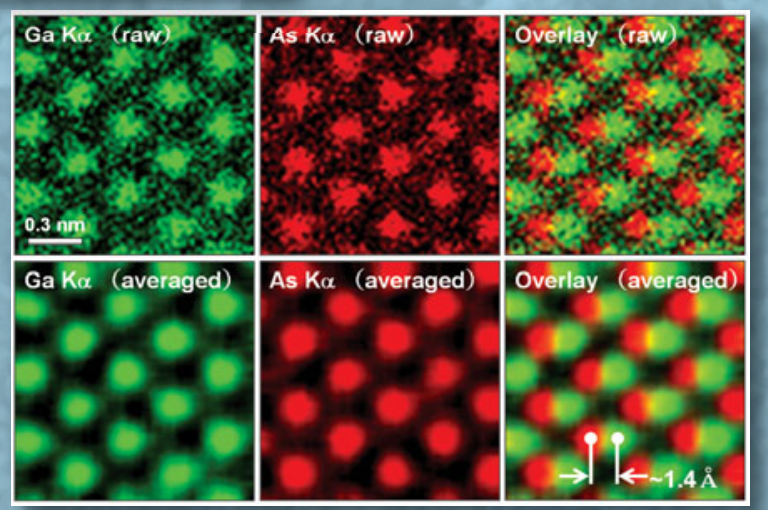

View our real-time

DRAM analysis video

at Www.jeolusa.com/UnrivaledEDS

High sensitivity

for fast mapping at atomic resolution
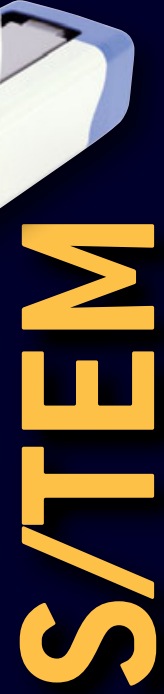

(2)
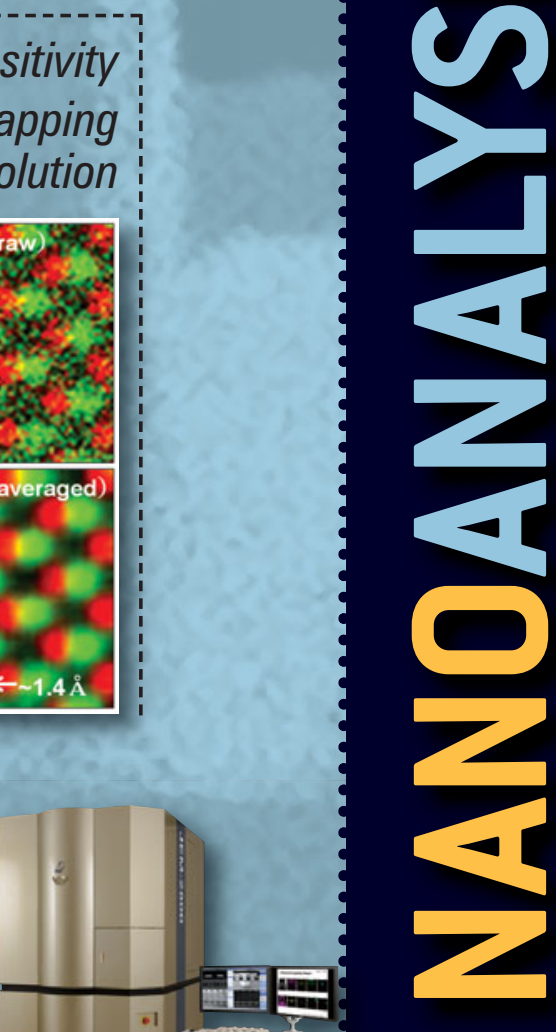

JEM-2800

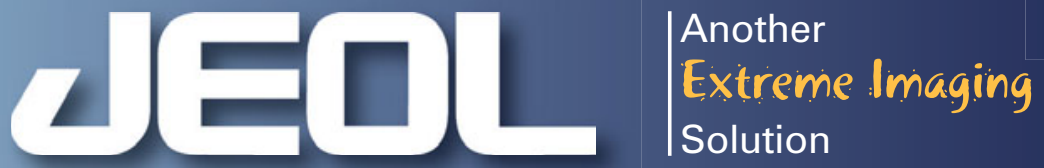

Global Solutions Provider for Advanced Technology www.jeolusa.com•salesinfo@jeol.com 978-535-5900

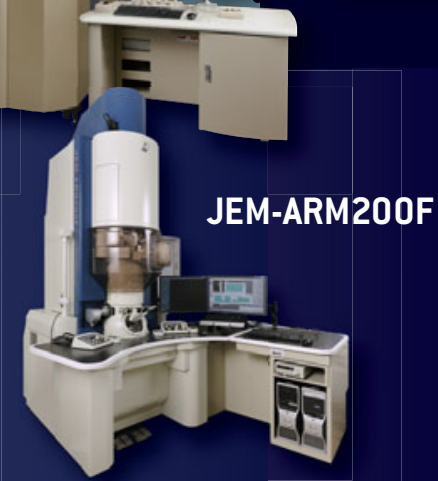




\section{Materials science and engineering's pivotal role in sustainable development for the 21 st century}

\section{Diran Apelian}

Perhaps the greatest challenge of the 21st century is to sustain the developmental needs of the world. The economic growth that occurred in developing countries over the past two decades is unprecedented. Materials science and engineering (MSE) innovations will continue to have a pivotal role as an enabling resource to address sustainable development needs. This article focuses on the opportunities for MSE in five key thematic areas: energy, transportation, housing, materials resources, and health.

\section{Introduction}

During the past two decades, an astounding one-third of the world population increased its standard of living ${ }^{1}$ and did so significantly and in unprecedented ways. However, such profound changes might not be sustainable if society continues on its current path.

As early as the 1700s, Thomas Malthus observed that the population in England was growing geometrically, whereas the food supply was increasing arithmetically. ${ }^{2}$ This led him to conclude that a human population would eventually outstrip its ability to find and produce new sources of food, thus leading to a catastrophe that would bring the population down to a more sustainable level. Although agricultural innovations have enabled the support of much larger populations than Malthus could have ever imagined, the real question is whether this can be continued. The answer is clear: only if development occurs sustainably.

Sustainable development is perhaps the most pressing issue of the 21 st century. At the same time, it is a remarkable opportunity for practitioners of materials science and engineering (MSE), as many of the approaches to address these challenges are materials-centric.

\section{Context}

To provide context for this discussion of sustainable development, it is important to understand the magnitude of the issues confronting society (highlighted in italics in the subsequent paragraphs). Since the 1700 s, the volume of goods traded worldwide has increased 800-fold. Between 1910 and 2010, the world's industrial production increased more than 100-fold, and between 1900 and 2000, global consumption of fossil fuels increased by a factor of $50 .{ }^{3}$ Although such growth represents remarkable development, it has been accompanied by other changes that call its continuation into question.

World population is projected to rise from the current 7 billion to over 9 billion in the next three to four decades. ${ }^{4}$ In comparison, the global population was only 1.6 billion in 1900 and grew to 6.1 billion by the end of the 20th century. Furthermore, the population growth has not been evenly distributed throughout the world, as more growth is occurring in less developed countries. The average population growth rate is hovering around $1.4 \%$, whereas in several African nations, Saudi Arabia, and Afghanistan, the population growth rate is over 3\%.

The presence of more people equates with higher energy usage. Indeed, whereas population is growing at an average rate of $1.4 \%$ a year, energy needs are growing at an average rate of $1.7 \%$. Average energy consumption per capita throughout the world is about 57 GJ. In contrast, it is 230 GJ for the United States and $119 \mathrm{GJ}$ for Europe, ${ }^{5}$ and many developing countries seek to emulate these developed nations and their energy consumption habits. Such consumption of energy is not sustainable.

Associated with energy usage is the production of greenhouse gases, which have adverse effects on the climate and the environment. The interrelation between human activity and the production of greenhouse gases is illustrated in Figure 1. The 


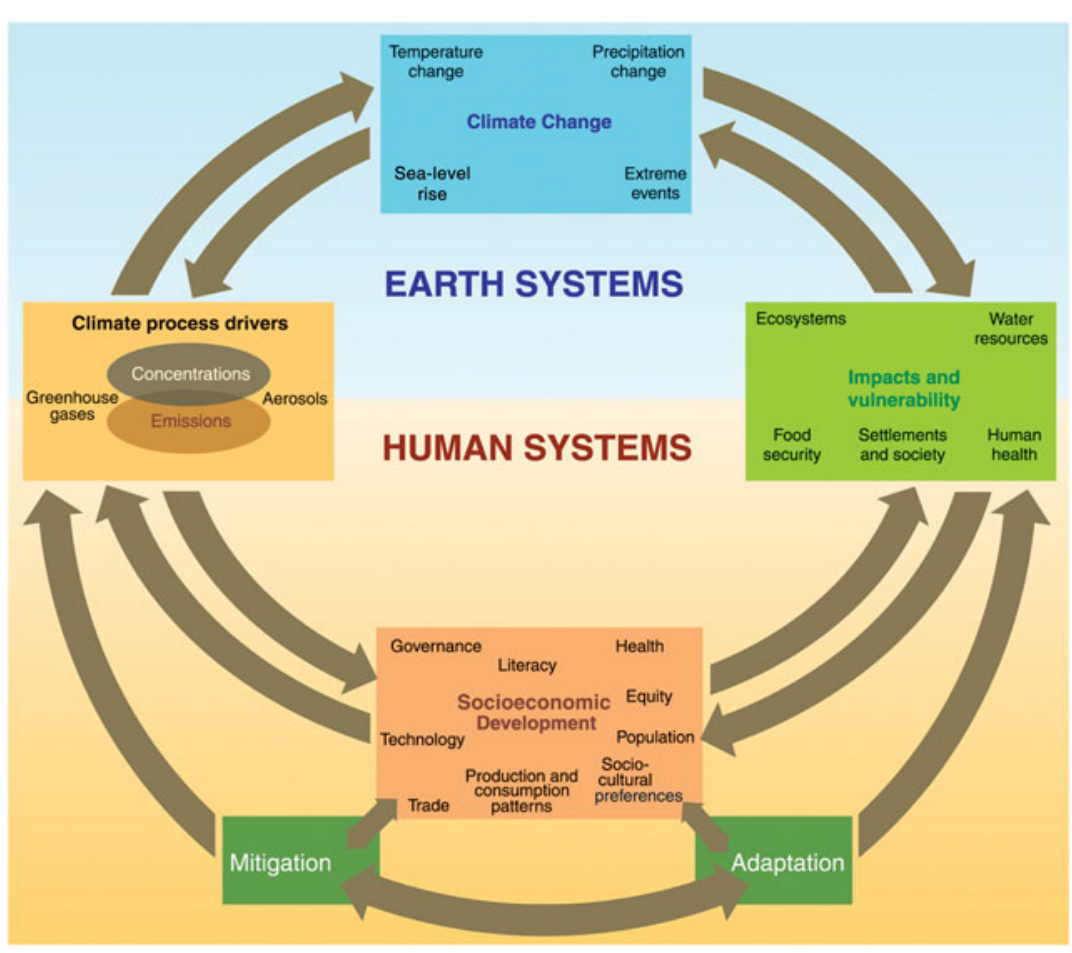

Figure 1. Interactions between human and Earth systems. Socioeconomic developments due to human activity affect climate change. In turn, climate process drivers, and impacts and vulnerabilities due to human activity, affect temperature, precipitation, and sea level and also cause extreme events. (Figure 1.1 from Reference 6 reproduced courtesy of the Intergovernmental Panel on Climate Change.)
Housing and shelter needs of the world are also increasing rapidly, tracking the expansion of population. In 1950 , less than $30 \%$ of the world's population lived in cities. This number grew to $47 \%$ in 2000 and is expected to exceed $60 \%$ by 2025 . $^{9}$ Infrastructure to sustain such a dramatic shift in urbanization is lacking.

Among the major ramifications of urbanization are shifting transportation needs. Specifically, the infrastructure that was built for a world of 5 billion in widely dispersed communities cannot sustain more than 7 billion people concentrated in dense population centers. Except in a few countries and major cities, mass transit systems that can efficiently transport large numbers of people are lacking. Systems such as high-speed trains and available lines between major hubs and airports are essential to address these needs.

Material consumption is at an all-time high. Most consumer goods are packaged, resulting in enormous amounts of waste. Given the comparatively small amounts of material recovered and recycled in the overall system, there is much room for improvement. (See the article in this issue by Gaines.) Another major issue is the increasing use of scarce elements, as discussed in detail in the article by Graedel et al. For example, the average smart phone contains overwhelming scientific consensus is that human emissions of greenhouse gases must be reduced in order to avoid catastrophic ecological consequences. For example, the shrinkage of the Grinnell glacier in Montana over 10 decades (1900-2000), documented by the U.S. Geological Survey in a series of photographs, ${ }^{7}$ clearly demonstrates the seriousness of the problem.

The basic human necessities of food and water are also being taxed. For example, $18 \%$ of the world's population lacks access to safe drinking water, and $20 \%$ of the world's population is living in absolute poverty (defined as living on less than US\$1 per day) and is thus subject to chronic hunger. ${ }^{8}$ To exacerbate the situation, $40 \%$ of the world's population has no access to sanitation. ${ }^{8}$ more than 50 elements - a good percentage of the periodic table. Yet, few programs have been established to ensure, at the time of purchase, the recovery and recycling of these elements at the end of a component's useful life, despite the fact that inorganic materials are not renewable. Evidence of the need for such programs is clearly provided by the volatility in the prices of rare-earth metals, which have increased dramatically even since the beginning of 2010 (see Table I), mainly because of supply and demand issues.

Finally, health is perhaps the most critical human need, and life expectancy around the world has increased significantly in recent decades, except in Africa, where it is decreasing in large part due to HIV/AIDS.${ }^{10}$ Health care needs around the world have increased, and the cost of health care delivery has also skyrocketed.

\begin{tabular}{|c|c|c|c|c|c|}
\hline \multirow{2}{*}{$\begin{array}{l}\text { Rare-earth } \\
\text { element }\end{array}$} & \multicolumn{3}{|c|}{ Price (US\$/kg) } & \multicolumn{2}{|c|}{ Price increase } \\
\hline & $\begin{array}{c}\text { January } 5, \\
2010\end{array}$ & $\begin{array}{c}\text { August 5, } \\
2010\end{array}$ & $\begin{array}{c}\text { August 5, } \\
2011\end{array}$ & $\begin{array}{c}\text { January } 2010 \text { to } \\
\text { August } 2010\end{array}$ & $\begin{array}{l}\text { August } 2010 \text { to } \\
\text { August } 2011\end{array}$ \\
\hline Yttrium & 10.25 & 34.50 & 210.00 & $236 \%$ & $508 \%$ \\
\hline Neodymium & 22.50 & 55.25 & 475.00 & $146 \%$ & $756 \%$ \\
\hline Lanthanum & 5.60 & 33.50 & 165.00 & $498 \%$ & $392 \%$ \\
\hline Samarium & 3.95 & 31.80 & 190.00 & $705 \%$ & $497 \%$ \\
\hline Cesium & 4.15 & 33.00 & 170.00 & $695 \%$ & $415 \%$ \\
\hline
\end{tabular}

\section{Critical needs}

Although society faces many challenges in the $21 \mathrm{st}$ century, this section outlines five distinct societal issues that are materials-centric and can be considered to be most critical for a sustainable future on Earth. These challenges offer a vista of opportunities for the next 
generation of scientists and engineers, especially the MSE community.

\section{Energy}

The global demand for energy is growing even faster than the population, and the escalating demand from developing countries will further exacerbate this situation. The current energy utilization worldwide is about $14 \mathrm{TW}$, and by the end of the 21 st century, it could reach 50 TW. ${ }^{11}$ Today, about $80 \%$ of the world's energy comes from fossil fuels. ${ }^{12}$ In North America, energy generation is responsible for $40 \%$ of greenhouse-gas emissions. Some of the ramifications of increasing greenhouse gases on our environment can be seen in Figure 2. An important consideration with respect to reducing demand is the need for efficiency in usage, especially in housing/buildings (see the Housing section below) and in the industrial sector.

In terms of supply, there must be a shift away from fossil fuels to renewable energy sources, which generate much lower levels of greenhouse gases. However, with current technology, renewable sources of energy (such as hydroelectricity, biofuels,

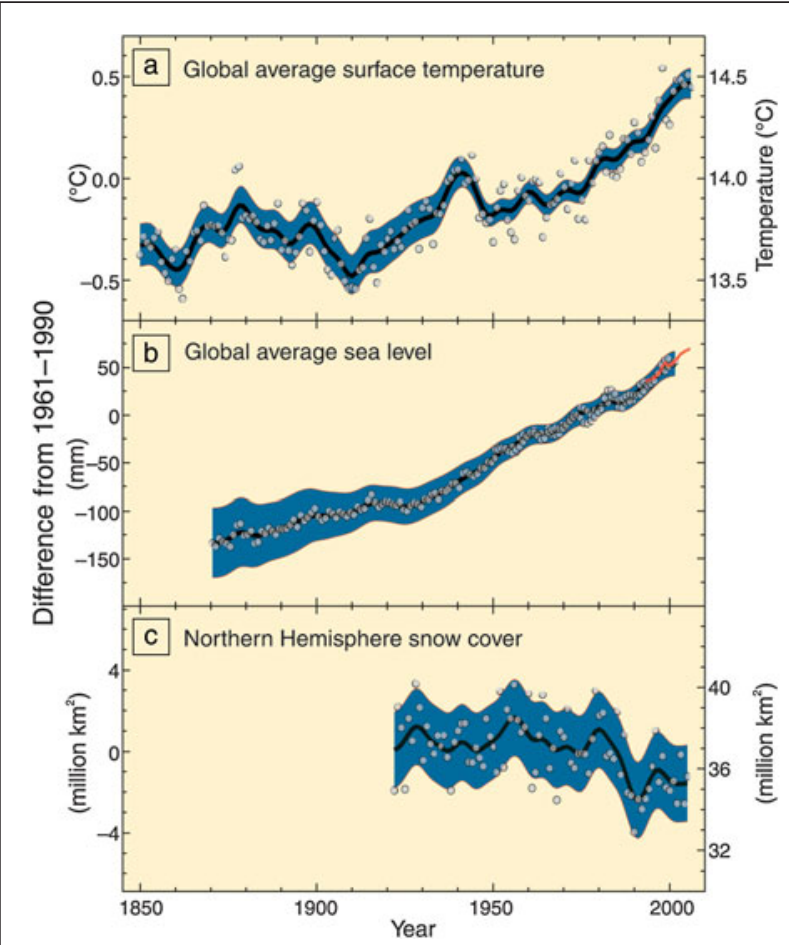

Figure 2. Changes in (a) global surface temperature, (b) global sea level, and (c) Northern Hemisphere snow cover over a period of 150 years (1850-2000). In each graph, "0" on the left vertical axis represents the average value for the period 1961-1990. Solid lines are 10-year averages of annual data (circles), and shaded regions represent uncertainty intervals. For sea level, the blue and red lines are from tide-gauge and satellite data, respectively. Global surface temperatures have risen significantly since the 1950 s compared to the period of 1850-1950. Similarly, the sea-level and snow-cover data indicate adverse changes, especially since the 1950s. (Figure 1.1 from Reference 6 reproduced courtesy of the Intergovernmental Panel on Climate Change.) and geothermal energy) will not be sufficient to meet the energy consumption needs of the world. Nevertheless, materials developments could make solar power, biofuels, and wind power into increasingly important resources. For expanded reliance on solar energy, future materials developments are needed in nanostructured materials and advanced photovoltaic materials such as nanocrystalline-silicon thin films and novel chalcogenides. For fuel cells and bio-derived liquid fuels, developments will need to include advanced catalysts with more accessible surface area, nanostructured catalyst supports, and membranes. For broader use of wind turbines with high power output, there is a great need for the development of high-strength non-rareearth-based permanent magnets for compact, low-maintenance generators.

In addition, "next-generation" nuclear energy has much to offer as a potential carbon-free baseload energy source (i.e., one that can provide the minimum amount of power needed to meet customer demands on a continuous basis). From a cost perspective, nuclear power also offers advantages over other non-fossil-based energy sources. The Nuclear Energy Institute reports: "Nuclear plants are the lowest-cost producer of baseload electricity. The average production cost [in North America] of 2.14 cents per kilowatt-hour includes the costs of operating and maintaining the plant, purchasing fuel, and paying for the management of used fuel."13

Several countries have established initiatives to reduce greenhouse-gas emissions from power production. For example, Tekes, the National Technology Agency of Finland, announced targets for increases in total supply of renewable energy by $40 \%$ by the year $2025 .{ }^{14}$ However, many more such initiatives are needed, and they are needed on a scale that will make a difference.

\section{Transportation}

Global use of powered vehicles will increase significantly in the next few decades, especially because some developing countries have been experiencing annual growth rates of around $8 \%$ for several years in succession. To meet these growing transportation demands, more sustainable materials and modes of transportation will need to be developed.

For example, public transportation will need to be the dominant means of transporting the masses. This approach has certainly proven effective in Japan, France, and many other European countries. Lightweight structural materials, specifically alloy development and processing, will be the focus of future materials advances in this field, including foamed structures, magnesium-based components, and advanced aluminum alloys that can be selectively stiffened. Future materials will also include innovative material uses such as recyclable composites and biocomposites. For example, Duralin fibers (made by Ceres in the Netherlands) are produced when flax straw is steamed, dried, and cured. ${ }^{14}$ Strong and lightweight materials, material source sustainability, and material recyclability will be some of the major factors influencing the development of future materials for transportation needs. 


\section{Housing}

With increasing world population, the materials research community has an opportunity to make a major impact by developing novel construction materials that are environmentally benign, energy-efficient, and affordable. Shelter needs for the world's population require novel material solutions as well as novel housing designs.

The future will likely witness more energy-efficient homes that use intelligent materials and intelligent designs. ${ }^{15}$ As an example, the Institute of Solar Energy Systems in Freiburg, Germany, discovered a means to make use of the temperatureequalizing effect of thick walls by incorporating a concentrated heat-retaining material within a millimeter-thin layer of plaster. ${ }^{16}$ The effects on energy savings and pollutant reductions, for example, are significant. The premise is that much more needs to be done in this whole arena of intelligent materials that are "green" and energy-efficient-a fertile area for materialsrelated discoveries and innovations.

Future developments in housing will also be realized through innovative design and collaboration with architects and builders. The scientific and engineering community has an opportunity to partner with leading architects to address energyefficient and sustainable construction materials, in addition to satisfying the shelter needs of the entire global population.

\section{Material resources}

Between 1960 and 2000, the amount of municipal solid waste generated annually in the United States increased from 88 million tons to 232 million tons (from 80 million tonnes to 210 million tonnes). On average, each American produced nearly $4.5 \mathrm{lb}$ $(2.0 \mathrm{~kg})$ of garbage per day in 2000 , up from $2.7 \mathrm{lb} /$ day ( $1.2 \mathrm{~kg} /$ day) in $1960 .{ }^{17}$ This waste is either burned, emitting pollutants, or deposited in landfills, introducing toxic substances into groundwater and soil. ${ }^{18}$ Considering the toxic materials found in municipal solid waste, there is cause for concern.

An additional problem with increased waste is that the materials contained in discarded objects are unavailable for further productive use. For example, one-third of the world's copper is currently found in landfills, rather than being incorporated in useful applications. ${ }^{19}$ In contrast, scarce materials, such as rare earths, are meticulously recycled to preserve their supply. Recycling can also be beneficial environmentally and economically. For example, the recycling of $1 \mathrm{~kg}$ of aluminum saves up to $6 \mathrm{~kg}$ of bauxite, $4 \mathrm{~kg}$ of chemical products, and $14 \mathrm{kWh}$ of electricity compared to the production of $1 \mathrm{~kg}$ of new aluminum. ${ }^{20}$ Future world needs will require materials that are fully recyclable or biodegradable, as well as a whole new paradigm for designing components by adopting a "cradle-to-cradle" philosophy that supports the remanufacturing of components from spent products into new products.

Effective and efficient recycling will be supported by technologies for sorting metals rapidly by composition. Moreover, with increased consumption providing more scrap (e.g., beverage cans) and enabling technologies that allow rapid recycling and rapid composition analysis, it will be possible to produce "new" aluminum ingots solely from scrap, without any ore refining. Because many materials used widely in desirable products are not renewable, the opportunities for resource recovery and recycling are vast.

\section{Health}

Life expectancy over the years has increased significantly. During the past five decades alone, life expectancy has risen by $15 \%$ (from 69 to 80 years) in North America, and similar trends have been experienced across the globe, except for sub-Saharan Africa. ${ }^{14}$ More importantly, not only are people in most areas of the world living longer, but they are enjoying better health as well, thanks to the many advances in medicine, biology, and MSE. Examples include the increased use of biomaterials, implantable medical devices, and tissue engineering. Some of the opportunities for further materials-centered medical innovations are noted below.

Biomaterials have made tremendous advances. For example, the market potential for structural tissue engineering is US\$90-100 billion, and for the biomaterials industry, growth in research and development spending is about $24 \%$ per year. ${ }^{21}$ Recent advances and developments include cornea tissue regeneration, artificial skin, and knee cartilage implantation in the perosteal flap. ${ }^{21}$ Devices such as artificial heart valves, coronary stents, and particularly drug-eluting stents have seen significant utilization. ${ }^{14}$ These developments are critically dependent on the advances that have been and continue to be made in the materials science and engineering of biocompatible materials.

Implantable medical devices have seen huge growth during the past decade. Hip joints, knees, and many other parts are now being replaced on an almost routine basis. Thus, in the past two decades alone, medical advances have profoundly improved the quality of life for many patients.

From an MSE perspective, there are many exciting opportunities to continue this positive impact on health. For example, major developments are needed in the area of surface modification of biomaterials to better control blood and tissue compatibility, such as through plasma treatment or chemical grafting. ${ }^{22}$ Through surface modification, it will be possible to manipulate material attributes such as resistance to infection, resistance to clot formation, lubricity, and wear resistance. A good example is how heparin (an anticoagulant) is covalently coupled to a multilayered base coat of a biomaterial surface. ${ }^{22}$ Implants and devices that are also vehicles for drug delivery will be another area for future developments. Tissue engineering coupled with innovative materials for the manufacture of "smart" heart valves is another area for growth and opportunities for future developments. The whole field of biomaterials for regenerative medicine is a fertile area; $\operatorname{Stupp}^{23}$ recently reviewed these opportunities and cited many examples of the potential use of biomaterials for regenerative medicine. In brief, biomaterials of the future will serve not only mechanical functions; rather, they will be regulators of biological activity.

Major advances in bioorganic-inorganic composites are also likely to continue. Langer and colleagues pioneered the 
controlled release of large molecules (e.g., polypeptides) using microspheres made of hydrophobic polymers. ${ }^{24}$ At present, bioerodible polyanhydrides are being synthesized as vehicles to release both large and small molecules; this field could give rise to the ability to carry out "local chemotherapy." 25 In addition, bioerodible polymers are being developed for use as implantable tissue scaffolds to create liver tissue, blood vessels, nerves, and heart muscle. ${ }^{24}$ The hope is that the fusion of biotechnology, nanotechnology, and information technology will allow not only the treatment but also the prevention and curing of disease.

The future is bright for such cutting-edge medical advances as a result of developments in materials engineering. Unfortunately, however, many parts of the globe cannot afford these technologies or do not have access to such medical services. Therefore, from a sustainable health perspective, there is a huge need for the engineering community to develop solutions that will have an impact on the masses and not just a small percentage of the population that has the resources to pay for such "boutique" solutions. In simple terms, there is a burgeoning need for the development of health-related solutions that have an enduring, positive impact on the average global level of health.

For example, breast cancer detection is a routine procedure in most developed countries. Magnetic resonance imaging (MRI) diagnostic techniques have been a major enabling technology for identifying breast cancer in the early stages, such that appropriate treatment can be prescribed and delivered. However, in most developing countries, and particularly on the African continent, many women go undiagnosed for breast cancer, with fatal consequences. To address this problem, the Ludwig research group at Worcester Polytechnic Institute ${ }^{26}$ has developed a low-cost radio-frequency coil that can be used for breast cancer screening by MRI. Such a coil design, costing approximately US\$150-200, can be used in parts of the world where, at present, there is no diagnostic screening at all.

In a broader sense, global health is affected by many factors beyond just medical care. For example, the World Health Organization has estimated that over $9 \%$ of the total burden of disease worldwide can be attributed to lack of access to safe drinking water and adequate sanitation systems. ${ }^{27}$ Further, indoor air pollution is estimated to cause approximately 2 million premature deaths per year, mostly in developing countries, with urban outdoor air pollution causing an additional 1.3 million deaths worldwide each year. ${ }^{28}$ Opportunities abound for MSE practitioners to have a dramatic impact in both of these areas. For example, IHSAN (Industry's Humanitarian Support Alliance $\mathrm{NGO}$, Inc.) has sponsored the deployment of inexpensive, lightweight, hand-cranked UV-based water-purification systems in communities in Iraq and Kenya. ${ }^{29,30}$ An alternative approach is taken by the company Vestergaard Frandsen, whose LifeStraw ${ }^{\mathbb{R}}$ product uses $0.2-\mu \mathrm{m}$ hollow-fiber ultrafiltration membranes to provide clean drinking water upon application of sufficient suction to the mouthpiece of the straw. ${ }^{31}$

High levels of indoor air pollutants, including carbon monoxide and small particulates, result from cooking and heating with solid fuels (e.g., coal and biomass) on open fires or traditional stoves. This significant cause of poor health can be addressed by developing cleaner and more efficient fuels (e.g., biogas) or energy technologies (e.g., solar power) that are also affordable. In addition, more efficient, cleaner-burning cookstoves are being distributed by a number of groups (see, for example, Reference 32). Continuing efforts will be required to make further progress in this area. Likewise, materials-related efforts to improve outdoor air quality, especially in urban areas, will continue to involve the development of cleaner energy technologies, cleaner transportation fuels, and more efficient transportation vehicles, as mentioned in preceding sections of this article and addressed in detail in the Transportation and Energy and Water sections of this special issue.

However, technology alone is not the answer. Leadership is needed in developing national policies not solely by government officials but also by engineers. The role of advocacy that our professional scientific and engineering societies must shoulder is pivotal and needs to be supported.

\section{Conclusions}

Society faces grand challenges to sustain continued development in the 21 st century. Although this article has focused on the need for technological innovations for charting a sustainable future, it is important to keep in mind that technical innovations are only part of the solution. Just as important is public policy, which influences the behavior of individuals, as well as that of corporations and communities. By implementing sustainable practices in the use of materials, the materials science and engineering (MSE) community will be well-positioned to take a much more active role in shaping public policy in support of sustainable development.

This is also an extraordinary time to make the case for MSE as a profession to the next generation of students. The challenges of sustainable development are so great that our collective ingenuity will be needed to achieve success. We should focus on the positives and the attributes that speak to the next generation of students, namely, making a world of difference through science and engineering. Let us make the case for engineering by linking the profession to societal issues and presenting engineering as an enabling profession.

\section{Acknowledgments}

Portions of this text were adapted from the book Shaping Our World: Engineering Education for the 21st Century by Gretar Tryggvason and Diran Apelian (Wiley, New York, 2012).

\section{References}

1. World of Work Report 2008: Income Inequalities in the Age of Financial Globalization (International Labour Organization, Geneva, Switzerland, 2008). 2. T.R. Malthus, An Essay on the Principle of Population (Oxford University Press, New York, 1993), Chapter II, p. 18.

3. T.E. Graedel, B.R. Allenby, Industrial Ecology and Sustainable Engineering (Prentice Hall, Upper Saddle River, NJ, 2010), Chapter 1

4. "World population to reach 9.1 billion in 2050, UN projects" (UN News Centre, New York, 2005), www.un.org/apps/news/story.asp?NewsID=13451 (accessed January 2012) 
5. D. Apelian, J. Met. 59 (2), 9 (2007).

6. Climate Change 2007: Synthesis Report. Contribution of Working Groups I,

II and III to the Fourth Assessment Report of the Intergovernmental Panel on

Climate Change, R.K. Pachauri, A. Reisinger, Eds. (Intergovernmental Panel on Climate Change, Geneva, Switzerland, 2007).

7. "Repeat Photography Project" (U.S. Geological Survey, Reston, VA), www. nrmsc.usgs.gov/repeatphoto/overview.htm (accessed January 2012).

8. 'We the Peoples': The Role of the United Nations in the 21st Century (United Nations, New York, 2000).

9. Global Change 2: Human Impacts Lecture "Urbanization and Global Change" (University of Michigan, Ann Arbor, MI, 2002), www.globalchange.umich.edu/ globalchange2/current/lectures/urban_gc (accessed January 2012).

10. "Life expectancy in sub-Saharan Africa is lower now than 30 years ago: UN index" (UN News Centre, New York, 2006), www.un.org/apps/news/story.asp? NewsID=20548 (accessed January 2012)

11. M.S. Dresselhaus, G.W. Crabtree, M.V. Buchanan, MRS Bull. 30 (7), 518 (2005).

12. M.F. Ashby, Materials and the Environment: Eco-informed Materials Choice (Butterworth Heinemann, Boston, 2009).

13. "Electricity Supply" (The Nuclear Energy Institute, Washington, DC), www. nei.org/keyissues/reliableandaffordableenergy/electricitysupply (accessed January 2012)

14. D. Apelian, J. Met. 59 (2), 9 (2007)

15. G. Tryggvason, D. Apelian, Shaping Our World: Engineering Education for the 21st Century (Wiley, New York, 2012).

16. B. Niesing, Fraunhofer Mag. 36, 1 (2004)

17. Municipal Solid Waste Generation, Recycling and Disposal in the United States: Facts and Figures for 2010 (Report EPA-530-F-11-05, U.S. Environmental Protection Agency, Washington, DC, November 2011), p. 9.

18. D.B. Spencer, wTe Corporation, Bedford, MA, corporate information.
19. R.B. Gordon, M. Bertram, T.E. Graedel, Proc. Natl. Acad. Sci. U.S.A. 103 (5), 1209 (2006).

20. "Metals-Aluminium and steel recycling" (Waste Online, London, UK, 2005), www.wasteonline.org.uk/resources/InformationSheets/metals.htm (accessed January 2012).

21. A. Courey, presented at the Materials Science \& Technology 2004 [sponsored by TMS (The Minerals, Metals and Materials Society) and AIST (The Association for Iron and Steel Technology)], New Orleans, LA, 26-29 September 2004.

22. R.M. Bergman, MRS Bull. 30 (7), 540 (2005)

23. S.I. Stupp, MRS Bull. 30 (7), 546 (2005).

24. N.A. Peppas, MRS Bull. 31 (11), 888 (2006).

25. MRS Bull. 31 (3), 232 (2006).

26. A. Obi, "A Novel Radio Frequency Coil Design for Breast Cancer Screening in a Magnetic Resonance Imaging System", M.S. Thesis, Worcester Polytechnic Institute, Worcester, MA, December 2003.

27. A. Prüss-Üstün, R. Bos, F. Gore, J. Bartram, Safer water, better health: Costs, benefits and sustainability of interventions to protect and promote health (World Health Organization, Geneva, Switzerland, 2008).

28. "Air quality and health" (Fact sheet no. 313, World Health Organization, Geneva, Switzerland, September 2011).

29. "Current Projects" (IHSAN, Washington, DC), www.ihsan-h20.org/projects/ (accessed February 2012).

30. "Hand cranked power = clean water!" (B9 Plastics, Inc., Ontario, NY), www. b9plastics.org/BWMfunction.html (accessed February 2012).

31. "Working Principle of LifeStraw" (Vestergaard Frandsen, Lausanne, Switzerland), www.vestergaard-frandsen.com/external/lifestraw-functioningand-efficacy-report.pdf (accessed February 2012).

32. "BIE Faculty Roundtable: Improved Cookstoves in Developing Countries" (Berkeley Institute of the Environment, Berkeley, CA), bie.berkeley.edu/cookstoves (accessed February 2012).

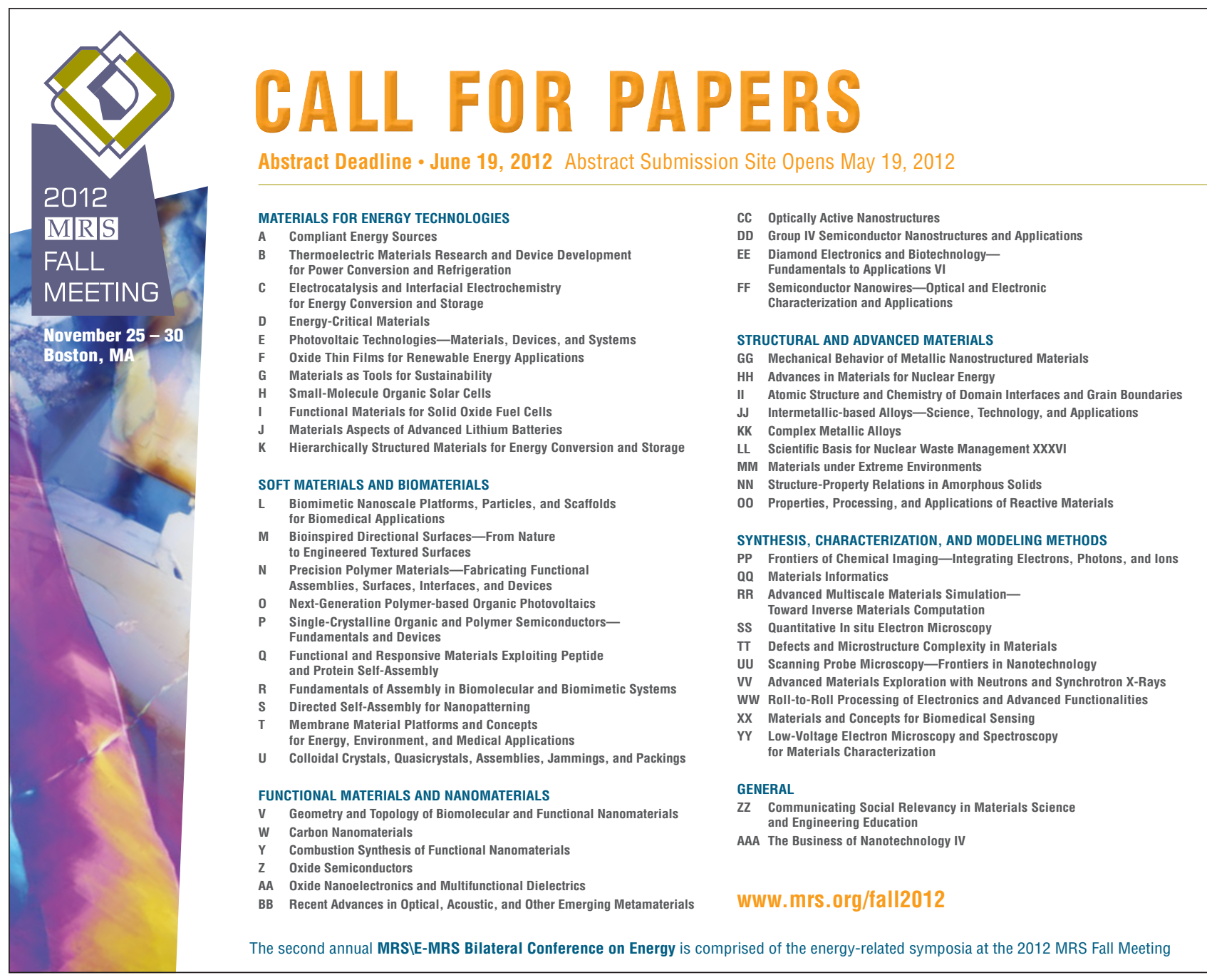




\section{Kurt.J. Leskero}
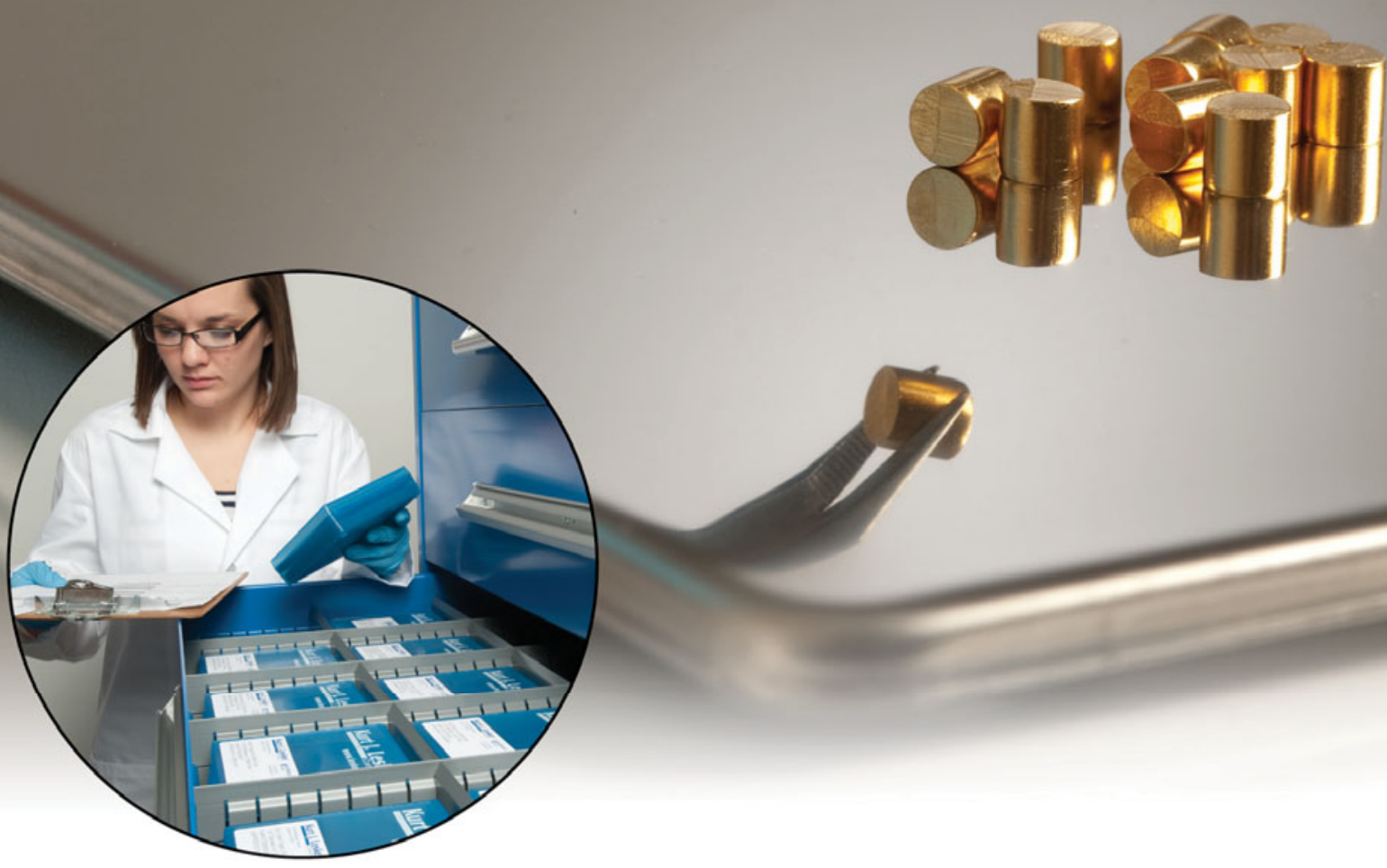

\section{Fuel for Your Research}

\section{All Things Vacuum}

$\mathrm{KJLC}^{\circledast}$ offers the most comprehensive inventory of pure elements, alloys, advanced metal oxides and compounds fabricated to meet the

most demanding physical vapor deposition process requirements.
- Largest Target and Evaporation Materials Inventory

- Custom Compositions, Purities and Quantities

- Unmatched Service and Technical Support

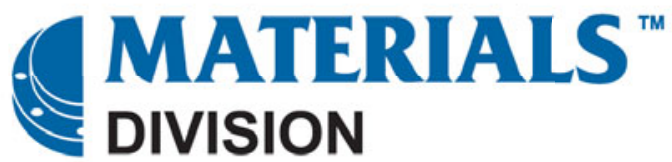




\section{Will metal scarcity impede routine industrial use?}

\section{T.E. Graedel and Lorenz Erdmann}

Materials scientists today employ essentially the entire periodic table in creating modern technology. In an age of sharply increasing usage, it is reasonable to wonder about the supplies of these elemental building blocks. In this article, we review current and prospective supply and demand for a variety of metals. Although data are often sparse, available information suggests that current practices are likely to lead to scarcity for some metals in the not-too-distant future. We conclude by discussing policies that, if adopted, might defuse some of these concerns.

\section{The dynamism of metal extraction and use}

As recently as 20 or 30 years ago, designers of most manufactured products drew from a palette of a dozen or so metals. That situation has changed remarkably, as modern technology employs virtually the entire periodic table. A few examples illustrate this point: turbine-blade alloys and coatings make use of more than a dozen metals; ${ }^{1}$ thousands of components are assembled into a single notebook computer; and medical equipment, medical diagnostics, and other high-level technological products incorporate more than 70 metals. $^{2}$ This transformation is the result of the continuing search for better materials performance. To improve operational characteristics, 60 or so metals are incorporated into each microchip, ${ }^{3}$ and microchips are increasingly embedded into industrial plants, means of transportation, building equipment and appliances, consumer products, and other devices. ${ }^{4}$ It is thus increasingly important to determine whether reliable supplies of all of these metals are available, because a product designer might wish to employ a material that is not available in sufficient quantity or at a suitable price when it is needed..$^{5}$

During the Industrial Revolution, vast metal deposits became accessible. Since then, wars or cartels have occasionally disrupted supplies for short periods, but the markets have always been restored over time. More recently, however, challenges to medium- or long-term supplies of a number of metals ${ }^{6,7}$ have led to increasing unease. This state of mind was reinforced in
2011 by a committee of the American Physical Society and the Materials Research Society that identified several elements, including 10 rare earth elements, as potentially critical for energy-related technologies. ${ }^{8}$

Metals, in particular, are being extracted at increasing rates (Figure 1), and end-of-life recycling rates for many of them are low to dismal. ${ }^{10}$ Moreover, for products with long service lifetimes such as turbine generators or high-speed locomotives, a stable set of materials must be available for maintenance and repair over several decades. It is therefore reasonable to ask: "Will supplies of any materials run out? If so, what and when?" In this article, we explore these questions by examining the present state of metal supply and demand, reviewing various studies of future needs, and then addressing potential limitations in response to those needs. Finally, we discuss some strategies and policies that corporations and governments might wish to consider in response to this information.

\section{Supply considerations Mining and processing}

Metals are not uniformly accessible in nature. Some metals form their own minerals, whereas some occur only in the lattices of other principal minerals (e.g., gallium in the aluminum ore bauxite). Average crustal abundance is not a good measure of overall availability, because geological processes create concentrations of individual elements or groups of elements 


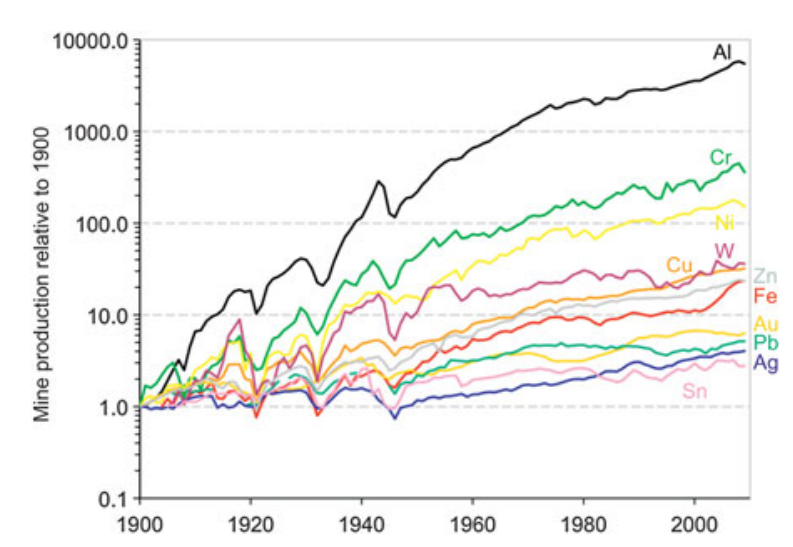

Figure 1. Relative rates of global use of materials in the 20th century. The use rate for each metal is normalized to unity in 1900. (Revised and updated from Reference 9.)

through episodic events. The deposits are dispersed geographically, and discovering them is often a challenge. For those metals that are widely used, such as lead or zinc, the occurrence and extraction potential are reasonably well known. For many of the scarcer metals, especially those brought into wide use relatively recently, information on occurrence, concentration, recovery efficiency, and so forth is often not routinely available.

Obviously, an ore body will be mined only if anticipated sales of its metals will make the venture profitable. Determining profitability in a fluctuating market is not simple, and the large investment needed to open a new mine is an ever-present barrier. Complicating the issue is the time required from discovery to production, typically a decade or more. ${ }^{11}$

\section{Companion metals}

The majority of metals in use today are not the direct target of mining, but rather are "companions" (trace constituents) in the ores of the more common metals (their "hosts"). If these companions (e.g., gallium) are to be available for use, they must be separated from their much more abundant host metals (e.g., aluminum) and then purified to a suitable (often very high) quality. The host metal's annual production value is often 100 times or more that of the byproduct metal. As a result, the value of the companion metal is unlikely to be the dominant factor in the decision to open or close a mine.

Nonetheless, much byproduct material is lost not at the mining stage but in the processing and/or refining of the ore. Over time, increased prices of the byproduct metals could encourage mining and refining companies to recover larger fractions of them rather than lose them in mine tailings, slag, or other discards.

\section{Geographical source concentration}

Mineral deposits are not equally or randomly distributed on Earth. Some minerals are predominantly found in only a few countries, whereas others have more widely dispersed ore deposits. In general, the more concentrated a mineral's deposits, the higher the risk that one or a few countries can restrict its supply. Analysis of metal reserves by the authors has identified the most geographically concentrated metals as strontium (China), the platinum group (South Africa, Russia), niobium (Brazil), tellurium (United States, Australia), and manganese (Ukraine, South Africa).

\section{Recycling}

Metals are extracted from natural deposits, processed, and then incorporated into products. When present as product constituents, the metals constitute anthropogenic metal stocks, providing the desired benefits during product in-service lifetimes. In principle, these stocks can be recovered and reused in the future, thus taking some of the pressure off virgin material supplies.

For some metals, recycling streams currently provide significant inputs to manufacturing, with lead being a prime example. Worldwide, some $80 \%$ of the lead removed from use is recycled, largely because it is predominantly employed in large amounts in relatively pure form in storage batteries that can be easily collected and processed. Copper is also widely recycled, reflecting the use of high-purity copper in such applications as power distribution and plumbing.

Such situations are unusual, however. As Figure 2 shows, most metals are primarily used in alloy form, in complex assemblages, or in uses that inherently dissipate the material. Only six metals - copper, gold, lead, platinum, palladium, and rhodium - are used predominantly in elemental form, thereby enabling recovery in that form. For nine others, including antimony and zirconium, the dominant use is dissipative, so that little or no recycling is possible. Gallium, yttrium, and 14 other metals are employed largely in complex assemblages from which recovery in elemental form is technologically very challenging and expensive. The remaining 27 elements, including molybdenum, gadolinium, and tellurium, are primarily used as alloy constituents. Even if recovered and properly identified, an alloy will likely be reused only if it or a similar alloy is needed, and the reuse will be in alloy form; the individual metals will not be recovered, meaning that their special properties in non-alloy form will be lost. The dissipation of certain metals into other recycling processes can even degrade the quality of the recycled material (e.g., the entry of copper into steel recycling from shredders).

\section{Demand}

\section{Factors affecting demand}

The single factor with the most influence on a country's demand for metals is per capita wealth, as demonstrated by Binder et $\mathrm{al}^{32}$ in a statistical analysis of copper and zinc. The same result was found by Graedel and $\mathrm{CaO}^{33}$ for a group of seven widely used metals: chromium, copper, lead, iron, nickel, silver, and zinc. Similar studies have not been carried out for other metals, but the incorporation of so many of the elements in a wide variety of consumer products that also contain the metals that have been studied suggests that the same pattern would hold for many others. 


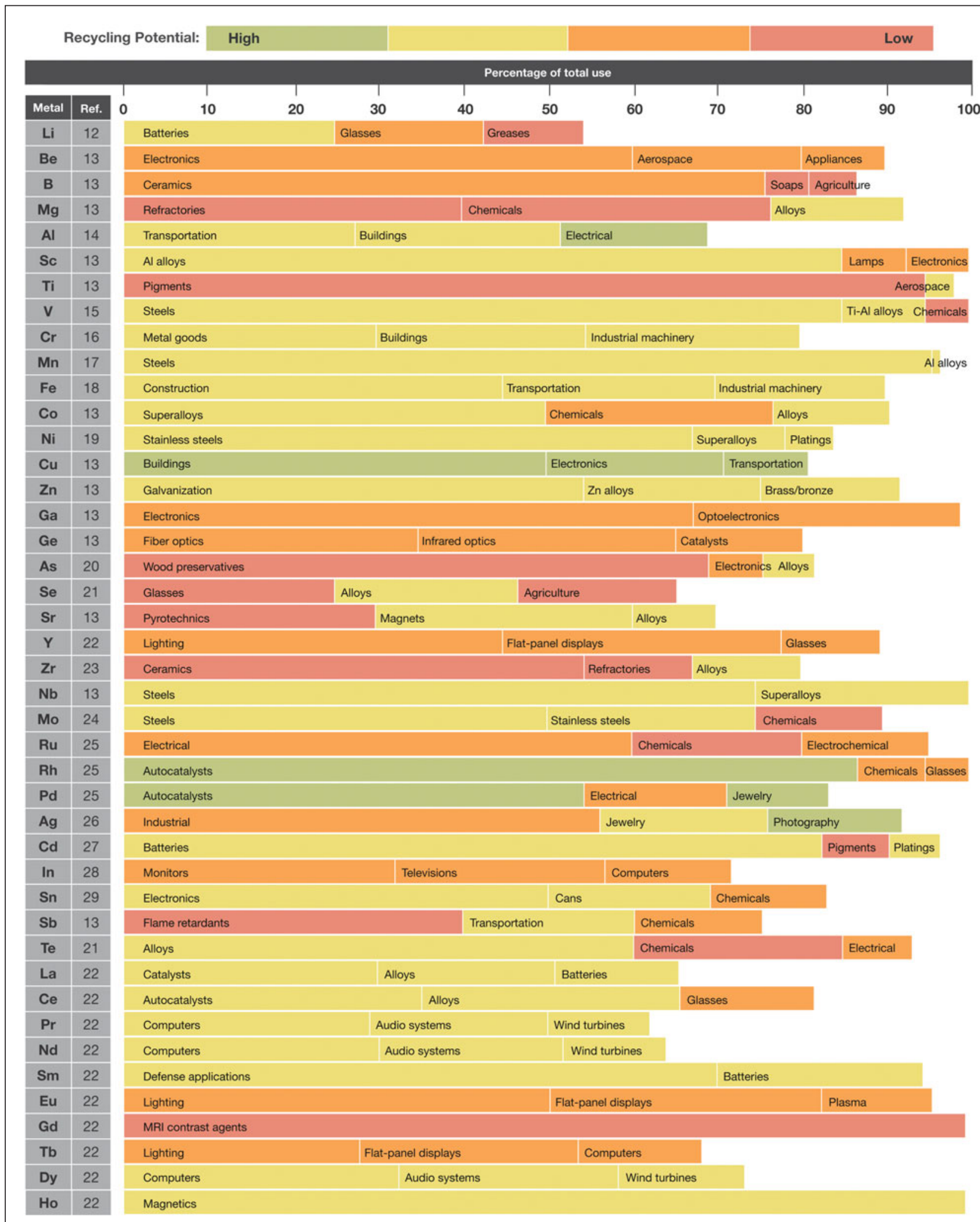

Figure 2. Principal uses and recycling potentials of selected metals. Bar length indicates the fraction of current use of the element devoted to the indicated application. Green, largely recoverable in pure form; yellow, largely in multicomponent alloy form; orange, largely in complex assemblages; red, largely in uses where the element is dispersed. 
(Figure 2 continued from previous page)

\begin{tabular}{|c|c|c|c|c|c|c|c|c|}
\hline \multicolumn{2}{|c|}{ Recycling Potential: } & High & & & \\
\hline
\end{tabular}

\section{Potential for substitution}

Economists often say that, if a material becomes too scarce or too highly priced, a suitable substitute will soon emerge. The actual situation is much more complicated. In today's technology, materials are selected for specific and often unique properties - emission spectrum, conductivity, electronic structure, magnetocaloric effect, and the like. In optoelectronics, for example, the central elements include gallium, germanium, tellurium, and indium. The most suitable substitutes tend to come from the same part of the periodic table, because they have similar physical and chemical properties. ${ }^{34}$ However, because of those same properties, the elements generally occur together in the same ore deposits in nature. As a consequence, the most suitable substitute for a given scarce element will often experience a similar scarcity.

This is not to imply that the economic generalization is completely incorrect. Scarcity does indeed stimulate new research, and full substitution of metals can and does occur at the element, material, component, product, or functional level. However, as technology demands materials with ever more specialized properties, the challenges related to substitution will only increase, and efforts to enhance the resilience of the material supply, such as the recovery of previously used materials, should receive at least as much attention as research on substitutes.

\section{Evolutionary demand change}

With population growing and personal wealth increasing throughout the world, the historic growth in metal demand shown in Figure 1 can be expected to continue. It has been suggested $^{33,35}$ that, by mid-century, the aggregated flows of metals into use could increase by a factor of 5-10 compared to today's levels.
This evolving demand is nicely illustrated by the case of the stainless steel cycle in China in 2000 and in 2005. From an already healthy flow into use of nearly $1600 \mathrm{kt}$ of stainless steel in year 2000, the flow nearly tripled in five years. At the same time, the outflow to recycling and waste management was very small in relation, a signal that the stainless steel was seeing first use in its applications rather than replacing existing obsolete uses.

However, predictions based on per capita metal use have limits. Müller et al. ${ }^{36}$ showed that iron use appears to have reached a plateau of 8-12 t per capita in France, the United Kingdom, and the United States (Figure 3). In other countries, a plateau has yet to be reached. It is not known whether a similar pattern applies to other metals, because the data are simply not available.

\section{Transformative demand change}

Rapid changes in demand can occur if new technologies gain a market foothold and then expand rapidly. The effect can be particularly dramatic in the case of lightly used specialty materials. For example, starting in the mid-1990s, gadolinium-based compounds gained favor as contrast agents in magnetic resonance imaging. ${ }^{37}$ As medical facilities worldwide adopted these agents, the use of gadolinium increased by a factor of five within a decade (Figure 4). Similarly, indium was used in only small quantities in electrical applications until the late 1990s. The advent of flat-panel display screens with outer surface coatings of indium tin oxide, however, increased indium use by a factor of about three within a decade (Figure 5).

A study of innovative technologies that could noticeably raise future raw-materials demand was carried out by Angerer et al. ${ }^{38}$ They reported that, by 2030, the demand for several elements $(\mathrm{Cu}, \mathrm{Pd}, \mathrm{Ti}, \mathrm{Ag}, \mathrm{Ta})$ used in emerging technologies 

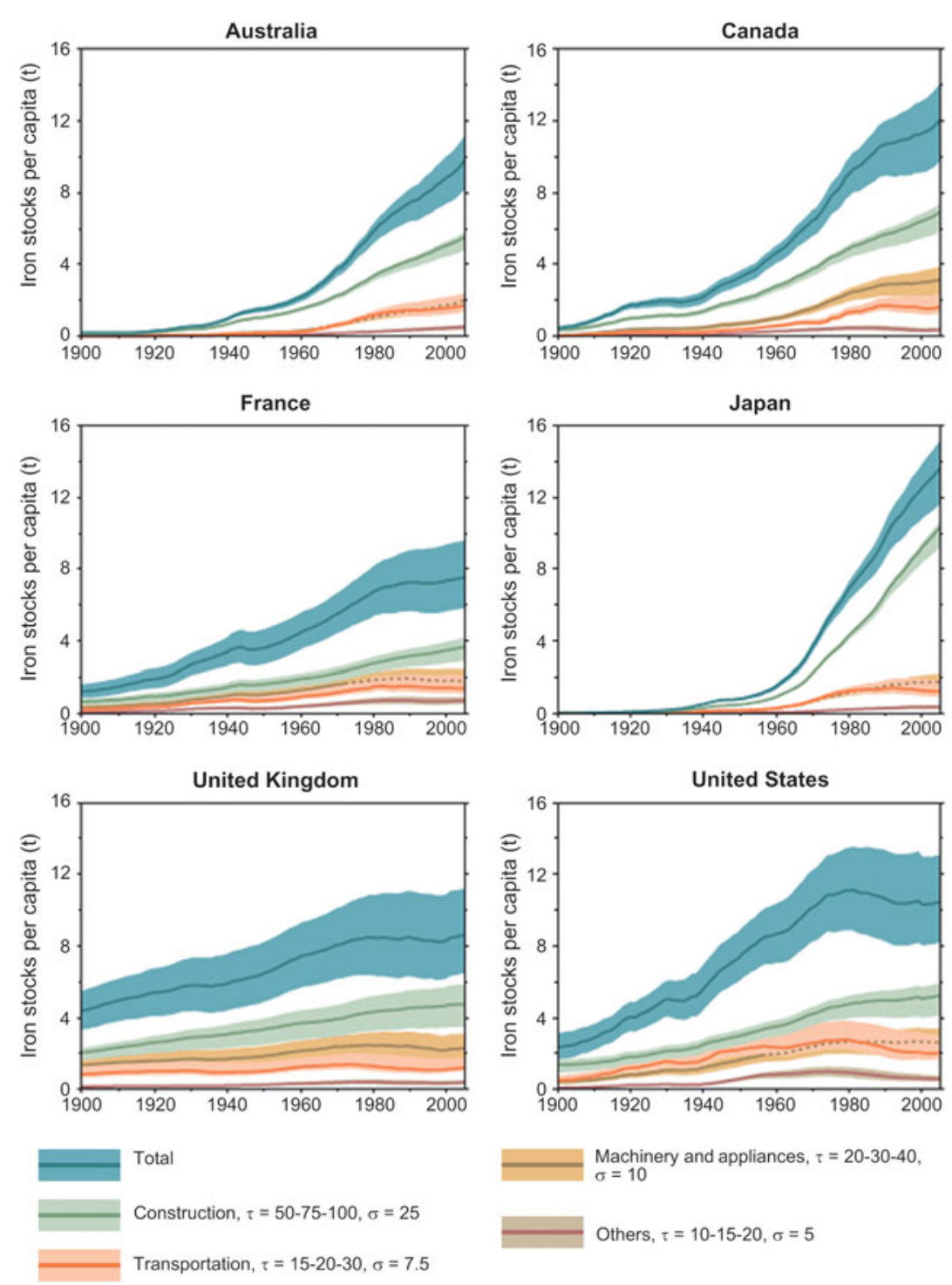

Figure 3. Total iron stocks (blue) over time in six countries, along with the decomposition of the stocks into four principal product categories. The shaded bands show the variations corresponding to the lower, middle, and upper estimates of mean product lifetimes in years, $\tau$, which span a range of $2 \sigma$, where $\sigma$ represents the standard deviation. (Reprinted with permission from Reference 36. (c) 2011, American Chemical Society.)

to predict because few complex, integrated medium- to long-term investigations have been performed. Nonetheless, the historical and prospective trends considered in the preceding sections indicate that manufacturers can no longer take adequate supplies of many materials for granted. For example, Kleijn and van der Voet $^{39}$ explored the impact on resource needs if the world were to transition to a hydrogen economy based on renewable energy sources. They showed that full implementation of wind turbines, automotive fuel cells, and an expanded electrical grid would likely be impeded by inadequate supplies of neodymium, platinum, and copper. A similar situation is likely to apply to a number of other technologies and their enabling materials.

A different aspect was considered by Müller et al., ${ }^{36}$ whose analysis of iron demand in China in the 21st century is shown in Figure 6. They calculated that the use of steel for new buildings will peak in about 2035, because, by then, all Chinese should be adequately housed. Consequently, demand will then drop sharply. As buildings begin to reach the end of their usable lives, around 2050 for those built near the turn of the century, demand will again begin to rise. Some of this renewed demand, however, can be met with steel recycled from the original pulse of building a half-century earlier.

\section{Policy considerations in metal supply and demand}

If the supply of specific materials could become constrained, what are the implications for corporations? Duclos et al. ${ }^{5}$ suggested the following steps for manufacturing industries to avoid severe impacts:

- Catalog all of the materials used in the company's products. (This is a major task for firms with diffuse supply chains.)

- Develop alternative sources for all materials

was likely to increase by about a factor of three compared with 2006 levels. For several scarce specialty metals, the anticipated increases are even more dramatic: seven times for neodymium (used in high-strength magnets in wind turbines and hybridautomobile engines), eight times for germanium (fiber-optic cables) and indium (flat-panel displays), and 22 times for gallium (thin-layer photovoltaics). These are plausible projections, not certainties, but they suggest the potential for transformative technologies to transform materials demand as well.

\section{Considering the future}

The various supply and demand factors can be significantly influenced by human intervention, but the effects are hard used.

- Consider long-term supply agreements with materials suppliers.

- Improve material utilization in manufacturing.

- Develop recycling technologies for potentially constrained materials, as well as a recovery infrastructure for retrieving discarded products.

- Reduce the use of at-risk materials through product redesign and consider the use of substitute materials.

- Consider whether alternative technologies will provide satisfactory service to the customer.

Current recycling systems mainly target commodity metals such as steel, copper, and aluminum. The related recycling 


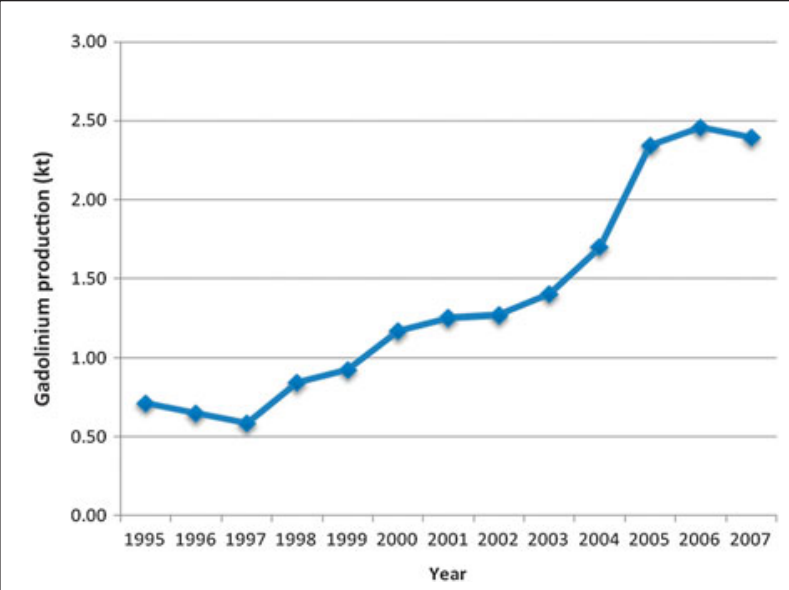

Figure 4. The rate of production of gadolinium shows a dramatic increase over the period 1995-2007. (Abstracted from Reference 22.)

processes, such as shredders for cars, were designed decades ago. However, current and future cars consist of many different materials (e.g., lithium-ion batteries, composites) that will be lost in outdated recycling processes. Thus, there is a clear need for better design for recycling (e.g., easily accessible components and easy opening of fastenings) and for new recycling processes that support the recovery of scarce metals (e.g., detection and highly efficient separation of materials) and do not pose risks of adulterating other recycling streams. In addition to automobiles, corresponding solutions are essential for buildings, electric and electronic equipment, consumer goods containing valuable materials, and other waste streams.

Just as product designers have learned to innovate under the restrictions of environmental legislation (e.g., lead-free electronics), they will adapt the design process to account for material availability and increased recycling. Better design for recycling requires cooperation with recycling companies, and accounting for materials availability might involve cooperation with other company departments, especially those responsible for procurement and disposal.

Raw-material acquisition has long been an operational activity within companies. Increasingly, raw-material supply is conceived as a strategic issue that requires risk management. Several large companies have developed strategies to increase resilience towards metal supply disruptions. For small- and medium-sized enterprises as well as entire industrial sectors, supply-chain roadmaps could provide the necessary information and timelines to decrease vulnerability.

All governments and their agencies also need to consider the possibility of supply constraints on vital materials, because no country contains within its borders the entire spectrum of resources. A typical desire is to protect the supply of materials that are vital to important domestic industries and/or to government functions, such as the manufacture and use of military hardware. A "supply-risk radar," developed in cooperation with their industries, could assist governments in monitoring and identifying potential supply risks and in launching the appropriate mitigation measures. For example, substitution for certain metals could be supported by government-funded materials research programs as part of a broader resilience strategy. Some of the suggestions above for corporate policy, such as the development of alternative sources of supply, might be appropriate at the government level as well.

\section{Conclusions}

Will the supply of metals run out? It will not do so in an economic sense, because, if a metal becomes very scarce, its price will rise, thus discouraging routine use. However, restricted use might cause opportunities, such as mass deployment of photovoltaics, to be missed. The supply of metals will also not run out in a physical sense, because metals are shifted from natural deposits to anthropogenic stocks, which can, in principle, be recycled. However, recycling of dissipated metals is restricted by related energy demand and costs.

A more insightful question is to ask whether supplies will be sufficiently constrained to impede routine industrial use. There, our conclusions are on shakier ground. Although recent attempts to classify metals as "critical" 41,42 are regarded as somewhat speculative and debatable, some general guidelines exist:

- Companion metals are riskier than host metals.

- Metals with highly concentrated sources are riskier than those with widely dispersed sources.

- Metals for which recycling is difficult are riskier than those that are readily recycled.

- Metals for which emerging technologies imply major transformations in demand are riskier than those for which demand is likely to be relatively stable. 


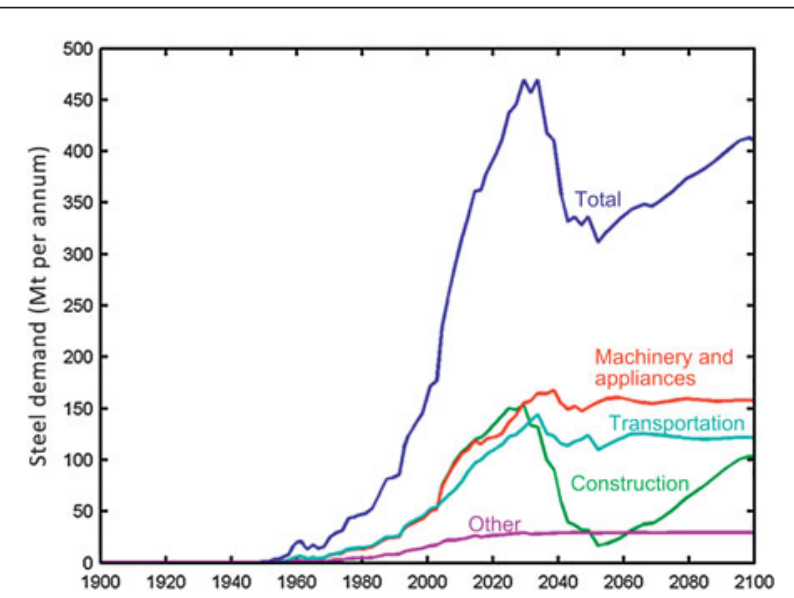

Figure 6. Historical and predicted demand for steel in China. (Courtesy of Pauliuk et al. ${ }^{40}$ )

This article provides perspectives on the supply and demand of metals and general guidelines for evaluating risk-but no firm answers. In a rapidly industrializing but finite world, the possibility for resource constraints to appear in the next few decades is very real and potentially very serious. The thoughtful materials scientist, corporate leader, or policy maker is well advised to understand the complex issue of resource supply and demand better than is now typical and to prepare for its possible eventualities.

\section{References}

1. P.W. Schilke, "Advanced Gas Turbine Materials and Coatings" (Report GER3569G, General Electric Company, Schenectady, NY, 2004).

2. S. Duclos, paper presented at Diminishing Natural Resources: Recognizing Limitations, Responding to the Challenges, Government-University-Industry Research Roundtable Meeting (sponsored by the National Academy of Sciences), Washington, DC, 20-21 October 2009

3. Minerals, Critical Minerals, and the U.S. Economy (National Academies Press, Washington, DC, 2008).

4. L. Erdmann, L.M. Hilty, J. Ind. Ecol. 14, 824 (2010).

5. S.J. Duclos, J.P. Otto, D.G. Konitzer, Mech. Eng. 132 (9), 36 (2010)

6. M. Jacoby, Chem. Eng. News 88 (35), 9 (2010).

7. C. Krauss, New York Times B1 (10 March 2010).

8. Energy Critical Elements: Securing Materials for Emerging Technologies (Materials Research Society/American Physical Society, Washington, DC, 2011).

9. E.M. Harper, J. Johnson, T.E. Graedel, Environ. Eng. Sci. 23, 493 (2006)

10. T.E. Graedel, J. Allwood, J.-P. Birat, M. Buchert, C. Hagelüken, B.K. Reck, S.F. Sibley, G. Sonnemann, J. Ind. Ecol. 15, 355 (2011).

11. R.C. Schodde, J.M.A. Hronsky, in Wealth Creation in the Mineral Industry: Integrating Science, Business, and Education, M.D. Doggett, J.A. Parry, Eds. (Special Publication No. 12, Society of Economic Geologists, Littleton, CO, 2006), pp. 71-90.

12. SQM 2007 Annual Report (Sociedad Quimica y Minera de Chile, S.A., Santiago, Chile, 2007)

13. Mineral Commodity Summaries (U.S. Geological Survey, Reston, VA, 2010). 14. Global Aluminium Recycling: A Cornerstone of Sustainable Development (International Aluminium Association, London, 2006).

15. L. Perron, "Vanadium," in Canadian Minerals Yearbook 2001 (Natural Resources Canada, Ottawa, Canada, 2001).

16. J. Johnson, L. Schewel, T.E. Graedel, Environ. Sci. Technol. 40, 7060 (2006).

17. K. Nakajima, K. Yokoyama, T. Nagasaka, ISIJ Int. 48, 549 (2008).

18. T. Wang, D.B. Müller, T.E. Graedel, Environ. Sci. Technol. 41, 5120 (2007).

19. B.K. Reck, D.B. Müller, K. Rostkowski, T.E. Graedel, Environ. Sci. Technol. 42, 3394 (2008).

20. Minerals Yearbook (U.S. Geological Survey, Reston, VA, 2007).

21. Kirk-Othmer Encyclopedia of Chemical Technology (Wiley-Interscience, New York, 2009).
22. X. Du, T.E. Graedel, Environ. Sci. Technol. 45, 4096 (2011).

23. Mineral Sands Annual Review (TZ Mineral International, Perth, Australia, 2007).

24. "Molybdenum Uses" (International Molybdenum Association, 2010), www.imoa.info/moly_uses/molybdenum_uses.html (accessed 17 January 2011).

25. J. Butler, Platinum 2010 Interim Review (Johnson Matthey Public Limited Company, London, 2010).

26. "The Indispensable Element" (The Silver Institute, Washington, DC, 2011), www.silverinstitute.org/silver_uses.php (accessed 17 January 2011).

27. Mineral Commodity Summaries (U.S. Geological Survey, Reston, VA, 2009). 28. G.R. Matos, J.D. Jorgenson, M.W. George, Historical Statistics for Mineral and Material Commodities in the United States (USGS Data Series 140, U.S. Geological Survey, Reston, VA, 2005).

29. New ITRI Study IIlustrates the Reasons Behind Continued Boom in Tin Use (Tin Technology Limited, St. Albans, UK, 2006).

30. N. Nassar, Yale University, New Haven, CT. Private communication, 2010.

31. J.S. Mao, J. Dong, T.E. Graedel, Resour. Conserv. Recycl. 52, 1058 (2008).

32. C.R. Binder, T.E. Graedel, B. Reck, J. Ind. Ecol. 12 (1-2), 111 (2006).

33. T.E. Graedel, J. Cao, Proc. Natl. Acad. Sci. U.S.A. 107, 20905 (2010).

34. C. Hagelüken, C.E.M. Meskers, in Linkages of Sustainability, T.E. Graedel,

E. van der Voet, Eds. (MIT Press, Cambridge, MA, 2010), pp. 163-187.

35. M. Hu, S. Pauliuk, T. Wang, G. Huppes, E. van der Voet, D.B. Müller, Resour. Conserv. Recycl. 54, 591 (2010).

36. D.B. Müller, T. Wang, B. Duval, Environ. Sci. Technol. 45, 182 (2011).

37. P.L. Verplanck, E.T. Furlong, J.L. Gray, P.J. Phillips, R.E. Wolf, K. Esposito, Environ. Sci. Technol. 44, 3876 (2010).

38. G. Angerer, L. Erdmann, F. Marscheider-Weidemann, M. Scharp, A. Lüllmann, V. Handke, M. Marwede, Rohstoffe für Zukunftstechnologien (Fraunhofer IRB Verlag, Karlsruhe, Germany, 2009).

39. R. Kleijn, E. van der Voet, Renewable Sustainable Energy Rev. 14, 2784 (2010). 40. S. Pauliuk, T. Wang, D.B. Müller, The future of the Chinese steel cycle, paper presented at the 2010 Gordon-Kenan Research Seminar on Industrial Ecology, New London, NH, July 10-11, 2010.

41. N. Morley, D. Eatherley, Material Security: Ensuring Resource Availability to the UK Economy (Oakedene Hollins/C-Tech Innovation Ltd., Chester, UK, 2008). 42. Critical raw materials for the EU: Report of the Ad-hoc Working Group on defining critical raw materials (European Commission, Brussels, Belgium, 2010). $\square$

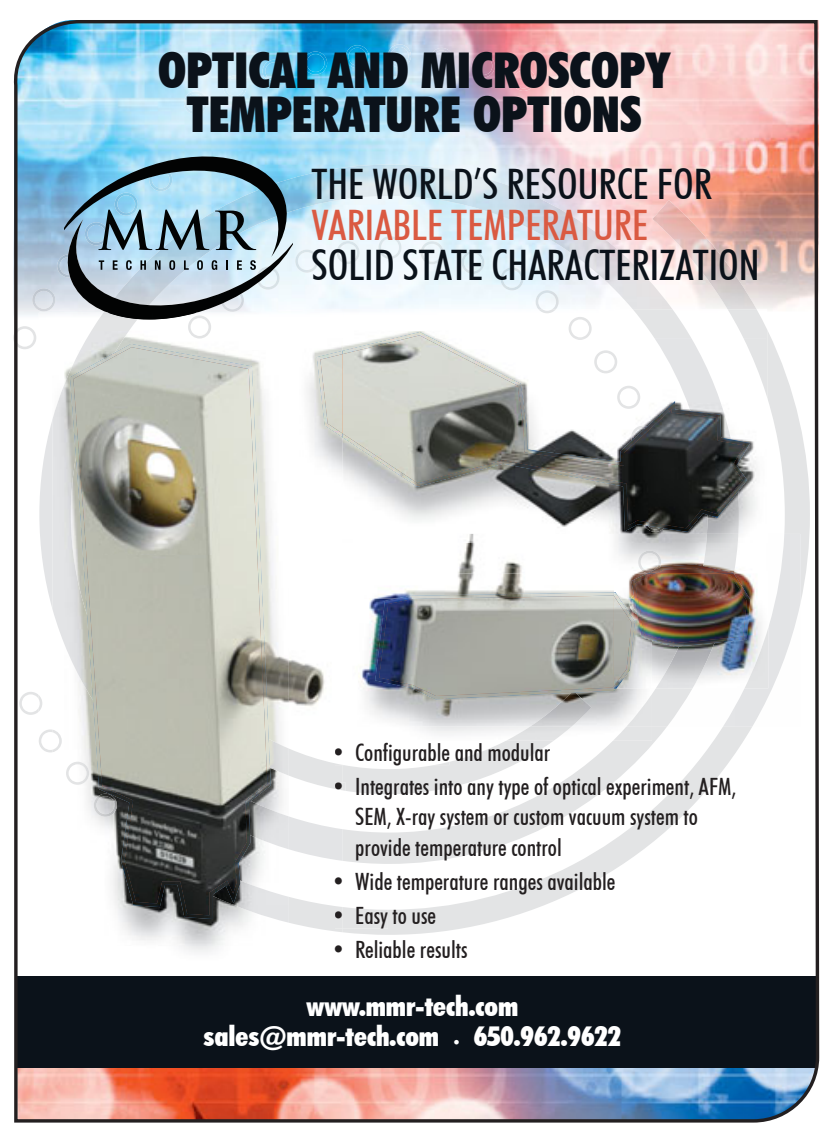




\section{ANNUAL REVIEWS Celebrating 80 Years of Excellence}

Annual Reviews offers comprehensive, timely collections of critical, topical reviews written by leading scientists. Annual Reviews journals examine 40 focused disciplines within the Biomedical, Life, Physical, and Social Sciences, including Economics. Our Editorial Committees select experienced researchers to examine and synthesize literature into concise, insightful review articles. As a result, Annual Reviews journals are among the most highly cited in scientific literature and are consistently ranked within the top ten of journals for their disciplines as indexed by the Journal Citation Reports ${ }^{\circledR}$ (Thomson Reuters).

\section{Order Today and Save $\mathbf{2 0} \%$ on ALL Annual Reviews Journals.}

Please mention priority code MRS when placing your order.

Handling and applicable sales tax additional. Order via phone, fax, or online. Institutional pricing and site license options available.

Contact Annual Reviews for details.

\section{Annual Reviews Physical Science Journals Include:}

- Annual Review of Analytical Chemistry

Volume 5 | Jul. 2012 | http://anchem.annualreviews.org

- Annual Review of Astronomy and Astrophysics

Volume 50 | Sept. 2012 | http://astro.annualreviews.org

- Annual Review of Biomedical Engineering

Volume 14 | Aug. 2012 | http://bioeng.annualreviews.org

- Annual Review of Biophysics

Volume 41 | Jun. 2012 | http://biophys.annualreviews.org

- Annual Review of Chemical and Biomolecular Engineering

Volume 3 | Jul. 2012 | http://chemeng.annualreviews.org

- Annual Review of Condensed Matter Physics

Volume 3 | Mar. 2012 | http://condmat.annualreviews.org

- Annual Review of Earth and Planetary Sciences

Volume 40 | May 2012 | http://earth.annualreviews.org
- Annual Review of Environment and Resources Volume 37 | Nov. 2012 | http://energy.annualreviews.org

- Annual Review of Fluid Mechanics Volume 44 | Jan. 2012 | http://fluid.annualreviews.org

- Annual Review of Marine Science

Volume 4 | Jan. 2012 | http://marine.annualreviews.org

- Annual Review of Materials Research

Volume 42 | Aug. 2012 | http://matsci.annualreviews.org

- Annual Review of Nuclear and Particle Science Volume 62 | Nov. 2012 | http://nucl.annualreviews.org

- Annual Review of Physical Chemistry Volume 63 | May 2012 | http://physchem.annualreviews.org

Access these and all Annual Reviews journals via your institution at www.annualreviews.org 


\section{To recycle, or not to recycle, that is the question: Insights from life-cycle analysis}

\section{Linda Gaines}

Everyone has heard the slogan "Reduce, Reuse, Recycle" - but does observing this hierarchy really minimize negative impacts? With respect to reduction, it seems clear that using less of something decreases the impact. Similarly, reuse of a material or product should decrease the impact of each use, as long as the resources needed to restore the item to usable condition each time are not too large. For recycling, the picture varies by material and often involves tradeoffs among impacts. Life-cycle analysis aims to comprehensively compare all of the impacts of various disposition options. This article summarizes the pros and cons of recycling materials used in paper, drink containers, and the complex batteries for electric vehicles from the perspective of life-cycle analysis.

\section{Why recycle?}

The most commonly stated reason for recycling is to reduce burdens associated with the disposal of our never-ending stream of wastes. Waste disposal potentially causes air and water pollution and is costly; moreover, landfills compete with other land uses. In addition, recycling can extend our supply of materials to alleviate scarcity and to moderate rising prices of raw materials. Furthermore, recycling is often more environmentally benign than using virgin raw materials and can reduce energy use and emissions of greenhouse gases and other pollutants.

\section{Life-cycle analysis}

Despite these positive attributes, not all recycling processes are created equal. For example, Figure 1 shows various alternative paths that might be used to recycle car batteries. As is evident from this figure (and from the definitions in the sidebar), recycling can re-introduce materials at different stages of a production process, thereby displacing parts of the virgin-material process. Each recycling option will create its own impacts, often but not always lower, which must be taken into account as well.

How does one identify the best options? A useful technique for comparing alternative technological options is life-cycle analysis (LCA). LCA takes a system-wide perspective, considering all stages of the life cycle of a product or service, including material production, system manufacture and assembly, service provision, maintenance and repair, and end-of-life processes. In the next section, we show how LCA compares disposition alternatives for discarded materials. The results are not always obvious, as they depend on many factors and can lead to tradeoffs among impacts. Other criteria, such as financial, institutional, or regulatory concerns, enter the picture as well.

\section{Examples}

This section provides three examples in which LCA is useful in comparing options for items that would otherwise be thrown away. The first two examples are short-lived consumer products - paper products and beverage containers - whereas the last is a complex, durable item - the battery for an electricdrive vehicle - that is expected to have a service life of about 10 years. Although this article is written from a U.S. perspective, the general principles of applying LCA to assess material disposition options are universal. The detailed conclusions for particular countries might differ, however, reflecting different prices and availability of raw and recycled materials, energy, and labor.

\section{Paper products ${ }^{1}$}

Newspaper and office paper are produced differently and therefore must be discussed separately. Newsprint is an inexpensive, lightweight paper made mainly from mechanical wood pulp, 


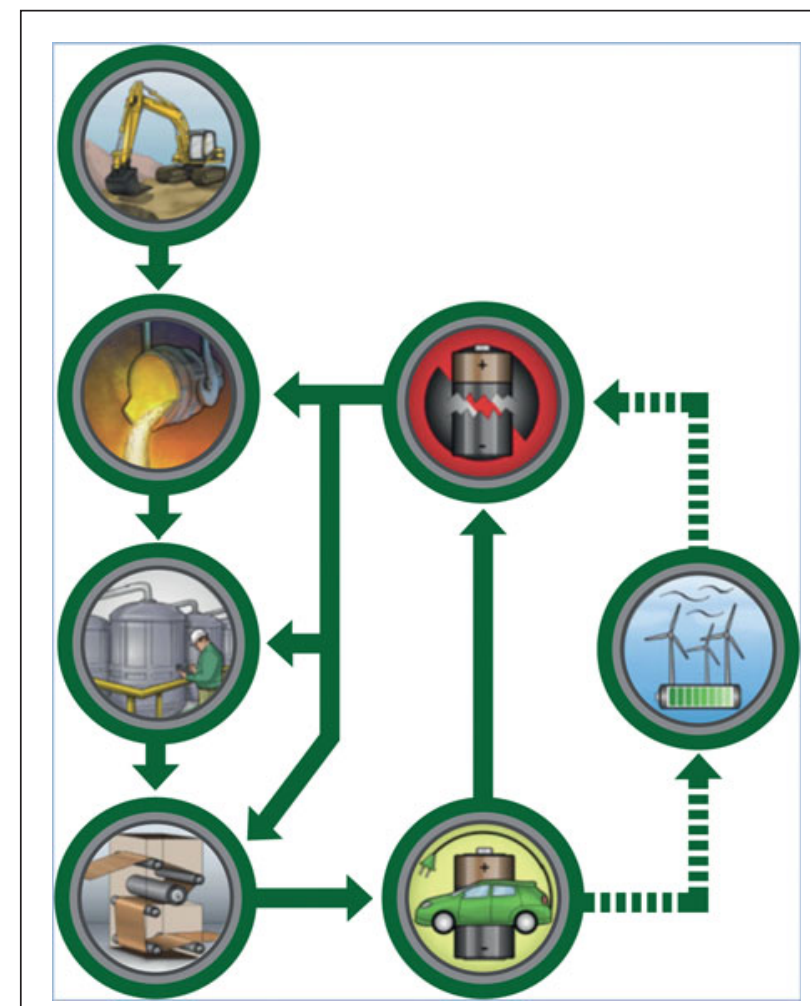

Figure 1. Schematic of battery recycling to different manufacturing stages: This figure depicts mining of ore, primary processing, chemical conversions, and fabrication into a battery. The finished battery is then used in a vehicle and is recycled back to one of the manufacturing steps, possibly after being reused to store energy for an electric utility.

engineered to be bright and opaque for the good print contrast needed by newspapers. The mechanical pulping process leaves most of the lignin in the pulp, which causes newsprint to rapidly become yellow and brittle upon exposure to air and/or sunlight. In contrast, office paper is made from chemical wood pulp obtained by a modified sulfate pulping process (called the kraft process) that removes most of the lignin but leaves the cellulose largely intact. Its natural unbleached color is brown, but it can be bleached to white. Kraft paper is used when strength and/or resistance to yellowing are important, such as in packaging, bags, envelopes, and coated paper, as well as printing and writing papers. Both types of paper can be recycled (either pre- or post-consumer) in a closed loop.

For newspapers, two dispositions that could potentially save energy are recycling to produce new newsprint and burning to displace fossil fuels in electricity generation (see Table I). Excluding the energy in the wood, the net energy difference between recycling and waste-to-energy (WTE) options for newspapers is small. However, recycling newspapers also saves the trees that would have been used to produce replacement newsprint. As a result, the total energy input, including wood, is reduced by recycling newsprint.
Therefore, recycling of newspapers makes sense and should be encouraged.

For office (kraft) paper, the situation is very different. In a modern kraft mill, much of the energy for primary production is supplied from byproduct fuels (e.g., the removed lignin), whereas energy for recycling must be purchased because no fuel byproducts are produced when waste paper is pulped. Because the purchased energy is generally derived from fossil fuels, combustion of waste paper in a WTE plant displaces additional fossil fuel, so the net non-wood energy use is much lower if the paper is burned (see Table I). Therefore, recycling office paper would result in increased use of nonrenewable fossil fuels in place of wood, which is renewable. Burning used kraft paper in U.S. municipal solid waste, instead of recycling it, could displace about 30 million tons of coal annually, or 3\% of U.S. annual coal consumption. It would be similarly beneficial in other countries that wish to reduce both fossil fuel use and waste-disposal costs. Indeed, combustion for energy recovery is an integral part of solid-waste management strategies in many countries throughout the world.

Another factor to be considered in decisions regarding paper production and disposition is carbon dioxide emissions. Young trees grown in plantations to replace those cut for paper production take in more carbon dioxide than do slow-growing trees in old forests. One study ${ }^{3}$ estimated the effects on carbon dioxide emissions for various options for paper production and disposition. This study concluded that producing kraft paper from plantation trees and burning the waste paper for energy recovery is preferable, from the standpoint of greenhouse-gas emissions, to all other options - including recycling. Thus, burning is the preferred disposition for office paper, regardless of whether the objective is to reduce greenhouse-gas emissions, minimize fossil fuel use, or preserve old-growth forests.

\section{Soda cans and bottles}

Per pound, fabricated aluminum is about nine times as energyintensive to produce as glass. However, aluminum cans are extremely light (typically under $0.5 \mathrm{oz}$ each), with a typical singleserve 12-fl-oz can weighing one-13th as much as a 12-fl-oz glass bottle. ${ }^{4}$ As a result, the energy required to produce a single-serve container from virgin material is about 50\% higher for glass bottles than for aluminum cans, as can be seen in Figure 2, which summarizes the LCA results. ${ }^{5}$

Furthermore, little energy is saved by recycling glass bottles (although landfill volume is decreased), because of the high temperatures required to remelt glass. If the cans are recycled, processing energy per use drops by almost a factor of 4.* Of course, glass bottles could be reused at only the small extra

\footnotetext{
* Note that much of the recycling literature claims that recycled aluminum requires only $5 \%$ as much energy as virgin aluminum. That is correct for aluminum ingots, but fabrication is still required to produce useful consumer products, leading to the still-impressive savings of $74 \%$, rather than the commonly cited $95 \%$.
} 


\section{Definitions}

A meaningful discussion of recycling requires a common vocabulary, based on clear and consistent definitions, as follows: Reduce can refer to (1) using or discarding less of a product or (2) decreasing its toxicity during production or in the waste stream. There is no obvious environmental downside to this option. A functioning item (or part thereof) can also be used again in its original form or with minimal alteration. Reuse occurs when the original function is maintained, such as a soft-drink bottle returned for refilling. Adapting an item for new use without changing its essential form or nature (e.g., use of a coffee can as a container for nuts and bolts) is called repurposing. If a product or part requires some cleaning or repair before it can be used again, it is remanufactured or refurbished. Material that can be reused is called reclaimed. Recycling is the transformation of waste (items that are unwanted or perceived as unusable and would otherwise be thrown away) into usable products or materials; it is sometimes referred to as resource recovery. A process can be considered recycling even if it recovers only one useful product from a multicomponent product. It is post-consumer recycling if the materials are generated from consumer waste and pre-consumer recycling if the materials are obtained from manufacturers.

In closed-loop recycling, recovered materials are used to replace virgin raw materials in the same product, possibly going back several steps from the finished product. A special case of closed-loop recycling is direct recycling, in which a material can be put back into the same product with minimal processing. Recycling of lead-acid batteries is an excellent example, in which all of the lead compounds are resmelted and put back in batteries. In contrast to closed-loop recycling, open-loop recycling uses material to produce a different product (e.g., plastic bottles made into drainage pipes). This could mean downcycling, which is converting waste materials into new materials or products of lesser value and reduced functionality compared to the original, or upcycling, which is converting a material into something of greater value in its second life, as in the case of a new process to convert plastic bags into carbon nanotubes. ${ }^{11}$

Several additional options are available for organic wastes. Wastes or refuse-derived fuel can be burned for energy recovery in a waste-to-energy (WTE) plant or other industrial facility. Wastes can also be burned at high temperature in an incinerator, to destroy potentially hazardous wastes, generating ash, flue gas, and heat. The heat energy can be, but is not always, recovered for useful purposes. Although many people still associate waste combustion with the highly polluting plants prevalent years ago, today's plants remove pollutants from the flue gas before releasing it to the atmosphere. Organic matter can also be partially decomposed to a gas by digestion or to a humus-like material by composting.

Disposal is the final placement or destruction of wastes, often in landfills.

\begin{tabular}{|c|c|c|c|c|c|}
\hline Type of paper & $\begin{array}{c}\text { Final } \\
\text { disposition }\end{array}$ & $\begin{array}{l}\text { Purchased } \\
\text { energy }^{\mathrm{a}} \\
\left(10^{6} \mathrm{Btu}\right)\end{array}$ & $\begin{array}{l}\text { Total energy } \\
\text { input } \\
\left(10^{6} \text { Btu }\right)\end{array}$ & $\begin{array}{l}\text { Energy displaced } \\
\text { by combustion } \\
\left(10^{6} \mathrm{Btu}\right)\end{array}$ & $\begin{array}{l}\text { Net nonwood } \\
\text { energy input } \\
\left(10^{6} \mathrm{Btu}\right)\end{array}$ \\
\hline \multirow[t]{3}{*}{ Kraft $^{\circ}$} & Landfill & 14.7 & 52.1 & 0 & 14.7 \\
\hline & $\begin{array}{l}\text { Combustion } \\
\text { (WTE) }\end{array}$ & 14.7 & 52.1 & 10.9 & 3.8 \\
\hline & Recycling & 14.3 & 19.9 & 0 & 14.3 \\
\hline \multirow[t]{3}{*}{ Newsprint } & Landfill & 32.3 & 50.2 & 0 & 32.3 \\
\hline & $\begin{array}{l}\text { Combustion } \\
\text { (WTE) }\end{array}$ & 32.3 & 50.2 & 11.9 & 20.3 \\
\hline & Recycling & 20.1 & 23.7 & 0 & 20.3 \\
\hline
\end{tabular}

Abbreviation: WTE, waste to energy.

a Includes fuels plus electricity, with electricity converted at 10,500 Btu/kWh; values are lower if some of the electricity is cogenerated.

${ }^{b}$ Includes energy content of the wood. Wood for kraft paper includes bark used as byproduct fuel. Newsprint input excludes bark, which is generally used elsewhere in integrated mills.

${ }^{c}$ Kraft refers to printing and writing grades; other paper or cardboard types would have somewhat different energy requirements.

energy cost of washing and sterilizing, although to match the energy use associated with the recycled aluminum can, a bottle must be used seven times. Moreover, this calculation assumes no breakage in the many refilling cycles, and water consumption for washing could be a constraint in drought-prone areas. In addition, refillable glass bottles have become unavailable in most areas of the world, because of higher costs and energy use and inconvenience. ${ }^{6}$ Thus, for singleserve drinks, recycling of cans appears to be preferable to reuse of glass bottles.

Note that these conclusions compare only aluminum and glass. For bottles made of the plastic poly(ethylene terephthalate) (PET), LCA indicates that reuse has the lowest energy use. Indeed, many countries have thriving refillable bottle programs for at least some beverages.

\section{Automotive batteries}

The next example considers a complex multiple-material product that is expected to last for at least 10 years. Both the 


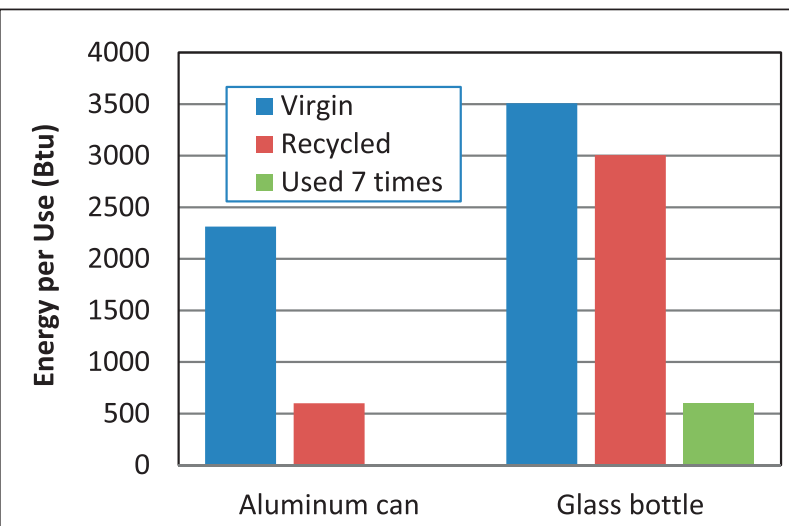

Figure 2. Energy per use for 12-oz. single-serving beverage containers. To compare different options, the total energy for original manufacturing and all processes involved in recycling or reuse is averaged over the number of uses.

complexity and the long life make appropriate disposition at the end of life much more complicated in this case.

The lead-acid batteries used to start conventional automobiles are a prime example of successful closed-loop recycling, with very high recycling rates and with most of the materials ending up back in batteries. In contrast, lithium-ion and nickel-metal hydride batteries from hybrid and electric vehicles have only recently entered the market and do not yet have an established recycling infrastructure. Several different schemes for recycling these new batteries are under development, and they differ dramatically in what is recovered, ranging from direct recycling of battery-grade materials to downcycling back to elements.

For such complex systems, to account for all of the unit processes in primary production and recycling, it is useful to employ a computer model, such as The Greenhouse Gases, Regulated Emissions, and Energy Use in Transportation (GREET) model developed at Argonne National Laboratory. ${ }^{7}$ It includes both a fuel-cycle model, encompassing fuel production and vehicle operation, and a vehicle-cycle model, which evaluates the effects on energy and emissions of the vehicle itself, from material recovery and production, component fabrication, and vehicle assembly to vehicle disposal/recycling. The vehiclecycle model (GREET 2.7) was used to estimate the impacts of battery production and recycling. ${ }^{\text {? }}$

LCA of lithium-ion automotive batteries reveals that emissions of sulfur dioxide from battery material production represent a significant fraction of a vehicle's lifetime emissions [20\% for a plug-in hybrid electric vehicle with a maximum electric driving range of 20 miles $(32 \mathrm{~km})$ and higher percentages for vehicles with greater all-electric ranges] that can be avoided by employing any of the recycling processes being considered. ${ }^{8}$

If the battery can be used again, the energy use and emissions are shared among the number of times the battery is used. For example, there is considerable interest from utilities in repurposing automotive batteries to store energy from intermittent sources, such as wind and solar power. ${ }^{9}$ Once the battery is no longer usable, it can still be recycled, although some of the materials might be more degraded after multiple uses and require more processing. The different processes have different advantages and disadvantages in terms of life-cycle energy use and emissions, resource use, and economics.

Figure 3 shows a schematic of lithium-ion battery production processes, with symbols indicating the stages to which various recycling processes return recovered materials. The more materials can be recovered and returned to forms closer to final use, the more the impacts from primary product production can be avoided.

At one extreme are smelting processes (red squares) that recover some basic elements or salts. These are currently operational on a large scale and can take almost any input, including different battery chemistries (lithium-ion, nickel-metal hydride, etc.) or mixed feed. Smelting takes place at high temperatures, and organics - including the electrolyte and carbon anodesare burned as fuel or reductants. The valuable metals (cobalt and nickel) are recovered and sent to refining so that the product is suitable for batteries (closed-loop recycling) or any other use (open-loop recycling). The other materials, including lithium and aluminum from lithium-ion batteries and metal hydrides from nickel-metal hydride batteries, are contained in the slag, which is currently used as an additive in concrete or aggregates for roadbeds (downcycled). These materials could be recovered using a hydrometallurgical process, but current lithium prices are too low to make recovery profitable. Cobalt recovery is the main economic driver for recycling lithium-ion batteries, although the use of newer cathode materials, which are displacing lithium cobalt oxide in electric vehicle batteries, would reduce the incentive to process batteries. Recycling avoids the process steps within the red shaded region in Figure 3, replacing them by the processes shown in the flow chart in Figure 4.

At the other extreme, direct recovery of battery-grade material (green triangles in Figure 3) for use in new batteries has also been demonstrated. This alternative approach to battery recycling is a low-temperature process with low energy requirements. The components are separated by various physical and chemical processes. Many of the process details are proprietary and thus cannot be specified here. The first process step involves breaching the cell packaging just enough to allow fluids to be exchanged. The electrolyte is extracted using supercritical carbon dioxide; it carries the salts with it and can be reused. The carbon dioxide can also be recovered. The remaining structure can then safely be chopped into small pieces that are amenable to a series of separation processes on the basis of surface properties and solubility. The active-material structures are maintained, and the materials can be used to produce new batteries with only minimal treatment. Over $80 \%$ of the material is recycled into useful products, including all active materials and metals. Only the thin plastic separator is unlikely to be usable, because its form cannot be retained. All of the steps in the green shaded region in Figure 3 are avoided (and replaced by lower-impact processes), so that almost all of the original 


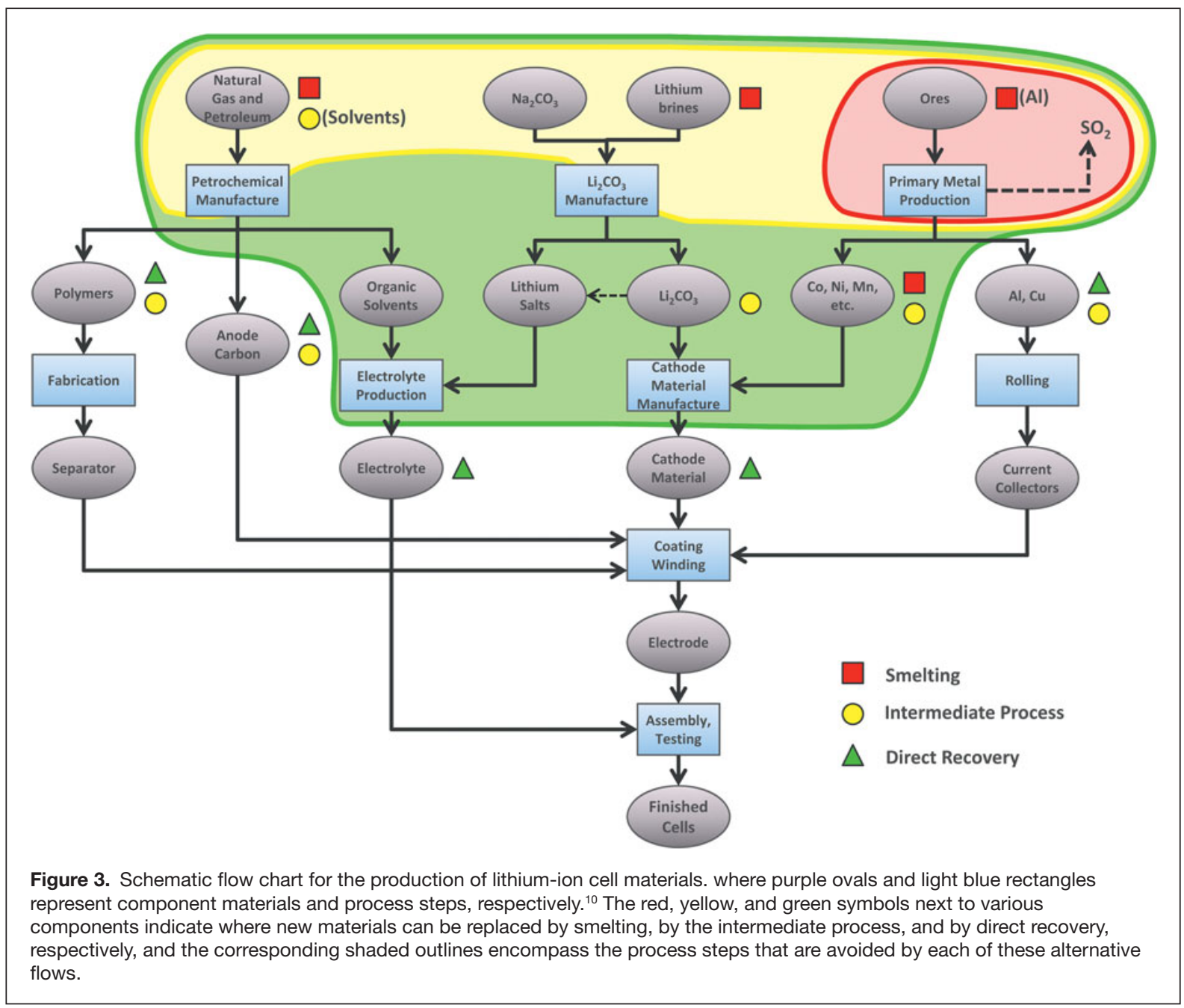

energy and processing required to produce battery-grade material from raw materials is saved. In addition, cathodegrade material would be a valuable product even if it did not contain cobalt, so there would be a continuing economic incentive to recycle the batteries.

Advanced batteries will likely require high-grade materials for their components, so it will be important to understand the quality of the output from recycling processes. Both the purity and microstructure of the recycled materials must be proven to be suitable for reuse in batteries or other products. Excellent cycle life of a cell made with recycled material has been reported. Such processes require as uniform a feed as possible, because impurities jeopardize product quality. Mixed-chemistry input would decrease the utility of the product, so presorting might be required. Cathode materials might also be separated from a mixture at the end of this process, but this has not yet been demonstrated. Because battery chemistries are evolving rapidly, a potential drawback to the direct recycling of battery materials is that the material being recovered in 10-15 years might be obsolete and might not be able to find a market.
The U.S. Department of Energy has funded the development of a process between the two extremes (yellow circles and yellow shaded region in Figure 3) to recover lithium from spent batteries as lithium carbonate (a precursor for the cathode material). It has low energy requirements and does not require high temperatures. Although the carbonate is less valuable than the cathode material, the process can handle a feed with a mixture of cathode materials. The feed need not be as uniform as for direct recycling, but the process recovers materials farther along the chain than smelting does. Cathode materials might also be recoverable. Recycling processes for lithium-ion batteries are still under investigation.

Today's consumer battery recyclers must deal with a highly diverse feedstock that includes numerous battery types and might even include harmful or dangerous components. Leadacid batteries are large and easily separated, but consumerelectronics batteries are smaller and varied, so that they are more difficult to sort. However, recycling them will keep the recycling companies operating until large quantities of automotive propulsion batteries are available. When automotive batteries finally arrive, recyclers will find their job somewhat 


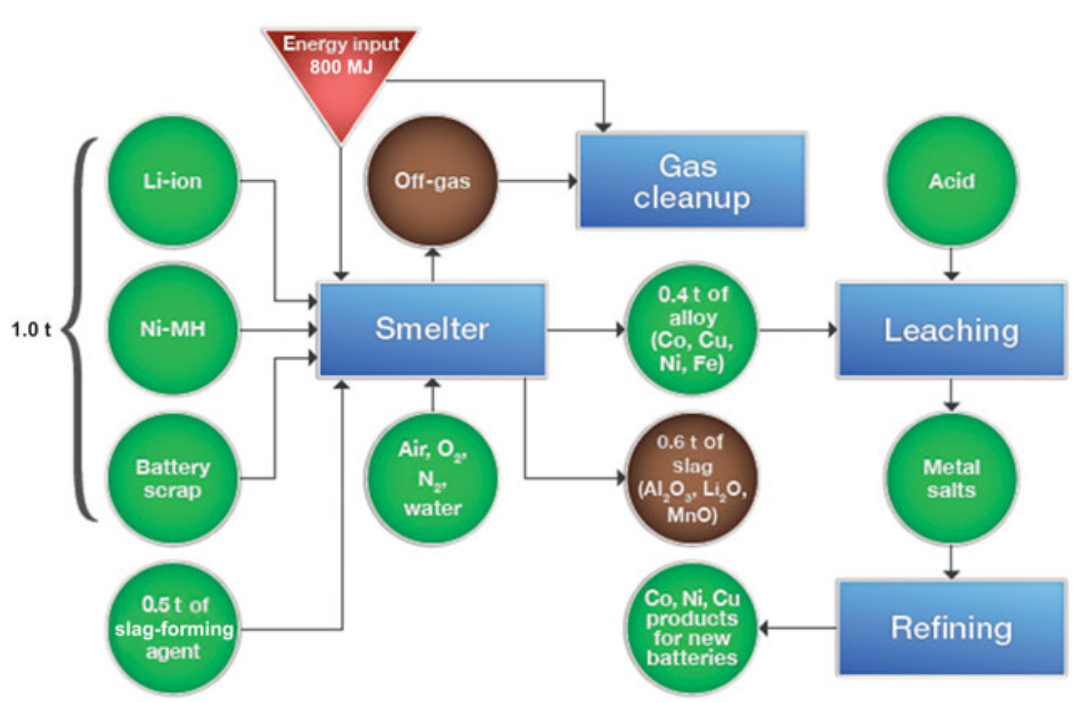

Figure 4. Flow chart for the recycling of lithium-ion batteries by smelting (data courtesy of Umicore). The blue rectangles indicate the steps in the process, whereas the green and brown circles represent material inputs and outputs, respectively. The red triangle shows an energy input of $800 \mathrm{MJ}$. alternative for a different product. The results of detailed life-cycle analysis vary somewhat for different locations, newer processes, or different electricity-generation mixes. Although different situations share common characteristics, each one is ultimately unique, and even a careful analysis of the energy use and environmental impacts of the alternatives is not always sufficient. Tradeoffs among environmental and economic benefits must be examined, and institutional constraints and consumer preferences and behaviors must be considered, before the best path forward can be determined.

\section{Acknowledgments}

This work was sponsored primarily by the U.S. Department of Energy's Office of Vehicle Technologies. The submitted article was created by UChicago Argonne, LLC, Operator of Argonne National Laboratory ("Argonne"). Argonne, a U.S. Department of Energy Office of Science laboratory, is operated under Contract No. DE-AC02-06CH11357. The U.S. Government easier because the batteries will be larger and will probably come in a much smaller number of types or chemistries.

\section{Enablers of recycling and reuse}

This article has applied LCA to assess the disposition options for existing products. However, to achieve the greatest benefit, the analysis should begin at the earliest stages of the life cycle, with consideration of the final disposition of an item included even during design and development of both products and constituent materials. For example, material separation is often a stumbling block for the recovery of high-value materials. Therefore, designing products for disassembly or recycling would be beneficial. Similarly, standardization of materials would reduce the need for separation. In the absence of material standardization, product labeling would enable recyclers to sort before recycling and would help consumers determine where to put unwanted items. Standardization of product design, at least in size and shape, would foster the design of automated recycling equipment. Standardization of battery configurations and specifications would also be beneficial for reuse schemes, where cells from various sources would be tested and repackaged in compatible groups for reuse by utilities.

\section{Conclusions}

The benefits of recycling are widely accepted, but applying a single strategy based on a catchy slogan might not lead to optimal results. Recycling might work better than reuse for one product, whereas combustion might be the most beneficial retains for itself, and others acting on its behalf, a paid-up nonexclusive, irrevocable worldwide license in said article to reproduce, prepare derivative works, distribute copies to the public, and perform publicly and display publicly, by or on behalf of the Government.

\section{References}

1. L. Gaines, in Encyclopedia of Energy (Elsevier, New York, 2004), pp. 253-260. 2. L. Gaines, F. Stodolsky, Mandated Recycling Rates: Impacts on Energy Consumption and MSW Volume (Report ANL/ESD-25, Argonne National Laboratory, Argonne, IL, December 1993).

3. R.E. Butner, M. Kangas, C.E. Stapley, Paper Recycling: Impact on Electricity Use, Electro-technology Opportunities (Report RP-3228-06, H.A. Simons, Decatur, GA, April 1993).

4. Life Cycle Inventory of Three Single-Serving Soft Drink Containers (Franklin Associates, Prairie Village, KS, August 2009).

5. L.L. Gaines, M. Mintz, Energy Implications of Glass-Container Recycling (Report ANL/ESD-18, Argonne National Laboratory, Argonne, IL, May 1993).

6. America's Experience with Refillable Beverage Containers (Institute for Local Self-Reliance, Washington, DC, 2002).

7. A. Burnham, M. Wang, Y. Wu, Development and Applications of GREET 2.7-The Transportation Vehicle-Cycle Model (Report ANL/ESD/06-5, Argonne National Laboratory, Argonne, IL, November 2006).

8. L. Gaines, J.L. Sullivan, A. Burnham, I. Belharouak, "Life-Cycle Analysis for Lithium-Ion Battery Production and Recycling," paper presented at the Transportation Research Board 90th Annual Meeting, Washington, DC, 23-27 January 2011; paper 11-3891.

9. J. Witkin, A Second Life for the Electric Car Battery (Wheels Blog, New York Times, 27 April 2011); green.blogs.nytimes.com/2011/04/27/a-second-life-forthe-electric-car-battery (accessed 26 May 2011).

10. L. Gaines, "How Can We Supply Personal Transportation with Minimal Impacts?," seminar presented at Rochester Institute of Technology, Rochester, NY, 16 February 2011.

11. "From Trash to Treasure: Turning Plastic Bags into Battery Anodes," in TransForum (Transportation Technology R\&D Center, Argonne National Laboratory, Argonne, IL, 2010), Vol. 10, No. 2, p. 2. 


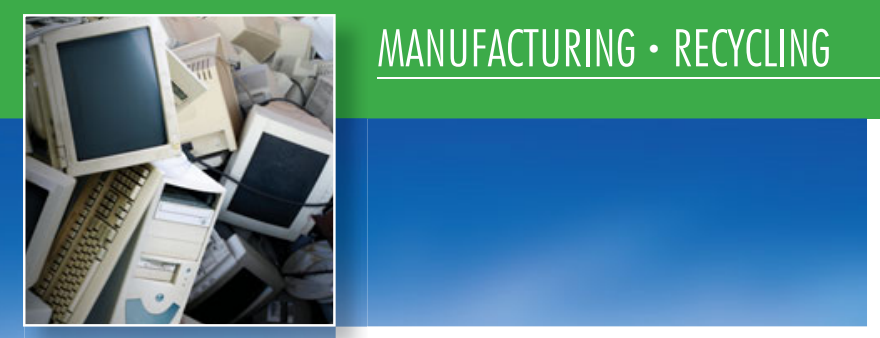

\title{
Opportunities and limits of recycling: A dynamic-model-based analysis
}

\section{Markus Reuter and Antoinette van Schaik}

\begin{abstract}
Ensuring the continued availability of materials for manufactured products requires comprehensive systems to recapture resources from end-of-life and wastewater products. To design such systems, it is critical to account for the complexities of extracting desired materials from multicomponent products and waste streams. Toward that end, we have constructed dynamic simulation-optimization models that accurately describe the recovery of materials and energy from products, residues, and wastewater sludges. These models incorporate fundamental principles such as the second law of thermodynamics, as well as detailed, empirically based descriptions of the mechanical separation of materials at the particulate level. They also account for the evolution of the recycling system over time. Including these real-world details and constraints enables realistic comparisons of recycling rates for different products and technological options and accurate assessments of options for improvement. We have applied this methodology to the recycling of complex, multimaterial products, specifically cars and electronic wastes, as well as wastewater and surface-water systems. This analysis clarifies how product design, recycling technology, and process metallurgy affect recycling rates and water quality. By linking these principles to technology-based design-for-recycling systems, we aim to provide a rigorous basis to reveal the opportunities and limits of recycling to ensure the supply of critical elements. These tools will also provide information to help policymakers reach appropriate decisions on how to design and run these systems and allow the general public to make informed choices when selecting products and services.
\end{abstract}

\section{Introduction}

"Natural resources underpin the functioning of the European and global economy and our quality of life," declares A resourceefficient Europe-Flagship initiative under the Europe 2020 strategy. ${ }^{1}$ Reliable access to critical raw materials is a persistent challenge for resource-dependent countries, and this initiative supports smarter use of natural resources to achieve sustainable growth. For example, a European Union document discussing scarce materials ${ }^{2}$ (Table I) highlights rare earths (REs), such as neodymium for magnets. REs enable products that are important for sustainable development, such as modern transport, wind-power energy, and energy-efficient lighting.

Like other elements, REs can be obtained not only from minerals but also from various consumer and industrial products that use them, such as electronic waste. Closure of material cycles and minimization of waste creation can achieve prudent use of resources and help secure supplies of critical materials. Metallurgy, which provides these elements from natural ores, plays a crucial role in enabling sustainability by also recovering them from manufactured products. Principles of physics, chemistry, engineering, thermodynamics, and economics all constrain the extraction of materials, metals, and energy from end-of-life (EOL) consumer goods, wastes, residues, wastewater sludges, and other sources.

The design of products profoundly affects the potential recyclability of the resources they contain. The philosophy of design for recycling (DfR) aims to improve this recyclability, often using generally accepted methodologies such as material flow analysis (MFA) and life-cycle assessment (LCA). However, an extensive review by Reuter ${ }^{3}$ concluded that these methods have not been implemented in enough detail to link to computer-aided design (CAD) systems to expose the full opportunities and limits of recycling, as these methodologies do not distinguish between metal-/material- and product-centric views of recycling.

The assessment of the recycling potential of each design should be based on established principles, including how the liberation of materials during breakage depends on the material 
Table I. List of critical raw materials identified by the European Union (in alphabetical order). ${ }^{2}$

\begin{tabular}{|l|l|}
\hline Antimony & Indium \\
\hline Berylium & Magnesium \\
\hline Cobalt & Niobium \\
\hline Fluorspar & Platinum-group metals \\
\hline Gallium & Rare earths \\
\hline Germanium & Tantalum \\
\hline Graphite & Tungsten \\
\hline
\end{tabular}

a Platinum-group metals include platinum, palladium, iridium, rhodium, ruthenium, and osmium.

' Rare earths include yttrium, scandium, and the lanthanides (lanthanum, cerium, praseodymium, neodymium, promethium, samarium, europium, gadolinium, terbium, dysprosium, holmium, erbium, thulium, ytterbium, and lutetium).

connections and particulate characteristics of the recyclate flows (recycled material that will be used to form new products), the physics and chemistry of sorting, and the thermodynamics of high-temperature processing and resource recovery.

These physical separation steps and the closely linked metallurgical processing steps are keys to recycling.

Therefore, we have developed process-simulation methods and applied them to the complex liberation of materials from particles during shredding and physical recycling separation technology. Many of the parameters that characterize these processes, including particle size, material combinations (liberated, mixed, and/or joined), chemical interactions, and physical properties, vary widely. In addition, the distributions of these parameters often deviate from the normal distributions assumed in simple models. These details must be included if the recycling of waste and EOL products is to be modeled well enough to predict the quality of the recyclates. This quality determines their economic value, and if it is too low, the recyclates will be discarded, making it impossible to achieve closed-loop material cycles. Many simpler models do not capture the particulate nature of recyclates and, hence, their quality. These features are crucial in predicting and improving recycling system performance and thereby enabling sustainable product designs and the closure of material cycles.

To address the deficiencies in the modeling of recycling systems, we have drawn on our experience in simulating classical mineral and metallurgical processing systems to develop first-principles models for complex recycling systems for cars and electronic waste. We have also extended this theoretical foundation to encompass the impact of recycling and product design on surface-water and wastewater quality. This article briefly reviews these dynamic simulation-optimization models and their role in assessing and improving product design and recycling systems.

To illustrate our methodology, we describe three examples of industrial applications. In the first, we applied our approach to electronic-waste recycling at Wecycle (formerly NVMP) in the Netherlands, ${ }^{4,5}$ to predict recycling rates for various electronic consumer products and to show how resource efficiency can be improved. Second, the approach was used in the automotive industry ${ }^{6-9}$ to predict the recycling rate of a SuperLIGHT-CAR (SLC) design. Finally, we used our dynamic-modeling approach for a governmental water board in the Netherlands, ${ }^{10}$ to analyze the use of metallurgical processing to remove phosphate from wastewater and return the treated water to the resource cycle.

At their core, these efforts and the associated resourcesystem models aim to maximize resource efficiency and help industry to provide customers with the most environmentally friendly products while safeguarding the supply of critical elements, especially for high-technology applications, through recycling. The work quantifies the limits and opportunities of recycling for different products and related material flows. At the same time, it gives policymakers reliable information and helps the public make informed choices when selecting products and services.

\section{Dynamic recycling models}

Our recycling models provide a common language and tool for the evaluation, control, and optimization of recycling, enabling the calculation of statistical distributions of recycling rates. The results are detailed enough that they can be linked to software employing CAD principles. This framework identifies critical parameters in the design of products and recycling systems in view of recycling performance and resource efficiency. Linking to generally accepted methodologies such as MFA and LCA provides a powerful basis for quantifying recycling performance. ${ }^{3}$ Figure 1 illustrates the many processes that must be integrated into simulation and optimization models, as described in the following subsections

\section{Physical separation}

Our models represent the complex liberation behavior of materials during shredding as a function of product-design characteristics, specifically the various material combinations and material connections in a product. This unique information and modeling were derived from a large body of data collected from various industrial shredder and recycling plant trials. Such practical knowledge is essential to fully model these systems, including the ways in which product design influences the enormously complex particulate streams emerging during recycling and, thus, recyclate quality and material recovery and loss. For example, the processes illustrated in Figure $\mathbf{2}$ might incompletely liberate pure materials from mixed particles, resulting in decreased separation efficiency. These models allow pinpointing of design deficiencies and opportunities related to recycling performance, in terms of both sorting and metallurgical recovery, to improve resource recovery from products such as cars and electronic waste. 


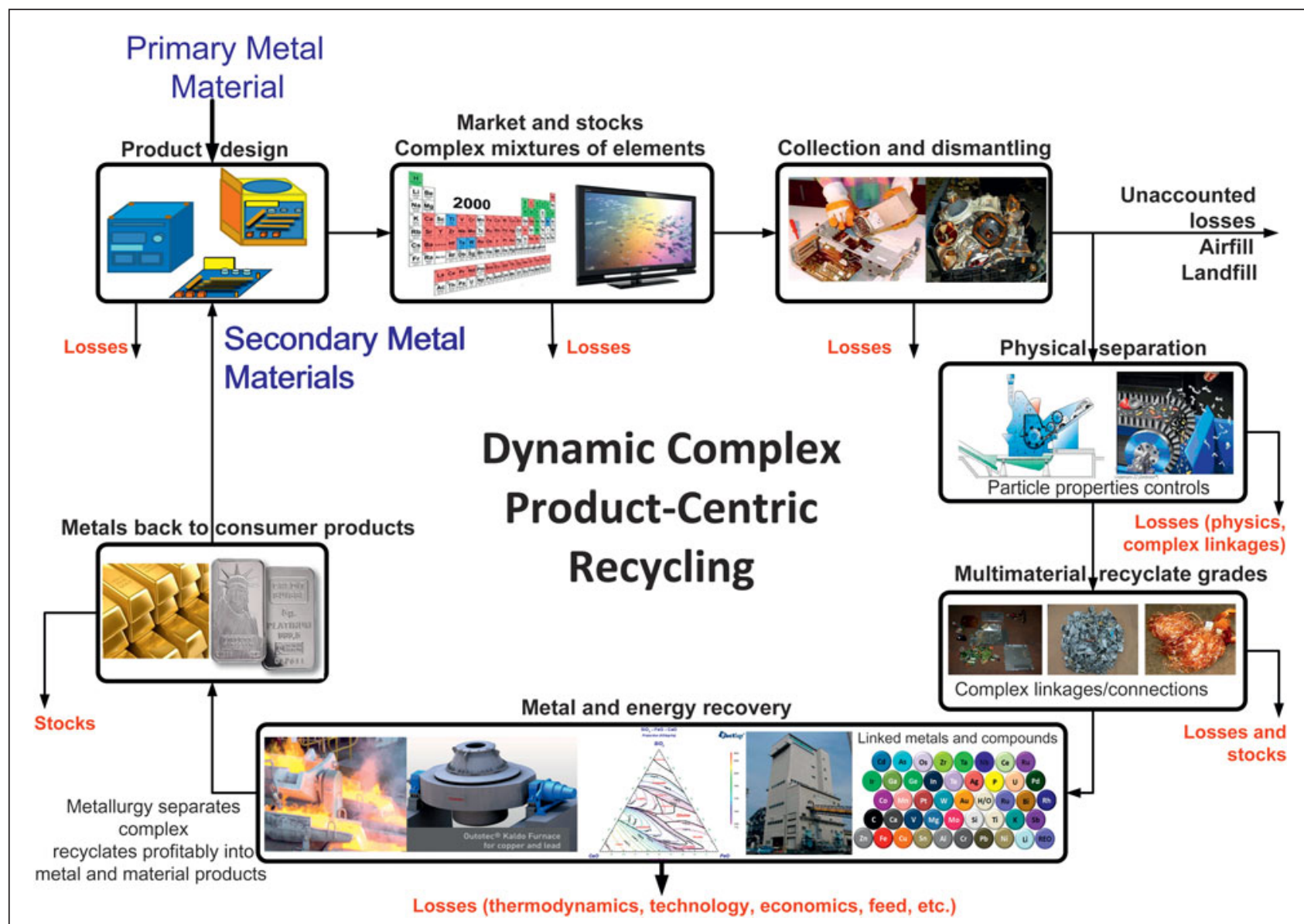

Figure 1. Summary of aspects that affect recycling rates of end-of-life products as included in recycling models: time and product property distributions, product design, degree of liberation, separation physics, recyclate quality, solution thermodynamics, and recycling technology.

\section{Fundamental materials limits}

After mechanical separation, recovery in final treatments, such as metallurgical and thermal processing, is limited at the microscopic level by the second law of thermodynamics. Thus, material separation and recovery in different phases (metal, matte,* speiss, ${ }^{\dagger}$ slag, ${ }^{\ddagger}$ flue dust, off-gas) are included in the models based on process thermodynamics and the chemical contents of and interactions among different elements/phases present in the recyclates obtained from dismantling and/or physical separation.

The simulation models are grounded in fundamental principles, as well as industrial experience with thermodynamics and associated process technology in a realistic economic environment. For example, Figure 3 shows the relative

\footnotetext{
* Matte is the molten metal sulfide phase generated by smelting nonferrous metals, such as copper and nickel.

${ }^{\dagger}$ Speiss is a molten phase consisting primarily of iron arsenide that is commonly encountered in lead smelting.

‡ Slag is a partially vitreous byproduct of smelting ore that usually consists of a mixture of metal oxides and silicon dioxide but can also contain metal sulfides and elemental metal.
}

stabilities of some oxides, which have a direct effect on their recovery and recycling rates. As another example, detailed materials properties such as oxidation states and vapor pressures also enter into the complexity associated with the recycling of many materials, such as indium-tin oxide from flat-panel displays, because of the various chemical species in which the constituent elements can appear when processed (see Figure 3b).

Exergy, the thermodynamically available energy in a particular environment, is introduced as an additional constraint in the optimization models. This allows the environmental performance of recycling systems to be evaluated and optimized by capturing the effect of recyclate quality, related to physical, metallurgical, and thermal processing and waste/losses in the system. ${ }^{3,4,9}$

\section{Software framework}

Recycling of complex, multimaterial consumer products demands an extended network of different types of processes to recover the different materials present. Figure $\mathbf{4}$ presents a software flow sheet illustrating the complexity and number of processes involved in resource recovery. These include manual 


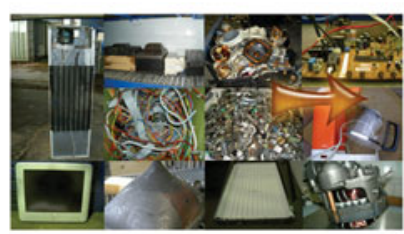

Design determines connections

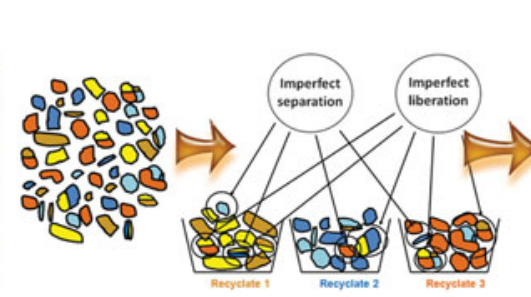

Various grades/qualities of recyclates

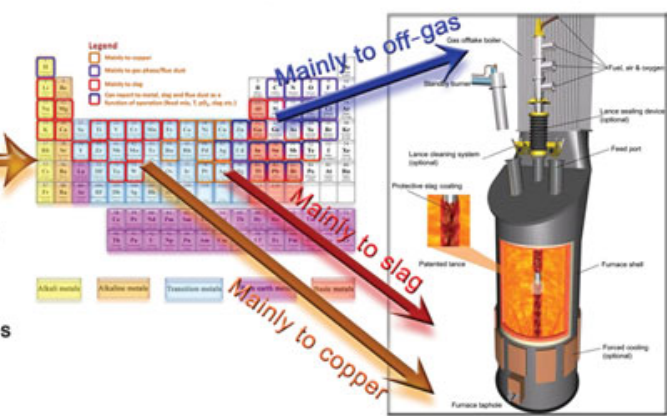

Figure 2. Product design and separation technology determine recyclate quality and recyclability resulting from liberation and separation of material particles. The models discussed in this article make it possible to link design with physical separation, metallurgical thermodynamics, and processing technology, providing the basis for quantifying design for sustainability and resource efficiency.

sorting and cleaning, shredding, physical sorting (e.g., magnetic separation, eddy current, density sorting, laser/color sorting), metallurgical processing for the different metals, plastic and inorganic treatment processes, and energy recovery. The selection and arrangement of processes determine the ultimate quality of recyclates and, hence, the resulting material and energy recovery.

Flow sheets including all possible recycling unit operations, such as that in Figure 4, provide a graphical and technological blueprint of models of recycling and illustrate the limits and possibilities of resource recovery. We have developed such flow sheets for several consumer products, including cars; refrigerators; cathode-ray-tube (CRT) televisions; washers and dryers; and small household appliances such as vacuum cleaners, toasters, mixers, and coffee makers. They provide a recycling simulation-optimization model for investigating existing and alternative processing routes for these products and/or product mixtures.

The input into any recycling system evolves over time because of changing (1) product design, (2) product composition (for example, in response to regulatory changes), (3) product-lifetime distributions, (4) consumer behavior, and (5) disposal behavior and stocks. All of these aspects have been included in our dynamic-modeling approach. The models can predict the recycling performance for different EOL systems and mixtures of products, recovery of precious or scarce materials, and leakage of minor elements for changing plant configurations (including dismantling), shredder settings, product designs, and recycling trends.

By capturing the effects of product design on liberation behavior, recyclate quality, separation and metallurgical process efficiency, and hence recyclability, this approach provides a

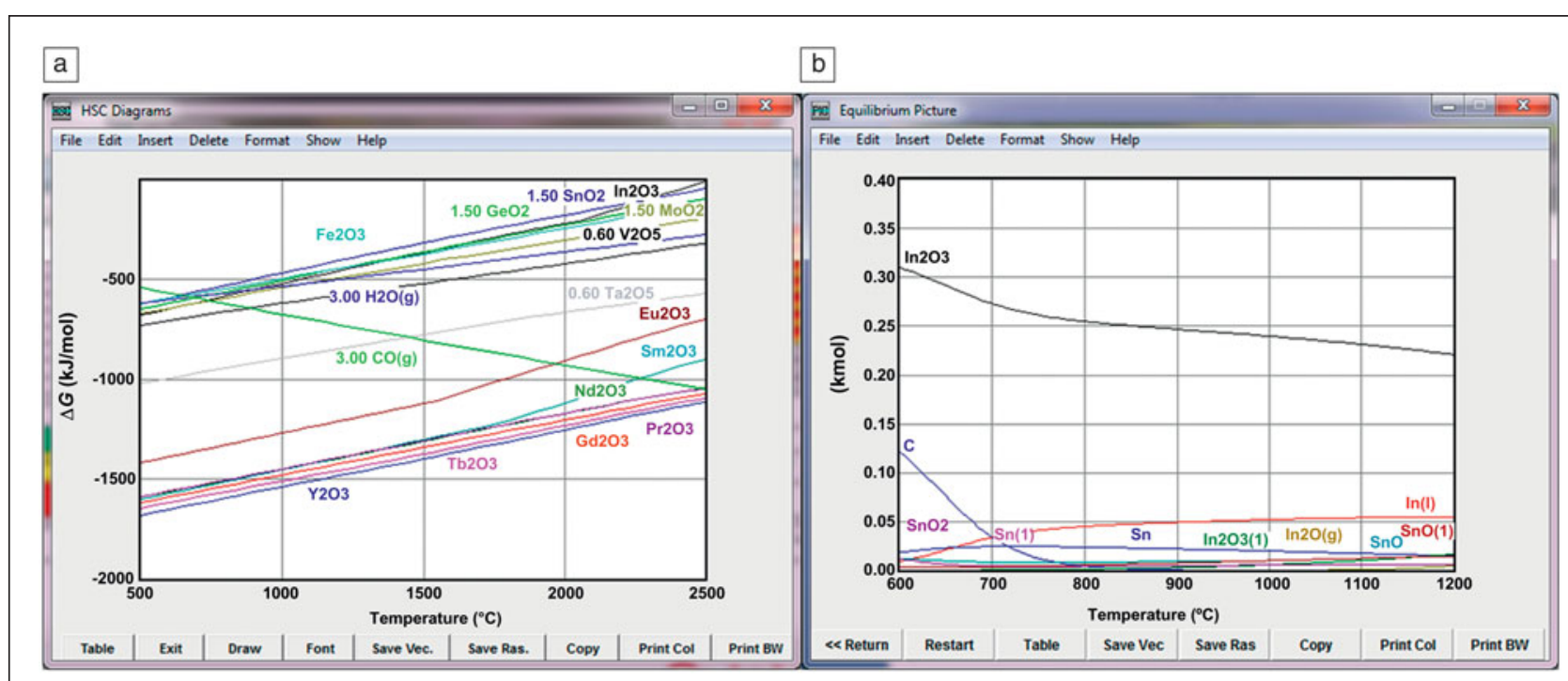

Figure 3. (a) Stabilities of some rare-earth and other oxides. The green $\mathrm{CO}$ line cutting through this plot defines where the oxides can be reduced by carbon. (b) Oxides of tin and indium under relatively oxidizing conditions, showing how well these elements can be recovered/ recycled. (If more carbon is added, conditions become more reducing, and more metal compounds are produced.) Plots created using the software program HSC Chemistry. ${ }^{11}$ 


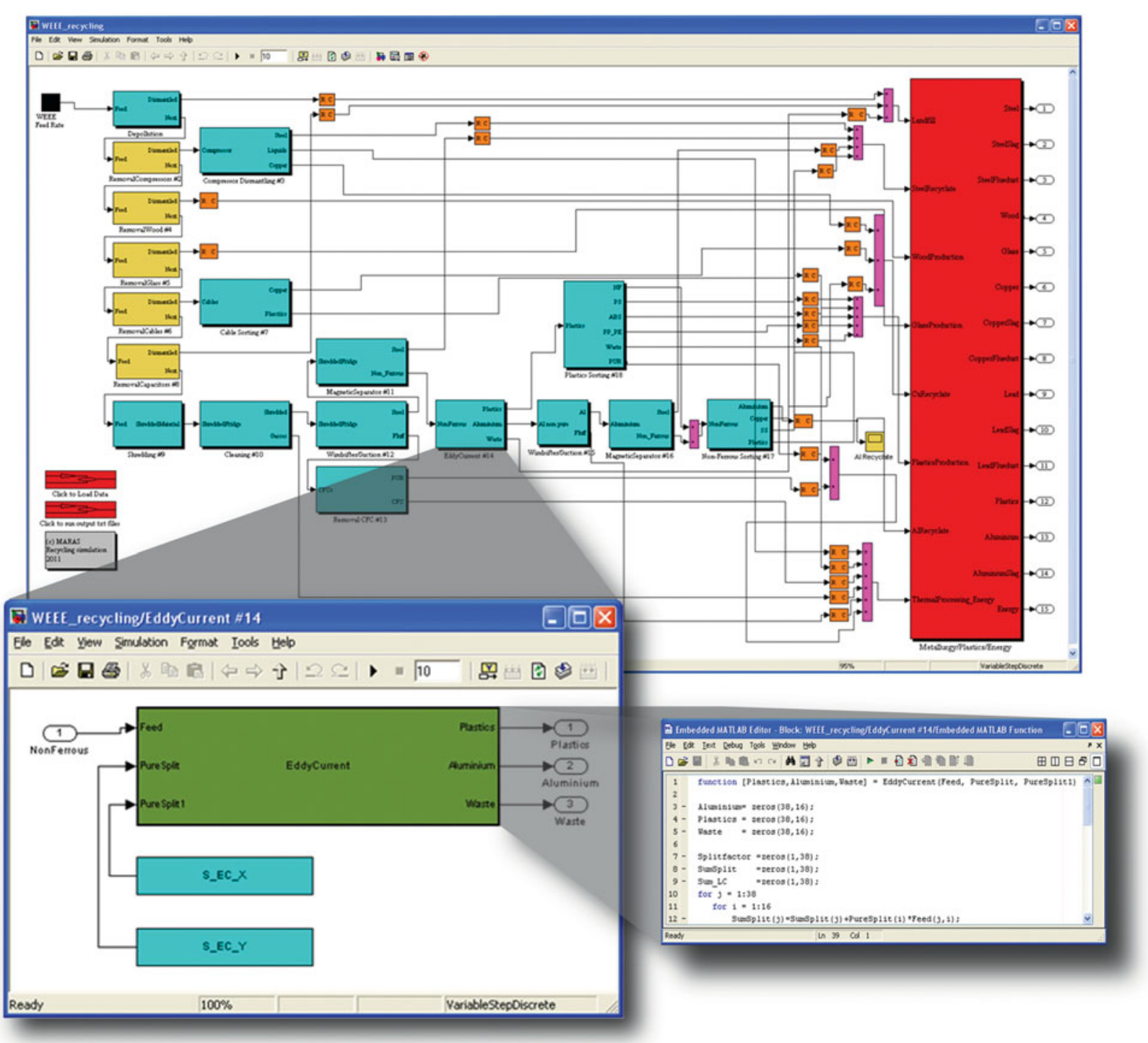

Figure 4. Example of a dynamic simulation model for the recycling of waste electrical and electronic equipment (WEEE) products including different manual and physical recycling options, a range of final treatment processes (e.g., metallurgical processing, thermal processing, plastic processing), and an example of the layered model structure showing the detail of different shredding and sorting options.

reliable basis for DfR. We have developed and applied fuzzy recycling models ${ }^{6,7}$ that capture the details of these rigorous recycling optimization models in a semiempirical way and linked them to CAD and LCA software to quantify recycling performance. ${ }^{6-9}$

\section{Applications of recycling system models}

Using the models described in the preceding section, we have performed the following industrial analyses:

- calculating and predicting the recycling and recovery rates of different types of electronic waste, EOL vehicles, and lightweight car-design concepts, including all individual materials in these products (e.g., compounds, alloys, composites, metals) in enough detail to provide an accurate picture of the losses, toxicology, and other characteristics;

- predicting the grade, in terms of both quality and composition, of all intermediate particulate recycling streams, including recyclates of steel, copper, and plastics, as well as recycling products such as metals, matte, slag, speiss, and flue dust; and

- predicting the recovery of scarce minor metals that are important for sustainable-energy and other high-technology industries, while tracking possible toxic or harmful components in recycling products and water.

The results of these analyses have provided critical information to manufacturers, consumers, and policymakers for use in making resource-efficient decisions about daunting and complex problems. 


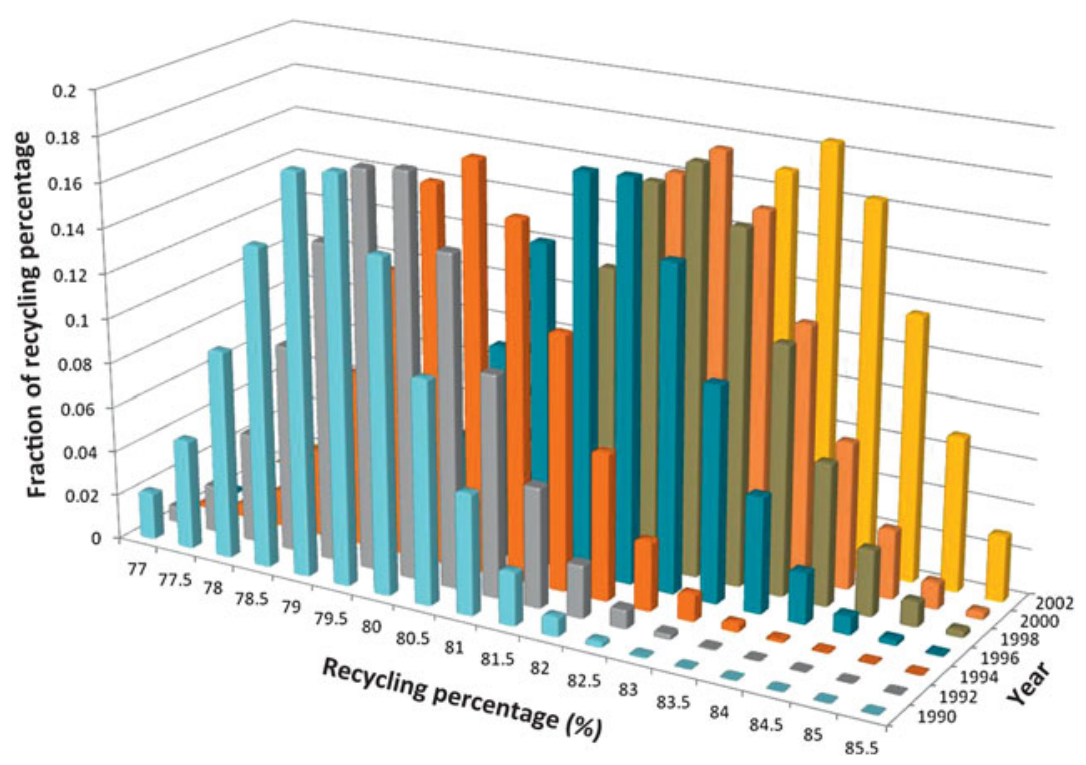

Figure 5. Dynamic recycling performance calculations for waste electrical and electronic equipment (WEEE) as a function of year, illustrating the evolution of recycling rates. For each year, modeling predicts a distribution of expected recycling rates, reflecting variations in properties such as material liberation, interlinked materials in complex products, quality of recyclates, range of products, and designs, to name a few.

such as $\mathrm{Pb}^{2+}, \mathrm{Mn}^{2+}$, or $\mathrm{Sb}^{3+}$ or an $\mathrm{RE}$ ion such as $\mathrm{Eu}^{2+}, \mathrm{Tb}^{3+}$, or $\mathrm{Ce}^{3+}$. Typically, the phosphors from fluorescent lamps are recovered easily from the inside of the tubing, whereas hydrometallurgical processing technology is used to recover the REs. ${ }^{14}$

In contrast, LEDs usually include compact combinations of organic materials and phosphors and require a different path. Indium and gallium are partially recovered in normal high-temperature smelting operations, for example, during WEEE/ copper scrap recycling. ${ }^{15}$ However, REs would be lost in the slag phase of the smelters.

Table II provides a qualitative overview of recycling/recovery possibilities for various critical materials in several types of WEEE. This table illustrates the influence of choices that can be made about recycling routes, such as the degree of dismantling. Extensive dismantling of RE-containing dielectric components on printed wiring boards or of getters ${ }^{\S}$ containing tungsten, cobalt, or tantalum from CRT televisions or lighting can recover materials that would otherwise be lost as contaminants to metal products or slag. A model, such as ours,

\section{Electronic waste/WEEE}

Valuable electronic waste, or the broader class of waste electrical and electronic equipment (WEEE), contains a variety of materials, ranging from commodity metals such as iron/steel, aluminum, and copper to critical minor elements including indium, antimony, cobalt, REs, precious metals, and platinumgroup metals. We have used our dynamic recycling models to predict the EOL recycling rates, and hence estimate the resource efficiency, of various products for all such materials, in both physical combinations and chemical compounds. ${ }^{4}$ This analysis was formulated for existing and alternative recycling routes, plant inputs (product mixtures, weights, and compositions that can change over time), and processing variations. A highly detailed description is required to cover the widely distributed and time-varying properties of recycling processes. ${ }^{3}$

Figure 5 shows an example of recycling performance simulations for large household appliances. The time-varying distribution of predicted recycling rates evolves in response to changing EOL product populations (different types of products from different production years), changing product weights and material compositions, and changing processing routes. The model captures the dynamic nature of product recycling and predicts recycling rates and resource availability. ${ }^{12}$

We have also used our simulation model to address the recycling of fluorescent lamps and light-emitting diodes (LEDs), both of which contain a variety of materials, including indium, gallium, and REs. Fluorescent powders, also called phosphors, generally consist of a host lattice $\left[\right.$ e.g., $\mathrm{Ca}_{5}\left(\mathrm{PO}_{4}\right)_{3}(\mathrm{Cl}, \mathrm{F})$, $\left.\mathrm{BaMgAl}_{10} \mathrm{O}_{17}, \mathrm{Y}_{2} \mathrm{O}_{5}, \mathrm{LaPO}_{4}, \mathrm{Y}_{3} \mathrm{Al}_{5} \mathrm{O}_{12}, \mathrm{YVO}_{5}\right]$ doped with a few percent of an activator. ${ }^{13}$ The activator can be a metal ion that is equipped with detailed material information allows users to assess different techniques. For example, the relative stability of oxides shown in Figure 3 indicates that the displayed REs form stable oxides that cannot generally be recovered by high-temperature means, but instead require hydrometallurgical processing. Table II also shows that the recovery of metals is ultimately dependent on their chemical properties, as metals with similar properties exhibit similar recoveries for various applications.

\section{Automobiles}

As part of the European Union's 6th Framework Programme, we used our model ${ }^{3}$ to simulate recycling for SuperLIGHTCAR (SLC) designs at the body-in-white (BIW) stage (i.e., comprising only the unpainted sheet metal frame of the vehicle). ${ }^{6,8}$ Specifically, we employed easy-to-use fuzzy models to (1) predict recycling/recovery rates with CAD software in "real design time" as a function of material usage, material combinations, and joints used and (2) provide detailed recycling data for environmental assessments using LCA software. In addition, the model results were used to guide DfR and recycling flow sheet configuration for multimaterial SLC designs. ${ }^{6,8}$

We also organized and managed a recycling trial in Belgium involving 1153 cars for the European automotive and recycling industries (see Figure 6). The objective was to measure, in a

${ }^{\S} \mathrm{A}$ getter is a deposit of reactive material that is deliberately placed inside a vacuum system, to complete and maintain the vacuum. 


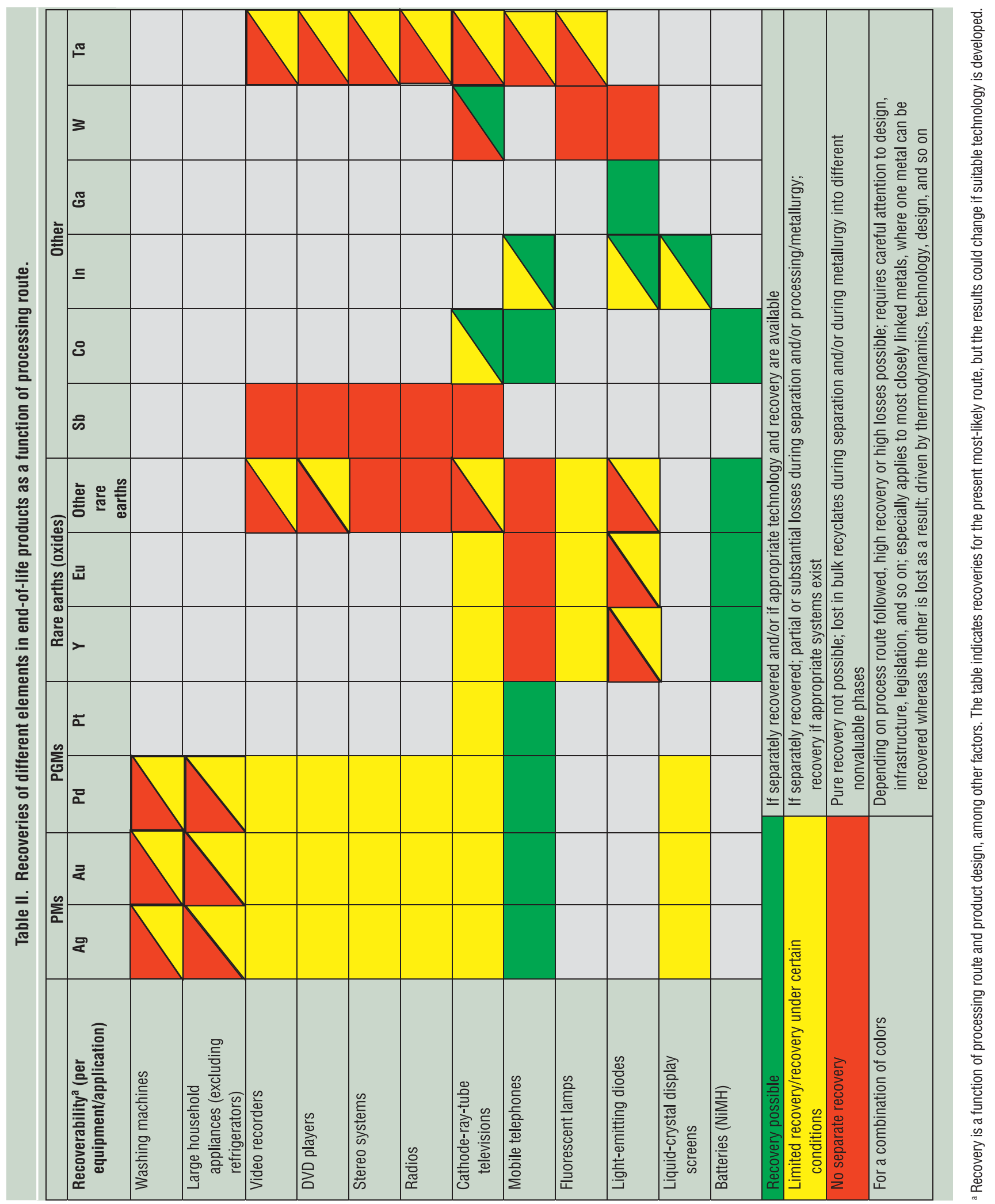




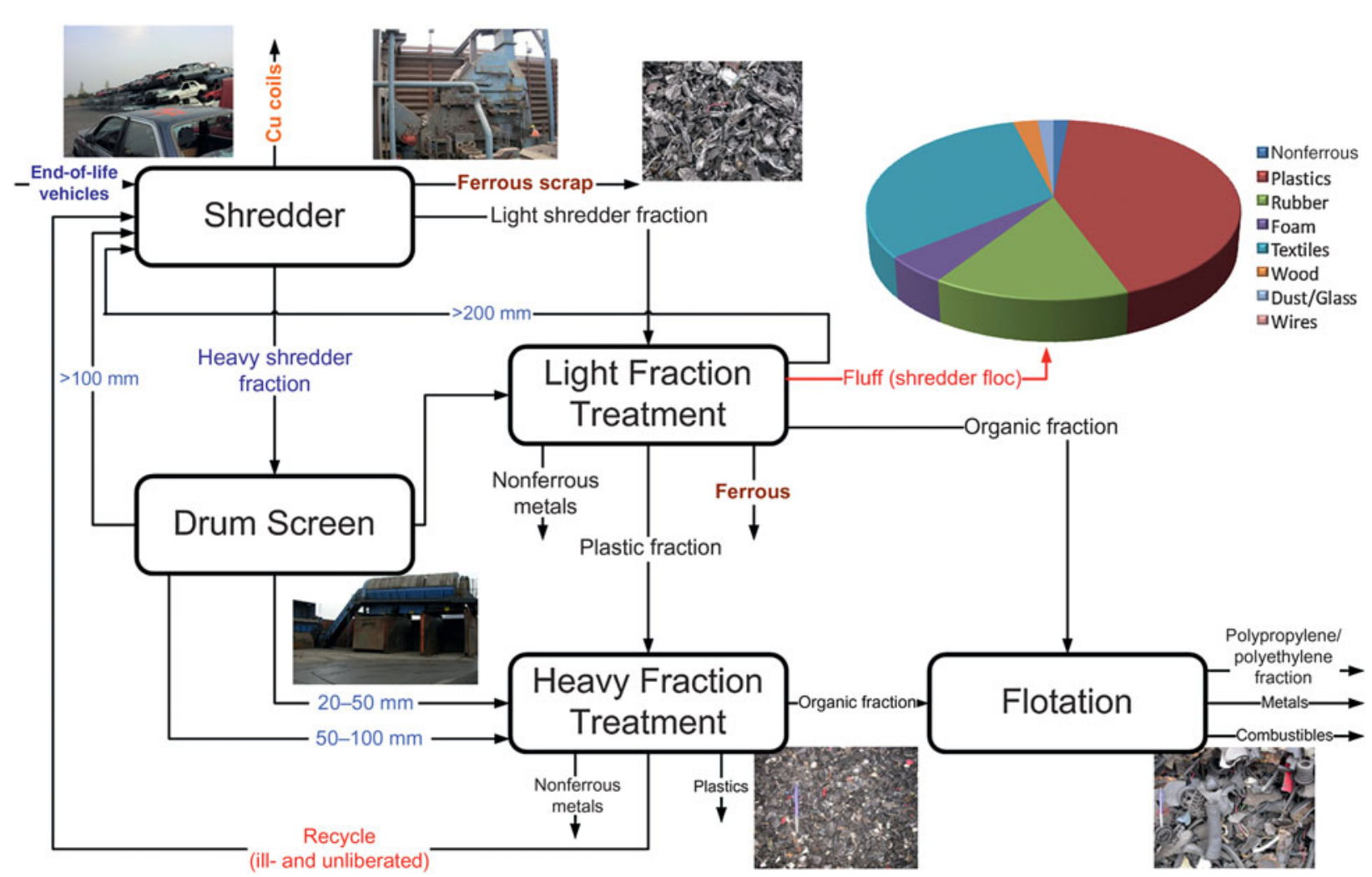

Figure 6. Overview flow sheet ${ }^{9}$ of the industrial plant and main groups of technologies that were used to recycle 1153 cars, including various main recyclate and intermediate process streams and the generalized composition of the unrecyclable fluff stream obtained after extensive treatment. Each of the elements in the numerous compounds, materials, and metals had to balance to create a consistent overall mass balance. This balance was achieved by data reconciliation incorporating all analysis standard deviations of samples of all streams, materials, and compounds. This level of detail and understanding lies at the core of quantifying recycling rates, system performance, and system improvements, as well as calibrating models.

statistically well-controlled trial, the average recycling rate for this population of cars. The trial included a statistical population of cars matching the types and ages discarded in the Netherlands at the time. The details of the methodology required to calculate recycling rates within sampling theory can be found in Reference 9. The various fractions recovered included those from depollution and dismantling; steel recovery after shredding; and recovery of metals, compounds, and materials from the light and heavy fractions through post-shredder processes including flotation. As described at the International Auto Recycling Conference in Geneva, Switzerland, in 2004, ${ }^{16}$ recoveries can easily reach values close to $86 \%$ using standard technology, and $90 \%$ recovery ${ }^{17}$ can be attained, inclusive of energy recovery, depending on the post-shredder technology available at a recycling plant, the geographical location of the plant, and national environmental legislation governing disposal.

Regardless of the technology available in the overall recycling chain, a fraction that is too expensive and complex to recycle will always remain; this fraction is represented by the fluff stream in Figure 6. Metals are usually recovered to a high degree, so little metal was left in the fluff. From the reported data, ${ }^{16}$ the fluff stream comprised around 10\% after advanced post-shredder treatment, determined by the factors mentioned in the preceding paragraph. (Usually, the fluff stream is not subjected to post-shredder treatment, so it comprises more than $15 \%$ of the vehicle mass and is much dirtier.) In general, this fraction, together with all of the absorbed oils and other unprocessable wastes, has to be landfilled if technology is not available that can recover its energy content.

\section{Wastewater and surface water}

Maximizing resource efficiency requires a holistic view. Such a view links the wastewater system with its residues (sludges), for example, or surface-water systems and emission sources such as households, industrial plants, farms, and transportation networks with technological end-of-pipe solutions such as wastewater and sludge treatment processes and metallurgical processing. Recently, we explored a wastewater system in terms of ${ }^{10}$

- all substances originating from different wastewater sources, their concentrations in the different streams, and their interactions in different processes;

- input and output streams, including emissions from industry, farming, households, and traffic, and intermediate/interprocess mass flows; and

- end-of-pipe technologies for wastewater treatment plants, including interfacing with thermal treatment, minerals, and 
metallurgical processing for the recovery of specific elements from wastewater sludge and other residues created during wastewater treatment.

The model that we developed links the processing of wastewater treatment plant (WWTP) sludges and energy and material recovery with the metal, material, and waste processing systems. The pivotal role of metallurgical/mineral processing is included through the recovery of substances such as phosphorus and zinc from the WWTP sludge. On this basis, policy measures for the different stakeholders can be formulated, and WWTP and sludge processing routes can be designed. The model elucidates the link between pharmaceuticals, farming, industry and consumer behavior, and product use and highlights how species get into surface water, how they can be recovered, and how this process can be managed in the future to control water quality.

We used our water-cycle model ${ }^{10}$ to provide information such as the optimal combination of input-reducing technology and policy measures into sustainability frameworks for the implementation of the European Wastewater Framework Directive for the Brabantse Delta Water Board in the Netherlands. The model also allows predictions of the required efficiency of possible future technology, such as additional wastewater processing steps. The model integrates water processing with material processing, recovery, and emissions and with energy recovery. As an example, it can be applied to predict the required wastewater treatment plant architecture, type of phosphorus removal process (biological or chemical treatment), and chemicals used in relation to the incineration of and phosphorus recovery from sludge for the most resource-efficient production of fertilizers.

\section{Summary}

Ensuring continued resource availability and material flow into sustainable products requires well-designed systems that capture these resources from end-of-life (EOL) products and recycle them into new applications. Understanding the impact of product design and recycling system performance on this closure of material cycles requires comprehensive approaches consistent with basic principles, as presented in this article.

To inform policy and design resource supply and recycling systems, one must have detailed knowledge and understanding of recycling and high-temperature processing technology, as well as the effects of product design and possible changes in products and consumer behavior. A robust system design will help maximize resource efficiency, for example, reducing landfill usage, while securing the long-term supply of metals for products in the renewable-energy and other sustainability sectors.

Ultimately, resource efficiency is determined by how well the links among products, EOL processing, recyclate quality, recycling, and metallurgical technology are understood and optimized and, thence, how much material eventually lands in landfill because its complex composition eliminates its economic value. Poor material stewardship occurs and ultimately landfills exist because of a failure to create economically viable recyclates. Although the second law of thermodynamics imposes limits on recyclability, such failures also result from avoidable mistakes such as inadequate product design, collection systems, and process optimization.

Our research and development provides a theoretical basis for understanding the minimization of waste creation and hence the environmental burden of product and metal usage. It underpins resource efficiency with a theoretical basis, which is an important tool to help maintain and safeguard resources used in manufactured products, including scarce critical elements.

The integration of systems discussed herein highlights the importance of visualizing Kaufmann's "adjacent possible,"18 that is, introducing innovations that can be achieved now while considering all possible future solutions, and thus creating an exploration platform for systems innovation. This supports a technoeconomic evaluation of systems inclusive of the physics of the systems and hence provides an enabling technology for sustainability with enough detail to reveal the opportunities and limits of recycling.

\section{References}

1. A resource-efficient Europe-Flagship initiative under the Europe 2020 Strategy [Report COM(2011) 21, European Commission, Brussels, Belgium, 2011]

2. Critical raw materials for the EU (2010): Report of the Ad-hoc Working Group on defining critical raw materials (European Commission, Brussels, Belgium, 2010).

3. M.A. Reuter, Waste Biomass Valorization 2, 183 (2011).

4. A. van Schaik, M.A. Reuter, Miner. Eng. 23, 192 (2010).

5. "About Wecycle" (Wecycle, Zoetermeer, The Netherlands, 2011), www.wecycle.eu (accessed February 2012)

6. S. Krinke, A. van Schaik, M.A. Reuter, J. Stichling, in Innovative Developments for Lightweight Vehicle Structures: Conference Proceedings (Volkswagen AG, Wolfsburg, Germany, 2009), pp. 196-208.

7. A. van Schaik, M.A. Reuter, Miner. Eng. 20, 875 (2007)

8. "SLC-SuperLIGHT-CAR: Introduction" (SLC Consortium, Project Leader Volkswagen AG, Wolfsburg, Germany, 2005-2009), www.superlightcar.com (accessed February 2012)

9. M.A. Reuter, K. Heiskanen, U. Boin, A. van Schaik, E. Verhoef, Y. Yang, The Metrics of Material and Metal Ecology, Harmonizing the Resource, Technology and Environmental Cycles (Elsevier BV, Amsterdam, 2005), vol. 16.

10. A. van Schaik, M.A. Reuter, H. van Stokkom, J. Jonk, V. Witter, Miner. Eng. 23, 157 (2010).

11. HSC Chemistry (Outotec Research Oy, Espoo, Finland, 2011), version 7.1.

12. A. van Schaik, M.A. Reuter, Resour. Conserv. Recycl. 40, 301 (2004).

13. W.J. van den Hoek, G.M.J.F. Luuks, C.G.H. Hoelen, in UIImann's Encyclopaedia of Industrial Chemistry (Wiley-VCH, Weinheim, Germany, 2010), p. 53.

14. I. McGill, in Ullmann's Encyclopaedia of Industrial Chemistry (Wiley-VCH, Weinheim, Germany, 2005), p. 46.

15. A. Anindya, D. Swinbourne, M.A. Reuter, R. Matusewicz, in Proceedings of the European Metallurgical Conference EMC 2011 (GDMB, Clausthal-Zellerfeld, Germany, 2011), Vol. 1, pp. 3-14.

16. Proceedings of the 4th International Auto Recycling Congress (2004).

17. ARN Recycling: What we do (ARN, Amsterdam, The Netherlands), www.arn. nl/english/ARN-Recycling/What-we-do (accessed February 2012).

18. S. Johnson, Where Good Ideas Come From-The Natural History of Innovation (Penguin, New York, 2010). 


\title{
Measurements, standards, and data in support of the sustainable use of materials
}

\author{
Dianne L. Poster, Michael J. Fasolka, Richard R. Cavanagh, \\ and Ellyn S. Beary
}

Industry is increasingly aware that sustainability combines environmental, societal, and economic considerations in product development and that this linkage, while driving improved performance, can pose both a business opportunity and a challenge. On one hand, innovations make good business sense by bringing new products to supply a growing market demand for sustainable goods. On the other hand, new regulatory standards demand cleaner, less-toxic products, which can be difficult to develop economically, and require an agreed-upon infrastructure to demonstrate compliance, which can also be difficult and expensive. In this article, we discuss how measurements, standards, and data, being developed and deployed worldwide by national metrology institutes (NMIs) and standards-developing organizations (SDOs), are helping industry enable the sustainable use of materials. Examples include bio-based polymers, lightweight automobiles, fly-ash-based concrete, and lead-free solders. Measurements, standards, and data also support energy efficiency and renewable energy and ease industry compliance with new and emerging regulations, including those that demand less-toxic components.

\section{Introduction}

Sustainability is at the intersection of public, government, and private interests. Citizens around the world are seeking products and practices that support the sustainable use of materials, governments are enacting policies that promote it, and businesses wish to provide products and services that appeal to consumers and meet government regulations. How can any of these groups be assured that their efforts to support sustainability are effective? The answer is "standards." Standards enable the public, governments, and businesses to make progress and realize improved sustainability in a uniform manner. Three different types of standards typically come into play: regulatory standards, documentary standards, and measurement standards.

Regulatory standards enforce the provisions of legislation. They set requirements that industry and the public must follow, and they allow government agencies to enforce conformance with those requirements. For example, the U.S. Environmental Protection Agency (EPA) sets standards that define how much asbestos is allowed in specific chemical forms in a variety of products. In addition, under the Resource Conservation and Recovery Act (RCRA), EPA regulates household, industrial, and manufacturing solid waste. The RCRA in particular gives the EPA the authority to control hazardous waste "from cradle to grave" and includes the rules necessary for governing its generation, transportation, treatment, storage, and disposal. ${ }^{1}$

Documentary standards specify uniform technical criteria and methods to enable comparisons among products, processes, and test results. They are established by various standardsdeveloping organizations (SDOs). SDOs can be national or international in scope and draw on a broad range of technical expertise. Familiar examples include the International Organization for Standardization (ISO), the American National Standards Institute (ANSI), and ASTM International. Other organizations set documentary standards within more specialized contexts, such as the Society of Automotive Engineers (SAE) International, the Institute of Electrical and Electronics Engineers (IEEE), and the American Petroleum Institute (API). Documentary standards from these or other 
independent organizations can be incorporated by reference and become the basis for regulatory standards. For example, in November 2010, the U.S. Department of the Interior proposed to incorporate by reference 15 new production measurement industry standards into the regulations governing oil, gas, and sulfur operations in the Outer Continental Shelf. ${ }^{2}$

Measurement standards are typically physical artifacts that provide a common reference for a property of interest, but they can also be critically evaluated data or calibrations or wellcharacterized samples. The highest-level standards are traceable to the fundamental constants of the International System of Units. Examples include a specific form of asbestos, a diesel fuel of known composition, a steel bar of known strength, or a light source of known spectral composition. These standards allow instruments to be calibrated and measurements to be made that, when required, can be traced back to fundamental constants with a known uncertainty. Figure 1 shows examples of reference materials produced by a variety of national metrology institutes (NMIs).

This article describes measurements, standards, and datadevelopment activities being conducted by the National Institute of Standards and Technology (NIST), other NMIs, and SDOs around the world to support the sustainable use of materials. In some cases, these standards are fully developed, whereas in others, SDOs and NMIs are performing research to support the development of both documentary and measurement standards.

\section{Measurements, standards, and data in support of materials substitution}

Materials substitution is a key strategy for manufacturers to improve the performance and lower the cost of products. Substitution can also foster sustainability, for example, if the original material is toxic or nonrenewable or if its production results in significant greenhouse-gas (GHG) emissions, energy use, or byproducts that are potentially hazardous. Substantial challenges to materials substitution include reformulating/redesigning products, determining feedstock manufacturability and quality-control metrics, and establishing long-term reliability.

\section{Lowering barriers to the use of bio-based feedstocks for polymer products}

Using more bio-based feedstocks in the manufacture of polymeric products has several advantages, including increasing the use of renewable plant-based sources and decreasing the dependence on the volatile oil market, while meeting increasing consumer demand. Many bio-based polymer materials are also biodegradable and could thus dramatically reduce the amount of plastics-based solid waste. A 2009 analysis showed that biobased polymers could provide technically suitable replacements for nearly $90 \%$ of petroleum-based plastics. ${ }^{7}$ However, if these potential applications of bio-based polymers are to be realized, proper data sets, quality-control systems, and manufacturing infrastructure must be built. A number of life-cycle assessments (LCAs) have demonstrated a significant net reduction in GHG emissions and fossil energy consumption in the case of bio-based replacements for fossil energy sources. ${ }^{8}$ However, in the case of bio-based polymer products, a recent study demonstrated that LCAs of these complex systems can be highly sensitive to the type and quality of materials data employed, which can lead to conflicting conclusions about environmental impacts, such as GHG emissions and energy consumption. ${ }^{9}$

To validate environmental claims about their products, polymer manufacturers need reliable measures of the biobased content in their feedstocks, which can also contain petroleum-based sources. The accepted measure of bio-based content is the level of ${ }^{14} \mathrm{C}$ isotope in the feedstock (basically, carbon dating), because ancient petroleum has lost its ${ }^{14} \mathrm{C}$ through radioactive decay whereas feedstocks derived from recently living organisms have a ${ }^{14} \mathrm{C}$ content related to the current equilibrium concentration in the atmosphere. ASTM has developed a protocol to quantify the bio-based content in materials by comparing the ${ }^{14} \mathrm{C} /{ }^{12} \mathrm{C}$ ratio to that of a standard specimen typical of living organisms. ${ }^{10}$
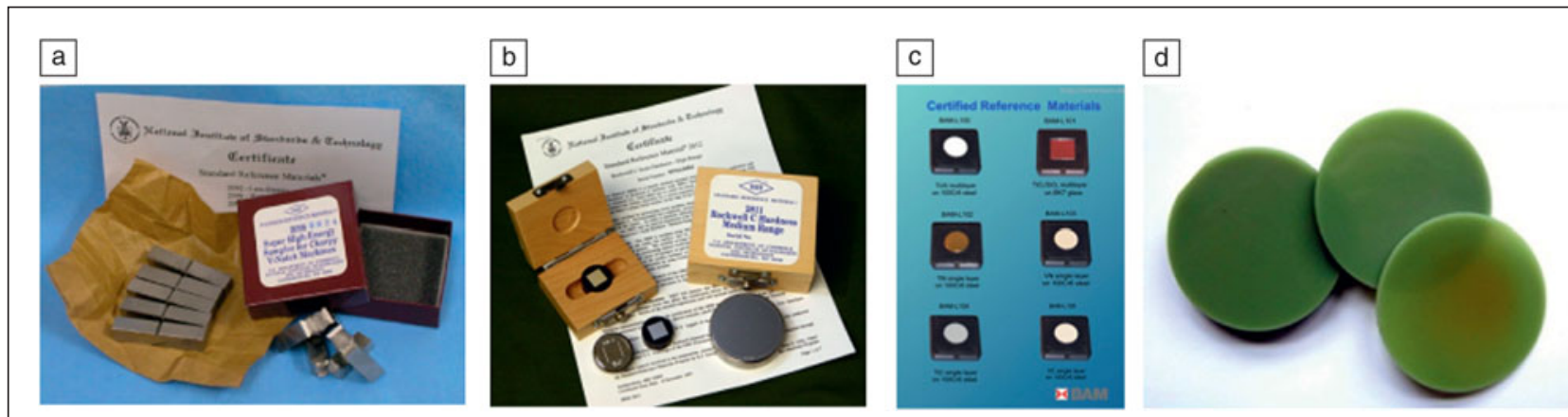

Figure 1. Reference materials, used to calibrate measurement instrumentation, come in many forms, from bulk metal artifacts to powders and films: (a,b) U.S. National Institute of Standards and Technology standard reference materials for calibrating (a) impact fracture ${ }^{3}$ and (b) hardness ${ }^{4}$ measurements. (c) Certified reference materials from Germany's Federal Institute for Materials Research and Testing (BAM) ${ }^{5}$ for calibrating the depth resolution of surface chemical analysis techniques, consisting of both single-layer and multilayered coatings of metals and oxides. (d) Another reference material from BAM ${ }^{6}$ for use in quality assurance, especially for measuring trace elements in polymers and related matrices. 
Measurement protocols have also been established to assess the biodegradability of bio-based polymers in various environments. For example, ASTM D5526 and a related set of documentary standards detail test methods to measure biodegradation of polymers under a variety of environments, including landfills and compost systems. ${ }^{11}$ The European Union has developed similar documentary standards for labeling a polymer product as biodegradable. ${ }^{12}$ These standard specifications and test methods validate claims made about bio-based products, thereby increasing consumers' confidence in such products.

\section{Automotive lightweighting}

Lighter cars are more fuel-efficient, resulting in lower emissions and fuel consumption. ${ }^{13}$ The auto industry is moving to replace traditional die-pressed sheet steels with new lightweight alloys (specifically, aluminum alloys, magnesium alloys, and high-strength steels) to help meet emerging fuel-economy regulations. However, the forming equipment, processes, and models used by the auto industry were designed for traditional die-pressed sheet steels. Material data, models, and standard tests are helping industry achieve its lightweighting goals. ${ }^{14}$ For example, in contrast to current industry design practice, which limits the maximum strain during forming, a more useful measure for the new materials is the stress. In response, NIST has leveraged an ASTM springback test ${ }^{15}$ and outfitted forming equipment with $\mathrm{x}$-ray-based instrumentation to measure stresses in sheets as they are shaped under actual manufacturing conditions. ${ }^{16}$ This work has provided time-saving measurement data and predictive models to automotive manufacturers and associations including Ford, General Motors, Volvo, and the United States Council for Automotive Research, as well as sheet metal manufactures such as Alcoa and U.S. Steel.

ASTM has a number of documentary standards relevant to lightweighting, for example, for radiographic inspection of magnesium castings. ${ }^{17}$ In principle, such standards could ensure the quality of engine blocks and other components cast from lightweight magnesium alloys, although one study suggests that these standards must be updated to be useful for automotive parts. ${ }^{18}$ The European Council for Automotive Research and Development highlighted the needs for lightweight composite, alloy, and hybrid materials in a 2011 position paper focusing on materials replacements in automotive interiors. ${ }^{19}$ Japan's National Institute for Materials Science has also highlighted automotive lightweighting, but has not yet issued standards. ${ }^{20}$ Indeed, the U.S. Department of Energy (DOE) Vehicle Technology Program Materials Research Roadmap, updated in 2010, suggests the need for at least five additional years of fundamental research for many substitute materials classes. ${ }^{21}$

\section{Reuse of fly ash for concrete production}

Fly ash is a well-suited replacement for siliceous and calcareous components of concrete when it has the correct composition and particulate properties. However, fly ash varies dramatically in composition depending on the quality of the coal from which it is derived and its combustion conditions, which complicates its use as a substitute feedstock. In part to meet this challenge, the U.S. EPA has issued guidelines on the levels of fly ash that can be used in concrete applications. ${ }^{22}$ In addition, ASTM has provided key quality-control measures by defining standard procedures for sampling and testing fly ash and has classified fly-ash feedstocks based on general ranges of composition, related mainly to the type of coal from which they are derived. Existing standards enable industry to reliably assess fly-ash feedstocks for their suitability in concrete. Ongoing measurement research in the United States and Europe targets guidelines and standards to support the even higher volume fractions of fly ash. NIST aims to establish measurement protocols (Figure 2) and models to better predict the short-term setting of high-volume-fly-ash cement binder formulations. ${ }^{23}$ Similar efforts to measure structure-propertyperformance relationships in fly-ash cement are underway in Europe. For example, Germany's Federal Institute for Materials Research and Testing is characterizing enhanced chemical degradation that has been observed in fly-ash cements to provide guidelines for formulations that would avoid this failure mode. ${ }^{24}$

In coming years, the levels of toxics will become increasingly important in measurement and standards research on

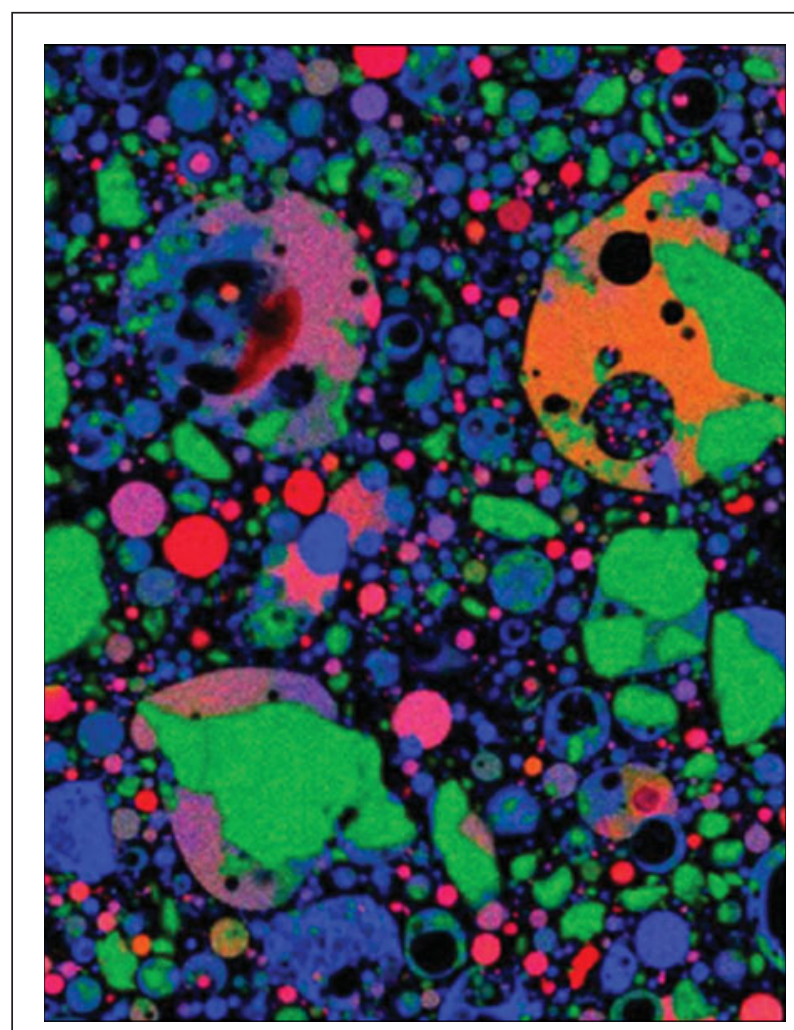

Figure 2. Scanning electron microscopy $x$-ray image $(150 \mu \mathrm{m} \times 133 \mu \mathrm{m})$ showing spatial distributions of calcium (red), silicon (green), and aluminum (blue) in coal fly-ash material. Such measurement techniques and data will help industry accommodate fluctuations in fly-ash feedstock composition that can lead to unacceptably long setting times and other degradations in binder performance when fly ash is used in high volumes. (Credit: Paul Stutzman, National Institute of Standards and Technology.) 
fly-ash-laden cements. For example, the European Union is developing revisions to standards and policy that would reclassify fly ash as a "waste product" rather than a "byproduct," 25 thereby making fly ash susceptible to the stringent REACH (Registration, Evaluation, Authorisation and Restriction of Chemical substances) ${ }^{26}$ and RoHS (Restriction of the Use of Certain Hazardous Substances in Electrical and Electronic Equipment $)^{27}$ regulations. New regulations are being considered in the United States as well. ${ }^{28}$ Standard protocols that quantify levels of toxics in fly ash will be needed to support industry compliance with these and related laws. Control technologies designed to reduce air pollution from power plants could shift pollutants from the flue gas to fly ash and other airpollution-control residues. The potential reuse of these materials raises concerns about the release of sequestered mercury during processing and the presence of toxics in the finished products. These issues warrant extensive characterizations of coal combustion residues, ${ }^{29}$ as well as the development of Standard Reference Materials (SRMs) consisting of these byproducts. ${ }^{30}$

\section{Properties and reliability of lead-free solders and finishes}

Driven in part by RoHS and the WEEE (Waste Electrical and Electronic Equipment) Directive ${ }^{31}$ in Europe and similar trends in Japan, electronics manufactures have transitioned to the use of lead-free solders in their products. Several lead-free solder materials are available, mainly $\mathrm{Sn}-\mathrm{Ag}-\mathrm{Cu}, \mathrm{Ag}-\mathrm{Cu}$, and $\mathrm{Sn}-\mathrm{Cu}$ alloys, but their full implementation in manufacturing is hindered by a lack of data supporting their quality control, processing limits, and long-term reliability. Accordingly, SDOs and NMIs have been developing measurements, data, and standards to support use of the most promising replacement materials. For example, to provide a reference for the compositional analysis of leadfree solder alloys, Japan's Society for Analytical Chemistry has produced a series of certified reference materials (JSAC 0131JSAC 0134$)^{32}$ for $\mathrm{Sn}-\mathrm{Ag}-\mathrm{Cu}$ solders, and NIST has deployed SRM $1728^{33}$ (Figure 3). In turn, measurement techniques, such as protocols for quantifying trace-element content using x-ray fluorescence spectrometry methods, ensure that lead-free products comply with regulatory and reporting thresholds. ${ }^{34}$

Driven by COST (European Cooperation in Science and Technology) Action $531^{35}$ on lead-free solder materials, databases of solder thermodynamic and physical properties have been compiled. For example, the National Physical Laboratory (NPL), the UK's NMI, has established a public database of critically evaluated thermodynamic parameters for over 50 binary alloys and numerous ternary systems of eleven elements that can potentially be used in lead-free solder formulations. ${ }^{36}$ The Polish Academy of Sciences compiled the downloadable SURDAT database, ${ }^{37}$ which lists experimentally determined molar volumes, densities, and surface tensions of $\mathrm{Ag}-\mathrm{Cu}$ and $\mathrm{Sn}-\mathrm{Ag}-\mathrm{Cu}$ systems. In addition, the Japanese Standards Association has established test methods for determining critical physical and engineering properties of lead-free solders (JIS Z 3198-1-JIS Z 3198-7).

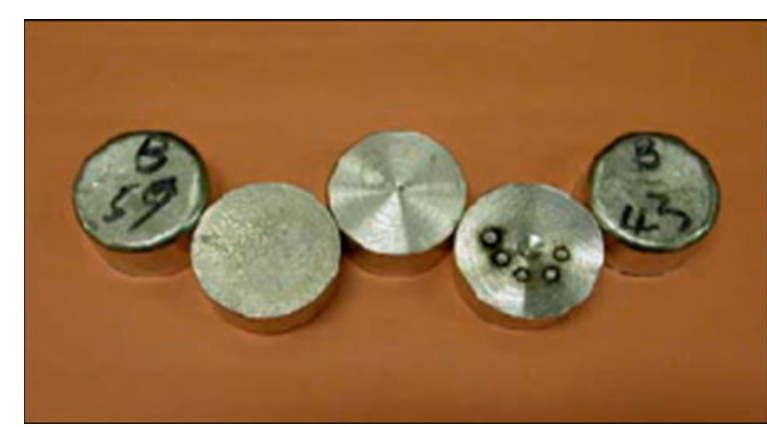

Figure 3. Disks of Standard Reference Material (SRM) 1728 Tin Alloy (Sn-3Cu-0.5Ag), a lead-free solder composition, showing various stages in manufacturing and testing. The alloy was created using a semi-chill casting process to ensure homogeneity of the disks to a depth of at least $10 \mathrm{~mm}$. The SRM provides values for bulk composition of a number of elements, including chromium, cadmium, mercury, and lead, which are restricted in products around the world for environmental and health reasons. ${ }^{33}$

Lead-free solders and finishes have been employed in some electronics applications for nearly 70 years, but the tremendous increase in their use over the past decade has brought attention to some ways in which these materials can fail. ${ }^{38}$ In particular, over long periods, normally stable solder balls and interconnects can develop structural and morphological changes that result in the formation of cracks, pull-offs, and "whiskers"-microscopic, hair-like protrusions of metal, sometimes centimeters long - that can cause short circuits in devices (Figure 4). Such failures are problematic for long-lifetime components, such as those found in mainframe computers, and can be catastrophic in critical

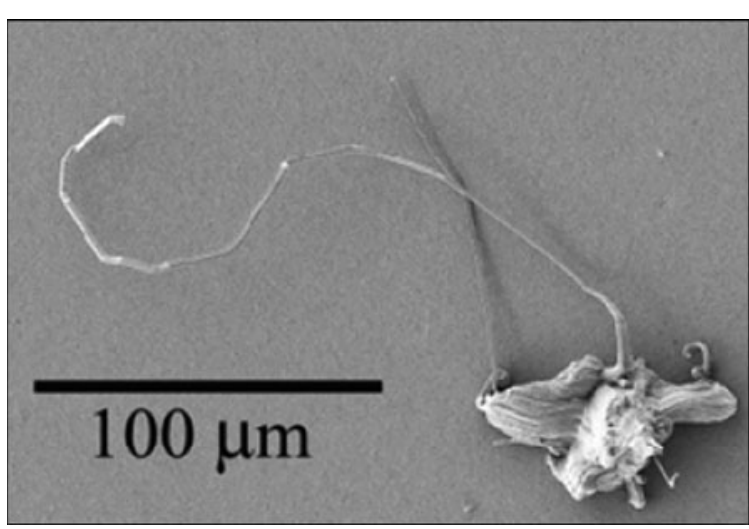

Figure 4. Scanning electron microscopy image of a tin whisker growing from a lead-free surface finish. ${ }^{39}$ The composition of the lead-free surface finish is tin with $3 \%$ mass fraction copper (Sn-3 wt\% Cu). The whisker growing out of the surface finish is tin. Tin whiskers often grow spontaneously from pure tin electrodeposits and short-circuit finely pitched electrical components. Adding a low percentage of lead inhibits whisker growth, but environmental concerns have resulted in a demand for lead-free finishes and whisker-mitigation strategies. (Credit: Maureen Williams, National Institute of Standards and Technology.) 
applications such as aircraft and medical devices. For example, according to the U.S. National Aeronautics and Space Administration, since 1992, at least four in-orbit satellites have lost full function as a result of the formation of tin whiskers from lead-free solders and finishes, and another four have partially lost function. ${ }^{40}$

Roadmaps by the International Electronics Manufacturing Initiative (iNEMI) have highlighted the reliability and failure mechanisms of lead-free solders as priority issues to address, leading to the establishment of a working group to produce accelerated test methods for measuring tin whisker growth. ${ }^{41,42}$ This work has enabled industry users and producers of lead-free finishes to assess the rate at which tin whiskers can form and grow from these materials under service conditions. NIST has also assessed the conditions of tin-whisker growth, ${ }^{43}$ demonstrating that whiskers grow only when column-shaped grains form perpendicular to the finish surfaces ${ }^{44}$ and that whisker growth releases residual stress in the material.

\section{Energy efficiency and renewable energy Tuning the color of solid-state lighting}

Solid-state lighting (SSL), historically limited to monochromatic light-emitting diodes (LEDs), became viable for broad consumer and commercial applications with the advent in 1997 of LED-driven devices that produce white light by incorporating phosphors. However, consumer acceptance of SSL depends on whether it can emit the "warmer" white tones of incandescent bulbs. Blue-tinged "bright-white" sources have a "cold" quality that many people find unpleasant. The color tone of the light from SSL devices can be controlled by tuning the phosphor materials, but developing, choosing, and processing these materials in ways that achieve consistent performance can be challenging. Standards help SSL manufacturers meet these challenges, by enabling them to tune the emission of phosphor mixtures and to gauge the performance of candidate phosphor and LED materials $^{45}$ (Table I).

\begin{tabular}{|c|c|c|c|}
\hline Standard and title & Developer(s) & Description & Year of publication \\
\hline CIE 127:2007 Measurement of LEDs & CIE, NIST 46 & $\begin{array}{l}\text { Provides recommendations on how to measure } \\
\text { the luminous/radiant intensity, total and } \\
\text { partial flux, and spectral power distribution; } \\
\text { requires standard LEDs to be calibrated } \\
\text { by National Metrology Laboratories or a } \\
\text { laboratory traceable to National Metrology } \\
\text { Laboratories }^{47}\end{array}$ & 2007 \\
\hline $\begin{array}{l}\text { IESNA LM-79 Electrical and Photometric } \\
\text { Measurements of Solid-State Lighting } \\
\text { Products }\end{array}$ & $\begin{array}{l}\text { ANSI, IESNA, CIE, } \\
\text { U.S. DOE, NIST }\end{array}$ & $\begin{array}{l}\text { Requires complete luminaire testing and } \\
\text { describes the methods for testing SSL } \\
\text { products for their light output (lumens), } \\
\text { energy efficiency (lumens per watt), } \\
\text { and chromaticity }{ }^{48}\end{array}$ & 2008 \\
\hline $\begin{array}{l}\text { IESNA LM-80 Measuring Lumen } \\
\text { Maintenance of LED Light Sources }\end{array}$ & $\begin{array}{l}\text { IESNA with collaborations } \\
\text { as above }\end{array}$ & $\begin{array}{l}\text { Provides for reliable comparisons of test results } \\
\text { among laboratories by establishing uniform } \\
\text { test methods; addresses the measurement } \\
\text { of lumen maintenance testing for LED light } \\
\text { sources including LED packages, arrays, and } \\
\text { modules }{ }^{49}\end{array}$ & 2008 \\
\hline $\begin{array}{l}\text { C78.377-2008 American National Standard } \\
\text { for Electric Lamps-Specifications for } \\
\text { the Chromaticity of Solid State Lighting } \\
\text { (SSL) Products }\end{array}$ & ANSI, NEMA, ANSLG, NIST & $\begin{array}{l}\text { Specifies the recommended color ranges } \\
\text { for SSL products using cool to warm } \\
\text { white LEDs with various correlated color } \\
\text { temperatures; } 50 \text { applies to LED-based SSL } \\
\text { products with control electronics and heat } \\
\text { sinks incorporated and covers fixtures } \\
\text { incorporating light sources as well as } \\
\text { integrated LED lamps }\end{array}$ & 2008 \\
\hline $\begin{array}{l}\text { NEMA SSL 3-2011 High-Power White LED } \\
\text { Binning for General Illumination }\end{array}$ & NEMA & $\begin{array}{l}\text { Offers categorization areas (bins) for } \\
\text { chromaticity (colors), forward voltage } \\
\text { measurements (an electrical designation), } \\
\text { and luminous flux (light output) for LEDs } \\
\text { used for general lighting }\end{array}$ & 2011 \\
\hline $\begin{array}{l}\text { CIE TC 1-69 Colour Rendition of White } \\
\text { Light Sources }\end{array}$ & CIE, NIST & $\begin{array}{l}\text { Addresses problems with the CIE Color } \\
\text { Rendering Index for SSL sources and } \\
\text { meets the new priority needs of the lighting } \\
\text { industry and consumers for communicating } \\
\text { color quality of lighting products }{ }^{51}\end{array}$ & In progress \\
\hline
\end{tabular}

Acronyms: ANSI, American National Standards Institute; ANSLG, American National Standard Lighting Group; CIE, International Commission on Illumination; IESNA, Illuminating Engineering Society of North America; LED, light-emitting diode; NEMA, National Electrical Manufacturers Association; NIST, National Institute of Standards and Technology; SSL, solid-state lighting; U.S. DOE, U.S. Department of Energy. 
The development of SSL standards is part of the U.S. government's effort to help the DOE reach its goal of developing and introducing SSL to reduce energy consumption for lighting by $50 \%$ by 2025 and to support the ENERGY STAR program, a joint program of the DOE and the EPA that promotes energy-efficient products and practices. NIST independently tested 150 ENERGY STAR-qualified products, using measurement methods traceable to national electrical standards, and confirmed that these products met EPA product specifications (100\% for digital versatile disc products and computer monitors and $95 \%$ for printers). ${ }^{52}$

\section{Photovoltaics}

In its 2010 Technology Roadmap for Solar Photovoltaic Energy, the International Energy Association (IEA) indicated that, since 2000, global photovoltaic (PV) capacity has been increasing by more than $40 \%$ per year, on average, and has significant potential for long-term growth in coming decades. The IEA envisions that, by 2050 , photovoltaics will provide $11 \%$ of global electricity production (4500 TWh per year). Achieving such growth, however, necessitates policies in the next decade that enable optimal technology progress, cost reduction, and an increase of industrial manufacturing. ${ }^{53}$

One approach offering the possibility of greatly reduced manufacturing cost compared to conventional inorganic semiconductor silicon technology is organic photovoltaics (OPV). These are solar cells that use organic molecules, including polymers, dendrimers, small molecules, and dyes. However, OPV devices have much lower efficiencies than those based on traditional PV materials. To provide design principles for optimizing OPV materials and devices, a suite of measurements aimed at determining the molecular and microstructural mechanisms of charge transport in these materials, especially across the complex interfaces within them, is being developed by NIST. Photoelectron spectroscopies, scanningprobe methods, and theoretical models of multiscale processes in thin organic films and polymeric heterojunctions are central to this pursuit. ${ }^{54}$ In addition to accelerating research, these measurement techniques could establish standard test methods for use by industry. Such methods for OPV and other organic electronic devices are being pursued through the Versailles Project on Advanced Materials and Standards (VAMAS), which includes efforts to develop reference methods and data to support the process optimization, quality control, and reliability of OPV devices. This effort is led by the VAMAS Organic Electronics Technical Working Area and is co-chaired by two NMIs: NPL and NIST. ${ }^{55}$

\section{Compliance with existing and emerging regulations}

In the mid-2000s, the European Union passed a series of "green directives" to reduce the levels of known hazardous substances in the environment. Implemented in February 2003 and updated in 2008, WEEE legislation restricts the use of hazardous substances in electrical and electronic equipment and promotes end-of-life collection and recycling of such equipment through electronic-waste collection schemes that are free of charge to the consumer. Another directive, $\mathrm{REACH}$, is the
European Community regulation on chemicals and their safe use (EC 1907/2006) and requires that the chemical industry provide safety information on all substances that its members produce. Product manufacturers are required to gather the relevant information and register it into a central database ${ }^{56}$ run by the European Chemicals Agency. The agency manages, operates, and evaluates data submitted by manufacturers and importers on the chemicals used in their products.

Perhaps more directly impacting materials development is the RoHS legislation, enacted in 2006 and updated in 2011. This directive has been widely implemented and has led to similar legislation from individual U.S. states and countries such as Japan and China. The WEEE and RoHS regulations are related, in that the WEEE Directive focuses on the design and recycling of electronic products whereas RoHS aims to reduce the amount of hazardous substances used in electronics manufacture. In the updated standard, the maximum allowable levels remain the same, but they now apply to toys, leisure and sports equipment, medical devices, industrial monitoring and control instruments, and selected electrical and electronic equipment that had been excluded from the original directive. The newly included equipment will be phased in through 2019. ${ }^{57}$

International metrology institutes, including NIST, the Institute for Reference Materials and Measurements (IRMM) in Europe, and the National Institute of Metrology in China, have been working together to value assign new relevant certified reference materials. Two certified reference materials for the determination of various polybrominated diphenyl ethers (PBDEs) and decabrominated biphenyl in polymers are available from IRMM. ${ }^{58}$ Total bromine and total antimony are also characterized in these polymer reference materials, as the measurement of bromine or antimony can be used as a screening method for brominated flame retardants. In addition to SRM 1728 Tin Alloy (Sn-3Cu-0.5Ag) mentioned earlier (Figure 3), SRM 1124 Free-Cutting Brass has been developed by NIST. ${ }^{59}$ Both of these materials contain known concentrations of restricted substances. Two solution SRMs have also been developed to address measurement issues related to PBDEs, and there are also new SRMs for lead in paint and phthalates in poly(vinyl chloride).

A large set of documentary and regulatory standards related to sustainability, including the ISO 14000 family, REACH, RoHS, and others, has been analyzed, and the consolidated information is available through a web portal. ${ }^{60}$ This effort has led to a framework for evaluating sustainability standards $\mathrm{s}^{61,62}$ and offers a tool for determining what to measure, how to measure it, and how to report and validate the results. Similarly, for the electronics industries, the iNEMI, Association Connecting Electronics Industries (IPC), and NIST have developed a standard reporting format for manufacturers to exchange material content information between supply-chain participants. This work includes the development of a data management tool to address regulations beyond RoHS. ${ }^{63}$

\section{Summary}

In all technological areas, the drivers for measurements and measurement standards are diverse. Standards are often 
required so that industry can ensure compliance with regulation. In the area of sustainable materials, REACH, RoHS, and other regulations have certainly spurred the development of replacement materials that contain fewer toxic substances. However, as discussed in this article for bio-based polymers, lead-free solders and finishes, and other applications, measurements and standards are not just reactive measures for regulatory compliance, but are also drivers for technological innovation. These tools clarify performance targets, as discussed for solid-state lighting. They can also substantiate claims of the environmental benefits of a product and thus attract customers for more sustainable goods, as described for bio-based polymers. Finally, measurement science, protocols, and standards support innovative research and development, as discussed for automotive weight reduction. Indeed, for sustainable materials research, such measurement solutions are especially important, because discovering, developing, and optimizing materials replacements depends strongly on the ability to determine their composition and structure and the properties that make them useful, less energy-intensive, less toxic, and renewable.

Disclaimer: Certain commercial entities are mentioned in this article. This does not imply recommendation or endorsement of these entities by the National Institute of Standards and Technology.

\section{References}

1. Summary of the Resource Conservation and Recovery Act. 42 U.S.C. $\S 6901$ et seq. (1976) (U.S. Environmental Protection Agency, Washington, DC, 2011), www.epa.gov/regulations/laws/rcra.html (accessed January 2012).

2. "Production Measurement Documents Incorporated by Reference," Fed. Regist. 75 (227), 72761-72766 (2010).

3. "Charpy Program" (National Institute of Standards and Technology, Gaithersburg, MD, 2011), www.nist.gov/mml/materials_reliability/structural_ materials/charpy-verification-program.cfm (accessed January 2012).

4. "Hardness Standard Reference Materials" (National Institute of Standards and Technology, Gaithersburg, MD, 2010), www.nist.gov/mml/metallurgy/materials_ performance/hardness_srms.cfm (accessed January 2012).

5. "Reference materials: Materials to calibrate GDOES depth profiles" (Federa Institute for Materials Research and Testing, Berlin, Germany, 2011), www. bam.de/en/kompetenzen/fachabteilungen/abteilung_6/fg64/fg64_ag1d.htm (accessed January 2012).

6. New Plastic Reference Material BAM-H010 (Federal Institute for Materials Research and Testing, Berlin, Germany, 2010).

7. L. Shen, J. Haufe, M.K. Patel, Product overview and market projection of emerging bio-based plastics. PRO-BIP 2009 (Utrecht University, Utrecht, The Netherlands, 2009)

8. F. Cherubini, A.H. Strømman, Bioresour. Technol. 102 (2), 437 (2011).

9. M.D. Tabone, J.J. Cregg, E.J. Beckman, A.E. Landis. Environ. Sci. Technol. 44 (21), 8264 (2010).

10. ASTM D6866-11. Standard Test Methods for Determining the Biobased Content of Solid, Liquid, and Gaseous Samples Using Radiocarbon Analysis (ASTM International, West Conshohocken, PA, 2011).

11. ASTM D5526-94(2011)e1. Standard Test Method for Determining Anaerobic Biodegradation of Plastic Materials Under Accelerated Landfill Conditions (ASTM International, West Conshohocken, PA, 2011).

12. BS EN 13432:2000. Packaging. Requirements for packaging recoverable through composting and biodegradation. Test scheme and evaluation criteria for the final acceptance of packaging (British Standards Institution, London, UK, 2000).

13. FY 2009 Progress Report for Lightweighting Materials (U.S. Department of Energy, Washington, DC, 2010).

14. "NIST Center for Metal Forming" (National Institute of Standards and Technology, Gaithersburg, MD, 2010), www.nist.gov/mml/metallurgy/materials_ performance/sheet_metal_forming.cfm (accessed January 2012).
15. ASTM E2492-07. Standard Test Method for Evaluating Springback of Sheet Metal Using the Demeri Split Ring Test (ASTM International, West Conshohocken, PA, 2007).

16. M.A. Iadicola, T. Foecke, S.W. Banovic, Int. J. Plast. 24, 2084 (2008).

17. ASTM E155-10. Standard Reference Radiographs for Inspection of Aluminum and Magnesium Castings (ASTM International, West Conshohocken PA, 2010).

18. S. Das, J.H. Peretz, B.E. Tonn, Automotive Lightweighting Materials Benefit Evaluation (Report ORNL/TM-2006/545, Oak Ridge National Laboratory, Oak Ridge, TN, 2006).

19. Challenges and Priorities for Automotive R\&D (European Council for Automotive R\&D, Brussels, Belgium, May 2011).

20. J. Rosalie, Materials Engineering: An Introduction (National Institute for Materials Science, Tokyo, Japan, 2008).

21. FreedomCAR and Fuel Partnership: Materials Technology Roadmap (U.S. Department of Energy, Washington, DC, 2010).

22. "Cement and Concrete Specifications" (U.S. Environmental Protection Agency, Washington, DC, 2008), www.epa.gov/osw/conserve/tools/cpg/products/ cemspecs.htm (accessed January 2012).

23. Hydration of Concrete-Making Materials Containing High Volumes of Fly Ash (National Institute of Standards and Technology, Gaithersburg, MD, 2011).

24. "Damage Mechanisms and Protective Measures: Degradation of Concrete by Alkali Silica Reaction" (Federal Institute for Materials Research and Testing, Berlin, Germany, 2011), www.bam.de/en/kompetenzen/fachabteilungen/abteilung_7/ fg71/fg71_ag2c.htm (accessed January 2012).

25. H. Feuerborn, paper presented at the World of Coal Ash Conference (sponsored by the American Coal Ash Association and the University of Kentucky's Center for Applied Energy Research), Denver, C0, 9-12 May 2011. 26. "REACH" (European Commission-Environment, Brussels, Belgium, 2011), ec.europa.eu/environment/chemicals/reach/reach_intro.htm (accessed January 2012). 27. "What is RoHS?" (National Measurement Office, Teddington, UK), www.bis. gov.uk/nmo/enforcement/rohs-home (accessed January 2012).

28. "Coal Combustion Residuals—Proposed Rule" (U.S. Environmental Protection Agency,Washington,DC,2011), www.epa.gov/osw/nonhaz/industrial/special/fossil/ ccr-rule/index.htm (accessed January 2012).

29. D. Kosson, F. Sanchez, P. Kariher, L.H. Turner, R. Delapp, P. Seignette, Characterization of Coal Combustion Residues from Electric Utilities-Leaching and Characterization Data (Report EPA-600/R-09/151, U.S. Environmental Protection Agency, Washington, DC, 2009).

30. "Activated Carbon and FGD Gypsum Standard Reference Materials" (National Institute of Standards and Technology, Gaithersburg, MD, 2011), www.nist.gov/ $\mathrm{mml} /$ analytical/inorganic/fgdgypsum.cfm (accessed January 2012).

31. "Waste Electrical and Electronic Equipment (WEEE)" (Environment Agency, Rotterham, UK, 2011), www.environment-agency.gov.uk/business/topics/waste /32084.aspx (accessed January 2012).

32. J. Noro, T. Korenaga, M. Kozaki, S. Kawada, K. Kurusu, M. Mizuhira, A. Ono, K. Katsumi, K. Kakita, K. Takimoto, M. Sakata, Bunseki Kagaku 59 (2), 107 (2010).

33. "NIST SRM 1728 Tin Alloy (Sn-3Cu-0.5Ag) Supports Testing of LeadFree Solder," in SRM Spotlight (National Institute of Standards and Technology, Gaithersburg, MD, March2011), www.nist.gov/srm/upload/March-2011-Spotlight-3. pdf (accessed January 2012)

34. J.R. Sieber, in Advances in X-ray Analysis: Proceedings of the Denver X-ray Conference (International Centre for Diffraction Data, Newton Square, PA, 2002), vol. 45, pp. 493-504.

35. "MPNS COST Action 531. Lead-free Solder Materials" (European Cooperation in Science and Technology, Brussels, Belgium, 2011), www.cost.esf.org/domains actions/mpns/Actions/531 (accessed January 2012).

36. "MTDATA: Phase Diagram Software from the National Physical Laboratory" (National Physical Laboratory, Teddington, UK, 2010), www.npl.co.uk/sciencetechnology/advanced-materials/measurement-techniques/mtdata (accessed January 2012).

37. "SURDAT Database of Lead-Free Soldering Materials" (Polish Academy of Sciences, Krakow, Poland, 2007), www.imim.pl/surdat-database (accessed January 2012).

38. G.T. Galyon, paper presented at the SMTAI Conference (sponsored by the Surface Mount Technology Association), Chicago, IL, 26-30 September 2004. 39. "Lead-Free Surface Finishes for Electronic Components: Tin Whisker Growth" (National Institute of Standards and Technology, Gaithersburg, MD, 2010), www.nist.gov/mml/metallurgy/thermodynamics_kinetics/lead-free_surface_ finishes.cfm (accessed January 2012)

40. "NASA Whisker Failures" (National Aeronautics and Space Administration, Washington, DC, 2009), nepp.nasa.gov/whisker/failures/index.htm (accessed January 2012).

41. "Roadmap" (International Electronics Manufacturing Initiative, Herndon, VA, 1998), www.nemi.org/cms/roadmapping/impact.html (accessed January 2012).

42. "Measuring Whisker Growth on Tin and Tin Alloy Surface Finishes. JESD22A121A" (JEDEC, Arlington, VA, 2008). 
43. G.R. Stafford, M.E. Williams, C.E. Johnson, K. Moon, U. Bertocci, O. Kongstein, W.J. Boettinger, ECS Trans. 1 (13), 71 (2006).

44. W.J. Boettinger, C.E. Johnson, L.A. Bendersky, K. Moon, M.E. Williams, G.R. Stafford, Acta Mater. 53 (19), 5033 (2005).

45. "Standards Set for Energy-Conserving LED Lighting" (National Institute of Standards and Technology, Gaithersburg, MD, 2008), www.nist.gov/pml/div685 /led_062408.cfm (accessed January 2012).

46. "Solid-state lighting metrology" (National Institute of Standards and Technology, Gaithersburg, MD, 2010), www.nist.gov/pml/div685/grp05/ssl.cfm (accessed January 2012).

47. Measurement of LEDs. CIE 127-2007 (Commission Internationale de L'Eclairage, Vienna, Austria, 2007)

48. Approved Method: Electrical and Photometric Measurements of Solid-State Lighting Products (Illuminating Engineering Society, New York, 2008).

49. Approved Method: Measuring Lumen Maintenance of LED Light Sources (Illuminating Engineering Society, New York, 2008).

50. American National Standard for Electric Lamps-Specifications for the Chromaticity of Solid State Lighting (SSL) Products (National Electrical Manufacturers Association, Rosslyn, VA, 2008)

51. "Color rendering of light sources" (National Institute of Standards and Technology, Gaithersburg, MD, 2010), www.nist.gov/pml/div685/grp05/vision_color.cfm (accessed January 2012).

52. ENERGY STAR Program Integrity Can Be Enhanced Through Expanded Product Testing (Report 10-P-0040, U.S. Environmental Protection Agency, Washington, DC, 2009).

53. Technology Roadmap: Solar Photovoltaic Energy (International Energy Agency, Paris, France, 2010)

54. "Electronic Structure and Excited-State Dynamics at Donor-Acceptor Interfaces" (National Institute of Standards and Technology, Gaithersburg, MD, 2010), www.nist.gov/mml/surface/excited_state_dynamics.cfm (accessed January 2012).
55. "Versailles Project on Advanced Materials and Standards (VAMAS), TWA 36 Organic Electronics" (VAMAS Secretariat, Gaithersburg, MD), www.vamas.org/ twa36/ (accessed January 2012)

56. "Candidate List of Substances of Very High Concern for Authorization" (European Chemicals Agency, Helsinki, Finland, 2011), echa.europa.eu/chem data/authorisation_process/candidate_list_table_en.asp (accessed January 2012). 57. "Directive 2011/65/EU of The European Parliament and of the Council of 8 June 2011 on the Restriction of the Use of Certain Hazardous Substances in Electrical and Electronic Equipment (Recast)," Off. J. Eur. Union L 174, 88 (2011).

58. T. Linsinger, A. Birgersson-Liebich, F. Pellizzato, T. Venelinov, S. Voorspoels, A. Lamberty, Certification Report: Certification of the mass fractions of various polybrominated diphenyl ethers (PBDES), decabrominated biphenyl and total $\mathrm{Br}$ and total $\mathrm{Sb}$ in two polymer reference materials. (Certified Reference Materials ERM@-EC590 \& ERM@-EC591 (Institute for Reference Materials and Measurements, Geel, Belgium, 2009).

59. "Support of Industry Compliance with the EU Directive on Restriction of Certain Hazardous Substances (RoHS)" (National Institute of Standards and Technology, Gaithersburg, MD, 2011),; www.nist.gov/mml/analytical/inorganic /rohs.cfm (accessed January 2012)

60. "Sustainability Standards Portal" (National Institute of Standards and Technology, Gaithersburg, MD, 2010), www.mel.nist.gov/msid/SSP (accessed January 2012).

61. S. Rachuri, P. Sarkar, A. Narayanan, J.H. Lee, P. Witherell, in Glocalized Solutions for Sustainability in Manufacturing: Proceedings of the 18th CIRP International Conference on Life Cycle Engineering. Technische Universität Braunschweig, Braunschweig, Germany, May 2nd-4th, 2011, J. Hesselbach, C. Herrmann, Eds. (Springer, New York, 2011), pp. 543-548.

62. "NIST Prototypes Framework for Evaluating Sustainability Standards" (National Institute of Standards and Technology, Gaithersburg, MD, 2011), www.nist.gov/el/msid/sustain-042611.cfm (accessed January 2012).

63. E.D. Simmon, J.V. Messina, paper presented th the IPC APEX Conference, Las Vegas, NV, 1-8 April 2008.

\begin{tabular}{|c|c|c|}
\hline 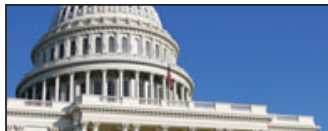 & $\sum_{\text {MAERIALSVICE }}^{\text {㲾 }}$ & $\begin{array}{l}\text { A Web-based tool to ensure that your voice } \\
\text { is heard on Capitol Hill }\end{array}$ \\
\hline
\end{tabular}

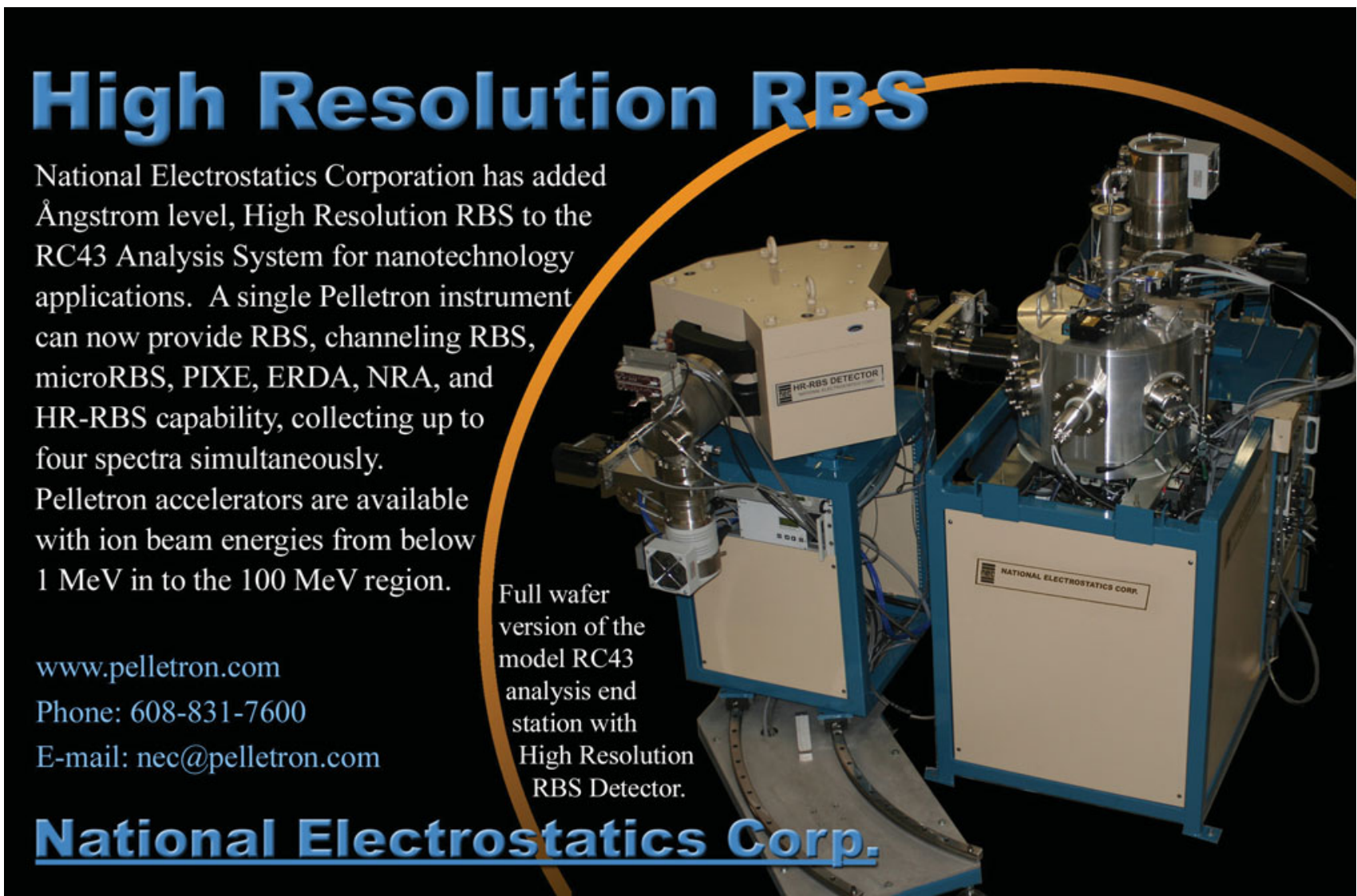




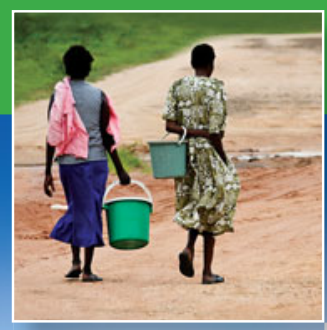

\title{
Human health and ecotoxicological considerations in materials selection for sustainable product development
}

\author{
Oladele A. Ogunseitan and Julie M. Schoenung
}

The cost and performance of materials have traditionally been the primary factors considered by designers of consumer products. Recent attempts to quantify the environmental sustainability of such products have stimulated the development of methods for assessing the reserves of raw materials compared to the demand for their use in manufacturing and impacts on energy resources. To a much more limited extent, these strategies also evaluate how chemical toxicity, arising from material production, use, and disposal, affects human and environmental health. The mechanisms and adverse impacts of toxic effects vary widely at different points within material life cycles, making it difficult to establish internally consistent methods and weighting criteria for quantitative evaluation of the environmental liability of consumer products. This article reviews advances in the methodology and application of health and ecological impact assessments of materials used in consumer products and argues for a stronger integration of toxicity metrics into materials informatics databases.

\section{Introduction}

In 1983, the United Nations convened the World Commission on Environment and Development in response to increasing international concerns about the depletion of natural resources and the global decline in the environment. The Commission's 1987 report produced a widely quoted definition of sustainable development as that which "meets the needs of the present without compromising the ability of future generations to meet their own needs." Although putting this definition into practice remains a challenge, assessing and controlling the rate at which raw materials are depleted for manufacturing has become an important focus for sustainability science. Beyond the supply of raw materials, however, the environmental and human health impacts of materials use can also impair society's ability to sustain the planet for future generations. This article highlights the need to minimize the use of and exposure to toxic chemicals and materials.

Approximately 83,000 chemicals are produced for commercial applications; many are used in widely distributed consumer products (e.g., electronics, furniture, textiles). Of these, characterizations of toxicity risks to people and the environment are available for less than $10 \% .^{2}$ Therefore, despite growing initiatives to substitute safer alternatives for toxic components, gaps persist in the knowledge on how to proceed. ${ }^{3}$
In response to this dearth of information, the U.S. Environmental Protection Agency (EPA) established the High Production Volume (HPV) Challenge Program, a voluntary initiative that asks manufacturers to publicize information on health and environmental effects of chemicals that are either manufactured or imported in the United States in annual quantities exceeding $453 \mathrm{t}$ ( 1 million pounds). In contrast, the Organization for Economic Cooperation and Development (OECD) and Japan set the annual threshold for reporting on HPV chemicals at production or import of $1000 \mathrm{t}$. Approximately 2200 chemicals are included in EPA's HPV Information System, and the data represent international consensus on which chemicals to include based on 18 Screening Information Data Sets. ${ }^{4,5}$

The EPA develops hazard characterizations, based on data submitted by chemical manufacturers, by cross-checking registries such as the International Agency for Research on Cancer (IARC) Cancer Epidemiology Database, Extension Toxicology Network (EXTOXNET), Integrated Risk Information System (IRIS), Agency for Toxic Substances Disease Registry (ATSDR), and Toxicology Literature Online (TOXLINE). ${ }^{6}$ The HPV Information System covers 50 characteristics organized under four domains, namely, ecotoxicity (including, for example, toxicity to fish, aquatic plants, or important ecosystem processes such as biological nitrogen fixation), environmental 
fate and pathways of chemical modification (including natural biological or photochemical degradation), mammalian health effects (e.g., toxicity to reproductive, neurological, or other developmental processes), and physical/chemical properties (e.g., melting point and vapor pressure). ${ }^{7}$ However, there is no consensus on how to aggregate data in these four domains for comparative assessments of materials. Invariably, the process requires tradeoffs, for example, between a chemical that appears to be less hazardous to mammalian health but more hazardous in terms of ecotoxicity. It is unclear how best to weight these impacts to produce consistent metrics. Moreover, the data sets have numerous gaps and poorly characterized uncertainties.

The lack of international consensus on the strategy for data integration led to the establishment in 2002 of the Life Cycle Initiative (LCI) through collaboration between the United Nations Environment Programme (UNEP) and the Society for Environmental Toxicology and Chemistry (SETAC) $)^{8,9}$ (Figure 1). The consideration of toxicity impacts in the selection of alternative materials as required in phase 1 of LCI is arguably the most methodologically contentious. This article discusses methodological approaches based on Life Cycle Impact Assessment (LCIA) tools for resolving difficult questions regarding the role of toxicity in materials selection.

\section{Integration of toxicity indices into materials informatics}

Environmental legislation has targeted the use of toxic substances for decades, but known human toxicants such as lead and mercury, as well as ecologically toxic pollutants such as copper, are still used in engineered products. Furthermore, numerous new substances, including organic chemicals, are added to industrial manufacturing every year. For many of these chemicals, there is deep uncertainty about their toxicity and environmental fate. Table I reports the magnitudes of toxic releases of selected metals and organic monomers into the environment in the United States, as reported in the EPA's Toxics Release Inventory (TRI). ${ }^{14}$ The adverse consequences of toxic releases are widely recognized as diverse and costly. Coherent procedures that enable design engineers to reduce or eliminate toxic substances in their products will be a major advance toward sustainability.

In December 2006, MRS Bulletin featured a special issue on the new concept of materials informatics, defined as "the application of computational methodologies to processing and interpreting scientific and engineering data concerning materials." 15 As envisioned at that time, materials informatics databases included primarily performance-related attributes and did not account for sustainability- or toxicity-related attributes in a substantial way. In fact, only the article by Cebon and Ashby in that issue mentioned such impacts, ${ }^{16}$ acknowledging the need for "environmental impact information," "recycling information," and "hazardous materials regulations." The article quantified the first two attributes simply as "energy content in $\mathrm{MJ} / \mathrm{kg}$ " and "recycling fraction" and made no attempt to incorporate toxicity metrics.

Since 2006, Ashby and colleagues have further developed their materials selection method and software databases. ${ }^{17-20}$ Although their approach provides an excellent foundation for materials selection, their databases do not yet account for material toxicity, except for the inclusion of a "yes/no" indicator in response to whether the material is approved for skin and food contact by the U.S. Food and Drug Administration.

In conventional materials selection for product development, the primary purpose is to link material and function. This is achieved by focusing on selected material attributes, including mechanical, thermal, electrical, optical, and chemical properties; processing characteristics; cost and availability; and environmental consequences of use. Ideally, the attributes should be quantifiable so that they can be used to screen and rank material alternatives. The design engineer defines material function, which ultimately determines the attributes of interest.

Once the function is defined, a list of viable materials is identified and ordered according to the materials' combinations of attributes. The conventional method considers both screening and ranking to entail quantitative manipulation of attribute data sets. In practice, though, ranking often requires significant subjective judgment to consider tradeoffs among attributes, as it is
Figure 1. The international materials Life Cycle Initiative was established by the United Nations Environment Programme (UNEP) and the Society for Environmental Toxicology and Chemistry (SETAC) in response to the collective declaration of national Ministers of Environment in the year 2000. Toxicity impacts of materials, including human health and ecosystem effects, are an essential part of the Life Cycle Impact Assessment component. 
Table I. Environmental releases (2009) and human health toxicity indices for selected chemicals. . $^{\mathrm{a} b}$

\begin{tabular}{|c|c|c|c|c|c|c|}
\hline & \multirow{2}{*}{$\begin{array}{l}\text { Total TRI }{ }^{10} \\
\text { releases in } \\
2009(\mathrm{~kg})\end{array}$} & \multicolumn{3}{|c|}{ Human exposure limits ${ }^{c, 11,12}$} & \multirow[t]{2}{*}{ IARC classification ${ }^{\mathrm{d}, 13}$} & \multirow[t]{2}{*}{ NTP classification } \\
\hline & & PEL $\left(\mathrm{mg} / \mathrm{m}^{3}\right)$ & $\operatorname{TLV}\left(\mathrm{mg} / \mathrm{m}^{3}\right)$ & $\operatorname{REL}\left(\mathrm{mg} / \mathrm{m}^{3}\right)$ & & \\
\hline \multicolumn{7}{|c|}{ Metals } \\
\hline Aluminum & $11,400,000$ & 5 & 1 & 10 & - & - \\
\hline Antimony & 444,000 & 0.5 & 0.5 & 0.5 & - & - \\
\hline Arsenic & 339,000 & 0.01 & 0.01 & - & Group 1 & Known carcinogen \\
\hline Barium & $2,310,000$ & 0.5 & 0.5 & 0.5 & - & - \\
\hline Beryllium & 4730 & 0.002 & 0.00005 & - & Group 1 & Known carcinogen \\
\hline Cadmium & 183,000 & 0.005 & 0.002 & 0.1 & Group 1 & Known carcinogen \\
\hline Chromium & $3,610,000$ & 0.5 & 0.5 & 0.5 & Group 3 & - \\
\hline Cobalt & 135,000 & 0.1 & 0.02 & 0.05 & Group 2B & - \\
\hline Copper & $4,440,000$ & 0.1 & 0.2 & 0.1 & - & - \\
\hline Lead & $6,480,000$ & 0.05 & 0.05 & 0.05 & Group 2B & Anticipated carcinogen \\
\hline Manganese & $6,420,000$ & - & 0.2 & 1 & - & - \\
\hline Mercury & 56,000 & - & 0.025 & 0.05 & Group 3 & - \\
\hline Nickel & $2,330,000$ & 1 & 1.5 & 0.015 & Group 2B & Anticipated carcinogen \\
\hline Selenium & 65,000 & 0.2 & 0.2 & 0.2 & Group 3 & - \\
\hline Silver & 62,000 & 0.01 & 0.1 & 0.01 & - & - \\
\hline Thallium & 171 & 0.1 & 0.1 & 0.1 & - & - \\
\hline Vanadium & 945,000 & - & - & - & - & - \\
\hline Zinc & $5,400,000$ & - & - & - & - & - \\
\hline \multicolumn{7}{|c|}{ Organic monomers } \\
\hline Acrylonitrile & $1,992,000$ & - & 4.3 & - & Group 2B & Anticipated carcinogen \\
\hline Bisphenol A & 563,000 & - & - & - & - & - \\
\hline 1,3-Butadiene & 533,000 & 2.21 & 4.4 & - & Group 1 & Known carcinogen \\
\hline Ethylene & $7,302,000$ & - & 230 & - & Group 3 & - \\
\hline Propylene & $4,870,000$ & - & 860 & - & Group 3 & - \\
\hline Styrene & $9,059,000$ & - & 85 & 215 & Group 2B & - \\
\hline Vinyl chloride & 177,000 & - & 2.6 & - & Group 1 & Known carcinogen \\
\hline
\end{tabular}

aAcronyms: IARC, International Agency for Research on Cancer; NTP, National Toxicology Program; PEL, permissible exposure limit; REL, reference exposure level; TLV, threshold limit value; TRI, Toxics Release Inventory.

${ }^{b}$ Cells highlighted in rose contain quantitative or qualitative information sufficient to trigger caution in using the corresponding chemicals in manufacturing. cHigh values are preferred for PEL, TLV, and REL.

'The specific IARC group classifications are as follows: Group 1, carcinogenic to humans; Group 2A, probably carcinogenic to humans; Group 2B, possibly carcinogenic to humans; Group 3, not classifiable as to carcinogenicity to humans; and Group 4, probably not carcinogenic to humans.

not generally possible to identify one material that is best in all aspects.

For sustainable product design, material toxicity data must be incorporated into the screening and ranking processes. Figure 2 illustrates how such data might be integrated into the progression from chemical inventory to materials formulation and product development. In this scheme, assessment and selection of an alternative material can be triggered by information on toxicity, including risks during manufacturing (occupational exposures), product use (general population exposures), and ultimate disposal into the environment at the end of the useful product lifetime (ecotoxicological and human health impacts).

\section{Human health impacts and ecotoxicity considerations}

In the United States, hazard data are reported in material safety data sheets (MSDSs), which focus on occupational exposure limits and physical traits such as flammability and explosiveness. The potential human health concerns identified in MSDSs 


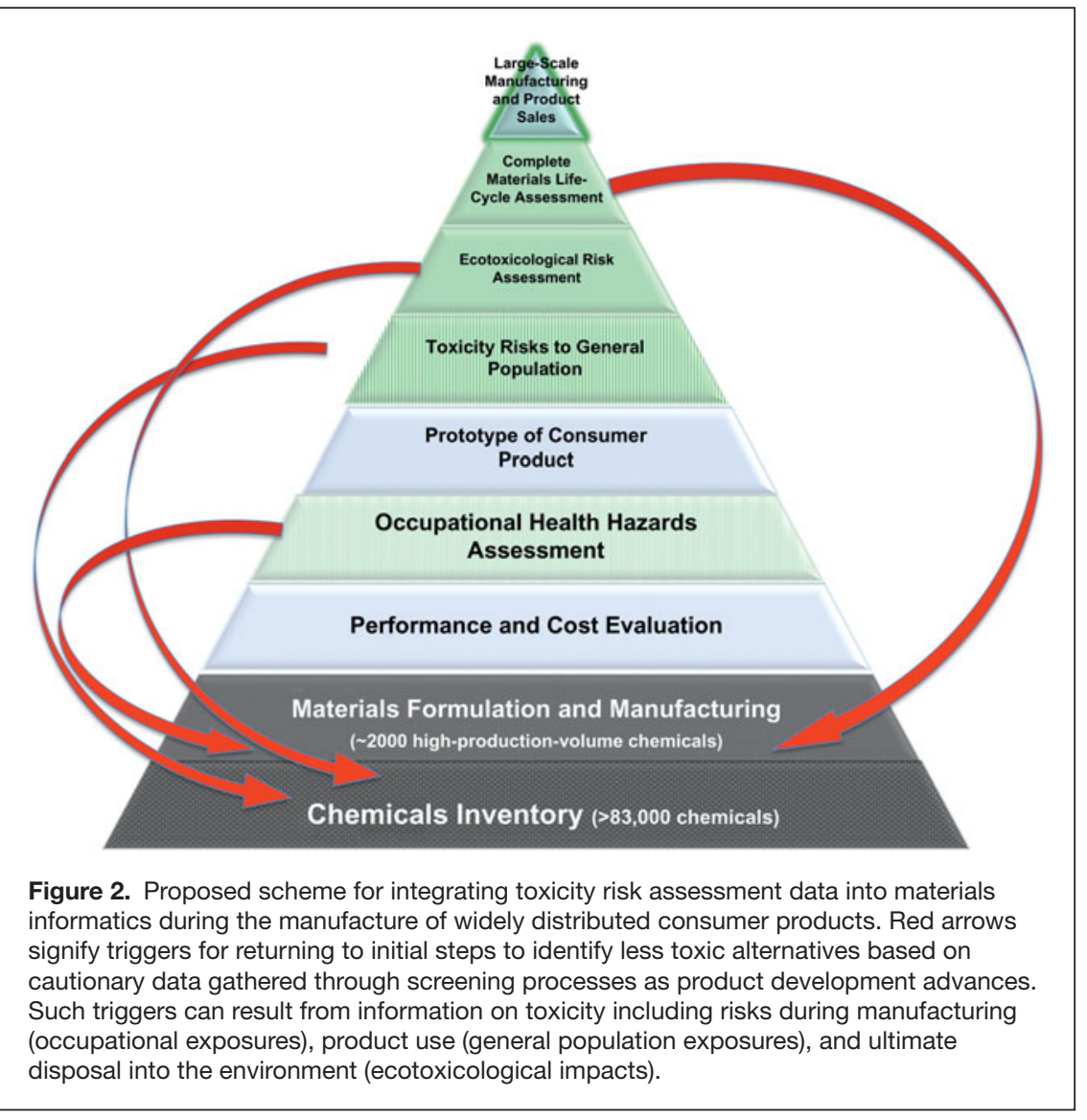

are based on the most sensitive adverse health effects reported in the toxicological literature. Published REL values typically include margins of safety, such that exposure of human populations to chemical levels that exceed the REL does not necessarily mean that adverse health impacts will occur. Because PELs, TLVs, and RELs capture different aspects of the intersection of chemical toxicity and human exposure, it is deemed valuable to develop integrative approaches through which all three measures are used to generate a more robust index of risk when screening and ranking material alternatives relative to their potential for adverse human health effects.

Measures of potential human health impact have also been developed that are specific to cancer causation, or carcinogenicity, reflecting the high societal investment in curbing such diseases. In the laboratory, carcinogenicity is assessed most often through long-term rodent studies. ${ }^{21}$ Although toxicological tests can quantitatively measure acute toxicity, clarifying potential chronic effects requires long-term monitoring of health and, ultimately, a full pathological analysis of the animal tissues and organs.

Substantial time and resources are needed to fully characterize the carcinogenic potential of a substance, and data availability can be prob-

provide a reasonable template, but a compilation of MSDS data across multiple material options does not currently exist. We provide in Table I such an aggregation, derived from sources independent of the material suppliers, of hazard-trait values for a select group of metals and monomers.

Based on the data in Table I, it is apparent that the three attributes considered, permissible exposure limit (PEL), threshold limit value (TLV), and reference exposure level (REL), do not rank the materials equivalently. For instance, the four metals of greatest concern when selected on the basis of PEL are beryllium, cadmium, arsenic, and silver. Although beryllium, cadmium, and arsenic are also prioritized by TLV, cobalt is now fourth on the list. The REL values prioritize silver and nickel, followed by cobalt, lead, and mercury.

These differences in priority are to be expected because these three quantitative measures of occupational hazard derive from differing objectives. Specifically, PEL defines the legal limit in the United States for exposure of an employee to a chemical substance or physical agent, typically as a time-weighted average, whereas TLV is the level to which it is believed a worker can be exposed to a chemical substance day after day for a working lifetime without adverse health effects. In comparison, REL, the concentration at or below which adverse health effects are not likely to occur, is intended to establish a reference point to gauge potential effects over a lifetime of exposure. RELs account for particularly susceptible subpopulations and lematic. Furthermore, interpretation of results requires extensive training in toxicology and related subdisciplines of public health. Moreover, despite the tedious and expensive process of generating chemical toxicity profiles based on animal studies, uncertainties remain in how to establish safety thresholds for human and ecological health. ${ }^{22}$ It is common to summarize the results using simplified carcinogenic classification schemes, two of which are briefly described here.

The IARC, part of the World Health Organization (WHO), publishes the series Monographs on the Evaluation of Carcinogenic Risks to Humans, which has been influential in the classification of carcinogens. ${ }^{23}$ During the classification process, interdisciplinary working groups review published toxicity studies and evaluate the weight of evidence that exposure to a given substance can potentially cause cancer in humans. On the basis of these reviews, substances are assigned to one of five groups based on carcinogenic risk.

The National Toxicology Program (NTP) of the U.S. Department of Health and Human Services produces a biennial report on carcinogens that includes newly reviewed substances as well as all those listed previously. ${ }^{11}$ This scientific and public-health document identifies and discusses agents, substances, mixtures, or exposure circumstances that could pose a carcinogenic hazard to populations. The NTP classifies carcinogens into only two groups: those that are known to be human carcinogens and those that are reasonably anticipated to be human carcinogens. 
These two classification schemes can be used to screen and rank material alternatives, as shown in Table I. They are consistent for known carcinogens but exhibit some discrepancies for anticipated carcinogens. Thus, the recommendation is to use multiple data sets for a more robust analysis.

Beyond human health concerns, potential impacts to the environment must also be addressed in materials selection. Table II provides information on two ecological toxicity indices for the materials considered previously. The ecotoxicological indices are the $\mathrm{EC}_{50}$ value, which is the effective concentration of a substance in water that will cause irreversible damage to one-half of a population, and the fish bioconcentration factor

\begin{tabular}{|c|c|c|}
\hline Metal & $\mathrm{EC}_{50}{ }^{24}(\mathrm{mg} / \mathrm{L})$ & Fish BCF \\
\hline Aluminum & - & - \\
\hline Antimony & 2.94 & $300^{25}$ \\
\hline Arsenic & 1.78 & $4^{26}$ \\
\hline Barium & 71.94 & $100^{25}$ \\
\hline Beryllium & 0.49 & $100^{25}$ \\
\hline Cadmium & 0.86 & $366^{26}$ \\
\hline Chromium & 3.91 & $2^{26}$ \\
\hline Cobalt & 3.96 & - \\
\hline Copper & 0.13 & - \\
\hline Lead & 3.84 & $155^{26}$ \\
\hline Manganese & - & - \\
\hline Mercury & 0.11 & $5000^{26}$ \\
\hline Nickel & 0.88 & - \\
\hline Selenium & 2.64 & $50,000^{25}$ \\
\hline Silver & 0.02 & - \\
\hline Thallium & 2.81 & $100,000^{25}$ \\
\hline Vanadium & 0.86 & - \\
\hline Zinc & 1.21 & $2000^{25}$ \\
\hline Acrylonitrile & 21.63 & $1.68^{25}$ \\
\hline Bisphenol A & - & - \\
\hline 1,3-Butadiene & - & $19^{27}$ \\
\hline Ethylene & - & - \\
\hline Propylene & - & - \\
\hline Styrene & 21.30 & $13.5^{25}$ \\
\hline Vinyl chloride & - & $7^{25}$ \\
\hline
\end{tabular}

aDefinitions: $\mathrm{EC}_{50}$, effective concentration of a substance in water that will cause irreversible damage in one-half of a population; BCF, bioconcentration factor by which the concentration of a substance in fish exceeds its concentration in the surrounding water. High values are preferred for $\mathrm{EC}_{50}$, and low values are preferred for BCF.

${ }^{b}$ Cells highlighted in rose contain values sufficient to trigger caution in using the corresponding chemicals in manufacturing.
(BCF), which is the ratio by which the concentration of a substance in fish is enhanced relative to the surrounding water and thus a measure of persistence and bioaccumulation potential.

On the basis of $\mathrm{EC}_{50}$ values, silver, mercury, and copper are of particular concern, whereas the fish BCFs for thallium $(100,000)$, selenium $(50,000)$, mercury $(5000)$, and zinc (2000) are disturbingly high. In general, BCFs greater than 1000 are considered high, and values less than 250 represent low to negligible risk, with intermediate values being considered moderately risky. The bioaccumulation of metals in fish tissue can produce cascading impacts up the food chain, ultimately affecting wildlife and human health, as demonstrated for mercury in edible fish. ${ }^{28}$ Again, the recommended approach is to use multiple indices to obtain a more complete representation of material hazards.

A new classification scheme, developed by the United Nations and called the Globally Harmonized System of Classification and Labelling of Chemicals (GHS), is intended to eliminate discrepancies resulting from nation-to-nation variability and thereby replace classification schemes such as IARC and NTP. With GHS, it will ideally be possible to systematically classify chemicals on the basis of multiple attributes such as carcinogenicity, as well as acute and chronic ecotoxicity. ${ }^{29}$ Because of its novelty, however, few substances have yet been fully classified within the GHS system. ${ }^{30}$

\section{Integrative approaches}

In addition to hazard-trait values and classification schemes, such as those described in the preceding section, a variety of tools have been developed that integrate several metrics to generate numerical indicators of human health and ecological toxicity. These methods include

- TRACI, Tool for the Reduction and Assessment of Chemical and Other Environmental Impacts (EPA); ${ }^{31,32}$

- USEtox ${ }^{\mathrm{TM}}$, the UNEP-SETAC consensus toxicity mode1; 33,34

- CHEMS-1, Chemical Hazard Evaluation for Management Strategies (EPA) ${ }^{35}$ and

- TPI, Toxic Potential Indicator (developed by the Fraunhofer Institut für Zuverlässigkeit und Mikrointegration, Hannover, Germany). ${ }^{36}$

A comparison of the main features of these methods is presented in Table III. Unlike the binned cancer classification schemes described in the preceding section, these four methods provide quantitative values unique to each substance (Table IV). To highlight the value of such methods, we describe and compare TRACI and TPI. TRACI represents a set of lifecycle impact-assessment modules that generate three characterization factors [cancer potential, noncancer potential (other human diseases), and ecotoxicity] in each of four environmental media (air, water, ground-surface soil, and root-zone soil). Six of these 12 factors are listed in Table IV for selected TRI metals. ${ }^{37}$

To produce quantitative measures of cancer and noncancer risks associated with specific chemicals, TRACI relies on a closed-system, steady-state chemical fate and exposure assessment model called CalTOX, developed by the Exposure 
Table III. Comparison of measures for selected alternative assessment tools. ${ }^{\mathrm{a}}$

\begin{tabular}{|c|c|c|c|c|}
\hline Method & TRACI & USEtox & CHEMS-1 & TPI \\
\hline Application & $\begin{array}{l}\text { Life-cycle impact } \\
\text { assessment }\end{array}$ & $\begin{array}{l}\text { Life-cycle impact } \\
\text { assessment }\end{array}$ & $\begin{array}{l}\text { Hazard-based chemical } \\
\text { prioritization }\end{array}$ & $\begin{array}{l}\text { Comparative materials } \\
\text { selection }\end{array}$ \\
\hline Complexity & High & High & Medium-high & Medium \\
\hline Transparency & Medium & Medium & High & High \\
\hline $\begin{array}{l}\text { Number of substances } \\
\text { covered }\end{array}$ & 932 & 3094 & $\begin{array}{l}\text { Depends on toxicity data } \\
\text { availability }\end{array}$ & $\begin{array}{l}\text { Depends on toxicity data } \\
\text { availability }\end{array}$ \\
\hline Metals/metal compounds & $\begin{array}{l}\text { Metals (18 metal types } \\
\text { listed) }\end{array}$ & $\begin{array}{l}\text { Metals (18 metal types } \\
\text { listed) }\end{array}$ & $\begin{array}{c}\text { Depends on toxicity data } \\
\text { availability }\end{array}$ & $\begin{array}{c}\text { Depends on toxicity data } \\
\text { availability }\end{array}$ \\
\hline Polymers & Some monomers & Some monomers & $\begin{array}{c}\text { Depends on toxicity data } \\
\text { availability }\end{array}$ & $\begin{array}{c}\text { Depends on toxicity data } \\
\text { availability }\end{array}$ \\
\hline
\end{tabular}

aModels: TRACI, Tool for the Reduction and Assessment of Chemical and Other Environmental Impacts; USEtox, UNEP-SETAC consensus toxicity mode1; CHEMS-1, Chemical Hazard Evaluation for Management Strategies; and TPI, Toxic Potential Indicator.

\begin{tabular}{|c|c|c|c|c|c|c|c|}
\hline \multirow[t]{2}{*}{ Metal } & \multicolumn{2}{|c|}{ TRACI cancer potential } & \multicolumn{2}{|c|}{ TRACI noncancer potential } & \multicolumn{2}{|c|}{ TRACI ecotoxicity potential } & \multirow{2}{*}{$\begin{array}{l}\text { TPI score } \\
\left(\mathrm{mg}^{-1}\right)\end{array}$} \\
\hline & Air & Water & Air & Water & Air & Water & \\
\hline Aluminum & - & - & 11,174 & 20 & 7030 & 1844 & 1.36 \\
\hline Antimony & - & - & $2,801,491$ & 4206 & - & - & 33.33 \\
\hline Arsenic & 8497 & 282 & 469,379 & 13,502 & 209 & 246 & 72.79 \\
\hline Barium & - & - & 18,046 & 57 & - & - & 1.99 \\
\hline Beryllium & 12 & $1.1 \times 10^{-46}$ & 167,536 & 1047 & - & - & 36.32 \\
\hline Cadmium & 25 & $5.4 \times 10^{-49}$ & 387,350 & $2,013,978$ & 6 & 10 & 85.05 \\
\hline Chromium & 70 & $5.6 \times 10^{-46}$ & 57,677 & 583 & 1049 & 780 & 1.20 \\
\hline Cobalt & - & - & 29,043 & $2.6 \times 10^{-43}$ & - & - & 35.35 \\
\hline Copper & - & - & 13,214 & 5903 & 21,665 & 11,537 & 4.48 \\
\hline Lead & 58 & $1.6 \times 10^{-47}$ & $2,173,733$ & $11,303,405$ & 1 & 2 & 63.42 \\
\hline Manganese & - & - & 6092 & 12 & - & - & 2.41 \\
\hline Mercury & - & - & 99,911 & 943,040 & 16 & 3114 & 78.91 \\
\hline Nickel & - & - & 71,919 & 93 & 7836 & 2671 & 38.01 \\
\hline Selenium & - & - & 71,282 & 1419 & 1528 & 1076 & 21.19 \\
\hline Silver & - & - & 39,323 & 539 & 8487 & 7535 & 4.48 \\
\hline Thallium & - & - & 208 & 16 & - & - & 66.67 \\
\hline Vanadium & - & - & 136,864 & 547 & - & - & 33.33 \\
\hline Zinc & - & - & 10,247 & 18 & 5879 & 2052 & 13.87 \\
\hline
\end{tabular}

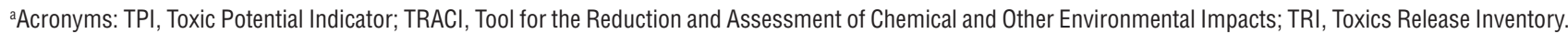
${ }^{b}$ Table cells highlighted in rose contain values sufficiently high, within the relevant risk category, to trigger caution in using chemicals for manufacturing consumer products. In general, low values are preferred for all characteristics reported in the table.

and Risk Analysis Group at Lawrence Berkeley National Laboratory. CalTOX combines the toxicity of a chemical with the amount released into the environment over a given period of time to calculate its human toxicity potential, which is expressed relative to baseline values for benzene (carcinogens) or toluene (noncarcinogens), two chemicals for which extensive toxicological data linking exposure to disease in a linear dose-response model exist. Thus, the output data are toxicity equivalencies that support comparisons of the impacts of different chemical emissions into a given environment. ${ }^{38}$ Similarly, the ecotoxicity potential outputs from TRACI represent toxicity-weighted chemical emission concentrations 
that allow for the comparison of the ecological impacts of a new chemical to those of a relatively well-characterized chemical, namely, the herbicide 2-4-dichlorophenoxyacetic acid (2,4-D).

In comparison, TPI requires the user to provide selected hazard data (i.e., for human health impact, environmental impact, and physical safety concerns) from which it derives a single indicator by integrating metrics for human health, ecological health, and physical/safety traits. ${ }^{39}$ To generate TPI scores such as those reported in Table IV, one must input data from original, authoritative, and valid sources.

All available alternative assessment techniques encounter methodological limitations, including complexity, lack of transparency, and limited data sets even for materials used frequently in engineered products (metals, polymers). Despite these limitations, these methods can be used to incorporate material toxicity into the screening and ranking of materials and thereby enable sustainable product design.

In one example, Lam and colleagues used TRACI to evaluate toxic releases from printed circuit board manufacturing facilities as a strategy to avoid pollution. ${ }^{40}$ Although the environmental releases of toxic chemicals such as methanol, glycol ethers, and dimethylformamide dominated reported air and water emissions, toxicity potentials and risk-screening scores showed that lead and copper actually generate the highest environmental impacts. Therefore, effective strategies for pollution prevention include recovering copper from spent etchant and employing lead-free substitutes for solder and other components.

Materials substitutions to reduce toxic impacts have also been studied for specific electronic products. For example, Lim and Schoenung ${ }^{41}$ evaluated the end-of-life toxicity potential from the heavy-metal content in flat-panel display devices that are replacing conventional cathode-ray-tube (CRT) devices. That study focused on plasma and liquid-crystal-display (LCD) televisions, LCD computer monitors, and laptop computers. The human health and ecotoxicity potentials were evaluated by combining data on the respective heavy-metal contents and the characteristic factors in TRACI. The results showed that the leading contributors to the toxicity potentials are lead, arsenic, copper, and mercury. Although the heavy-metal content in newer flat-panel display devices produces lower human health toxicity potentials than that in CRTs, the newer devices are worse in terms of ecological toxicity impacts because of the mercury in the fluorescent backlights in LCD televisions and the copper in plasma televisions.

Similar integrative approaches have been used to evaluate cellular phones and light-emitting diodes to pinpoint specific material constituents that exceed hazard thresholds specified in risk-based policy regulations. These materials could be targeted by product designers and manufacturers for substitutions to make safer, environmentally sustainable products. ${ }^{42-44}$ In concert, these studies demonstrate the usefulness of integrative methods such as TRACI and TPI that generate simple quantitative values combining both human health and ecotoxicological impact rankings. However, much research remains to be done to make such models consistent in terms of the quality and format of raw data inputs and the translation of the output into guidance for the selection of sustainable alternative materials for designers and manufacturers of consumer products.

\section{Conclusions}

Whereas the selection of materials for use in products has traditionally focused solely on cost and performance characteristics, sustainability must also become an important factor. Avoiding human health and ecological impacts requires their assessment at the level of materials selection in the early stages of product design and manufacturing. For such strategies to become viable, toxicity metrics need to be integrated into materials informatics frameworks in a transparent way that supports the selection of safer alternatives.

\section{References}

1. Report of the World Commission on Environment and Development. Our Common Future (Annex to Document A/42/427, Oxford University Press, Oxford, UK, 1987)

2. Toxic Substances Control Act Chemical Substance Inventory (U.S. Environmental Protection Agency, Washington, DC), www.epa.gov/opptintr/existingchemicals/ pubs/tscainventory/ (accessed November 2011).

3. S.O. Hansson, L. Molander, C. Rudén, Regul. Toxicol. Pharmacol. 59, 454 (2011). 4. High Production Volume (HPV) Challenge Program (U.S. Environmental Protection Agency, Washington, DC), www.epa.gov/chemrtk/ (accessed November 2011). 5. High Production Volume (HPV) Challenge Program: Guidance Documents (U.S. Environmental Protection Agency, Washington, DC), www.epa.gov/chemrtk pubs/general/guidocs.htm (accessed November 2011).

6. Risk Assessment Guidelines (U.S. Environmental Protection Agency, Washington, DC), http://cfpub.epa.gov/ncea/cfm/recordisplay.cfm?deid=55907 (accessed November 2011).

7. High Production Volume Information System (HPVIS) (U.S. Environmental Protection Agency, Washington, DC), www.epa.gov/chemrtk/hpvis/index.html (accessed November 2011).

8. Malmö Ministerial Declaration (United Nations Environment Programme, Nairobi, Kenya, 2000).

9. The Life Cycle Initiative (United Nations Environment Programme, Nairobi, Kenya), http://Icinitiative.unep.fr/ (accessed November 2011).

10. Toxics Release Inventory (TRI) Program (U.S. Environmental Protection Agency, Washington, DC), www.epa.gov/tri/ (accessed November 2011).

11. 12th Report on Carcinogens (ROC) (National Toxicology Program, Washington, DC, 2011).

12. 2009 Guide to Occupational Exposure Values (American Conference of Governmental Industrial Hygienists, Cincinnati, OH, 2009).

13. Agents Classified by the IARC Monographs, Volumes 1-102 (World Health Organization, Lyon, France), monographs.iarc.fr/ENG/Classification/index.php (accessed November 2011).

14. Toxics Release Inventory (TRI) Explorer: Release Reports (U.S. Environmental Protection Agency, Washington, DC), iaspub.epa.gov/triexplorer/tri_release. chemical (accessed November 2011)

15. J.R. Rodgers, D. Cebon, MRS Bull. 31 (12), 975 (2006).

16. D. Cebon, M.F. Ashby, MRS Bull. 31 (12), 1004 (2006).

17. M.F. Ashby, Materials Selection in Mechanical Design (Elsevier, Amsterdam, ed. 4,2011 ).

18. M.F. Ashby, A. Miller, F. Rutter, C. Seymour, U.G.K. Wegst, The CES EduPack Eco Selector-Background Reading (Granta Design, Cambridge, UK, 2009).

19. M. Ashby, P. Coulter, N. Ball, C. Bream, The CES EduPack Eco Audit Tool-A White Paper (Granta Design, Cambridge, UK, 2009).

20. Granta CES 2012 Eco Selector (Granta Design Ltd., Cambridge, UK), www. grantadesign.com/products/ces/ (accessed November 2011).

21. OECD Guidelines for Testing of Chemicals. Section 4: Health Effects (Organisation for Economic Co-operation and Development, Paris, France, 2011).

22. D. Krewski, M.E. Anderson, E. Mantus, L. Zeise, Risk Anal. 29 (4), 474 (2009).

23. IARC Monographs on the Evaluation of Carcinogenic Risks to Humans: Preamble (World Health Organization, Lyon, France, 2006).

24. ECOTOX Database (U.S. Environmental Protection Agency, Washington, DC), cfpub.epa.gov/ecotox/ (accessed November 2011). 
25. National Recommended Water Quality Criteria (U.S. Environmental Protection Agency, Washington, DC), http://water.epa.gov/scitech/swguidance/standards/ current/index.cfm (accessed November 2011).

26. Technical Support Document for Exposure Assessment and Stochastic Analysis (Office of Environmental Health Hazard Assessment, Sacramento, CA, 2000), Appendix H: Fish Bioconcentration Factors.

27. 1,3-Butadiene Human Health Aspects (Concise International Chemical Assessment Document 30, World Health Organization, Geneva, Switzerland, 2001)

28. Mercury Levels in Commercial Fish and Shellfish (1990-2010) (U.S. Food and Drug Administration, Washington, DC), www.fda.gov/Food/FoodSafety/ProductSpecificInformation/Seafood/FoodbornePathogensContaminants/Methylmercury/ ucm115644.htm (accessed November 2011).

29. A Guide to The Globally Harmonized System of Classification and Labelling of Chemicals (GHS) (Occupational Safety and Health Administration, Washington, DC, 2004), section 3.2

30. Globally Harmonized System of Classification and Labelling of Chemicals (GHS) (United Nations, New York), live.unece.org/trans/danger/publi/ghs/ghs rev02/02files_e.html (accessed November 2011).

31. J.C. Bare, G.A. Norris, D.W. Pennington, T.E. McKone, J. Ind. Ecol. 6, 49 (2003).

32. J.C. Bare, Clean Technol. Environ. Policy 12, 341 (2010).

33. R.K. Rosenbaum, T.M. Bachmann, L.S. Gold, M.A. Huijbregts, 0. Jolliet,

R. Juraske, A. Koehler, H.F. Larsen, M. MacLeod, M. Margni, T.E. McKone,
J. Payet, M. Schuhmacher, D. van de Meent, M.Z. Hauschild, Int. J. Life Cycle Assessment 13, 532 (2008).

34. M.A. Huijbregts, M.Z. Hauschild, O. Jolliet, M. Margni, T.E. McKone, D. van de Meent, USEtox ${ }^{T M}$ User manual (USEtox TM Team, 2010).

35. M.B. Swanson, G.A. Davis, L.E. Kincaid, T.W. Schultz, J.E. Bartmess, S.L. Jones, E.L. George, Environ. Toxicol. Chem. 16, 372 (1997)

36. N.F. Nissen, I. Griese, A. Middendorf, J. Müller, H. Pötter, H. Reichl, in Proceedings of the 1998 IEEE International Symposium on Electronics and the Environment (IEEE Press, New York, 1998), pp. 106-111.

37. Tool for the Reduction and Assessment of Chemical and Other Environmental Impacts (TRACI): User's Guide and System Documentation (Report EPA/600/ R-02/052, U.S. Environmental Protection Agency, Washington, DC, 2003)

38. E.G. Hertwich, S.F. Mateles, W.S. Pease, T.E. McKone, Environ. Toxicol. Chem. 20 (4), 928 (2001)

39. Toxic Potential Indicator Calculator (Fraunhofer Institut für Zuverlässigkeit und Mikrointegration, Hannover, Germany), www.izm.fraunhofer.de/EN/abteilungen/ere/ dienstleistungen/izmeetoolbox/TPICalculator.jsp (accessed November 2011).

40. C.W. Lam, S.-R. Lim, J.M. Schoenung, J. Hazard. Mater. 189, 315 (2011).

41. S.-R. Lim, J.M. Schoenung, J. Hazard. Mater. 177, 251 (2010).

42. J.D. Lincoln, O.A. Ogunseitan, J.-D. Saphores, A.A. Shapiro, Environ. Sci. Technol. 41 (7), 2572 (2007)

43. S.-R. Lim, J.M. Schoenung, Waste Manage. 30, 1653 (2010).

44. S.-R. Lim, D. Kang, O.A. Ogunseitan, J.M. Schoenung, Environ. Sci. Technol. 45, 320 (2011).
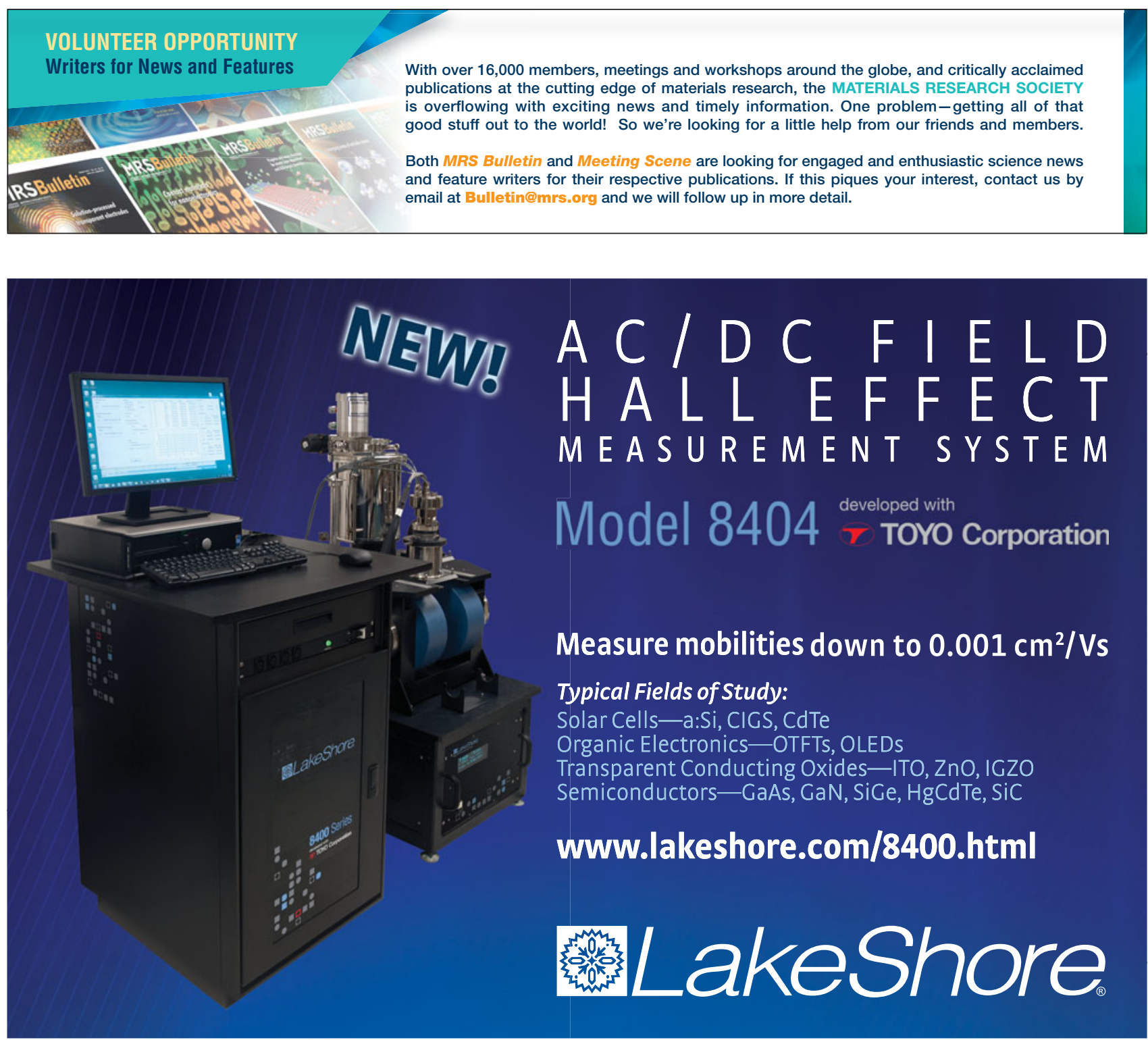


\section{J.A. Woollam Co., Inc.}

Ellipsometry Solutions ${ }^{\text {sm }}$ for your Thin Film Characterization.

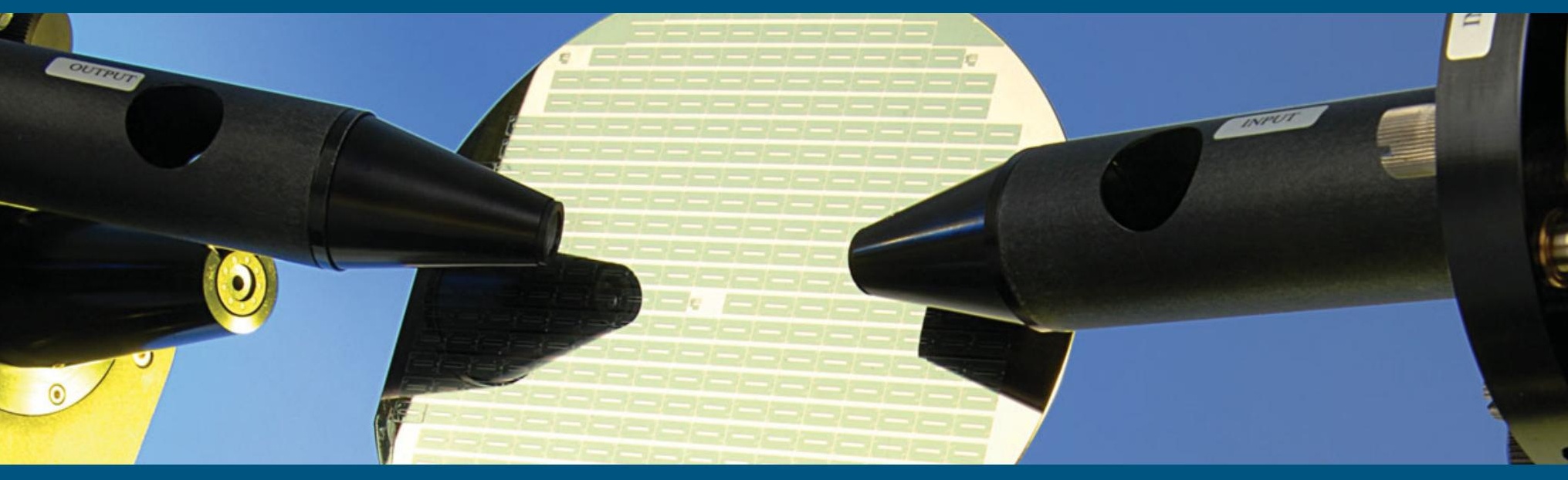

J.A. Woollam Co. has the world's widest variety of Spectroscopic Ellipsometers with $\mathbf{8}$ different models to non-destructively characterize thin film thickness and optical constants. After twenty-four years, over 15,000 samples characterized in our lab, and over 140 patents - we are the Ellipsometry Experts.

\section{Ellipsometry Solutions}

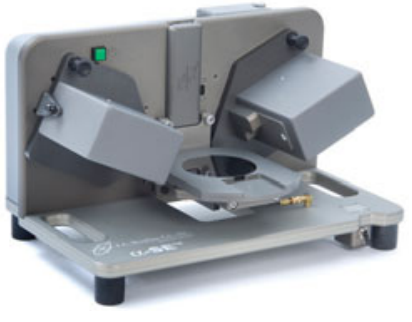

alpha-SE ${ }^{\circledR}$

A great solution for routine measurements of thin film thickness and refractive index. Designed for ease-ofuse: simply mount a sample, choose the model that matches your film, and press "Measure". Results are yours within seconds.

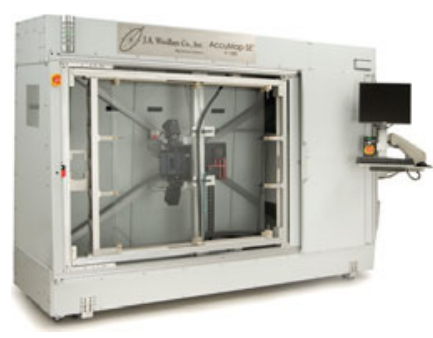

\section{AccuMap-SE ${ }^{\circledR}$}

Characterize thin film uniformity of large panels with ease. The AccuMap-SE combines a high-speed M-2000 ellipsometer, wide spectral range, and fast mapping for large panels. Perfect for photovoltaic or flat panel display thin films.

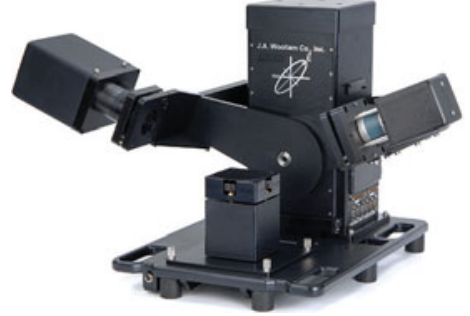

M-2000 ${ }^{\circledR}$

The M-2000 line of

ellipsometers is engineered to meet the diverse demands of thin film characterization. An advanced optical design, wide spectral range, and fast data acquisition make it extremely powerful for in situ, in-line and ex situ applications.

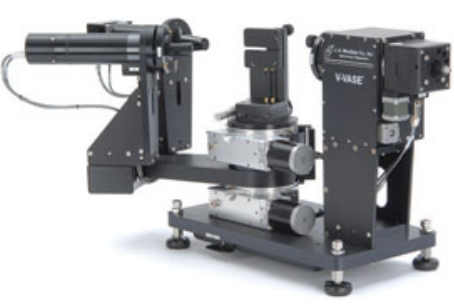

VASE

The VASE is our most accurate and versatile research ellipsometer for all types of materials: semiconductors, dielectrics, organics, metals, multi-layers, and more. Now available with the widest spectral range from ultraviolet to infrared. 
.

\title{
Materials challenges and opportunities for enhancing the sustainability of automobiles
}

\begin{abstract}
Gregory A. Keoleian and John L. Sullivan
Materials play a major role in defining the sustainability performance of automobiles throughout their materials-production, manufacturing, use, and end-of-life stages. Materials production and manufacturing raise many sustainability issues, including resource scarcity and materials sourcing, energy and carbon intensity, and materials efficiency in parts fabrication. In the use stage, materials properties such as density and strength directly affect materialsmass requirements, which influence two dominant sustainability parameters for vehicles: fuel economy and service life. For conventional vehicles, the operation segment of the use stage accounts for about $85 \%$ of the total life-cycle energy consumption and greenhouse-gas emissions. Consequently, powertrain technologies and efficiencies as well as fuel-cycle processes control these impacts. Future trends in vehicle electrification will shift the magnitude and distribution of life-cycle impacts and the effectiveness of materials strategies for improving sustainability, such as lightweighting. In many cases, the materials-production stage could become a greater determinant in life-cycle impacts. With current vehicle end-of-life management infrastructure, $85 \%$ of materials are recyclable, but recovery of plastics and segregation of metal alloys represent opportunities for improvement. Life-cycle assessment and cost analysis provide the most comprehensive methods for evaluating the sustainability of materials strategies. Using a life-cycle framework, this article highlights the current and future materials challenges and opportunities driving vehicle sustainability performance.
\end{abstract}

\begin{abstract}
Introduction
Automobiles provide tremendous mobility to consumers and have added considerably to the standard of living in the developed world. On the other hand, vehicles are resource-intensive products that significantly impact the environment throughout their lifetime. Each year in the United States, cars and light-duty trucks collectively consume about $17.3 \mathrm{EJ}$ of energy during operation, comprising $\sim 60 \%$ of U.S. transportation energy use and $\sim 17 \%$ of total U.S. energy consumption. As of 2009, 684 million cars were registered worldwide, with $19.4 \%$ (132 million) in the United States, even though the United States represents only $4.5 \%$ of the world's population. ${ }^{1}$ Vehicle ownership in 2009 was 828 vehicles per thousand people in the United States compared to around 46 per thousand in China. ${ }^{1}$ As automobile use grows in developing countries, this will pose even greater sustainability challenges in terms of materials and energy resources, as well as environmental impacts. This article explores the role materials play in influencing the sustainability of automobiles from a life-cycle perspective.
\end{abstract}

The life-cycle assessment framework shown in Figure 1 provides a systematic method and set of metrics for analyzing the environmental sustainability performance of vehicles over their useful life. This article focuses on the environmental dimension of sustainability, which also has social and economic dimensions. A typical vehicle, including its approximately 20,000 parts, can be examined across its major life-cycle stages (and substages): materials production; manufacturing (comprising part fabrication and vehicle assembly); use (comprising vehicle operation and service); and finally, vehicle end-of-life (EOL) management. Of these stages and substages, two dominate the environmental sustainability performance of a vehicle: materials production and vehicle operation. Moreover, these two are interlinked in the design phase of vehicle production by two design features: (1) materials composition and mass and (2) powertrain efficiency and fuels. The key materialssustainability issues described herein are also highlighted in the white boxes in Figure 1. 


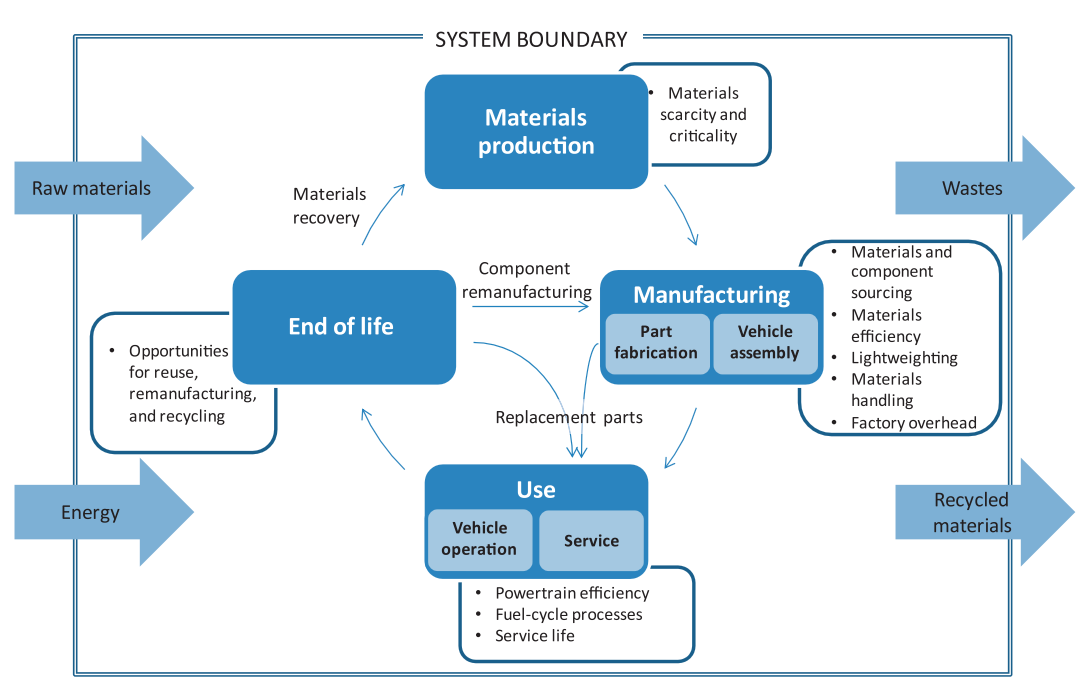

Figure 1. The life-cycle framework for a vehicle examines the environmental impacts from every stage of its life.

durability, aesthetics, materials and fabrication costs, and recyclability.

The automotive industry is responsible for a large portion of materials consumption globally. As an example, in 2009, the U.S. automotive industry accounted for $12.9 \%$ of total U.S. steel consumption ( 7.3 million tonnes), $24.7 \%$ of U.S. aluminum consumption (1.7 million tonnes), $72.8 \%$ of U.S. lead consumption (1.0 million tonnes), $19.1 \%$ of U.S. iron consumption (1.1 million tonnes), $13.1 \%$ of U.S. alloy steel consumption $(310,000$ tonnes), $21.0 \%$ of U.S. stainless steel consumption (310,000 tonnes), $22.7 \%$ of U.S. zinc consumption (180,000 tonnes), $10.8 \%$ of U.S. copper consumption (290,000 tonnes; copper data are for 2008 , as no 2009 data were available), and $40.0 \%$ of U.S. consumption of non-tire rubber products $(340,000$ tonnes). ${ }^{3}$

Lightweighting, which aims to preserve

Key materials-related strategies for improvement include reduction in materials intensity, materials efficiency in manufacturing, lightweighting, and recovery options from reuse to recycling. Life-cycle assessment provides an analytical framework to ensure that these strategies reduce the total vehicle life-cycle burdens and impacts and avoid shifting them from one vehicle system or life-cycle stage to another. For example, vehicle lightweighting with an aluminum-intensive body would reduce fuel consumption in the use stage but increase burdens from materials production relative to those of a conventional vehicle. $^{2}$

The objectives of this article are twofold: first, to highlight the environmental sustainability challenges relating to materials for automotive applications and, second, to identify opportunities for improvement. The article focuses on the vehicle life-cycle stages and their interactions that are most strongly influenced by the materials that embody the vehicle.

\section{Scope of materials usage in the automotive industry}

Materials-related life-cycle impacts of a vehicle are ultimately shaped by its materials composition and mass. The average materials compositions of U.S. automobiles for model years 1995, 2000, and 2009 are provided in Table I. In 1995, steel accounted for $55.5 \mathrm{wt} \%$, aluminum $6.3 \mathrm{wt} \%$, and plastics $6.5 \mathrm{wt} \%$. By 2009 , the corresponding values were $54.4 \mathrm{wt} \%$, $8.3 \mathrm{wt} \%$, and $9.8 \mathrm{wt} \%$, respectively. Most of aluminum's inroads have come at the expense of iron castings. The table shows that the materials composition of vehicles has shifted only slightly over the past 15 years. Materials selection and specification for vehicles is a complex process governed by a broad set of requirements including functional performance and physical/chemical properties, structural integrity, safety, vehicle size but at a lower weight, could significantly reduce the environmental footprint of vehicles. However, market trends in vehicle fleets in the past two decades have largely offset any gains in fuel economy from lightweighting. From 1987 to 2010 , despite lightweighting initiatives, the average vehicle weight increased by $24 \%$, because of the growth in the sport utility vehicle (SUV) market share. Over the same period, horsepower increased by over $86 \%$, and acceleration [reported as the time required to go from rest to $60 \mathrm{mph}$ (or to $100 \mathrm{~km} / \mathrm{h}$ outside the United States)] increased by $27 \%$. Had vehicle weights remained at 1988 levels, model year 2010 cars could have achieved a $12 \%$ higher fuel economy; trucks, a $13 \%$ increase. ${ }^{4}$ Nevertheless, inroads are being made by lightweight materials in vehicles such as high-strength steel, aluminum, and fiber-reinforced composites. Other factors influence materials consumption as well, such as market trends of the past few years showing a shift back to smaller vehicles, presumably because of higher fuel prices and other economic factors.

\section{Materials-production stage}

Key sustainability issues arising from materials production include energy intensity, carbon intensity, and materials scarcity.

\section{Energy and greenhouse-gas intensities of materials production}

The energy and greenhouse-gas (GHG) intensities of materials production, in units of megajoules per kilogram $(\mathrm{MJ} / \mathrm{kg})$ and kilograms of carbon dioxide equivalents per kilogram ( $\mathrm{kg}$ of $\mathrm{CO}_{2} \mathrm{e} / \mathrm{kg}$ ), respectively, are key parameters that define materials-production burdens and impacts for vehicles. The materials-production stage includes resource extraction (mining, petroleum extraction), materials or feedstock processing (ore sizing, chemical feedstock production), and refining or synthesis (smelting, steelmaking, polymerization). Typical values for 
Table I. Average materials composition for a North American domestic light vehicle, model years 1995, 2000, and 2009.

\begin{tabular}{|c|c|c|c|c|c|c|}
\hline \multirow[t]{2}{*}{ Material } & \multicolumn{2}{|c|}{1995} & \multicolumn{2}{|c|}{2000} & \multicolumn{2}{|c|}{2009} \\
\hline & kg & $\begin{array}{c}\text { Mass } \\
\text { percentage }\end{array}$ & kg & $\begin{array}{c}\text { Mass } \\
\text { percentage }\end{array}$ & kg & $\begin{array}{c}\text { Mass } \\
\text { percentage }\end{array}$ \\
\hline Regular steel & 739 & $44.1 \%$ & 751 & $42.4 \%$ & 681 & $38.3 \%$ \\
\hline $\begin{array}{l}\text { High- and medium- } \\
\text { strength steel }\end{array}$ & 147 & $8.8 \%$ & 185 & $10.5 \%$ & 238 & $13.4 \%$ \\
\hline Stainless steel & 23 & $1.4 \%$ & 28 & $1.6 \%$ & 31 & $1.8 \%$ \\
\hline Other steels & 21 & $1.2 \%$ & 12 & $0.7 \%$ & 14 & $0.8 \%$ \\
\hline Iron castings & 211 & $12.6 \%$ & 196 & $11.1 \%$ & 93 & $5.3 \%$ \\
\hline Aluminum & 105 & $6.3 \%$ & 122 & $6.9 \%$ & 147 & $8.3 \%$ \\
\hline Magnesium castings & 2 & $0.1 \%$ & 4 & $0.2 \%$ & 5 & $0.3 \%$ \\
\hline Copper and brass & 23 & $1.4 \%$ & 24 & $1.3 \%$ & 29 & $1.6 \%$ \\
\hline Lead & 15 & $0.9 \%$ & 16 & $0.9 \%$ & 20 & $1.1 \%$ \\
\hline Zinc castings & 9 & $0.5 \%$ & 6 & $0.3 \%$ & 4 & $0.2 \%$ \\
\hline Powder metal parts & 13 & $0.8 \%$ & 16 & $0.9 \%$ & 19 & $1.0 \%$ \\
\hline Other metals & 2 & $0.1 \%$ & 2 & $0.1 \%$ & 2 & $0.1 \%$ \\
\hline $\begin{array}{l}\text { Plastics and plastic } \\
\text { composites }\end{array}$ & 109 & $6.5 \%$ & 130 & $7.3 \%$ & 174 & $9.8 \%$ \\
\hline Rubber & 68 & $4.0 \%$ & 75 & $4.3 \%$ & 96 & $5.4 \%$ \\
\hline Coatings & 10 & $0.6 \%$ & 11 & $0.6 \%$ & 15 & $0.9 \%$ \\
\hline Textiles & 19 & $1.1 \%$ & 20 & $1.1 \%$ & 24 & $1.4 \%$ \\
\hline Fluids and lubricants & 87 & $5.2 \%$ & 94 & $5.3 \%$ & 99 & $5.6 \%$ \\
\hline Glass & 44 & $2.6 \%$ & 47 & $2.6 \%$ & 42 & $2.4 \%$ \\
\hline Other materials & 29 & $1.7 \%$ & 32 & $1.8 \%$ & 41 & $2.3 \%$ \\
\hline Total & 1676 & $100.0 \%$ & 1770 & $100.0 \%$ & 1776 & $100.0 \%$ \\
\hline
\end{tabular}

Sources: Reference 3, p. 65, and 2009 data from Reference 1, p. 4.16

energy and GHG intensities for the materials-production stage are reported in Table II.

The dramatic differences between the values for production of primary and secondary (recycled) materials illustrate the substantial potential benefits of recycling. These are particularly significant for materials such as aluminum, nickel, and lead. Because most recycled metals are recovered in the reduced state, recovery processes for secondary materials are generally less energy-intensive than those for virgin materials.

Energy intensity is highly correlated with carbon-emissions intensity, because most carbon emissions arise from the combustion of fuels. In the case of plastics, a significant fraction of the energy input is embodied in the materials (feedstocks) and does not contribute directly to the carbon intensity, unless the plastic is burned. Some materials-production processes result in emissions of greenhouse gases other than carbon dioxide, such as perfluorocarbons from aluminum production and sulfur hexafluoride from magnesium production. Process improvements have targeted these emissions. In the case of aluminum production, for example, perfluorocarbons $\left(\mathrm{CF}_{4}\right.$ and $\mathrm{C}_{2} \mathrm{~F}_{6}$ ) were reduced by $88 \%$ between 1990 and 2009.?

The values shown in Table II, taken from the GREET 2.7 model (The Greenhouse Gases, Regulated Emissions, and Energy Use in Transportation model developed at Argonne National Laboratory), ${ }^{5}$ are the best available life-cycle data for North American vehicle modeling. Significant variations occur depending on technology age, processes, fuels, and electricity sources. The sourcing of materials can strongly change the environmental impacts. For example, aluminum produced in Asia has significantly higher greenhouse-gas emissions $(21.9 \mathrm{~kg}$ of $\mathrm{CO}_{2} \mathrm{e} / \mathrm{kg}$ of $\mathrm{Al}$ ) than that produced in North America $\left(10.7 \mathrm{~kg}\right.$ of $\mathrm{CO}_{2} \mathrm{e} / \mathrm{kg}$ ) or Latin America $\left(7.1 \mathrm{~kg}\right.$ of $\left.\mathrm{CO}_{2} \mathrm{e} / \mathrm{kg}\right){ }^{8}$ The difference is determined largely by differences in the carbon intensity of the electricity employed, which is generated mainly by coal in Asia but includes hydroelectricity in Latin America. ${ }^{8}$

\section{Resource sourcing and scarcity}

Materials supply is ultimately determined by the availability and concentration of primary resources in Earth's crust (i.e., the reserves, $R$, of economically extractable resources) and the rates of global annual production $(P)$. Some mineral resources are relatively abundant, as characterized by the adequacy of mineral reserves (high $R / P$ ratio). For example, for aluminum (bauxite) and iron and steel (iron ore), this ratio easily exceeds 100 years. Other materials are much scarcer (as detailed further in the article by Graedel et al. in this issue). A recent study explored the resource supply for key elements, including those used in advanced battery materials and permanent magnets for vehicles. ${ }^{9}$ Cobalt; lithium; and rare-earth (RE) elements including lanthanum, cerium, praseodymium, and neodymium are used in electric-vehicle batteries. Neodymium, praseodymium, dysprosium, and samarium are used in permanent magnets to develop high-power-density motors for electric vehicles. Cerium is also used in autocatalytic converters to catalyze the oxidation of carbon monoxide and accounted for $9 \%$ of all U.S. RE consumption in 2008. Of the REs listed, five (dysprosium, 
Table II. Production energy and greenhouse-gas (GHG) emissions for various materials from the GREET 2.7 transportation life-cycle model. ${ }^{5}$

\begin{tabular}{|c|c|c|}
\hline Material & Total energy (MJ/kg) & GHG emissions $\left(\mathrm{kg}\right.$ of $\left.\mathrm{CO}_{2} \mathrm{e} / \mathrm{kg}\right)$ \\
\hline \multicolumn{3}{|l|}{ Steel } \\
\hline Primary & 27 & 3.6 \\
\hline Secondary & 19 & 1.2 \\
\hline Cast iron & 33 & 0.5 \\
\hline \multicolumn{3}{|l|}{ Aluminum } \\
\hline Primary (ingot) & 149 & 10 \\
\hline Secondary (ingot) & 13 & 0.9 \\
\hline \multicolumn{3}{|l|}{ Lead } \\
\hline Primary & 29 & 0.9 \\
\hline Secondary & 5 & 0.5 \\
\hline \multicolumn{3}{|l|}{ Nickel } \\
\hline Primary & 148 & 12 \\
\hline Secondary & 37 & 2.9 \\
\hline \multicolumn{3}{|l|}{ Copper } \\
\hline Primary & 111 & 8.5 \\
\hline \multicolumn{3}{|l|}{ Plastics } \\
\hline Polypropylene & 49 & 3.7 \\
\hline Polyester & 87 & 6.9 \\
\hline High-density polyethylene & 53 & 4.1 \\
\hline Glass-fiber-reinforced plastic & 85 & 4.8 \\
\hline Carbon-fiber-reinforced plastic & 160 & 9.7 \\
\hline Glass & 20 & 1.6 \\
\hline Fiber glass & 21 & 1.5 \\
\hline Rubber & 44 & 3.2 \\
\hline \multicolumn{3}{|l|}{ Nickel hydroxide } \\
\hline Primary & 104 & 8.2 \\
\hline Secondary & 6 & 0.5 \\
\hline Potassium hydroxide & 11 & 0.8 \\
\hline \multicolumn{3}{|l|}{ Cobalt oxide } \\
\hline Primary & 148 & 12 \\
\hline Secondary & 37 & 3 \\
\hline Zinc & 121 & 8.8 \\
\hline Magnesium & 372 & 29 \\
\hline Platinum & 199 & 16 \\
\hline Zirconium & 226 & 16 \\
\hline Rare earth & 336 & 27 \\
\hline Manganese & 121 & 8.8 \\
\hline Nafion 117 sheet & 24 & 1.8 \\
\hline Nafion dry polymer & 24 & 1.8 \\
\hline Polytetrafluoroethylene & 113 & 8.4 \\
\hline
\end{tabular}

Note: Updated values for new and existing materials were developed by the Center for Sustainable Systems ${ }^{6}$ and are currently under review for inclusion in the GREET model. neodymium, terbium, europium, and yttrium), as well as indium, were assessed as most critical in the short term. "Criticality" is a measure that combines importance of the resource to the economy and risk of supply disruption. For example, Toyota is sufficiently concerned about the supply of rare-earth magnet materials for its hybrid vehicles that it is developing induction motors that do not need permanent magnets. ${ }^{10}$

Earth's crust contains sufficient REs and other critical resources to meet projections for the coming decades. However, the current supply might not satisfy the demand in the short (0-5 years) or medium (5-15 years) terms. One problem is that mining operations have significant lead times to start up, from 2 to 10 years. Currently, the rareearth metals used in magnets and batteries are mined almost exclusively in China (95\% of all REs). This is changing, with significant mining capacity expected to come online by 2015 in California, Australia, and other places and to provide an almost $50 \%$ increase in RE supply. ${ }^{9}$

Magnets in vehicle motors can contain up to $1 \mathrm{~kg}$ of neodymium and/or praseodymium. Additionally, approximately $5.5 \%$ of the weight of these magnets is dysprosium. Neodymium and dysprosium are the only REs that have been identified as critical. In the near term, the needs for lanthanum and cerium are also expected to become near-critical, but they should not be critical once the increased mining comes online. Praseodymium and samarium are not expected to be at risk for supply disruptions.

Lithium is largely mined in Chile, in shallow brine pools. However, in the next five years, additional lithium production is expected to be developed (by current lithium producers) in the western United States, Argentina, and Chile. In the next five years, these developments could account for an approximately $85 \%$ increase in lithium supply. ${ }^{9}$ Lithium is used as a cathode or electrolyte in advanced batteries for longer-range electrified vehicles. 
Although demand for lithium could increase significantly, its supply is ample to meet demand well beyond midcentury. ${ }^{11-13}$ Cobalt, used in nickel-metal hydride (NiMH) batteries for current hybrid electric vehicles, is not expected to reach a critical supply level in the next 15 years. ${ }^{9}$

Currently, recycling of REs in permanent magnets is not economically viable. Although automotive batteries are recycled, the lithium in the batteries is rarely harvested; instead, other more valuable materials are collected, and the hazardous waste is properly disposed. Further, REs used in NiMH batteries are not recycled and end up in slag that is typically used for road beds. More efficient use, reuse, and recycling of these materials would clearly lower world demand for new extraction.

\section{Bio-based materials}

As a potentially more-sustainable alternative to conventional materials, several bio-based materials and products have been introduced in the automotive industry, including bio-based and soy-based resins, biofillers in plastics, natural fiber fillers in plastics, and fabrics. ${ }^{14}$ For example, Ford Motor Company demonstrated the first use of soy-based foam for seats in 2008 and for headliners in 2010. ${ }^{15}$ A new head-restraint foam in which $25 \%$ of the polyol is replaced by soy was also recently launched. ${ }^{15}$

Bio-based composites can be made from biological fibers, such as grass, corn straws, flax, hemp, kenaf, jute, pineapple leaf fiber, and sisal, mixed with some sort of polymer matrix. These composites are 25-30\% stronger than glass-fiber-based composites of the same weight, their fracture is nonbrittle (important for automotive applications), and their fibers take much less energy to produce (approximately one-quarter of the energy by weight for kenaf compared to glass). ${ }^{16}$ (See the article in this issue by Duflou et al. for more information on bio-based polymer composites.)

\section{Manufacturing stage}

The manufacturing stage of the vehicle life cycle comprises two separate operations: part and component manufacturing and vehicle assembly. The former involves shape-forming processes such as stamping, casting, forging, extrusion, and plastic molding, along with joining operations such as gluing, welding, and fastening. The latter encompasses assembling vehicle components into a car, as well as painting, anodizing, and galvanizing the vehicle surfaces. These two operations are typically performed at different facilities, with separate overhead costs.

In terms of energy and carbon intensities, the manufacturing stage contributes a small fraction (typically 4-5\%) of the life-cycle totals, ${ }^{17,18}$ but it can have significant indirect impacts on materials production. In fact, the materials efficiency in the manufacturing stage is a key factor influencing materials sustainability. The scrap rates for manufacturing processes can vary from as high as $40 \%$ for stamping to $5 \%$ for plastic molding. Although industrial scrap steel and aluminum are highly recycled, their scrap rates do impact the materials-production stage of the vehicle life cycle. For example, if it takes $5 \mathrm{~kg}$ of sheet aluminum to make a $3-\mathrm{kg}$ stamped part, the vehicle's life cycle is charged for all $5 \mathrm{~kg}$ of environmental impacts associated with aluminum production. This is because it takes energy to make sheet aluminum, whether it is recycled or not. If it is recycled, then that metal comes to the vehicle manufacturer with its own set of environmental burdens. Note that modeling of material recycling and allocation of the impacts related to the use of recyclable materials are controversial issues in life-cycle assessment. ${ }^{19}$ Moreover, the specific allocation rules used can significantly influence the outcome of life-cycle assessments.

\section{Use stage}

The use stage can be divided into two parts: operation and service (maintenance and repair). This discussion focuses on operation because its contributions to the vehicle life-cycle energy and emissions are almost 100 times greater than those of service. The life-cycle primary energy consumption, based on a 120,000 mile (193,000 km) service life, is compared in Figure 2 for three midsized vehicle categories. For each category, the energy burden is broken into (1) the operation part of the use stage, which accounts for $84-88 \%$ of a vehicle's life-cycle energy consumption, and (2) the vehicle cycle, which is the sum of everything else, namely, materials production, manufacturing, the service part of the use stage, and vehicle end of life. Clearly, the operation part of the use stage represents a prime opportunity for improving the overall sustainability of vehicles.

Approaches to improve the environmental footprint of operation include using lightweight materials, making vehicles smaller, and developing advanced powertrains. However, tradeoffs must be kept in mind when implementing any of these approaches. For

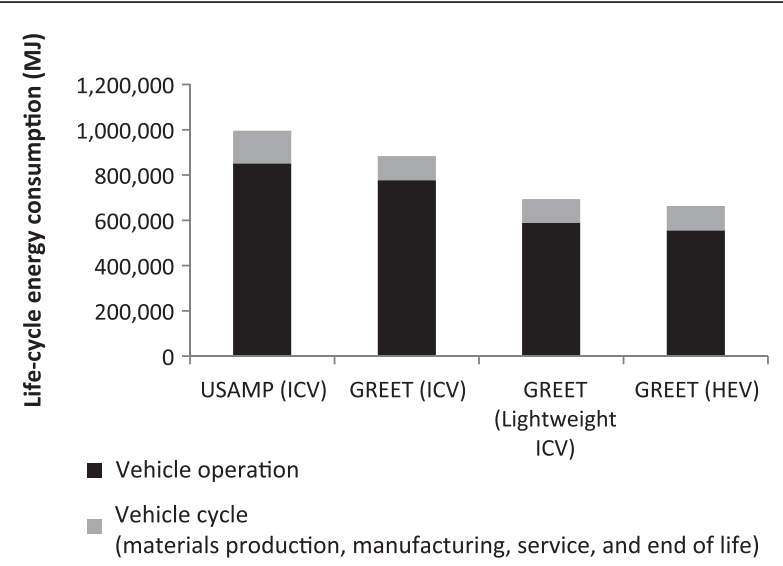

Figure 2. Comparison of life-cycle energy consumption results for passenger vehicles with a 120,000-mile (193,000-km) service life [U.S. Automotive Materials Partnership (USAMP) internal-combustion vehicle (ICV) reported in References 20 and 21; GREET ICV, Lightweight ICV, and hybrid electric vehicle (HEV) computed using GREET 2.7 and 1.8, Argonne National Laboratory]. 
example, the life-cycle energy of a vehicle generally decreases when it is made lighter, but the amount of the decrease depends on the approach used to decrease the vehicle weight, as demonstrated by the following mathematical analysis.

The life-cycle energy (LCE) of a vehicle is the sum of the energy consumption from each of the stages in Figure 1

$$
\mathrm{LCE}=E_{\mathrm{mp}}+E_{\mathrm{mf}}+E_{\mathrm{op}}+E_{\mathrm{mr}}+E_{\mathrm{eol}},
$$

where $\mathrm{mp}$ denotes materials production; $\mathrm{mf}$, part manufacturing and vehicle assembly; op, vehicle operation; mr, vehicle maintenance and repair (i.e., service); and eol, vehicle end of life.

If a vehicle of total mass $p_{\mathrm{T}}$ is made lighter by materials substitution, then the change in LCE is dominated by the changes in the materials-production and operation terms $\mathrm{s}^{22}$ and can, to a good approximation, be written as

$$
\Delta \mathrm{LCE}=\left(\frac{\mathrm{d} E_{\mathrm{mp}}}{\mathrm{d} p_{\mathrm{T}}}+\frac{\mathrm{d} E_{\mathrm{op}}}{\mathrm{d} p_{\mathrm{T}}}\right) \Delta p_{\mathrm{T}} .
$$

The energy required to operate a vehicle over its lifetime under the conditions of a fixed drive cycle (for example, city or highway) can be written as

$$
E_{\mathrm{op}}=\frac{1}{\varphi}\left(A p_{\mathrm{T}}+B\right) \times \mathrm{LTDST} \times \mathrm{LHV},
$$

where $A$ characterizes the part of the fuel consumption that scales with the mass of the vehicle and $B$ is the corresponding parasitic loss (aerodynamic drag, tire and chassis losses). LTDST is the lifetime distance driven, LHV is the lower heating value for the fuel, and $\varphi$ is the fuel production efficiency. The quantities $A$ and $B$ are expressed per unit distance driven.

The materials-production energy for the vehicle is given by

$$
E_{\mathrm{mp}}=\sum_{i} \frac{p_{i} E_{i}^{\prime}}{C_{i}}
$$

where $E_{i}^{\prime}$ is the materials-production energy per unit mass of material $i ; p_{i}$ is the mass of material $i$ on the vehicle; and $C_{i}$ is the production efficiency, which is the mass fraction of the input of material $i$ that goes into the final part.

For the case of replacing material $a$ by material $b$, the change in mass of the vehicle is related to amount of $a$ removed and $b$ added: $\Delta p_{\mathrm{T}}=\Delta m_{a}+\Delta m_{b}=\Delta m_{\mathrm{a}}(1-f)$, where $f$ is the substitution factor representing the relative mass of material $b$ needed to replace a functionally equivalent unit of material $a$. The change in LCE, including both $E_{\mathrm{mp}}$ and $E_{\mathrm{op}}$, is obtained by substituting Equations 3 and 4 into Equation 2:

$$
\begin{aligned}
\Delta \mathrm{LCE}= & {\left[\left(E_{a}^{\prime} / C_{a}-f E_{b}^{\prime} / C_{b}\right) /(1-f)+\frac{A}{\varphi}\right.} \\
& \times \mathrm{LTDST} \times \mathrm{LHV}] \Delta p_{\mathrm{T}} .
\end{aligned}
$$

Clearly, Equations 2 and 5 demonstrate that, when the lighter material takes more energy to produce, there is a tradeoff between the materials-production and operation stages of the life cycle. More elaborate treatments of this approach have been conducted by Geyer ${ }^{12}$ for greenhouse-gas emissions. His treatment includes the effects of secondary weight savings and materials recycling.

As an example of the application of Equation 5, suppose that a manufacturer wishes to improve the fuel economy of one of its vehicles by replacing steel by aluminum to reduce the vehicle weight. Based on vehicle-simulation programs for a D-class vehicle (a six-passenger vehicle with a curb weight of around $1500 \mathrm{~kg})$, the constant $A$ has the value $3.72 \times 10^{-5} \mathrm{l} /(\mathrm{kg} \mathrm{km})$. Using $C_{\text {steel }}=C_{\text {aluminum }}=1, f=0.55, \varphi=0.80$ (corresponding to reformulated low-sulfur gasoline), $E_{\text {steel }}^{\prime}=33.1 \mathrm{MJ} / \mathrm{kg}$ and $E_{\text {aluminum }}^{\prime}=145.2 \mathrm{MJ} / \mathrm{kg}$ (both from the GREET 2.7 model $^{5}$ ), $\mathrm{LHV}=32.0 \mathrm{MJ} / 1$ (for gasoline), and LTDST $=240,000 \mathrm{~km}$ in Equation 5 gives $\triangle \mathrm{LCE}=104-357=-253 \mathrm{MJ}$ for a $1-\mathrm{kg}$ reduction of vehicle weight. In this case, a reduction in vehicle LCE is realized.

However, the assumption of $C_{\text {steel }}=C_{\text {aluminum }}=1$ implies $100 \%$ production efficiencies in making both steel and aluminum parts. In reality, it takes around $10 \mathrm{~kg}$ of steel or aluminum to stamp a $5.5-\mathrm{kg}$ metal part, so $C_{\text {steel }} \approx C_{\text {aluminum }} \approx 0.55$; the rest is scrap, often referred to as offal. Taking this factor into account, for a $1-\mathrm{kg}$ vehicle weight reduction, $\Delta \mathrm{LCE}$ becomes $188-357=$ -169 MJ. Although this case also demonstrates a reduction in LCE, it is considerably less than that calculated for perfect production efficiencies.

Both examples clearly show that there is a tradeoff between materials production and vehicle operation when lightweighting through materials substitution is employed, as the lighter material generally requires more energy to produce. Further, the operational efficiency of the vehicle assumed in this example is that of a conventional D-class vehicle. For higher-efficiency vehicles such as compression-ignited direct-injection diesels $\left(A=1.56 \times 10^{-5}\right)$, the operational term is considerably smaller, and hence, the benefit of weight reduction through materials substitution is much smaller. In principle, $\triangle \mathrm{LCE}$ could even be positive upon a weight reduction.

Energy is not the only life-cycle inventory metric of interest. Greenhouse-gas (GHG) emissions are also an important consideration. Hence, if the fuel used to power the vehicle were based solely on cellulosic ethanol, which has a lower carbon footprint than gasoline, then the GHG emissions in operation of the vehicle would decrease considerably, and the life-cycle change in GHG emissions through the materials-substitution scenario just discussed would be positive.

It is clear that such estimates of changes in life-cycle impacts depend on the parameters employed. Additional relevant considerations include credits for recycling (a controversial issue) and secondary weight savings.

Individual choices also matter at the broader systems level. Vehicle size and model selection by consumers ultimately determines the materials consumption for the automotive sector. Consumers often drive oversized passenger vehicles, which can be considered a materials and energy inefficiency. A single driver commuting to work in a large SUV is an obvious mismatch between need and utility. The average occupancy 
for automobiles in the United States is around 1.6 and represents underutilized capital. Better household vehicle fleet composition and utilization to match trip activities could result in fuel savings and ultimately reduced automotive materials consumption. ${ }^{23}$

\section{End-of-life stage}

The EOL management of retired automobiles includes several resource-recovery processes. Parts and components are reused (e.g., tires) or remanufactured (e.g., engines, motors, transmissions), and materials are recycled following dismantling, shredding, and separation of nonferrous and ferrous metals. A key parameter that impacts resource flows is the vehicle service life. The median life for new 1970-model cars was 11.5 years compared to 16.9 years for 1990-model vehicles, whereas light-truck age has remained constant at 15-16 years over this period. ${ }^{1}$

Automobiles are among the most-recycled consumer products. Manufacturers such as General Motors Company and Ford Motor Company report that their new vehicles are 85\% recyclable (by weight). ${ }^{24,25}$ A European Union End-of-Life Vehicles Directive sets targets for reuse, recycling, and recovery of vehicles and their components that has pushed manufacturers to further enhance vehicle recyclability. ${ }^{26}$

The established vehicle-recycling infrastructure is effective in recovering ferrous and nonferrous metals, but significant amounts of auto-shredder residues consisting of plastics, rubber, glass, and other nonmetals are not recycled and are disposed in landfills. About $95 \%$ of EOL vehicles enter the auto-recycling infrastructure. ${ }^{27} \mathrm{~A}$ majority of these vehicles are initially processed by a dismantler, who removes components for reuse or remanufacturing, before sending the "hulk" (the remaining portion of the vehicle) to a shredder. Shredders recover about $95 \%$ of the ferrous and nonferrous metals in the vehicle. Various methods including mechanical separation, energy recovery, and thermochemical processes have been developed to sort or process plastics and foams from auto-shredder residue, but they are practiced on only a very limited basis. ${ }^{28}$ A study of the U.S. Automotive Recycling Centers published in 2001 determined that $84 \%$ of the mass of retired vehicles is recycled, although it was acknowledged that this estimate is likely to be high. ${ }^{29}$ This percentage includes recycled metals, other materials, and fluids as well as reused parts.

One of the challenges facing materials recycling, especially in the United States, is profitability. In the United States, auto recycling is entirely profit-driven, in contrast to Europe or Japan, where it is driven by the policy/regulatory environment and a lack of available landfill space. The recovery of metals is highly profitable, but that of plastics, especially those recovered from vehicles, is not. If vehicles become less reliant on ferrous materials as a result of lightweighting with aluminum and magnesium, recycling is likely to become more profitable, as aluminum and magnesium command higher prices in the scrap market. A key challenge for these industries is to develop an infrastructure for recycling alloys back into high-value applications such as closed-loop recycling of aluminum body panels.

Jody et al. ${ }^{28}$ discussed three different metrics for vehicle recyclability, all based on the percentage of the vehicle weight that is recycled. In our view, such metrics are flawed, because if aluminum were used to replace some of the steel, for example, the calculated recyclability of the vehicle would decrease, even though the two metals are equally recycled. This is because the amount of nonrecyclable material has remained the same whereas the weight of recycled materials has decreased. As alternative environmentally relevant metrics, we suggest choosing a suitable base case as a reference and tracking (1) the change in mass of material required to provide the same service, (2) the amount of the vehicle entering the waste stream, and (3) the change in the mass of waste over time.

\section{Policy impacts on materials and the vehicle life cycle}

The vehicle life cycle is governed by a complex mesh of policies and regulations. In the United States, for example, the Mining Law of 1872 governs the prospecting and mining of minerals on federal public lands. Recent legislation proposed in Congress would establish royalties on mining operations that could increase the price of primary metals, which could increase the market for secondary metals and encourage recycling.

One critique of the proposed U.S. legislation is that it could simply shift mining out of the country. Weaker regulations governing manufacturing operations in developing countries have already impacted sustainability. Weak or unenforced laws lower costs and are, in part, responsible for a shift in materials production from the United States to China, which has carbonintensive electricity and lacks stringent pollution controls. This has become an important issue in the sourcing of rare earths for magnet applications. In contrast, the vehicle-recycling regulations in Europe were instrumental in promoting greater attention to resource recovery throughout the vehicle cycle.

Fuel-economy standards are currently the most critical regulations impacting the vehicle life-cycle performance in the United States. However, these standards, including the 2012-2016 fuel-economy standards and the proposed 20172025 standards, do not address the vehicle-production stage, which is expected to make a greater contribution to the lifecycle burdens as fuel economy improves. Carbon regulation, which could serve as a more systematic mechanism to lower life-cycle impacts, is also stalled in the United States. Without a comprehensive market or regulation for carbon, emissions can simply be shifted from the use stage to vehicle production.

\section{Conclusions}

Materials and energy are the two most significant inputs for vehicle systems, and current vehicle fleets are heavily dependent on nonrenewable resources for both of them. Unlike nonrenewable energy resources, which are exhausted by their use, many materials resources can be recovered and reutilized in the economy through reuse, remanufacturing, and recycling. 
Recovery of metals during end-of-life management is better for vehicles than for most product systems, but recovery of nonmetals is not. Materials industries have opportunities to continue to improve materials-production efficiencies, recover secondary materials, and reduce impacts from virgin resources.

The vehicle life cycle and associated materials selection, sourcing, and design decisions represent a complex large-scale optimization problem with multiple objectives, constraints, and stakeholders, often with competing interests. As pressures for materials resources increase because of new markets for vehicles and increasing demands from other sectors, more sophisticated life-cycle design methods and more advanced vehicle-remanufacturing and -recycling infrastructures will be required to solve the sustainability challenges faced by the auto industry. Ultimately, providing sustainable mobility for a growing population of seven billion people requires dramatic innovations by the materials and automotive industries; international commitments and policy for addressing greenhouse-gas emissions; and a more informed consumer base that understands basic sustainability concepts and factors vehicle size, fuel economy, and other environmental attributes into their vehicle purchasing and driving decisions.

\section{Acknowledgments}

Funding from the National Science Foundation's Materials Use Science Engineering and Society (MUSES) Project, Grant CMMI 0628162, and the Department of Energy U.S.-China Clean Energy Research Center (CERC) on Clean Vehicles is acknowledged. Research assistance was provided by Robb De Kleine and Jason MacDonald of the Center for Sustainable Systems at the University of Michigan.

\section{References}

1. Transportation Energy Data Book: Edition 30 (Report ORNL-6986, Oak Ridge National Laboratory, Oak Ridge, TN, 2011).

2. H.-J. Kim, C. McMillan, G. Keoleian, S.J. Skerlos, J. Ind. Ecol. 14 (6), 929 (2010).

3. Ward's Motor Vehicle Facts \& Figures 2010: Documenting the Performance and Impact of the U.S. Auto Industry (Ward's Communications, Detroit, MI, 2010). 4. Light-Duty Automotive Technology and Fuel Economy Trends: 1975 through 2010 (Report EPA420-S-05-001, U.S. Environmental Protection Agency, Washington, DC, 2011).

5. A. Burnham, M. Wang, Y. Wu, Development and Applications of GREET 2.7-The Transportation Vehicle-Cycle Model (Report ANL/ESD/06-5, Argonne National Laboratory, Argonne, IL, November 2006).
6. "Update Material Production Modules in the GREET 2 Model" (Center for Sustainable Systems, University of Michigan, Ann Arbor, MI, 2011), css.snre. umich.edu/project/update-material-production-modules-greet-2-model.

7. International Aluminium Industry's Perfluorocarbon Gas Emissions Reduction Programme-Update 2009 (International Aluminium Institute, London, 2009).

8. C.A. McMillan, G.A. Keoleian, Environ. Sci. Technol. 43 (5), 1571 (2009).

9. Critical Materials Strategy (U.S. Department of Energy, Washington, DC, December 2010).

10. "Toyota Developing Induction Motors to Break Reliance on China" (Electric Vehicle News, 2011), electric-vehicles-cars-bikes.blogspot.com/2011/01/toyotadeveloping-induction-motors-to.html (accessed 28 October 2011).

11. L. Gaines, P. Nelson, Lithium-Ion Batteries: Possible Materials Issues (Argonne National Laboratory, Argonne, IL, 2008), www.transportation.anl.gov/pdfs/ B/583.PDF (accessed 28 October 2011).

12. R. Geyer, Environ. Sci. Technol. 42, 6973 (2008).

13. P. Gruber, P. Medina, G. Keoleian, S. Kesler, M. Everson, T. Wallington, J. Ind. Ecol. 15 (5), 760 (2011).

14. SAE 2011 Workshop to Characterize Biobased Materials in Vehicles for the USDA BioPreferred Program, Detroit, MI, 15 April 2011.

15. "Head's Up: Ford Increases Soy Content in Foam, Adds Head Restraint as Newest Component for Sustainable Material” (Ford Motor Company, Dearborn, MI, 2011), media.ford.com/article_display.cfm?article_id=35137 (accessed October 2011). 16. A.K. Mohanty, M. Misra, L.T. Drzal, J. Polym. Environ. 10 (1), 19 (2002).

17. J.L. Sullivan, A. Burnham, M. Wang, "Model for the Part Manufacturing and Vehicle Assembly Component of the Vehicle Life Cycle Inventory," J. Ind. Ecol., in press.

18. J.L. Sullivan, A. Burnham, M.Q. Wang, Energy and Carbon Emissions Analysis of Vehicle Manufacturing and Assembly (Technical Report ANL/ESD 10-6, Argonne National Laboratory, Argonne, IL, 2010).

19. C.A. McMillan, S.J. Skerlos, G.A. Keoleian "Evaluation of the Metals Industry's Position on Recycling and Its Implications for Environmental Emissions," J. Ind. Ecol., in press.

20. G.A. Keoleian, G. Lewis, R.B. Coulon, V.J. Camobreco, H.P. Teulon, "LCI Modeling Challenges and Solutions for a Complex Product System: A MidSized Automobile," in Total Life Cycle Conference Proceedings, P-339 (SAE International, Warrendale, PA, 1998), paper no. 982169, pp. 71-84.

21. J.L. Sullivan, R.L. Williams, S. Yester, E. Cobas-Flores, S.T. Chubbs, S.G. Hentges, S.D. Pomper, Life Cycle Inventory of a Generic U.S. Family Sedan Overview of Results USAMP Project (SAE Technical Paper 982160, SAE International, Warrendale, PA, 1998)

22. J.L. Sullivan, J. Hu, Life Cycle Energy Analysis for Vehicles (SAE Technical Paper 951829, SAE International, Warrendale, PA, 1995).

23. K. Bolon, G. Keoleian, L.P. Kostyniuk, Transp. Res. Rec. 2139, 73 (2009). 24. "Waste Reduction" (General Motors, Detroit, MI, 2012), www.gm.com/vision/ waste_reduction_.html (accessed March 2012).

25. "Ford's Sustainable Materials Strategy" (Ford Motor Company, Dearborn, MI, 2012), media.ford.com/images/10031/Ford_Sustainable_Materials_Fact_ Sheet.pdf (accessed March 2012).

26. Directive 2000/53/EC of the European Parliament and of the Council of 18 September 2000 on end-of life vehicles (European Commission, Brussels, Belgium, 2000).

27. V. Kumar, J.W. Sutherland, Int. J. Sustainable Manuf. 1 (1-2), 145 (2008).

28. B.J. Jody, E.J. Daniels, C.M. Duranceau, J.A. Pomykala Jr., J.S. Spangenberger, End-of-Life Vehicle Recycling: State of the Art of Resource Recovery from Shredder Residue (Technical Report ANL/ESD/10-8, Argonne National Laboratory, Argonne, IL, 2010).

29. R.T. Paul, How Prepared Are U.S. Dismantlers to Meet the EU Directive for ELV Recycling? (SAE Technical Paper 2001-01-3744, SAE International, Warrendale, PA, 2001)

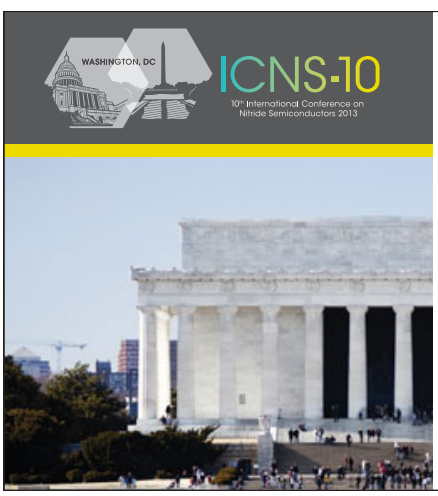

SAVE THE DATE

$10^{\text {th }}$ International Conference on Nitride Semiconductors | August 25-30, 2013 Gaylord National Hotel and Convention Center-Washington, D.C.

Join us for the 10th International Conference on Nitride Semiconductors 2013 (ICNS-10). The conference will present high-impact scientific and technological advances in materials and devices based on group-III nitride semiconductors.

Scientific Program

The six-day conference will concentrate on the following topical categories:

- Bulk Crystal Growth - Defect Characterization and Engineering

- Epitaxial Growth

- Structural Analysis

- Optical and Electronic Properties - Theory and Simulation

- Processing and Fabrication - Nanostructures

- Light Emitting Devices

- Electron Transport Devices

- Photovoltaics and Energy Harvesting

- New Materials and New Device Concepts

For the most up-to-date information on ICNS-10, visit www.ICNS10.org. 


\section{HD/1/5:/1011 \\ Metals \& Materials}

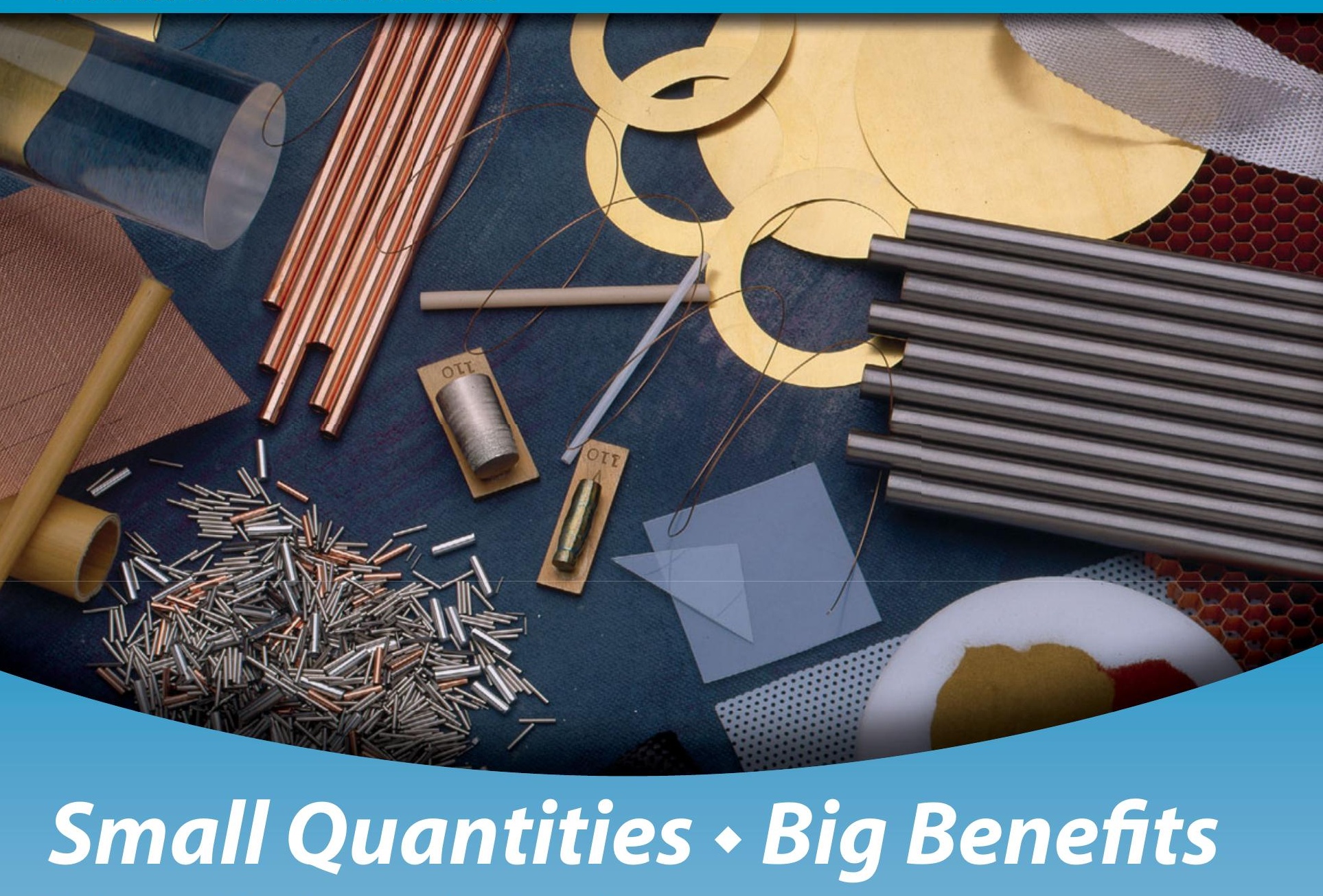

Offering quantities from one piece to small production runs, Goodfellow is your ideal source for metals and materials for research and product design.

- More than 70,000 products at goodfellowusa.com

- An extremely wide range of forms

- Custom finishing, fabrication \& specialized services

- Expert technical assistance

- Outstanding customer service

$\checkmark$ Metals

$\checkmark$ Ceramics, standard \& complex

$\checkmark$ Polymers

$\checkmark$ Composites

$\checkmark$ Specialty \& optical glass NEW

$\checkmark$ Machined ceramic \& glass components ${ }^{N E W}$

We welcome special requests!

It's easy to learn more!

For standard items: goodfellowusa.com

Questions and special requests: info@goodfellowusa.com

To speak to a real live person: 1-800-821-2870 


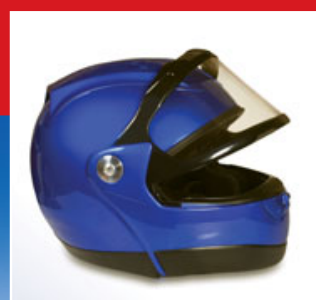

\title{
Do fiber-reinforced polymer composites provide environmentally benign alternatives? A life-cycle-assessment-based study
}

\author{
Joost R. Duflou, Yelin Deng, Karel Van Acker, and Wim Dewulf \\ This article summarizes the energy savings and environmental impacts of using traditional \\ and bio-based fiber-reinforced polymer composites in place of conventional metal-based \\ structures in a range of applications. In addition to reviewing technical achievements in \\ improving material properties, we quantify the environmental impacts of the materials over \\ the complete product life cycle, from material production through use and end of life, using \\ life-cycle assessment (LCA).
}

\section{Introduction}

Fiber-reinforced polymers (FRPs) are among the most widely produced categories of composite materials. ${ }^{1}$ Initially developed decades ago for the aerospace industry, these composites have spread to a wide range of applications, including automobiles, shipbuilding, circuit boards, construction materials, and household equipment (Figure 1). Because of their high stiffness, strength, and fatigue resistance, as well as their low density and ease of shaping, FRPs provide attractive alternatives to steel and nonferrous metals in structural applications. ${ }^{3}$ Recently, researchers have also explored bio-based FRPs, in which either the polymer matrix or the reinforcement fibers, or both, come from renewable resources. ${ }^{4}$

This article discusses the environmental impacts of transitioning from conventional materials to FRPs, as determined by life-cycle assessment (LCA). The net change depends on many processes throughout the life cycle of an envisaged application, including energy and mass flows as well as emissions and waste (Figure 2). Because FRP components are often lighter than their traditional counterparts, it is important to compare their impacts on a functionally equivalent basis.

\section{Traditional and bio-based fiber-reinforced polymers Fiber materials}

The best-established FRPs are glass-fiber-reinforced polymers (GFRPs), which are used in a variety of products, including printed circuit boards, tanks and pipes, car body panels, and wind turbine blades. The high melting temperature of glass (glass-fiber production occurs at $\sim 1550^{\circ} \mathrm{C}$ ) makes energy intensity the major environmental issue. ${ }^{5}$

Carbon-fiber-reinforced polymers (CFRPs) use carbon fibers that require considerable energy to produce, because they are made by pyrolysis at $1000-1400^{\circ} \mathrm{C}$ for high-modulus fibers or at $1800-2000^{\circ} \mathrm{C}$ for high-strength fibers. ${ }^{6}$ The energy expenditure has decreased, however, as production methods have evolved. ${ }^{7-9}$

One promising class of carbon fibers, carbon nanofibers, requires more energy to produce, depending on the feedstock and other details, and generally gives low yields of $15-50 \% .{ }^{10}$ A major concern for nanofibers is their potential human toxicity and ecotoxicity. Although they are probably less harmful in a matrix, free particles in the nanometer size range raise health and environmental concerns because of their large surface-areato-mass ratios and their ability to penetrate biological cells. ${ }^{11}$ 


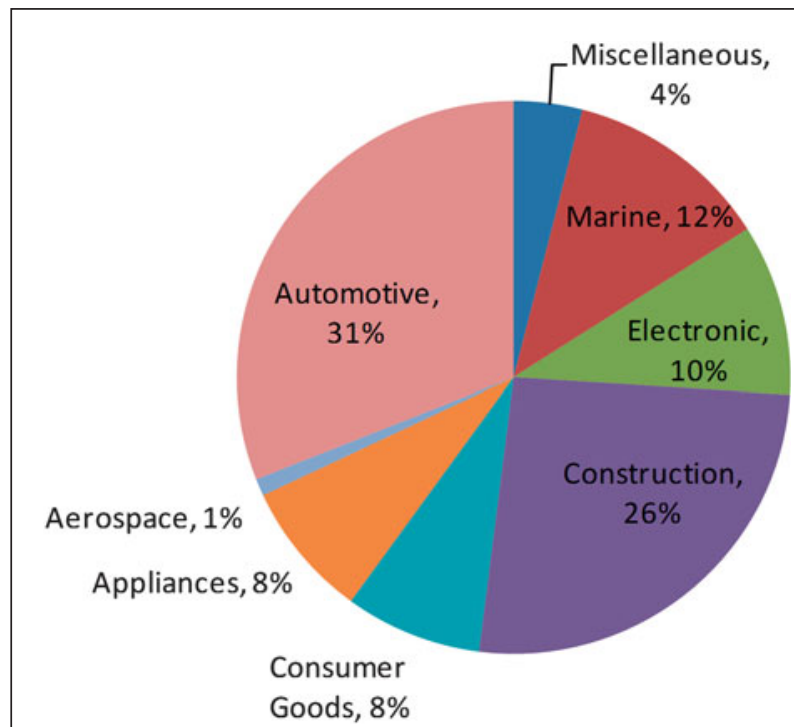

Figure 1. Market share distribution of fiber-reinforced polymers (FRPs) by application. ${ }^{2}$

Carbon nanofibers could hence exhibit toxic properties similar to those of asbestos, but because of a lack of data, this effect has not yet been taken into account in LCA studies.

Natural-fiber-reinforced polymers (NFRPs), which incorporate animal-, mineral-, and plant-based fibers, can be used as reinforcements in composites. Little information is available on animal- and mineral-based fibers, but properties of plant-based fibers and composites reinforced with such fibers are well-documented. ${ }^{12-14}$ In general, the tensile strength and Young's modulus of widely used plant-based fibers (e.g., hemp, flax fibers) are lower than those of commonly used glass fibers. However, because their density $\left(\sim 1.4 \mathrm{~g} / \mathrm{cm}^{3}\right)$ is less than that of glass fibers $\left(\sim 2.5 \mathrm{~g} / \mathrm{cm}^{3}\right)$, plant-based fibers have a higher specific strength and modulus, making them attractive when weight reduction is critical. ${ }^{14}$

\section{Matrix materials}

Matrix materials for FRPs conventionally include thermosets, such as epoxy, unsaturated polyester, and phenolic resins, but thermoplastic matrix materials are also used for processing and recyclability reasons. Energy consumption occurs during the many synthesis steps, involving first extraction of mineral oil, then separation and refining, and finally characterization and polymerization.

Common bio-based matrix materials include modified starch, ${ }^{15,16}$ bio-based polyester [e.g., poly(lactic acid) (PLA) ${ }^{17,18}$ ], microbial synthesis polymers [e.g., polyhydroxyalkanoates (PHAs $\left.)^{17,18}\right]$, and polymers synthesized from functionalized vegetable oil [e.g., epoxidized linseed oil (ELO) ${ }^{19-26}$ ].

\section{Comparing materials using life-cycle assessment}

LCA evaluates potential environmental costs or benefits for a particular application, quantifying the many tradeoffs between different life phases. This article explores three impact measures. First, cumulative energy demand (CED) can be an effective screening indicator for overall environmental impact, because energy consumption, especially fossil-fuel consumption, is a major driver for several environmental impact categories. ${ }^{27}$ Second, greenhouse-gas (GHG) emissions and the climate change to which they contribute are among the most significant environmental issues. ${ }^{28}$ The units for measuring greenhouse gas emissions are $\mathrm{CO}_{2}$ equivalents $\left(\mathrm{CO}_{2} \mathrm{e}\right)$, which account for the different global-warming potentials of different gases. The third assessment measure, used when sufficient data are available, consists of aggregate environmental impact scores, expressed in ecopoints. Unless stated otherwise, the ecopoint values discussed in this article were calculated using the impact-assessment method $\mathrm{ReCiPe}^{29}$ and are given in milli-ecopoints (mPt).

A per-kilogram basis provides a clear picture of the environmental intensity of raw materials production, but would inappropriately penalize the lighter polymer composites in components where stiffness, strength, or both determine the amount of material used. Instead, other indicators (see online supplementary materials) have been proposed that yield minimum weight or minimum environmental impact under constraints such as equal stiffness, ${ }^{30-33}$ equal strength, ${ }^{33,34}$ equal weight and geometry, ${ }^{35,36}$ or metrics based on measurements on specific components. ${ }^{37-39}$

\section{Materials impacts at different life-cycle phases Production phase}

Table I lists CED values, GHG emissions, and ecopoints associated with production of several matrix and fiber materials, as well as manufacturing methods for composites. In some cases, different production methods show widely varying environmental impacts. For example, making the PHA matrix material poly( $\beta$-hydroxybutyrate) (PHB) by fermentation releases energy, with a negative CED of $-22.7 \mathrm{MJ} / \mathrm{kg}$ and $\mathrm{GHG}$ emissions of $-3.1(\mathrm{~kg}$ of $\left.\mathrm{CO}_{2} \mathrm{e}\right) / \mathrm{kg}$, whereas PHB obtained from corn starch has a large positive CED (38.6 MJ/kg) but essentially zero GHG emissions. ${ }^{40}$

Table II provides an overview of LCA studies on production-phase environmental impacts
Figure 2. Generic life-cycle phases of a composite component. Each phase might require resource inputs and might create other impacts. 
Table I. Cumulative energy demand (CED), greenhouse-gas (GHG) emissions, and ecopoints for various materials and production processes.

\begin{tabular}{|c|c|c|c|}
\hline Material & CED (MJ/kg) & $\begin{array}{l}\mathrm{GHG}(\mathrm{kg} \text { of } \\
\left.\mathrm{CO}_{2} \mathrm{e} / \mathrm{kg}\right)\end{array}$ & Ecopoints (mPt/kg) \\
\hline \multicolumn{4}{|l|}{ Matrix } \\
\hline Liquid epoxy & $76-137^{41-43}$ & $4.7-8.1^{42,43}$ & $734^{44}$ \\
\hline Polyester (PES), unsaturated & $62.8-78^{41,42,45}$ & $2.3^{42}$ & $644^{44}$ \\
\hline Polypropylene (PP) & $73.4^{43}$ & $2.0^{43}$ & $276^{44}$ \\
\hline Mater-Bi ${ }^{\circledR}$-modified starch & $54.8^{46}$ & $1.3^{46}$ & $275^{44}$ \\
\hline $\begin{array}{l}\text { Ingeo } 2009^{\mathrm{TM}} \text { poly(lactic acid) } \\
\text { (PLA) }\end{array}$ & $67.8^{47}$ & $1.3^{47}$ & $312^{44}$ \\
\hline Polyhydroxyalkanoates (PHAs) & $59-107^{48-50}$ & $0.7-4.4^{48-50}$ & NA \\
\hline $\begin{array}{l}\text { Epoxidized linseed oil (ELO) } \\
\text { monomer }\end{array}$ & $19^{51}$ & $1.2^{51}$ & NA \\
\hline \multicolumn{4}{|l|}{ Reinforcement } \\
\hline $\begin{array}{l}\text { Polyacrylonitrile- (PAN-) based } \\
\text { carbon fiber (CF) }\end{array}$ & $286-704^{8,9,41}$ & $22.4-31^{8,9}$ & $833^{44}$ \\
\hline Carbon nanofiber (CNF) & $654-1807^{10}$ & $70-92^{10}$ & NA \\
\hline Glass fiber (GF) & $45^{5}$ & $2.6^{5}$ & $264^{44}$ \\
\hline Flax fiber, with irrigation & $9.6-12.4^{35,52}$ & $0.4^{52}$ & $350^{44}$ \\
\hline Hemp fiber, without irrigation & $6.8-13.2^{52,53}$ & $1.6^{52}$ & NA \\
\hline Jute fiber & $3.8-8.0^{54}$ & $1.3-1.9^{54}$ & NA \\
\hline Sugarcane bagasse & $11.7^{37}$ & NA & NA \\
\hline \multicolumn{4}{|c|}{ Manufacturing Processes for Selected Composites } \\
\hline Sheet molding compound (SMC) & $3.5-3.8^{8,41}$ & NA & $13^{44}$ \\
\hline Resin transfer molding (RTM) & $12.8^{30}$ & NA & $46^{44}$ \\
\hline Pultrusion & $3.1^{41}$ & NA & $11^{44}$ \\
\hline Autoclave & $21.9^{30}$ & NA & NA \\
\hline Injection molding & $21.1-29.9^{40,43}$ & $0.5-1.2^{40,43}$ & $126^{44}$ \\
\hline
\end{tabular}

NA, not available.

of different products made of composites, compared to their counterparts based on traditional materials. The values of CED and GHG emissions for matrixes and reinforcements in Table II do not fully agree with those in Table I because they were derived from different sources. Nevertheless, the trends are the same. Both GFRPs and CFRPs have been proposed as replacements for steel and aluminum in structural components. However, whereas GFRPs show consistently lower productionphase CED values and GHG emissions than either steel or aluminum, CFRPs generally score significantly worse than the metals.

\section{Use phase}

In the use phase, the impact of composite products is typically indirect. For example, FRPs are more durable than many traditional materials, such as steel and concrete, because they resist corrosion and fatigue better. ${ }^{1}$ According to a study performed by the Rotterdam city government, bridges made from CFRPs or GFRPs need no additional resources for maintenance. In contrast, for concrete or steel bridges, $5 \%$ of the initial materials for construction generally have to be replaced after 50 years. ${ }^{57}$ However, no quantitative data on the environmental impact of the maintenance of FPR components could be found in the literature.

In dynamic systems, such as vehicles, FRPs are used to achieve lightweight structures, thus reducing fuel consumption and related environmental impacts. Consequently, transportation systems are their major application, with automotive, aerospace, and marine uses representing $44 \%$ of total FRP consumption (see Figure 1). GFRPs are already used for decorative, nonstructural, and semistructural parts in cars, ${ }^{58,59}$ railway vehicles, ${ }^{60}$ ships, ${ }^{61}$ and aircraft. ${ }^{62}$

Substituting natural fibers for glass fibers in automotive applications has also drawn significant interest. ${ }^{63-70}$ Compared to similar combinations based on glass fibers, NFRPs have lower costs, weights, and environmental impacts for functionally equivalent solutions including door panels, car interiors, package trays, and rear shelves. ${ }^{71}$ Shifting from glass to natural fibers has been reported to save $22-27 \%$ in weight. ${ }^{72}$

For structural parts in vehicles, which are currently made from steel or aluminum, CFRPs (e.g., carbon-fiber-reinforced epoxy or polypropylene) have been proposed as substitutes, because CFRPs can satisfy severe structural requirements while providing significant weight reductions. ${ }^{58}$ Examples include the early "body-in-white" (BIW) stage of automobile manufacturing (consisting of the unpainted sheet metal frame of the vehicle),${ }^{73-76}$ railway carriage structures, ${ }^{77}$ vertical stabilizers and fin boxes in aircraft, ${ }^{78}$ and ship hulls. ${ }^{79,80}$ Weight reductions of $50-70 \%$ can be anticipated if CFRPs are used in place of conventional, metal-based components.

In addition to such primary weight savings, secondary weight savings, known as mass decompounding, are also expected. For example, a lightweight body requires a lighter chassis, lighter brakes, a less powerful power train, and so on. Secondary savings of an additional $0.5-1.5 \mathrm{~kg}$ per kilogram of primary savings have been reported..$^{8,58,81,82}$

Fuel consumption of a vehicle is determined by many factors (e.g., weight, shape, and route characteristics) and is therefore hard to estimate absolutely. However, other factors being equal, fuel consumption is proportional to vehicle mass for cars,${ }^{83}$ trains,${ }^{77}$ and aircraft. ${ }^{84}$ For ships, the 
Table II. Summary of life-cycle assessment (LCA) studies for fiber-reinforced polymers (FRPs) in the production phase.

\begin{tabular}{|c|c|c|c|c|c|}
\hline Product & Composite material & $\begin{array}{c}\text { Replaced traditional } \\
\text { material }\end{array}$ & Change in weight & $\begin{array}{l}\text { Change in cumulative } \\
\text { energy demand }\end{array}$ & $\begin{array}{l}\text { Change in greenhouse- } \\
\text { gas emissions }\end{array}$ \\
\hline \multirow[t]{4}{*}{ Bridge $\mathrm{e}^{38, \mathrm{a}}$} & \multirow[t]{4}{*}{ GF/PES pultruded } & Structural steel & $-33 \%$ & $-57 \%$ & \multirow[t]{4}{*}{ NA } \\
\hline & & Stainless steel & $-28 \%$ & $-68 \%$ & \\
\hline & & Concrete & $-85 \%$ & $-62 \%$ & \\
\hline & & Aluminum & $+25 \%$ & $-56 \%$ & \\
\hline Car side door ${ }^{39}$ & Hemp/EP & $A B S$ & $-27 \%$ & $-45 \%$ & $-15 \%$ \\
\hline Under-floor pan ${ }^{35}$ & Flax/PP & GF/PP & 0 & $-14 \%$ & NA \\
\hline Rotor blade ${ }^{36}$ & Flax/EP & CF/EP & 0 & $-50 \%$ & $-45 \%$ \\
\hline Car interior ${ }^{37, b}$ & Bagasse/PP & Talc/PP & $-20 \%$ & $-22 \%$ & $-21 \%$ \\
\hline \multirow[t]{2}{*}{ Car door ${ }^{34}$} & \multirow[t]{2}{*}{ GF/PP } & Steel & $-31 \%$ & $-59 \%$ & $+2 \%$ \\
\hline & & Aluminum & $+25 \%$ & $-87 \%$ & $-74 \%$ \\
\hline \multirow[t]{2}{*}{ Rear body of truck ${ }^{30}$} & \multirow[t]{2}{*}{ GF/PES } & Steel & $-44 \%$ & $-20 \%$ & \multirow[t]{2}{*}{ NA } \\
\hline & & Aluminum & $+11 \%$ & $-44 \%$ & \\
\hline \multirow[t]{3}{*}{ Closure panel ${ }^{55, c}$} & \multirow[t]{3}{*}{ CF/EP } & Steel & $-60 \%$ & $+280 \%$ & $+41 \%$ \\
\hline & & Aluminum & $-27 \%$ & $-65 \%$ & $-54 \%$ \\
\hline & & GF/PET & $-42 \%$ & $+127 \%$ & $+116 \%$ \\
\hline Sedan $^{33}$ & CF/EP (virgin) & Steel & $-38 \%$ & $+30 \%$ & NA \\
\hline \multirow[t]{2}{*}{ Propeller shaft ${ }^{66, d}$} & \multirow[t]{2}{*}{ GFCF/EP } & Steel & $-63.5 \%$ & $-13 \%$ & \multirow[t]{2}{*}{ NA } \\
\hline & & Aluminum & $-55 \%$ & $-83 \%$ & \\
\hline Car floor pan ${ }^{31}$ & CNF/PP or CNF/PES & Steel & $-18.9 \%$ to $-61.2 \%$ & $+30 \%$ to $+1000 \%$ & NA \\
\hline Car floor pan ${ }^{8, e}$ & CFRP & Steel & $-17 \%$ & $+363 \%$ to $+412 \%$ & $+136 \%$ to $+219 \%$ \\
\hline
\end{tabular}

NA, not available.

Acronyms: ABS, poly(acrylonitrile butadiene styrene); CF, carbon fiber; CFRP, carbon-fiber-reinforced polymer; CNF, carbon nanofiber; EP, epoxy; GF, glass fiber; PES, polyester; PET, poly(ethylene terephthalate); PP, polypropylene.

a Energy for maintenance not included because of high estimated uncertainty. S235J0 or S355J0 for structural steel, X2CrNi18-11 or X2CrNiM018-14-3 for stainless steel, AlMgSi1,0F31 for aluminum, B35 for concrete.

b $50 \%$ content of recycled polypropylene

${ }^{c}$ Closure panels of a midsize passenger car consisting of four doors, hood, and deck lid; $11 \%$ content of recycled aluminum.

d STAM735H for steel, modified 6061-T8 for aluminum.

e CFRP contains polyacrylonitrile- and lignin-based carbon fibers obtained by sheet molding or powdering manufacturing methods

energy consumption is proportional to weight to the power of $2 / 3$ within a specific velocity range. ${ }^{85}$ The energy savings induced by a certain amount of weight reduction by FRPs for a specific type of vehicle are more robust and widely adopted in LCA studies

Table III lists changes in CED values and GHG emissions during the use phase of a vehicle that can be obtained by using composites in place of traditional materials. CFRPs generally show dramatic energy savings compared to steel, aluminum, and even GFRPs, by virtue of the significant weight savings they make possible. NFRPs, such as bagasse/ polypropylene (PP) and china reed/PP, contribute to further weight reductions and energy savings compared to GFRPs. A crucial assumption is that the useful life of NFRPs will be the same as or comparable to that of traditional composites, but in fact little is known about the long-term durability of these materials, which is mostly determined by the moisture level in the composite. ${ }^{71}$ A systematic, quantitative analysis of the useful life of bio-based composites has not yet been performed.

\section{End-of-life phase}

Different end-of-life (EOL) scenarios lead to different impacts. Table IV provides an overview of CED values and GHG emissions for different EOL options. Recycling methods in Table IV include mechanical recycling for sheet-molding-compound composites and glass-mat-reinforced thermoplastics (GMTs), thermal treatment for CFRPs to recover carbon fibers, and remelting and recasting of steel and aluminum. Because the secondary use of the recycled materials is not clear, the environmental credits from recycling are not included in this table.

Landfills once were the common disposal approach for composite components. However, landfilling requires large 
Table III. Changes in cumulative energy demand (CED) and greenhouse-gas (GHG) emissions during the use phase for different material combinations.

\begin{tabular}{|c|c|c|c|c|c|}
\hline Product & $\begin{array}{l}\text { Composite } \\
\text { materials }\end{array}$ & $\begin{array}{l}\text { Substituted } \\
\text { materials }\end{array}$ & Lifetime (km) & $\begin{array}{l}\text { CED change } \\
\text { (GJ/piece) }\end{array}$ & $\begin{array}{l}\text { GHG change (kg } \\
\left.\text { of } \mathrm{CO}_{2} \mathrm{e} / \mathrm{piece}\right)\end{array}$ \\
\hline Car interior ${ }^{37}$ & Bagasse/PP & Talc/PP & 150000 & -19.3 & -206 \\
\hline $\begin{array}{r}\text { Transport } \\
\text { pallet }^{32}\end{array}$ & China reed/PP & GF/PP & $5000-200000$ & -0.6 to -2.3 & NA \\
\hline \multirow[t]{2}{*}{ Propeller shaft ${ }^{56}$} & \multirow[t]{2}{*}{$\mathrm{CF}$ and GF/EP } & Steel & \multirow[t]{2}{*}{150000} & -3.7 & -227 \\
\hline & & Aluminum & & -2.5 & -158 \\
\hline \multirow{3}{*}{$\begin{array}{l}\text { Closure panel of } \\
\text { carr }^{55, a}\end{array}$} & \multirow[t]{3}{*}{ CF/EP } & Steel & \multirow[t]{3}{*}{200000} & -26.9 & -2096 \\
\hline & & Aluminum & & -6.8 & -531 \\
\hline & & GF/PET & & -13.1 & -1023 \\
\hline \multirow[t]{2}{*}{ Car door ${ }^{34}$} & \multirow[t]{2}{*}{ GF/PP } & Steel & \multirow[t]{2}{*}{150000} & -2.0 & -150 \\
\hline & & Aluminum & & +0.8 & +67 \\
\hline \multirow{2}{*}{$\begin{array}{l}\text { Rear body of } \\
\text { truck }^{30}\end{array}$} & \multirow[t]{2}{*}{ GF/PES } & Steel Aluminum & \multirow[t]{2}{*}{190000} & -181 & NA \\
\hline & & Aluminum & & +23 & NA \\
\hline
\end{tabular}

NA, not available.

Acronyms: CF, carbon fiber; EP, epoxy; GF, glass fiber; PES, polyester; PET, poly(ethylene terephthalate); PP, polypropylene. a Closure panels of a midsized passenger car consisting of four doors, hood, and deck lid.

areas of land and does not allow for the recovery of the embodied energy of composites. Furthermore, waste typically must still undergo pretreatment to reduce its volume and hazardous effects before being landfilled. ${ }^{91}$

In most cases, FRPs are incinerated, for instance, in cement kilns, to recover embodied energy. A model for calculating the energy recovery from incineration of CFRPs was derived assuming complete conversion of carbon fibers and the polymer matrix into $\mathrm{CO}_{2}, \mathrm{H}_{2} \mathrm{O}$, and $\mathrm{N}_{2} \mathrm{O}$ by means of the modified Dulong formula: ${ }^{92}$

$$
\mathrm{TE}=337 C+1419(H-0.125 O)+93 S+23 N
$$

where TE, the total energy, is expressed in kilojoules per kilogram and $C, H, O, S$, and $N$ are the weight fractions, in percentages, of the corresponding elements. Glass-fiber-reinforced composites can also be incinerated, but the incombustible glass fibers hinder the incineration, consuming $\sim 1.7 \mathrm{MJ}$ per kilogram of glass-fiber content..$^{53}$

Through incineration, for example, burning composite scrap in cement kilns, one can not only recover the embodied energy, but incorporate the incombustible parts, such as glass fibers or mineral fillers, into cement production. ${ }^{93}$ Incineration is also a logical way to dispose of NFRPs. Unlike glass fibers, natural fibers are combustible and therefore contribute to a higher heating value of components for incineration.

The four main recycling methods for FRPs ${ }^{94}$ are

mechanical recycling, pyrolysis, fluidized-bed processing, and chemical treatment. Mechanical recycling is used for both GFRPs ${ }^{93}$ and CFRPs ${ }^{95}$ but is mainly applied to GFRPs. It does not recover individual fibers. Instead, mechanical recycling is performed at the composite level ${ }^{94}$ and involves shredding, crushing, or milling FRPs and then separating the crushed pieces into fiber-rich and resin-rich fractions. These fractions are incorporated into new composites as fillers or reinforcements or used directly in the construction industry. ${ }^{93}$

The mechanical properties of FRPs containing recyclates can be severely affected. Depending on the content of recyclates (5-70\% by weight), flexural-strength reductions of $10-54 \%$ have been recorded. ${ }^{96-98}$ As a result of these degraded mechanical properties, FRP recyclates are usually used in low-end applications such as construction fillers, which is best considered downcycling.

Other recycling meth-

\begin{tabular}{|c|c|c|c|c|c|c|}
\hline & \multicolumn{2}{|c|}{ Landfill } & \multicolumn{2}{|c|}{ Recycling } & \multicolumn{2}{|c|}{$\begin{array}{l}\text { Incineration with } \\
\text { energy recovery }\end{array}$} \\
\hline & $\begin{array}{l}\text { CED } \\
(\mathrm{MJ} / \mathrm{kg})\end{array}$ & $\begin{array}{c}\text { GHG } \\
\left.\text { (kg of } \mathrm{CO}_{2} \mathrm{e} / \mathrm{kg}\right)\end{array}$ & $\begin{array}{c}\text { CED } \\
\text { (MJ/kg) }\end{array}$ & $\begin{array}{c}\mathrm{GHG} \\
\left(\mathrm{kg} \mathrm{of} \mathrm{CO}_{2} \mathrm{e} / \mathrm{kg}\right)\end{array}$ & $\begin{array}{c}\text { CED } \\
(\mathrm{MJ} / \mathrm{kg})\end{array}$ & $\begin{array}{c}\mathrm{GHG} \\
\left(\mathrm{kg} \mathrm{of} \mathrm{CO}_{2} \mathrm{e} / \mathrm{kg}\right)\end{array}$ \\
\hline SMC & NA & NA & $7^{86}$ & $0.4^{86}$ & $-7.5^{87}$ & $0.9^{87}$ \\
\hline GMT & $0.09^{34,55}$ & $0-0.02^{34,55}$ & $11^{86}$ & $0.9^{86}$ & $-25.2^{87}$ & $1.9^{87}$ \\
\hline CFRP & $0.11^{55}$ & $0.02^{55}$ & $10-15^{34,41}$ & NA & -31.7 to $-34^{87,88}$ & $3.2-3.4^{87,88}$ \\
\hline NFRP & NA & NA & NA & NA & -12 to $-34^{32,37,39,87}$ & $2.3-2.9^{37,87}$ \\
\hline Steel & NA & NA & $11.7-19.2^{89}$ & $0.5-1.2^{89}$ & NA & NA \\
\hline Aluminum & NA & NA & $2.4-5.0^{90}$ & $0.3-0.6^{90}$ & NA & NA \\
\hline
\end{tabular}

NA, not available.

Acronyms: SMC, sheet-molding-compound composites (e.g., glass-fiber-reinforced polyester resins); GMT, glass-mat-reinforced thermoplastics (e.g., glass-fiber-mat-reinforced polypropylene).

ods, such as pyrolysis, ${ }^{93,99,100}$ the fluidized-bed process, ${ }^{93,94}$ and chemical processing, ${ }^{94,101}$ aim to reclaim individual fibers in CFRPs or GFRPs. The mechanical properties of carbon fibers can be retained at relatively high levels after pyrolysis $^{99,102-104}$ and chemical recycling. ${ }^{102}$ Glass fibers recycled by pyrolysis suffer a significant reduction in tensile strength as the pyrolysis temperature 
increases from $650^{\circ} \mathrm{C}$ to $800^{\circ} \mathrm{C} .{ }^{105}$ In the fluidized-bed process, glass fibers suffer a 50-90\% reduction in strength, depending on processing temperature. ${ }^{93}$ The tensile strength of recycled carbon fibers also decreases sharply (by 20-34\%), whereas the elastic modulus remains stable. ${ }^{106,107}$

From an environmental perspective, pyrolysis generally consumes $2.8 \mathrm{MJ}$ of energy per kilogram, while providing liquefied petroleum gas ( 2 MJ/kg), heating fuel oil $(9.2 \mathrm{MJ} / \mathrm{kg})$, and composite fillers $(\sim 10.6 \mathrm{MJ} / \mathrm{kg})$. Thus, compared to EOL scenarios without recycling, a net energy retrieval of approximately $19 \mathrm{MJ} / \mathrm{kg}$ can be achieved. ${ }^{30}$

NFRP composites are recycled through multiple mechanical and thermal reprocessing procedure ${ }^{108-110}$ and generally retain their mechanical properties. For example, after seven cycles, the tensile modulus and tensile strength for a sisal fiber/PP NFRP were found to drop by only $10.1 \%$ and $17.2 \%$, respectively, in contrast to $40.1 \%$ and $52.5 \%$ losses in a glass fiber/PP GFRP. ${ }^{110}$ However, the process temperatures cannot exceed $200^{\circ} \mathrm{C}$ during NFRP recycling without degradation of the structural properties. ${ }^{111,112}$ This might make recycling of NFRPs impractical for matrixes that require high temperatures, for instance, to achieve remelting.

A seemingly attractive way to dispose of bio-based composite waste is biodegradation (anaerobic digestion or composting). Biodegradation mechanisms for typical bio-based composites, including natural-fiber-reinforced starch-based composites, ${ }^{113,114}$ natural-fiber-reinforced PLA, ${ }^{115,116}$ PHA-based bio-based composites, ${ }^{117,118}$ and blends of these polymers, ${ }^{119,120}$ have been comprehensively investigated.

An important concern for biodegradation is whether the process itself or its products exhibit ecotoxicity, which can be measured with microorganisms, soil fauna, and terrestrial plants. ${ }^{121}$ Initial studies support ecological safety of biodegradation for starch blends, ${ }^{122}$ cellulose-fiber-reinforced starch composite, ${ }^{123}$ and lactic-acid-based polymers that do not contain the connecting agent 1,4-butane diisocyanate. ${ }^{124}$ Although quantitative LCA studies of biodegradation are rare, one such study reported that composting and incineration are comparable in terms of GHG emissions, but incineration provides significantly higher nonrenewable energy recovery. ${ }^{125}$

\section{Life-cycle tradeoffs}

The preceding sections highlighted potential environmental impacts and benefits related to a switch to composites. However, increases in environmental impacts during one life-cycle phase can be compensated by reductions during another phase. This section illustrates such tradeoffs using three examples.

\section{GFRP versus steel and aluminum in transportation vehicles}

Two studies ${ }^{30,34}$ reported that GFRPs are environmentally beneficial compared to steel for interior panels and doors in automobiles (20\% and 59\% CED reductions for GF/PES and GF/PP, respectively) in both the production and use phases because of their lower weights. The environmental problem lies in the EOL phase. Mechanical recycling of GFRPs severely damages their intrinsic properties, and the incineration potential of GFRPs is also limited because of their relatively low heating value and high ash content. ${ }^{30}$

In contrast, making components from aluminum instead of GFRPs results in slightly lighter structures. Even though virgin aluminum consumes more energy during production, it is easily recycled, so that designers can substantially reduce energy demand by using recycled aluminum. In general, ${ }^{34}$ therefore, aluminum is better for these uses than GFRPs, from a full life-cycle perspective.

\section{CFRP versus steel and aluminum in transportation vehicles}

A graphical comparison of the environmental impacts of using CFRPs and steel in automobiles is presented in Figure $\mathbf{3}$ as an example. Quantitative information on various contributions to the production-phase impact of shifting from steel to CFRPs can be found in Table II. In the EOL stage, incineration of CFRPs will provide energy credits, but the overall EOL ecological impact is still negative (positive ecopoint values) because of $\mathrm{CO}_{2}, \mathrm{NO}_{x}$, and $\mathrm{SO}_{2}$ emissions. ${ }^{88}$ In contrast, steel can be almost $100 \%$ recycled, with relatively low energy consumption and without degrading its materials properties, resulting in a comparatively beneficial EOL environmental impact. However, beyond a certain breakeven point in mileage, the environmental benefits of weight reduction in the use stage will overcome the negative impacts of CFRPs in the production and EOL stages. ${ }^{126}$ In one analysis, the breakeven point was found to be $132,000 \mathrm{~km}$ for CFRP versus steel for automotive panels, as shown in Figure 3. ${ }^{126}$

Such a breakeven point can also be determined for CFRPs compared to aluminum. An LCA comparison found that, if both the production and EOL stages are taken into account, an aluminum-based plane panel contributes fewer ecopoints (2 Pt) than a CFRP panel (10 Pt), because

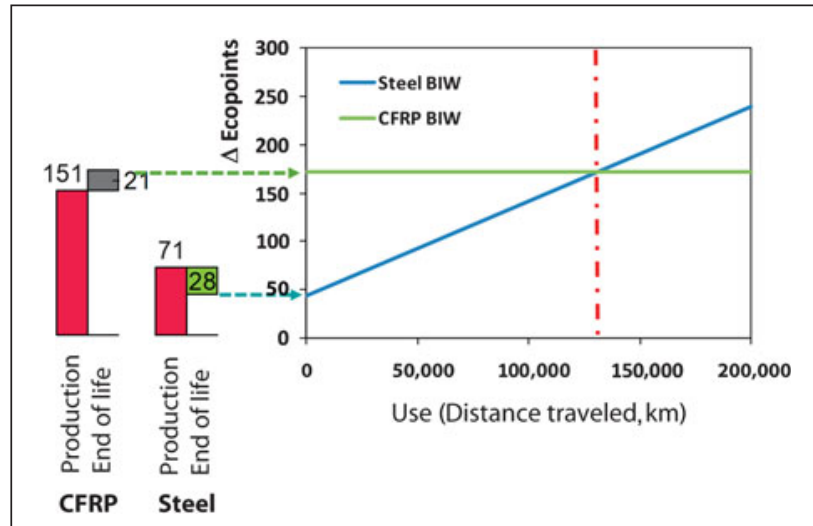

Figure 3. Total life cycle impact of carbon-fiber reinforced polymer (CFRP) body in white (BIW) compared to conventional steel BIW. The lower weight of the CFRP design and the secondary weight reduction it allows contribute to lower fuel consumption in the use phase that eventually overcomes its greater negative impact in production and end of life. Only the difference in fuel consumption is considered in the use phase for the steel based design. 
Table V. Comparison of cumulative energy demand (CED) values for natural-fiber-reinforced polymers (NFRPs) and glass-fiber-reinforced polymers (GFRPs).

\begin{tabular}{|c|c|c|c|c|c|}
\hline \multirow[b]{2}{*}{ Product } & \multirow[b]{2}{*}{ NFRP } & \multirow[b]{2}{*}{$\begin{array}{l}\text { Substituted } \\
\text { material }\end{array}$} & \multicolumn{3}{|c|}{ CED change (MJ/piece) } \\
\hline & & & $\begin{array}{l}\text { Production } \\
\text { phase }\end{array}$ & Use phase & EOL phase \\
\hline $\begin{array}{l}\text { Side panel of } \\
\text { light } \text { car }^{39, a}\end{array}$ & Hemp/EP & ABS & -59 & -71 & +27 \\
\hline $\begin{array}{l}\text { Side panel of } \\
\text { heavy } \operatorname{car}^{39, a}\end{array}$ & Hemp/EP & ABS & -59 & -118 & +27 \\
\hline Car interior ${ }^{37, b}$ & Bagasse/PP & Talc/PP & -222 & -19313 & +62.3 \\
\hline
\end{tabular}

a Component consists of $820 \mathrm{~g}$ of hemp/epoxy (EP) versus $1125 \mathrm{~g}$ of poly(acrylonitrile butadiene styrene). Distance of use is $200,000 \mathrm{~km}$.

${ }^{b}$ Component consists of $20 \mathrm{~kg}$ of bagasse/polypropylene (PP) versus $25 \mathrm{~kg}$ of glass fiber (GF)/PP. Distance of use is $150,000 \mathrm{~km}$. End-of-life (EOL) phase is $50 \%$ recycling and $50 \%$ incineration with energy recovery. environmental impacts caused during production and expected savings during use are less obvious and should be studied on a caseby-case basis.

According to the studied environmental impact evaluation criteria and the available data, when bio-based composites can provide the required material properties, they are valid alternatives with a reduced overall impact compared to traditional matrix and fiber materials. However, in terms of both further improving material properties and aluminum can also be easily recycled. ${ }^{84}$ Because of the significant weight reduction, the ecopoint breakeven point for CFRP versus aluminum in aircraft applications is only $70,000 \mathrm{~km}$ of flight. ${ }^{84}$

\section{NFRP versus GFRP in transportation vehicles}

Table $\mathbf{V}$ compares the CED values of NFRPs and GFRPs during the different life-cycle phases. The EOL scenario for all three listed cases involves incineration with energy recovery. Compared to GFRPs, NFRPs typically provide fewer energy credits in the EOL phase because of the lower equivalent product mass generally required for NFRP-based product designs, resulting in less material to be burned. NFRPs, however, provide favorable CED scores during both the production and use phases, which results in significantly reduced CED values for the total life cycle. The main environmental concerns for NFRPs, particularly biobased polymers/natural fibers, are emissions of nitrogen and phosphorus during cultivation, ${ }^{127}$ large arable-land requirements, ${ }^{128,129}$ and ecosystem deterioration. ${ }^{127,129}$ Presently, these impacts are too uncertain to be included in LCA studies, ${ }^{127}$ and more data on the production-phase impacts of NFRPs are needed.

\section{Conclusions}

Comparison of the environmental performance of FRP composites with that of traditional material solutions at a product level requires a thorough analysis of the complete life cycle of the product. The production of matrix and fiber materials generates considerable environmental impacts, especially because of the energy intensity of carbon fiber production. End-of-life processing creates comparatively less impact and therefore does not dominate environmental tradeoff considerations.

Depending on the application, the environmental payback during the product-use phase can be substantial: In aerospace applications, for example, weight reductions and related energy savings clearly dominate the life-cycle assessment. For applications with less energy-intensive use phases, such as automotive structures, the tradeoff between investigating environmental impacts, there is still significant scope for further research.

\section{Supplementary materials}

For supplementary materials for this article, please visit http:// dx.doi.org/10.1557/mrs.2012.33.

\section{References}

1. D.L. Chung, Composite Materials: Science and Applications (Springer, New York, ed. 2, 2010).

2. R.D. Anandjiwala, S. Blouw, J. Nat. Fibers 4, 91 (2007).

3. A.N. Netravali, S. Chabba, Mater. Today 6, 22 (2003).

4. F. Vilaplana, E. Strömberg, S. Karlsson, Polym. Degrad. Stab. 95, 2147 (2010).

5. D. Kellenberger, H.-J. Althaus, N. Jungbluth, T. Kunniger, M. Lehmann,

P. Thalmann, Life Cycle Inventories of Building Products (Swiss Centre for Life Cycle Inventories, Dübendorf, Switzerland, 2007).

6. A. Subic, A. Mouritz, 0. Troynikov, Sports Technol. 2, 67 (2009).

7. J. Takahashi, H. Zushi, T. Suzuki, H. Nagai, K. Kageyama, H. Yoshinari, in Proceedings of the 5th International Conference on EcoBalance (Society of NonTraditional Technology, Tsukuba, Japan, 2002), pp. 259-262.

8. S. Das, Int. J. Life Cycle Assessment 16, 268 (2011).

9. $\mathrm{LCl}$ values of carbon fiber (Japan Carbon Fiber Manufacturers Association, Tokyo, Japan, 2009).

10. V. Khanna, B.R. Bakshi, L.J. Lee, in Proceedings of the 2007 IEEE International Symposium on Electronics and the Environment (IEEE, New York, 2007), pp. 128-133.

11. A. Dowling, R. Clift, N. Grobert, D. Hutton, R. Oliver, 0. O'Neill, J. Pethica, N. Pidgeon, J. Porritt, J. Ryan, Nanoscience and nanotechnologies: opportunities and uncertainties (The Royal Society \& The Royal Academy of Engineering, London, 2004).

12. M.J. John, S. Thomas, Carbohydr. Polym. 71, 343 (2008).

13. A.K. Mohanty, M. Misra, G. Hinrichsen, Macromol. Mater. Eng. 276-277, 1 (2000).

14. P. Wambua, J. Ivens, I. Verpoest, Compos. Sci. Technol. 63, 1259 (2003).

15. H. Liu, F. Xie, L. Yu, L. Chen, L. Li, Prog. Polym. Sci. 34, 1348 (2009).

16. L. Avérous, P.J. Halley, Biofuels, Bioprod. Biorefin. 3, 329 (2009).

17. A.K. Mohanty, M. Misra, L.T. Drzal, Eds. Natural Fibers, Biopolymers, and Biocomposites (Taylor \& Francis, Boca Raton, FL, 2005).

18. K. Van de Velde, P. Kiekens, Polym. Test. 21, 433 (2002).

19. J.C. Ronda, G. Lligadas, M. Galià, V. Cádiz, Eur. J. Lipid Sci. Technol. 113, 46 (2011).

20. Y. Lu, R.C. Larock, ChemSusChem 2, 136 (2009).

21. D.D. Andjelkovic, M. Valverde, P. Henna, F. Li, R.C. Larock, Polymer $\mathbf{4 6}$ 9674 (2005).

22. M. Sacristán, J.C. Ronda, M. Galià, V. Cádiz, Polymer 51, 6099 (2010).

23. Y. Xia, R.C. Larock, Green Chem. 12, 1893 (2010).

24. M. Galià, L.M. de Espinosa, J.C. Ronda, G. Lligadas, V. Cádiz, Eur. J. Lipid Sci. Technol. 112, 87 (2010).

25. V. Sharma, P.P. Kundu, Prog. Polym. Sci. 33, 1199 (2008).

26. P. Czub, Polym. Adv. Technol. 20, 194 (2009).

27. M.A.J. Huijbregts, L.J.A. Rombouts, S. Hellweg, R. Frischknecht, A.J. Hendriks, D. van de Meent, A.M.J. Ragas, L. Reijnders, J. Struijs, Environ. Sci. Technol. 40, 641 (2005). 
28. Kyoto Protocol to the United Nations Framework Convention on Climate Change (UN Document FCCC/CP/1997/7/Add.1, Decision 1/CP.3, Annex 7, United Nations, New York, 1997).

29. M. Goedkoop, R. Heijungs, M. Huijbregts, A. De Schryver, J. Struijs, R. van Zelm, ReCiPe 2008, A life cycle impact assessment method which comprises harmonised category indicators at the midpoint and the endpoint level. Report I: Characterisation (VROM, The Hague, The Netherlands, 2009).

30. Y.S. Song, J.R. Youn, T.G. Gutowski, Composites A 40, 1257 (2009).

31. V. Khanna, B.R. Bakshi, L.J. Lee, in Proceedings of the 2008 IEEE International Symposium on Electronics and the Environment (IEEE, New York, 2008), pp. 1-6.

32. T. Corbière-Nicollier, B.G. Laban, L. Lundquist, Y. Leterrier, J.A.E. Månson, 0. Jolliet, Resour. Conserv. Recycl. 33, 267 (2001).

33. T. Suzuki, T. Odai, R. Hukui, J. Takahashi, paper presented at the International Conference on Life Cycle Assessment 2005, San Jose, Costa Rica, 25-28 April 2005.

34. P. Puri, P. Compston, V. Pantano, Int. J. Life Cycle Assessment 14, 420 (2009).

35. J. Diener, U. Siehler, Angew. Makromol. Chem. 272, 1 (1999).

36. 0. De Vegt, W. Haije, Comparative Environmental Life Cycle Assessment of Composite Materials (Report ECN-I-97-050, Netherlands Energy Research Foundation, Petten, The Netherlands, 1997).

37. S.M. Luz, A. Caldeira-Pires, P.M.C. Ferrão, Resour. Conserv. Recycl. 54 1135 (2010).

38. R.A. Daniel, paper presented at Lightweight Bridge Decks: European Bridge Engineering Conference, Rotterdam, The Netherlands, 27-28 March 2003.

39. K. Wötzel, R. Wirth, M. Flake, Angew. Makromol. Chem. 272, 121 (1999)

40. M. Pietrini, L. Roes, M.K. Patel, E. Chiellini, Biomacromolecules 8, 2210 (2007).

41. T. Suzuki, J. Takahashi, in 9th Japan International SAMPE Symposium \& Exhibition (JISSE-9) (SAMPE-Japan, Tokyo, Japan, 2005), pp. 14-19.

42. M. Patel, Energy 28, 721 (2003).

43. I. Boustead, Eco-profiles of the European Plastics Industry (Association of Polymer Manufacturers in Europe, Brussels, Belgium, 2005).

44. Ecolizer 2.0 (Openbare Vlaamse Afvalstoffenmaatschappij, Mechelen, Belgium, 2003-2011).

45. H. Kindler, A. Nikles, Kunststoffe 70, 802 (1980).

46. Environmental Production Declaration (EPD). MATER-BI NF Type:Biodegradable

Plastic Pellets for Films, (Novamont, Novara, Italy, 2001).

47. E.T.H. Vink, S. Davies, J.J. Kolstad, Ind. Biotechnol. 6, 212 (2010).

48. T.U. Gerngross, Nat. Biotechnol. 17, 541 (1999)

49. M. Akiyama, T. Tsuge, Y. Doi, Polym. Degrad. Stab. 80, 183 (2003)

50. S. Kim, B. Dale, Int. J. Life Cycle Assessment 10, 200 (2005).

51. A. Diehlmann, G. Kreisel, Ökologische Bilanzierung ausgewählter Lackrohstoffe: Vergleich von Bindemitteln auf nativer und petrochemischer Basis (Jena University, Jena, Germany, 2000).

52. S. González-García, A. Hospido, G. Feijoo, M. Moreira, Resour. Conserv. Recycl. 54, 923 (2010).

53. L. Shen, M. Patel, J. Polym. Environ. 16, 154 (2008).

54. J.E.G.V. Dam, H.L. Bos, The Environmental Impact of Fibre Crops in Industrial Applications (Food and Agriculture Organization, Rome, Italy, 2004).

55. S.M. Schexnayder, S. Das, R. Dhingra, J.G. Overly, B.E. Tonn, J.H. Peretz, G. Waidley, G.A. Davis, Environmental Evaluation of New Generation Vehicles and Vehicle Components (Report ORNL/TM-2001-266, Oak Ridge National Laboratory, Oak Ridge, TN, 2001)

56. J. Kasai, JSAE Rev. 20, 387 (1999)

57. Sustainability of Fibre-Reinforced Plastics-An Assessment Based on Selected Examples of Application (Industrievereinigung Verstärkte Kunststoffe e.V., Frankfurt am Main, Germany, 2010).

58. D. Codd, Advanced, Lightweight Materials Development and Technology for Increasing Vehicle Efficiency (KVA Incorporated, Escondido, CA, 2008).

59. S. Das, The Cost of Automotive Polymer Composites: A Review and Assessment of DOE's Lightweight Materials Composites Research (Report ORNL/TM-2000/283, Oak Ridge National Laboratory, Oak Ridge, TN, 2001).

60. J. Batchelor, Mater. Des. 2, 172 (1981)

61. P. Noury, B. Hayman, D. McGeorge, J. Weitzenböck, paper presented the 37th Western Europe Graduate Education Marine Technology Summer School, Madrid, Spain, 11-15 November 2002

62. D. Gay, Composite Materials: Design and Applications (CRC Press, Boca Raton, FL, 2003).

63. B. Dahlke, H. Larbig, H.D. Scherzer, R. Poltrock, J. Cell. Plast. 34, 361 (1998) 64. T.G. Schuh, Renewable Materials for Automotive Applications (DaimlerChrysler AG, Stuttgart, Germany, 2000).

65. L.T. Drzal, paper presented at the 2001 SPE Automotive Composites Conference, Troy, MI, 19-20 September 2001.

66. R. Joffe, L. Wallström, L. Berglund, paper presented at the International Scientific Colloquium "Modelling for Saving Resources," Riga, Latvia, 17-18 May 2001.
67. M. Pervaiz M.M. Sain, Macromol Mater Eng 288, 553 (2003)

68. M.G. Kamath, G.S. Bhat, D.V. Parikh, D. Mueller, Int. Nonwovens J. 14 (1), 34 (2005)

69. J. Holbery, D. Houston, JOM 58, 80 (2006)

70. E. Mangino, J. Carruthers, G. Pitarresi, Int. J. Vehicle Des. 44, 211 (2007).

71. B. Svennerstedt, paper presented at the 9th International Conference on Durability of Building Materials and Components, Brisbane, Australia, 17-21 March 2002

72. S.V. Joshi, L. Drzal, A. Mohanty, S. Arora, Composites A 35, 371 (2004). 73. F. Stodolsky, A. Vyas, R. Cuenca, paper presented at the Second World Car Conference, Riverside, CA, 22-24 January 1995.

74. I. Verpoest, T.C. Thanh, S. Lomov, in 9th Japan International SAMPE Symposium \& Exhibition (JISSE-9) (SAMPE-Japan, Tokyo, Japan, 2005), pp. 56-61.

75. TECABS: Technologies for Carbon Fibre Reinforced Modular Automotive Body Structures (Department of Metallurgy and Materials Engineering, Katholieke Universiteit Leuven, Leuven, Belgium), www.mtm.kuleuven.be/Onderzoek/ Composites/projects/finished_projects/ (accessed January 2012).

76. A.B. Lovins, D.R. Cramer, Int. J. Vehicle Des. 35, 50 (2004).

77. P.S. Castellan, I. Blanc, M.G. Ferrier, B. Caber, M. Wakeman, J.A. Manson, D. Emery, S.H. Han, J. Hong, O. Jolliet., Int. J. Life Cycle Assessment 14, 429 (2009).

78. C. Souris, Mater. Sci. Eng. A 412, 171 (2005)

79. K. Olofsson, G. Arnestad, A. Lönnö, A. Hedlund-Åström, T. Jansson, M. Hjortberg, paper presented at 13th European Conference of Composite Materials (ECCM-13), Stockholm, Sweden, 2-5 June 2008

80. I. Stenius, A. Rosén, J. Kuttenkeuler, Mar. Struct. 24, 43 (2011).

81. D. Malen, K. Reddy, Preliminary Vehicle Mass Estimation Using Empirical Subsystem Influence Coefficients (Auto/Steel Partnership, University of Michigan, Ann Arbor, MI, 2007)

82. T.C. Moore, paper presented at the 13th International Electric Vehicle Symposium (EVS-13), Osaka, Japan, 13-16 October 1996.

83. M. Bertram, K. Buxmann, P. Furrer, Int. J. Life Cycle Assessment 14, 62 (2009).

84. L. Scelsi, M. Bonner, A. Hodzic, C. Souris, C. Wilson, R. Scaife, K. Ridgway, eXPRESS Polym. Lett. 5, 209 (2011)

85. H. Helms, U. Lambrecht, Energy Saving by Light-Weighting I/ (Institute for Energy and Environmental Research, Heidelberg, Germany, 2004).

86. Y. Leterrier, in Comprehensive Composite Materials, K. Anthony, Z. Carl, Eds. (Pergamon, Oxford, UK, 2000), pp. 1073-1102.

87. A. Hedlund-Aström, Model for End of Life Treatment of Polymer Composite Materials (Royal Institute of Technology, Stockholm, Sweden, 2005).

88. J.R. Duflou, J. De Moor, I. Verpoest, W. Dewulf, CIRP Ann. 58, 9 (2009)

89. A Report on the Environmental Benefits of Recycling-A Critical Review of the Data for Steel (Bureau of International Recycling, Brussels, Belgium, 2010). 90. A Report on the Environmental Benefits of Recycling-A Critical Review of the Data for Aluminum (Bureau of International Recycling, Brussels, Belgium, 2010). 91. Council Directive 1999/31/EC of 26 April 1999 on landfill of waste, in Official Journal L 182, 16/07/1999 (European Commission, Brussels, Belgium, 1999).

92. G. Tchobanoglous, H. Theisen, S. Vigil, Integrated Solid Waste Management: Engineering Principles and Management Issues (McGraw-Hill, New York, 1993).

93. S.J. Pickering, Composites A 37, 1206 (2006).

94. S. Pimenta, S.T. Pinho, Waste Manage. 31, 378 (2011).

95. J. Takahashi, N. Matsutsuka, T. Okazumi, K. Uzawa, I. Ohsawa, K. Yamaguchi, A. Kitano, in 10th Japan International SAMPE Symposium \& Exhibition (JISSE-10) (SAMPE-Japan, Tokyo, Japan, 2007). pp.8-11.

96. R. Derosa, E. Telfeyan, J.S. Mayes, J. Thermoplastic Composite Mater. 18, 219 (2005)

97. J.D. Diniz Melo, E.A. Dos Santos, J. Reinforced Plastics Composites 28 2459 (2009)

98. J. Palmer, Ph.D thesis, University of Exeter, Exeter, Exeter, U.K., 2009.

99. L.O. Meyer, K. Schulte, E. Grove-Nielsen, J. Compos. Mater. 43, 1121 (2009). 100. J. Gañan, J.F. González, C.M. González-García, E.M. Cuerda-Correa, A. Macías-García, Bioresour. Technol. 97, 711 (2006)

101. W. Dang, M. Kubouchi, H. Sembokuya, K. Tsuda, Polymer 46, 1905 (2005). 102. C.-K. Lee, Y.-K. Kim, P. Pruitichaiwiboon, J.-S. Kim, K.-M. Lee, C.-S. Ju, Transp. Res. D 15, 197 (2010)

103. E. Lester, S. Kingman, K.H. Wong, C. Rudd, S. Pickering, N. Hilal, Mater. Res. Bull. 39, 1549 (2004).

104. J.P. Heil, M.J. Hall, D.R. Litzenberger, R. Clearfield, J.J. Cuomo, P.E. George, W.L. Carberry, paper presented at SAMPE '09, Baltimore, MD, 18-21 May 2009. 105. A.M. Cunliffe, N. Jones, P.T. Williams, Environ. Technol. 24, 653 (2003) 106. G. Jiang, S.J. Pickering, G.S. Walker, K.H. Wong, C.D. Rudd, Appl. Surf. Sci. 254, 2588 (2008)

107. K.H. Wong, S.J. Pickering, T.A. Turner, N.A. Warrior, paper presented at Composites Innovation 2007-Improved Sustainability and Environmental Performance, Barcelona, Spain, 4-5 October 2007 
108. V. Srebrenkoska, G.B. Gaceva, M. Avella, M.E. Errico, G. Gentile, Polym Int. 57, 1252 (2008).

109. A. Le Duigou, I. Pillin, A. Bourmaud, P. Davies, C. Baley, Composites A 39, 1471 (2008).

110. A. Bourmaud, C. Baley, Polym. Degrad. Stab. 92, 1034 (2007).

111. G. Marsh, Mater. Today 6, 36 (2003).

112. F.P. La Mantia, M. Morreale, Composites A 42, 579 (2011).

113. R.P. Singh, J.K. Pandey, D. Rutot, P. Degée, P. Dubois, Carbohydr. Res. 338, 1759 (2003).

114. C.R. di Franco, V.P. Cyras, J.P. Busalmen, R.A. Ruseckaite, A. Vázquez, Polym. Degrad. Stab. 86, 95 (2004).

115. D. Plackett, T. Løgstrup Andersen, W. Batsberg Pedersen, L. Nielsen, Compos. Sci. Technol. 63, 1287 (2003).

116. R. Kumar, M. Yakubu, R. Anandjiwala, eXPRESS Polym. Lett. 4, 423 (2010).

117. N.M. Barkoula, S.K. Garkhail, T. Peijs, Ind. Crops Prod. 31, 34 (2010).

118. G.R. Saad, H. Seliger, Polym. Degrad. Stab. 83, 101 (2004).

119. T. Ohkita, S.-H. Lee, J. Appl. Polym. Sci. 100, 3009 (2006).

120. L. Yu, K. Dean, L. Li, Prog. Polym. Sci. 31, 576 (2006).

121. A. Kapanen, M. Itävaara, Ecotoxicol. Environ. Saf. 49, 1 (2001).
122. R. Jayasekara, S. Sheridan, E. Lourbakos, H. Beh, G.B.Y. Christie, M. Jenkins, P.B. Halley, S. McGlashan, G.T. Lonergan, Int. Biodeterior. Biodegrad 51, 77 (2003).

123. E. Rudnik, N. Milanov, G. Matuschek, A. Kettrup, Chemosphere 70, 337 (2007).

124. J. Tuominen, J. KyImä, A. Kapanen, O. Venelampi, M. Itävaara, J. Seppälä, Biomacromolecules 3, 445 (2002).

125. B.G. Hermann, L. Debeer, B. De Wilde, K. Blok, M.K. Patel, Polym. Degrad. Stab. 96 (6), 1159 (2011).

126. K. Van Acker, I. Verpoest, J. De Moor, J.-R. Duflou, W. Dewulf, Rev. Met. Paris, 541 (2009).

127. S.A. Miller, A.E. Landis, T.L. Theis, Environ. Sci. Technol. 41, 5176 (2007).

128. V. Piemonte, F. Gironi, Environ. Prog. Sustainable Energy 30 (3), 459 (2010). 129. Y. Deng, K. Van Acker, W. Dewulf, J.R. Duflou, in Glocalized Solutions for Sustainability in Manufacturing: Proceedings of the 18th CIRP International Conference on Life Cycle Engineering, Technische Universität Braunschweig, Braunschweig, Germany, May 2nd-4th, 2011, J. Hesselbach, C. Herrmann, Eds. (Springer, New York, 2011); pp. 605-610.

\section{The 2012 MRS Spring Meeting Isn't Over Yet!}

This was our biggest Spring Meeting yet, and now you can view selected talks and lectures, complete with slides, from the comfort of your home or office, or on the go!

The following presentations are available on the MRS website as video broadcasts.

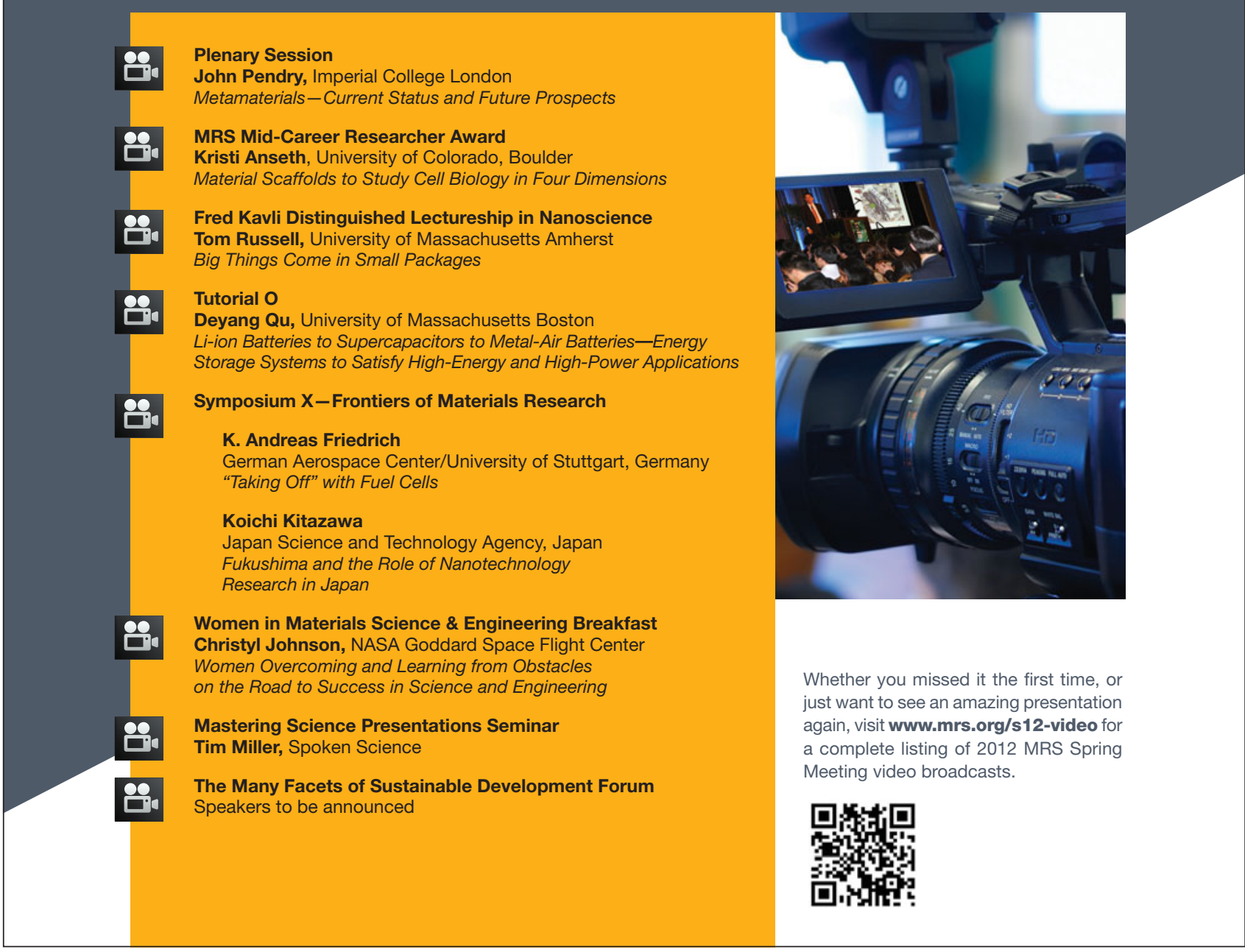




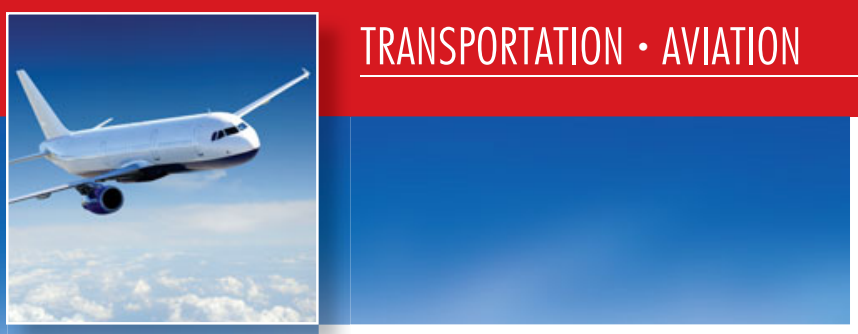

\title{
Materials for sustainable turbine engine development
}

\section{Doug Konitzer, Steve Duclos, and Todd Rockstroh}

\begin{abstract}
Turbine engine performance, as measured by specific fuel consumption (defined as fuel consumed relative to the thrust produced by the engine), is a key criterion in engine selection. To achieve the specific fuel consumption required of modern engines, engineers combine advanced designs and materials to achieve higher operating temperatures and, therefore, higher engine efficiency. One of the difficulties of using advanced materials is that they exploit scarce, hard-to-replace elements to allow higher operating temperatures. In this article, we describe steps being taken by General Electric Co. and the turbine engine industry to continue to improve engines in a material space constrained by material availability. As a specific example, we focus on the transition metal rhenium.
\end{abstract}

\section{Introduction}

In their drive to increase engine efficiency, materials engineers have developed a wide range of materials. Whereas early engines were made from steel and exhibited relatively simple geometries, today's engines incorporate many different materials and complex geometries depending on the needs of each specific component. Materials such as polymer-matrix composites, titanium alloys, wrought nickel and cobalt superalloys, and both equiaxed and single-crystal cast superalloys have all found applications in engines. In addition, each of these new material classifications has a range of associated compositions. For example, cast single-crystal nickel-based superalloys are classified into generations depending on the amount of rhenium in the specific alloys. Whereas rhenium is not present in firstgeneration single-crystal superalloys, it is used in increasing quantities in the second- and third-generation single-crystal superalloys. To continue to improve engine efficiency, it will be necessary to develop even more advanced materials for high-temperature use. In general, the advanced materials being developed are more complex and contain elements that are scarcer than was the case for previous generations of materials.

The challenge of sustainability was addressed at the International Congress on Sustainability Science \& Engineering forum in 2009, for which the overview stated: "Sustainability has become a common currency in describing proactive plans and solutions in many scientific, engineering, and social science disciplines with no consensus on what sustainability means."1 To some extent, this remains true today, as the general definition of sustainable development (see the introductory article in this issue by Green et al.) is of limited use in assessing the sustainability of a given part or product. For the purposes of this article, we focus on a more specialized aspect of sustainability that strongly affects current and future aviation technology: conserving elements that are critical to producing components that enable efficiency improvements in turbine engines. In this case, the focus on sustainability arises because of the business desire to meet the market demand for more fuel-efficient engines when one of the critical elements for meeting that demand is in short supply.

For sustainable development of advanced engines, it is necessary to have a stable supply chain for each of the materials used. In the past, there have been concerns about the supply and/or cost of various elements. For example, the price of tantalum increased significantly in 2000, from approximately US $\$ 34 / 1 \mathrm{~b}$ (US\$75/kg) to approximately US\$220/lb (US\$485/kg), based on "overoptimistic forecasts of market growth and an apparent shortage of tantalum source material for processing." Many materials that are critical for engine manufacture are in short supply because they are present at very low levels in Earth's crust; have environmental issues associated with their smelting; are from less politically stable parts of the world; or are associated with negative social consequences, such as mining being done to support conflict. Each of these supply-chain 
issues can change the sustainability of using these materials in manufacturing operations.

In this article, we discuss the procedures used to identify which materials could have an impact on the ability to manufacture engines and some of the developments that might mitigate an imprudent reliance on certain materials. To simplify the discussion, we concentrate on metallic structural materials because they are the predominant materials used in engines and discuss rhenium as a specific example of a critical element.

\section{Identifying critical elements}

Quantitative methods have recently been developed to evaluate the relative supply risks posed by raw materials at the element level. The U.S. National Research Council outlined an assessment tool that builds a "criticality matrix" in which risks are quantified element by element in two categories: "supply risk" and "impact of supply restriction." ${ }^{3}$ The U.S. Department of Energy recently used this methodology to determine the criticality of elements to renewable energy technologies. ${ }^{4}$ Methods are being developed to refine the supply risk category by using well-established indices that quantify element availability, as well as economic and geopolitical factors. ${ }^{5}$ A recent joint study group of the American Physical Society and the Materials Research Society also evaluated the landscape of energy-critical elements required for large-scale deployment of new technologies for the production, transmission, efficient use, or conservation of energy. ${ }^{6}$

The process that General Electric Co. (GE) uses to evaluate the risks associated with material shortages is a modification of the method developed by the National Research Council. ${ }^{7}$ The supply risk category is expanded to "price and supply risk" and includes an assessment of demand and supply dynamics, price volatility, geopolitics, and coproduction with other elements. The assessment of this first category relies on supply data from the U.S. Geological Survey, as well as knowledge of company-specific supply dynamics and current and projected future uses of the element. The second category is focused on the "impact of a restricted supply on GE" and includes an assessment of the company's volume of usage compared to the world supply, the criticality of the element to products, and the impact on revenue of products containing the element. The results of a 2008 assessment for the element rhenium are shown in Figure 1, where the areas of the circles are proportional to the amount of usage by the company. This analysis thus indicated the need to develop risk-mitigation strategies for rhenium, because of its criticality as a constituent of the superalloys used in aircraft engines.

\section{Material conservation}

Once critical elements have been identified using the quantification method discussed in the preceding section, it is necessary to identify all of the sources and sinks for the critical elements throughout the production process. Thus, for each critical element, each step of the component manufacturing process and the component life cycle is audited to determine the amount of

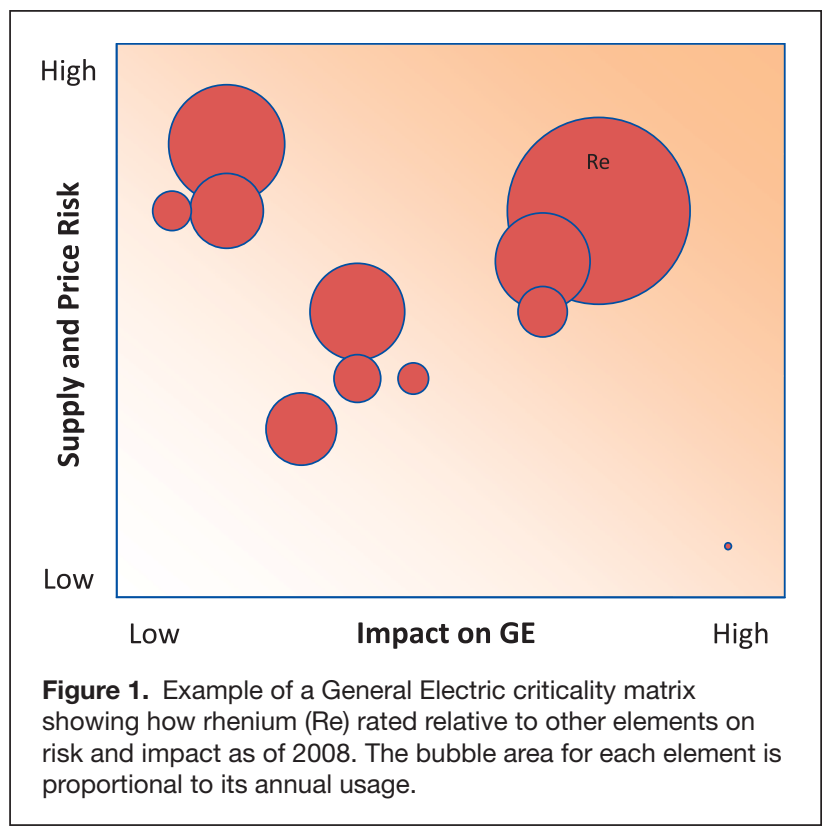

the critical element that is either added or discarded at that step. After the audit, it is necessary to develop the technologies and business plans to ensure that as little as possible of the critical element escapes from the life-cycle loop.

A schematic of such a life-cycle loop for a part made by casting is shown in Figure 2. The loop starts with melting of the primary alloy, which has a composition designed to provide a certain set of properties in the finished part. It is possible to reduce the amount of the critical element used at this point if an alternate composition, containing smaller amounts of the element, can be found that also produces the required final properties. Once the master alloy has been produced and castings have been made, it is common foundry practice to use the scrap

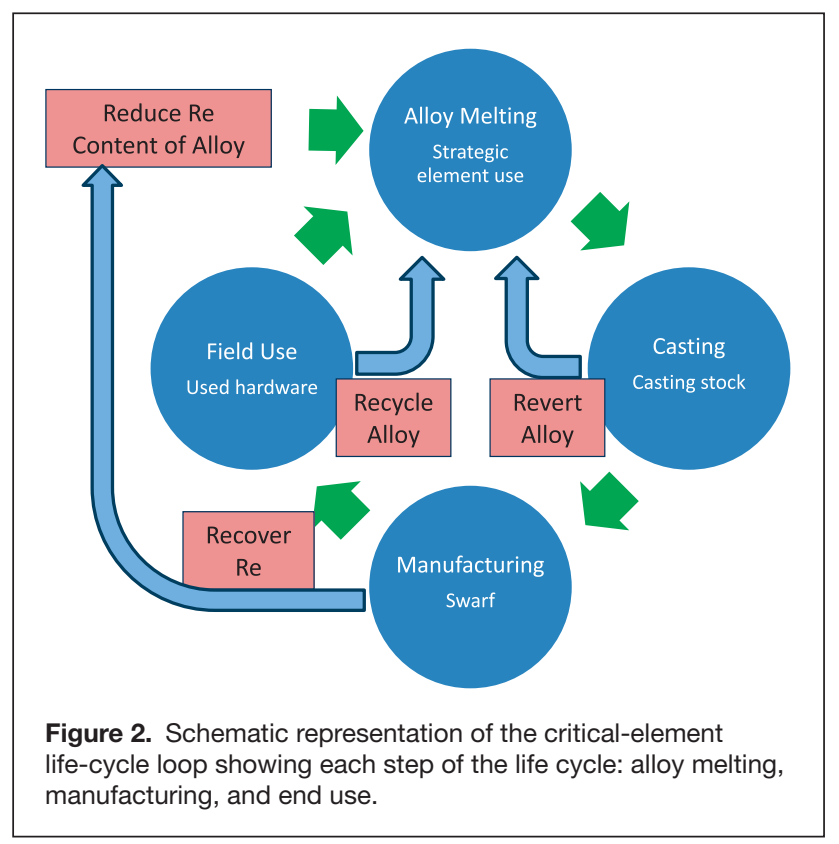


from the casting process, such as gates or runners, as feedstock for the next master alloy. This process is called revert. As the castings move through the manufacturing process, they are machined and ground to produce the finished part geometry. These manufacturing processes generate chips, filings, or turnings, which are collectively called swarf. If the chips are large enough, they can go into the revert stream, similarly to gates and runners. Other technologies, usually chemical reduction to the elemental state, have been developed to recover the critical elements from the smaller swarf, such as filings. ${ }^{8}$ At the end of its useful life, a part can be recycled back to the alloy melting stage for recasting, usually through some sort of business arrangement to return used parts to the manufacturer.

In each step of the life-cycle loop, it is necessary to determine the most cost-efficient method of working with the material. In many cases, it is better to work with the material as an alloy. For example, it does not make economic sense to extract specific elements from alloys in larger pieces such as casting gates or runners; it is much easier to revert the alloy. However, in the case of the fine chips or swarf, it is usually easier to remove the alloying element chemically. This difference arises partly because of the difficulty of melting very fine metallic swarf.

\section{Technologies for preventing loss of critical elements}

The overall goal of materials for sustainable development is to have a closed-loop material stream. Any material that is injected into the closed-loop stream would ideally stay in the stream indefinitely. To prevent loss of the critical elements, various technologies are used to return the element back to the start of the loop. These technologies are discussed here using the specific example of rhenium in superalloys.

Rhenium is a scarce element in Earth's crust, estimated at 0.4 parts per billion. ${ }^{9}$ Rhenium is recovered as a byproduct of molybdenite concentrates that are, in turn, recovered as a byproduct from copper ores. ${ }^{10}$ Thus, if the demand for copper decreases, there will also be a reduction in the supply of rhenium, because it is not economically viable to produce copper and molybdenum just to obtain the rhenium byproduct. There are two major uses for rhenium: as a constituent of platinumrhenium catalysts and as an alloy addition to high-temperature superalloys. ${ }^{10}$ Approximately three-quarters of the rhenium is used as a strengthener in nickel-based superalloys, where it improves their ability to withstand high temperatures in turbine engines. All of the major producers of turbine engines, including GE, Pratt \& Whitney, and Rolls Royce, use rheniumcontaining alloys in their engines. ${ }^{10}$

\section{Reduce}

Motivated by concerns about potential supply restrictions, GE recently undertook a program to reduce the usage of rhenium. ${ }^{7,8}$ In particular, the production supply of this strategic element was forecast to be less than the demand from the catalyst and superalloy markets described above. In response, alloy development was initiated to reduce the amount of rhenium in the superalloys while still maintaining the properties required for the finished parts. One aspect of this program involves developing alloys for specific applications. In the past, when supply problems were not an issue, it was common practice to develop a single alloy that could cover multiple applications. With the advent of element shortages, however, it has become necessary to tailor each alloy to meet the precise criteria for specific applications.

Extensive effort is expended during the development of these new alloys to ensure that they meet all of the property requirements for the specific applications. Also, manufacturing trials must be performed to show that the manufacturing process is not changed significantly. Finally, engine testing must be performed to demonstrate that the alloys have no detrimental effects on the other parts of the engine system

\section{Revert}

Revert involves collecting various pieces of scrap, cleaning them to remove any unwanted surface debris, and melting the scrap to produce the next master alloy for casting. The sources of this scrap could include portions of a casting that were not used in the final part or parts that have been retired from service. The main task for rhenium-containing revert is to make sure that as much of it as possible is collected and kept separate from other scrap. These scrap pieces are used as alloy and are not reduced to elements. The strategies around material revert are well-established. One of the main challenges is determining the composition of all of the input materials. In particular, supply-chain practices must be established to prevent mixing of chips with different compositions. ${ }^{11}$ Mixed-input stock can cause a whole ingot to have the wrong chemistry, which would exclude it from further use in the closed-loop stream for an advanced material.

One area of development is the reduction of revert generated by the casting process. Reducing the amount of scrap generated during casting reduces the possibility of losing the critical element. Techniques such as computer modeling of the casting process can be used to optimize the runners and gates and thus minimize the material sent to revert.

\section{Recover}

One of the more commonly overlooked leakage paths from the closed-loop stream is material that is converted into very fine pieces, such as the fine chips that result from grinding. When superalloys are ground, the resulting very fine shavings can be collected. Grinding medium is included with this swarf and must be removed as much as possible to concentrate the alloy. At this point, a decision must be made whether to continue to recover the material as an alloy or to remove the rhenium only. In the specific example mentioned previously, the choice was made to remove the rhenium from the alloy through a proprietary chemical process. ${ }^{8}$ The rhenium was removed from the alloy and concentrated to produce pure rhenium, which was then used as input stock for producing new alloy. 


\section{Recycle}

Once a manufactured part has reached the end of its usable life, it becomes a candidate for recycling. Previously, this was one of the major leakages from the closed-loop stream because scrap parts were added to the general metal recycling stream and used as input for other alloys. For example, some superalloy was recycled as input stock for stainless steels because of the high nickel and chromium contents of the superalloy. In this way, the strategic elements from the superalloys were lost to future superalloys and instead became impurities in the steel rather than vital elements in new superalloy. To prevent this loss of rhenium from the closed-loop system, a specific recycling stream was developed within GE for rhenium-containing superalloys.

The process of recycling consists of identifying the material, removing the coatings, and cleaning the metal. In the case of recycling of superalloys from turbine engine components, the identification of material is greatly facilitated because each of the parts has a part number that can be correlated back to an alloy composition, thus reducing the amount of mixed scrap, as discussed in the Revert section. Most engine components have a coating of some kind, and any residual coating must be removed prior to remelting of the alloy, to prevent contamination. The material cleaning is similar to the cleaning done for revert. Once all of these process steps are completed, the material can be used in the revert stream.

It should be noted that, during the coating removal and cleaning stages, the cleaning solution might remove small amounts of the rhenium-containing superalloy, which must also be taken into account in the closed-loop process. The cleaning solution thus becomes another candidate for further recovery.

\section{Reduced material usage: Additive manufacturing}

As mentioned in the Revert section, one way to reduce the leakage of rhenium is to reduce the amount of material generated as scrap during the casting process. An alternative to the casting process for producing components that can help in reaching this goal is additive manufacturing. ${ }^{12,13}$ In additive manufacturing, a computer is used to represent a three-dimensional shape as a large number of two-dimensional shapes in a computer. These two-dimensional shapes are then built up layer by layer using a computer-controlled melting or sintering process. The result of additive manufacturing is that very little waste material is produced, so that the revert and recover processes become negligible. Additive manufacturing also has the ability to eliminate manufacturing steps by producing a single component for parts that would otherwise require the production and joining of several smaller components.

Airbus has formed an Additive Layer Manufacturing Center, ${ }^{14}$ and the other aerospace manufacturers have various developmental programs in the United States and globally. These efforts aim to reduce the "buy-to-fly" ratio between the amounts of material in the original rough component shape and in the final product. For many parts in gas turbines, this ratio is around 2:1, meaning that one-half of the raw material remains as swarf generated during machining. For some parts, however, the buy-to-fly ratio is over 10:1, corresponding to $90 \%$ material loss.

Clearly, additive manufacturing poses an attractive alternative for the fabrication of parts, as it could reduce the amounts of waste material being produced and the potential loss of critical elements such as rhenium. In practice, additive manufacturing has been used exclusively to produce parts that are relatively small. The time needed to produce large parts by additive manufacturing would be prohibitive with today's technology. However, accelerating the additive manufacturing process is an area of active development.

An example of a monolithic component that was formed using additive manufacturing is shown in Figure 3: a fuel circuit from a combustion module. This part would conventionally consist of $12-20$ piece parts, brazed together. In this case, the process is simplified by using additive manufacturing technology to fabricate a single-piece fuel circuit. The process simplification results in a reduction in the amount of energy used in the process through elimination of high-temperature braze cycles. In addition, reduced machining is required, which results in additional energy reduction and reduced opportunity for loss of critical elements.

There is much to learn to exploit these emerging additive manufacturing processes. Figure 4 shows the evolution of the fuel circuit in Figure 3 from initial design to final configuration. The original design (Figure $4 \mathrm{a}$ ) was built based on a computer model of the conventionally produced fuel circuit components. When this geometry was first produced

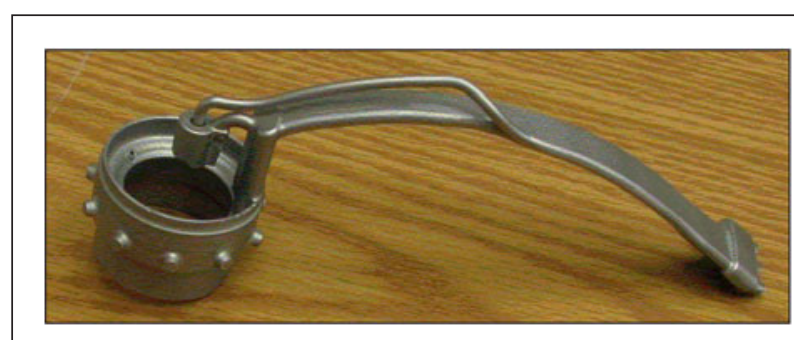

Figure 3. Fuel circuit made by direct metal additive manufacturing.

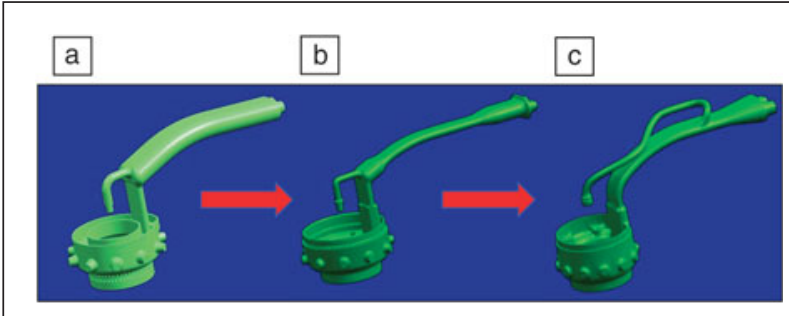

Figure 4. Progression of an additively manufactured component through successive design iterations that required no retooling: (a) original design, (b) improved design, (c) productivity design. 
by additive manufacturing and tested, several problems were identified, so the part geometry was reconfigured to that shown in Figure $4 b$ to mitigate these problems. An advantage of the additive manufacturing process is that changing from the geometry in Figure $4 \mathrm{a}$ to that in Figure $4 \mathrm{~b}$ required only a modification of the geometry in the computer model. No hard tooling, such as of fixtures or gauges, was required. Thus, the redesigned part could be fabricated within one week. As additional quantities of fuel circuits were built and productivity/ throughput was sought, it was realized that various additional changes in the part geometry could eliminate $10 \%$ of the cycle time from the fabrication cycle, resulting in the configuration shown in Figure 4c.

\section{Summary}

This article has described several of the steps that General Electric Co. and the turbine engine industry have taken and continue to pursue to address the sustainable development of aviation technology. Of specific concern is the need to conserve scarce elements that are critical to producing components that drive efficiency improvements in turbine engines. In this article, the scarce element rhenium was used as an example. Methods have been developed to first identify critical elements and then take actions to reduce the reliance on those critical elements. The actions include both the evaluation of processes and the development of new technologies. Future developments in casting modeling and additive manufacturing to reduce the amounts of

\section{COMING SOON!}

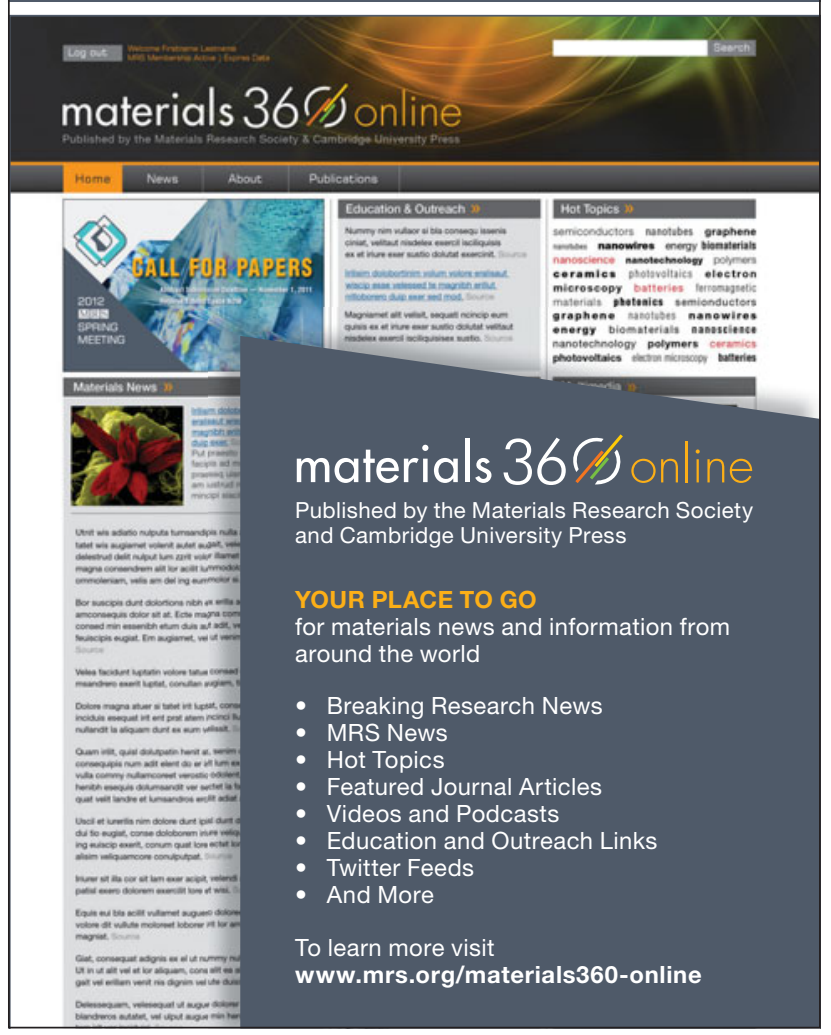

material entering the revert and recover streams will be beneficial in reducing the loss of scarce elements. In turn, reducing the loss of elements that are required to meet societal market demands will allow companies to meet their business goals while sustaining the development of future engine advances.

\section{References}

1. First International Congress on Sustainability Science and Engineering, Cincinnati, OH, 9-12 April 2009, http://www.aiche.org//FS/Conferences/ ICOSSE09.aspx (accessed January 2012).

2. M.J. Magyar, in 2004 Minerals Yearbook (U.S. Geological Survey, Reston, VA, 2004).

3. Minerals, Critical Minerals, and the U.S. Economy (National Academies Press, Washington, DC, 2008).

4. Critical Materials Strategy (U.S. Department of Energy, Washington, DC, 2010). 5. T.E. Graedel, R. Barr, C. Chandler, T. Chase, J. Choi, L. Christofferson,

E. Friedlander, C. Henly, C. Jun, N.T. Nassar, D. Schechner, S. Warren, M.-y. Yang,

C. Zhu, Environ. Sci. Technol. 46, 1063 (2012).

6. R. Jaffe, J. Price, Energy Critical Elements: Securing Materials for Emerging Technologies (American Physical Society, Washington, DC, 2011)

7. S.J. Duclos, J.P. Otto, D.G. Konitzer, Mech. Eng. 132 (9), 36 (2010).

8. P.J. Fink, J.L. Miller, D.G. Konitzer, JOM 62 (1), 55 (2010).

9. "Re - Rhenium" (Minor Metals Trade Association, London, UK, 2008), www.mmta.co.uk/metals/Re/ (accessed January 2012).

10. D.E. Polyak, in 2009 Minerals Yearbook (U.S. Geological Survey, Reston, VA, 2011).

11. S. Sikkenga, INCAST Mag. 10 (May 1998).

12. D. Abbott, paper presented at the International Conference on Additive Manufacturing, Leicestershire, UK, 12-13 July 2011.

13. "Print me a Stradivarius: How a new manufacturing technology will change the world," The Economist (10 February 2011).

14. "EADS, GKN Aerospace Launch Additive Layer Manufacturing Collaboration" (EADS, Munich, Germany, 2011), www.eads.com/eads/int/en/our-innovation/latestnews/EADS--GKN-AEROSPACE-LAUNCH-ADDITIVE-LAYER-MANUFACTURINGCOLLABORATION-.html (accessed January 2012).

\section{J A N I S}

\section{Probe Stations}

Cryogenic Wafer

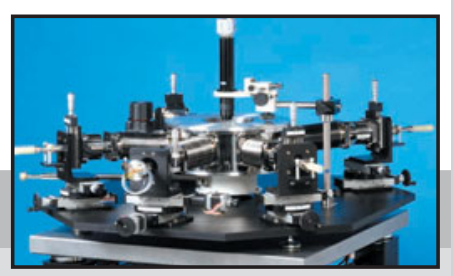

- Applications include nano science, materials and spintronics

- $3.2 \mathrm{~K}-675 \mathrm{~K}$; high vacuum or UHV

Up to 8 probes, DC to $67 \mathrm{GHz}$, plus fiber optics

Zoom optics with camera and monitor

- Cooling options: liquid helium, liquid nitrogen or cryogen free

- Horizontal, vertical or vector magnetic field options are available

\section{Contact us today:}

sales@janis.com +1978 657-8750

www.janis.com/Probestations.aspx

www.facebook.com/JanisResearch 


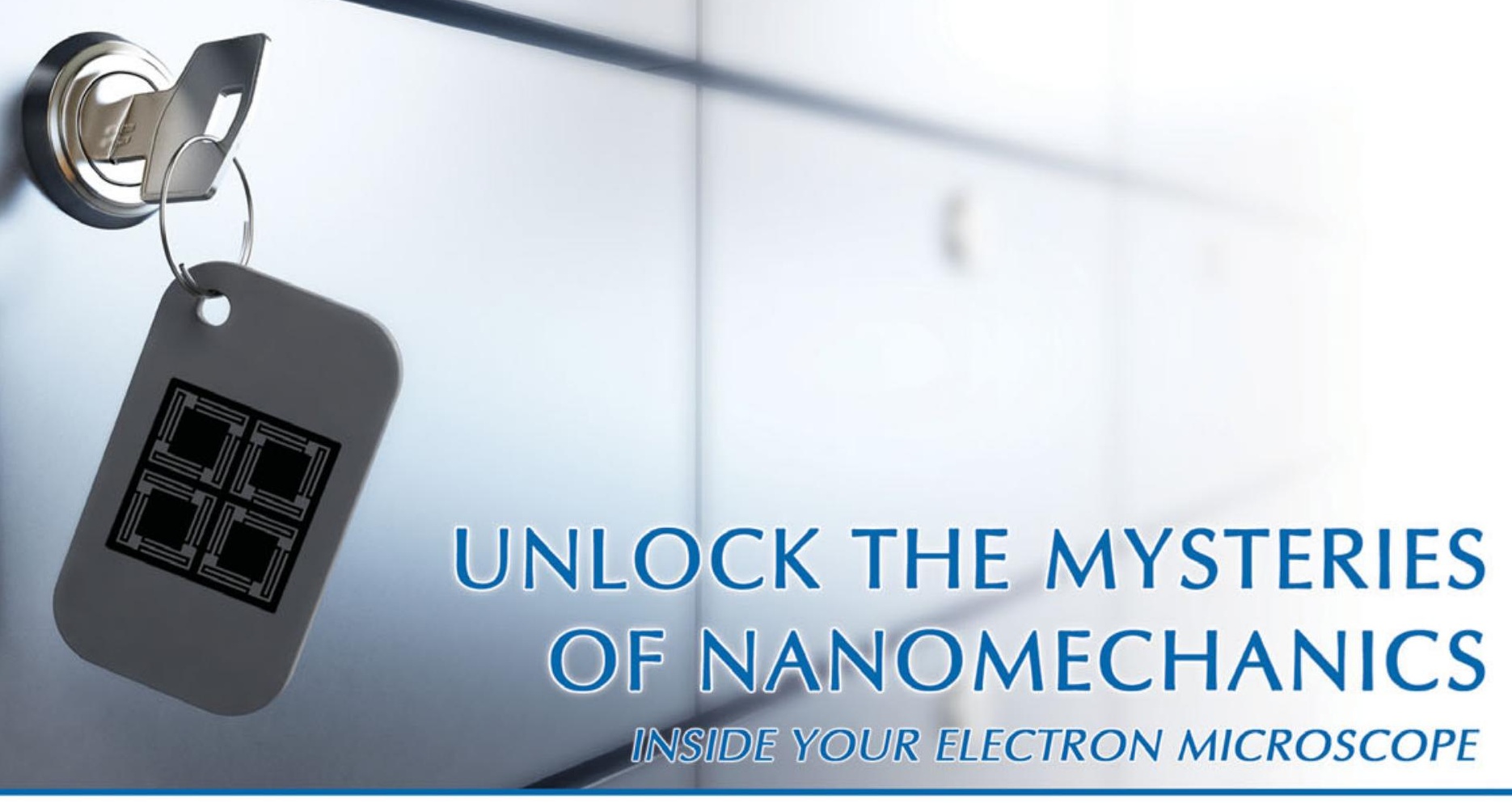

IN-SITU NANOMECHANICAL TESTING \& HYBRID TECHNIQUES
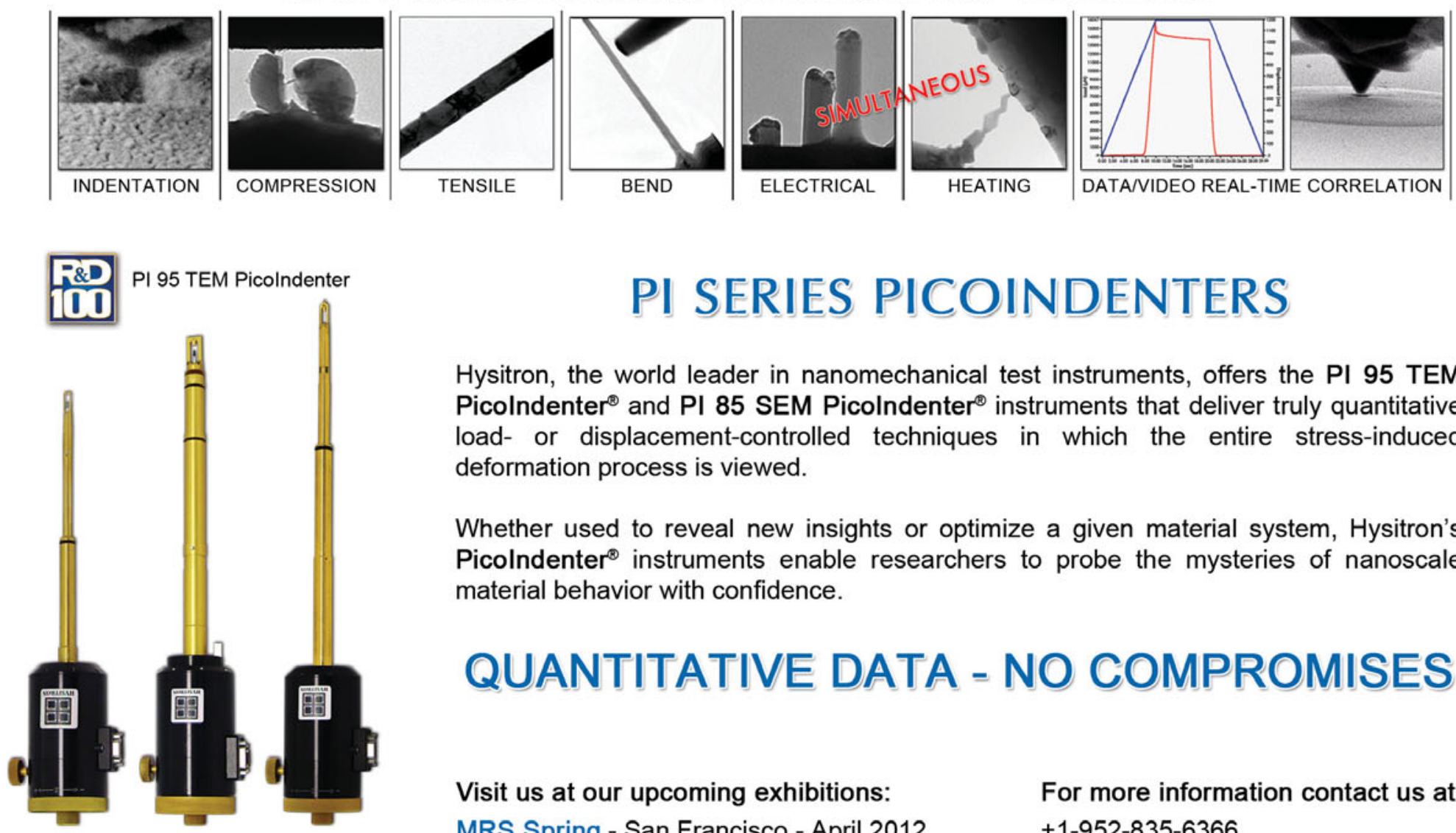

Visit us at our upcoming exhibitions:

MRS Spring - San Francisco - April 2012

Booth 412 \& 515

JSM - Tsukuba, Japan - May 2012
For more information contact us at: +1-952-835-6366

picoindenter@hysitron.com

www.hysitron.com
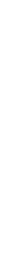


\title{
Sustainable development and physical infrastructure materials
}

\author{
Robert Heard, Chris Hendrickson, and Francis C. McMichael
}

Physical infrastructure, including buildings, roads, pipelines, bridges, power lines, communications networks, canals, and waterways, make up a substantial fraction of worldwide material usage and flows. Consequently, the overall mass of materials and the associated environmental impacts must be addressed to achieve sustainable development of infrastructure. This article surveys the magnitude of material use for infrastructure, including trends in the use per person, environmental impacts of the production and use of infrastructure materials, variations in the longevity of physical infrastructure, and changes in the recycling of infrastructure materials.

\section{Introduction}

Physical infrastructure provides the foundation for human society and economic activity and represents the greatest use of raw and processed materials by weight. This article discusses some of the largest infrastructure applications of materials, such as buildings and transportation, and the trends in material use for current and emerging applications. These topics have profound implications for sustainable development. In addition to the sheer mass of material resources required, infrastructure construction and operation require vast energy inputs and generate substantial flows of wastes and pollution. To plot a more sustainable course for infrastructure, society must become more diligent in the selection and use of materials. This includes considering the lifetimes of structures with the goal of minimizing the embodied energy as amortized over their time in use, so that the best long-term solution is achieved through a combination of reduced energy requirements and avoided pollution and waste.

Concrete, sand, and other natural minerals make up the greatest tonnage for infrastructure applications. Next are metals, primarily steel, but increasingly aluminum for some weightsensitive applications. The third most widely used material grouping is biomass. These materials, primarily wood, had declined from their original dominance of infrastructure, but are now becoming increasingly interesting as renewable building materials. The next three sections of this article describe the magnitudes and trends in use of these three material classifications. The article then considers the environmental impacts of infrastructure material production and use and discusses various factors that affect this impact, namely, the longevity of infrastructure, the recycling of construction materials, and the use of waste streams as a source of materials for infrastructure.

\section{Natural minerals used for physical infrastructure}

Even though physical infrastructure is a worldwide social need, data on materials used in infrastructure are often inconsistent, incomplete, and uncertain. ${ }^{1}$ Nevertheless, international efforts have been made to compile consistent data on overall material flows within each country, from which reliable infrastructurerelated data can be extracted. Figure 1a shows the magnitudes of construction minerals extracted worldwide for the period 1980-2007. ${ }^{2}$ Construction minerals include asphalt, clay (for bricks), rock (for concrete and structures), limestone, sand, slate, and gravel. ${ }^{3}$ Extraction has been steadily increasing over time as worldwide population has grown and economies have made additional infrastructure investments. By 2007, total worldwide extraction was about 20 billion tonnes per year.

From a material-flow standpoint, the increase in extraction is particularly notable for Asia, which has extracted the greatest 

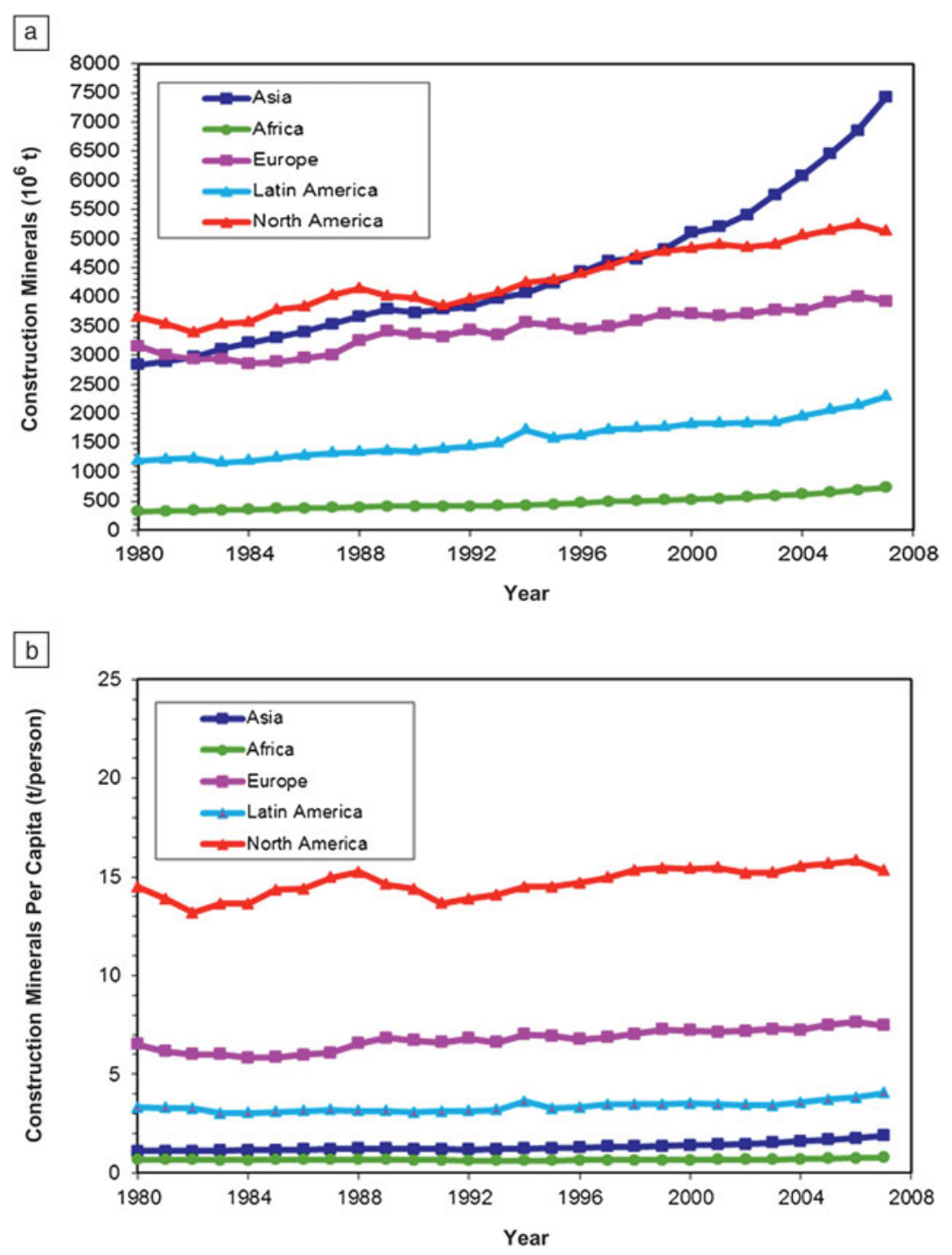

Figure 1. Annual extraction of construction minerals for five global regions, 1980-2007: (a) total and (b) per capita. Authors' summation of data from Reference 2.

North America stands out for using the largest amounts of construction minerals, reflecting its higher level of development and economic activity. This would suggest that, of the three factors influencing the magnitude of material used for construction, affluence of the population is the strongest contributing factor. Note that, for most regions, the use of construction minerals per person has been relatively constant over the time period represented in the figure.

\section{Metals used for physical infrastructure}

Although construction minerals represent the largest portion of materials used for physical infrastructure, metals are another widely used class. Metallic construction materials primarily consist of steel for buildings and reinforcement for concrete. In 2009, the total global "apparent" steel use (excluding changes in stock levels) was just over 1.4 billion tonnes, ${ }^{5}$ and of this amount, more than 500 million tonnes was likely consumed by the construction industry. ${ }^{6}$ Although this seems like a large amount, note that it is dwarfed by the 20-billion-tonne flow of construction minerals, as shown in Figure 2. Also note that, for both steel and construction minerals, significant fractions are recycled from past uses rather than being newly extracted. Whereas recycled metals are included as a separate category in Figure 2, recycled construction minerals are not; thus, even the large flow of extracted minerals (crushed stone, sand, and gravel) shown in Figure 2 underestimates their total use for physical infrastructure.

Whereas metals offer advantages as construction materials by virtue of their improved strength and mechanical performance, they suffer in terms of sustainability from high embod-

amount each year since 2000. The accelerating extraction of raw materials in this region could result from increases in the number of local construction projects and perhaps in exported construction goods. Over the same time period, extraction in Europe and North America rose more slowly, matching upturns and downturns in their economies, whereas other regions of the world showed steady increases.

The implication of these trends is that material flows are primarily related to economic growth, which depends in turn on population growth, affluence, and degree of technological development, although affluence and development overlap to some extent. These dependencies are reflected in the accepted IPAT model, wherein the impact on sustainability (I) is expressed as a product of population (P), affluence (A), and technology (T). ${ }^{4}$

To compensate for population differences, Figure $1 \mathrm{~b}$ shows the same data as Figure 1a, expressed on a per capita basis. ied energies needed for extraction and refinement and often have limited lifetimes as a result of environmental degradation. On the other hand, once extracted, metals perform at a high strength-to-weight ratio, meaning that, compared to other materials, equal performance can be obtained at reduced crosssectional area (or mass) or improved performance can be expected from equivalent structures. Also, being malleable, metals allow for shape changes in beams, columns, and ties that can be used to further reduce the mass of material required for a desired performance. Perhaps the greatest sustainability advantage of metals, however, lies with the simplicity of recycling them, as discussed in more detail later in this article.

\section{Biomass used for physical infrastructure}

Another trend apparent in Figure 2 is the increasing use of agricultural and forest products. For the most part, this increase 


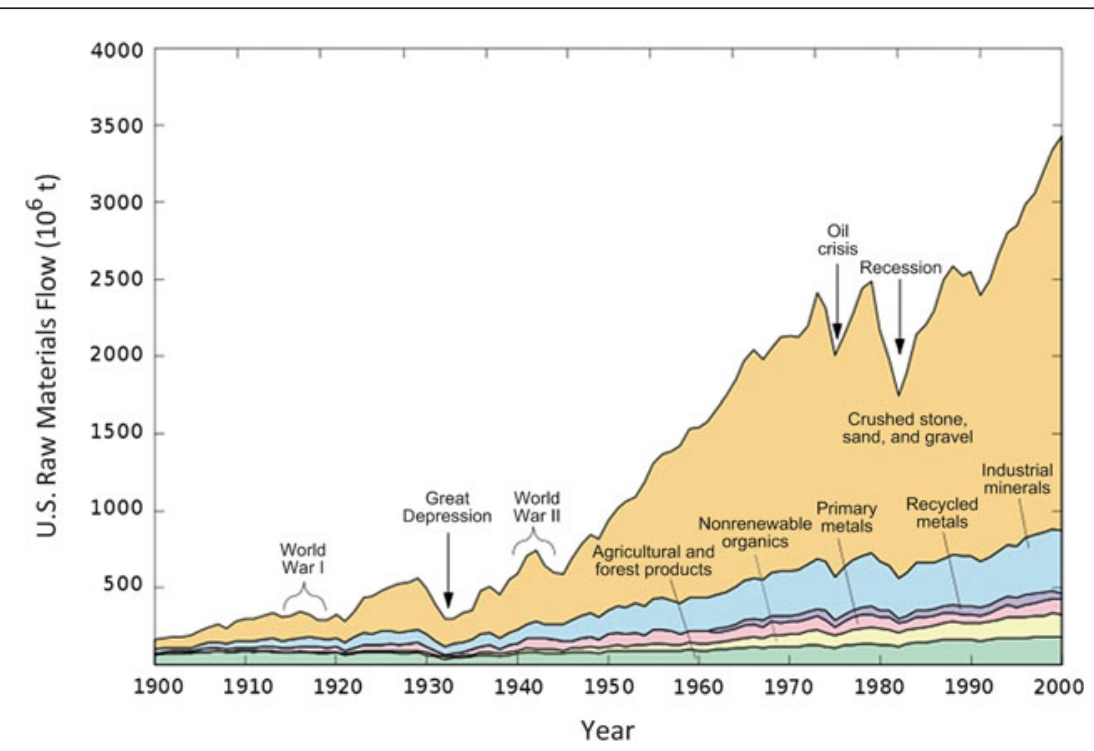

Figure 2. U.S. flow of raw materials by weight, $1900-1998 .{ }^{7}$ Recycled construction minerals (crushed stone, sand, and gravel) are not included.

in biomass is represented by wood products. Whereas wood historically was a primary building material, it has not exhibited the significant growth trend notable for construction minerals and metals. This is not surprising, given the limitations of the resource and the mechanical challenges of modern infrastructure. The more recent growth in wood might reflect an interest in replacing conventional construction materials with biomass materials as a means of enhancing sustainability. ${ }^{8} \mathrm{~A}$ recent report by the Consortium for Research on Renewable Industrial Materials (CORRIM) found that the inherent low embodied energy, carbon sequestration ability, and renewability of wood make it the material of choice for construction in many locations. For example, wood framing was found to use $17 \%$ less energy than steel for a house in Minnesota and $16 \%$ less energy than concrete for a house in Atlanta, GA, and to reduce the overall global warming potential in both cases. ${ }^{9}$

\begin{tabular}{|c|c|c|c|c|}
\hline $\begin{array}{l}\text { Construction } \\
\text { sector }\end{array}$ & $\begin{array}{l}2002 \text { output } \\
\text { (billion \$US) }\end{array}$ & $\begin{array}{l}\text { Energy input } \\
\text { (MJ/US\$) }\end{array}$ & $\begin{array}{l}\text { Water input } \\
\text { (I/US\$) }\end{array}$ & $\begin{array}{l}\text { Greenhouse-gas emissions } \\
\left(\mathrm{kg} \text { of } \mathrm{CO}_{2} \mathrm{e} / \mathrm{US} \$\right)\end{array}$ \\
\hline $\begin{array}{l}\text { Commercial and } \\
\text { health care } \\
\text { structures }\end{array}$ & 129 & 8 & 18.9 & 0.6 \\
\hline $\begin{array}{l}\text { Permanent } \\
\text { residential } \\
\text { structures }\end{array}$ & 305 & 9 & 30.2 & 0.7 \\
\hline $\begin{array}{l}\text { Manufacturing } \\
\text { structures }\end{array}$ & 23 & 6 & 15.1 & 0.4 \\
\hline $\begin{array}{l}\text { Heavy } \\
\text { constructiona }\end{array}$ & 292 & 8 & 22.7 & 0.6 \\
\hline
\end{tabular}

a Heavy construction consists primarily of construction for large-scale infrastructure, such as bridges, manufacturing facilities, and large civil construction projects.
Indirect applications of biomass in infrastructure are also possible. Specifically, biomass cellulose structures offer renewable sources for polymeric precursors of lightweight plastics and for fiber structures used in composite materials. Although such applications are still in their infancy, organically derived polymers and fillers of natural materials such as bamboo and hemp fibers could be viable substitutes for petrochemically derived polymers and composites used in certain construction applications.

\section{Environmental impacts of infrastructure material production and use}

As expected for a large, material-intensive industry, construction of physical infrastructure has numerous environmental impacts. ${ }^{10,11}$ As an example, Table I lists energy and water inputs and greenhouse-gas (GHG) emissions for several U.S. construction sectors. These impacts were estimated for the entire supply chain of construction production, so they include emissions for materials production, as well as emissions from construction equipment. The overall environmental impact of a sector can be assessed by multiplying the sector output by the emissions or resource use per dollar of output.

The construction sectors listed in Table I all have similar overall energy and water requirements and GHG emissions per dollar of output. However, when disaggregated, different activities within the construction industry have differing resource requirements and pollution emissions because of their different construction inputs. Suppliers of materials to the construction industry, such as cement manufacturers and iron and steel mills, have significantly higher energy and water requirements and GHG emissions per dollar of output than biomass providers or the construction industry in general, as reported in Table II. Although much of this greater impact can be associated with the processing required for these construction materials, for metals, some can be attributed to the global sourcing and long-distance transport of these commodities. For biomass (wood), supply is generally more local, and wood construction products generally require minimal shaping.

To reduce the environmental impact of heavy-construction activities, there is a need for improved supply-chain management. In Table III, the $\mathrm{CO}_{2}$ contributions are given, first for the total of all U.S. sectors and then for the 12 highest-contributing sectors. Direct emissions originating on-site from heavy construction activities have the largest individual contribution (largely fuel combustion to power equipment); however, the total of all contributions from the supply-chain sectors actually exceeds this value. Of these, it 
Table II. Energy and water requirements and greenhouse-gas emissions for seven common material inputs to infrastructure. ${ }^{13}$

\begin{tabular}{|c|c|c|c|}
\hline Material & $\begin{array}{l}\text { Energy } \\
\text { required } \\
\text { (MJ/US\$) }\end{array}$ & $\begin{array}{l}\text { Water } \\
\text { required } \\
\text { (I/US\$) }\end{array}$ & $\begin{array}{l}\text { Greenhouse-gas } \\
\text { emissions } \\
\text { (t of } \mathrm{CO}_{2} \mathrm{e} / \mathrm{US} \$ \text { ) }\end{array}$ \\
\hline Aluminum & 49 & 158.8 & 3340 \\
\hline Brick & 31 & 52.9 & 2010 \\
\hline Iron and steel & 43 & 79.4 & 3660 \\
\hline Paint & 17 & 529.2 & 1070 \\
\hline Plastic pipe & 24 & 71.8 & 1420 \\
\hline $\begin{array}{r}\text { Ready-mix } \\
\text { concrete }\end{array}$ & 24 & 68.0 & 2740 \\
\hline Wood & 14 & 41.6 & 522 \\
\hline
\end{tabular}

can be seen that cement, steel, and lime products alone contribute nearly one-half of the total emissions (in $\mathrm{CO}_{2}$ equivalents) of the supply-chain contributions.

To help manage supply-chain impacts, environmental lifecycle assessment is increasingly being applied to construction materials for physical infrastructure. Examples include buildings, ${ }^{14,15}$ transportation infrastructure, ${ }^{16}$ and cement. ${ }^{17,18}$ In addition to the classic difficulties with life-cycle assessments, such as data uncertainty and ambiguity in choosing what to include within the boundaries of the analysis, these studies have been hampered by the heterogeneity of facility designs and construction practices, as well as the inherent variability in construction materials themselves. For example, concrete can have a variety of different material compositions.

Several strategies to improve the sustainability of physical infrastructure emerge from this literature on life-cycle assessment:

- substituting materials with lower environmental impacts, such as concrete for steel in bridges; ${ }^{19}$

- making construction processes more efficient, such as using energy-efficient construction equipment; ${ }^{20}$

- reducing the size of facilities, either in space requirements or in materials requirements for structures; and

- making facilities more energy-efficient, with the requirement that additional capital and energy expenditures for efficiency result in overall life-cycle savings. ${ }^{21}$

\section{Design and longevity of infrastructure}

Thus far, this article has considered the use of materials for physical infrastructure and the associated environmental impacts on an annual basis. However, infrastructure is usually intended to be in use for many years. Indeed, one strategy to reduce infrastructure material use for sustainability is to keep facilities in service longer. Some well-designed and -maintained infrastructure can last for decades, whereas other infrastructure systems rapidly become obsolete, as a result of design decisions; maintenance practices; or changes in circumstances, regulations, or technology. A typical expected lifetime range for infrastructure systems such as roads and bridges is 20-60 years, ${ }^{22}$ but longer lifetimes are certainly possible.

\begin{tabular}{|c|c|c|c|c|c|c|}
\hline \multirow[t]{2}{*}{ Sector } & \multicolumn{6}{|c|}{ Contributions to greenhouse-gas emissions ( $\mathrm{t}$ of $\left.\mathrm{CO}_{2} \mathrm{e}\right)$} \\
\hline & Total & From fossil fuels & From processes & From methane & From $\mathrm{N}_{2} \mathrm{O}$ & $\begin{array}{c}\text { From halogenated } \\
\text { gases }\end{array}$ \\
\hline Total for all U.S. sectors & 612 & 488 & 71.2 & 38.3 & 9.68 & 4.83 \\
\hline $\begin{array}{l}\text { Heavy construction direct } \\
\text { emissions }\end{array}$ & 200 & 200 & 0 & 0 & 0 & 0 \\
\hline Power generation and supply & 110 & 109 & 0 & 0 & 1 & 1 \\
\hline Cement manufacturing & 60 & 25 & 35 & 0 & 0 & 0 \\
\hline Oil and gas extraction & 38 & 11 & 7 & 21 & 0 & 0 \\
\hline Iron and steel mills & 33 & 13 & 21 & 0 & 0 & 0 \\
\hline Petroleum refineries & 29 & 29 & 0 & 0 & 0 & 0 \\
\hline Truck transportation & 19 & 19 & 0 & 0 & 0 & 0 \\
\hline Fertilizer manufacturing & 9 & 2 & 3 & 0 & 4 & 0 \\
\hline $\begin{array}{l}\text { Lime and gypsum product } \\
\text { manufacturing }\end{array}$ & 7 & 2 & 4 & 0 & 0 & 0 \\
\hline Pipeline transportation & 7 & 3 & 0 & 4 & 0 & 0 \\
\hline $\begin{array}{l}\text { Waste management and } \\
\text { remediation services }\end{array}$ & 6 & 0 & 0 & 6 & 0 & 0 \\
\hline Coal mining & 5 & 1 & 0 & 5 & 0 & 0 \\
\hline
\end{tabular}


The design and selection of materials for a particular structure have a significant impact on the quantity of materials used. For some infrastructure applications, steel, steel and concrete, and wood all compete for application. When multiple materials satisfy the engineering constraints, the material selected usually has the lowest cost (likely corresponding to lowest weight or volume). Unfortunately, this option is not always consistent with lower environmental impacts. Other times, when engineering constraints are severe, the selection process might require special consideration regarding material performance. In these cases, unique shape and material solutions can be used to lower the overall material usage while still providing the required performance.

For example, domed structures were first constructed from grass and clay; then wood; and eventually brick, metals, and structural concrete. Each of these innovations allowed for larger dome radii and provided structural improvements (e.g., windows) but came at the cost of increased weight and material usage. In today's large dome structures, new materials and improved designs allow for a wide array of options, including metal frames covered by fabrics and synthetics. Modern domes are essentially multiple structures or composite structures built with relatively lightweight supports and coverings. These structures and materials provide unique solutions for infrastructural designs, and a great deal of material savings and improvements in longevity can be achieved by appropriate combinations of shape and materials.

In addition to considerations given to external design and material selection, the material itself can be "designed" or engineered for performance. In fact, a widely used material for modern concrete structures is a fiber-reinforced composite of concrete and steel reinforcement bar. These composite structures take advantage of gains in performance achieved through interactions between the matrix (concrete) and the embedded fibers (steel). Whereas concrete has excellent compression properties, addition of steel to the concrete matrix greatly improves its resistance to tensile loads, thus improving its durability. The amount of steel used varies from $1 \%$ to $6 \%$ of the load-carrying cross section, depending on the application.

The combination of steel and concrete is a continuing area of research. Considerable work is currently being done to evaluate steel encased in concrete structures, concrete encased in steel forms (such as tubing or box beams), and concrete filled with steel and/or polymeric fibers. It is presumed that the performance gains achieved will result in improved shape efficiencies and an overall reduction of material required for longer-lasting structures.

\section{Recycling of construction materials}

Reuse of facility components and recycling of infrastructure materials are important strategies for reducing material demands and related environmental impacts. Indeed, of the estimated 155 million tonnes of obsolete materials generated in 2003, approximately $48 \%$ was recovered for reuse. ${ }^{23}$ Some categories of debris have higher recycling rates. For example, reuse of cement concrete and asphalt pavement debris for 1996 in the United States are estimated to be in the range of $50 \%$ for the former and near $80 \%$ for the latter. ${ }^{23}$ Policies increasing landfill costs and higher prices for raw materials would spur more recycling of this type.

Of all materials used in infrastructure, metals have the most recycling programs in place. The result can be seen in Figure 2, with steady or growing use of recycled metals after 1960 coming primarily from the technological changes in steel production. Still, despite the high rates of metal recycling, the flow of recycled metal is less than $10 \%$ of the overall flow of new construction materials. The greatest hurdle to increasing the recycling flow of construction materials is the cost. Construction mineral debris and metals present economical options for recycling depending on form. Davis et al. reported that, in the United Kingdom, an estimated $85 \%$ of structural steel work is recycled ${ }^{22}$ and, in the United States, beams, girders, and other major structural components are recycled at greater than $98 \%$ (approaching their limit for recyclability).

In contrast, composite structures often pose more technical problems owing to the additional work of separating two (or more) materials. For infrastructure materials, the primary concern is with concrete-steel composite material structures, and significant improvements have been made in the recovery of steel components from such structures. There also has been steady growth in recovery of reinforcing steel, as shown in Figure 3. Although this trend is supported by technology changes in the steel industry, it also must reflect increased recycling efforts and increased value in recycled steel.

\section{Waste streams as a raw material source}

Another potential strategy for the construction industry is to utilize waste streams from other industrial products in place of raw materials. For example, the waste streams of fly ash from coal combustion for power generation and slag from iron blast furnaces have been used to replace a portion of the cement binder in concrete. ${ }^{17,25}$ Blast-furnace slag, in particular, is a highly desirable input for concrete providers. Granulated blast-furnace slag can be substituted 1:1 for Portland cement binder and, when used up to $50 \%$, generally leads to a stronger

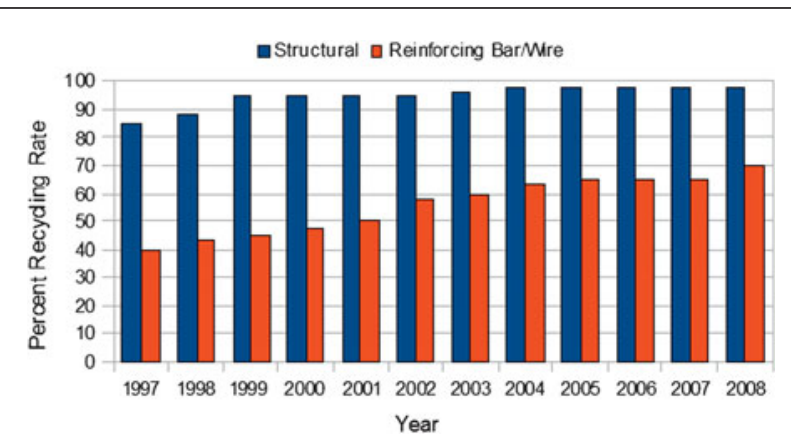

Figure 3. Recycling rates for construction steels in the United States. ${ }^{24}$ 


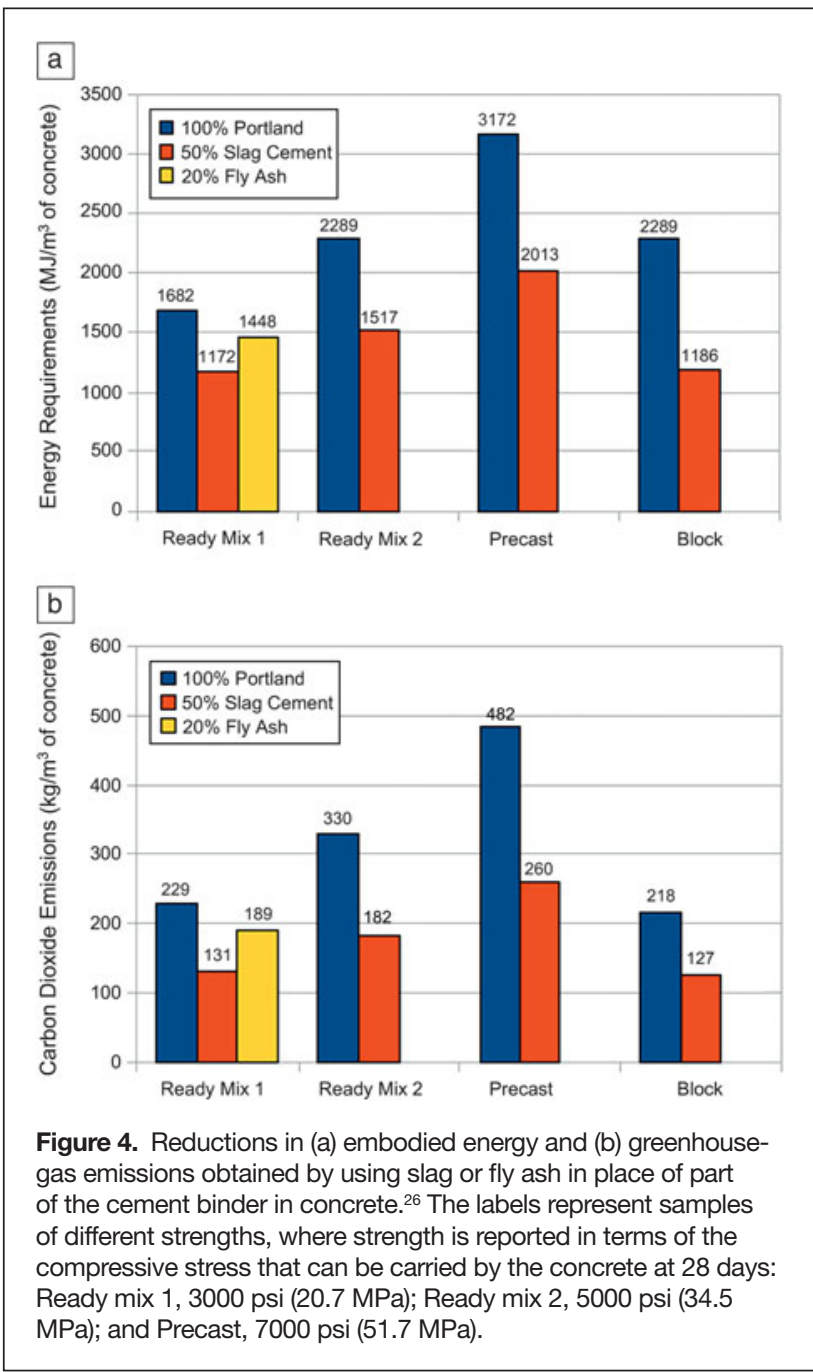

product, although final strength appears to depend on the grade (granulation size) of the slag. Figure 4 shows the potential energy savings and reductions in GHG emissions that can be obtained through reuse of these byproducts as substitute materials in cement products.

It is not yet clear how widely the use of waste streams from other industrial processes could be applied to construction materials. The economic viability of reusing a waste stream clearly depends on the material value and processing costs. Also, legal, supply, quality, and consistency issues must all be resolved to properly leverage the advantages of byproduct reuse. However, employing waste from other processes in infrastructure reduces waste streams, capitalizes on embodied energy, and in many cases provides a superior product, making it highly attractive in efforts to achieve sustainable infrastructure.

\section{Summary}

This article draws attention to the large quantity of materials used for infrastructure construction. Clearly, this sector utilizes the largest portion of physical raw material flow, and the trend for increasing material use is growing, especially in developing economies. For the construction and material supply communities to reach a more sustainable future, strategies should include greater efforts to reduce apparent consumption of extracted raw materials and incorporate more recycled or byproduct materials. Design and construction should also strive for longer life and more efficient use and support recycling efforts, employing material selection methodologies that support all of these goals.

\section{Acknowledgments}

This article is based in part on work supported by the National Science Foundation under Grants CMMI-1030708 and CTS0628084. Any opinions, findings, and conclusions or recommendations expressed in this material are those of the author(s) and do not necessarily reflect the views of the National Science Foundation.

\section{References}

1. P.H. Brunner, H. Rechberger, Practical Handbook of Material Flow Analysis (CRC Press, Boca Raton, FL, 2003).

2. The Online Portal for Materials Flow Data (Sustainable European Research Institute, Vienna, Austria, 2011), www.materialflows.net (accessed 7 February 2011).

3. Technical Report on the compilation of the material flow database for www. materialflows.net(SustainableEuropeanResearch Institute,Vienna,Austria,2010). www.materialflows/mfa/index2.php (accessed 7 February 2011).

4. T.E. Graedel, B.R. Allenby, Industrial Ecology and Sustainable Engineering (Prentice Hall, Upper Saddle River, NJ, 2010).

5. Steel Statistical Yearbook 2009 (World Steel Association, Brussels, Belgium, 2010).

6. Trends in the Global Steel Market. DSTI/SU/SC(2009)4, 66th Steel Committee Meeting, Paris, 8-9 June 2009 (Organisation for Economic Co-operation and Development, Paris, France, 2009).

7. L.A. Wagner, Materials in the Economy-Material Flows, Scarcity, and the Environment (U.S. Geological Survey Circular 1221, U.S. Geological Survey, Denver, CO, 2002).

8. R. Anex, J. Ind. Ecol. 7 (3), 1 (2003).

9. Phase 2 Research Report-Environmental-performance measures for renewable building materials with alternatives for improved performance (Consortium for Research on Renewable Industrial Materials, Seattle, WA, 2010).

10. A. Horvath, Annu. Rev. Environ. Resour. 29, 181 (2004).

11. C. Hendrickson, A. Horvath, J. Constr. Eng. Manage. 126 (1), 38 (2000).

12. Benchmark Input-Output Data (Bureau of Economic Analysis, Washington, DC, 2011), www.bea.gov/industry/io_benchmark.htm (accessed 21 February 2011).

13. Economic Input-Output Life Cycle Assessment (EIO-LCA) (Green Design Institute, Carnegie Mellon University, Pittsburgh, PA, 2011), www.eiolca.net (accessed 21 February, 2011).

14. P. Baccini, P.H. Brunner, Metabolism of the Anthroposphere (SpringerVerlag, Berlin, 1991).

15. S. Junnila, A. Horvath, A. Guggemos, J. Infrastruct. Syst. 12 (1), 10 (2006).

16. M. Chester, A. Horvath, S. Madanat, Atmos. Environ. 4 (8), 1071, (2010).

17. D. Huntzinger, T. Eatmon, J. Cleaner Prod. 17 (7), 668 (2009).

18. C.V. Nielsen, M. Glavind, J. Adv. Concr. Technol. 5 (1), 3 (2007).

19. A. Horvath, C. Hendrickson, J. Infrastruct. Syst. 4, 111 (1998).

20. A.L. Sharrard, H.S. Matthews, M. Roth, J. Constr. Eng. Manage. 133, 846 (2007).

21. J. Davis, R. Geyer, J. Ley, J. He, R. Clift, A. Kwan, M. Sansom, T. Jackson, Resour. Conserv. Recycl. 51 (1), 118 (2007).

22. Real Prospects for Energy Efficiency in the United States (National Academy of Sciences Press, Washington, DC, 2010).

23. Estimating 2003 Building-Related Construction and Demolition Materials Amounts (Report EPA530-R-09-002, U.S. Environmental Protection Agency, Washington, DC, 2009).

24. Steel Recycling Rates at a Glance (Steel Recycling Institute, Pittsburgh, PA, 2008).

25. J. Bijen, Constr. Build. Mater. 10 (5), 309 (1996)

26. Slag Cement and the Environment (SCIC No. 22, Slag Cement Association, Glenview, IL, 2003). 


\title{
Set in stone? A perspective on the concrete sustainability challenge
}

\author{
Krystyn Van Vliet, Roland Pellenq, Markus J. Buehler, Jeffrey C. \\ Grossman, Hamlin Jennings, Franz-Josef Ulm, and Sidney Yip
}

\begin{abstract}
As the most abundant engineered material on Earth, concrete is essential to the physical infrastructure of all modern societies. There are no known materials that can replace concrete in terms of cost and availability. There are, however, environmental concerns, including the significant $\mathrm{CO}_{2}$ emissions associated with cement production, which create new incentives for university-industry collaboration to address concrete sustainability. Herein, we examine one aspect of this challenge-the translation of scientific understanding at the microscale into industrial innovation at the macroscale-by seeking improvements in cement-paste processing, performance, and sustainability through control of the mechanisms that govern microstructure development. Specifically, we consider modeling, simulation, and experimental advances in fracture, dissolution, precipitation, and hydration of cement paste precursors, as well as properties of the hardened cement paste within concrete. The aim of such studies is to optimize the chemical reactivity, mechanical performance, and other physical properties of cement paste to enable more sustainable processing routes for this ubiquitous material.
\end{abstract}

\section{Sustainability challenges and opportunities}

With more than one-half of the world's growing population (now $\sim 7$ billion) living in cities, a sustainable physical infrastructure is central to improving and maintaining a high quality of life. Concrete is an important component of this infrastructure, with a current annual per capita consumption of about 2.8 tonnes ( $\mathrm{t}$ ) (Figure 1). Concrete powers a worldwide US $\$ 35$ billion industry, employing more than two million workers in the United States alone. This high demand is driven by a number of remarkable properties of this material (Table I), with which a structural composite with complex geometry and high strength can be created on demand by mixing water with cement powder and stone. This "liquid stone" processing capacity enables rapid construction and repair of geometrically complex pavements, bridges, buildings, and waterways. However, such high usage carries a price associated with Earth's finite resources and limited tolerance for industrial byproducts. Sustainable use of concrete requires that its function and costs (in economic, environmental, energy, and social terms) be evaluated within the context of its end use and that new and highly optimized materials be developed (Table I). Life-cycle assessment shows quantitatively that the greatest environmental burden from structures such as buildings occurs during the use stage, ${ }^{5}$ which presents new priorities for the exploration of property and processing optimization.

As illustrated in Figure 2, concrete is manufactured locally and directly from readily available limestone and clay, which are mixed without refinement and then heated in a large, rotating kiln (up to $200 \mathrm{~m}$ in length) to temperatures of about $1500^{\circ} \mathrm{C}$. Carbon dioxide is generated from both the combustion to provide heat and the decomposition of limestone $\left(\mathrm{CaCO}_{3}\right)$. A large kiln can produce up to $10,000 \mathrm{t}$ of so-called clinker nodules per day, which are then ground into a fine gray powder, with addition of gypsum. The resulting so-called portland cement is transformed into familiar concrete by the addition of sand and gravel and, most importantly, water. Whereas sand and gravel are largely inert fillers, a chemical transformation occurs that turns the cement-water mixture from a liquid suspension into a solid binding matrix called cement paste. One indication of the 


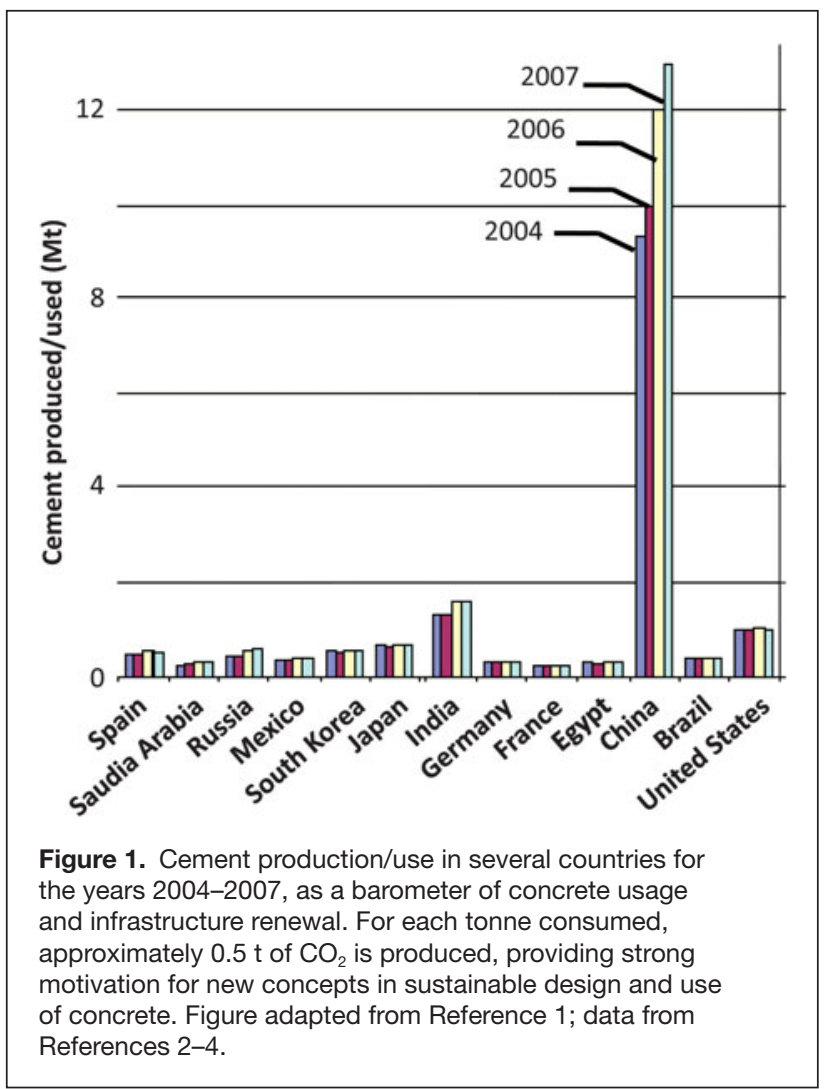

complexity of the reaction is the long induction period, lasting for several hours after mixing, giving time for transport and placement. This is followed by relatively rapid hardening into a load-bearing solid.

For decades, it has been broadly accepted that the scale of relevance for several properties of cement-based materials is the atomic scale, although realization of the structure and properties at this scale has been achieved only recently. This

\begin{tabular}{|c|c|c|}
\hline Property & Range & Goal to meet sustainability challenge \\
\hline Compressive strength & 20-200 MPa & $\begin{array}{l}\text { Control target strength to exact requirements to } \\
\text { avoid overdesign and excessive use of raw } \\
\text { materials }\end{array}$ \\
\hline Flexural strength & $4-16 \mathrm{MPa}$ & Increase tensile strength and reduce reinforcement \\
\hline Shrinkage & $300-800 \mu \mathrm{m} / \mathrm{m}$ & $\begin{array}{l}\text { Reduce shrinkage, particularly for slabs and } \\
\text { pavements }\end{array}$ \\
\hline Creep & $2-8 \mu \mathrm{m} /(\mathrm{m} \cdot \mathrm{kPa})$ & Reduce creep in reinforced concrete \\
\hline Density & $2500 \mathrm{~kg} / \mathrm{m}^{3}$ & $\begin{array}{l}\text { Predict and optimize magnitude directly from mix } \\
\text { design }\end{array}$ \\
\hline Embodied $\mathrm{CO}_{2}$ & $\begin{array}{l}150-300 \mathrm{~kg} \text { of } \mathrm{CO}_{2} / \mathrm{m}^{3} \\
\text { of concrete }\end{array}$ & $\begin{array}{l}\text { Reduce through changes in processing and/or } \\
\text { composition }\end{array}$ \\
\hline Embodied energy & $0.95 \mathrm{MJ} / \mathrm{kg}$ & Reduce \\
\hline Cost & US\$110/t & Maintain low \\
\hline
\end{tabular}

a Data acquired from broad literature and Portland Cement Association. article discusses the opportunities and challenges inherent in predicting key synthesis and property benchmarks of cement paste, with a specific focus on connecting atomistic simulations to performance. Ultimately, the goal is to identify opportunities for improving the sustainability of our built infrastructure. Such potential can be illustrated by considering how changes in the composition of precursor materials affect energy consumption; how simulations can predict rates of setting, which, in turn, affect construction speed and thus pollution; and how the improved physical and mechanical properties of cement paste can reduce materials and energy consumption in new infrastructural designs.

We first outline the key steps in cement and concrete production, to illustrate opportunities for innovation at the microscale to lead to improvements at the macroscale. Next, we discuss specific examples wherein computational modeling and simulation have been related to experiments in a way that both offers new routes of inquiry and exposes the current challenges in relating molecular mechanisms to practical performance and sustainability.

\section{Innovation in cement and concrete science}

Traditionally, advances in cement and concrete performance have been made through iterative experiments focused on macroscale behavior in physical structures that have lifetimes of several decades. Such approaches can be regarded as "top-down" in that the engineering of the mechanical properties of the system is governed by the design goals at the macroscale. In contrast, the "bottomup" approach to materials design starts at a smaller scale, where the material is described as an assembly of atoms and molecules arranged in a certain structure, and works up through the mesoscale to the macroscale to achieve improved functionality. In this article, we discuss the latter approach in the context of cement-science innovation, with attention to the challenges and opportunities of bridging the microscale-macroscale gap to address challenges in environmental sustainability and enable new applications.

To relate the basic steps of concrete production to fundamental material processes and sustainability, consider the simplified schematic in Figure 2. The final product for infrastructure is typically concrete, obtained by adding aggregate (e.g., gravel, stone) at the mixing stage. The cohesion within concrete is attributed to the hardened paste, also called the binder phase. It is a noncrystalline compound of calcium silicate hydrate, $\mathrm{CaO}-\mathrm{SiO}_{2}-\mathrm{H}_{2} \mathrm{O}$ (C-S-H), where the hyphens indicate a variable, nonstoichiometric composition. From the standpoint of materials science innovation, there exist 


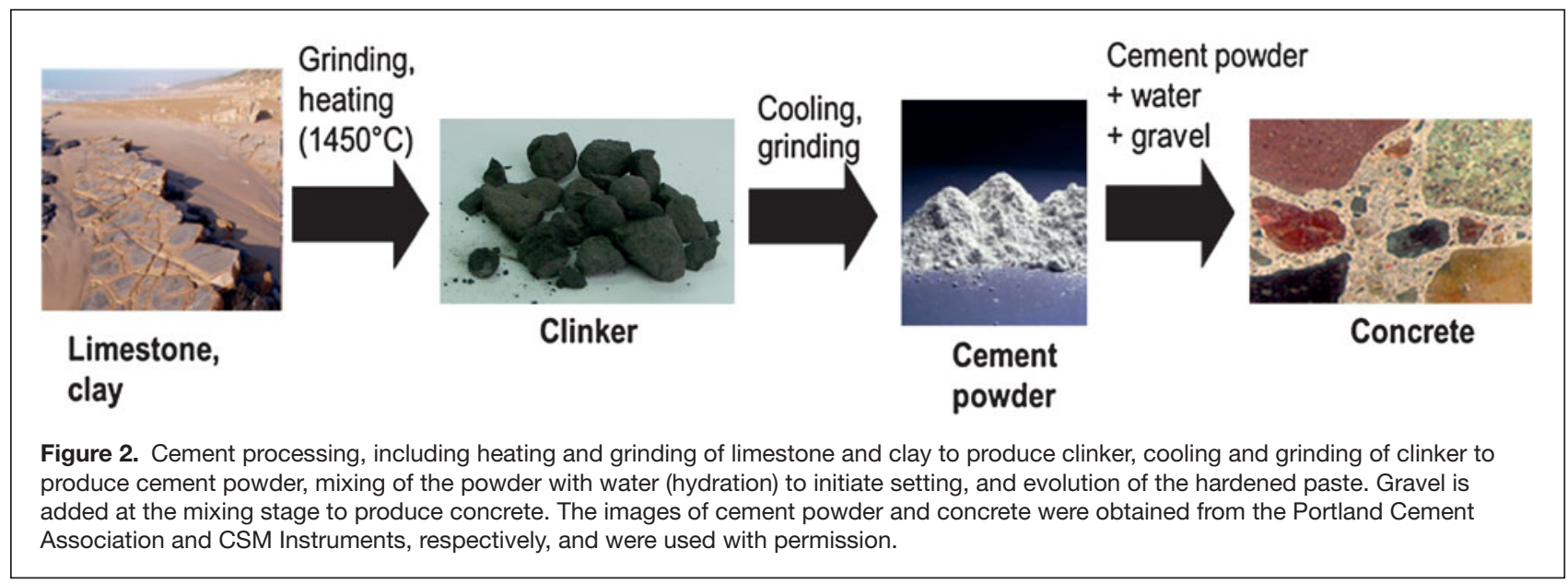

several opportunities for fundamental studies that can impact concrete sustainability. We illustrate this by (1) considering the clinker grinding process from a fracture-mechanics perspective, (2) modeling clinker dissolution through electronic-structure calculations, (3) studying C-S-H precipitation and cement paste setting through atomistic simulations, and (4) probing the structural and mechanical behavior of the hardened paste.

In materials research, it has been recognized that a multiphysics (or multidisciplinary), multiscale approach can be useful in correlating complex microstructures with macroscopic physical properties. Given the structural, chemical, and mechanical phenomena indicated in Figure 2 and the emerging tools of both modeling and simulation ${ }^{6,7}$ and characterization, ${ }^{7}$ one can identify a number of materials phenomena for the study of mechanisms at the microscale. A selection of the processes relevant to concrete processing (in Figure 2) is shown in Figure 3. What is envisaged is a progression (from left to right) in capability to perform modeling studies at increasingly larger scales. In the microscale domain, individual phenomena such as clinker grinding, clinker dissolution, C-S-H precipitation, and setting can be investigated as standalone problems. This type of research is feasible through materials modeling and simulation. The results of such studies can then be passed to mesoscale simulations, performed using cement hydration codes that are currently being developed. ${ }^{8,9}$ The expectation is that these simulations will give hydration characteristics (heat curves and set times) that also can be obtained in macroscale industrial laboratory tests on specimens of the actual cement paste and concrete that will be poured at a construction site. It is the linking of the micro- to the macroscale-from computational predictions to experiments - that will enable atomic-scale innovations to impact performance relevant to industry and users. This, then, is the goal of mechanism-based concrete sustainability research. It is clear that bridging this gap - from microscale to macroscale and from fundamental research to industrial implementation - is an endeavor critical to the advancement of sustainable concrete, as well as a challenge shared with nearly all materials-enabled applications.

\section{Stages of cement-paste development Clinker grinding and dissolution}

Today's cement is essentially created from a synthetic rock, called clinker, which is a heterogeneous material. ${ }^{10}$ Alite and belite, the two major clinker phases, are solid solutions of calcium silicates, $\mathrm{Ca}_{3} \mathrm{SiO}_{5}$ (denoted $\mathrm{C}_{3} \mathrm{~S}$ ) and $\mathrm{Ca}_{2} \mathrm{SiO}_{4}$ (denoted $\mathrm{C}_{2} \mathrm{~S}$ ), respectively, typically stabilized by a few percent of impurities. (Aluminates and ferrites are the other phases

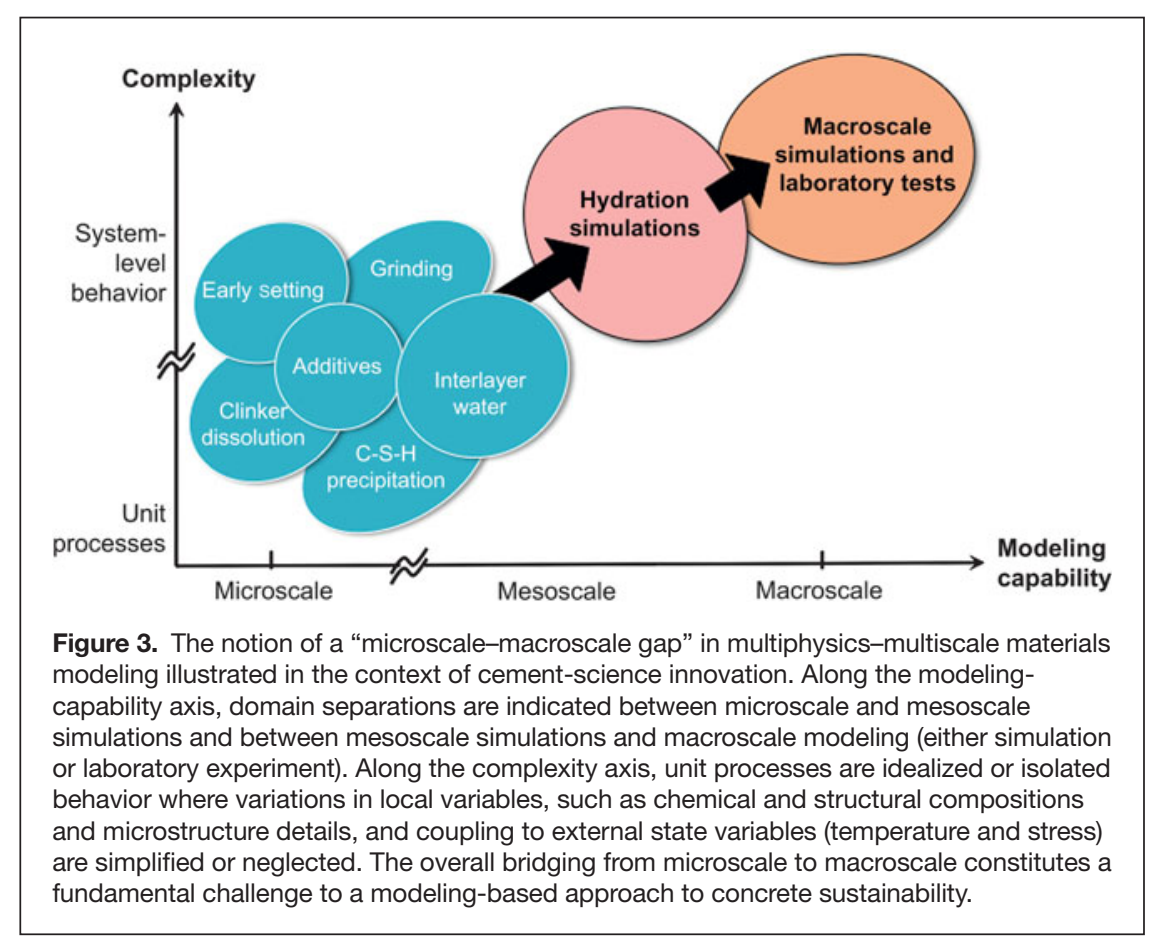


commonly present in industrial clinker.) For all cement clinker compositions, the last manufacturing step includes mechanical grinding. The energy required to grind these nodules into powder can be related to the fundamental fracture properties of clinker, which can be accessed by experiment and simulation. Ulm et al. developed a scratch-based experimental approach to estimate a mixed-mode fracture toughness, $K_{\mathrm{c}}$, from lateral scratch-force-versus-distance measurements (Figure 4a,b) and showed that the $K_{\mathrm{c}}$ value of belite is 2-3 times that of alite, ${ }^{11}$ implying that the grinding energy is 4-9 times greater for belite. This quantification of the microscale fracture toughness of belite (and thus greater mechanical energy and associated $\mathrm{CO}_{2}$ production to fracture it) presents an interesting environmental tradeoff, in that increased use of belite clinker would reduce the associated $\mathrm{CO}_{2}$ burden of the clinker because belite contains less calcium oxide than does alite.

Indeed, researchers have long pursued a modification to the manufacturing process that would allow for a decrease in cement's environmental footprint through the use of belite as the main clinker phase. This motivation is due in part to the lower $\mathrm{CaO}$ composition and in part to the lower temperature necessary to produce belite $\left(\sim 1200^{\circ} \mathrm{C}\right.$, or $\sim 300^{\circ} \mathrm{C}$ less than that required for alite). ${ }^{9}$ Clearly, the reduction in energy required to form belite would provide both economic and environmental benefits. ${ }^{12}$ However, the lower reactivity of belite with water prevents belite-rich cement from fulfilling the required strength development standards (i.e., sufficiently short reaction times and setting/curing times) under time constraints of construction, ${ }^{13}$ which dramatically reduces its use. Thus, the more reactive alite phases dominate (typically 70-80\%) in new infrastructure.

An atomic understanding of clinker solubility has not yet been achieved, with intriguing hypotheses awaiting validation. ${ }^{14}$ In fact, despite the vast recent literature on cement hydrates, ${ }^{11,15-19}$ previous studies on clinker are rather scarce ${ }^{20,21}$ and mainly focused on structural properties, ${ }^{22}$ with a few experimental results suggesting possible influences on reactivity. ${ }^{23,24}$ These limited data show discrepancies and leave many unanswered questions, and thus, the search for a belite phase with higher reactivity has been carried out chiefly by trial and error. Several strategies have been attempted, including modifying the chemical structure of belite by thermal processing or by including chemical impurities. ${ }^{25-28}$ Despite partial success, ${ }^{28}$ there is little control or understanding of where atomic substitutions take place, their effect on structure, or their role in chemical reactions. For these reasons, a more detailed, accurate, and clear understanding is needed to suggest new paths for improving the reactivity of cement components producing lower amounts of $\mathrm{CO}_{2}$.

Figure $4 \mathrm{c}$ illustrates one possible path forward in understanding the impurity-altered reactivity of clinker, using electronicstructure-based calculations of pure and chemically substituted belite to design "quantum clinker." The crystallographic faceting (as determined using the well-known Wulff construction) and dissolution reactions with water can be understood and manipulated from first-principles calculations for $\mathrm{C}_{2} \mathrm{~S}$ as a function of impurities. ${ }^{29}$ The charge densities of both the conduction-band maximum (CBM) and the valence-band maximum (VBM) are considered upon the introduction of magnesium, aluminum, and iron impurities into $\mathrm{C}_{2} \mathrm{~S}$ at concentrations of $0.5 \%, 1 \%$, and $2 \%$. Compared with pure $\mathrm{C}_{2} \mathrm{~S}$, the delocalized conduction band is altered upon magnesium and aluminum substitution, accumulating on the oxygen atoms and around the impurities. This localization effect is stronger for aluminum, resulting in a more reactive region around the impurity that is susceptible to nucleophilic attack, for example, upon exposure to water during dissolution. The VBM is still primarily located at the oxygen atoms upon magnesium and aluminum substitution, although it is more localized on those oxygen atoms that are nearest the impurities. One can hypothesize that this change might increase the reactivity of silicate groups near the impurity, at the cost of decreasing the number of sites that can interact with electrophilic cations; such predictions can be tested experimentally. This perspective on the role of impurities 
will be needed to design new clinker materials with enhanced dissolution properties. Further, the correlation of fracture resistance upon grinding with chemical reactivity upon dissolutionthrough both experiment and modeling at larger length scaleswill help to elucidate the relative effects of faceted surface energy and reaction kinetics of clinker. These nanoscale effects facilitate C-S-H precipitation and cement-paste setting at longer time and length scales.

\section{C-S-H precipitation and early setting}

The hardening of cement paste, once the powder is mixed with water, is what gives concrete its wide utility. ${ }^{30}$ Despite its importance, several recent reviews make clear that the processes that occur at the microstructure level and various stages of hydration are not yet well understood. ${ }^{7,8,31,32}$ Figure 5a shows how the complex shear modulus of a cement paste, measured by ultrasonic wave propagation, increases during two distinct intervals, separated by a period of apparent inactivity. ${ }^{33}$ This is the characteristic behavior of cement setting, the mechanical response of the paste undergoing cement hydration. Although the overall increase in stiffness is universally accepted, detailed analysis of such data is currently not feasible because the microstructure evolution of the paste has not been characterized. To contrast this behavior with the kinetics of setting, Figure $5 \mathrm{~b}$ shows a typical heat-release curve commonly considered in discussions of cement hydration. ${ }^{30}$ Five stages of temporal evolution are distinguished: initial deceleration, incubation, strong acceleration, second deceleration, and slow decay.

Attempts have been made to interpret various parts of the hydration curve. ${ }^{8,30,31}$ For example, the first deceleration

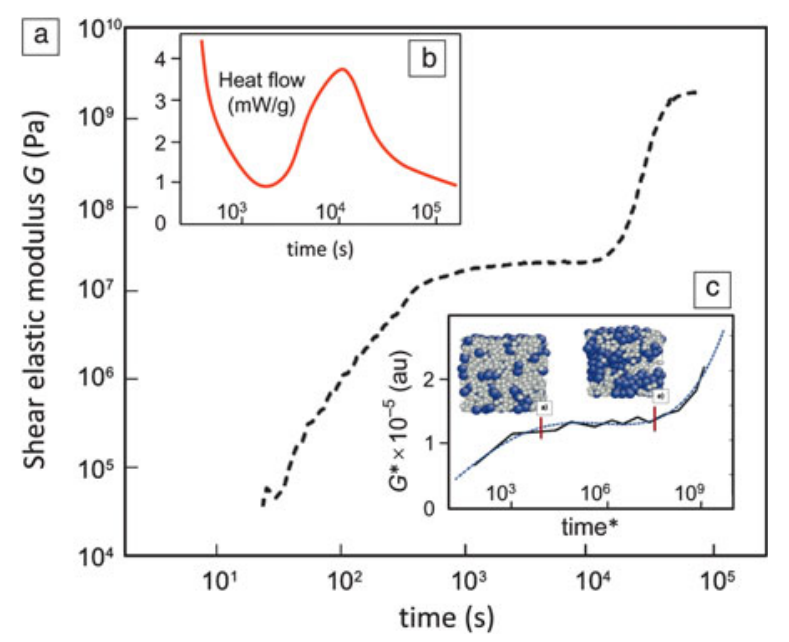

Figure 5. Time responses of a freshly made cement paste. (a) Increase of the shear elastic modulus measured by ultrasonic propagation in a paste with a water-to-cement ratio of 0.8; data from Reference 33. (b) Schematic of a hydration curve measured by calorimetry. (c) Shear modulus of a binary colloidal model simulated using a combination of molecular dynamics and metadynamics, as described in the text. ${ }^{38,39}$ is associated with the precipitation of hydration products, principally C-S-H but also "CH" [portlandite, $\left.\mathrm{Ca}(\mathrm{OH})_{2}\right]$. The incubation period and the onset of a strong acceleration are generally attributed to delayed nucleation of hydrates prior to an autocatalytic growth of the hydration products. The second deceleration signals the growth (precipitation) of the hydration products into open spaces (pores), whereas the slow decay indicates densification in the paste. Beyond such qualitative interpretations, quantitative description of any portion of the hydration curve remains a subject of future research. In the same context, a systematic study of the correspondence and differences between measurements of setting and hydration is also in order.

Current efforts in modeling and simulation of cement hydration kinetics and associated microstructure evolution have focused primarily on development of mesoscale codes that can account for particular measurements. ${ }^{8}$ Emphasis has been placed on hydration morphology, ${ }^{34}$ coupled diffusion and reaction, ${ }^{35}$ cellular-automata descriptions of reaction and transport ${ }^{36}$ and a rule-based simulation platform allowing for input distributions of hydration products and particle sizes. ${ }^{9}$ Collectively, these codes represent mesoscale simulation capabilities that can potentially incorporate input from microscale modeling and simulation studies (such as clinker dissolution rates) to predict hydration behavior measurable in a laboratory (of the entire paste volume). This is the role envisaged for hydration simulation capabilities in Figure 3, where links to laboratory tests will be a critical step in bridging the "microscalemacroscale" gap.

A specific example of microstructure development in cement setting that needs better understanding is the heterogeneous precipitation (nucleation and growth) of C-S-H and other hydration products that gives rise to the second increase in stiffness in Figure 5a. It is possible that atomistic simulations could help elucidate hydration mechanisms at the molecular level, but this is not as straightforward as it might first appear. Standard molecular-dynamics simulations will have difficulties accessing the relevant time scales indicated in Figure 5, as such simulations are capable of resolving time scales on the order of nano- or microseconds. Simulation techniques that accelerate the sampling of rare events by using history-dependent bias potentials (metadynamics) are being developed..$^{37,38}$ One such algorithm has been applied to the kinetics of microstructure evolution of a binary colloidal mixture (with angle-dependent interactions) as a conceptual model for cement setting. ${ }^{39,40}$ The time variation of the shear modulus simulated by this model is displayed in Figure 5c, showing a qualitative correspondence with the experimental setting curve. On the basis of this model, one would interpret the initial modulus increase as arising from gelation of the solvent particle (species A), the induction period as diffusion of the solute particles (species B) to form clusters, and setting as the percolation of clusters of B. Work is ongoing to introduce the precipitation and packing of C-S-H particles more explicitly to test the hypothesis that hardening of the paste can be described as heterogeneous densification. ${ }^{40}$ 


\section{Properties of the hardened paste}

The hardened paste, mainly the C-S-H phase, can be considered as a continuous porous matrix with multiple characteristic length scales ranging from nanometers to millimeters (based on smallangle $\mathrm{x}$-ray or neutron scattering data $^{41}$ ) or as a granular material (based on nanoindentation measurements ${ }^{42}$ ). The dimensions and structure of the C-S-H unit (i.e., of the C-S-H grain in a granular interpretation) are matters of active experimental and computational study, with reported dimensions ranging from a few nanometers ${ }^{15}$ to a few tenths of a nanometer. ${ }^{43} \mathrm{As} \mathrm{C}-\mathrm{S}-\mathrm{H}$ is a nonstoichiometric compound, composition is measured in terms of the $\mathrm{Ca} / \mathrm{Si}$ ratio (often denoted as $\mathrm{C} / \mathrm{S}$ ), which ranges from 1.2 to $2.2,{ }^{44}$ with maximum probability at $\mathrm{C} / \mathrm{S}=1.7$. The precise $i$ in situ measurement of the density of this common material $(2.6 \mathrm{~g} /$ $\mathrm{cm}^{3}$ ) was reported only recently. ${ }^{15} \mathrm{At}$ the nanoscale, diffraction and transmission electron microscopy (TEM) indicate that the $\mathrm{C}-\mathrm{S}-\mathrm{H}$ phase is semicrystalline, with layered crystalline regions with lateral dimensions of $\sim 0.1-1 \mathrm{~nm}$ dispersed within a gel-like phase. ${ }^{45}$ However, challenges remain in experimentally determining the detailed structure of this phase, in large part because this structure depends strongly on water content.

The correlation of composition and structure within the $\mathrm{C}-\mathrm{S}-\mathrm{H}$ phase thus remains an open issue. Several models have been proposed over the years ${ }^{46}$ to resolve apparently contradictory constraints, typically creating defects within crystalline mineral analogues to increase the calcium content while increasing the density. Although all such models can be adjusted to reproduce the experimentally measured $\mathrm{C} / \mathrm{S}$ ratio, it has remained challenging to simultaneously satisfy the constraints of the known water content and phase density. Additionally, such models describe purely crystalline structures that are not consistent with scattering and TEM data at the nanometer scale and the presence of a gel phase gluing layered crystallites. ${ }^{17} \mathrm{We}$ recently developed a structural description of C-S-H, based on Monte Carlo simulations, incorporating water molecules within a highly defective mineral structure that gives a $\mathrm{C} / \mathrm{S}$ ratio of about 1.7 and also a reasonable density of $\sim 2.4-2.5 \mathrm{~g} / \mathrm{cm}^{3}$. In this model, C-S-H has a defective structure with only shortrange order among silicate-rich layers, as distinguished from the original tobermorite mineral-based model of Pellenq and Van Damme that exhibited long-range order. ${ }^{47}$

A consistent structural description of C-S-H is desirable. Beyond addressing the longstanding composition/density puzzle at the nanoscale and the gel-versus-nanogranular interpretation of organization at the microscale, there are obvious consequences for concrete sustainability. For example, knowing the cement-paste stiffness or strength at the nano- and microscales, relative to cement chemistry in terms of the $\mathrm{C} / \mathrm{S}$ ratio, provides a direct path toward engineering a stiffer or stronger C-S-H phase. For structural applications such as pavements and buildings, this engineering of cement-paste mechanical properties can result in a reduced volume of C-S-H required and, thus, a lower associated carbon footprint of the embodied energy within such structures. Interestingly, a recent life-cycle assessment indicated that the embodied energy of buildings in the United States amounts to only a few percent of the use-stage energy (heating and cooling over the building lifetime), whereas this ratio can approach unity in Europe. ${ }^{48}$ The relevant material property here is thermal conductivity, and an open fundamental question is the relevant scale (if any) at which thermal transport properties of cement paste within concrete can be engineered to impact operational energy.

To refine multiscale C-S-H computational models and to test hypotheses for lowered $\mathrm{CO}_{2}$ contributions and increased sustainability of cement paste and concrete, experimental validation is required. Fortunately, C-S-H within hardened cement paste is accessible to nanoscale, microscale, and mesoscale analysis by both simulation and experiment (Figure 6). Characterization methods that are common to engineering materials, including instrumented indentation, scratch testing, electron microscopy, wavelength-dispersive $\mathrm{x}$-ray diffraction spectroscopy (WDS), and solid-state nuclear magnetic resonance (NMR) spectroscopy, are now being used to quantify how the mechanical, chemical, and structural properties depend on the chemical and physical environments of these pastes. In Figure 6, we show instrumentation and results for WDS analysis of chemical composition (Figure 6a); nanoindentation analysis of phase stiffness and strength (Figure 6b); and scratch-based estimation of fracture toughness (Figure 6c), along with typical results for a portland cement paste. Importantly, these and other chemical and mechanical properties (e.g., creep, shrinkage), as well as thermal properties (e.g., heat capacity ${ }^{49}$ and conductivity), can be measured for C-S-H and other phases within cement pastes and concrete over similar length scales and correlated with simulation predictions across length scales.

Further, water and electrolyte play a crucial role in the evolution and aging of the cement paste. This is particularly relevant at the level of $\mathrm{C}-\mathrm{S}-\mathrm{H}$, where classical molecular simulations indicate that water is confined in nanopores..$^{17}$ This nanopore region is hydrophilic because the nonbridging oxygen atoms on the disordered silicate chains act as hydrogen-bond-acceptor sites, orienting the hydrogen atoms of the interfacial water molecules toward the calcium silicate layers. Furthermore, the volume and mechanical properties of C-S-H vary strongly with ambient humidity, ${ }^{50}$ and shrinkage is governed by water-filled pores at multiple length scales.

Exploration of silicate chain lengths as a function of water content is underway, comparing advanced techniques such as solid-state ${ }^{29}$ Si NMR spectroscopy (Figure 6d), which indicates the extent of silicate linkages and chain length, with molecular simulations of C-S-H..$^{50}$ Nanopore water dynamics (reported as relaxation times) are also accessible with ${ }^{1} \mathrm{H}$ nuclear spin relaxation NMR spectroscopy. ${ }^{51}$ Bridging this microscale-macroscale gap has direct implications for concrete durability, as the motion of water among pores relates directly to the cohesion of the binding phase as a function of humidity and temperature and the physical state of water within pores affects durability under extreme changes in humidity, temperature, and mechanical strain. Here, predictable shrinkage and durability of the cement paste within concrete has an immediate impact on sustainability, for example, 


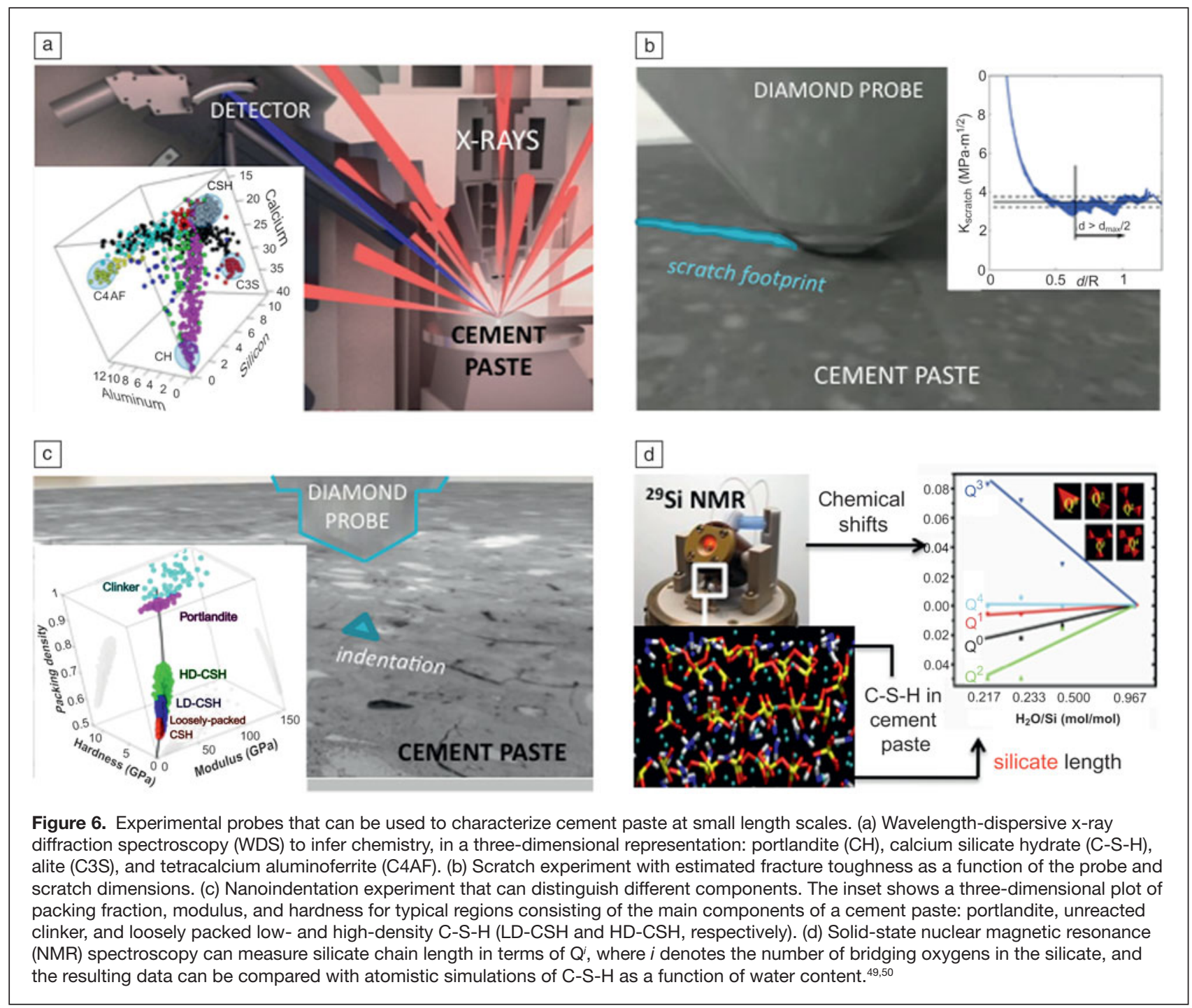

as relates to decreased replacement demands for new raw materials in pavements and buildings and to improved performance in extreme weather, heating rates, or loading environments that currently cause warping, cracking, or phase changes.

\section{A view of mechanism-based concrete sustainability}

An increasing reliance on a mechanism-based approach to concrete sustainability reflects the general belief that more fundamental understanding of a phenomenon can translate into ways to reduce its impact. Thus, insights into clinker grinding and dissolution, C-S-H precipitation and setting, and the structure and durability of hardened paste could contribute to the development of alternative processing routes. For example, these insights could enable cement production at lower kiln temperatures and/or lower grinding energies, both of which would lower associated $\mathrm{CO}_{2}$ production. Additionally, correlation of $\mathrm{C}-\mathrm{S}-\mathrm{H}$ structure and multiscale mechanical and thermal properties will allow tailoring of such properties to infrastructure applications, potentially resulting in lowered demand for raw materials (and associated $\mathrm{CO}_{2}$ production). We have indicated a number of current examples of focused research that serve only as illustrations of the vast research opportunities available to the materials community. Indeed, one important trend in improving concrete sustainability is partial replacement of cement paste with recycled materials such as fly ash or fumed silica. However, the effects of such incorporation on reaction kinetics and achievable strength of such mixes add further complexity that can be addressed best by predictive understanding of cement paste. It should be clear that a decisive impact cannot be achieved without the active collaboration of industry, the end users of concrete science and technology who will make, modify, and innovate new applications for this amazing material called "liquid stone" that holds the world together.

\section{Acknowledgments}

We acknowledge the Concrete Sustainability Hub at Massachusetts Institute of Technology, supported by the Portland 
Cement Association and the National Ready Mix Concrete Association. K.J.V.V. also acknowledges the U.S. Department of Homeland Security, Science and Technology Directorate, Infrastructure Protection and Disaster Management Division and Engineer Research and Development Center (ERDC), U.S. Army Corps of Engineers.

\section{References}

1. S. Staniford, "A Pretty Stunning Graph of World Cement Production" (Institute for the Study of Energy and Our Future, Fort Collins, CO), oildrum.com/node/ 4162 (accessed March 2012).

2. H.G. van Oss, in Mineral Commodity Summaries 2006 (U.S. Geological Survey, Reston, VA, 2006), pp. 44-45.

3. H.G. van Oss, in Mineral Commodity Summaries 2008 (U.S. Geological Survey, Reston, VA, 2008), pp. 44-45.

4. Global Cement Report (International Cement Review, London, ed. 9, 2011).

5. J.E.A. Ochsendorf, L.K. Norford, D. Brown, H. Durschlag, S.L. Hsu, A. Love, N. Santero, O. Swei, A. Webb, M. Wildnauer, Methods, Impacts, and Opportunities in the Concrete Building Life Cycle (Research Report R11-01, Massachusetts Institute of Technology, Cambridge, MA, 2011).

6. S. Yip, Ed., Handbook of Materials Modeling (Springer, New York, 2005).

7. J. Stark, Cem. Concr. Res. 41, 666 (2011).

8. J.J. Thomas, J.J. Biernacki, J.W. Bullard, S. Bishnoi, J.S. Dolado, G.W. Scherer, A. Luttge, Cem. Concr. Res. 41, 1257 (2011).

9. S. Bishnoi, K. Scrivener, Cem. Concr. Res. 39, 266 (2009).

10. H.F. Taylor, Cement Chemistry (Thomas Telford, London, ed. 2, 1997)

11. F.J. Ulm, A.T. Akono, P.M. Reis, Phys. Rev. Lett. 106, 204302 (2011).

12. A.K. Chatterjee, Cem. Concr. Res. 26, 1213 (1996).

13. C.D. Popescu, M. Muntean, J.H. Sharp, Cem. Concr. Compos. 25, 689 (2003).

14. E.M. Gartner, D.E. Macphee, Cem. Concr. Res. 41, 736 (2011).

15. A.J. Allen, J.J. Thomas, H.M. Jennings, Nat. Mater. 6, 311 (2007).

16. L.B. Skinner, S.R. Chae, C.J. Benmore, P. Monteiro, Phys. Rev. Lett. 104, $195502(2010)$

17. R.J.-M. Pellenq, A. Kushima, R. Shahsavari, K.J. Van Vliet, M.J. Buehler, S. Yip, F.J. Ulm, Proc. Natl. Acad. Sci. U.S.A. 106, 16102 (2009).

18. B. Yildiz, M. Youssef, R.J.-M. Pellenq, J. Am. Chem. Soc. 133, 2499 (2011). 19. M. Vandamme, F.-J. Ulm, Proc. Natt. Acad. Sci. U.S.A. 106, 10552 (2009). 20. H. Manzano, J.S. Dolado, A. Ayuelaz, J. Am. Ceram. Soc. 92, 897 (2009). 21. T.T. Tran, D. Herfort, H.J. Jakobsen, J. Skibsted, J. Am. Chem. Soc. 131 14170 (2009).

22. A. Rawal, B.J. Smith, G.L. Athens, C.L. Edwards, L. Roberts, V. Gupta, B.F. Chmelka, J. Am. Chem. Soc. 132, 7321 (2010).

23. D. Stephan, S. Wistuba, J. Eur. Ceram. Soc. 26, 141 (2006).

24. Y.M. Kim, S.H. Hong, J. Am. Ceram. Soc. 87, 900 (2004).

25. A.J.M. Cuberos, A.G. De la Torre, G. Alvarez-Pinazo, M.C. Martin-Sedeno, K. Schollbach, H. Pollmann, M.A.G. Aranda, Environ. Sci. Technol. 44 (17), 6855 (2010).
26. M.C. Martin-Sedeno, A.J.M. Cuberos, A.G. De la Torre, G. Alvarez-Pinazo, L.M. Ordonez, M. Gateshki, M.A.G. Aranda, Cem. Concr. Res. 40 (3), 359 (2010). 27. A.G. De la Torre, K. Morsli, M. Zahir, M.A.G. Aranda, J. Appl. Crystallogr. 40, 999 (2007).

28. G.S. Li, G.M. Gartner, "High-Belite Sulfoaluminate Clinker: Fabrication Process and Binder Preparation," French Patent Application 04-51586 (27 January 2006). 29. E. Durgun, H. Manzano, R.J.-M. Pellenq, J.C. Grossman, "Understanding and Controlling the Reactivity of the Calcium Silicate Phases from First Principles," Chem. Mater., in press.

30. E.M. Gartner, J.F. Young, D.A. Damidot, I. Jawed, in Structure and Performance of Cements, P. Barnes, J. Bensted, Eds. (Spon Press, London, ed. 2, 2002), pp. 57-103

31. J.W. Bullard, H.J. Jennings, R.A. Livingston, A. Nonat, G.W. Scherer, J.S. Schweitzer, K.L. Scrivener, J.J. Thomas, Cem. Concr. Res. 41, 1208 (2011). 32. K.L. Scrivener, A. Nonat. Cem. Concr. Res. 41, 651 (2011).

33. D. Lootens, P. Hebraud, E. Lecolier, H. Van Damme, Oil Gas Sci. Technol. 59, 31 (2004).

34. K. van Breugel, Cem. Concr. Res. 25, 522 (1995).

35. E.J. Garboczi, D.P. Bentz, K.A. Snyder, N.S. Martys, P.E. Stutzman, C.F. Ferraris, J.W. Bullard, An Electronic Monograph: Modeling and Measuring the Structure and Properties of Cement-Based Materials (National Institute of Standards and Technology, Gaithersburg, MD, 2005), concrete.nist.gov/monograph (accessed February 2012).

36. J.W. Bullard, Modell. Simul. Mater. Sci. Eng. 15, 711 (2007).

37. A. Laio, F.L. Gervasio, Rep. Prog. Phys. 71, 126601 (2008).

38. A. Kushima, J. Eapen, J. Li, S. Yip, T. Zhu, Eur. Phys. J. B 82, 271-293 (2011).

39. P.R. Monasterio, Ph.D. thesis, Massachusetts Institute of Technology, Cambridge, MA (2010).

40. P.R. Monasterio, E. Masero, R. Pellenq, S. Yip, paper presented at the 13th International Congress on the Chemistry of Cement (ICCC), Madrid, Spain, 3-8 July 2011.

41. J.J. Thomas, H.M. Jennings, A.J. Allen, Adv. Cem. Based Mater. 7, 119 (1998). 42. G. Constantinides, F.-J. Ulm, J. Mech. Phys. Solids 55, 64 (2007).

43. S. Garrault-Gauffinet, Experimental investigation of calcium silicate hydrate (C-S-H) nucleation. J. Cryst. Growth 200, 565 (1999).

44. I.G. Richardson, Cem. Concr. Res. 29, 1131 (1999). 45. Z. Xu, D. Viehland, Phys. Rev. Lett. 77, 952 (1996). 46. I.G. Richardson, Cem. Concr. Res. 38, 137 (2007). 47. R.J.-M. Pellenq, H. Van Damme, MRS Bull. 29, 319 (2004) 48. Y.G. Yohanis, B. Norton, Energy 27, 77 (2002)

49. F. Vodak, R. Cerny, J. Drchalova, S. Hoskova, 0. Kapickova, O. Michalko, P. Semerak, J. Toman, Cem. Concr. Res. 27, 415 (1997).

50. Q. Ji, R.J.-M. Pellenq, K.J. Van Vliet, C-S-H: Water, water everywhere (Research Profile Letter, Concrete Sustainability Hub@MIT, Cambridge, MA, December 2010), web.mit.edu/cshub/news/pdt/12-2010\%20CSHub-NewsBrief\%20(1).pdf (accessed February 2012).

51. P.J. McDonald, J.-P. Korb, J. Mitchell, L. Monteilhet, Phys. Rev. E72, 011409 (2005).

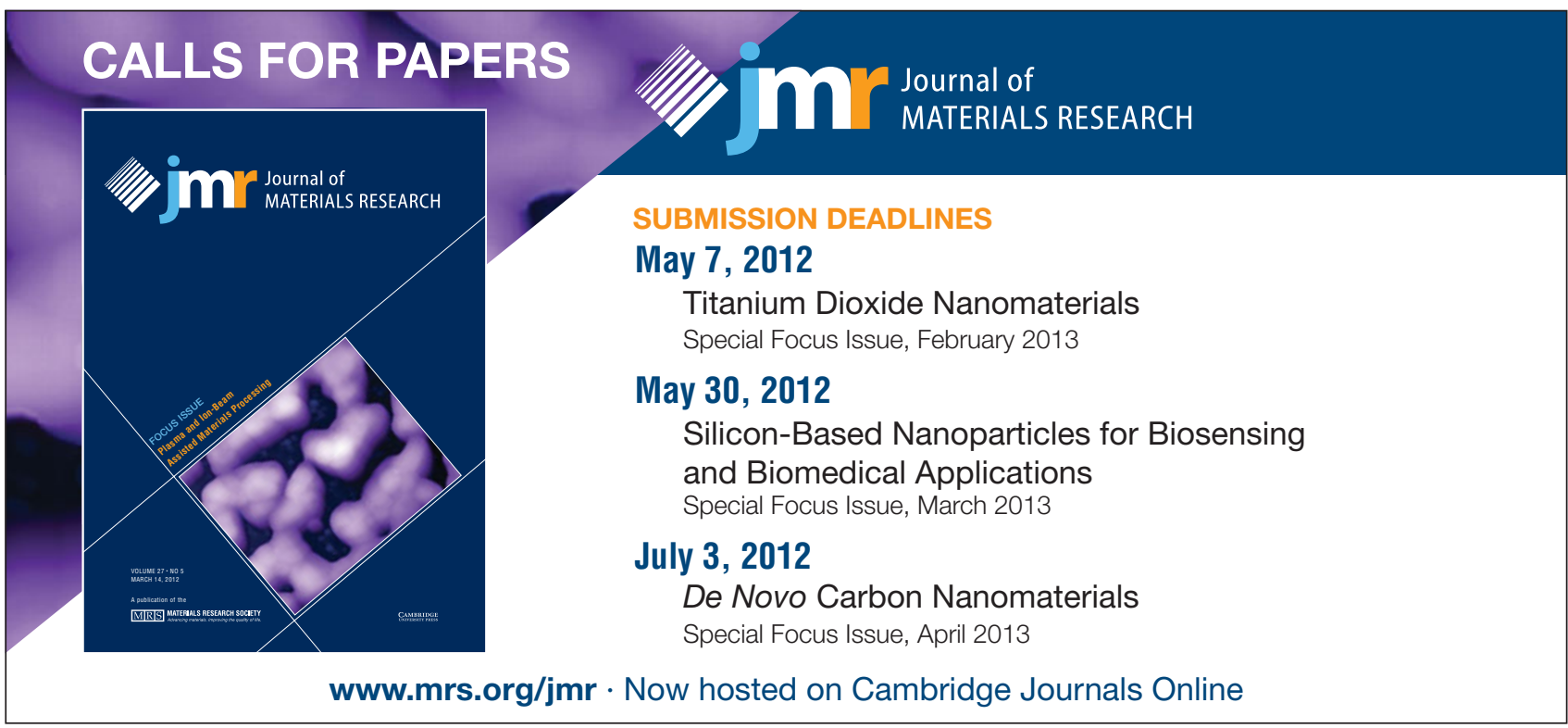




\section{The first truly global foundry}

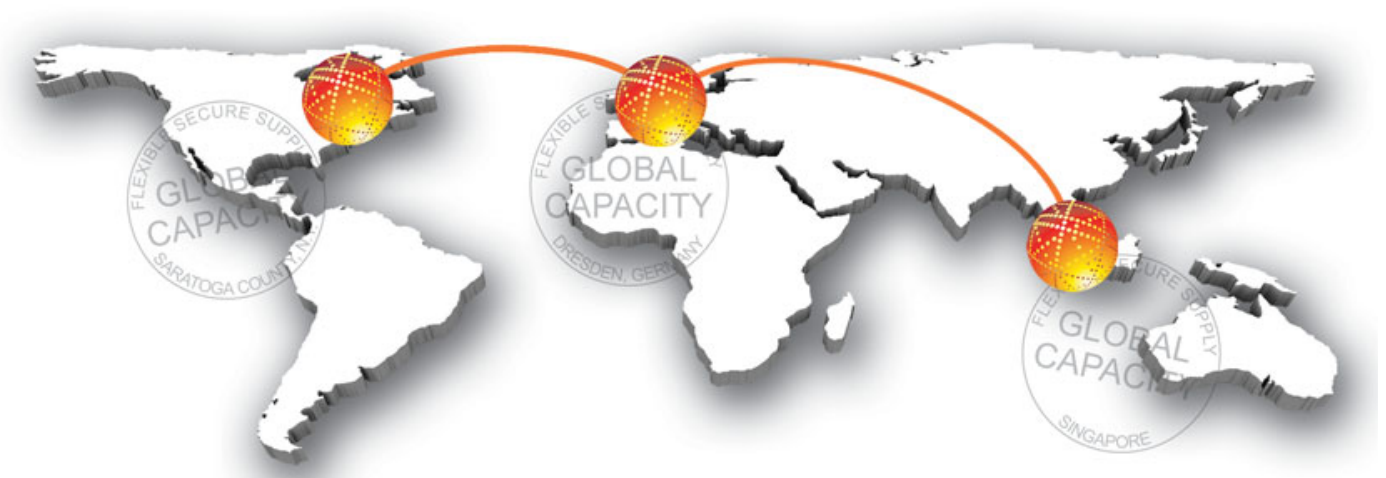

In January 2010, the semiconductor foundry landscape changed forever with the launch of the new GLOBALFOUNDRIES. This new entrant to the market combined the leading-edge integrated device manufacturing heritage of Advanced Micro Devices (AMD) with the pure-play semiconductor foundry heritage of Chartered Semiconductor to create a company with an impressive capacity and technology footprint and a world-class customer base.

Headquartered in Silicon Valley, our leading edge technology company has well over 10,000 employees with an extensive $200 \mathrm{~mm}$ and $300 \mathrm{~mm}$ silicon wafer manufacturing campus in Singapore. This is complemented by a leading-edge $300 \mathrm{~mm}$ manufacturing campus in Dresden, Germany and a third campus under construction in Saratoga County, New York, that once complete should be the most advanced in the world. These global operations provide a unique opportunity for us to attract and leverage the best engineering and technical talent from around the world to support long-term growth and expansion opportunities. 


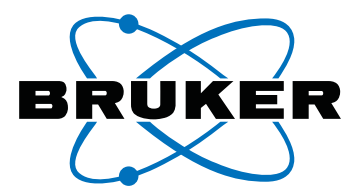

\section{The World's Fastest AFM}

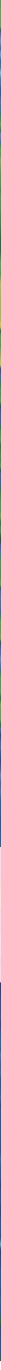

Imagine working 100s of times faster... and imagine doing it with an AFM that breaks the mold for speed and imaging performance. Well, there is no need to dream, Bruker's Dimension FastScan is the new gold standard in AFM technology. Dimension FastScan provides true fast scanning, on any sample, air or fluid, is easy to use and provides the world's highest AFM resolution and performance due to the system's lowest drift and low noise. Speed up your productivity and discover Dimension FastScan for yourself. View high-resolution FastScan images at our website, or experience it on your sample - call for a demonstration.

For more information visit www.bruker-axs.com, email productinfo@bruker-nano.com or call +1.805.967.1400 / 800.366.9956

Innovation with Integrity 

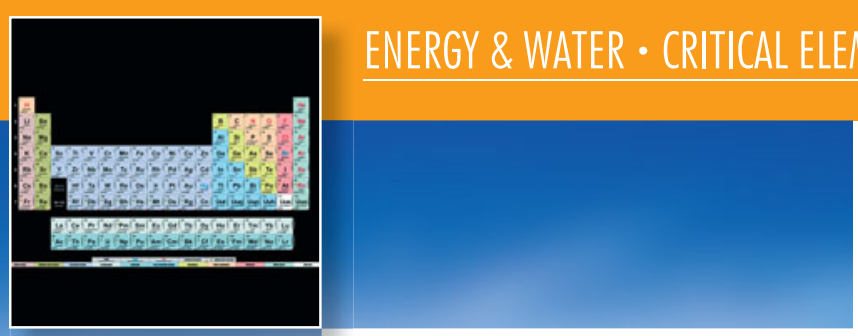

\title{
Energy-criticall elements for sustainable development
}

\author{
Alan J. Hurd, Ronald L. Kelley, Roderick G. Eggert, \\ and Min-Ha Lee
}

\begin{abstract}
Energy-critical elements (ECEs) are chemical and isotopic species that are required for emerging sustainable energy sources and that might encounter supply disruptions. An oft-cited example is the rare-earth element neodymium used in high-strength magnets, but elements other than rare earths, for example, helium, are also considered ECEs. The relationships among abundance, markets, and geopolitics that constrain supply are at least as complex as the electronic and nuclear attributes that make ECEs valuable. In an effort to ensure supply for renewable-energy technologies, science decision makers are formulating policies to mitigate supply risk, sometimes without full view of the complexity of important factors, such as unanticipated market responses to policy, society's needs for these elements in the course of basic research, and a lack of substitutes for utterly unique physical properties. This article places ECEs in historical context, highlights relevant market factors, and reviews policy recommendations made by various studies and governments. Actions taken by the United States and other countries are also described. Although availability and scarcity are related, many ECEs are relatively common yet their supply is at risk. Sustainable development requires informed action and cooperation between governments, industries, and researchers.
\end{abstract}

\section{Introduction}

The term "energy-critical elements" (ECEs) was coined by a joint committee of the American Physical Society (APS) and Materials Research Society (MRS) assembled in 2009 to investigate the material resources available to support emerging energy technologies ${ }^{1}$ (see Figure 1). By the time the APS-MRS study was published in 2011, several countries had already started acting on concerns about the supply risk of critical minerals and materials. ${ }^{2}$

In the United States, congressional committee hearings, legislation, and administration studies were initiated. The U.S. Department of Energy released an important report in late $2010^{3}$ and a comprehensive follow-up in late $2011^{4}$ that identified 14 critical elements: cerium, cobalt, dysprosium, europium, gallium, indium, lanthanum, lithium, neodymium, praseodymium, samarium, tellurium, terbium, and yttrium (see Figure 1). These materials were selected based on supply risk factors, including small global market, lack of supply diversity, and market complexities caused by coproduction and geopolitical risks. The
APS-MRS and Department of Energy reports are foundational to U.S. policy and legislative flow.

Also in 2010, Korea and Japan undertook broad programs in research and recycling of rare metals, ${ }^{5}$ and the European Union (EU) issued memoranda establishing a critical-materials list. ${ }^{6}$

The sudden concern over ECEs was touched off by international events occurring over at least a decade. As described below, the United States lost its leadership of the rare-earth markets and by 2002 was effectively out of the business. In its place, China rapidly filled the market niche by tapping underutilized deposits using new mining technology. However, on July 8, 2010, China formally announced a $40 \%$ reduction in its export quota for rare-earth (RE) elements, which sent a shock wave through the markets. By that time, China accounted for more than $95 \%$ of worldwide production of rare-earth oxides. Within weeks, the export price of neodymium, a rareearth metal used in high-strength magnets for windmills and electric-car motors, nearly tripled, and in November 2011, it was some seven times higher than it had been in July 2010 


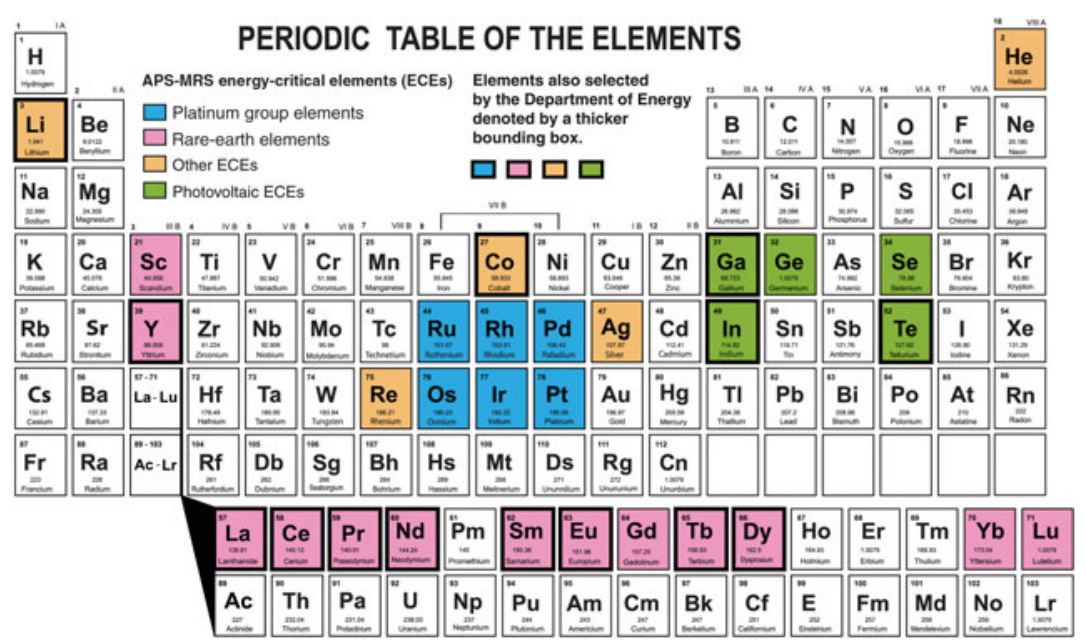

Figure 1. Critical elements chosen by the American Physical Society (APS)-Materials Research Society (MRS) energy-critical element study panel ${ }^{1}$ and by the U.S. Department of Energy Office of Energy Policy., ${ }^{3,4}$ Selection criteria differed in the two studies, leading to 29 elements for the APS-MRS and 14 elements for the U.S. Department of Energy.

Energy-critical elements are not just rare earths

As noted earlier in this issue by Graedel and Erdmann, there are many definitions of critical materials or elements. We confine our comments to energy-critical elements as defined in the APS-MRS study, ${ }^{1}$ unless stated otherwise. ECEs are chemical elements that are necessary for emerging or transformative energy technologies but whose supply risk could limit research, development, or deployment of a technology. Typically, ECEs have not been widely extracted, traded, or utilized in the past and lack a well-established, regulated, or stable market. Non-rare-earth examples include indium for solar cells and energy-efficient displays, tellurium for solar cells and detectors, platinum for novel catalysts, and rhenium for energy-saving superalloys. It is important to appreciate the study's inclusive scope for energy research: research materials such as

(see Figure 2). Regardless of the reason for China's quota action, its effect was to reinforce international concerns about rare-earth elements.

In the wake of these events, the APS-MRS committee published its report on the raw-materials supply risk to emerging energy technologies, including recommended actions. This article reviews that APS-MRS report and others, as well as responses by governments to ECE supply risks. (The article by Graedel and Erdmann in this issue also discusses supply limitations, but of a broader spectrum of metals for manufacturing technologies.) After defining ECEs, we discuss some aspects of their supply chains and markets, U.S. and international policy developments, factors specific to REs and helium, critical-materials lists from selected countries, and the recommendations of the APS-MRS study.

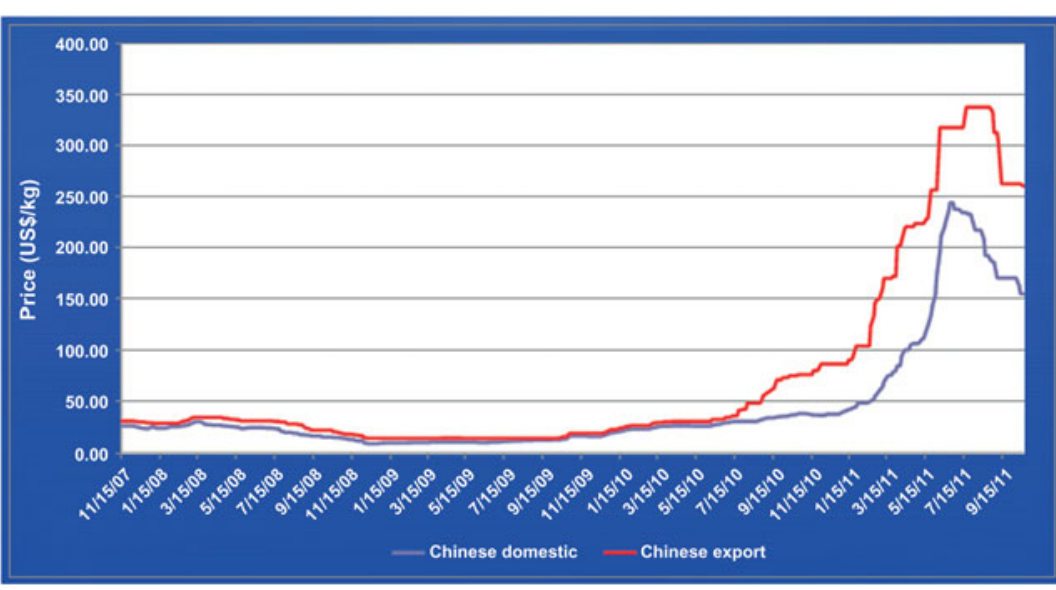

Figure 2. Recent price history of neodymium oxide (2007-2011), as an example of supply risk. Chinese domestic prices (blue line) are less than the Chinese export price for customers outside of China. (From Reference 7 courtesy of the U.S. Geological Survey.) helium for cryogenics can also be "critical" because they are required to develop transformative energy technologies.

ECE lists are neither universal nor constant over time. In 1940, the emerging energy technology was nuclear fission; hence, the ECEs of the day were natural uranium, deuterium, and highly purified graphite, the last two for neutron moderation. Indeed, at that time, committees recommended policies for these then-ECEs, but world events prompted the classification of nuclear policies as national secrets. ${ }^{8}$ Today, uranium, carbon, and deuterium are still critical elements, but they are not energy-critical elements, as they are now governed by highly regulated markets, national security considerations, and public concerns. By 2050, one hopes that progress on sustainable development will likewise have moved some elements off today's ECE lists, perhaps to be replaced by other elements.

By analogy to nuclear power in 1940 , today's new or anticipated markets in sustainable energy involving hydro, wind, sea, geothermal, and solar power require a new set of raw materials. Not to be forgotten, however, advanced nuclear reactors are considered by many as a sustainable technology. (See the article in this issue by Englert et al.) Low environmental impact throughout a material's life cycle is a key to sustainability for any ECE supply.

\section{Rare earths}

Despite their name, rare-earth elements are not rare; they are just rarely used. If society is able to adopt new, contemplated energy infrastructure, as well as improved processes for extracting and recovering rare earths, this will change. 
The special electronic and optical properties that make REs useful derive from their unique $4 f$ electrons, which cause the "lanthanide contraction" of ionic radii due to comparatively ineffective screening of the nuclear charge. Because the $4 f$ electrons hug the nucleus, higher-shell electrons in the $5 \mathrm{~s}$ and $6 s$ orbitals are left to interact with other atoms. Therein lie the complex electronic behaviors that endow neodymium with powerful magnetism and europium with unique optical interactions, indispensible for lightweight electric motors and energy-efficient lighting, respectively.

Crustal abundance is one factor in the economics of element extraction, and enrichment into ore bodies is another (see Figure 3). Owing to their unique chemistry, rare earths are not efficiently mineralized by geological processes into concentrated ores. However, when geologically concentrated, they occur together (often partitioned into "light" and "heavy" rare-earth ore bodies) and sometimes with more lucrative commodity metals, such as iron, uranium, and niobium; therefore, they are mostly coproduced as byproducts of the mining of those metals. Because they are difficult to separate from host minerals, often including radioactive uranium and thorium, REs can have high environmental impacts in mining and extraction.

The near-monopoly in RE mining achieved by China by 2009 was enabled in part by the invention of an innovative separation technique requiring low capitalization that opened low-grade ion-absorbed clays to economic production. ${ }^{9}$ Numerous small mines practiced this hydraulic mining process under previous regulations, and even now, it accounts for about $35 \%$ of China's RE production. ${ }^{10}$ Using hydraulic water pressure in vegetation-cleared hills, the whitish-colored clay is washed into pits lined with plastic. Sulfuric acid or ammonium sulfate is added to dissolve the desired minerals, and then the fluids are siphoned downhill into a concrete pool where they are treated with oxalic acid. Rare-earth oxalates precipitate out and are calcined to oxides in a kiln. In an important final step, the depleted fluids are washed into rivers (in unregulated operations). Thus, river contamination and erosion are two impacts of mining ion-absorbed clays. ${ }^{9}$ Minimizing environmental impacts was a contributing factor in China's revised RE export policy, as noted in the section Actions in Europe and Asia.

Afghanistan reportedly contains rich sources of REs. ${ }^{11}$ Prospecting by Soviet geologists during their intervention in the early 1980 s established several promising sites in the country's rugged interior. Over the period from 2004 to 2011, under heavy security provided by the U.S. Armed Forces, geologists from the U.S. Geological Survey confirmed the Russian findings and estimated resources when possible. A Chinese company had already contracted in 2011 to invest $\$ 2.4$ billion in a copper mine in Afghanistan and associated transportation infrastructure. Further development by mining entities awaits political stabilization.

\section{Hellium}

Because helium has utterly unique physical attributes, it could be considered an ECE solely by virtue of its value to energy research as a cryogenic fluid. Helium has technological uses important to emerging energy technologies as well. In some advanced nuclear reactor concepts, helium offers unmatched heat conduction while resisting nuclear activation. It serves as

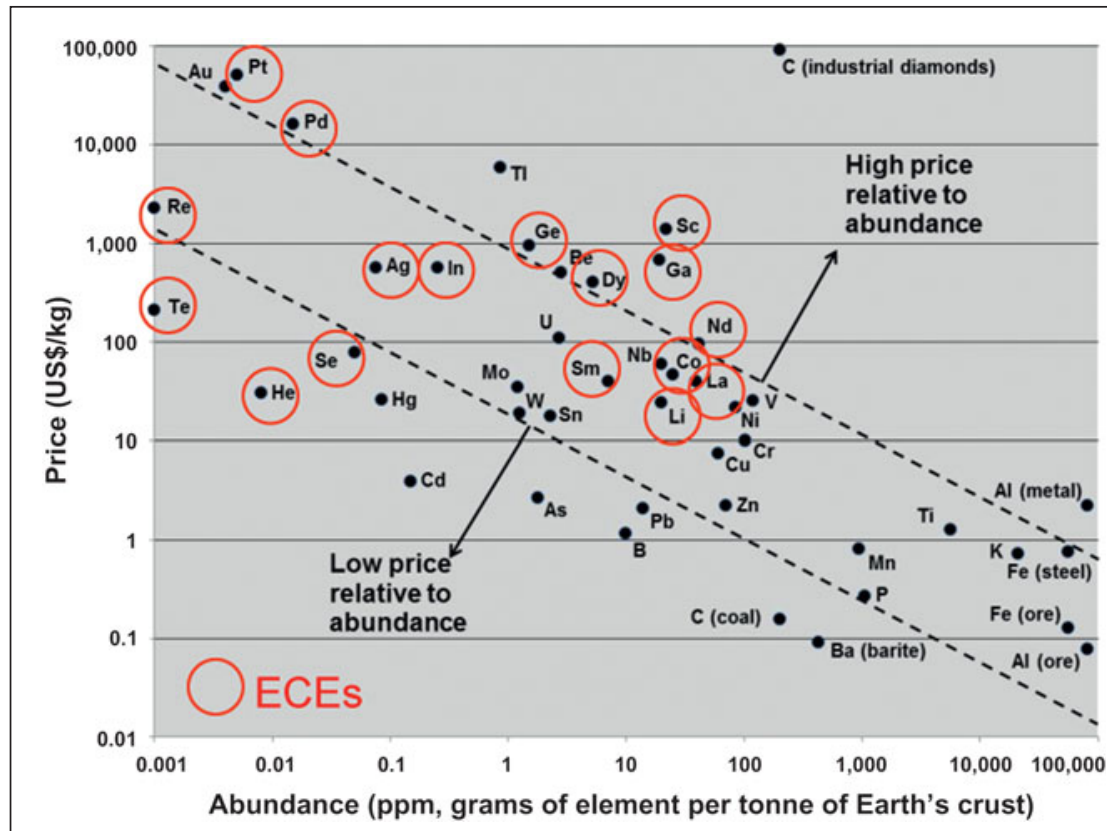

Figure 3. Price-abundance plot for many elements, specifically those for which there is a market. Energy-critical elements are circled in red. (From J. Price, personal communication, who derived the data from various sources, including the CRC Handbook of Chemistry and Physics, the U.S. Geological Survey, and the U.S. Energy Information Administration.) a shroud gas for welding, an inert processing gas in semiconductor manufacturing, a cryogen for medical magnetic resonance imaging, and an indispensible flushing agent for liquid-oxygen lines in rocket motors.

Contradictorily, helium is the second most common atom in the universe, but it is among the rarest (by weight) of all elements in the Earth's crust. It has been stockpiled by the United States since 1925, yet helium is so inexpensive that it fills party balloons. The APS-MRS study panel concluded, however, that the helium supply is dangerously at-risk within the time frame for attaining global energy sustainability. In addition, helium serves as a useful cautionary tale of government market interventions. Hence, it was identified as an ECE by the panel even though no other similar study considered it in the energy context. ${ }^{1,12,13}$

The issue with helium is that it is not gravitationally bound to Earth. Generated as a radioactive decay product in Earth's interior, helium is mobile enough to collect, conveniently for our uses, in natural gas reservoirs. However, once released to the atmosphere, helium escapes into space and is essentially lost to humanity. Most 
of the time, it is simply released during natural gas recovery processes as unwanted waste.

In 1925, anticipating strategic military uses such as dirigibles, the United States created the Federal Helium Reserve in a natural structural dome under Amarillo, TX. During the Cold War, the U.S. strategic-missile fleet required ample helium flushing gas to be ready at all times. By 1970, the stockpile exceeded one billion cubic meters - a projected 50-year supply - hence, the government ceased buying more gas. After the demise of the Soviet Union, the U.S. Congress decided in 1996 that the full reserve was no longer needed, so it enacted legislation to sell off almost all federally owned helium gas by 2015 to repay the costs of the reserve itself. Unexpectedly, prices rose after the federal selloff began owing to unanticipated demand from the high-technology sector in developing countries and to increased production and compliance costs in the United States. The selling of federal helium, even at prices significantly higher than private helium stocks, depressed U.S. helium prices relative to foreign gas and, in combination with higher production costs, disadvantaged U.S. producers.

The helium case was the prime stockpiling example the APS-MRS study panel encountered in which government market intervention created market instabilities. Because of this example, the panel recommended against market interventions in general, including stockpiling. However, because helium has unique physical properties that are indispensible in research, medicine, and, for now, in national security, the panel felt that helium should be stockpiled despite market instabilities.

At this writing, a bill is working through U.S. Senate committees to prescribe steps for a sustainable future in U.S. helium supplies. The bill encourages private development of new sources while ensuring ample supplies for research needs.

\section{Actions taken by governments}

Even before China formally announced its intent to cut exports of REs in the summer of 2010, U.S. government agencies were monitoring the supply risk. The heightened attention to REs in energy, defense, and electronic applications increased awareness by the public and the press of U.S. dependency on other countries for specific critical elements.

The APS-MRS energy-critical elements policy study panel convened workshops and interviews with stakeholders in the field. Meanwhile, the Washington, DC, offices of both APS and MRS monitored, and later directly participated in, the development of some of the legislative bills, and these offices provided their respective society's federal interface.

This section also discusses actions taken by several European and Asian countries.

\section{U.S. legislation}

During 2011, a variety of related bills were drafted and introduced to relevant congressional committees for consideration.
At this writing, none of these bills have passed their full respective chambers. This pattern is very common when more than one congressional cycle is required to pass authorization bills.

Of the various minerals- and materials-related bills to be drafted and considered by Congress, RE legislation is the most common type. The issues covered by the broad term "critical minerals and materials" have not yet been fully recognized as a high priority. In part, this is because the media have discussed concerns regarding price, availability, and foreign control primarily with respect to REs without noting that ECEs of all types face similar supply risks.

\section{Broad differences in bills}

Some of the proposed legislation calls for studies for additional information, for example, H.R. 1314 and H.R. 2011. A few of the bills support a particular interest by a member of Congress on behalf of his or her constituents and, in some cases, the desire to impact the mining or rare-earth industry, including H.R.1388, H.R.618, S.383, and S.1113. The closest bill that contains a legislative agenda similar to the recommendations of the APS-MRS energy-critical elements study is H.R.2090. A broader bill, H.R.952, addresses a previous minerals and materials act while adding updates that are needed to address current concerns. Interested readers can review the details in any of these specific bills by going to the Library of Congress "Thomas" web site ${ }^{14}$ and searching for the 2011 bills by their respective numbers. Each of the bills will need to be reintroduced with a new bill number in 2012 and essentially restarted through the legislative process.

Some of the bills emphasize substitution research, recycling, and improved information gathering and dissemination for ECEs and REs. Other bills or components of some bills are focused on revitalizing the mining industry in specialty minerals and materials. Some of the legislative efforts are directed at encouraging investment by government and industry in the value-added chain of products that use ECEs and REs such as magnets, solar cells, wind turbine blades, and batteries.

Legislators have recognized that centers of expertise and professional talent in these difficult scientific areas are critical to sustainability success. The U.S. administration has proposed an energy center devoted to critical minerals and materials as a portion of its fiscal year 2012 Department of Energy budget request. As recommended in the APS-MRS study, a number of bills acknowledge the critical and unmet need of having the federal government more involved in providing credible information on the rapidly changing availability and applications for REs and ECEs. Which specific agency should purvey this information and expertise is a point of debate.

\section{Interest in APS-MRS policy study and outlook for 2012}

One of the most interesting outcomes of the APS-MRS study has been the attention paid to it by senior leaders in both the legislative and executive branches of the U.S. federal government. In 2011, a number of briefings and meetings were arranged 
for the co-chairs of the policy study, Dr. Robert Jaffe of the Massachusetts Institute of Technology and Dr. Jonathan Price of the University of Reno, NV, who is also the State Geologist for Nevada. They testified directly to House and Senate committees in hearings on REs and critical materials. Staff crafting legislation used the resources of professional societies and asked for input from the ECE study panel. Other members of the study panel provided congressional testimony, including Dr. Karl Gschneidner, of Ames Laboratory and Iowa State University, and one of us (Eggert).

Remarkably, one recommendation from the APS-MRS study was implemented within weeks of the study's February 2011 publication. The study recommended that a high-level formal group, beyond a task force, be established in the National Science and Technology Council to follow issues related to ECEs.

Members of the study panel also made presentations to the White House Office of Science and Technology Policy, Department of Defense, Department of Energy, and other groups within the administration interested in these topics. In addition to briefings with staff from all of the relevant committees in the House and Senate, the ECE report gave MRS and APS an opportunity to interact with many groups in Washington that had policy interests in ECEs, including the MIT Washington Office, American Enterprise Institute, TransAtlantic Business Dialogue, and Heritage Foundation.

The topic will continue to gain attention in Washington, DC, in 2012, even in an election year. As with many topics that are of interest to Congress and Washington, however, the amount of priority time given to the subject will depend on evolving market and global conditions, China-U.S. relations, and general export control of China's REs. If producers and suppliers continue to make supply-risk mitigation a priority for the 112th Congress in the second session, the issue of ECEs will continue to gain momentum in 2012, and final legislation will result.

\section{Actions in Europe and Asia}

China's publicly stated motives for restricting exports of REs were to regulate domestic mines, to encourage development of foreign resources, to control illegal mining, to reduce environmental impacts, and to evolve China from an external supplier to an internal supplier. ${ }^{15}$ Some in the West have speculated that China also wishes to stockpile some ECEs. ${ }^{16}$

The European Union established the Raw Materials Initiative and named 14 mineral groups as critical. ${ }^{6}$ Canada adopted the EU report as well. In addition to sharing most of the elements in the ECE list except helium, tellurium, silver, rhenium, and lithium, the EU list includes antimony, beryllium, magnesium, tungsten, tantalum, and niobium and the minerals fluorspar (fluorite, $\mathrm{CaF}_{2}$ ) and graphite. The EU list is based on an analysis of projected demand for emerging technologies in 2030 compared to 2006. Gallium and indium are expected to exhibit the largest increases, according to the EU analysis. The EU initiative calls for updating the critical raw-materials list every five years, improving statistical information about resources in an annual yearbook, and researching life-cycle assessments and demand for emerging technologies. Additional research is recommended in mineral engineering, exploration, and substitution.

A novel supply-risk analysis with an emphasis on instability underwrites South Korea's list of 56 elements required for domestic use, microelectronics manufacturing, and energy technologies. This large list covers most of the ECEs, but like the EU report, it omits helium as critical. The South Korean analysis ${ }^{5}$ considers rarity, geopolitical supply factors, and recent price variations. In 2007, the platinum-group metals were rated as most rare, REs as most unstable in supply, and selenium as most unstable in price.

The South Korean program emphasizes research in raremetal science; in fact, the Korea Institute for Rare Metals in Incheon was created for this very purpose. In addition, Korea has reached out to the international community to co-develop strategy and perspectives for rare metals.

In Japan, a comprehensive program of recycling, reuse, replacement, reduction in consumption, and stockpiling is underway. Having been the apparent targets of China's reduced export quotas in 2010, Japan ${ }^{5}$ emphasizes new sources of minerals and their concomitant diplomatic relationships.

\section{Recommendations and outlook}

This article draws on studies of critical materials and programs established by governments to ensure stable supplies of elements required to achieve global sustainability in energy. Because the necessary technologies require a great deal of research, we have adopted the APS-MRS study on energy-critical elements as a baseline.

The recommendations by the study panel, paraphrased below, speak to both governments and the international research community.

- Federal agency coordination. The Office of Science and Technology Policy should create a subcommittee within the National Science and Technology Council to examine the production and use of ECEs within the United States and to coordinate the federal response. This action was completed in early 2011.

- Information collection, analysis, and dissemination. The U.S. government should gather, analyze, and disseminate information on ECEs across the mineral supply chain, from cradle to grave, as a "Principal Statistical Agency" with survey enforcement authority. The federal government should regularly survey emerging energy technologies to identify critical applications and shortfalls.

- Research, development, and workforce enhancement. The federal government should establish a research and development effort focused on ECEs and possible substitutes.

- Efficient use of materials. The government should establish a consumer-oriented "Critical Materials" designation for ECE-related products and a recycling program. 


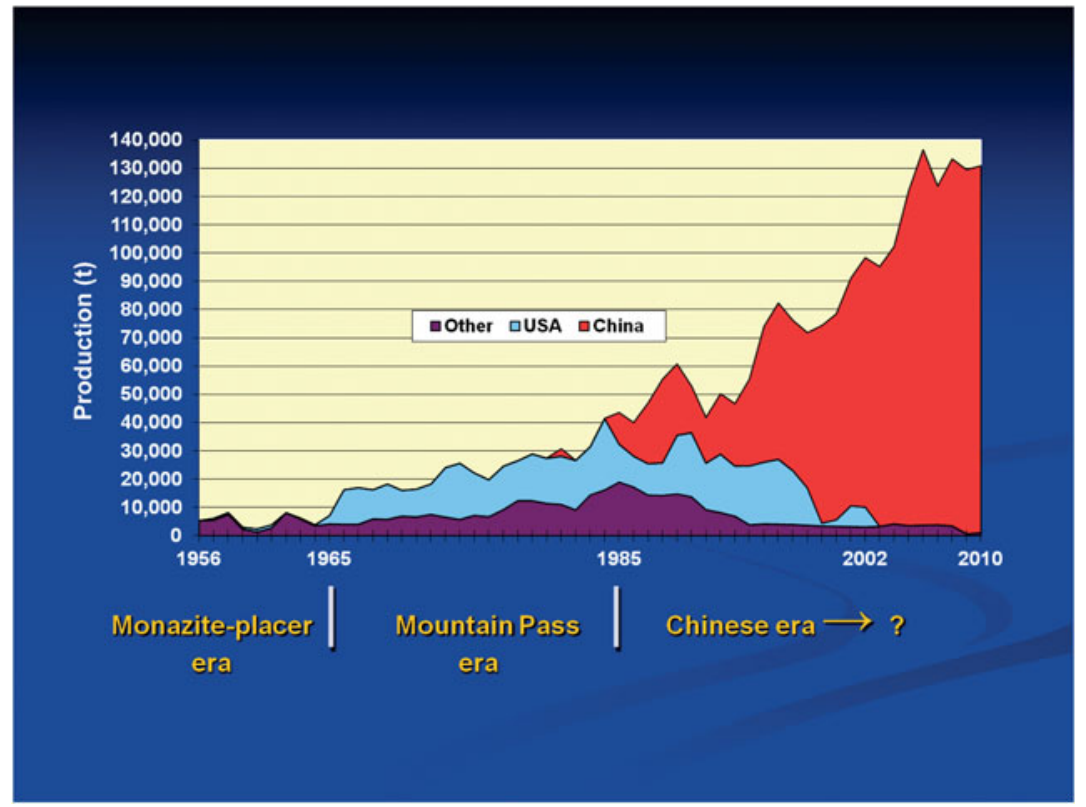

Figure 4. Global production of rare-earth oxides. The Mountain Pass Mine in the U.S. state of California dominated world production of rare earths through 1985, when Chinese production, particularly at the Bayan Obo Mine in Inner Mongolia, became a factor. In 2010, China supplied $97 \%$ of the market. (From Reference 17 courtesy of the U.S. Geological Survey.) with the mine's RE ores. Processing of legacy tailings started in 2009, along with new mining production in 2011. Further, Molycorp plans to scale up production over the next year or so.

The reopening of the Mountain Pass mine is the result of changes in China-where the advantage of mining ion-adsorbed clays by environmentally damaging techniques is being reduced by Chinese policy - and in the United States. Molycorp has devoted significant effort to minimizing the environmental damages associated with RE mining and mineral processing. With this success as an example, other mines, including urban mines, promise a sustainable future pathway paved by materials research.

\section{Acknowledgments}

This work benefited from the Santa Fe Institute and the Lujan Neutron Scattering Center at Los Alamos National Laboratory funded by the U.S. Department of Energy's Office of Basic Energy Sciences (Contracts DE-AC52-06NA25396 and LA-UR 11-06728).
- Market interventions. With the exception of helium, government should avoid interventions in markets including non-defense-related economic stockpiles.

Helium is unique even among ECEs. Measures should be adopted that will both conserve and enhance the nation's helium reserves. Draft legislation for helium was circulated in October 2011.

Supply risks of ECEs involve geopolitical factors. China's near-monopoly in 2011 and Afghanistan's promise as a future supplier imply precarious supply for some consumers. Sustainable supply is not guaranteed to all societies involved in creating the future energy infrastructure. Publicly, at least, major stakeholder countries now strive to balance natural and urban mining to achieve approximate sustainability.

Although REs are far from the whole story of ECEs, society's industrial pressure for REs has led to a useful paradigm in new supply-chain development as illustrated by California's Mountain Pass mine (see Figure 4). Although discovered as a uranium deposit in 1949, the Mountain Pass mine was opened as an RE mine in 1952 and was the dominant RE producer through the 1980s. However, by 2002, the overwhelming price advantage of Chinese suppliersalong with regulatory compliance issues associated with the mine's faintly radioactive tailings and process waterforced closure. By 2011, owner Molycorp became licensed to handle radioactive trace thorium and uranium associated

\section{References}

1. Energy Critical Elements: Securing Materials for Emerging Technologies (Materials Research Society/American Physical Society, Washington, DC, 2011). 2. A. Evans-Pritchard, "World Faces Hi-Tech Crunch As China Eyes Ban on Rare Metal Exports," New York Times (24 August 2009).

3. Critical Materials Strategy (U.S. Department of Energy, Washington, DC, December 2010), energy.gov/sites/prod/files/piprod/documents/cms_dec_17_full_ web.pdf (accessed February 2012).

4. Critical Materials Strategy (U.S. Department of Energy, Washington, DC, December 2011), energy.gov/sites/prod/files/DOE_CMS2011_FINAL_Full.pdf (accessed February 2012).

5. J.-C. Bae, "Strategies and Perspectives for Securing Rare Metals in Korea," presented at the MIT Energy Workshop on Critical Elements for New Energy Technologies, Cambridge, MA, 29 April 2010.

6. Critical raw materials for the EU: Report of the Ad-hoc Working Group on defining critical raw materials (European Commission, Brussels, Belgium, 2010). 7. "Rare Earths: Statistics and Information" (U.S. Geological Survey, Reston, VA), minerals.usgs.gov/minerals/pubs/commodity/rare_earths/ (accessed February 2012). 8. R. Rhodes, The Making of the Atomic Bomb (Simon \& Schuster, New York, 1986). 9. N. Mariano, paper presented at the MIT Energy Workshop on Critical Elements for New Energy Technologies, Cambridge, MA, 29 April 2010.

10. Minerals, Critical Minerals, and the U.S. Economy (National Academies Press, Washington, DC, 2008).

11. S. Simpson, Sci. Am. 58 (October 2011).

12. The Impact of Selling the Federal Helium Reserve (National Academies Press, Washington, DC, 2000).

13. Selling the National Helium Reserve (National Academies Press, Washington, DC, 2011).

14. The Library of Congress, Thomas Home page, thomas.gov (accessed February 2012).

15. Z. Yan, "Suspension Set to Make Rare Earths Even Rarer," China Daily (USA) (19 October 2011)

16. G.P. Hatch, China's Rare Earths Game Plan: Part 1-The Effects Of Reduced Export Quotas (Technology Metals Research, LLC, Carpentersville, IL, 2010).

17. "Global Rare Earth Oxide (REO) Production Trends" (U.S. Geological Survey, Reston, VA), minerals.usgs.gov/minerals/pubs/commodity/rare earths/ree-trends2010.pdf (accessed February 2012). 


\section{ADVANGED ENERGY MATERIALS}

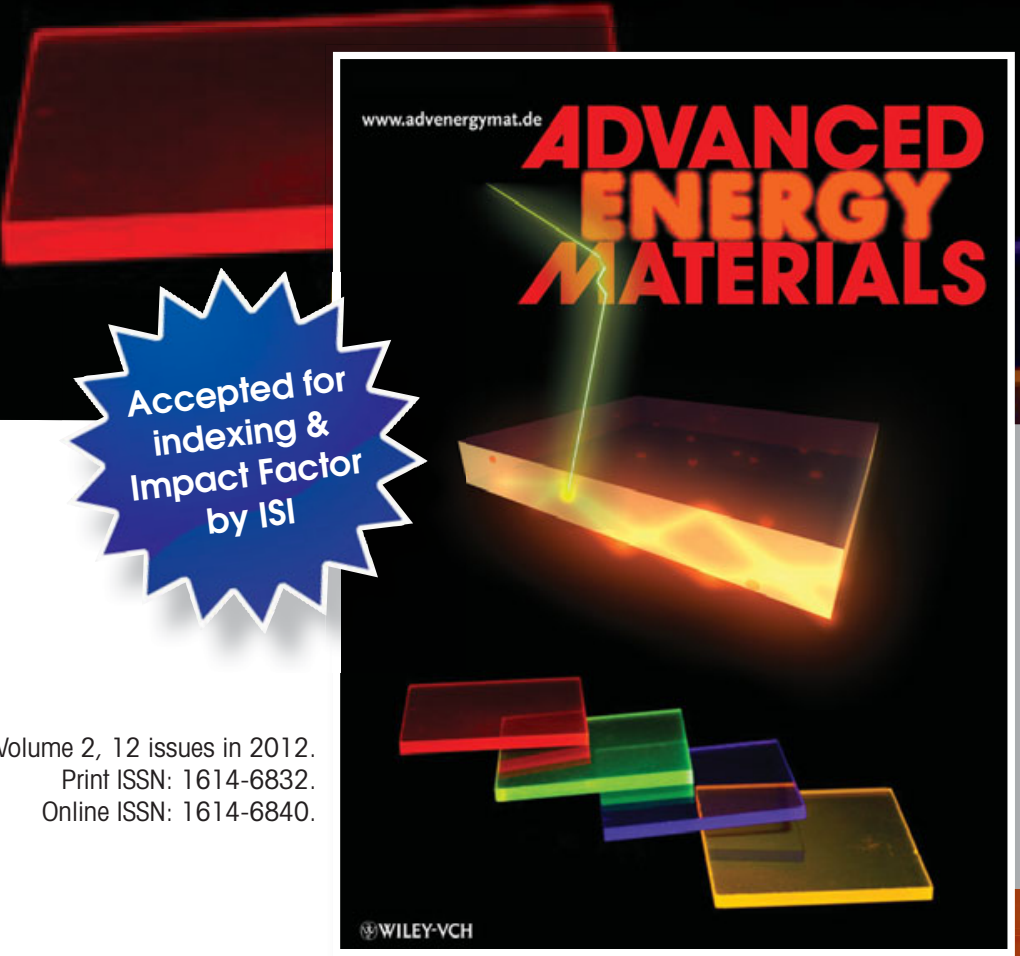

\section{Scope}

Advanced Energy Materials is an international, interdisciplinary, English-language journal of original peer-reviewed contributions on materials used in all forms of energy harvesting, conversion and storage.

\section{Advanced Energy Materials covers} all topics in energy-related research:

- all photovoltaics and artificial photosynthesis

batteries and supercapacitors

ruel cells and biofuel cells

rhydrogen generation and storage

thermoelectrics, magnetocalorics, and more

\section{Don't miss the opportunity to receive} COMPLIMENTARY ONLINE ACCESS

$$
\text { until the end of } 2012 .
$$

Reports, high-impact Full Papers, and rapid Communications.

- Advanced Energy Materials is committed to swift processing and publication of contributions: Using the new Advanced Materials online page proofing system, the editor and the publisher aim to publish papers online within ten weeks of submission.

- Advanced Energy Materials is read by materials scientists, chemists, physicists and engineers in academia as well as industry.

\section{Editorial Advisory Board}

\section{Christoph Brabec (Chair)}

Manfred Waidhas (Chair)

Peter Bruce

Jaephil Cho

Anne C. Dillon

Bruce Dunn

Alan J. Heeger

Wenping $\mathrm{Hu}$

John T. S. Irvine

René A. J. Janssen

Hagen Klauk

Frederik C. Krebs

Karl Leo
Max Lu

David B. Mitzi

Peter H. L. Notten

John A. Rogers

Debra Rolison

Gregory D. Scholes

Henning Sirringhaus

Takao Someya

Michael Strano

Zhonglin Wang

Martin Winter

Dongyuan Zhao

\section{Editorial Office}

Advanced Energy Materials is handled by the experienced Advanced Materials and Advanced Functional Materials editorial team at Wiley-VCH.

\section{Submit your work now!}

Submit your manuscript for Advanced Energy Materials

$$
\text { online via Www.manuscripłXpress.com }
$$

Manuscripts emphasizing the demonstration of applications, exploring structure-property relationships and addressing fabrication issues are particularly welcome. 


\title{
Energy limitations on materials availlability
}

\section{Igor Lubomirsky and David Cahen}

\begin{abstract}
Rapid changes in energy availability lead to the question of whether the sustainable availability of energy implies the sustainable availability of materials and vice versa. In particular, many researchers assume that materials can be produced from any resource type, irrespective of scarcity, by providing enough energy. We revisit this issue here for two reasons: (1) To avoid significant disruptions in daily life, no more than a few percent of total energy production and materials usage can be diverted to support a transition to new energy sources. (2) Such a transition could also be problematic if it requires large quantities of materials that are byproducts of other large-scale production cycles, as any increase in the production of a byproduct typically requires an almost proportional increase in the production of the primary product. In turn, increased production of the primary product could require materials and energy expenditures that are too large to be practical. Both limitations have to be taken into account in future energy planning.
\end{abstract}

\section{Introduction}

The availability of a material for technological purposes is, in practice, defined not only by its abundance in Earth's crust, but also by the amount of energy necessary for its extraction from ores. The latter factor, although frequently overlooked, is often decisive. Therefore, in this article, we discuss the thesis that the energy costs of critical materials can severely limit the transition from existing technologies to new ones. This thesis includes three parts that we view as critical in considering materials-energy interdependence:

(1) There is very little flexibility in the ability to divert energy resources to new technologies.

(2) Production of materials that are currently obtained as byproducts of other, more prominent materials cannot be increased rapidly, a fact that imposes severe restrictions on the rate of technology change.

(3) Recycling can provide only partial relief of the demand for energy to produce materials, because many items that are energy-intensive to make and/or use (not just sophisticated items such as spectacles and contact lenses, but also rather basic high-volume items such as fertilizer and cement) cannot be recycled. Moreover, recycling of some items might consume excessive amounts of energy.

\section{Difficulties estimating the true energy cost of materials}

The energy cost of a material is complicated, as it balances the amounts of energy used (or recovered) during the material's production, use, and ultimate disposal or recycling. A steel-frame building provides a good illustration of this tradeoff. Use of a steel frame is one of the most energy-efficient methods of construction; however, steel is a very good thermal conductor, which makes such a building more expensive to heat and cool. ${ }^{*, 1-5}$ Calculating the energy cost of production of materials is not easy, but a methodology based on the general principle of conservation of energy and matter is available, because it has been "inherited" from chemical engineering calculations and is actively used for life-cycle assessment and net energy analysis (see, for example, References 6 and 7). In contrast, calculating or measuring the energy consumed during use is not trivial because there are many contributions that are difficult or even impossible to estimate correctly. Therefore, the total energy cost of a certain material cannot be determined very accurately, at least at present. However, even if reliable estimates were available, their use in material-energy efficiency planning would be possible only after one considered the flexibility of allocation of energy resources.

\section{Five "major" energy-consuming materials and the flexibility of energy consumption}

More than half $(\sim 55 \%)^{8}$ of global energy consumption is by industry and transportation $(\sim 27.5 \%$ each $) .{ }^{8,9}$ The other half

* It should be noted that significant portions of the data discussed here were obtained from the websites of various governmental and commercial/industrial organizations, as such data are often not published in any more standard resources, such as journal articles. 
is by services, residential consumers, and infrastructure. The energy used by industry is mostly for materials processing. Remarkably, comparison of the energy costs of materials production shows that more than half of all industrial energy use goes to a very small number of materials, namely, steel $(\sim 6 \%),{ }^{10,11}$ cement $(\sim 3 \%$; see the article by Van Vliet et al. in this issue), ${ }^{12}$ ammonia ${ }^{13,14}$ by the Haber-Bosch process (1-2\%), aluminum by the Hall-Héroult process $(\sim 1.8 \%),{ }^{10,11}$ and plastics $(2-4 \%) .{ }^{11,15}$ It is also important to emphasize that, although new "high-tech" materials have penetrated almost all parts of modern technologies (e.g., titanium, magnesium, tungsten carbide, mu-metal, industrial diamond, conducting and antistatic plastics), they account for a very small fraction of the materials used in everyday life.

These five major energy-consuming materials are, together with the other top energy consumer, transportation, vital for daily life, and therefore, their production (and consumption) cannot be restricted without an immediate and drastic drop in living standards. This implies that, at the current stage, society has restricted its ability to divert energy resources anywhere else on a large scale, leaving only residential use ( $24 \%$ of the total) and commercial services $(<10 \%)$ as major sources for such a diversion, should it become necessary. One could also expect some contribution from transportation. However, unless there is a mass transition from private cars to public transport or a dramatic drop in cargo shipments, transportation will not be able to contribute significantly. Therefore, based on the variations in materials and energy consumptions that have occurred during periods of economic crisis, when people tend to cut the least essential expenditures, one can "guesstimate" that at most $\sim 10 \%$ of these energy uses (i.e., about $3.5 \%$ of total global energy production) can be diverted to a transition to alternative technologies without disrupting living standards in a major way.

\section{How can sustainable energy availlabillity affect sustainable materials availability?}

The very close connection between materials and energy suggests that changes in the availability of one energy source will immediately cause changes in the availability of all other energy sources and, in that way, cause a ripple throughout the system, affecting all materials. At the same time, the analysis in the preceding section indicates that diversion of a few percent of total energy resources for "transition purposes" is very likely possible. Because the range of materials in practical use is restricted by the amount of energy required for their production, a rapid rise in energy costs will inevitably be accompanied by a reduction in (or even the complete elimination of) the use of materials with high energy costs. If changes are sufficiently gradual, as many economists (and others) predict, then the adaptation of materials production to changes in energy sources will also be smooth, and the materials in use will adapt to the new restrictions on energy availability. Examples of such smooth transitions include the replacements of blubber by kerosene for lighting in the late 19th century and of Bakelite by modern polyethylene-based plastics after the development of the latter in the 1950 s.
If changes were rapid, which could happen if, for example, oil supply dropped by $50 \%$ within a few months, then many materials would rapidly disappear from use because of the jump in energy prices, causing severe disruptions. The degree of these disruptions would depend on how fast an alternative energy source could be deployed. In some cases, such alternatives exist now, but their deployment is obstructed for various reasons. An example of such a case is the possible replacement of gasoline by methanol (see the sidebar). ${ }^{16,17}$ Although such a replacement seems to be viable already with the current wholesale prices, it has not yet taken place for political reasons that are beyond the scope of this article and issue. Similar economically feasible or almost feasible alternatives exist for many (if not all) energy-production technologies. Thus, even with rapid changes and severe disruptions, one can expect that adaptation will eventually take place.

However, the example with methanol involves two hidden assumptions: that the changes in energy availability will be on a scale of a few percent of the actual energy consumption and that the materials necessary for a transition to a new energy-generation technology will be available. Although the first condition is almost guaranteed because oil wells will not go dry instantaneously and coal fields will not be exhausted at once, the second condition is questionable, as discussed in detail in the next section.

\section{Availability of materials produced as byproducts}

Apart from a relatively large but finite list of materials that are produced and extracted directly from ores (so-called primary products, such as iron, copper, aluminum, and tin), many materials are extracted as byproducts of a primary product.

\section{Methanol versus gasoline} prices

Price of methanol on 3 August 2011: US\$459/t

Density of methanol: $0.79 \mathrm{~g} / \mathrm{cm}^{3}$

Ratio of methanol to gasoline energy content $(w / w)$ : 0.55

Cost of the amount of methanol equivalent to $1 \mathrm{gal}$ (U.S.) of gasoline:

$$
\begin{aligned}
\text { cost } & =\frac{\left(459 \times 10^{-6} \mathrm{US} \$ / \mathrm{g}\right) \times\left(0.79 \mathrm{~g} / \mathrm{cm}^{3}\right) \times\left(3.785 \times 10^{3} \mathrm{~cm}^{3} / \mathrm{gal}\right)}{0.55} \\
& =\mathrm{US} \$ 2.50
\end{aligned}
$$

$\mathrm{Cost}^{\dagger}$ of 1 gal (U.S.) of gasoline before taxes on 3 August 2011: US\$3.20

† Includes the costs of crude oil (US\$2.56/gal) and refining (US\$0.64/gal). 
For instance, selenium and tellurium are byproducts of the electrolytic refining of copper, during which they accumulate in anode residues. The total annual production is $\sim 2300-2500 \mathrm{t}$ of selenium (2009) and $\sim 150$ t of tellurium (2010). ${ }^{10}$ Significantly increasing the production of these two elements using the existing technological route is not an option in the short term (a few years), because it would require a many-fold increase of copper production, which is not viable, either practically or economically. Production of refined copper, excluding its transport, has an energy price of $\sim 23 \mathrm{GJ} / \mathrm{t},{ }^{18}$ which is increasing steadily as high-grade ores become exhausted and hauling distances increase. One can expect rising prices to be an incentive for more efficient extraction, but even in the best scenarios, increased efficiency is unlikely to increase the production several-fold.

The case of photovoltaics illustrates the dilemma of depending on materials that are byproducts. Whereas the article by Fthenakis in this issue discusses the availability of materials for new solar cells, we focus here on the energy required to acquire the materials. For the sake of argument, assume that we want to achieve a 100-fold increase in materials supply, from today's $0.07 \mathrm{TW}_{\mathrm{p}}$ (terawatt-peak) installed generating capacity to $7 \mathrm{TW}_{\mathrm{p}}$, which corresponds to $\sim 1.15 \mathrm{TW}_{\mathrm{c}}$ (terawatt-continuous, assuming optimal use of the generating capacity).

For the increasingly popular CdTe solar cell, this increased energy production would require a 100 -fold increase in tellurium production, assuming current efficiencies. In the following discussion, for the sake of simplicity, we assume that all of the new tellurium goes to CdTe solar cell production. In that case, a 100-fold increase in copper production would be required. In 2009, copper production $(\sim 16 \mathrm{Mt})^{10,18}$ used about $0.08 \%$ of all global energy. Increasing this value 100 -fold is hardly realistic, because it would consume all of the "flexible" part of the available energy defined in the preceding section. Furthermore, it would require construction for primary copper ore treatment on a huge scale, which is not a realistic proposition, especially within a period of a few years.

The situation is very similar for gallium and indium, required for $\mathrm{Cu}(\mathrm{In}, \mathrm{Ga}) \mathrm{Se}_{2}$ (CIGS) solar cells. Both of these elements are byproducts of the production of other elements. Gallium is mostly produced from residues of bauxite (aluminum ore) or extracted from zinc-processing residues. In both cases, the gallium content does not exceed $50 \mathrm{ppm}$, and its annual total production is $\sim 180 \mathrm{t}$ (2008). Furthermore, even though the total content of gallium in known deposits of bauxites and zinc ores is $\sim 1 \mathrm{Mt}$, a 100-fold increase of gallium production would require that all energy currently used for industrial consumption be directed to gallium production. To install $0.01 \mathrm{TW}_{\mathrm{c}}$ capacity based on CIGS solar cells would require more than $10^{5} \mathrm{t}$ of gallium, so that a 100-fold increase might not suffice (again, assuming that all new gallium went to CIGS cell production). The value of this example is that it demonstrates a material (gallium) that is known to exist and to have an accessible extraction technology, but for which the extraction energy requirements are prohibitively high. In answer to the question posed at the beginning of this article, then, this implies that sustainable energy availability and sustainable materials availability are not equivalent. In practice, the term "energy availability" always refers to some reference value, which is typically the current level of consumption. One of the most obvious consequences of this conclusion is that, as things stand now, the world in $\sim 2040$ will not be able to rely on these compound solar cells for, say, $5 \%$ of global electricity generation $\left(\sim 1-2 \mathrm{TW}_{c}\right.$, which requires a global average of 6-12 $\mathrm{TW}_{\mathrm{p}}$ ) with present types of cells and present mining and extraction technologies.

Now consider the energetic viability of crystalline-silicon solar cells. In contrast to the thin-film cells just discussed, in these cells, the raw material is plentiful and is obtained as a primary product. For crystalline-silicon solar cells, the energy payback time, which is the time required for the cells to produce the amount of energy needed to make them, is still several years. ${ }^{19}$

Because of this long payback time, one can expect that, even if $1 \%$ of all energy for industrial use $(0.25 \%$ of the total use) were diverted to create silicon solar cells, issues such as borrowing costs and return-on-investment times would impede the rapid manufacturing of all of the cells needed for this extent of electrical power generation. Also, even if ways are found to decrease the energy payback time (e.g., metallurgical refinement of silicon in place of silane-based purification), it will take decades for silicon cells to make a significant contribution to total global energy production. Nevertheless, this shows that, after a few decades, a transition to solar power based on crystalline silicon is energetically feasible. (Other problems associated with the technology, such as land availability and dust control, will also need to be solved.)

As a final example, consider the production of hydrogen through water electrolysis using platinum-based electrodes. The total amount of platinum produced each year from ores (not recycled) is $\sim 180$ t. $^{10}$ Assume that one-tenth of this total production is diverted to water electrolysis. Then, running a cell at a most optimistic $1.5 \mathrm{~V}$ potential ( $82 \%$ efficiency), using 100 -nm-thick electrodes and restricting the current to $0.1 \mathrm{~A} / \mathrm{cm}^{2}$ to minimize platinum gas erosion, one could convert $135 \mathrm{GW}$ of electrical energy into hydrogen. This is less than $0.3 \%$ of the energy required for transportation. Even if such a diversion of platinum continued for 50 years, which is unlikely because platinum is needed for other purposes, hydrogen would still not be an important transportation fuel. The scale of platinum extraction that would be needed to support a major portion of global fuel needs would require prohibitively high energy diversion. Nickel-based catalysts can be used instead of platinum, but at present, their use exacts a significant increase in energy price. Moreover, a sizable increase in platinum production is not feasible at present, because the platinum content of the richest known ore (Buchveld, South Africa, responsible for more than $75 \%$ of world production) is only $\sim 8-9 \mathrm{~g} / \mathrm{t}(4-7 \mathrm{~g} / \mathrm{t}$ 


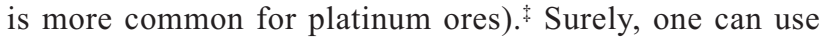
electrodes other than platinum; however, this would result in a considerable efficiency loss (more than a factor of two) and require correspondingly higher amounts of energy.

Even for common materials, energy availability must be considered, as a sudden increase in usage could cause significant upheaval. For instance, if cement production had to be increased by one-third, a $1 \%$ increase in total world energy production would be required. Although possible, this increase would be hard to achieve within a short time and would severely strain society's ability to undertake other large-scale projects.

Two conclusions can be drawn from the analyses in this section: (1) The idea that sustainable availability of energy is equivalent to sustainable availability of materials is true only in the long run. In the short run of a few years, any increase in the production of byproducts (secondary mining products) is essentially impossible. (2) Some materials are physically unavailable at any energy price in the quantity needed or desired.

\section{Energy efficiency and the potential of recycling}

One often hears that, with time, production becomes less materials- and energy-intensive, because of the introduction of increasingly efficient processes. Although this trend is generally valid, production of materials might prove to be an exception for a number of reasons, the most obvious of which is the depletion of rich ores (although there are different opinions on this matter ${ }^{21,22}$ ). Increased hauling distances are also a factor, as is becoming increasingly evident, for instance, for copper production. ${ }^{18}$ In this view, the impact of energy costs on materials availability results from more than one trend. Therefore, the question of whether consumption of materials will continue to grow or stabilize becomes clearly linked to the monetary cost of energy (and to the energy cost of the forms of energy needed). As noted by Krausmann et al., global materials extraction increased rapidly (close to exponentially) during the past 100 years (although much of this increase comes from increasing population; the increase in materials use per capita was much more modest), ${ }^{23}$ as shown in Figure 1. Therefore, both the total amount of energy used by industry and the industrial fraction of total energy consumption have increased steadily and will continue to do so.

One of the main, and probably most efficient, ways to alleviate this trend is recycling. (See the article in this issue by Gaines.) Currently, metals are recycled at reasonable rates, with the following fractions of recycled metals in new products: lead, $>90 \%$; iron, 55-65\%; aluminum, 40-50\%; tin, $>50 \%$;

‡ The presently used dye-sensitized solar cells use tiny amounts of a ruthenium dye. Can $1 \mathrm{TW}_{\mathrm{c}}$ of electrical power be generated from large-scale use of these cells? Assuming $10 \%$ efficiency, a factor of 5 to account for peak versus continuous power, and at least $0.02 \mathrm{~g} / \mathrm{m}^{2}$ of ruthenium (estimate for full dye coverage), we find that the required $5 \times 10^{10} \mathrm{~m}^{2}$ area would use some $1000 \mathrm{t}$ of ruthenium. Given today's yearly production of ruthenium ( $12 \mathrm{t}$ according to Reference 20 ), this becomes a difficult proposition and explains the intense search for ruthenium-free alternatives.
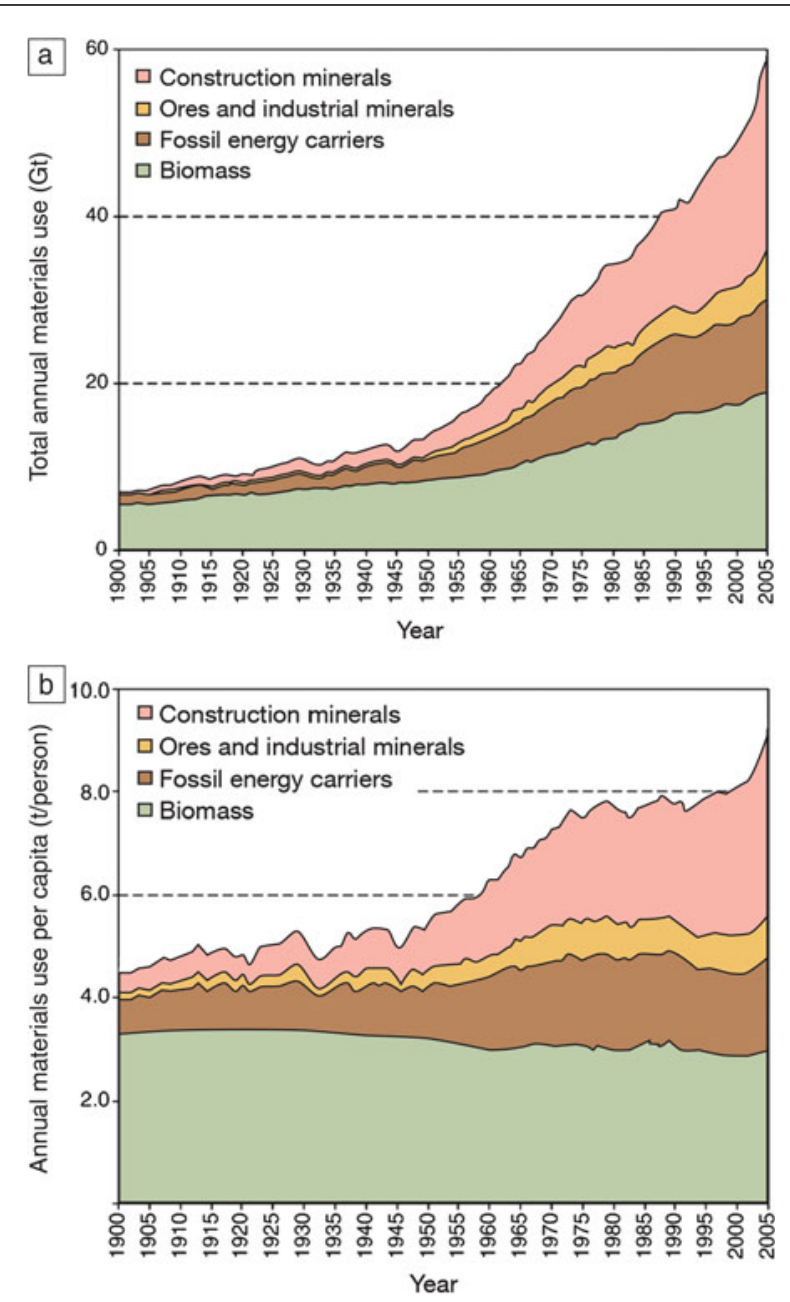

Figure 1. (a) Total annual materials use per year and (b) annual materials use per capita. Data and figure used with permission from Reference 23. (c) 2009, Elsevier.

magnesium, $>40 \%$; and copper, $>25 \% .{ }^{24}$ Naturally, these are materials with high to very high energy price tags, and one can expect their degrees of recycling to continue to increase, although it will never reach $100 \%$. However, two large contributors to industrial energy use cannot be efficiently recycled, even in theory, namely, cement and fertilizer. Taken together, these materials comprise about $4-5 \%$ of global energy consumption and about $20-25 \%$ of global industrial energy consumption (see the section Five "major" energy-consuming materials and the flexibility of energy consumption). With continuing increases in standard of living, production and consumption (Figure 1) 2 $^{23}$ of these materials will continue to rise, and according to current trends, within the next few decades, one can expect these materials to become even more dominant energy consumers than they are now. Furthermore, as natural (as opposed to cultivated) food resources dwindle (for instance, caught rather than farmed fish) and the number of cultivated products increases, the amount of energy required for engineered replacements will continue to grow. ${ }^{25}$ Thus, although 
extremely important, recycling will not be a universal cure for energy savings, and the price of energy will continue to influence everyday life significantly.

In conclusion, materials availability is indeed limited by energy availability. However, because the amount of energy that can be diverted for transitioning to new technologies at any given moment is limited, sustainable availability is not equivalent for these two entities. This thesis is of the utmost importance for making decisions about which types of alternative technologies are to be adopted, because current prices and current energy expenditures might not reflect those that will be relevant if even a small increase in demand occurs. Indeed, it is possible that, even after a transition is initiated, materials unavailability could render its completion impossible.

\section{References}

1. "Advantages and Disadvantages of Steel Frame Buildings" (Steel Buildings Blog, 9 September 2010), capitalsteelbuildings.wordpress.com/2010/09/09/ advantages-and-disadvantages-of-steel-frame-buildings (accessed 24 February 2012).

2. "The Concrete Advantage" (Reinforced Concrete Construction Committee, Wilmington, MA), www.rc3online.com/advantages.html (accessed 24 February 2012).

3. "Sustainable Development with Concrete" (Portland Cement Association, Skokie, IL), www.concretethinker.com/Benefits.aspx (accessed 24 February 2012). 4. N. Gurung, M. Mahendran, Building Res. Inf. 30, 35 (2002).

5. P. Winistorfer, Z.J. Chen, B. Lippke, N. Stevens, Wood Fiber Sci. 37, 128 (2005).

6. C. Oloman, Material and Energy Balances for Engineers and Environmentalists (Imperial College Press, London, 2009).
7. S. Hirschberg, S. Roth, C. Bauer, P. Burgherr, R. Dones, T. Heck, W. Schenler Ann. Nucl. Energy 36, 409 (2009).

8. International Energy Outlook 2011 (Report DOE/EIA-0484, U.S. Department of Energy, Washington, DC, 2010).

9. World Energy Outlook 2009 (Organisation for Economic Co-operation and Development, Paris, France, 2009).

10. 2010 Minerals Yearbook (U.S. Geological Survey, Washington, DC, 2011).

11. K. Scrivener, H. Van Damme, MRS Bull. 29, 308 (2004).

12. A.R. West, Solid State Chemistry and Its Applications (Wiley, Chichester, UK, 1984), chapter 19.

13. "3. Benchmarking Results" (Natural Resources Canada, Ottawa, Ontario, Canada), oee.nrcan.gc.ca/industrial/technical-info/benchmarking/ammonia/results.cfm? attr=24 (accessed 24 February 2012)

14. "Greener industry" (Chemical Industry Education Centre, University of York, York, UK), www.greener-industry.org.uk/pages/ammonia/1ammoniaapq.htm (accessed 24 February 2012)

15. B. Kuhlke, T. Walsh, presented at the Annual Technical Conference of the Society of Plastics Engineers (ANTEC 2002), San Francisco, CA, 5-9 May 2002. 16. "Methanol Price" (Methanex Corporation, Vancouver, BC, Canada), www. methanex.com/products/methanolprice.html (accessed 24 February 2012).

17. "U.S. Pump Price Update-August 3, 2011 (American Petroleum Institute, Washington, DC), www.api.org/aboutoilgas/gasoline/upload/PumpPriceUpdate. pdf (accessed 24 February 2012)

18. Greenhouse Gas Emissions from World Copper Mining: A Mine-by-Mine Analysis (Metalytics Pty Limited, Sydney, NSW, Australia)

19. "PV FAQs" (National Renewable Energy Laboratory, Golden, CO, 2010), www.nrel.gov/docs/fy05osti/37322.pdf (accessed 24 February 2012).

20. "Ruthenium - Ru" (Lenntech BV, Delft, The Netherlands), www.lenntech.com/ periodic/elements/ru.htm (accessed 24 February 2012).

21. G.M. Mudd, Resour. Policy 35, 98 (2010).

22. J. West, J. Ind. Ecol. 15, 165 (2011).

23. F. Krausmann, S. Gingrich, N. Eisenmenger, K.H. Erb, H. Haberl, M. Fischer-Kowalski, Ecol. Econ. 68, 2696 (2009).

24. Recycling Rates of Metals (United Nations Environment Programme, Paris, France, 2011).

25. K.H. Erb, F. Krausmann, V. Gaube, S. Gingrich, A. Bondeau, M. Fischer-Kowalski, H. Haberl, Ecol. Econ. 69, 250 (2009).

\section{NEW TEXTBOOK}

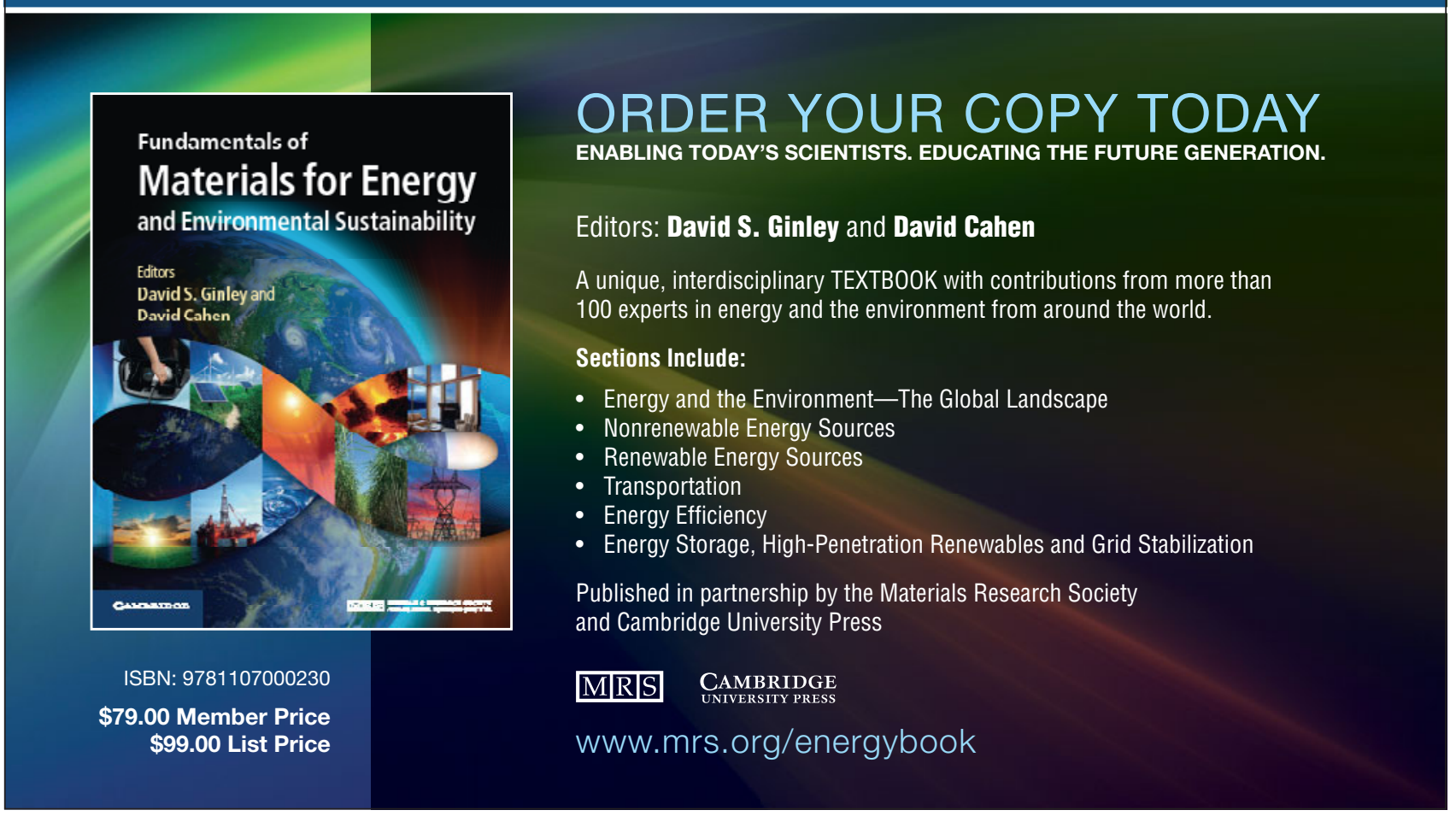




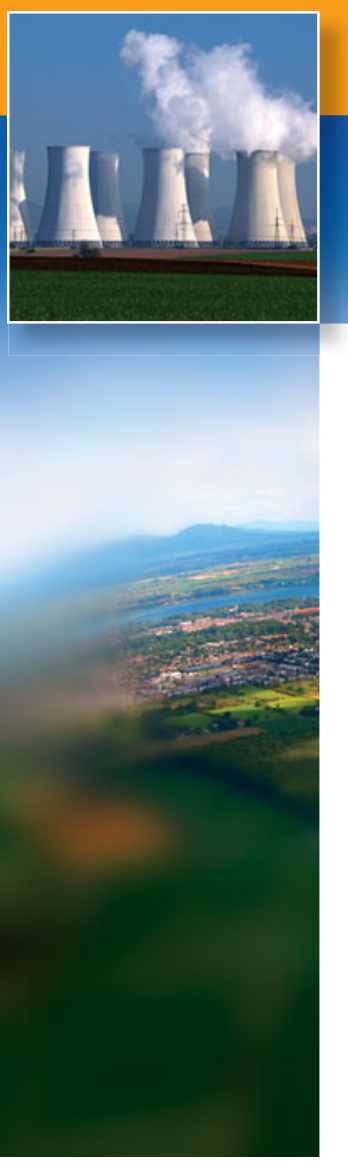

\title{
Is nuclear fission a sustainable source of energy?
}

\author{
Matthias Englert, Lindsay Krall, and Rodney C. Ewing
}

\begin{abstract}
During this century, humankind must deal with increasing demand for energy and the growing impact of burning fossil fuels. Nuclear power, which presently produces $14 \%$ of global electricity, is a low-carbon-emissions alternative. However, the sustainability of nuclear power depends on the amounts of uranium and thorium available, the economics of their recovery from ore deposits, and the safety and security of nuclear materials. Unlike combustion of hydrocarbons, which determines the amount of fuel needed for a given amount of energy, nuclear reactions can create additional fissile isotopes. Hence, the choice of nuclear fuel cycle profoundly affects the size of the nuclear resource, as well as nuclear waste management and the risk of proliferation of nuclear weapons. We argue that uranium resources, identified and yet to be discovered, could sustain increases in nuclear power generation by a factor of two or three through the end of this century, even without advanced closed-fuel-cycle technologies.
\end{abstract}

\section{Introduction}

Nuclear power could ease the transition to a more sustainable energy economy, if it can substitute for enough fossil fuel. Key to evaluating the potential of nuclear energy to meet future demands are the amounts of uranium and thorium economically available. Estimates are necessarily speculative, as they require knowledge of the abundance, quality, and distribution of the metals in ore deposits, as well as the costs of extraction (mining and milling). In addition, the potential energy production is profoundly affected by the choice of nuclear fuel cycle.

For the open fuel cycle, which entails direct disposal of used nuclear fuel, nuclear power capacity depends directly on the amounts of uranium and thorium available. Today's estimates of uranium resources have identified 6300 kilotonnes (kt) (at a price of up to US $\$ 260 / \mathrm{kg}$ of uranium), which would sustain the current demand of roughly $63 \mathrm{kt} / \mathrm{yr}$ until the end of this century. If nuclear power generation were to double or triple by the end of the century, the currently estimated 10,400 kt of undiscovered resources would have to be brought into production as well.

The open fuel cycle uses less than $1 \%$ of the energy content of the uranium fuel. In contrast, the closed fuel cycle, with reprocessing to reclaim fissile nuclides such as plutonium, can extend the uranium resource by breeding fissile ${ }^{239} \mathrm{Pu}$ from the much more abundant ${ }^{238} \mathrm{U}$ or fissile ${ }^{233} \mathrm{U}$ from ${ }^{232} \mathrm{Th}$. The fully closed fuel cycle requires advanced processing technologies that can efficiently separate fissile actinides, as well as the development and use of fast reactors that employ higher-energy neutrons that fission actinides more efficiently. Such fully closed systems could use as much as $70 \%$ of the energy content of the nuclear fuel. In addition to efficiency, however, the sustainability of nuclear power also depends on how each type of fuel cycle affects the risk of nuclear proliferation and the disposal of nuclear waste.

\section{Uranium as a reactor fuell}

Mined uranium ore, mainly $\mathrm{UO}_{2}$ and $\mathrm{USiO}_{4}$, is chemically concentrated in the form of so-called yellowcake $\left(\mathrm{U}_{3} \mathrm{O}_{8}\right)$. This natural uranium produced from mines contains only $0.72 \%$ fissile ${ }^{235} \mathrm{U}$; the remainder is ${ }^{238} \mathrm{U}$. It can be directly used only in reactors that use heavy water ( $>99 \%$ deuterium) or graphite as a moderator to slow the high-energy neutrons released in a fission event. For use in light-water-moderated reactors (LWRs), yellowcake is converted to gaseous uranium hexafluoride $\left(\mathrm{UF}_{6}\right)$ and enriched, typically to $3.5-5 \%{ }^{235} \mathrm{U}$, by either centrifuge or gaseous-diffusion technologies. In most of today's reactors, the final fuel is $\mathrm{UO}_{2}$, although some use metallic uranium. Some advanced designs envision the use of ceramic or molten-salt uranium fuels. 
Most nuclear power plants today use the uranium/plutonium fuel cycle. The world's 440 or so reactors produce $375 \mathrm{GW}$ of electricity $\left(\mathrm{GW}_{\mathrm{e}}\right),{ }^{1}$ about $14 \%$ of the global supply. ${ }^{2}$ Most reactors are LWRs. A typical core contains $100 \mathrm{t}$ of fuel, in the form of ${ }^{235} \mathrm{U}$-enriched $\mathrm{UO}_{2}$, and generates approximately 20-30 t of spent fuel per year. Together, the world's reactors require the production of approximately $63 \mathrm{kt}$ of natural uranium each year. ${ }^{3}$

\section{Uranium resource estimates}

Every two years, the International Atomic Energy Agency (IAEA) and the Nuclear Energy Agency of the Organization for Economic Co-operation and Development jointly publish global estimates of the uranium available in various categories of resources in the "Red Book" (Table I), based on mining-company estimates. In 2009, 4000 kt of uranium was classified as being in reasonably assured resources (RAR), for which there is direct geological evidence. Knowledge of existing deposits leads with high confidence to the location and size of an additional $2300 \mathrm{kt}$ in inferred resources (IR). Together, these two classes constitute identified resources, and their distribution is shown in Figure 1. The world's largest known deposit, Olympic Dam in South Australia, is estimated to have $1447 \mathrm{kt}$ of uranium in RAR

Note: Data from the International Atomic Energy Agency (IAEA) "Red Book." ${ }^{\prime 6}$ As of June 2011, yellowcake $\left(\mathrm{U}_{3} \mathrm{O}_{8}\right)$ was priced at US\$56/lb

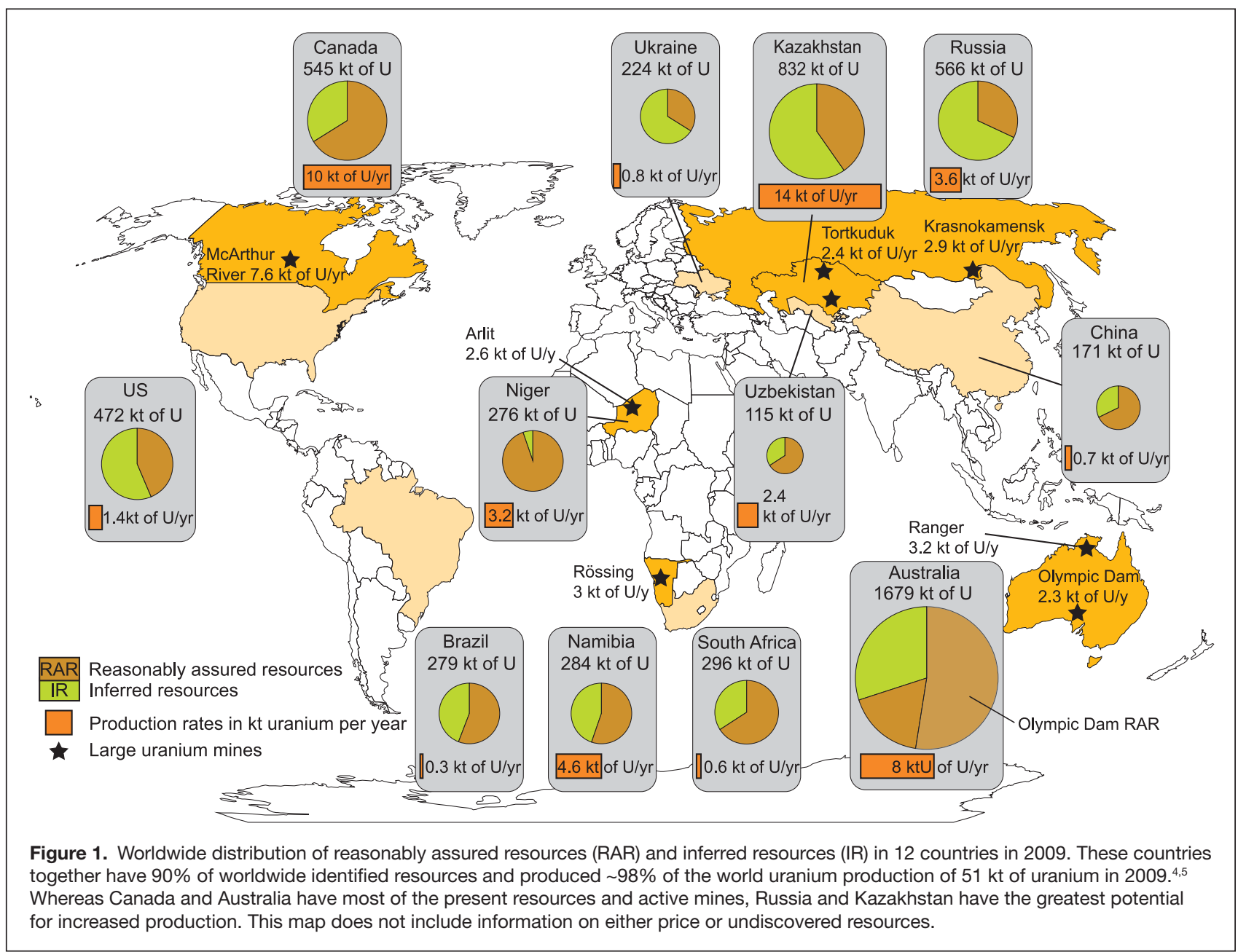


and $625 \mathrm{kt}$ in IR (2010). ${ }^{6}$ Other deposits are much smaller, some having IR of 100-300 kt of uranium and many more with less than $100 \mathrm{kt}$.

Beyond these identified resources, the Red Book estimates an additional 10,400 kt of uranium in undiscovered resources. Extrapolations concerning the existence of these deposits are based on evidence in known uranium provinces where there is either some direct evidence (prognosticated) or similarities in geologic occurrence (speculative).

In addition, there are unconventional sources of uranium, such as the tailings left behind at gold or uranium mines. Elevated uranium concentrations also occur in phosphate deposits and black shales. Uranium resources in phosphates are estimated to be more extensive than conventional uranium deposits. Extracting uranium as a byproduct of the production of phosphate-based fertilizers could yield up to roughly $10 \mathrm{kt}$ per year, depending on the average ore concentration and world fertilizer demand. Finally, uranium could be extracted from seawater, where it constitutes about $3 \mathrm{ppb}$ by weight, but technological advances are still required to make large-scale extraction economical. ${ }^{7}$

A key issue in estimating the size of a resource is the interplay between the ore grade and the costs of exploration and extraction. The market price of uranium and the exploration activity are strongly correlated (Figure 2). Because increasing price (or more efficient extraction technology) makes it economical to mine lower concentrations, a higher price makes more resources economically attractive, as shown in Table I. The past 40 years of reported uranium resources are summarized in Figure 2. The resource estimates for identified and prognosticated resources have remained constant or increased despite the total cumulative production of $2500 \mathrm{kt}$.

\section{Uranium production and secondary sources of uranium}

During the past 20 years, the amount of uranium mined globally has been less than the global demand for nuclear reactors (Figure 3). Up to $50 \%$ of the demand has been satisfied from

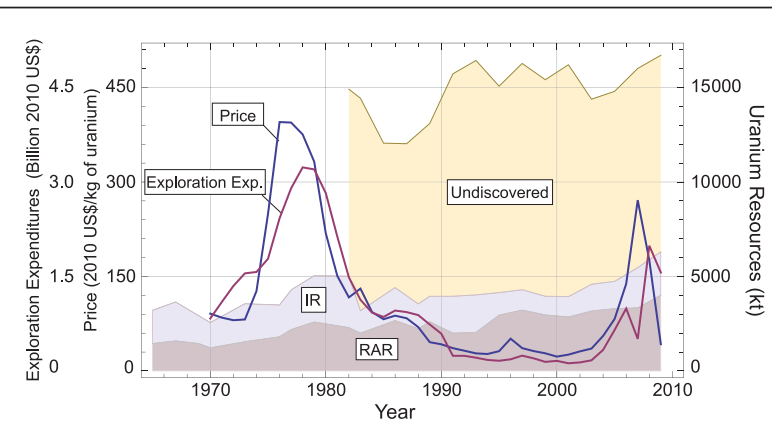

Figure 2. World uranium spot prices and exploration expenditures, as reported in the "Red Book" of the International Atomic Energy Agency (IAEA). ${ }^{4}$ Uranium prices and expenditures are inflation-adjusted and reported in 2010 U.S. dollars. Reported undiscovered resources fluctuated substantially, partly because of the failure of some countries to report. $4,8-11$ stockpiles built up in the 1970s and from secondary sources. The latter include highly enriched uranium (HEU) from nuclear weapons that have been dismantled and blended down for use in reactor fuels as part of the U.S.-Russian Megatons-toMegawatts collaboration. ${ }^{12}$ By the end of 2013, this program will have blended down a total of $500 \mathrm{t}$ of $\mathrm{HEU}\left(>90 \%{ }^{235} \mathrm{U}\right)$ from Russian nuclear weapons to low-enriched reactor-grade fuel. The low-enriched uranium has been used in civilian reactors since 1993, displacing 5-7 kt of natural uranium per year.

Excess plutonium from weapons and separated plutonium from civilian power-production reactors can also be used to fabricate a fuel that is a mixed oxide of uranium and plutonium (MOX). As a rule, roughly $1 \mathrm{t}$ of HEU or separated plutonium will support the operation of a $1 \mathrm{GW}_{\mathrm{e}}$ reactor for one year. The global HEU stockpile of $\sim 1700 \mathrm{t}$ and stocks of separated plutonium of $\sim 500 \mathrm{t}$ can provide nuclear fuel for 5-6 years of global demand, assuming the present consumption level. ${ }^{13}$

Another secondary source of uranium is the waste streams from enrichment plants. Depleted uranium, usually regarded as waste, still contains $0.2-0.4 \%{ }^{235} \mathrm{U}$. The world stockpile of $1900 \mathrm{kt}$ of depleted uranium could provide the equivalent of about $500 \mathrm{kt}$ of natural uranium, 7-8 years of today's global demand.

Because of the scheduled end of the Megatons-to-Megawatts program in 2013 and some technical, political, and financial difficulties in mine openings and operations, there have been predictions in the past several years that the strategic gap between supply and demand could increase after 2013. Despite a substantial increase in uranium production between 2003 and 2010 from $35 \mathrm{kt}$ to $53 \mathrm{kt}$, current production is still short of the global demand. Nevertheless, the mining industry has already reacted, and more mining projects or extensions are scheduled to begin operation within the next 5-10 years. ${ }^{4}$ Most current projections now show a probable overproduction of uranium during the next 15 years. ${ }^{4}$ However, a tight supply situation might develop if some of the new projects do not develop as expected, leading to increased uranium prices but also to opportunities for uranium producers with new projects.

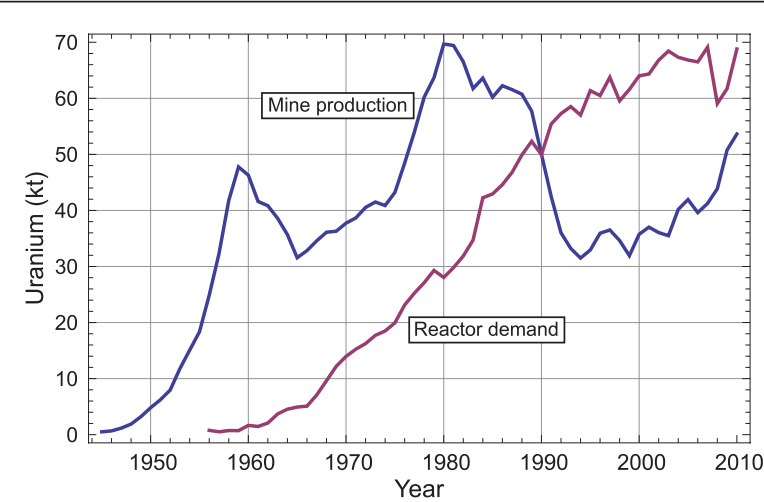

Figure 3. Historical annual uranium production and demand. Because early uranium mining was mainly for military purposes, peak production occurred in the 1970s because of high uranium prices and military needs. ${ }^{10}$ 


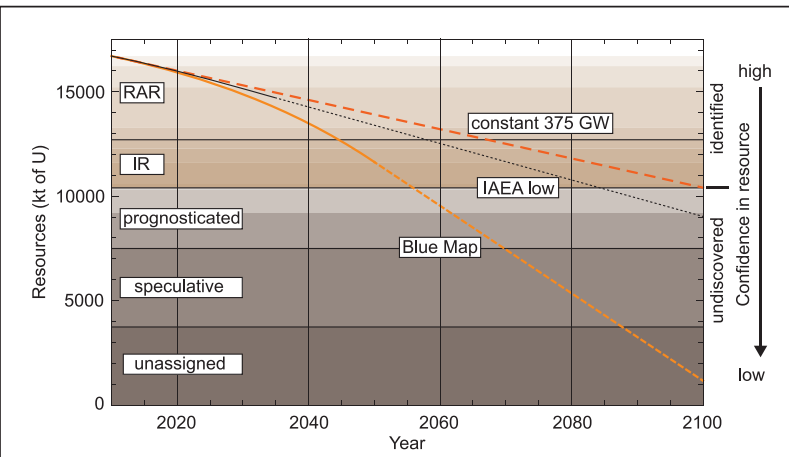

Figure 4. Estimated usage of uranium resources in different categories ${ }^{4}$ according to different scenarios. The solid (orange) line shows the demand for uranium from the International Energy Agency (IEA) BLUE Map scenario. ${ }^{15}$ The dashed (red) line shows the demand for continued use of nuclear power at the current level $\left(375 \mathrm{GW}_{\mathrm{e}}\right)$ throughout the 21st century. For comparison, the dotted (black) line shows the IAEA low-demand scenario until $2035 .{ }^{4}$ This plot extends the BLUE Map and the low-demand scenarios to 2100 assuming constant total power generation.

\section{Scenarios for demand and consumption}

Most studies that envision increasing nuclear power to reduce greenhouse gas emissions project a two- to tenfold expansion during the 21 st century, although increases by a factor of two or three are the most that can reasonably be expected by $2050 .{ }^{14}$ As an example, the BLUE Map scenario from the International Energy Agency (IEA) aims to decrease $\mathrm{CO}_{2}$ emissions to $50 \%$ of the 2005 level by 2050 . In this scenario, nuclear power would more than triple, to $1200 \mathrm{GW}_{\mathrm{e}}$, by $2050 .{ }^{15}$ Such an effort could increase the global nuclear share of electricity production to $\sim 24 \%$ by 2050 , contributing $\sim 6 \%$ to the total reduction in global $\mathrm{CO}_{2}$ emissions. In addition to the necessary replacement of the current fleet of reactors, 362 of which will have surpassed a 60-year lifetime by $2050,{ }^{1}$ more than 1000 new reactors would have to be constructed worldwide, a very demanding task.

Based on the IEA BLUE Map scenario, a once-through open cycle would consume all present RAR by 2045 (Figure 4). IR would satisfy demand until 2055, when the annual uranium demand is projected to be about $210 \mathrm{kt} / \mathrm{yr}$. Before this time, substantial uranium resources must be discovered to meet the demand for the rest of the century, even with the projected threefold increase.

Although such projections of future energy utilization are highly speculative, they show that current identified resources by themselves cannot sustain a threefold increase in nuclear power from LWRs. Rather, to satisfy an extrapolated constant demand until 2100 (obtained by extending the BLUE Map scenario beyond 2050), all of today's prognosticated and speculative uranium resources that are projected to cost less than US $\$ 130 / \mathrm{kg}$ must be discovered and brought into production, and lower-grade ores must be more efficiently extracted. Changes in the fuel cycle to extend uranium supply can help meet these requirements, but the advantages and disadvantages of each approach must be weighed carefully.

\section{Higher-efficiency nuclear fuel cycles}

To extend uranium resources, fissile nuclides can be reclaimed from spent nuclear fuel (SNF). In addition to the residual ${ }^{235} \mathrm{U}$ in SNF, neutron captures by ${ }^{238} \mathrm{U}$ and subsequent $\beta$-decay create ${ }^{239} \mathrm{Pu}$. Even in present-day LWRs, ${ }^{239} \mathrm{Pu}$ accounts for about onethird of the fission energy produced. Different fuel cycles reflect different strategies for utilizing ${ }^{235} \mathrm{U}$ and ${ }^{239} \mathrm{Pu}$, with important implications for uranium demand.

The once-through open cycle treats SNF as a waste that is directly discarded in a geological repository (Figure 5). This is the present strategy in the United States, Germany, Canada, Finland, and Sweden.

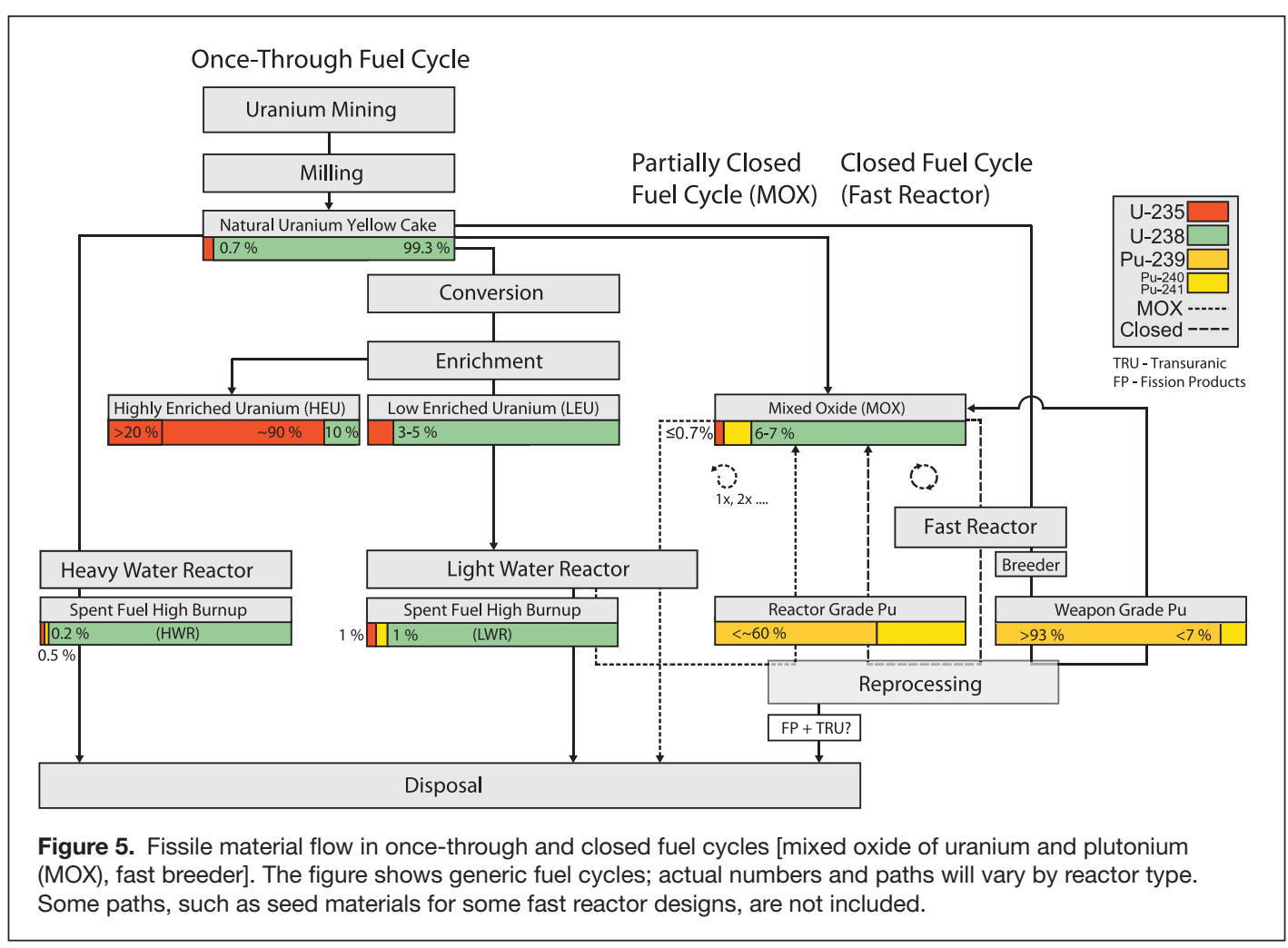


In contrast, France, Japan, and Russia consider the plutonium $(\sim 1$ atom $\%)$ and residual uranium in SNF as a recyclable resource. A closed fuel cycle with reprocessing retrieves approximately $99 \%$ of the fissile nuclides. Reusing reprocessed uranium in fresh fuel reduces an LWR's demand for natural uranium by up to $10 \%$. The separated plutonium can be combined with natural uranium to make MOX, reducing uranium demand by another $15 \% .^{16}$

A detailed analysis ${ }^{17}$ of the cost of reprocessing suggests that an open fuel cycle using LWRs will prevail as long as the price of new uranium fuel is lower than the cost of reprocessing and MOX fuel fabrication. However, several countries (e.g., France, United Kingdom, and Japan) reprocess used civilian fuel. Today, about 30 LWRs in Europe and several in Japan use MOX fuel, accounting for $2 \%$ of the total fuel used per year. ${ }^{18}$

Plutonium can also be used in MOX fuel in fully closed fuel cycles with fast reactors (Figure 5), which use higher-energy (fast) neutrons. A fast "breeder" reactor can be designed that actually produces more fissile material in the SNF than in the original fuel, which allows multiple cycles of reprocessing.

A scarcity of uranium resources would argue for reprocessing to reclaim fissile material. A closed fuel cycle can significantly reduce demand for fresh ore. In the long term, when the new breeder fuel cycle reaches steady state, it could even become almost fissile self-sufficient. ${ }^{19}$ In the near term, uranium savings in a closed fuel cycle depend on the scale and speed of fast reactor deployment and on the number of fissile atoms produced per destruction of a fissile atom (the breeding ratio). According to a recent study performed at the Massachusetts Institute of Technology (MIT), ${ }^{16}$ natural uranium usage could be reduced by $13 \%$ by 2050 and by up to $45 \%$ by 2100 through large-scale deployment of breeder reactors, but such deployment is not expected before 2040. Indeed, no fast breeder reactor has yet been operated commercially. ${ }^{20}$

For both the open and closed fuel cycles, uranium- and thorium-based fuels can be used in other new reactor types, such as advanced heavy-water reactors (AHWRs), supercritical water-cooled reactors (SCWRs), high-temperature gas-cooled reactors (HTGRs) [also called very high-temperature reactors (VHTRs)], and molten salt reactors (MSRs). ${ }^{19}$ However, new fuels, new reactors, and advanced fuel cycles will require considerable resources and experience prior to deployment, so none of these reactors is likely to play a major role in energy production during the next 40 years.

Another method to extend uranium resources is using higher enrichments to more efficiently utilize the fissile ${ }^{235} \mathrm{U}$. The efficiency of fuel use is usually expressed as the "burnup," in gigawatt days per ton of heavy metal (GWd/tHM). Raising the burnup above the $40-50 \mathrm{GWd} / \mathrm{tHM}$ that is typical for LWRs could reduce uranium requirements by $4-5 \% .{ }^{21}$ To take advantage of even higher burnup, however, new fuel-assembly materials must be developed to withstand the higher cumulative irradiation. ${ }^{22}$

Another candidate design using high burnup is the travelling wave reactor (TWR), a type of fast reactor. After starting the reactor with a fissile material, fresh natural or even depleted uranium fuel assemblies are inserted and periodically shuffled to breed and burn plutonium in situ. Such a reactor could run for decades without reprocessing or refueling with fissile material.

\section{Environmental impacts of different nuclear fuel cycles}

The selection of a fuel cycle is complicated and depends on each country's environmental, proliferation, economic, and energy policies. ${ }^{23}$ For all fuel cycles, the local environmental impacts of mining directly scale with the uranium consumption. The major issue is the voluminous mine and mill tailings from open pits or underground workings that contain radioactive uranium and thorium decay products, such as ${ }^{222} \mathrm{Rn}$, as well as toxic metals, such as arsenic. Mining techniques used from the 1950s through the early 1970 s led to contamination of near-surface water and soil. ${ }^{24}$ More recently, in situ leaching has been used to dissolve and extract uranium. Mildly oxidizing carbonated water $\left(1 \mathrm{~g} / 1 \mathrm{NH}_{4} \mathrm{HCO}_{3}\right)$ or more aggressive concentrations of sulfuric acid $\left(2-5 \mathrm{~g} / 1 \mathrm{H}_{2} \mathrm{SO}_{4}\right)^{25}$ is circulated through porous, uranium-bearing rock confined between impermeable layers of clay or shale. The fluids are treated at the surface to remove uranium. This technique economically recovers lower concentrations of uranium, and the radioactive decay products remain underground. An important concern, however, is the impact of these circulating fluids on local aquifers. ${ }^{25}$

With regard to nuclear weapons proliferation and nuclear waste disposal, two recent MIT studies compared generic fuel cycles for a two- or threefold global-growth scenario ${ }^{16,26}$ and came to the following conclusions: The once-through cycle followed by direct geological disposal generates the largest volumes of SNF that contains substantial quantities of plutonium. The short-term proliferation risks are reduced because the plutonium is not separated from the SNF and is protected from diversion by the strong radiation generated by fission products. ${ }^{27}$ A closed fuel cycle (MOX with one recycle) generates lower SNF volumes but has similar repository requirements because the vitrified waste releases more heat. Plutonium, which can be viewed as either a source of energy or an environmental hazard, causes acute and long-term health effects upon ingestion or inhalation, ${ }^{28}$ which is an important public health concern.

Any closed fuel cycle will result in the separation of hundreds of tonnes of plutonium, exacerbating existing proliferation concerns. Since plutonium was first isolated in microgram quantities in 1941, more than 2000 t has been created in civilian reactors around the world, generally left in SNF. However, roughly 250 t has been separated from commercially generated SNF. In addition, approximately 70-80 t of new plutonium is added to the global inventory each year, and 10-20 $t$ is separated. Depending on the sophistication of the design, almost all isotopic compositions of separated plutonium are potential weapons material. ${ }^{29}$ A nuclear device can be made with less than $5 \mathrm{~kg}(0.005 \mathrm{t})$ of ${ }^{239} \mathrm{Pu} .{ }^{30}$

The use of fast reactors without breeding can significantly reduce the inventories of plutonium and minor actinides in the final waste stream, transmuting the actinides to shorter-lived 
radionuclides. In this scheme, actinides produced in thermal reactors would be recycled and incorporated into MOX fuels for fast reactors. The amount of plutonium can be further reduced by burning the actinides in inert-matrix fuels (IMFs) that do not contain fertile ${ }^{238} \mathrm{U}$, for example, zirconia $\left(\mathrm{ZrO}_{2}\right) \cdot{ }^{31,32}$ Reactors would probably use a mixture of MOX and IMF, and irradiation would substantially reduce the plutonium and minor actinide contents of the IMF. ${ }^{33} \mathrm{ZrO}_{2}$ is recognized as a durable, radiationresistant waste form for direct disposal. ${ }^{34}$

\section{Thorium fuel cycle and resources}

Thorium, although itself not fissile, is an alternative to uranium as a nuclear fuel. Specifically, through neutron capture and subsequent $\beta$-decay reactions, ${ }^{232} \mathrm{Th}$ is transmuted to fissile ${ }^{233} \mathrm{U}$, in the same way that ${ }^{239} \mathrm{Pu}$ is created from ${ }^{238} \mathrm{U}$.

Thorium has only one naturally occurring isotope, ${ }^{232} \mathrm{Th}$, but is three times more abundant in Earth's crust than uranium. However, thorium is less often concentrated into economical ore deposits, because there are few geochemical processes for its concentration.

\section{Thorium resource estimates}

Figure 6 shows the distribution of identified thorium resources by country and type of deposit. In all countries, for a cost below US $\$ 80 / \mathrm{kg}$, there are $829 \mathrm{kt}$ of RAR and $1400 \mathrm{kt}$ of IR, with another $1387 \mathrm{kt}$ in prognosticated resources. Information on thorium reserves is limited (just one of the Red Book's 457 pages), ${ }^{4}$ and some of the data are more than 20 years old, ${ }^{10}$ so estimates are much less certain than for uranium. Nevertheless, Australia, Brazil, India, the United States, and Venezuela have significant identified resources of thorium, of between 300 and $450 \mathrm{kt}^{4}$

Because the current market for thorium is modest, it is produced only as a byproduct of rare-earth (RE) recovery, largely from monazite $\left(\mathrm{CePO}_{4}\right)$. This mineral contains an average of $8-10 \mathrm{wt} \%$ thorium, so its processing theoretically recovers $500-740$ t of thorium metal per year worldwide. ${ }^{36}$ Some countries, such as India, stockpile this excess inventory for future nuclear fuel applications, whereas others dispose of it. For example, the United States disposed of 3220 t of thorium nitrate as low-level radioactive waste at the Nevada Test Site in $2005 .{ }^{37}$ Thorium disposal costs are partially responsible for the decrease in the production of REs in the United States. If the thorium were instead used in a nuclear fuel cycle, it would limit the need for expensive disposal. ${ }^{36,38}$

Because of the modest market for thorium, there has been little incentive to explore for new deposits or to survey known deposits. Most resources have been discovered and evaluated during exploration for uranium and REs. If thorium were exploited for commercial nuclear fuel applications, the minerals bastnaesite $\left[(\mathrm{Ce}, \mathrm{Th}, \mathrm{La}, \mathrm{Y}, \mathrm{Ca}) \mathrm{CO}_{3} \mathrm{~F}\right]$ and thorite $\left(\mathrm{ThSiO}_{4}\right)$, which have higher thorium contents, would likely be exploited. ${ }^{35}$

\section{Thorium fuel cycle}

Any thorium fuel cycle will need a neutron source, such as fission of ${ }^{239} \mathrm{Pu}$ or ${ }^{235} \mathrm{U}$ to breed fissile ${ }^{233} \mathrm{U}$ from ${ }^{232} \mathrm{Th}$. Reactors

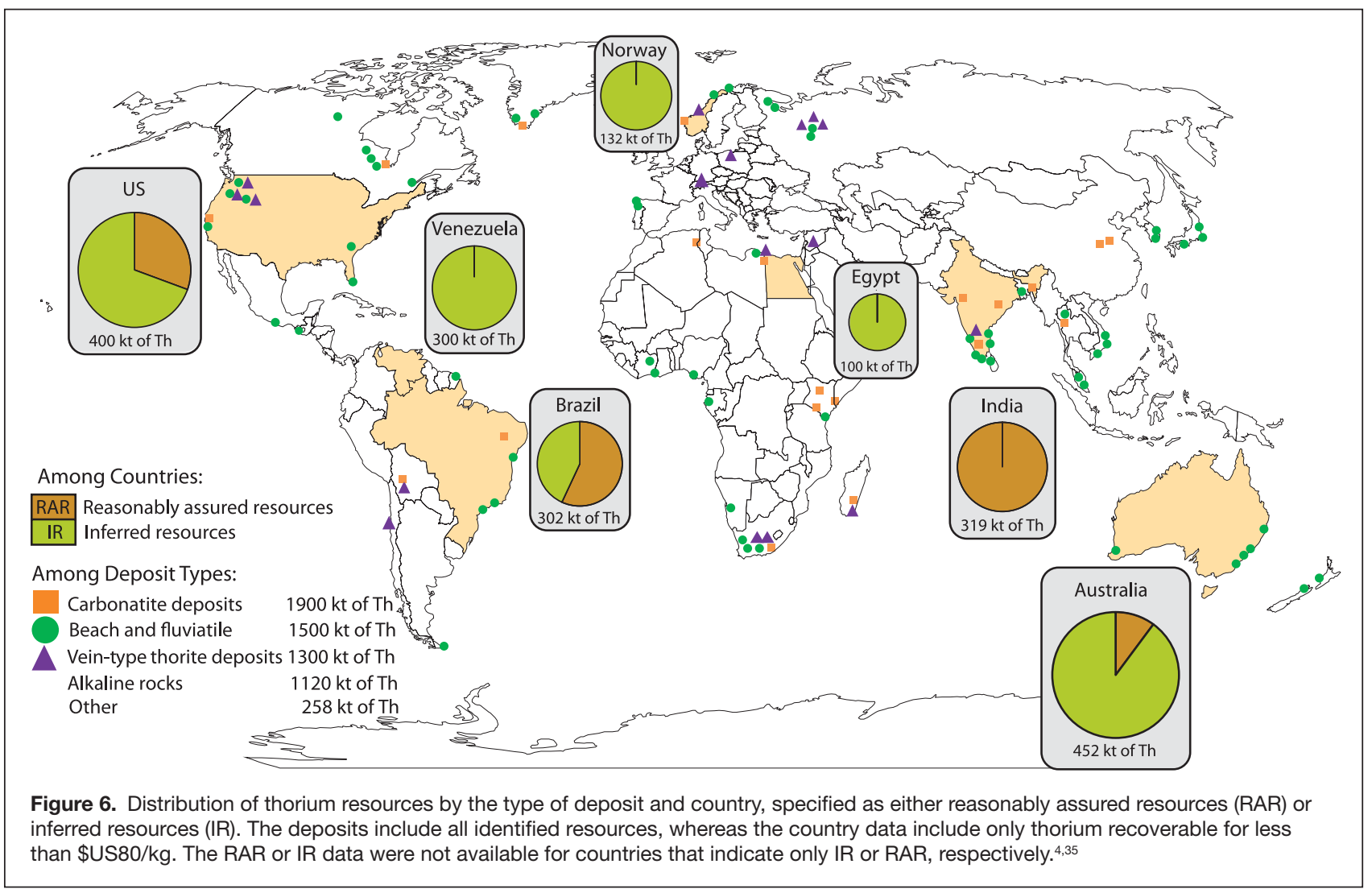


and fuel cycles using thorium have been investigated since the 1950s. From the mid-1950s to the mid-1970s, several experimental and prototype reactors were operated. However, thorium fuels and fuel cycles have not received the attention required for their development because uranium reserves have thus far been judged to be adequate for the uranium/ plutonium fuel cycle. A fuel cycle that reduces uranium demand is most important to countries with extensive thorium resources. India and China are actively developing the thorium fuel-cycle technology.

Like uranium, thorium can be used in either an open oncethrough cycle or a closed fuel cycle with reprocessing to reclaim the fissile ${ }^{233} \mathrm{U}$. In an open fuel cycle using LWRs, ${ }^{235} \mathrm{U}$ or ${ }^{239} \mathrm{Pu}$ can be used as a neutron source to generate ${ }^{233} \mathrm{U}$ from ${ }^{232} \mathrm{Th}$. Because the nuclear reactions build up ${ }^{233} \mathrm{U}$, less ${ }^{235} \mathrm{U}$ is needed during burnup. One simple fuel is a homogeneous 3:1 mixture of thorium and enriched uranium $\left(20 \%{ }^{235} \mathrm{U}\right) .{ }^{16,39}$ A more efficient approach involves the use of a heterogeneous fuel, in which either the core of a fuel assembly or even each fuel pin is a uranium "seed" of $20 \%$ enriched ${ }^{235} \mathrm{U}$ surrounded by a (Th,U)O $\mathrm{O}_{2}$ "blanket."

A preliminary reference design using heterogeneous thorium fuel assemblies is the Radkowsky Thorium Reactor (RTR), proposed for the Russian VVER-1000 pressurized water reactor (PWR). This design would consume $20 \%$ less natural uranium than using standard uranium fuel and was shown to be economically feasible. ${ }^{40}$ The RTR is more proliferation-resistant than an LWR, because it produces $80 \%$ less plutonium with an isotopic mixture that is less usable for weapons.

For the initial neutron investment of thorium-based fuels to break even with those of uranium-based fuels, a burnup of more than $100 \mathrm{GWd} / \mathrm{tHM}$, more than double that typical for LWRs, will be required. ${ }^{16}$ A major challenge for thorium-based fuels is that new materials would have to be developed to withstand long irradiation times, just as for high-burnup uranium/plutonium fuel cycles.

One early study of thorium-recycling options in a closed fuel cycle compared resource utilization of various reactor fuel cycles in the Canadian heavy-water (CANDU) reactors. The thorium cycles considered only homogeneous fuel whose initial fissile material was either ${ }^{235} \mathrm{U}$ or $\mathrm{Pu}$ and assumed that ${ }^{233} \mathrm{U}$ and remaining fissile materials were recycled from the SNF whereas new fissile material was added to maintain burnup. At steady state, the analysis found a savings of up to $90 \%$ in natural-uranium usage compared with a once-through fueling with natural uranium. ${ }^{35}$

India has greater thorium than uranium resources, which has led to a unique nuclear strategy employing (1) uraniumfueled pressurized heavy-water reactors (PHWRs) that produce plutonium, (2) plutonium-fueled fast breeder reactors (FBRs) that breed ${ }^{239} \mathrm{Pu}$ and ${ }^{233} \mathrm{U}$, and (3) AHWRs that will enable a selfsustained ${ }^{232} \mathrm{Th}-/{ }^{233} \mathrm{U}$-based fuel cycle and obtain $65 \%$ of their power from thorium. ${ }^{41}$ Full commercialization of the AHWRs is not expected before $2030 .^{42}$
Although a thorium-based fuel cycle produces no plutonium, fissile ${ }^{233} \mathrm{U}$ bred from ${ }^{232} \mathrm{Th}$ is still very attractive for weapons purposes. However, accumulation of other radioactive isotopes, notably ${ }^{212} \mathrm{Bi}$, which is a daughter product of ${ }^{232} \mathrm{U}$, and gammaemitting ${ }^{208} \mathrm{Tl}$, which accumulates during irradiation of ${ }^{232} \mathrm{Th}$, increase proliferation resistance. ${ }^{43}$

\section{Conclusions}

Identified uranium resources can sustain the present scale of nuclear energy production until the end of the 21 st century. However, pursuing a two- to threefold increase in nuclear power generation would require development of presently undiscovered uranium resources, both prognosticated and speculative. Even with such a tripling of nuclear power generation, the reduction of $\mathrm{CO}_{2}$ emissions would be modest, some $6 \%$ as compared to the reductions that are required for limiting atmospheric $\mathrm{CO}_{2}$ levels to no more than twice preindustrial levels by $2050 .^{15}$

Uranium resources can be extended to a certain extent for either open or closed fuel cycles. For closed fuel cycles, fissile nuclides, ${ }^{235} \mathrm{U}$ and ${ }^{239} \mathrm{Pu}$, can be reclaimed and utilized in MOX fuel or IMF in current LWRs. More efficient utilization of fissile actinides can be attained by the use of advanced fast reactors that employ higher-energy neutrons. However, closed fuel cycles with reprocessing pose the risk of diversion of fissile material to weapons production. Whether one follows a strategy of direct disposal of spent nuclear fuel or reprocessing and some combination of LWRs or advanced reactors, geologic disposal of used nuclear fuel and/or highly radioactive waste is always required. Present uranium resources are large enough that the development of new nuclear fuel cycle strategies is not immediately required.

The thorium fuel cycle offers some enhancements for expansion of nuclear power generation. Nuclear fuels that use both uranium and thorium can extend the resources available to support nuclear power production. In addition, the thorium/ uranium fuel cycle has some advantages over the plutonium/ uranium fuel cycle in terms of geologic disposal. As an example, thorium-based fuels are remarkably durable, because of the single oxidation state of thorium, and could be disposed of in a number of different types of geology. For some countries with substantial thorium resources, the thorium fuel cycle might be a viable option. However, few countries actively develop this technology, and as long as natural uranium is not scarce, it is unlikely that a thorium-based fuel cycle will be implemented on a global scale.

\section{Acknowledgments}

M.E. and R.C.E. thank the Center for International Security and Cooperation (CISAC), part of the Freeman Spogli Institute for International Studies, Stanford University, where they were both guest scholars during the preparation of this article. Financial support came from an institutional grant to CISAC from The John D. and Catherine T. MacArthur Foundation. 


\section{References}

1. Power Reactor Information System (PRIS): Latest News Related to PRIS and the Status of Nuclear Power Plants (International Atomic Energy Agency, Vienna, Austria, 2011), www.iaea.org/programmes/a2 (accessed May 17, 2011).

2. World Energy Outlook 2010 (Organisation for Economic Co-operation and Development, Paris, France, 2010).

3. World Nuclear Power Reactors \& Uranium Production (World Nuclear Association, London, 2011), www.world-nuclear.org/info/reactors.html (accessed September 2011).

4. Uranium 2009: Resources, Production and Demand (NEA Report No. 6891 Organisation for Economic Co-operation and Development, Paris, France, 2010). 5. World Uranium Mining (World Nuclear Association, London, 2010), www. world-nuclear.org/info/inf23.html (accessed September 2011).

6. Our Strategy Delivers, Annual Report 2010 (BHP Billiton, Melbourne, Victoria, Australia, 2010)

7. A.M. MacFarlane, M. Miller, Elements 3, 185 (2007)

8. Uranium 2005: Resources, Production and Demand (NEA Report No. 6098 Organisation for Economic Co-operation and Development, Paris, France, 2006). 9. Uranium 2007: Resources, Production and Demand (NEA Report No. 6345, Organisation for Economic Co-operation and Development, Paris, France, 2008). 10. Forty Years of Uranium Resources, Production and Demand in Perspective (NEA Report No. 6096, Organisation for Economic Co-operation and Development, Paris, France, 2006)

11. ESA average uranium prices for 2009 (Euratom, Luxembourg, 2011), http:// ec.europa.eu/euratom/observatory price.html (accessed June 2011).

12. J.P. Timbie, Sci. Global Secur. 12, 165 (2004).

13. Global Fissile Material Report 2010. Balancing the Books: Production and Stocks (International Panel on Fissile Materials, Princeton, NJ, 2010).

14. Energy, Electricity and Nuclear Power Estimates for the Period up to 2050 (Report IAEA-RDS-1/30, International Atomic Energy Agency, Vienna, Austria, 2010).

15. Energy Technology Perspectives 2010: Scenarios \& Strategies to 2050 (International Energy Agency, Paris, France, 2010).

16. M. Kazimi, E.J. Moniz, C.W. Forsberg, S. Ansolabehere, J.M. Deutch, M.J. Driscoll, M.W. Golay, A.C. Kadak, J.E. Parsons, M. Regalbuto, G. Apostolakis, P. Hejzlar E. Shwageraus, The Future of the Nuclear Fuel Cycle (Massachusetts Institute of Technology, Cambridge, MA, 2011).

17. M. Bunn, S. Fetter, J.P. Holdren, B. van der Zwaan, The Economics of Reprocessing vs. Direct Disposal of Spent Nuclear Fuel (Project on Managing the Atom, Final Report DE-FG26-99FT4028, Harvard University, Cambridge, MA, 2003)

18. "Mixed Oxide (MOX) Fuel" (World Nuclear Association, London, 2011), www. world-nuclear.org/info/inf29.html (accessed January 2012).

19. C. Forsberg, D. Wade, A. Bement, C. Boardman, B. Boullis, D. Crawford, K. Fukada, J.P. Glatz, D. Greneche, W. Halsey, J.S. Herring, M. Leroy, D. Lewis, H. Noda, P. Peterson, L. van den Durpel, M.S. Yang, A. Caponiti, B.J. Garrick, H. Khalil, A. Moisseysev, J.M. Ryskamp, Generation IV Roadmap Fuel Cycle Assessment Report [Report GIF-014-00, U.S. Department of Energy Nuclear Energy Research Advisory Committee (NERAC) and Generation IV International Forum (GIF), Paris, France, 2002].
20. T.B. Cochran, H.A. Feiveson, W. Patterson, G. Pshakin, M.V. Ramana, M. Schneider, T. Suzuki, F. von Hippel, Fast Breeder Reactor Programs: History and Status (Research Report 8, International Panel on Fissile Materials, Princeton, NJ, 2008)

21. Very High Burn-ups in Light Water Reactors (NEA Report No. 6224 Organisation for Economic Co-operation and Development, Paris, France, 2006).

22. T.K. Kim, T.A. Taiwo, Fuel Cycle Analysis of Once-Through Nuclear Systems (Report ANL-FCRD-308, ANL, Argonne, IL, 2010).

23. R.C. Ewing, W. Runde, T.E. Albrecht-Schmitt, MRS Bull. 35, 859 (2010).

24. A. Abdelouas, Elements 2, 335 (2006).

25. Uranium Extraction Technologies (Technical Reports Series No. 359, International Atomic Energy Agency, Vienna, Austria, 1993).

26. S. Ansolabehere, J. Deutch, M. Driscoll, P.E. Gray, J.P. Holdren, P.L. Joskow, R.K. Lester, E.J. Moniz, N.E. Todreas, E.S. Beckjord, The Future of Nuclear Power (Massachusetts Institute of Technology, Cambridge, MA, 2003).

27. Management and Disposition of Excess Weapons Plutonium (National Academies Press, Washington, DC, 1994)

28. W.G. Sutcliffe, R.H. Condit, W.G. Mansfield, D.S. Myers, D.W. Layton, P.W. Murphy, A Perspective on the Dangers of Plutonium (Report UCRL-JC-118825, Lawrence Livermore National Laboratory, Livermore, CA, 1995).

29. C.G. Bathke, R.K. Wallace, J.R. Ireland, M.W. Johnson, K.S. Bradley, B.B. Ebbinghaus, H.A. Manini, B.W. Smith, A.W. Prichard, paper presented at the 8th International Conference on Facility Operations: Safeguards Interface (sponsored by the American Nuclear Society), Portland, OR, March 30-April 4, 2008.

30. J.C. Mark, Sci. Global Secur. 4, 111 (1993).

31. P.G. Boczar, M.J.N. Gagnon, P.S.W. Chan, R.J. Ellis, R.A. Verrall, A.R. Dastur Can. Nucl. Soc. Bull. 18, 2 (1997).

32. V.M. Oversby, C.C. McPheeters, C. Degueldre, J.M. Paratte, J. Nucl. Mater 245, 17 (1997).

33. C. Pistner, W. Liebert, F. Fujara, J. Nucl. Mater. 352, 268 (2006).

34. W.L. Gong, W. Lutze, R.C. Ewing, J. Nucl. Mater. 277, 239 (2000).

35. Thorium Fuel Cycle-Potential Benefits and Challenges (IAEA-TECDOC-1450, International Atomic Energy Agency, Vienna, Austria, 2005).

36. J.B. Hedrick, "Thorium," in 2007 Minerals Yearbook (U.S. Geological Survey, Washington, DC, 2008), chap. 76

37. J.B. Hedrick, "Rare Earths," in 2004 Minerals Yearbook (U.S. Geological Survey, Washington, DC, 2005), chap. 60

38. R. Jaffe, J. Price, G. Ceder, R. Eggert, T. Graedel, K. Gschneidner, M. Hitzman, F. Houle, A. Hurd, R. Kelley, A. King, D. Milliron, B. Skinner, F. Slakey, Energy Critical Elements: Securing Materials for Emerging Technologies (Materials Research Society/American Physical Society, Washington, DC, 2011).

39. A. Galperin, E. Shwageraus, M. Todosow, Nucl. Technol. 138, 111 (2002). 40. A. Galperin, P. Reichert, A. Radkowsky, Sci. Global Secur. 6, 265 (1997).

41. D.J. Cordier, "Thorium," in 2008 Minerals Yearbook (U.S. Geological Survey, Washington, DC, 2010), chap. 76

42. A. Kakodkar, Statement by Dr Anil Kakodkar, Chairman of the Atomic Energy Commission and leader of the Indian delegation, International Atomic Energy Agency 53rd General Conference, Vienna, Austria, September 16, 2009; http://www iaea.org/About/Policy/GC/GC53/Statements/india.pdf (accessed September 2011). 43. J. Kang, F.N. von Hippel, Sci. Global Secur. 9, 1 (2001)

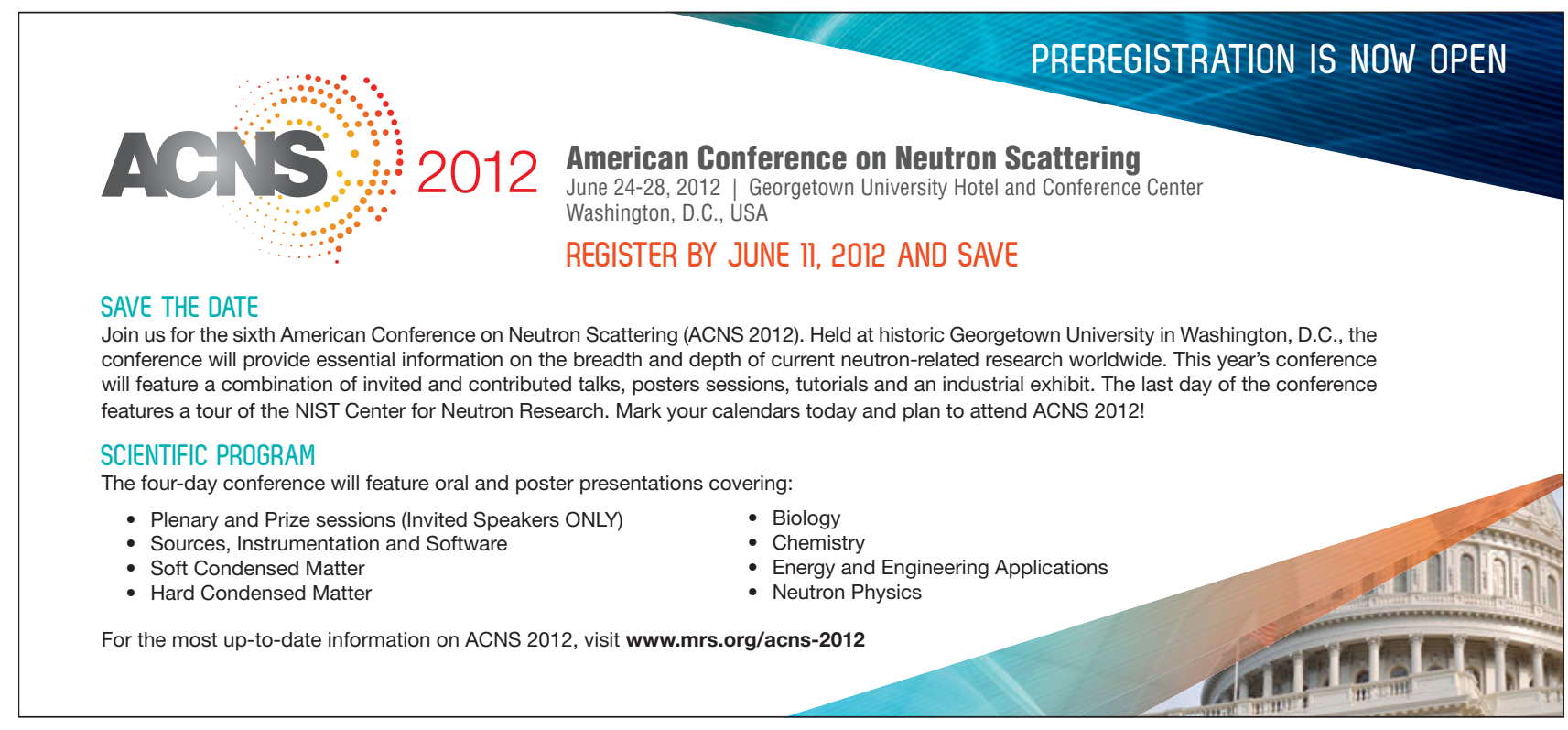




\title{
Sustainability metrics for extending thin-film photovoltaics to terawatt levels
}

\begin{abstract}
Vasilis Fthenakis
Over the past 12 years, photovoltaics enjoyed an average growth of $45 \%$ per year that was affected only marginally by the recent global financial crisis. Industrial roadmaps and analysts' forecasts share visions of solar power becoming a major contributor to national and global electricity grids, with several terawatts of cumulative deployment by 2050 or earlier. For photovoltaics technology to become a major sustainable player in a competitive powergeneration market, it must provide abundant, affordable electricity, with environmental impacts dramatically lower than those from conventional power generation. This article summarizes the prospects in each of three basic aspects of sustainability, namely, system costs, environmental impacts, and resource availability, all of which are examined in the context of prospective life-cycle assessment. Indeed, these three aspects are closely related: Increasing the efficiency of material recovery by recycling spent modules will become increasingly important in resolving cost, resource, and environmental constraints on large-scale sustainable growth.
\end{abstract}

\section{Introduction}

As discussed throughout this issue, sustainable development is development that "meets the needs of the present without compromising the ability of future generations to meet their own needs." Photovoltaic devices, as fuel-free energy sources, are inherently sustainable unless they are too expensive to produce, are manufactured using materials that are depletable, or are environmentally unsafe.

Assessing the sustainability of continued rapid growth of photovoltaic use requires the investigation of three measurable aspects: cost, resource availability, and environmental impact. The question of cost concerns the affordability of solar energy compared to other energy sources throughout the world. Environmental impacts include local, regional, and global effects, including land use, that must be considered over a long time horizon. Finally, availability of material resources matters to current and future generations under the constraint of affordability. More concisely, photovoltaics (PV) must meet the need for generating abundant electricity at competitive costs while conserving resources for future generations and having environmental impacts lower than those of current modes of power generation and preferably also lower than those of alternative future energy options.
The challenges vary among different photovoltaic technologies. For example, first-generation crystalline-silicon photovoltaics relies on abundant silicon, but its costs are relatively high. By comparison, second-generation technologies are cheaper but less efficient. Cadmium telluride thin-film modules, for example, have the lowest production costs, but there are concerns about the availability of tellurium and the toxicity of cadmium used as a precursor to CdS and CdTe. Similarly, copper indium gallium (di)selenide (CIGS) technologies share these concerns about materials availability (i.e., gallium, indium), and some high-performance silicon technologies use potent greenhouse gases (e.g., $\mathrm{NF}_{3}$ ).

This article discusses the factors that determine whether photovoltaics can be sustainably expanded to supply a large fraction of the world's energy needs, focusing on three second-generation PV technologies: cadmium telluride (CdTe), copper indium gallium selenide (CIGS), and amorphous silicon-germanium (a-SiGe). These technologies combine reasonable efficiencies with low costs and, because they require only thin films of semiconductor material, modest materials demands. Nonetheless, each of them uses some elements (tellurium, indium and gallium, and germanium, respectively) of constrained availability that could limit their application on a large scale. Increases 
in efficiency and reductions in thin-film layer thickness will ease some of this burden, as described in Table I, which lists a range of plausible scenarios for these improvements. The most likely scenarios therein correspond to module efficiencies in 2020 of $80 \%$ of the current record cell efficiencies for each of the thin-film technologies. ${ }^{2}$

\section{Economics}

Photovoltaics currently enjoys rapid growth in a subsidized market, as many countries offer financial incentives for installing and using solar power. However, such funding will not last forever, and to be sustainable, the expense of PV power must reach parity with the direct cost of grid electricity. On the other hand, arguably, subsidies should continue on the basis that photovoltaics received much lower subsidies during its first stage of deployment than other electricity-generation technologies. ${ }^{3}$ For example, starting in the 1950 s, nuclear power in the United States garnered support worth US\$3.3 billion per year in today's dollars (viz., 1\% of the 1965 federal budget) during its first 15 years. Nuclear power plants in the United States still benefit from the Price-Anderson Act (which partially indemnifies nonmilitary nuclear facilities against liability claims arising from nuclear incidents) and cannot break ground without loan guarantees from the U.S. federal government. ${ }^{3}$ Oil and gas received an average of US $\$ 1.8$ billion per year, or $0.5 \%$ of the federal budget, in their first 15 years. $^{3}$ In contrast, the total subsidies to solar and wind power averaged less than US\$0.4 billion/year (i.e., $0.01 \%$ of the current federal budget) from 1994 to $2009 .^{3}$

The issue of cost and affordability demands a full accounting of the price of electricity. To its direct cost should be added the external costs assumed by society at large, such as impacts on ecosystem and human health, food supply, and land use. A recent study from the Harvard School of Public Health estimated that coal costs the U.S. public an additional US $\$ 300-500$ million annually. ${ }^{4}$ Including these damages would double or triple the price per kilowatt-hour of electricity generated from coal, making photovoltaics economically competitive.

In 2011, PV electricity from utility installations under irradiation conditions equivalent to those in the southwestern United States cost US\$0.12-0.14/kWh (alternating current). This is already competitive with peak rates for grid electricity in California but about three times more expensive than average wholesale electricity prices (Figure 1). Industry forecasts suggest that, by 2020, the expense of producing modules for

\begin{tabular}{|c|c|c|c|c|c|c|c|c|}
\hline \multirow[t]{3}{*}{ PV type } & \multicolumn{4}{|c|}{ Efficiency (\%) } & \multicolumn{4}{|c|}{ Layer thickness $(\mu \mathrm{m})$} \\
\hline & \multirow[t]{2}{*}{2010} & \multicolumn{3}{|c|}{2020} & \multirow[t]{2}{*}{2010} & \multicolumn{3}{|c|}{2020} \\
\hline & & Conservative & Most likely & Optimistic & & Conservative & Most likely & Optimistic \\
\hline CdTe & 11.7 & 13 & 13.2 & 14 & 3 & 2.5 & 1.5 & 1 \\
\hline CIGS & 11.5 & 14 & 15.9 & 16.3 & 1.6 & 1.2 & 1 & 0.8 \\
\hline a-SiGe & 6.8 & 9 & 9.7 & 10 & 1.2 & 1.2 & 1.1 & 1 \\
\hline
\end{tabular}

thin-film photovoltaics will fall to US\$0.50-0.70/ $\mathrm{W}_{\mathrm{p}}$ (watt-peak) with system prices of US $\$ 1.5-2.5 / \mathrm{W}_{\mathrm{p}}$, assuming sufficient market incentives to maintain technology progress throughout this period. The U.S. Department of Energy (DOE) SunShot Initiative is even more ambitious, targeting system costs of US $\$ 1 / \mathrm{W}_{\mathrm{p}}$ by $2020 .{ }^{7}$ At a cost of US $\$ 2.50 / \mathrm{W}_{\mathrm{p}}$ per system, the price of electricity from the U.S. southwest is $\sim \mathrm{US} \$ 0.08 / \mathrm{kWh}$, in parity with global averages of utility-scale electrical power generation without carbon mitigation. ${ }^{6}$ Further reductions toward US $\$ 1.50 / \mathrm{W}_{\mathrm{p}}$ could cover the expenses of storing electricity from the sunniest regions, thereby transforming photovoltaics into a continuous source that can be easily deployed on demand. ${ }^{8}$ These reductions will be driven by economies of scale, improved production, and higher module efficiencies. ${ }^{8}$ However, these scales will be attained only by the maintenance of financial incentives and stability in the outlook for incentives and markets for solar electricity.

\section{Environmental impacts \\ Land use}

Photovoltaics offers advantages for distributed power generation, and rooftop installations represent $66 \%$ of today's world market. Concerns have been raised about the land requirements for installing large-scale ground-mount PV systems, but these requirements should be examined within a life-cycle context. In fact, historical data show that ground-mount solar farms often use less land during their life cycle than does coal during its life cycle, ${ }^{9}$ and there are plenty of desert lands and rooftops to support many terawatts of PV installations. The land use requirements for hydroelectric and biomass fuel life cycles are considerably larger. ${ }^{9}$

\section{Emissions and disposal}

The operation of fossil-fuel-burning power plants is causing adverse health effects and increased atmospheric carbon dioxide concentrations. Although photovoltaic systems do not generate any toxic or greenhouse gases during operation, such emissions can occur during the production of the materials used for solar cells and systems. Recent assessments of the life-cycle emissions from photovoltaic systems showed that, under conditions equivalent to those in the southwestern United States, they emit about $17-39 \mathrm{~g}$ of $\mathrm{CO}_{2} / \mathrm{kWh}$, in comparison to 500-1100 $\mathrm{g}$ of $\mathrm{CO}_{2} / \mathrm{kWh}$ from fossilfuel plants and $16-55 \mathrm{~g}$ of $\mathrm{CO}_{2} / \mathrm{kWh}$ from nuclear-power plant life cycles in the United States. ${ }^{10}$ Some facilities producing tandem a-Si/multicrystalline silicon (mc-Si) cascade thinfilm or high-performance monocrystalline-silicon modules use potent greenhouse gases, such as $\mathrm{NF}_{3}$, as agents for reactor cleaning or texturing, but such agents can be replaced or their emissions abated.

Similarly to greenhousegas emissions, releases of 


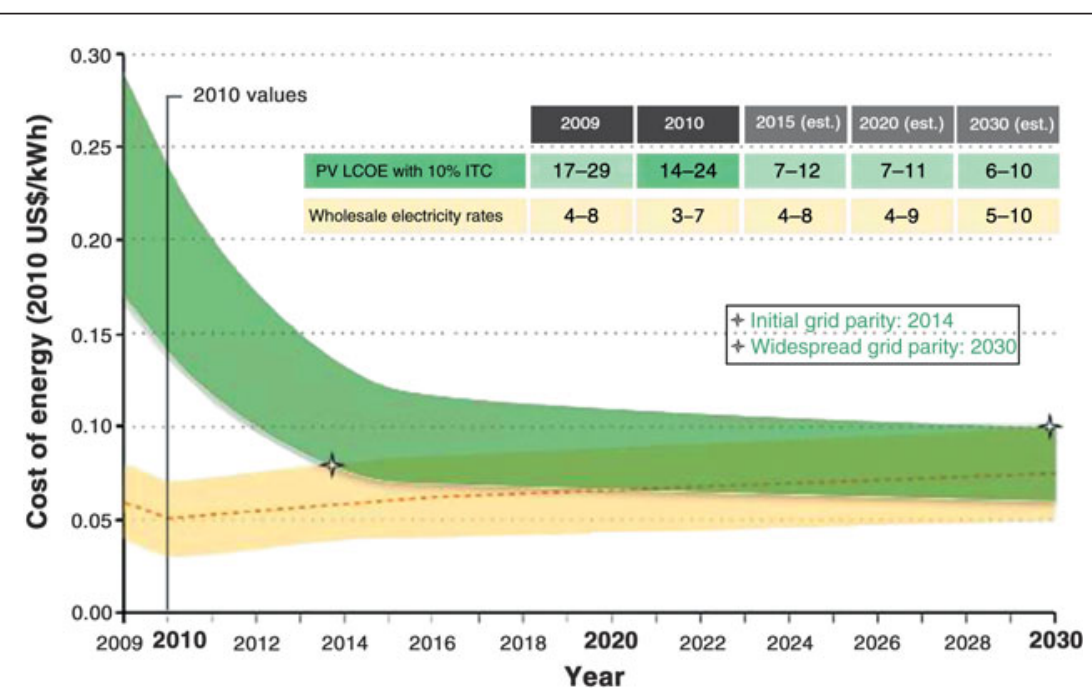

Figure 1. Projections of levelized costs of energy (LCOE) for utility-scale photovoltaic electricity and grid electricity in the United States, assuming a 10\% investment tax credit (ITC) for photovoltaics. The width of the photovoltaics (green) band reflects the differences between high (Phoenix, AZ) and low (New York) solar radiation levels and between low $(8.2 \%)$ and high (9.9\%) financing interest rates. The vertical line at 2010 denotes rates at the time of the analysis, and the crosses show when the two electricity sources will become cost-competitive for some conditions (left cross) and for typical conditions (right cross). (Reproduced from Reference 5 courtesy of the U.S. Department of Energy.) procedure (TCLP),$^{14}$ which simulates the leaching of wastes, substantiates module safety under controlled conditions. Emissions of cadmium from current-vintage double-glass photovoltaics were shown to be extremely small. ${ }^{14} \mathrm{Nev}-$ ertheless, there could be other pathways for uncontrolled releases in extreme situations, and therefore, every effort should be made to collect the modules and recycle the contained metals at the end of their useful lifetimes. The greatest challenge might lie in ensuring a high recovery rate of spent modules from dispersed residential installations. Also, the cost of infrastructure for both collection and recycling must be optimized to ensure affordability. Processes for separating polymeric materials such as ethylene vinyl acetate from glass must be improved so that the purity of recovered glass is sufficient for reuse in soda-lime glass manufacturing. Estimates of residual risks should be compared with the risks inherent over the life cycles of alternative systems and of conventional power-generation systems that photovoltaics would replace. Toxic emissions are much lower in the life cycle of thin-film photovoltaics than in the life cycles of alternative photovoltaic and conventional power systems. ${ }^{13}$ priority pollutants (e.g., $\mathrm{SO}_{2}, \mathrm{NO}_{x}$, particulates) from photovoltaic life cycles comprise only $2-4 \%$ of those from fossil-fuel plants. Heavy-metal emissions deserve special consideration, as certain thin-film solar cells use such metals (e.g., cadmium in CdTe and CdS, selenium in CIGS). An experimental investigation of the potential for liberating cadmium from solar cells during residential fires demonstrated that $99.5-99.96 \%$ of the cadmium would be safely encapsulated in the molten glass. ${ }^{11}$ Direct cadmium emissions in the life cycle of $\mathrm{CdTe}$ solar cells amount to $0.016 \mathrm{~g}$ per gigawatt-hour of energy produced under average U.S. conditions. ${ }^{11}$ On the other hand, a typical coal-burning plant in the United States, equipped with electrostatic precipitators or baghouses (fabric filters) operating at $98.6 \%$ cadmium removal efficiency, emits $2 \mathrm{~g}$ of cadmium per gigawatt-hour. ${ }^{12}$ Replacing grid electricity with PV systems would result in $89-98 \%$ reductions in the emissions of greenhouse gases, criteria pollutants, heavy metals, and radioactive species. ${ }^{13}$

Although these results offer a comparative picture of the environmental benefits from employing thin-film photovoltaics, the potential risks from PV modules at the end of their useful life merit further discussion. For example, there are concerns about the cadmium and selenium components in CdTe and CIGS/CdS thin-film solar cells. However, the potential for harm to humans or the environment is related not to the quantity of toxic compounds in a module but rather to their potential for leaking out. Release scenarios that have been tested include leaching from modules abandoned in landfills and emissions during fires. The first problem, addressed by the toxicity characteristic leaching

\section{Material use}

The availability of materials for very large growth in the use of photovoltaics is of some concern. (For an overview of metal element availability, see the article by Graedel et al. in this issue.) A recent European Commission report ${ }^{15}$ lists four elements as critical in terms of supply risk and economic importance to the European Union markets: germanium, gallium, indium, and tellurium. A U.S. DOE report focusing on U.S. and global markets also deems the last three as critical, but does not include germanium. ${ }^{16}$ Indium is considered as having the highest short-term criticality in the DOE report.

Most sources agree that gallium, indium, and tellurium use in photovoltaics will increase because the entire PV industry is experiencing high growth. Furthermore, beyond photovoltaics, the usage of gallium in integrated circuits and optoelectronics and of indium in flat-panel displays is expected to rise.

These materials are limited in supply because they are minor byproducts of aluminum, zinc, copper, and lead production; accordingly, their production is inherently linked to that of the base metals, and thus, the rate of production of these base metals must be examined. The energy to extract the elements might pose an additional limitation. (See the article in this issue by Lubomirsky and Cahen.)

\section{Base metals: Copper, zinc, lead, and aluminum}

Copper is the parent metal for tellurium; zinc for indium, germanium, and gallium; lead for tellurium, cadmium, and indium; and aluminum for gallium. The demand for copper is expected 
to reach a peak within 50 years, and those for zinc and lead are expected to peak in $\sim 20$ years, whereas the demand for aluminum is forecasted to increase through the end of the century. ${ }^{17-19}$ The U.S. Geological Survey ${ }^{20,21}$ predicted a rate of growth in global demand for copper of 3.1\% per year between 2000 and 2020; so far, this prediction has been correct. Although primary production in the world's metal smelters fluctuates highly, ${ }^{22}$ the average production is in line with the average demand. Forecasts beyond 2020 are less certain. Ayres et al. ${ }^{18}$ developed eight scenarios of future demand and growth rates for both primary and secondary production of copper until 2100, based on the economic growth models of the International Panel on Climate Change. Their model predicts a peak in copper production in 2050-2055; thereafter, demand is expected to decrease gradually or remain about constant during the rest of the $21 \mathrm{st}$ century, as the role of recycling becomes more significant. Zinc extraction grew by $3.2 \%$ annually between 1910 and 2002, and this trend has continued over the past 10 years. ${ }^{23,24}$ The growth in demand for zinc through 2030 is assumed to be the same as that for copper.

\section{Tellurium}

The assessment of tellurium resources is debatable. ${ }^{25-27}$ The main sources of tellurium are the anode slimes from copper electrorefining operations, for which global tellurium recovery rates of $33-40 \%$ have been estimated. In contrast, the recovery rate of copper from the same ores was $80 \%$ or better, and that of gold was over $95 \%$. Evidently, the market drives the rate of recovery, with a higher demand and price justifying additional processing. Nothing inherently prevents recovery rates for tellurium from being as high as those for copper, or perhaps even gold, provided that the price is sufficiently high. (Indeed, the concentration of gold in anode slimes typically is lower than that of tellurium.) However, there is a limit to the price of tellurium that will sustain affordable CdTe photovoltaics. At US\$200/kg, the tellurium currently used in CdTe modules is $\sim \mathrm{US} \$ 0.03 / \mathrm{W}_{\mathrm{p}}$; it will fall to US\$0.01/ $\mathrm{W}_{\mathrm{p}}$ when the module efficiency increases to $13.2 \%$ and the thickness of the CdTe layer drops to $1.5 \mu \mathrm{m}$. Thus, tellurium prices up to 5-10 times higher than current levels might not affect the goal for module production of US\$0.50-0.70/ $\mathrm{W}_{\mathrm{p}}{ }^{2}$

Several scenarios are suitable for assessing the future availability of tellurium. All are related to projected copper production because, with very few exceptions, the quantities and prices of the minor metals do not warrant the extraction and processing of ores without the simultaneous recovery of copper. Starting with the tellurium content in copper anodes of $1250 \mathrm{t} / \mathrm{yr}$ and assuming $3.1 \%$ annual growth and a gradual increase to $80 \%$ recovery from anode slimes, by 2020, the annual primary production of metallurgical-grade tellurium would be $1450 \mathrm{t} / \mathrm{yr}$. In line with this estimate, the U.S. DOE forecasts $1220 \mathrm{t}$ of tellurium production in $2015 .^{16}$

In addition to tellurium from copper mines, there are other types of smaller reserves, including tellurium-rich mineral deposits in China and Mexico from which the near-term direct mining of tellurium is economically feasible. Over the longer term, tellurium recovery from mining tailings and from refining of lead-zinc ores is also possible. In addition, massive resources of tellurium exist in ocean-floor ferromanganese nodules, reportedly as much as nine million tonnes at mean concentrations of $50 \mathrm{ppm} .{ }^{28}$ However, because quantitative information is not available for the former and because the recovery of metals from deep ocean is not currently cost-efficient, these resources were not included in the current analysis.

Presently, about $42 \%$ of tellurium (based on 2006 production) is used in iron and steel, and $23 \%$ is used in chemicals; recycling of tellurium from these products is not currently practiced. However, the tellurium content in CdTe modules is relatively high ( $500 \mathrm{ppm})$, so that end-of-life modules are the obvious choice for extracting and recovering scarce metals. The technical and economic feasibility of recycling CdTe solar cells is well confirmed. Small-scale operations have achieved $99.99 \%$ separation of tellurium and cadmium from end-of-life modules at an estimated cost of US $\$ 0.02 / \mathrm{W}_{\mathrm{p}}$. On an industrial scale, a $90 \%$ overall recovery rate is expected. ${ }^{29}$

At the module level, with economic incentives and laws regulating disposal, the collection of spent modules can be expected to reach $100 \%$ from large utility installations and $80 \%$ from residential installations. Accordingly, after 2045, recycling will become an increasingly significant source of secondary tellurium (Figure 2). This evaluation is incorporated into material constraints on CdTe PV growth.

\section{CdTe PV production}

Under these assumptions, the total annual production of CdTe photovoltaics that tellurium availability in copper smelting can support is constrained to $16-24 \mathrm{GW}_{\mathrm{p}}$ in $2020,44-106 \mathrm{GW}_{\mathrm{p}}$ in 2050, and 60-161 GW in 2075 (Figure 3a). The telluriumbased limit of cumulative global production of CdTe photovoltaics (Figure 3b) is $120 \mathrm{GW}_{\mathrm{p}}$ by 2020 , rising to $0.9-1.8 \mathrm{TW}_{\mathrm{p}}$

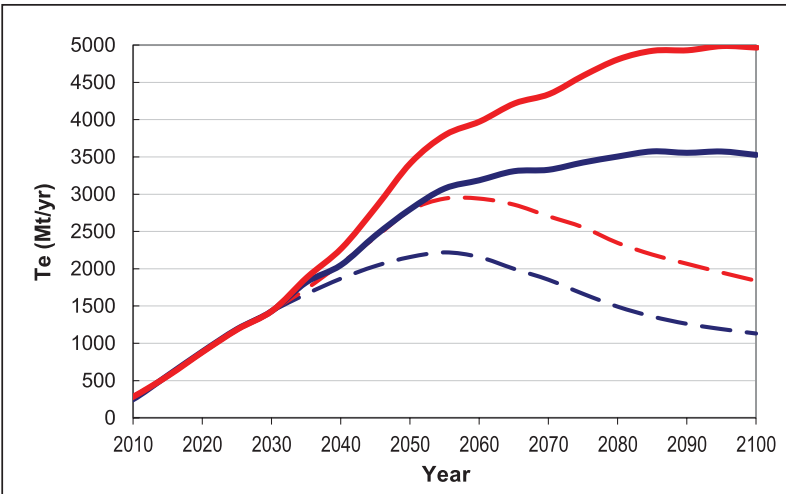

Figure 2. Projections of tellurium availability for photovoltaics from copper smelters (dashed lines; peaking in 2055) and tota from copper smelters and recycling of end-of-life photovoltaic modules (solid lines; continuing upward trend until 2095). The red and blue curves in each pair correspond to high and low projections, respectively. Note: A tellurium demand of $322 \mathrm{t} / \mathrm{yr}$ for non-photovoltaic uses was subtracted. Reproduced from Reference 30 courtesy of Brookhaven National Laboratory. 


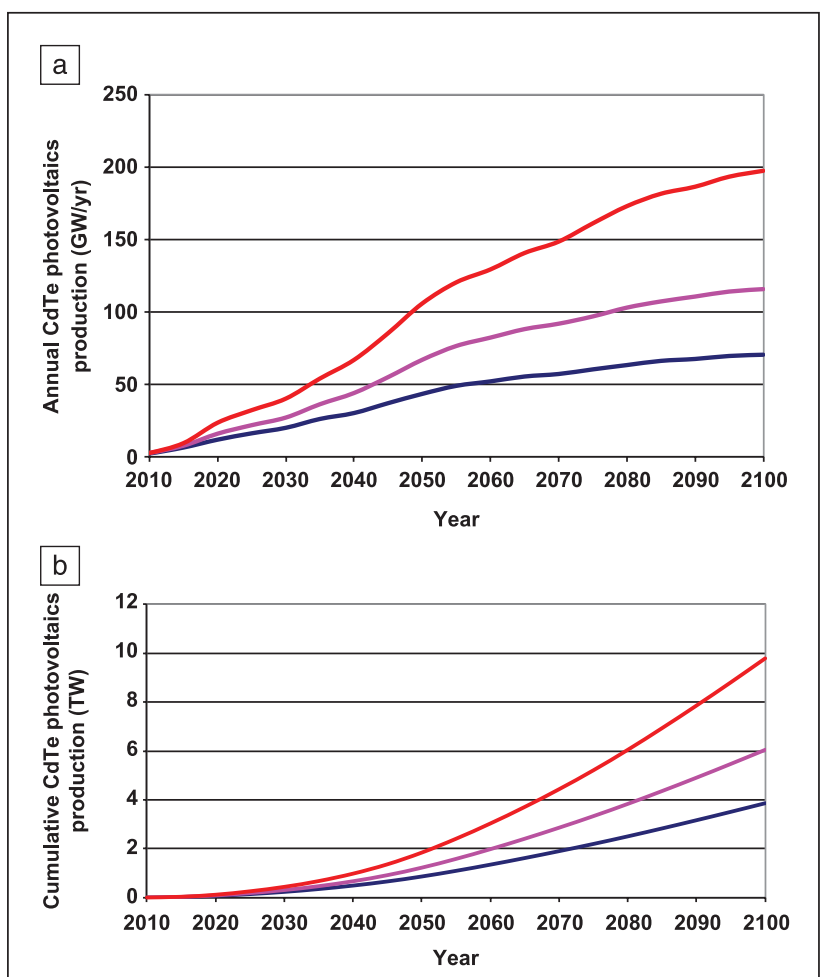

Figure 3. Projections of CdTe photovoltaics (a) annual and (b) cumulative production limits under tellurium production constraints shown in Figure 2. The red, pink, and blue curves correspond to the optimistic, most likely, and conservative scenarios, respectively, listed in Table I. Reproduced from Reference 30 courtesy of Brookhaven National Laboratory.

by 2050 and $3.8-10 \mathrm{TW}_{\mathrm{p}}$ by 2100 . These limits are based strictly on tellurium coproduction during copper production from known resources and do not include the potential for direct mining or the discovery of additional resources.

For the production of CdTe photovoltaics to continue growing by $40 \%$ per year, tellurium recovery from anode slimes must increase to $80 \%$, for which there is already a technological basis. In addition, the CdTe film thickness must decrease by a factor of two from the current thickness of films formed by vaportransport deposition, as assumed in the "most likely" scenario in Table I, which will require additional research and engineering.

\section{Indium}

The supply of indium is tied to the production of zinc and is likely to remain so in the future. The price of indium reached a high of US\$1,000/kg in 2005, but is currently about US\$600/kg. In 2010, the estimated production of indium was $1345 \mathrm{t}$, of which $480 \mathrm{t}$ came from mining and another $865 \mathrm{t}$ came from recycling of used indium sputtering targets. The main use of indium today is in liquid-crystal displays (LCDs), accounting for $65 \%$ of current consumption; photovoltaics uses an estimated $5 \%$ of the primary production of indium. Competing applications of indium present extra challenges to PV growth, and further, its recovery from the zinc circuit is already high
( 70-80\%), leaving little room for enhancement. The estimated production for 2015 is only $1612 \mathrm{t}$, a large fraction of which is expected to be used in LCDs.

\section{Gallium}

Most gallium is produced as a byproduct of treating bauxite ore to extract aluminum; about $10 \%$ originates in sphalerite, and it is produced during the purification stages of the zinc production circuit. The world resources of gallium in bauxite ore are estimated to be about one million tonnes, but evaluations of the reserves (deposits that currently can be mined economically) are lacking. Most gallium is extracted electrolytically from a solution of crude aluminum hydroxide in the Bayer process for producing alumina and aluminum. In 2010, the production of gallium was estimated to be $207 \mathrm{t}$, of which $100 \mathrm{t}$ was derived from mining and the rest from recycling scrap. ${ }^{16,31}$ Only $~ 10 \%$ of alumina producers extracted gallium, with the others not finding it economical. The price of gallium reached a peak of US\$2,500/kg in early 2015 and is currently US\$500-600/kg. Presently, almost all of the gallium produced is used in integrated circuits $(67 \%)$ and optoelectronics (31\%), with both usages exhibiting upward trends. ${ }^{19}$ The estimated 2015 supply is $325 \mathrm{t}$.

\section{CIGS production}

Under the listed assumptions on indium and gallium availability, the material-constrained growth potential of CIGS photovoltaics has been calculated as $13-22 \mathrm{GW}_{\mathrm{p}} / \mathrm{yr}$ in 2020 , 17-106 $\mathrm{GW}_{\mathrm{p}} / \mathrm{yr}$ in 2050, and 17-152 $\mathrm{GW}_{\mathrm{p}} / \mathrm{yr}$ in 2075. ${ }^{2}$ These estimates assume $80 \%$ extraction recoveries and use of only $50 \%$ of the growth in the supply of indium for CIGS photovoltaics, as well as improvements in module efficiency and material requirements, as shown in Table I. Note that the estimates for midcentury and beyond are based on the presumption that the growth of zinc extraction will follow that of copper; this is questionable because the depletion time of zinc might be shorter than that of copper. Furthermore, recovering indium and gallium from CIGS is more challenging than recouping tellurium from $\mathrm{CdTe}$, as their respective concentrations are lower and their separations are more difficult.

\section{Germanium}

Zinc mineral deposits are also the main source for germanium. In 2006 , germanium production was estimated to be $\sim 100$ t. Estimates of germanium availability carry higher uncertainty than those for indium because of the dearth of resource data for germanium.

\section{a-SiGe production}

The germanium-related constraints of amorphous silicongermanium (a-SiGe) photovoltaics are estimated to be 3-11 $\mathrm{GW}_{\mathrm{p}} / \mathrm{yr}$ in 2020 , 5-49 $\mathrm{GW}_{\mathrm{p}} / \mathrm{yr}$ in 2050 , and $10-120 \mathrm{GW}_{\mathrm{p}} / \mathrm{yr}$ in 2100 (Table II). Tellurium, gallium, and indium cannot be replaced in current technologies because of their particular functions. However, germanium can be superseded by nanostructured layers of mc-Si and in tandem a-Si/mc-Si cascade thin-film modules. 


\begin{tabular}{|l|c|c|c|c|c|c|}
\hline \multicolumn{5}{|c|}{ Table II. Limits on annual production of various thin-film photovoltaic (PV) } \\
of metal availability.
\end{tabular}

a Estimates based only on coproduction with copper; direct tellurium mining is not included. basic sustainability criteria (i.e., low cost, resource availability, and minimum environmental impact): it will lower the cost of materials while increasing their supply and resolving environmental concerns associated with end-of-life modules. Thus, current PV technologies appear to be sustainable in very large growth scenarios, supporting the cumulative

\section{Conclusions}

Current-generation thin-film PV technologies (i.e., CdTe, CIGS, and a-SiGe) use elements (i.e., tellurium, indium, gallium, and germanium) whose availabilities are constrained by the rates of production of the corresponding base metals (i.e., copper, zinc, and aluminum). Nevertheless, such coproduction is sufficient for each of the thin-film technologies to continue its current growth rate (i.e., $\sim 40-50 \% / y r$ ) through 2020 . Aggressive scenarios of continuing high growth rates to midcentury prescribe 2.8 TW by 2050 for the United States, to support $70 \%$ electricity generation from renewable energy for current uses and hybrid plug-in electric cars. ${ }^{8}$ A global plan of the same proportions will need at least three times more capacity. A single thin-film PV technology might not achieve this goal, but it can be supported by a combination of the three PV technologies discussed herein.

Photovoltaics are following a path of cost reduction and market growth that should enable them to become major players in global energy markets, providing terawatts of renewable energy. The sustainability of very large scales of market penetration, however, depends on cost, resource availability, and potential environmental impacts. It is likely that target costs will make photovoltaics cost-competitive in large parts of the world, but for this to happen, incentives that open new markets should remain in place. A full accounting of the cost of electricity that includes externalities shows that photovoltaics is already cost-competitive with coal in the United States. The issue of land resources is even less problematic: During their life cycles, PV technologies often use less land than the conventional power-generation systems they displace, and they are not constrained by the large consumption of water that thermoelectric power generation requires.

The availability of some elements employed in thin-film PV technologies (i.e., gallium, germanium, indium, and tellurium) is constrained by the annual production of the corresponding base metals. Among these, indium apparently has the greatest criticality in the short and medium terms. Increases in the production of tellurium to sustain the dynamic growth of CdTe photovoltaics appear to be in place, as the leading company is investing in direct mining of tellurium that can increase its availability in the near term. Materials-related sustainability deficits will be eased with enhanced recovery during primary production, reductions of the thickness of semiconductor layers, increases in the efficiency and life expectancy of modules, and recycling of spent modules. Recycling is especially important as it pertains to the three deployment of several terawatts by midcentury or earlier.

\section{References}

1. Report of the World Commission on Environment and Development: Our Common Future (Annex to Document A/42/427, Oxford University Press, Oxford, UK, 1987). 2. V. Fthenakis, Renewable Sustainable Energy Rev. 13, 2746 (2009).

3. N. Pfund, B. Healey, "What Would Jefferson Do? The Historical Role of Federal Subsidies in Shaping America's Future" (DBL Investors, San Francisco, CA, September 2011).

4. P. Epstein, J. Buonocore, K. Eckerle, M. Hendryx, M. Benjamin, B. Stout III, R. Heinberg, R. Clapp, B. May, N. Reinhart, M. Ahern, S. Doshi, L. Glusstrom, Ann. N.Y. Acad. Sci. 1219, 73 (2011).

5. J. Lushetsky, paper presented at the 25th European Photovoltaics Conference, Valencia, Spain, 3-8 September 2010.

6. World Energy Assessment Overview: 2004 Update (United Nations Development Programme, New York, 2004).

7. "SunShot Initiative: Solar Program Highlights" (U.S. Department of Energy, Washington, DC), www1.eere.energy.gov/solar/sunshot/highlights.html (accessed 8 February 2012).

8. V. Fthenakis, J. Mason, K. Zweibel, Energy Policy 37, 387 (2009).

9. V.M. Fthenakis, H.C. Kim, Renewable Sustainable Energy Rev. 13, 1465 (2009). 10. V.M. Fthenakis, H.C. Kim, Energy Policy, 35, 2549 (2007).

11. V. Fthenakis, Renewable Sustainable Energy Rev. 8, 303 (2004).

12. V.M. Fthenakis, M. Fuhrmann, J. Heiser, A. Lanzirotti, J. Fitts, W. Wang, Prog. Photovoltaics Res. Appl. 13, 713 (2005).

13. V.M. Fthenakis, H.C. Kim, E. Alsema, Environ. Sci. Technol. 42 (6), 2168 (2008) 14. V. Fthenakis, Regulations on Photovoltaic Module Disposal and Recycling (Informal Report BNL-68142, Brookhaven National Laboratory, Upton, NY, 2011). 15. Critical raw materials for the EU, Report of the Ad-hoc Working Group on defining critical raw materials (European Commission, Brussels, Belgium, 2010) 16. Critical Materials Strategy (U.S. Department of Energy, Washington, DC, December 2010)

17. A. Kapur, Futures 37, 1067 (2005).

18. R.U. Ayres, L.W. Ayres, I. Råde, The Life Cycle of Copper, its Co-Products and By-Products (Mining, Minerals and Sustainable Development Working Paper no. 24, International Institute for Environment and Development, London, 2002).

19. T.E. Graedel, Annu. Rev. Mater. Res. 41, 323 (2011).

20. D.W. Menzie, D.A. Singer, J.J.H. DeYoung, in Scarcity and Growth Revisited, D.R. Simpson, M.A. Toman, R.U. Ayres, Eds. (Resources for the Future, Washington, DC, 2005), pp. 142-154.

21. D.W. Menzie, Congressional Testimony before the Committee on Resource, Subcommittee on Energy and Mineral Resources (U.S. Geological Survey, Reston, VA, 2006).

22. "Forecast 2008-2009" (Press release, International Copper Study Group, Lisbon, Portugal, 8 October 2008).

23. R.B. Gordon, M. Bertram, T.E. Graedel, Proc. Natl. Acad. Sci. U.S.A. 103, 1209 (2006) 24. "Indium," in 2006 Minerals Yearbook (U.S. Geological Survey, Reston, VA, 2007). 25. C. Wolden, J. Kurtin, J. Baxter, I. Repins, S. Shaheen, J. Torvik, A. Rockett, V. Fthenakis, E. Aydil, J. Vac. Sci. Technol. A 29 (30), 30801 (2011).

26. M.A. Green, Prog. Photovoltaics Res. Appl. 14, 743 (2006).

27. K. Zweibel, Science 328, 699 (2010).

28. J.R. Hein, A. Koschinsky, A.N. Halliday, Geochim. Cosmochim. Acta 67 (6), 1117 (2003)

29. V.M. Fthenakis, W. Wang, Prog. Photovoltaics Res. Appl. 14, 363 (2006).

30. V. Fthenakis, paper presented at the 35th IEEE Photovoltaic Specialists Conference, Honolulu, HI, 20-25 June 2010.

31. "Gallium," in 2006 Minerals Yearbook (U.S. Geological Survey, Reston, VA, 2007) 


\title{
Materials challenges in carbon- mititigation technologies
}

\section{Laura Espinal and Bryan D. Morreale}

\begin{abstract}
Given the increasing size of $\mathrm{CO}_{2}$-generating industries and the mounting awareness of their environmental impact, carbon-management technologies are expected to play an important role in curtailing environmental emissions in coming years. A major challenge in carbon management is the development of cost-effective, technologically compatible, and efficient $\mathrm{CO}_{2}$ capture and storage technologies. The development of energy-efficient solvent, solid-sorbent, and membrane materials to capture $\mathrm{CO}_{2}$ from industrial exhaust streams can take improvements in process efficiency one step further. Also, the permanent storage of $\mathrm{CO}_{2}$ in geologic formations is critical to the success of carbon-management technologies and requires better understanding of interactions of $\mathrm{CO}_{2}$ with underground materials. These and other materials challenges must be solved to make carbon capture and storage an economically viable and reliable technology to be adopted by the power and product manufacturing industries.
\end{abstract}

\section{Introduction}

Reducing greenhouse gas emissions from the power generation and industrial sectors is an important component of environmental sustainability. The large volume of $\mathrm{CO}_{2}$ emissions from these point sources and their stationary nature makes them particularly attractive targets. The complex global challenge is to reduce $\mathrm{CO}_{2}$ emissions while simultaneously generating energy, products, services, buildings, and public infrastructure for the continuously rising population worldwide, estimated to surpass nine billion by $2050 .{ }^{1}$

Global efforts to stabilize the atmospheric $\mathrm{CO}_{2}$ concentration require continual advances in carbon-mitigation technologies to reduce carbon sources and increase carbon sinks. Approaches to reduce carbon sources include increasing the efficiency of energy conversion and utilization; improving building insulation for energy conservation; and adopting more alternative, non-carbon energy sources such as nuclear energy and renewable fuels. In addition, natural carbon sinks, such as forests and soils, can be expanded to enhance their $\mathrm{CO}_{2}$-absorption capacities, and artificial carbon sinks can be engineered in oceans and underground geological formations for long-term storage of $\mathrm{CO}_{2}$ through a process called carbon sequestration. ${ }^{2}$

The life cycle for a fossil fuel, including proposed carbon capture and storage (CCS) in underground geological formations, is illustrated in Figure 1. The fossil fuel extracted during mining (step 1) is used for power generation by a thermochemical conversion process, which produces $\mathrm{CO}_{2}$ emissions. The exciting mitigation opportunities for a materials scientist begin at the smokestack (step 2), where significant advances in solvent, solid-sorbent, and membrane materials are needed to cost-efficiently capture significant amounts of $\mathrm{CO}_{2}$ before it spreads into the atmosphere. Once the $\mathrm{CO}_{2}$ is captured, the role of a materials scientist continues downstream. For example, low-cost corrosion-resistant pipelines are needed to transport $\mathrm{CO}_{2}$ (step 3) to a suitable site for injection (step 4) and storage (step 5) underground, where the interactions between fluids (e.g., $\mathrm{CO}_{2}$, water, oil) and natural and engineered materials (e.g., minerals, cement, steel) are very important. In the present article, we survey research opportunities for materials scientists in the development of carbonmitigation technologies for energy and other industrial sectors. We emphasize storage of captured carbon in underground geological formations, which can lower emissions from large, stationary, point sources.

\section{Carbon dioxide sources and flue-gas types}

A "large" source is defined as one that emits more than $0.1 \mathrm{Mt}$ of $\mathrm{CO}_{2}$ per year. Approximately 8000 large $\mathrm{CO}_{2}$ sources have been identified worldwide, including coal-fired power plants, oil refineries, and cement manufacturers, together emitting 18 Gt of $\mathrm{CO}_{2}$ per year., ${ }^{2,4}$ The purpose of $\mathrm{CO}_{2}$ capture from a stationary or point source is to produce a stream of concentrated $\mathrm{CO}_{2}$ 


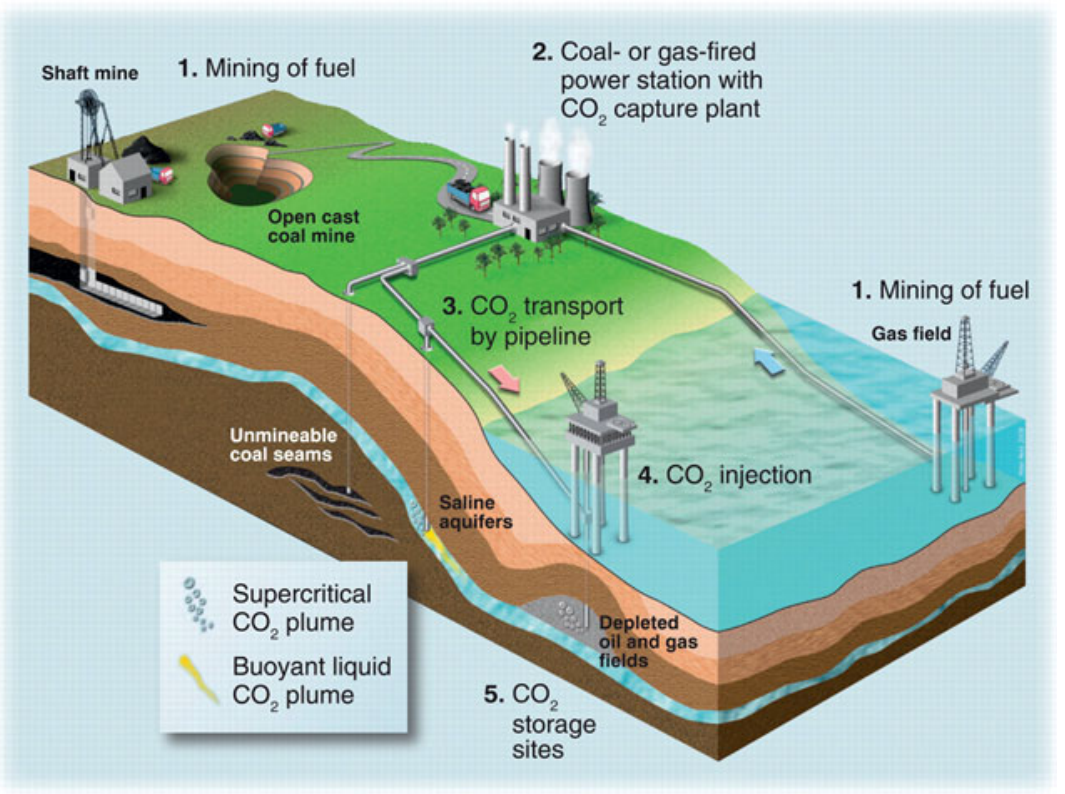

Figure 1. Schematic representation of the life-cycle chain of a fossil fuel with carbon capture and storage into underground geological formations. (Reproduced with permission from Reference 3. (C) 2009, American Association for the Advancement of Science.)

reducing agent and produces a flue gas with a $\mathrm{CO}_{2}$ concentration between $15 \mathrm{vol} \%$ and $27 \mathrm{vol} \%$ and partial pressures between 0.3 bar and 0.6 bar. $^{2,4}$ Although fermentation, natural-gas processing, and gasification emit less than $2 \%$ of the $\mathrm{CO}_{2}$ from large, stationary sources, their high $\mathrm{CO}_{2}$ partial pressures make them promising for early deployment of CCS systems. ${ }^{2}$

\section{Carbon dioxide capture systems and technologies}

The main approaches to $\mathrm{CO}_{2}$ capture from power plants and industrial emissions are classified according to the fuel conversion process, as illustrated in Figure 3. Post-combustion refers to the separation of $\mathrm{CO}_{2}$ from flue gas produced by conventional complete oxidation of the primary fuel — coal, natural gas, oil, or biomassin air. Oxy-combustion, a technology that is still under development, instead uses high-purity $\mathrm{O}_{2}$ as the oxidizing agent. This makes recovery of $\mathrm{CO}_{2}$ easier, because the resultant flue gas is mainly $\mathrm{H}_{2} \mathrm{O}$ and $\mathrm{CO}_{2}$. Pre-combustion starts with the partial oxidation of the primary carbon fuel to produce synthesis gas, or "syngas," com-

that can be pressurized and transported to a suitable location for permanent storage. The extra cost depends on many details about the source, especially the partial pressure of $\mathrm{CO}_{2}$.

In conventional fossil-fuel combustion, the primary fuel is burned in air to produce heat, which generates steam and power. The effluent, referred to as "flue gas," typically has a $\mathrm{CO}_{2}$ concentration on the order of $15 \mathrm{vol} \%$ for air-fired, coalbased processes. ${ }^{2}$ The temperature and pressure of the flue gas depend on process conditions including feedstock, oxidant, and gas-processing steps, but are typically $\sim 65^{\circ} \mathrm{C}$ and $\sim 2$ bar, respectively. Such dilute, low-pressure streams of $\mathrm{CO}_{2}$ present a challenge for cost-effective gas separation. Advanced energy-conversion technologies are under development to increase the energy-conversion efficiency and facilitate carbon capture. These include the use of coal with indigenous or carbon-neutral "opportunity fuels" such as biomass. ${ }^{5}$

Industrial processes employ similar fossilfuel-based conversion technologies to meet process-related energy requirements and supply chemical feeds. Figure 2 shows an example of an industrial source of $\mathrm{CO}_{2}$ : iron and steel production. Depending on the specifics of the process, chemical reactions and material transformations might be deployed in combination with the combustion step, producing a flue gas distinct from that of power plants. For example, the extraction of metals from ores uses carbon as a posed of $\mathrm{CO}$ and $\mathrm{H}_{2}$. The carbon monoxide is further oxidized with steam in the catalyzed water-gas shift reaction to produce a mixture of hydrogen with $\mathrm{CO}_{2}$, which is then captured. ${ }^{2}$ Each option poses a different gas-separation problem: $\mathrm{CO}_{2}$ from $\mathrm{N}_{2}$ at atmospheric pressure for post-combustion, $\mathrm{O}_{2}$ from $\mathrm{N}_{2}$ in air (or $\mathrm{O}_{2}$ generation) for oxy-combustion, and $\mathrm{CO}_{2}$ from $\mathrm{H}_{2}$ at elevated pressure for pre-combustion. 


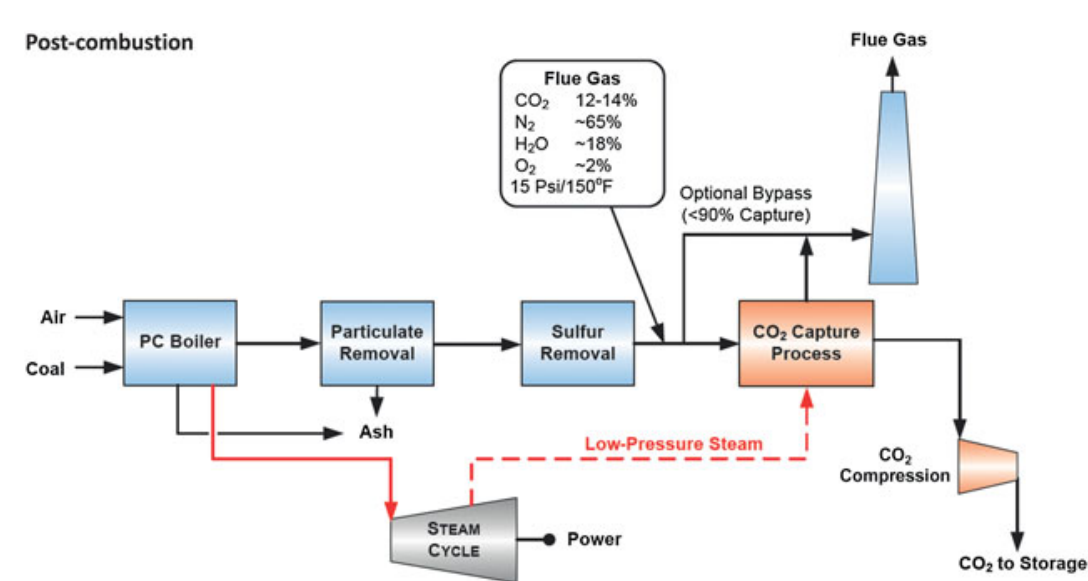

Oxy-combustion

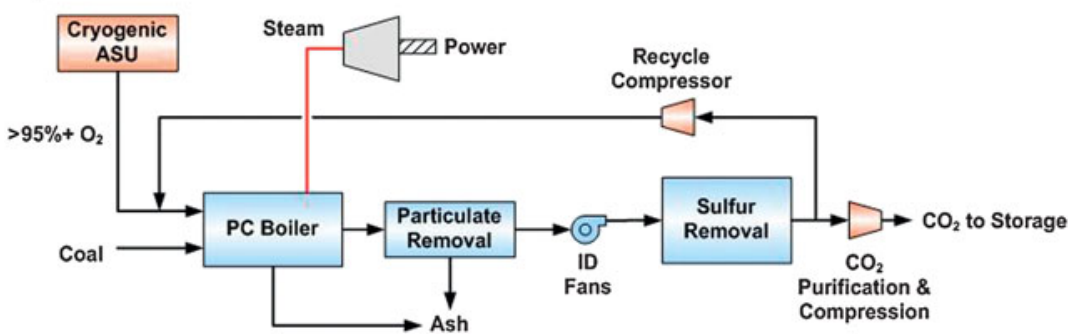

Pre-combustion

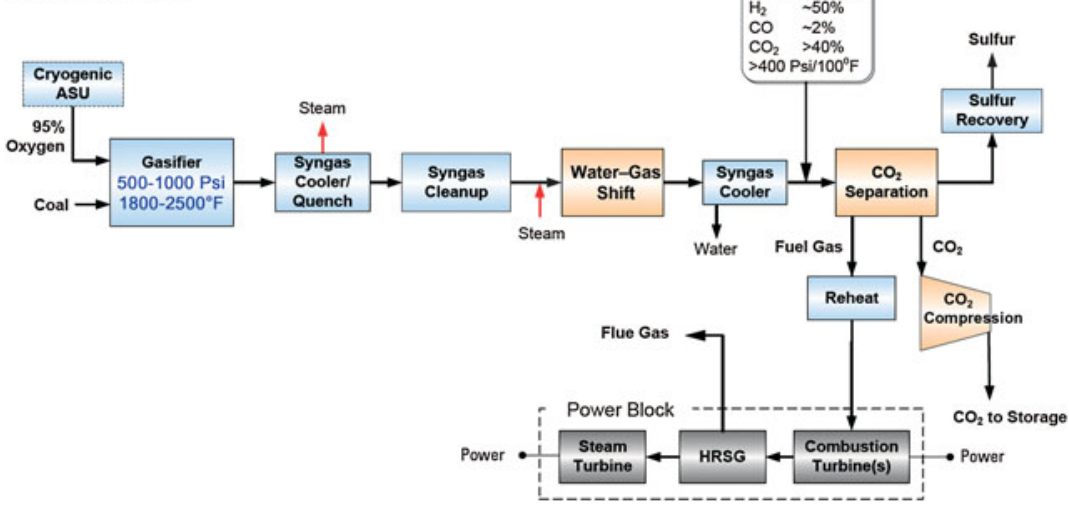

Figure 3. $\mathrm{CO}_{2}$-capture systems for coal-based power generation can be classified according to the fuel conversion processes: post-combustion, oxy-combustion, and pre-combustion, as described in the text. Each process poses a different $\mathrm{CO}_{2}$ gas separation problem. Acronyms: ASU, air separation unit; HRSG, heat-recovery steam generator; ID, induced draft; PC, pulverized coal. (Reproduced from Reference 6 courtesy of the U.S. Department of Energy.)

where components of the gas mixture permeate through the membrane at different rates because of their physical and chemical interactions with the membrane. In cryogenic distillation, a gas mixture is liquefied through a series of compression, cooling, and expansion steps, and the gas components are separated by distillation.

The best currently available capture technology is based on chemical solvent absorption in a post-combustion system. This technology is expensive and energy-intensive, in great part because of the energy required to regenerate the capture material. ${ }^{7}$ Incorporating such capture technology into a supercritical coal power plant is estimated to increase electricity cost by $70 \%$ relative to a similar plant without capture. $^{8}$ The major contributors are equipment and materials ( $27 \%$ of the increase); capture-material regeneration $(\sim 44 \%)$; process pumping and compression ( $6 \%) ; \mathrm{CO}_{2}$ compression $(\sim 13 \%)$; and $\mathrm{CO}_{2}$ transport, storage, and monitoring $(\sim 9 \%) .{ }^{9}$ Given the substantial costs associated with current technology, great opportunities exist for materials scientists to develop improved carbon-capture materials. The following sections describe the materials challenges for the different combustion systems.

The $\mathrm{CO}_{2}$-capture research and development (R\&D) program at the National Energy Technology Laboratory (NETL) of the U.S. Department of Energy (DOE) established overall targets for capture technologies of $90 \% \mathrm{CO}_{2}$ capture efficiency, with an associated increase in electricity costs of less than $10 \%$ for pre-combustion capture and less than $30 \%$ for post- and oxy-combustion capture. ${ }^{6,10}$ Near- and long-term strategies for improving carbon capture through advanced materials science research have also been highlighted in recent reports summarizing carboncapture workshops. ${ }^{11,12}$

\section{Materials for post-combustion capture}

The state of the art for post-combustion carbon capture is $\mathrm{CO}_{2}$ separation by chemical absorption, with solvents consisting of aqueous amine solutions that provide high absorption rates and

Each of these $\mathrm{CO}_{2}$ capture systems can employ any of the known technologies for gas separation (Figure 4). In the most mature method, a gas mixture is placed in close contact with a liquid solvent, and one component separates from the others as a result of differences in solubility. The differential solubility can be physical in origin, but it is often chemical. Gas separation can also be achieved by preferential adsorption on the surface of a solid sorbent, followed by desorption driven by changes in pressure or temperature. Another method uses a membrane, high $\mathrm{CO}_{2}$ absorption capacities. ${ }^{2,13}$ However, the commercial viability of CCS is hindered by the substantial capital and operating costs of the solvent technology. In addition, amine-based solvents must contain $70 \mathrm{wt} \%$ water to minimize corrosion; have high heats of absorption; and are prone to thermal and oxidative degradation in the presence of common flue-gas components including $\mathrm{O}_{2}, \mathrm{SO}_{x}$, and $\mathrm{NO}_{x}$.

Improved solvent formulations could overcome these challenges. For example, blending the most widely used primary 

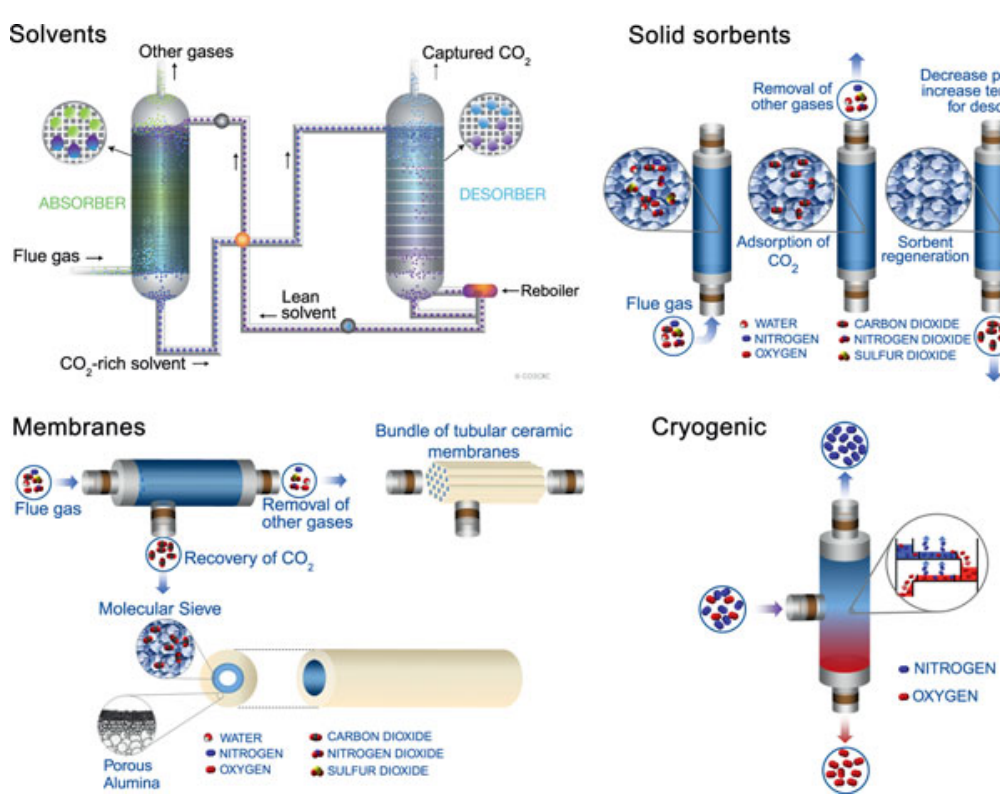

Figure 4. $\mathrm{CO}_{2}$-capture technologies include solvents, solid sorbents, membranes, and cryogenic distillation. (Image for solvents obtained from CO2CRC, Cooperative Research Centre for Greenhouse Gas Technologies, Canberra, Australia. (c) 2011, CO2CRC.)

carbon. ${ }^{27}$ However, zeolites require higher regeneration temperatures because of their sensitivity to moisture and higher heats of $\mathrm{CO}_{2}$ adsorption. ${ }^{28,29}$ For increased capacities and selectivities, hybrid materials are being developed by amine functionalization of pore walls in activated carbons and porous silica, ${ }^{30-33}$ although further understanding of the interaction between $\mathrm{CO}_{2}$ and functional amine groups is needed. Some hyperbranched aminosilicas can adsorb up to $5.5 \mathrm{mmol}$ of $\mathrm{CO}_{2}$ per gram at atmospheric pressure..$^{34}$

An emerging class of materials called metalorganic frameworks (MOFs), constructed by bridging transition-metal nodes with organic ligands, have considerable potential as $\mathrm{CO}_{2}$ sorbents, with some exhibiting $\mathrm{CO}_{2}$ uptakes up to $33 \mathrm{mmol} / \mathrm{g}$ at $32 \mathrm{bar} .{ }^{35}$ However, MOF uptakes surpass those of zeolites only at pressures higher than 10 bar. To enhance their uptake and selectivity for post-combustion-like gas streams with low $\mathrm{CO}_{2}$ partial pressures, functionalization is being pursued through incorporation of $\mathrm{CO}_{2}$-philic ligands (e.g., amine-functionalized ligands $)^{36,37}$ or coordination to unsaturated metal centers. ${ }^{38,39}$ Further details on current and emerg-

alkanolamine, monoethanolamine (MEA), with sterically hindered amines could reduce the amount of steam needed for regeneration. ${ }^{14,15}$ Incorporation of promoters such as piperazine could accelerate the absorption of $\mathrm{CO}_{2}$ and minimize the required concentration of amine. ${ }^{15-17}$ Corrosion could also be inhibited by adding, for example, scavengers for binding with oxygen and other reaction intermediates, chelating agents for reacting with dissolved metals that take part in degradation, or heavy-metal salts that increase the ionic strength and thus decrease the oxygen solubility. ${ }^{18}$ Researchers are also seeking alternative solvents, including $\mathrm{CO}_{2}$-philic ionic liquids, ${ }^{19-21}$ amine-neutralized amino-acid salts, ${ }^{22}$ and solvents whose viscosity and polarity change upon contact with $\mathrm{CO}_{2} \cdot{ }^{23,24}$

Solid sorbents are also being explored as a way to reduce costs by avoiding the volatility and corrosion problems of aqueous amine solvents. Some of the key desired solid-sorbent properties include large surface area, strong affinity toward $\mathrm{CO}_{2}$ compared to other gas constituents, low energy consumption during $\mathrm{CO}_{2}$ desorption (sorbent regeneration), and high stability to moisture. A recent cost analysis of a vacuum-swing process suggested that an adsorbent with a working capacity of $4.3 \mathrm{mmol} / \mathrm{g}$ (millimoles of $\mathrm{CO}_{2}$ per gram of sorbent) and a $\mathrm{CO}_{2} / \mathrm{N}_{2}$ selectivity of 150 would reduce the capture cost to US $\$ 30$ per tonne of post-combustion $\mathrm{CO}_{2}$ avoided. ${ }^{25}$

There are several candidate materials with uptakes and selectivities that are competitive with those of liquid solvents. Activated carbons have $\mathrm{CO}_{2}$ uptakes up to $4 \mathrm{mmol} / \mathrm{g}$ and $\mathrm{CO}_{2} / \mathrm{N}_{2}$ selectivities near 10 at atmospheric conditions ( 1 bar and room temperature) ${ }^{26}$ Zeolitic materials offer $\mathrm{CO}_{2}$ adsorption uptakes up to $4.5 \mathrm{mmol} / \mathrm{g}$ and much larger selectivities than activated ing $\mathrm{CO}_{2}$ adsorbent materials, including the issues of thermal degradation, poisoning, attrition, and thermal management, can be found in recent review articles. ${ }^{40,41}$

Passive $\mathrm{CO}_{2}$ separation using membranes is attractive because it eliminates the need for thermal or pressure cycling for regeneration. ${ }^{42}$ However, membrane separation requires a pressure differential, which can be costly in atmospheric-pressure postcombustion streams with $\mathrm{CO}_{2}$ concentrations below $15 \mathrm{vol} \%$. The $\mathrm{CO}_{2}$-capture capability of a membrane is governed by the $\mathrm{CO}_{2}$ permeability, which determines the rate at which $\mathrm{CO}_{2}$ is removed from the feed gas, and the $\mathrm{CO}_{2} / \mathrm{N}_{2}$ selectivity, which affects the purity of the $\mathrm{CO}_{2}$-containing effluent. One study found that a membrane with a $\mathrm{CO}_{2}$ permeability of 300 barrer and a $\mathrm{CO}_{2} / \mathrm{N}_{2}$ selectivity of 250 costing US $\$ 10 / \mathrm{m}^{2}$ would reduce the capture cost below US $\$ 25$ per tonne of post-combustion $\mathrm{CO}_{2}$ avoided. ${ }^{43}$

Several inorganic and organic membrane materials are being considered for post-combustion capture. Molecular-size sieving is a common mechanism for gas separation, but the similar kinetic diameters of $\mathrm{CO}_{2}(3.30 \AA)$ and $\mathrm{N}_{2}(3.64 \AA)^{44}$ make this approach very challenging. Another difficulty is the design of chemically stable membranes compatible with large-scale fabrication. Although large-area polymeric membranes are easily fabricated, their size-sieving ability can be reduced by polymer swelling when $\mathrm{CO}_{2}$ is present. ${ }^{45}$ Inorganic membranes are more chemically stable in the presence of $\mathrm{CO}_{2}$, but they are hard to fabricate at a large scale. One approach that could combine the strengths of the two technologies is the dispersion of inorganic particles into a continuous polymeric base membrane.

Functionalization of pore walls with $\mathrm{CO}_{2}$-philic compounds is also being evaluated to increase $\mathrm{CO}_{2} / \mathrm{N}_{2}$ selectivity. ${ }^{46}$ Amine 
functionalization of some zeolite-based membranes can increase the $\mathrm{CO}_{2}$ separation index (a measure that combines selectivity and permeability) by more than $150 \%{ }^{47}$ and can raise the $\mathrm{CO}_{2} / \mathrm{N}_{2}$ selectivity of the bare polymeric membrane. ${ }^{48}$ Introduction of magnesia into alumina-based membranes has been explored to induce the preferential surface diffusion of $\mathrm{CO}_{2} \cdot{ }^{49}$ Beyond molecular-size sieving, research is also exploring the separation of gas molecules based on their relative solubilities in membranes, where gas molecules can cross the membrane through a solution-diffusion transport mechanism. ${ }^{50,51}$ Incorporation of $\mathrm{CO}_{2}$-philic ionic liquids into membrane assemblies is being used to facilitate the transport of $\mathrm{CO}_{2}$ molecules. ${ }^{52} \mathrm{~A}$ recent topical report on $\mathrm{CO}_{2}$-selective membranes provides further details on a wide range of membrane materials. ${ }^{53}$

\section{Materials for oxy-combustion capture}

Oxygen separation from air by cryogenic distillation is a mature technology. However, alternative materials and approaches are being explored to inexpensively produce the vast quantities of pure $\mathrm{O}_{2}$ needed for CCS. For $\mathrm{O}_{2}$ sorbents, for example, efforts center on increasing the framework stability and decreasing the energy required for oxygen desorption.

For solid sorbents, $\mathrm{O}_{2}$ separation from $\mathrm{N}_{2}$ using molecular-size sieves is challenging because of the similar kinetic diameters of these molecules, $3.46 \AA\left(\mathrm{O}_{2}\right)$ and $3.64 \AA\left(\mathrm{N}_{2}\right) .{ }^{44}$ Hybrid composite materials provide additional separation mechanisms, for example, through the incorporation of transition-metal complexes that reversibly bind to $\mathrm{O}_{2}$ with high specificity. ${ }^{54-56}$ The intrinsic exposed metal sites in some MOFs, such as $\mathrm{Cr}$ (II)-based MOFs, also allow for selective binding to $\mathrm{O}_{2}$ over $\mathrm{N}_{2}{ }^{57}$

Ceramic- and polymer-based oxygen-capture materials are also being considered in membrane configurations. The most commonly used polymeric membranes exhibit physical aging, which reduces overall gas permeability but increases $\mathrm{O}_{2}$ sensitivity. ${ }^{58}$ Hemoglobin-inspired polymeric membranes containing cobalt complexes are being explored to increase the $\mathrm{O}_{2} / \mathrm{N}_{2}$ selectivity by reversibly binding with molecular oxygen. ${ }^{59}$ Metal complexes have also been incorporated into aluminazeolite composite membranes to improve oxygen selectivity. ${ }^{60}$

Mixed metal oxide membranes are also being used to separate oxygen from air by virtue of oxygen ion conduction, ${ }^{61,62}$ which could enable the integration of oxygen separation and combustion in one unit. As an alternative to oxygen extraction from air, transition-metal oxide particles can be employed as oxygen carriers, in a process known as chemical-looping combustion, in which the metal oxide goes through oxidation/reduction cycles between two reactors. Deposition of the active metal oxides onto inert supports made of silica and alumina is being studied to increase the reactivity and durability of the metal oxide particles. ${ }^{63}$

\section{Materials for pre-combustion capture}

To separate $\mathrm{CO}_{2}$ from $\mathrm{H}_{2}$-rich gasification-derived gas streams, absorption using physical solvents based on methanol or mixtures of dimethyl ethers of polyethylene glycol has been the most common method. Physical solvents are highly efficient in capturing $\mathrm{CO}_{2}$ at high partial pressures and temperatures between $-60^{\circ} \mathrm{C}$ and $40^{\circ} \mathrm{C}$, depending on the nature of the solvent. ${ }^{6}$ Research efforts are focused on developing solvents that can operate closer to the $200-400^{\circ} \mathrm{C}$ temperatures of the water-gas shift reaction and thus reduce the energy penalties associated with temperature cycling. ${ }^{64}$

Apart from solvents, several solid sorbents and membranes are being considered for pre-combustion. Porous materials containing $\mathrm{CO}_{2}$-philic functional groups have shown great promise for $\mathrm{CO}_{2} / \mathrm{H}_{2}$ separation. For example, MOFs with surfaces containing exposed metal-cation sites outperform the $\mathrm{CO}_{2}$ uptakes of zeolite 13X (a common molecular sieve) at pressures between 5 bar and 40 bar, while retaining comparable heats of adsorption. ${ }^{65}$

$\mathrm{CO}_{2}$ can also be separated from a $\mathrm{CO}_{2} / \mathrm{H}_{2}$ mixture through solution-diffusion in dense membranes. Integration of specific ionic liquids into polymeric membranes has been reported to preferentially facilitate the transport of $\mathrm{CO}_{2}$ over $\mathrm{H}_{2}$. The low vapor pressure and high thermal stability of ionic liquids make them suitable for high-temperature applications, ${ }^{52,66}$ but support materials with higher thermal stability than porous polymers will be needed. For high-temperature applications, adsorption of $\mathrm{CO}_{2}$ onto basic sites in alkaline-earth oxides (e.g., $\mathrm{CaO}$, $\mathrm{MgO})$ is being explored. Although the $\mathrm{CO}_{2}$ adsorption uptake of $\mathrm{CaO}\left(\sim 1.092 \mathrm{~g}\right.$ of $\mathrm{CO}_{2}$ per gram of sorbent $)$ is larger than that of $\mathrm{MgO}(\sim 0.785 \mathrm{~g} / \mathrm{g})$ at high temperatures, regeneration of $\mathrm{MgO}$ requires less energy. ${ }^{67}$

The anionic clays known as hydrotalcites represent another class of materials suitable for $\mathrm{CO}_{2}$ adsorption at temperatures of $400-500^{\circ} \mathrm{C}$. Impregnation with $\mathrm{K}_{2} \mathrm{CO}_{3}$ has been reported to enhance the $\mathrm{CO}_{2}$ uptakes in these materials. ${ }^{68,69}$ Both alkalineearth oxides and hydrotalcites degrade after several cycles, but the regeneration ability of hydrotalcites can be improved through variations in the calcination step..$^{70}$ Lithium-containing oxides, such as $\mathrm{Li}_{2} \mathrm{ZrO}_{3}$ and $\mathrm{Li}_{4} \mathrm{SiO}_{4}$, have also gained considerable attention for high-temperature $\mathrm{CO}_{2}$ sorption. ${ }^{71,72}$ Further details on sorbent materials for pre-combustion can be found in References 40 and 41.

An alternative to extracting the $\mathrm{CO}_{2}$ from gasification-based streams is removing the $\mathrm{H}_{2}$. Such processes already produce clean streams of hydrogen for use as fuel in integrated gasification combined cycle (IGCC) plants or as a feedstock in the production of chemicals. They leave behind a $\mathrm{CO}_{2}$-rich gas under high pressure, which would facilitate the $\mathrm{CO}_{2}$ compression needed for transport and storage. Because of the slightly smaller kinetic diameter of $\mathrm{H}_{2}(\sim 2.89 \AA)$ compared to $\mathrm{CO}_{2}$ ( $3.30 \AA)$, molecular-size sieving has been used for $\mathrm{H}_{2} / \mathrm{CO}_{2}$ separation. Porous amorphous silica and zeolite membranes have shown good $\mathrm{H}_{2}$ selectivity with respect to other gases. ${ }^{73}$ Progress is being made to avoid structural defects, reduce fabrication costs, and increase operational stability. Zeolitic imidazole frameworks, a subset of MOFs, supported on porous alumina substrates have been reported to have adequate $\mathrm{H}_{2} / \mathrm{CO}_{2}$ selectivities and exceptional hydrothermal stability up to $500^{\circ} \mathrm{C} . .^{74}$ 
To facilitate membrane fabrication with inorganic components and overcome the selectivity/permeability tradeoffs imposed by bare polymeric membranes, hybrid membrane composites are being evaluated. ${ }^{75,76}$ Integration of layered silicate into a porous polymeric substrate doubles the $\mathrm{H}_{2} / \mathrm{CO}_{2}$ selectivity compared to that of the bare substrate at $35^{\circ} \mathrm{C} .{ }^{77}$ Other materials used commonly for hydrogen separation are dense (nonporous) inorganic membranes that can selectively separate hydrogen through a solution-diffusion mechanism and withstand elevated temperatures. ${ }^{78}$ High-purity hydrogen can be obtained with dense palladium-based membranes. However, because of the high cost of pure bulk palladium membranes, efforts have focused on developing composites through the deposition of a thin layer of palladium or palladium alloy onto a porous support. ${ }^{79-81}$ Further information on membrane materials can be found in Reference 53 .

\section{Prospects for capture materials}

Solvent-free technologies such as solid sorbents and membrane materials for post-, oxy-, and pre-combustion applications can, in principle, be engineered with specific physical and chemical functionalities to meet carbon-capture performance targets. Systematic approaches to the rapid design and assessment of these materials with respect to gas selectivity, regeneration ability (for sorbents), gas permeance (for membranes), and scale-up potential are essential. One challenge relates to the complex dynamic response of some of these materials to stimuli such as temperature, pressure, and gas composition, which makes characterization of the interaction between a particular gas and solid material "in action" very difficult. A multidisciplinary team of scientists at the National Institute of Standards and Technology (NIST), in collaboration with NETL, has begun to develop sophisticated in situ measurements to address this issue..$^{82}$

\section{Compression, transportation, and geological storage}

Once the capture step has been completed, the $\mathrm{CO}_{2}$-rich gas must be compressed to approximately 100 bar to reach a liquid or dense state. This compression facilitates its transportation by pipelines or ships to a suitable location for long-term storage.

\section{Compression and transportation materials}

As mentioned earlier, almost one-quarter of the increase in electricity costs from post-combustion capture comes from compression, transportation, and storage of $\mathrm{CO}_{2}$ and post-injection monitoring. ${ }^{9}$ The energy required for compressing and pumping $\mathrm{CO}_{2}$ depends on its thermodynamic and flow properties, which are affected by any impurities remaining after capture (e.g., $\mathrm{O}_{2}$, water, $\mathrm{SO}_{x}$, and $\left.\mathrm{NO}_{x}\right) .{ }^{3}$ Water and oxygen in the $\mathrm{CO}_{2}$ stream restrict the range of suitable compressor and pipeline materials, because they increase corrosion. $\mathrm{CO}_{2}$ pipelines, typically made of carbon steel, have already been extensively used to transport clean, dry $\mathrm{CO}_{2}$ for enhanced oil recovery applications, ${ }^{3,83}$ but the corrosion rate increases significantly as $\mathrm{CO}_{2}$ dissolves and ionizes in water to form a weak acid. Using corrosion-resistant alloys or purifying the $\mathrm{CO}_{2}$ stream can be very expensive. The relationship between impurity levels, materials performance, and cost must be understood to design the large networks of compression equipment and pipelines needed for carbon mitigation. ${ }^{84}$

\section{Materials for geologic storage}

Geologic storage of $\mathrm{CO}_{2}$ entails injection of dense or supercritical $\mathrm{CO}_{2}$ into deep underground formations, such as depleted oil and gas fields, saline formations, and deep coal seams, for permanent storage. Efficient $\mathrm{CO}_{2}$ storage can be achieved in the pores of sedimentary rocks because $\mathrm{CO}_{2}$ has a liquid-like density at depths of 800-1000 m, depending on the vertical temperature gradient. ${ }^{85}$

Geologic storage of anthropogenic $\mathrm{CO}_{2}$ builds on a fundamental understanding of earth science, decades of oil and gas industry practice, and extensive experience with injecting $\mathrm{CO}_{2}$ underground for enhanced oil recovery. Injection at scales of $6 \mathrm{Mt}$ of $\mathrm{CO}_{2}$ per year from non-power-plant sources has been demonstrated, and larger projects storing $\mathrm{CO}_{2}$ from fossil-fuel power plants are underway. More than eight projects currently store $\mathrm{CO}_{2}$ from pilot-scale ( $<80 \mathrm{MW}$ ) fossil-fuel power plants worldwide, and about 20 large-scale projects will come online over the next decade to store $\mathrm{CO}_{2}$ from power plants generating up to $1200 \mathrm{MW}$ each, on the order of $10 \mathrm{Mt}$ of $\mathrm{CO}_{2}$ per year. ${ }^{86}$

From the materials perspective, there is a great need to understand the kinetics of geochemical trapping, the long-term impact of $\mathrm{CO}_{2}$ on pore fluids and mineral rocks, and the effects of $\mathrm{CO}_{2}$ adsorption and $\mathrm{CH}_{4}$ desorption on coal seams. Further, solid plugs made of steel and cement, typically used to seal boreholes drilled through the cap rock, can degrade in the acidic $\mathrm{CO}_{2}$ storage environment over the extensive lifetimes of $\mathrm{CO}_{2}$ wells. For example, details such as curing conditions affect the chemical stability of cement upon exposure to a simulated $\mathrm{CO}_{2}$ storage environment. Figure 5a shows backscattered-electron scanning electron microscope images of cement samples cured at different temperatures and pressures and then exposed to aqueous $\mathrm{CO}_{2}$ under high-pressure and high-temperature conditions $\left(50^{\circ} \mathrm{C}\right.$ and $\left.30.3 \mathrm{MPa}\right)$ for nine days. The extent of cement degradation, as indicated by the dashed lines, depends on the curing conditions prior to exposure to the simulated $\mathrm{CO}_{2}$ storage conditions. Figure $5 \mathrm{~b}$ illustrates the proposed cement degradation mechanism, involving dissolution of $\mathrm{CO}_{2}$ and calcium migration. ${ }^{87}$

Developing low-cost corrosion-resistant cements and piping materials and improving in situ methods for characterizing their conditions over time are critical for controlling the risk of leakage. Mechanistic studies of the interactions between $\mathrm{CO}_{2}$, surrounding fluids, and wellbore materials under geological storage conditions are of great importance. ${ }^{88}$ Impurities such as $\mathrm{H}_{2} \mathrm{~S}, \mathrm{SO}_{2}$, and $\mathrm{O}_{2}$ in the $\mathrm{CO}_{2}$ stream change its behavior. They can increase the risk of formation plugging and jeopardize well integrity by supporting precipitation, mineral dissolution, or biofouling, and they also present an environmental risk if 

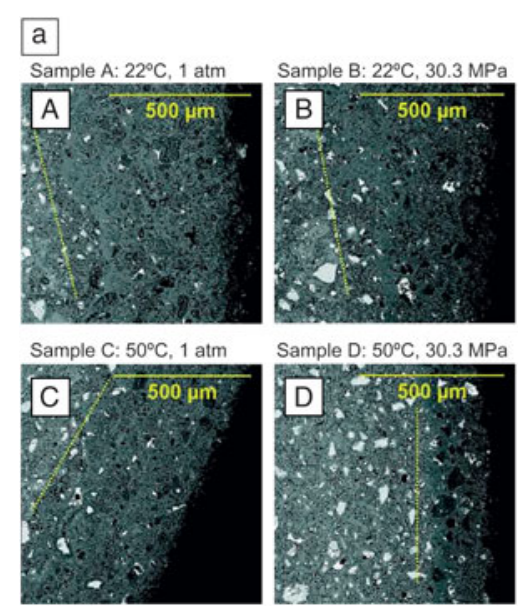

b

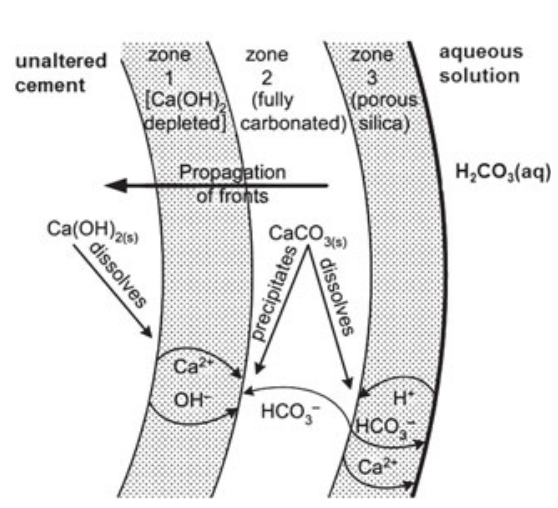

Figure 5. (a) Backscattered-electron scanning electron microscope images of cement samples show the effects of different curing temperatures and pressures upon nine days of exposure to aqueous $\mathrm{CO}_{2}$ under the same high-pressure and high-temperature sequestration conditions $\left(50^{\circ} \mathrm{C}\right.$ and $\left.30.3 \mathrm{MPa}\right)$. Dashed lines indicate approximate boundary of degradation. (b) Schematic illustration of the proposed degradation mechanism and formation of distinct zones in the cement. (Reproduced with permission from Reference 87. (c) 2007, American Chemical Society.) requires extensive data on geological sites and the geochemical interactions between impure $\mathrm{CO}_{2}$ and the natural and engineered materials in the intended storage media.

Research and development efforts in multiple laboratories worldwide are underway to reduce the costs of CCS technologies for commercial development. Advancing materials in this challenging field presents an exciting opportunity for the scientific community to put manufacturing and fossil-fuel energy generation on a more sustainable path.

\section{References}

1. World Population Prospects: The 2008 Revision, Highlights (United Nations, New York, 2009).

2. IPCC Special Reporton Carbon Dioxide Capture and Storage, Contribution of the Working Group III of the Intergovernmental Panel on Climate Change (Intergovernmental Panel on Climate Change, Cambridge, UK, 2005).

3. R.S. Haszeldine, Science 325, 1647 (2009).

4. IEA GHG $\mathrm{CO}_{2}$ Emissions Database (IEA Greenhouse Gas R\&D Programme, Cheltenham, UK, 2006).

5. C.A. Powell, B.D. Morreale, MRS Bull. 33, 309 (2008).

6. DOE/NETL Advanced Carbon Dioxide Capture R\&D Program: Technology Update (Department of Energy, Washington, DC, 2010)

contamination of an underground source of drinking water occurs.

Studies under the NETL R\&D program on carbon-storage technologies consider 11 types of geologic formations and two classes of geologic seals. They will investigate the effects of $\mathrm{CO}_{2}$ injection on fluids, minerals, seals, and faults or fractures in the formations; improve understanding of cap-rock integrity; refine predictive models of $\mathrm{CO}_{2}$ movement after injection; and evaluate the prospects of permanently storing $\mathrm{CO}_{2}$ through mineralization. ${ }^{10} \mathrm{~A}$ multiyear information-exchange program at the Electric Power Research Institute (EPRI) aims to determine the purity level of $\mathrm{CO}_{2}$ required for maximum injection rate and capacity in a particular basin that avoids potential contamination of underground sources of drinking water by storage operations. ${ }^{84}$

\section{Conclusions}

Several opportunities are available for materials scientists to help manage atmospheric $\mathrm{CO}_{2}$ through reduction of $\mathrm{CO}_{2}$ emissions from point sources. Cost-efficient solvents, sorbents, and membranes with better carbon-capture performance will have a profound impact on the sustainable use of fossil-fuel-based energy and the fabrication of products. Although the manufacture and operating costs of sorbents and membranes can be improved through advances in materials science, widespread adoption will take time. ${ }^{89}$ Predicting how improvements at the laboratory scale will translate into overall savings in electricity and/or product manufacturing costs is an enormous challenge.

Beyond $\mathrm{CO}_{2}$ capture, materials optimization is needed to extend the lifetime of compression equipment and pipelines that contact $\mathrm{CO}_{2}$ from power plants or industry. Reliable assessment of geological locations for long-term $\mathrm{CO}_{2}$ storage worldwide
7. A.B. Rao, E.S. Rubin, Environ. Sci. Technol. 36, 4467 (2002).

8. E.S. Rubin, The Outlook for Power Plant $\mathrm{CO}_{2}$ Capture, (Paper 61, Department of Engineering and Public Policy, Carnegie Mellon University, 2009).

9. J. Black, Cost and Performance Baseline for Fossil Energy Plans. Volume 1: Bituminous Coal and Natural Gas to Electricity (Report DOE/NETL-2010/1397, Department of Energy, Washington, DC, 2010).

10. DOE/NETL Carbon Dioxide Capture and Storage RD\&D Roadmap (Department of Energy, Washington, DC, 2010).

11. Basic Research Needs for Carbon Capture: Beyond 2020 (Department of Energy, Washington, DC, 2010).

12. Carbon Capture 2020 Workshop: Workshop Summary (Department of Energy, Washington, DC, 2009).

13. G. T. Rochelle, Science 325, 1652 (2009).

14. A. Aroonwilas, A. Veawab, Ind. Eng. Chem. Res. 43, 2228 (2004).

15. P.D. Vaidya, E.Y. Kenig, Chem. Eng. Technol. 30, 1467 (2007).

16. F. Bougie, M.C. Iliuta, Chem. Eng. Sci. 65, 4746 (2010).

17. C.S. Tan, J.E. Chen, Sep. Purif. Technol. 49, 174 (2006)

18. G.S. Goff, G.T. Rochelle, Ind. Eng. Chem. Res. 45, 2513 (2006).

19. D. Camper, J.E. Bara, D.L. Gin, R.D. Noble, Ind. Eng. Chem. Res. 47, 8496 (2008).

20. E.D. Bates, R.D. Mayton, I. Ntai, J.H. Davis, J. Am. Chem. Soc. 124, 926 (2002).

21. B.E. Gurkan, J.C. de la Fuente, E.M. Mindrup, L.E. Ficke, B.F. Goodrich, (2010).

22. U.E. Aronu, H.F. Svendsen, K.A. Hoff, Int. J. Greenhouse Gas Control 4, 771 (2010).

23. L. Phan, D. Chiu, D.J. Heldebrant, H. Huttenhower, E. John, X. Li, P. Pollet, R. Wang, C.A. Eckert, C.L. Liotta, P.G. Jessop, Ind. Eng. Chem. Res. 47, 539 (2007). 24. P.G. Jessop, D.J. Heldebrant, X.W. Li, C.A. Eckert, C.L. Liotta, Nature 436, 1102 (2005).

25. M.T. Ho, G.W. Allinson, D.E. Wiley, Ind. Eng. Chem. Res. 47, 4883 (2008). 26. M. Radosz, X. Hu, K. Krutkramelis, Y. Shen, Ind. Eng. Chem. Res. 47, 3783 (2008).

27. J. Merel, M. Clausse, F. Meunier, Ind. Eng. Chem. Res. 47, 209 (2008).

28. J.A. Dunne, M. Rao, S. Sircar, R.J. Gorte, A.L. Myers, Langmuir 12, 5896 (1996).

29. K. Berlier, M. Frere, J. Chem. Eng. Data 41, 1144 (1996).

30. M.G. Plaza, C. Pevida, A. Arenillas, F. Rubiera, J.J. Pis, Fue/ 86, 2204 (2007).

31. P.J.E. Harlick, A. Sayari, Ind. Eng. Chem. Res. 46, 446 (2007).

32. J.C. Hicks, J.H. Drese, D.J. Fauth, M.L. Gray, G. Qi, C.W. Jones, J. Am. Chem. Soc. 130, 2902 (2008).

33. D. Wang, C. Sentorun-Shalaby, X. Ma, C. Song, Energy Fuels 25, 456 (2011). 34. J.H. Drese, S. Choi, R.P. Lively, W.J. Koros, D.J. Fauth, M.L. Gray, C.W. Jones, Adv. Funct. Mater. 19, 3821 (2009). E.A. Price, W.F. Schneider, J.F. Brennecke, J. Am. Chem. Soc. 132, 2116 
35. A.R. Millward, 0.M. Yaghi, J. Am. Chem. Soc. 127, 17998 (2005) 36. R. Vaidhyanathan, S.S. Iremonger, G.K.H. Shimizu, P.G. Boyd, S. Alavi, T.K. Woo, Science 330, 650 (2010).

37. A. Demessence, D.M. D’Alessandro, M.L. Foo, J.R. Long, J. Am. Chem. Soc 131, 8784 (2009).

38. Z. Liang, M. Marshall, A.L. Chaffee, Energy Fuels 23, 2785 (2009).

39. D. Britt, H. Furukawa, B. Wang, T.G. Glover, O.M. Yaghi, Proc. Natl. Acad. Sci. U.S.A. 106, 20637 (2009).

40. D.M. D’Alessandro, B. Smit, J.R. Long, Angew. Chem., Int. Ed. 49, 6058 (2010). 41. S. Choi, J.H. Drese, C.W. Jones, ChemSusChem 2, 796 (2009).

42. T.C. Merkel, H. Lin, X. Wei, R. Baker, J. Membr. Sci. 359, 126 (2010).

43. M.T. Ho, G.W. Allinson, D.E. Wiley, Ind. Eng. Chem. Res. 47, 1562 (2008).

44. D. Breck, Zeolite Molecular Sieves: Structure, Chemistry, and Use (Wiley, New York, 1974)

45. S.R. Reijerkerk, K. Nijmeijer, C.P. Ribeiro Jr., B.D. Freeman, M. Wessling, J. Membr. Sci. 367, 33 (2011).

46. M. Ostwal, R.P. Singh, S.F. Dec, M.T. Lusk, J.D. Way, J. Membr. Sci. $\mathbf{3 6 9}$ 139 (2011).

47. S.R. Venna, M.A. Carreon, Langmuir 27, 2888 (2011).

48. J. Zou, W.S.W. Ho, J. Membr. Sci. 286, 310 (2006)

49. R.J.R. Uhlhorn, K. Keizer, A.J. Burggraaf, J. Membr. Sci. 46, 225 (1989).

50. H.Q. Lin, E. Van Wagner, B.D. Freeman, L.G. Toy, R.P. Gupta, Science 311 639 (2006).

51. D.H. Kim, I.H. Baek, S.U. Hong, H.K. Lee, J. Membr. Sci. 372, 346 (2011). 52. J. Ilconich, C. Myers, H. Pennline, D. Luebke, J. Membr. Sci. 298, 41 (2007) 53. D. Shekhawat, D.R. Luebke, H.W. Pennline, A Review of Carbon Dioxide Selective Membranes. A Topical Report (Report DOE/NETL-2003/1200, Department of Energy, Washington, DC, 2003).

54. G.Q. Li, R. Govind, Ind. Eng. Chem. Res. 33, 755 (1994).

55. N.D. Hutson, R.T. Yang, Ind. Eng. Chem. Res. 39, 2252 (2000).

56. D.D. Miller, R.V. Siriwardane, T. Simonyi, Energy Fuels 25, 4261 (2011).

57. L.J. Murray, M. Dinca, J. Yano, S. Chavan, S. Bordiga, C.M. Brown, J.R. Long, J. Am. Chem. Soc. 132, 7856 (2010).

58. B.W. Rowe, B.D. Freeman, D.R. Paul, Polymer 50, 5565 (2009)

59. A. Figoli, W.F.C. Sager, M.H.V. Mulder, J. Membr. Sci. 181, 97 (2001).

60. M.P. Bernal, M. Bardaji, J. Coronas, J. Santamaria, J. Membr. Sci. 203, 209 (2002)

61. M. Dumelie, G. Nowogrocki, J.C. Boivin, Solid State Ionics 28, 524 (1988).

62. H. Zhao, N. Xu, Y. Cheng, W. Wei, N. Chen, W. Ding, X. Lu, F. Li, J. Phys.

Chem. C114, 17975 (2010).

63. M.M. Hossain, H.I.D. Lasa, Chem. Eng. Sci. 63, 4433 (2008).

64. Y.J. Heintz, L. Sehabiague, B.I. Morsi, K.L. Jones, H.W. Pennline, Energy Fuels 22, 3824 (2008).

65. Z.R. Herm, J.A. Swisher, B. Smit, R. Krishna, J.R. Long, J. Am. Chem. Soc. 133, 5664 (2011).
66. C. Myers, H. Pennline, D. Luebke, J. Ilconich, J.K. Dixon, E.J. Maginn, J.F. Brennecke, J. Membr. Sci. 322, 28 (2008).

67. B. Feng, H. An, E. Tan, Energy Fuels 21, 426 (2007)

68. H.T.J. Reijers, S.E.A. Valster-Schiermeier, P.D. Cobden, R.W. van den Brink, Ind. Eng. Chem. Res. 45, 2522 (2006).

69. N.D. Hutson, S.A. Speakman, E.A. Payzant, Chem. Mater. 16, 4135 (2004).

70. M.K.R. Reddy, Z.P. Xu, G.Q. Lu, J.C.D. da Costa, Ind. Eng. Chem. Res. 45 7504 (2006)

71. E. Ochoa-Fernandez, M. Ronning, T. Grande, D. Chen, Chem. Mater. 18, 6037 (2006).

72. M. Kato, K. Nakagawa, K. Essaki, Y. Maezawa, S. Takeda, R. Kogo, Y. Hagiwara, Int. J. Appl. Ceram. Technol. 2, 467 (2005).

73. H. Verweij, Y.S. Lin, J.H. Dong, MRS Bull. 31, 756 (2006).

74. Y.-S. Li, F.-Y. Liang, H. Bux, A. Feldhoff, W.-S. Yang, J. Caro, Angew. Chem. Int. Ed. 49, 548 (2010)

75. S. Konduri, S. Nair, J. Phys. Chem. C 111, 2017 (2007).

76. E.V. Perez, K.J. Balkus, J.P. Ferraris, I.H. Musselman, J. Membr. Sci. 328, 165 (2009).

77. S. Choi, J. Coronas, Z. Lai, D. Yust, F. Onorato, M. Tsapatsis, J. Membr. Sci. 316, 145 (2008).

78. S. Adhikari, S. Fernando, Ind. Eng. Chem. Res. 45, 875 (2006)

79. B.D. Morreale, M.V. Ciocco, R.M. Enick, B.I. Morsi, B.H. Howard, A.V. Cugini, K.S. Rothenberger, J. Membr. Sci. 212, 87 (2003).

80. V. Jayaraman, Y.S. Lin, M. Pakala, R.Y. Lin, J. Membr. Sci. 99, 89 (1995).

81. S.C. Yan, H. Maeda, K. Kusakabe, S. Morooka, Ind. Eng. Chem. Res. 33 616 (1994).

82. K.L. Kauffman, J.T. Culp, A.J. Allen, L. Espinal, W. Wong-Ng, T.D. Brown, A. Goodman, M.P. Bernardo, R.J. Pancoast, D. Chirdon, C. Matranga, Angew. Chem., Int. Ed. 50 (46), 10888 (2011).

83. F.M. Orr Jr., Science 325, 1656 (2009).

84. $\mathrm{CO}_{2}$ Capture and Storage - Program 165: Program Overview (Electric Power Research Institute, Palo Alto, CA, 2011), http://mydocs.epri.com/docs/Portfolio/ PDF/2011_P165.pdf (accessed June 2011).

85. S.M. Benson, F.M. Orr Jr., MRS Bull. 33, 297 (2008)

86. Carbon Dioxide Capture and Storage Projects: Map of Projects, Carbon Capture and Sequestration Technologies Program at MIT Massachusetts Institute of Technology, Worldwide Carbon Dioxide Capture and Storage (CCS) Project database at MIT, http://sequestration.mit.edu/tools/projects/map_projects.htm (accessed June 2011)

87. B.G. Kutchko, B.R. Strazisar, D.A. Dzombak, G.V. Lowry, N. Thaulow, Environ. Sci. Technol. 41, 4787 (2007).

88. S.M. Benson, F.M. Orr Jr., MRS Bull. 33, 303 (2008)

89. J.D. Figueroa, T. Fout, S. Plasynski, H. Mcllvried, R.D. Srivastava, Int. J. Greenhouse Gas Control 2, 9 (2008).

\section{FCMUA $2^{\text {nd }}$ Global Congress on Microwave Energy Applications July 23-27, 2012 - Hilton Long Beach - Long Beach, California, USA}

PREREGISTRATION DEADLINE-

June 11, 2012

\section{MARK YOUR CALENDAR}

Join us for the only microwave conference of 2012 ! The $2^{\text {nd }}$ Global Congress on Microwave Energy Applications (2GCMEA 2012), hosted in beautiful Long Beach, California, will feature plenary sessions, parallel topical sessions, poster sessions, an industrial exhibition and short courses. An exclusive dinner aboard the historic Queen Mary, the iconic floating museum, is also included. Mark your calendar today and plan to attend 2GCMEA 2012, where the theme is "EM Solutions for Our Changing World."

\section{SCIENTIFIC PROGRAM}

The five-day conference will concentrate on the following four topical categories:

- Energy/Environment

- Microwaves in Every Day Life

- Chemistry and Medicine

- Manufacturing, Equipment and Process Control

For the most up-to-date information on 2GCMEA 2012 and to view the complete list of topics, visit www.mrs.org/2gcmea-2012. 


\section{The energy-water nexus: Waiter use trends in sustainable energy and opportunities for materials research and development}

\section{Anthony Y. Ku and Andrew P. Shapiro}

Over the next few decades, the challenge of water scarcity is expected to grow more acute as water demands from the power generation, agriculture, industrial, and municipal sectors all increase. Energy production requires copious amounts of water, with the volume of water used by power generation ranking second only to that used for agriculture. This article reviews options for managing the water requirements associated with power generation. Although the effects of both existing and emerging modes of power generation on water use trends are explored, the primary focus is on thermal systems, which account for the majority of existing capacity.

\section{Introduction}

Global electricity demand is projected to increase strongly over the next several decades. Efforts to build the energy infrastructure needed to meet this demand must reflect (1) regional differences in economic growth rates and energy resources, (2) policy and social considerations such as safety, (3) environmental concerns such as ecosystem health and climate change, (4) the technological maturity of various options, and (5) the availability of sufficient supplies of water. ${ }^{1}$ This article focuses on the last aspect, as many forms of power generation, including the dominant modes used today, require copious amounts of water. The largest use of water in power generation, by far, is for the removal of waste heat.

Currently, global water use in power generation ranks second only to that in agriculture, although there is wide variation between countries. The challenges posed by water scarcity are expected to grow more acute because of increasing demand from the power generation, agriculture, industrial, and municipal sectors. Indeed, in the past decade, drought conditions have forced nuclear power plants in France and the southeastern United States to curtail power generation on several occasions. ${ }^{2}$ Managing the competition for water will be one of the major challenges facing policy makers, industry leaders, and technologists as they work toward the goal of sustainable development. ${ }^{3}$
The research and development (R\&D) needs at the interface between energy ${ }^{4,5}$ and water treatment ${ }^{6}$ present a wide range of opportunities that can be addressed by the materials research community. This article provides a framework for prioritizing materials R\&D efforts in water use for electricity generation. The discussion is divided into three parts. The first section reviews trends in power generation and water use and introduces a metric for comparing different technologies. The second section focuses on water use in power plants and considers ways in which materials innovations can reduce water demand. These include improving the efficiency of gas and steam turbines through the development of next-generation superalloys, high-temperature materials such as ceramic matrix composites, and hydrophobic condenser surfaces. Because cooling accounts for the majority of water use in thermal systems, lower-cost heat-transfer materials can improve the economic competitiveness of air-cooled condensers and other low-water-demand cooling options. The final section addresses ways in which materials R\&D can help to expand the supply of water suitable for power-generation use, particularly for cooling in thermal plants. Nontraditional water sources such as brackish aquifers and produced water from oil and gas operations have a higher tendency to foul equipment, and materials advances such as biofilm resistance coatings and membranes have the potential to enable the use of these water resources for cooling. 


\section{Water use trends and metrics}

Figure 1 provides a snapshot of global power generation and its associated water footprint. Thermal processes, which generate electricity from heat, account for almost $80 \%$ of total generating capacity - including fossil-fuel, nuclear, geothermal, solar-thermal, and biomass sources. A necessary step in these cycles is the rejection of lower-grade waste heat to the environment, for which water-based methods are among the most effective. As discussed in the next section, water use for cooling is the major driver for demand. ${ }^{8,9}$

The sidebar provides a detailed look at water demands from power generation and how they could evolve over the next few decades. Water usage is expected to increase because of increased power generation. According to U.S. Energy Information Administration (EIA) projections, the single largest driver will be the growth of coal-fired capacity in Asia, especially China. ${ }^{9,12}$ Improvements in plant efficiency through new technology and consolidation could drive down specific water use, as would the maturation and adoption of less-water-demanding renewable energy technologies

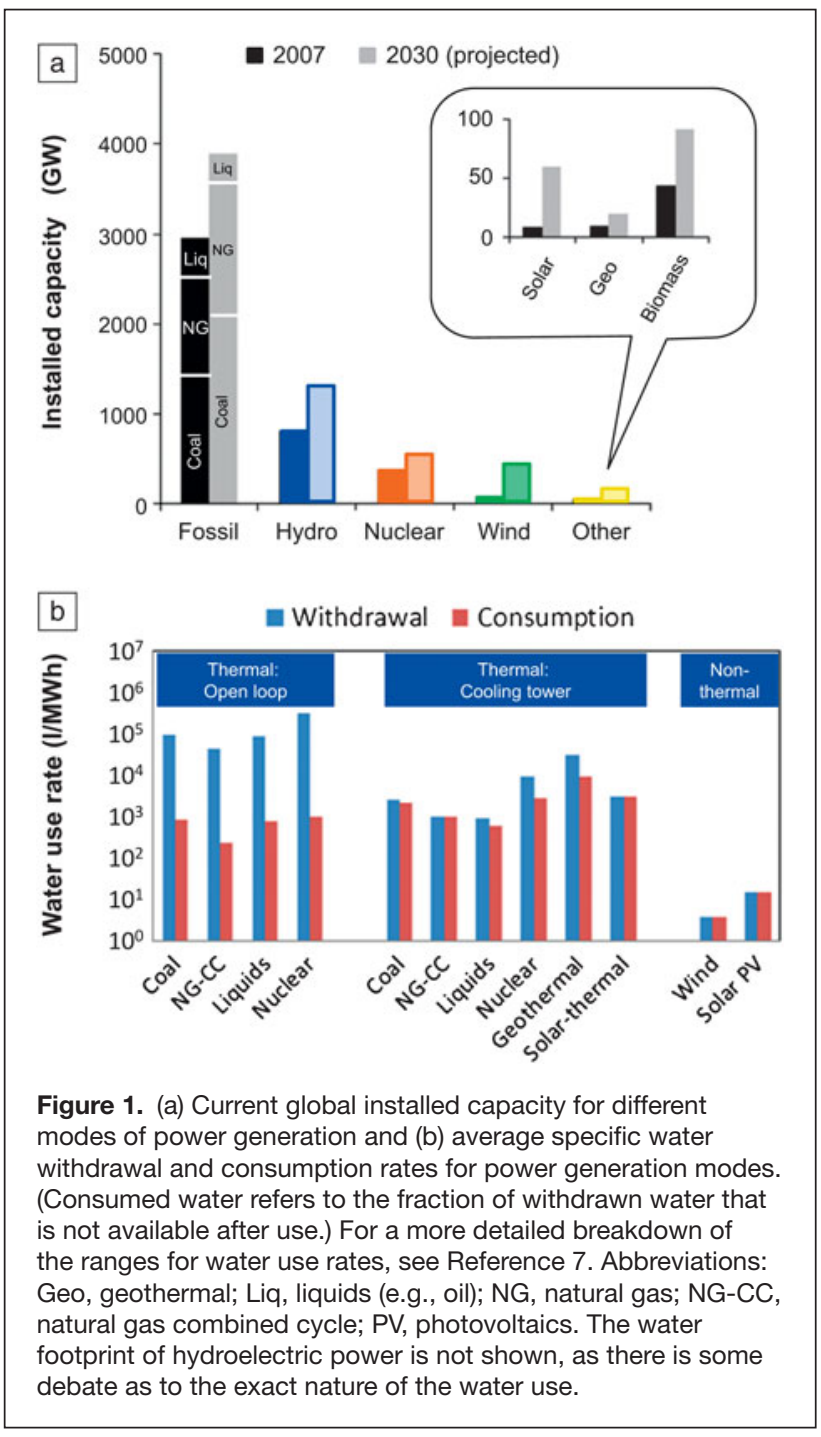

such as wind and solar. Conversely, the widespread adoption of carbon capture technologies for fossil-fuel-based power could increase specific water use.

The most significant distinction in water use is between thermal and nonthermal systems. Among thermal modes, water consumption further depends on how the water is used for cooling. In once-through (or open-loop) cooling, water is withdrawn from a source and returned at a higher temperature. In contrast, cooling-tower-based approaches require much lower withdrawal rates, because a significant amount of heat is removed by evaporation. Both cooling modes are discussed in detail in the next section.

Among nonthermal processes, hydroelectric power has the largest installed capacity, ranking third among the power modes. There is debate as to the ultimate rates of water usage by hydroelectric power: Some reports focus on the higher evaporation rates from reservoirs created by dams, whereas others note that most of the water is returned for downstream use. ${ }^{8}$ Wind is the next-largest nonthermal generation mode, accounting for about $2 \%$ of global capacity. Installed capacity for photovoltaic solar generation is currently small but growing rapidly. Both wind and solar power use water for cleaning of equipment during operation, but their largest water footprints are associated with manufacturing. ${ }^{8}$

Several metrics are used to track water use in power generation: Water withdrawal rate refers to all water removed from a source, some of which could be returned, whereas water consumption rate refers to the fraction of withdrawn water that is not available after use. Some authors also calculate energy return on water invested from a life-cycle assessment of water use. ${ }^{13}$ In this article, we compare alternate technologies using a monetary metric, the cost of conserved water $(\mathrm{CCW})$, defined as ${ }^{14}$

$$
\operatorname{CCW}\left(\$ / \mathrm{m}^{3}\right)=\frac{\Delta \operatorname{LCOE}(\$ / \mathrm{MWh})}{\Delta \mathrm{WD}\left(\mathrm{m}^{3} / \mathrm{MWh}\right)},
$$

where $\triangle \mathrm{LCOE}$ is the difference in the levelized cost of electricity (LCOE) between the alternate power generation system and a baseline pulverized-coal plant employing cooling towers that withdraw surface water and $\triangle \mathrm{WD}$ is the reduction in specific water withdrawal rate between the same two systems. The LCOE accounts for the cost of power generation over the lifetime of the power plant, including both initial capital investments and fuel costs. The cost of conserved water is a simple way to rate the economic impact of adopting less-water-intensive technology against the local cost of water. If water is relatively abundant and inexpensive, it makes economic sense to simply use it for evaporative or once-through cooling. In regions where water is scarce, the higher cost of water can justify the deployment of alternatives.

Several approaches can improve water utilization in power production. This article focuses solely on thermal processes, because of their dominant share of electricity generation; ${ }^{15}$ nonthermal processes are discussed in Reference 8. On the demand side, this means reducing the cost of conserved 
water by decreasing specific water use through (1) the use of alternate cooling fluids such as air and (2) increased power-plant efficiency. A complementary approach is to tap nontraditional water resources. Seawater, brackish aquifers, processed municipal wastewater, produced water from hydrocarbon extraction, and abandoned mine drainage are all potential sources that could conserve freshwater for other uses. Materials breakthroughs can help in each of these areas, but it is necessary to critically evaluate where investment is justified, as not all opportunities have equal potential impacts.

As a concrete example of how the cost of conserved water can be used to benchmark the competitiveness of a watersaving technology, consider air-cooled condensers (ACCs), which are being deployed as an alternative to wet cooling. The U.S. Department of Energy (DOE) estimated that, for a 500-MW subcritical pulverized-coal plant, this technology increases the LCOE by $\$ 3.50 / \mathrm{MWh}$, while eliminating $\sim 90 \%$ of water withdrawals (2300 1/MWh). ${ }^{14}$ Substituting these values into Equation 1 gives a CCW of about $\$ 1.50 / \mathrm{m}^{3}$, so dry cooling becomes economically competitive where the cost of available water is more than this. Put another way, ACC technologies have the potential to reduce water use in coal plants by up to $90 \%$ but result in an increase of about $5 \%$ in the LCOE. ${ }^{16}$

Table I compares water costs from the United States and China and provides context for the economic competitiveness of the alternate cooling technology. ACC water "costs" are at the high end of the range for both U.S. and Chinese water supplies. The economics become more favorable in arid regions and can also be improved through technology innovation. U.S. DOE R\&D programs call for a reduction in the cost of alternate cooling for existing plants by $25 \%$ to $\$ 1.15 / \mathrm{m}^{3}$ of water conserved by 2015 and by $50 \%$ to $\$ 0.75 / \mathrm{m}^{3}$ of water conserved by 2020. ${ }^{14}$ Success in achieving these targets would significantly improve the economic competitiveness of non-water-based cooling technologies.

\section{Options for reducing water demand}

Any survey of options for reducing water demand must begin with the drivers for water use. Given the dominant role of thermal processes in electricity generation, a useful starting point is the thermodynamics of power plants. Thermal processes used for power production require a heat source and a lower-temperature heat sink. The maximum efficiency, $\eta$, of any thermal cycle is the Carnot efficiency,

$$
\eta=\frac{\text { work produced }}{\text { thermal energy input }}=\frac{T_{\mathrm{h}}-T_{\mathrm{c}}}{T_{\mathrm{h}}},
$$

where $T_{\mathrm{h}}$ is the temperature of the heat source and $T_{\mathrm{c}}$ is the temperature of the heat sink. The Carnot efficiency is maximized by high-temperature sources and low-temperature sinks. Heatsource temperatures are usually limited by material constraints (e.g., maximum temperature for combustors and turbine blades in gas turbines). Heat-sink temperatures are set by local climate and water availability.

In practice, about $80 \%$ of all electricity is produced using steam turbines configured in a Rankine cycle. In a Rankine cycle, the heat-sink temperature is governed by the steam condenser. For maximum power output and efficiency, the

\begin{tabular}{|c|c|c|c|}
\hline Water option & Cost of water & Notes & Reference \\
\hline \multicolumn{4}{|c|}{ Air-cooled condensers: Cost of conserved water } \\
\hline Baseline & US $\$ 1.50 / \mathrm{m}^{3}$ & U.S. Department of Energy estimate, 2008 & 14 \\
\hline Target for 2015 & US $\$ 1.15 / \mathrm{m}^{3}$ & $25 \%$ savings versus baseline & 14 \\
\hline Target for 2020 & US $\$ 0.75 / \mathrm{m}^{3}$ & $50 \%$ savings versus baseline & 14 \\
\hline \multicolumn{4}{|c|}{ North America: U.S. supply (2007) } \\
\hline Municipal & & US $\$ 0.30-2.30 / \mathrm{m}^{3}$ & 17 \\
\hline Industry & & US $\$ 0.30-1.80 / \mathrm{m}^{3}$ & 17 \\
\hline Agriculture & & US\$0.01-1.50/m³ & 17 \\
\hline \multicolumn{4}{|c|}{ Asia: China supply (2008) ${ }^{\mathrm{a}}$} \\
\hline Municipal & US $\$ 0.15-1.00 / \mathrm{m}^{3}$ & $1-6.9 \mathrm{RMB} / \mathrm{m}^{3}$ & 18 \\
\hline Industry & US $\$ 0.22-1.00 / \mathrm{m}^{3}$ & $1.5-6.9 \mathrm{RMB} / \mathrm{m}^{3}$ & 18 \\
\hline Agriculture & US $\$ 0.01-0.07 / \mathrm{m}^{3}$ & $0.1-0.5 \mathrm{RMB} / \mathrm{m}^{3}$ & 18 \\
\hline \multicolumn{4}{|c|}{ Water treatment } \\
\hline Desalination (brackish) & US $\$ 0.45 / \mathrm{m}^{3}$ & Total dissolved solids of $8000-1000 \mathrm{ppm}$ & 17 \\
\hline Desalination (seawater) & US $\$ 0.53-0.65 / \mathrm{m}^{3}$ & Reverse-osmosis membrane & 17 \\
\hline Desalination (seawater) & US $\$ 0.77-1.14 / \mathrm{m}^{3}$ & Multistage flash & 17 \\
\hline
\end{tabular}
condenser should be as cool as possible. In a typical steamturbine system, the condenser is cooled to about $40^{\circ} \mathrm{C}$, so the condensed steam is under a vacuum $(\sim 0.1$ bar absolute). This low condenser pressure is transmitted to the last stage of the steam turbine and governs how much power can be produced. The heat at $40^{\circ} \mathrm{C}$ is truly waste heat, as it is presently uneconomical to extract more work from it.

Condensers are cooled by water or air. The choice depends on the local climatic, environmental, and regulatory conditions. Water-cooled condensers are smaller and less expensive, and they provide lower, more stable temperatures than air-cooled condensers, but their water requirements are greater. 
When surface water is available and regulations allow, oncethrough water cooling is usually the most cost-effective solution. ${ }^{19}$ In once-through cooling systems, water is withdrawn from the source, pumped through the condenser, and returned to the source at a higher temperature (typically $10-15^{\circ} \mathrm{C}$ warmer). For a 33\% efficient Rankine cycle, each megawatt of power production requires approximately $30 \mathrm{l} / \mathrm{s}$ of water withdrawals. A 500-MW plant withdraws nearly $1.4 \times 10^{6} \mathrm{~m}^{3} /$ day $[250,000$ gallons per minute (gpm)] of water.

Plants that use cooling towers withdraw less water but consume more, relative to once-through systems. Cooling towers remove heat primarily through evaporation after the water has been heated in the condenser. A typical cooling tower evaporates $0.5 \mathrm{l} / \mathrm{s}$ of water per megawatt of generated power. To prevent salts from building up in the cooling water, a "blowdown" stream comprising concentrated salts is also removed from the cooling loop. This blowdown typically accounts for $10-20 \%$ of the total water consumption. A 500MW plant consumes approximately $26,000 \mathrm{~m}^{3} /$ day $(4800$ gpm) of water.

The two main themes for reducing water demand for power-plant cooling through materials innovations are developing alternate cooling fluids to replace water and improving thermal efficiency in the turbine. Following the first approach, air or hybrid cooling can eliminate most of the water demand, but progress is needed to make these approaches economical. To increase power-plant efficiency, specific materials needs include next-generation superalloys and coatings for higher-temperature gas and steam turbines.

\section{Air cooling}

Air-cooled condensers (ACCs) work by blowing ambient air over a set of finned condenser coils. Because of the lower heat capacity and density of air compared to water, the heat-transfer area of an ACC is $20-50$ times larger than that of a water-cooled condenser. In addition, ACCs penalize power-plant performance more than water-cooled condensers, because the air is usually much warmer than local water. This problem is particularly acute in warm locations, where the power demand peaks during the hottest part of the day.

As discussed in the previous section, cost reductions on the order of $25-50 \%$ are needed for ACCs to become economically competitive in most regions of the world. The footprints and heights of current ACC configurations are about twice those of conventional cooling towers, leading to twice the capital cost. ${ }^{14,20} \mathrm{R} \& \mathrm{D}$ efforts are progressing on several fronts, including more compact designs that use less material and the development of wind-guide technology to better manage performance under changing ambient conditions. ${ }^{19}$

\section{Improved efficiency in the steam cycle}

Increasing the thermal efficiency of power plants is another way to reduce water demand. In a Rankine-cycle plant (see Figure 2), the working fluid (usually water) is pumped to high pressure in the liquid state and heated in a boiler to create high-pressure, high-temperature vapor. The vapor expands through a turbine, generating power, and then condenses back to a liquid by rejecting heat to the environment in a condenser, which is where most of the water is used. The cooled liquid is then pumped back to high pressure, completing the cycle.

Thermal efficiencies over $45 \%$ have been achieved by increasing the steam temperature and pressure to supercritical $\left(600^{\circ} \mathrm{C}, 250\right.$ bar $)$ and ultrasupercritical $\left(720-760^{\circ} \mathrm{C}, 340\right.$ bar) conditions. Because water usage in a thermal power plant scales inversely with efficiency, shifting to supercritical plants could reduce water usage by $27 \%$ compared to the installed base. ${ }^{21}$ Materials are needed for next-generation turbine components, because advanced 9-12Cr martensitic-ferritic steels approach their operating limit at around $620^{\circ} \mathrm{C} .{ }^{22} \mathrm{Nickel}$ and nickel-cobalt superalloys offer the necessary creep strength and steam oxidation resistance for steam turbine blades and heat-transfer surfaces that operate near and above $700^{\circ} \mathrm{C}$, but development is needed to bring down manufacturing costs. Austenitic stainless steels and alloys offer designers an intermediate option, with temperature capabilities between those of existing steels and nickel-based superalloys but at lower cost than superalloys.

Materials advances can also improve the operation of condensers in steam cycles, leading to both economic benefits and reductions in water use. Laboratory studies have shown that hydrophobic and superhydrophobic surfaces improve heat-transfer rates by promoting dropwise condensation over film condensation. ${ }^{23}$ The benefits of higher heattransfer coefficients would be accrued mainly through cost savings due to smaller heat exchangers. Savings in water use 
are possible if the improved heat transfer leads to lower temperatures and pressures on the vapor side of the condenser. This would increase the power and efficiency of the plant. To date, most studies have used organic coatings, and work is needed to move to more robust materials for energy applications. Efforts to develop inorganic coatings with hydrophobic properties are still at a relatively early stage. ${ }^{24}$

\section{Gas-turbine and combined-cycle plants}

Further water savings can be achieved by using power cycles that do not require cooling water. After steam turbines, gas turbines are the most productive power-generation method. They operate with much higher heat-source temperatures than steam turbines and, therefore, higher efficiencies. In a simple gas-turbine, or Brayton, cycle, the exhaust is released to the environment after passing through the turbine and a recuperative heat exchanger. No cooling water is required, although water is often used to cool the inlet air for power augmentation and to provide a diluent for combustion to control $\mathrm{NO}_{x}$ formation. As examples, wet $\mathrm{NO}_{x}$ control uses approximately $0.05 \mathrm{l} / \mathrm{s}$ of water per megawatt of generated power, and steam injection for power augmentation uses about $0.1-0.2 \mathrm{l} / \mathrm{s}$ per megawatt of generated power. ${ }^{25,26}$

In a combined-cycle power plant, the exhaust from the gas turbine is used to generate steam that runs a steam turbine. Thermal efficiency in combined-cycle systems approaches $60 \%$, with the gas turbines accounting for about $65 \%$ of the total electrical generating capacity. Because most of the water use is for cooling the steam-turbine condenser, the specific water usage of combined-cycle plants is about $35 \%$ that of a simple steam turbine plant (see Figure 3). For a 500-MW plant, this is about $9300 \mathrm{~m}^{3} /$ day (1700 gpm).

\section{Materials opportunities}

As with steam turbines, an important path toward increased efficiency in gas turbines is the use of turbine blades and

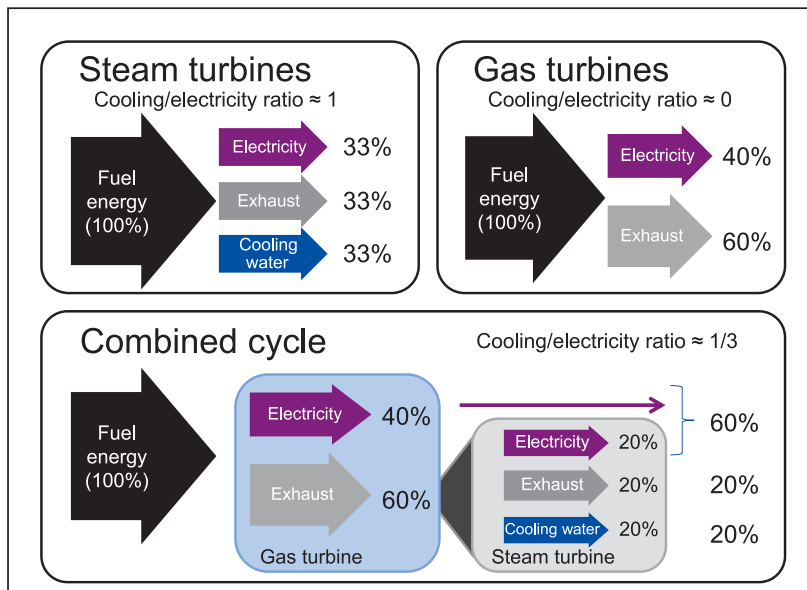

Figure 3. Allocations of energy in Rankine (steam turbine) and Brayton (gas turbine) thermodynamic cycles and in a combined cycle that uses the high-temperature exhaust from the Brayton cycle as input for the Rankine cycle. other hot-path components capable of operating at higher temperatures and pressures. Today's most advanced blades comprise single-crystal, directionally solidified nickel-based superalloys containing rhenium. ${ }^{16}$ Through the use of ceramic thermal-barrier coatings and advanced designs capable of delivering appropriate cooling, these blades can function at gas temperatures above the melting point of the superalloy, or about $1300^{\circ} \mathrm{C} .{ }^{27}$ In addition to improved mechanical properties (e.g., creep strength, oxidation resistance, and hot corrosion resistance), superalloy-related materials development efforts are focused on reducing manufacturing costs through improved process control and the formulation of alloys with reduced amounts of expensive elemental components such as rhenium (see the article in this issue by Konitzer et al.). An alternate path toward high-temperature-capability materials involves the use of ceramic matrix composites. ${ }^{28}$ As with superalloys, development efforts are split between improving mechanical properties and reducing manufacturing costs.

In the longer term, further gains are possible using emerging technologies such as high-temperature fuel cells. Solidoxide fuel cells can be combined with gas turbines or other engines to achieve even higher thermal efficiencies, further reducing the cooling water requirements. ${ }^{29}$ Current R\&D efforts in this area seek to increase current densities and improve reliability through engineering of the cell and stack components and to reduce costs by optimizing the manufacturing process. ${ }^{30}$

\section{Options for increasing water supply}

An important feature of the supply-side dynamic is that water is sometimes available in the form of nontraditional sources that require treatment before use. Examples include brackish aquifers, municipal wastewater, produced water from hydrocarbon extraction processes, and acidic mine-pool waters. In 2006, the U.S. DOE set a goal of increasing the current utilization rate of about $8 \%$ to $25 \%$ within 10 years and has funded a range of activities including cataloguing potential sources, developing treatment technologies, and evaluating system integration issues. ${ }^{19}$

Materials innovations can contribute to expanded use of nontraditional water supplies in two ways. The first involves upgrading the water quality to match that of existing fresh water supplies. This includes removing problematic components, reducing variability, and improving the robustness of treatment equipment to handle "impaired" water. A second approach is to improve the ability of cooling systems to directly use impaired water. In both cases, the goal is to make the cost of the treated water competitive with that of freshwater or alternate cooling technologies.

\section{Upgrading nontraditional water quality}

Water used for cooling in thermal systems must be treated to manage scale deposition, fouling through biofilm formation, and corrosion. In freshwater systems, these challenges 
are managed through chemical additives, along with careful operation of the cooling system. Nontraditional water resources present two challenges. First, they can contain elevated concentrations of components that can foul or damage equipment. Examples include (1) dissolved hardness or silica (brackish water) leading to enhanced scaling tendencies, (2) residual organics (municipal wastewater or produced water) leading to elevated microbiological activity, and (3) extremes in $\mathrm{pH}$ (acidic mine pools) leading to accelerated corrosion. Second, the water volumes and quality, especially from natural aquifers or hydrocarbon extraction operations, can vary with time, making it difficult to achieve stable performance. Variability also increases maintenance requirements and, consequently, the cost of treatment. Table II summarizes typical water-quality requirements for cooling towers and the challenges posed by several nontraditional water resources. ${ }^{28}$

Multiple technologies exist for improving nontraditional water quality:

- Chemical additives act in a variety of ways, including inhibiting precipitation and biological activity or altering interfacial properties.

- Gravity-based separations, such as settling tanks and flotation processes, separate particulate matter (includ-

Table II. Summary of water quality requirements, issues, and treatment options.

\begin{tabular}{|c|c|c|c|c|c|c|}
\hline & $\begin{array}{l}\text { Suspended } \\
\text { solids }\end{array}$ & $\begin{array}{l}\text { Acidity } \\
\text { (pH) }\end{array}$ & Hardness & $\begin{array}{c}\text { Oils/ } \\
\text { organics }\end{array}$ & Salinity & Silica \\
\hline \multicolumn{7}{|c|}{ Cooling tower specification } \\
\hline Range & $\begin{array}{c}<300 \mathrm{mg} / \mathrm{l} \\
\text { (Total suspended } \\
\text { solids) }\end{array}$ & $6-8.4$ & $\begin{array}{l}<900 \mathrm{mg} / \mathrm{l} \\
\left(\mathrm{CaCO}_{3}\right)\end{array}$ & Varies & $\begin{array}{c}<70,000 \mathrm{mg} / \mathrm{l} \\
\text { (Total dissolved } \\
\text { solids) }\end{array}$ & $<200 \mathrm{mg} / \mathrm{l}$ \\
\hline \multicolumn{7}{|c|}{ Nontraditional water resources } \\
\hline \multicolumn{7}{|l|}{ Brackish } \\
\hline \multicolumn{7}{|c|}{ Municipal waste } \\
\hline \multicolumn{7}{|c|}{ Produced water } \\
\hline \multicolumn{7}{|c|}{ Mine drainage } \\
\hline \multicolumn{7}{|c|}{$\begin{array}{l}\text { Key: } \bigcirc=\text { Consistently within acceptable range, } \mathrm{O} \text { = Potentially above acceptable range, } \mathrm{O}=\text { Consistently } \\
\text { exceeds acceptable range }\end{array}$} \\
\hline \multicolumn{7}{|c|}{ Water treatment options } \\
\hline \multicolumn{7}{|c|}{ Chemicals } \\
\hline \multicolumn{7}{|l|}{ Gravity } \\
\hline \multicolumn{7}{|l|}{ Filtration } \\
\hline \multicolumn{7}{|l|}{ Electrical } \\
\hline Thermal & & & & & & \\
\hline
\end{tabular}

Key: $\mathrm{O}=$ Conventional technology exists, $\mathrm{O}=$ Potential solution available (with technology development or in combination with another method), $\mathrm{O}=$ Significant innovation required ing chemically precipitated components) using density differences.

- Membranes and filters physically exclude one or more components on the basis of size or solubility.

- Electrical processes remove charged particles as well as dissolved ions.

- Thermal evaporation processes such as distillation produce clean water through evaporation and condensation.

These technologies can be used individually or in concert. Field experience has shown that the most effective configurations typically involve multiple treatment steps, selected based on local conditions. ${ }^{31}$ Table II also rates the watertreatment options against the various nontraditional water sources

Materials breakthroughs can improve the performance and economics of many of these technologies. Figure 4 shows some recent examples for membranes. Membranes are typically classified according to pore size. In general, reducing the pore size improves the selectivity but diminishes the flux. Membranes with pores in the range of micrometers to tens of nanometers are used to remove suspended solids, emulsified oil, microbes, and colloidal material through microfiltration or ultrafiltration processes. Smaller pores, such as those in the nanometer range, can allow removal of multivalent ions and some biological molecules through a nanofiltration process. Reverse-osmosis membranes are used to remove dissolved salts as part of a desalination process.

A wide range of activities are underway to improve the permeability of reverse-osmosis membranes..$^{32,33}$ One approach involves the modification of commercial membrane materials to adjust their surface charge or to attach molecules that sterically hinder the adsorption of foulants (Figure 4a). Another interesting direction involves new membrane materials based on carbon nanotubes or aquaporin proteins. Laboratory studies suggest that these materials have the potential to increase permeability by up to two or three orders of magnitude over those of conventional polymer materials (Figure 4b). ${ }^{34-36}$ In both cases, the underlying idea is to incorporate the carbon nanotubes or protein into a polymer matrix to provide 


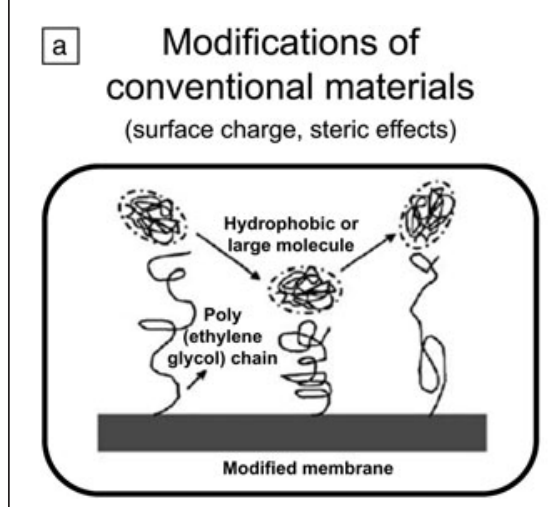

b Carbon nanotube based membranes

(up to $1000 \times$ flux enhancement)

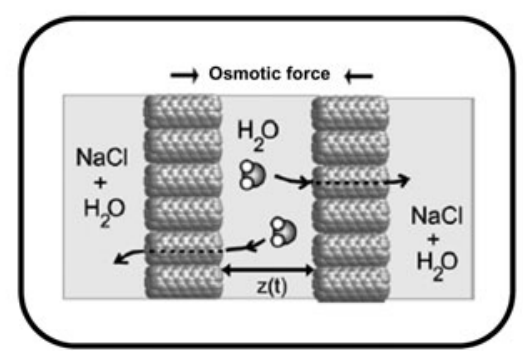

c

\section{protein membranes}

Aquaporin/

(up to $100 \times$ flux enhancement)

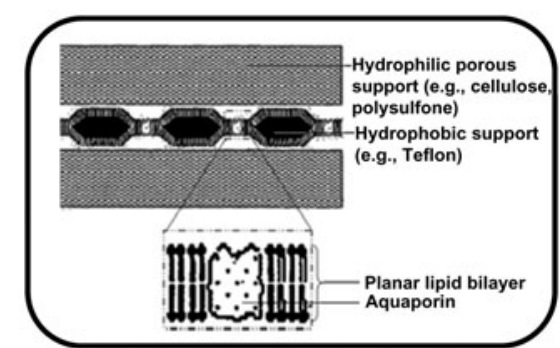

Figure 4. Innovative concepts for improving flux in reverse-osmosis membranes: (a) modification of conventional polymeric materials, (b) carbon nanotubes, (c) aquaporins and protein-based membranes. Parts a-c adapted with permission from References 33, 34, and 32 , respectively.

pathways for water transport. A key challenge is to maximize the loading while also ensuring that the water-transport pathways are accessible. Further work is also needed to validate membrane performance under realistic operating conditions, improve the manufacturability of the materials, and develop integrated modules for field testing. Success could lower the cost of desalination by reverse-osmosis membranes, but further analysis is needed to quantify the potential benefits.

\section{Improving the robustness of cooling equipment}

An alternative approach to utilizing nontraditional water is to modify existing equipment to accept it. Over the past decade, there has been considerable work on coatings with modified surface properties that could be useful for this application. For example, wet-surface air coolers are hybrid water-cooling systems that direct a co-current flow of air and water droplets over closed-loop cooling tubes. A uniform distribution of water over the tubes is essential to minimize scale deposition. ${ }^{37,38}$ To this end, surface-energy modifications through the use of hydrophilic or superhydrophilic coatings could promote wetting to help manage scaling problems and prevent oil deposition. As with the hydrophobic and superhydrophobic surfaces discussed earlier for condensers, the primary materials issues relate to durability under field conditions.

A second area of interest is developing heat-transfer materials with improved resistance to biofouling and saltwater corrosion. Insights from work in marine applications could provide the basis for advanced coatings technologies that could be useful for power-plant cooling. ${ }^{39}$ Such coatings are typically polymeric surfaces intended to resist biofouling by resisting initial protein adsorption or by reducing the adhesion of biofilms to the heat-transfer surfaces. For example, hydrophobic polymers such as polydimethylsiloxane (PDMS) have shown "fouling release" tendencies, and hydrophilic polymers resist protein adsorption. Work is needed to tailor materials for the specific extracellular polymeric substances secreted by microorganisms encountered in power-plant environments. Coating robustness is also an open question.

Finally, recent work with nontraditional materials of construction such as polymers or composites could also be promising. ${ }^{40}$ Such materials offer different surface chemistries that could prove beneficial in reducing scale and biofilm adhesion and increasing corrosion resistance. Although most nonmetallic materials lack the high thermal conductivity of traditional metal options, they open up the possibility of alternate configurations such as polymeric hollow-fiber systems with heat-transfer coefficients that rival those of traditional heat exchangers. ${ }^{41}$ As with the other materials innovations discussed in this section, the possibility of using nonmetallic heat exchangers in power generation is still in the early stages, and a sustained and focused R\&D effort will be needed.

\section{Conclusions}

Water is, and will remain, a critical input to the power-generation process for the foreseeable future. Given the increasing demand on water resources from all sectors, significant innovations will be required to ensure that adequate supplies are available to meet both global and regional needs. Opportunities for materials research that helps address this challenge are numerous and diverse. Superalloys and ceramic-matrix composites to improve gas-turbine efficiency, hydrophobic and hydrophilic coatings to improve heat-exchanger performance, and lowcost materials for compact air-cooled condensers are a few examples. This article has proposed a framework for evaluating different technology options for reducing water use in power production, namely, calculating the cost of conserved water based on the change in levelized cost of electricity and improved specific water usage. The hope is that this article has provided guidance to the materials research community in identifying some of the most pressing needs and opportunities for innovation in this area. 


\section{A closer look at the global water footprint for electricity production}

Here we present the relative water footprints of different modes of electricity production and explore how the overall footprint could evolve in coming decades. In the figure, the area of each block corresponds to the projected water footprint for each power-generation mode. Separate blocks are shown for the footprint in 2007 and the projected increment by 2030 , based on projections from the EIA base-case scenario. ${ }^{9}$ The potential increment associated with adoption of carbon capture and storage (CCS) for coal and the projected reduction of liquid (oil) generation are also shown.

Several assumptions were used to construct this figure. First, the specific water requirements are weighted averages for each fuel source, based on available data for different modes (open-loop versus closed-loop) of cooling. Such data exist in detail only for fossil-fuel-based systems in the United States, so the U.S. distribution was assumed to apply globally. Because growth forecasts do not provide projections for changes in the distribution of cooling modes, current distributions were assumed to remain constant. Second, the utilization of the installed generating capacity ranges from $90 \%$ for baseload systems to $30 \%$ for intermittent sources, reflecting the complexity of matching real-time variations in demand. Finally, water requirements are sensitive to technology innovations that reduce the specific water use, as well as policy decisions such as emissions controls. Without specific projections for how these capacity factors or technologies might change in the future, we simply extrapolated from current values.

Several major trends emerge from the figure:

- Fossil-fuel-based generation (coal, natural gas, oil) dominates the overall water footprint and will continue to do so. Coal-based power comprises the single largest component of the installed base and is forecasted to grow significantly, primarily in China, where coal fuels $80 \%$ of power plants. Recent developments that can help manage the growing water demand in China include (1) consolidation of older, smaller units into larger, more thermally efficient plants; (2) use of lower-water-intensity designs (higher-efficiency pulverized-coal and integrated gasification combined-cycle plants); and (3) further deployment of air cooling in its arid northern regions (where air cooling had been installed on $35 \mathrm{GW}$ of capacity by 2008). ${ }^{10}$

- Carbon-capture technologies can significantly increase the water footprint of fossil-fuel-based power generation (see the CCS scenario in the figure). Currently available technologies such as solvent capture can double the water requirements. ${ }^{7}$ Some of this impact could be mitigated through the development of less water-intensive capture technologies.

- There is considerable uncertainty regarding the deployment of nuclear power. Nuclear-based generation was projected to grow in the EIA base case, but the Fukushima Daiichi nuclear disaster in Japan following the earthquake and tsunami in March 2011 has led to the shutdown of some existing facilities and the cancellation or postponement of others. ${ }^{11}$

- Renewable thermal (geothermal, concentrated solarthermal) power accounts for only a small part of the overall water footprint. The smaller scale of these systems (tens of megawatts) compared to fossil-fuel or nuclear plants results in more manageable heat rejection loads and allows for more extensive use of air cooling. 


\section{References}

1. N. Onat, H. Bayar, Renewable Sustainable Energy Rev. 14, 3108 (2010).

2. M. Hightower, S.A. Pierce, Nature 452, 285 (2008).

3. R. Pate, M. Hightower, C. Cameron, W. Einfeld, Overview of Energy-Water Interdependencies and the Emerging Energy Demands on Water Resources (Report SAND 2007-1349C, Sandia National Laboratories, Los Alamos, NM, 2007).

4. V.S. Arunachalam, E.L. Fleischer, MRS Bull. 33, 264 (2008).

5. A.E. Farrell, A.R. Gopal, MRS Bull. 33, 373 (2008).

6. M.A. Shannon, R. Semiat, MRS Bull. 33, 10 (2008).

7. J. Macknick, R. Newmark, G. Heath, K.C. Hallett, A review of operational water consumption and withdrawal factors for electricity generating technologies (Technical Report NREL/TP-6A20-50900, National Renewable Energy Laboratory, Golden, CO, March 2011)

8. V. Fthenakis, H.C. Kim, Renewable Sustainable Energy Rev. 14, 2039 (2010). 9. International Energy Outlook 2010 [Report DOE/EIA-0484(2010), Energy Information Administration, Washington, DC, 2010].

10. Reducing Freshwater Consumption at Coal-Fired Power Plants: Approaches Used Outside the United States (Report DOE/NETL-2011/1493, National Energy Technology Laboratory, Pittsburgh, PA, 2011).

11. M. Schneider, A. Froggatt, S. Thomas, Nuclear Power in a Post-Fukushima World: 25 Years After the Chernobyl Accident (World Watch Institute, Washington, DC, 2010).

12. Y. Yang, X. Guo, N. Wang, Energy 35, 4336 (2010).

13. K. Mulder, N. Hagens, B. Fisher, AMBIO: J. Hum. Environ. 39, 30 (2010).

14. Existing Plants, Emissions and Capture-Setting Water-Energy R\&D Program Goals (Report DOE/NETL-2009/1372, National Energy Technology Laboratory, Pittsburgh, PA, 2009).

15. J.R. Wolfe, R.A. Goldstein, J.S. Maulbetsch, C.R. McGowin, J. Contemp. Water Res. Educ. 143, 30 (2009).

16. M. Konter, M. Thumann, J. Mater. Process. Technol. 117, 386 (2001).

17. A. Voinov, H. Cardwell, J. Contemp. Water Res. Educ. 143, 17 (2009).

18. S. Powell, C. Loh, G. Peiyin, "Falling up! Water pricing must meet true costs," in Blue Books: Experts' views for expert investors (CLSA Asia-Pacific Markets, Hong Kong, 2010).

19. Department of Energy/National Energy Technology Laboratory's WaterEnergy Interface Research Program: December 2010 Update (National Energy Technology Laboratory, Pittsburgh, PA, 2010).
20. W.C. Micheletti, J.M. Burns, paper presented at the Water Issues in Fossil Energy Workshop, National Energy Technology Laboratory, Pittsburgh, PA, 27 June 2002. 21. Power Plant Water Usage and Loss Study (National Energy Technology Laboratory, Pittsburgh, PA, 2005)

22. P.J. Maziasz, I.G. Wright, J.P. Shingeldecker, T.B. Gibbons, R.R. Romanosky, paper presented at the 19th Annual Conference on Fossil Energy Materials (sponsored by the U.S. Department of Energy), Knoxville, TN, 9-11 May 2005.

23. P.J. Marto, D.J. Lookey, J.W. Rose, A.S. Wanniarachchi, Int. J. Heat Mass Transfer 29, 1109 (1986).

24. M.M. Gentleman, J.A. Ruud, Langmuir 26, 1408 (2010).

25. Power Generation Water Use in Texas for the Years 2000 to 2060: Final

Report (Texas Water Development Board, Austin, TX, 2003).

26. F.J. Brooks, GE Gas Turbine Performance Characteristics (Report GER-3567H, GE Power Systems, Schenectady, NY, 2000)

27. N.P. Padture, M. Gell, E.H. Jordan, Science 296, 280 (2002).

28. G.S. Corman, K.L. Luthra, in Handbook of Ceramic Composites, N.P. Bansal, Ed. (Kluwer Academic Publishers, New York, 2005), pp. 99-115.

29. D.W. Richerson, Modern Ceramic Engineering: Properties, Processing, and Use in Design (CRC Press, Boca Raton, FL, 2006).

30. N.H. Menzler, F. Tietz, S. Uhlenbruck, H.P. Buchkremer, D. Stover, J. Mater. Sci. 45, 3109 (2010).

31. Use of Non-Traditional Water for Power Plant Applications: An Overview of DOE/NETL R\&D Efforts (Report DOE/NETL-311/040609, National Energy Technology Laboratory, Pittsburgh, PA, 2009).

32. K.P. Lee, T.C. Arnot, D. Mattia, J. Membr. Sci. 370, 1 (2010).

33. D. Li, H. Wang, J. Mater. Chem. 20, 4551 (2010).

34. A. Kalra, S. Garde, G. Hummer, Proc. Natl. Acad. Sci. U.S.A. 100, 10175 (2003).

35. J.K. Holt, H.G. Park, Y. Wang, M. Stadermann, A.B. Artyukhin, C.P. Grigoropoulos, A. Noy, O. Bakajin, Science 312, 1034 (2006).

36. M. Kumar, M. Grzelakowski, J. Zilles, M. Clark, W. Meier, Proc. Natl. Acad. Sci. U.S.A. 104, 20719 (2007)

37. R.M. Manglik, M.A. Jog, J. Heat Transfer 131, 121001 (2009).

38. L. Liu, A.M. Jacobi, J. Heat Transfer 131, 051802 (2009).

39. S. Krishnan, C.J. Weinman, C.K. Ober, J. Mater. Chem. 18, 3405 (2008).

40. H.T. El-dessouky, H.M. Ettouney, Desalination 122, 271 (1999).

41. D.M. Zarkadas, K.K. Sarkar, Ind. Eng. Chem. Res. 43, 8093 (2004).

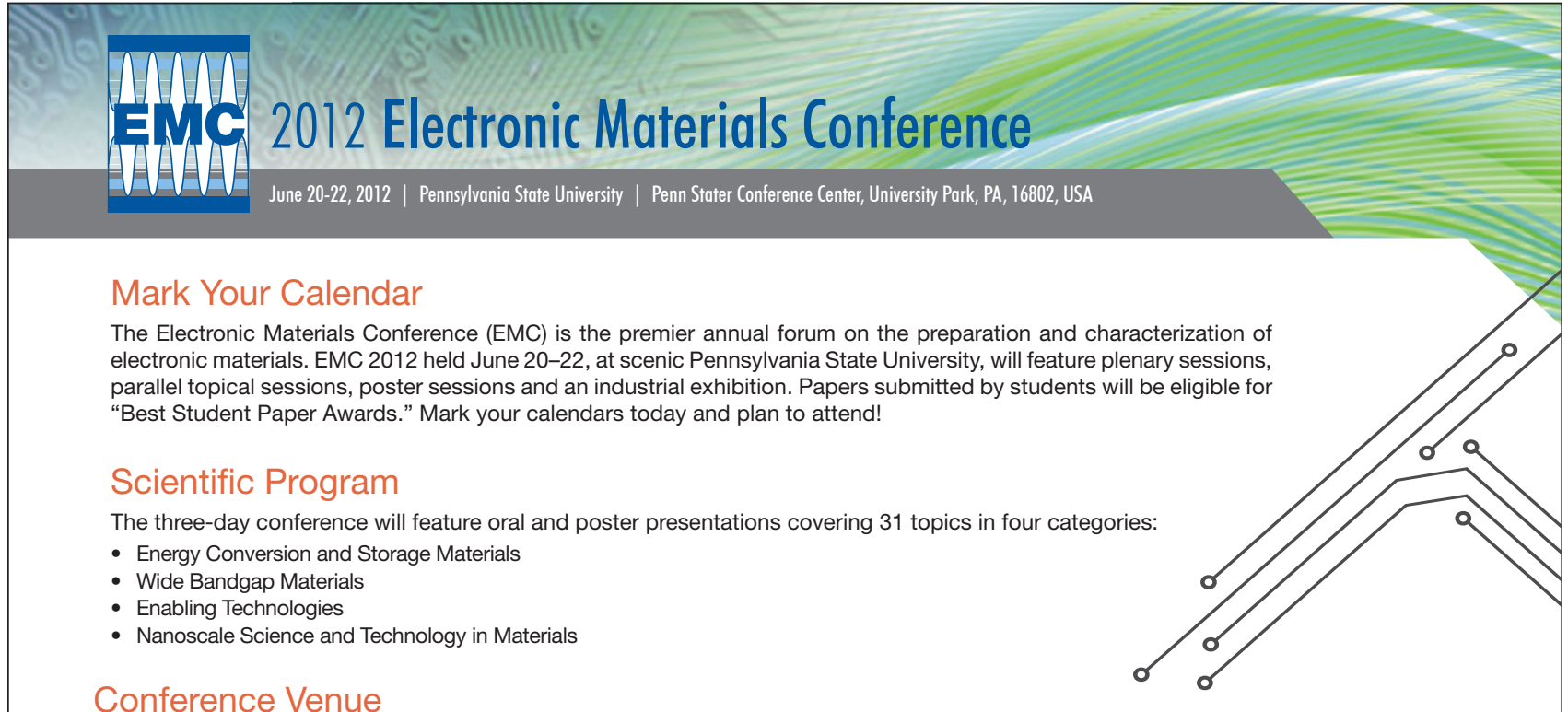

Pennsylvania State University (PSU) is consistently ranked one of the leading universities for materials science and engineering by the National Science Foundation, making it an ideal conference location. The campus is nestled among the beautiful Pennsylvania countryside, and is rich with trails to explore. From sightseeting to action-packed adventures, you won't want to miss a moment. After all, it's not called the "Happy Valley" for nothing!

TMTS Student participation in this conference is partially supported by a grant from the TMS Foundation.

www.mrs.org/emc2012 


\section{CONFIDENCE COMES WITH GREAT RESULTS}
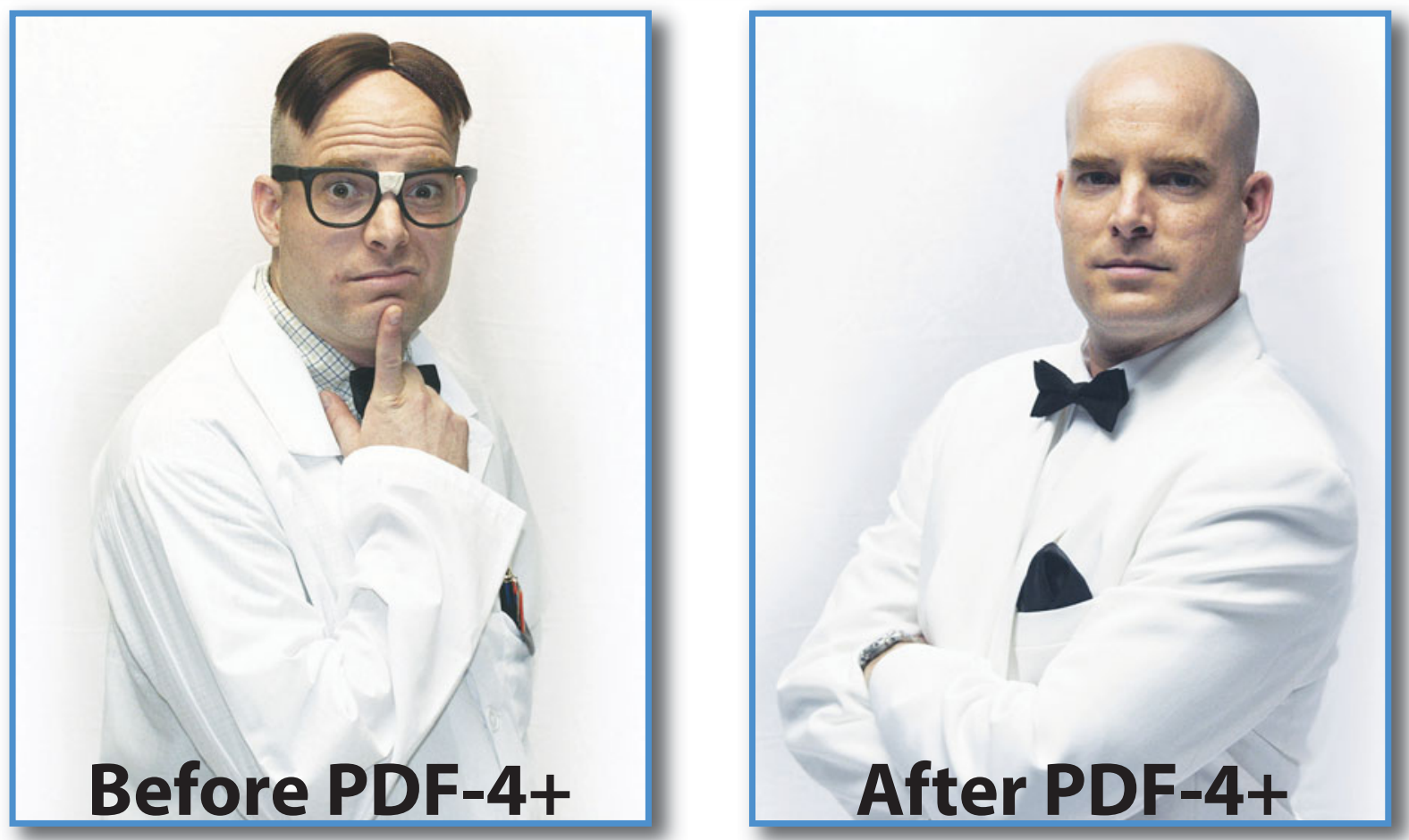

\section{$\mathrm{PDF}=4+2011$ \\ More Data • More Data Mining}

The most comprehensive collection of inorganic powder patterns

Phase identification using physical, chemical and crystallographic data

* Comprehensive materials database featuring 316,291 data sets

Standardized, edited data from four crystallographic databases

* Utilize quantitative analysis methods

160,183 Data sets with atomic parameters for Rietveld analysis

221,102 Data sets with $I / I_{c}$ for Reference Intensity Ratio (RIR)

316,291 Data sets with full digital patterns for total pattern analysis

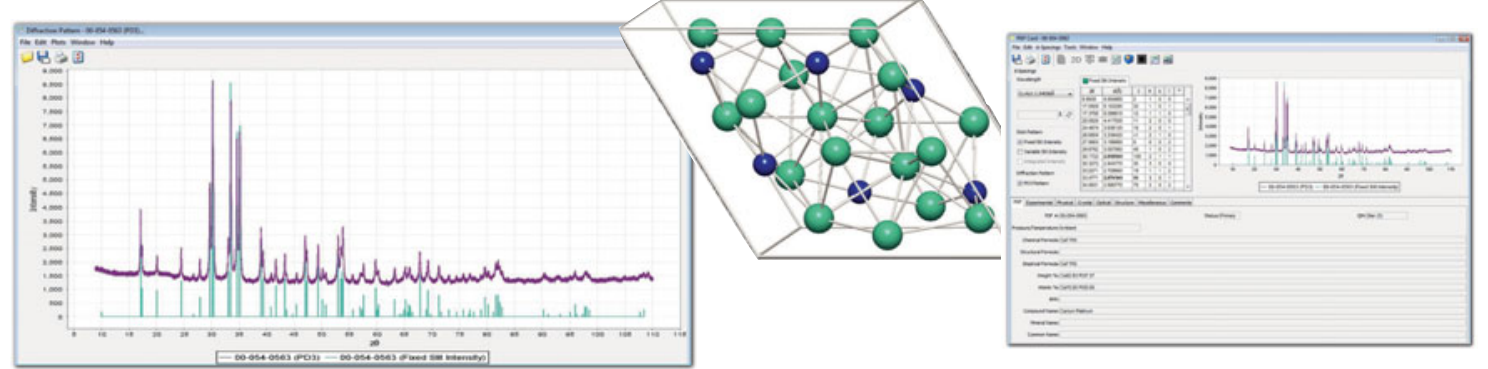

International Centre for Diffraction Data

Phone: 610.325.9814 / Toll-free U.S. \& Canada: 866.378.9331

marketing@icdd.com・ www.icdd.com

ICDD, the ICDD logo and PDF are registered in the U.S. Patent \& Trademark Office. 


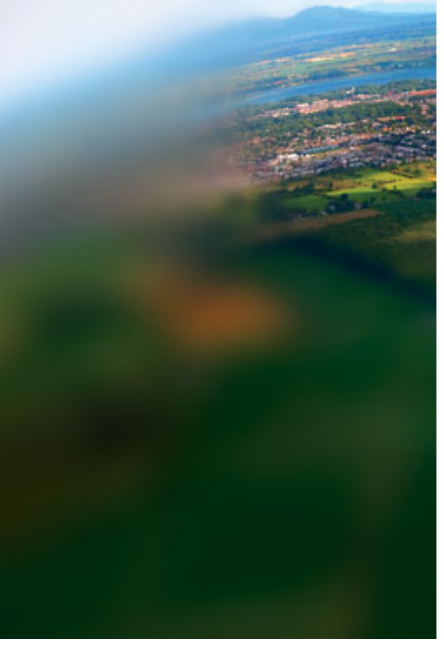

\title{
Teaching sustainable development in materials science and engineering
}

\author{
R. LeSar, K.C. Chen, and D. Apelian
}

Preparing the next generation of materials scientists and engineers requires more than teaching them knowledge of material properties and behaviors. Materials science and engineering must also take into account materials sustainability in the context of society and the environment, as discussed throughout this issue. Including topics such as sustainability in a materials curriculum is not new. Issues of ethics, costs, and so on have long been an integral part of our education. Although detailed treatment of all such topics cannot be included in a general materials education curriculum, the concepts of sustainable development and the role of materials in a sustainable future can be introduced. Indeed, many materials science programs are beginning to include these topics in their curricula. This article discusses three such programs that the authors have helped design and implement in the United States, each taking a different approach to engaging students in these topics. The intention is not to provide an exhaustive overview of education in sustainable development, but rather to describe a range of strategies that are currently being applied and to raise pertinent issues in materials science education.

\section{Introduction}

The challenges of sustainable development will require materials engineers and scientists to think beyond the current definition of what constitutes the "best" material for a given application. Increasingly, considerations of issues such as resources, toxicity, and life cycles will also be necessary. The question for engineering faculty is how to prepare students to meet these challenges. In this article, we describe some ways in which our separate institutions are currently teaching sustainable development to engineering students, especially materials scientists and engineers. Rather than providing a comprehensive review, we focus on three programs that can serve as examples of various pedagogical approaches. Before discussing these examples, however, we review some concepts that provide a basis for understanding sustainable development in a broader context.

The first step in designing a curriculum in sustainable development is to agree on a common definition of what is meant by the term. As noted in the introductory article to this issue, the United Nations' Brundtland Commission defined sustainable development as development that "meets the needs of the present without compromising the ability of future generations to meet their own needs." Such a definition yields a broad and flexible starting point for discussion. The advantage of a broad definition is that it does not restrict sustainable development to mean any specific technological or environmental topic but rather includes all current activities that could affect future generations. Thus, the definition can be refined accordingly for a specific course or project.

In the most general sense, the goal of sustainable development is to create a sustainable global society, where society is viewed as a system. In the simplest version of this view, often called the "triple bottom line," a society is considered as the union of environmental, economic, and social (cultural) systems, ${ }^{2,3}$ that is, a system of rather complex subsystems.

A sustainable society is thus one that meets societal needs while maintaining the integrity of the environment and ecosystems, the economy, and the social needs of individuals. Thinking of a society as a system is essential, because it implies that optimization of the system as a whole will not generally entail optimization of the individual subsystems; rather, tradeoffs between the constituent components are the norm. Thus, traditional linear, sequential optimization strategies are inadequate. Moreover, given the complexity and nonlinearity of the interactions among the components, society is a complex system exhibiting emergent behavior that is not generally obvious from 
the properties of its processes and parts. Consequently, the optimal technological solution in any situation might not be the best solution for society as a whole.

A course in sustainable development must thus teach students to recognize that engineering operates in a broad societal context and to take that context into account. This view is easily incorporated into the classic definition of engineering as "design under constraint," as sustainable development (in the broad sense discussed above) simply creates a new set of constraints. Indeed, future physical constraints on technology will be increasingly stringent with, for example, growing energy costs and requirements for low emissions of greenhouse gases. Equally demanding will be the societal and economic constraints. These additional constraints will require a different way to think about technology.

More specifically, these constraints might include limited availability of some materials, arising from their natural distribution in the lithosphere or from geopolitical forces, materials toxicity, and the like. Resource limitations will likely require the replacement of materials, as well as the design of products for enhanced recyclability. The issues facing specific technologies, including materials, however, are all based on the basic system-level concepts of sustainable development described above.

The question, then, is how one introduces students to these ideas about sustainable development. Because sustainable development is a relatively new topic in higher education, there is no standard curriculum, and a great variety of approaches could be taken. Herein, we highlight three approaches that range from a common course for all first-year students to an integrated set of courses to an entirely revamped curriculum that incorporates sustainable development throughout as a central theme. Although all programs have their own constraints and many other universities are working to establish such programs, it is our hope that these few examples will prompt discussion and generate new ideas.

\section{Teaching sustainable development at Worcester Polytechnic Institute (WPI)}

WPI started teaching sustainability-related courses for firstyear students in 2007, in a series called the Great Problems Seminars. 5 The first courses were called "Power the World" and "Feed the World." The Great Problems Seminars were conceived to immerse first-year students in societal issues and to inspire and engage them. They are offered to students in all fields (life sciences, humanities, business, and engineering), and as of 2010 , about $40 \%$ of the first-year students opted to enroll. At present (2011-2012 academic year), discussions about making the courses mandatory are ongoing.

In the development of this program, the faculty established several objectives:

- to encourage critical thinking, information literacy, and evidence-based writing;

- to engage first-year students with current events, societal problems, and human needs;
- to cultivate in each student a personal foundation for lifelong learning;

- to contribute to a more intellectually stimulating environment at WPI; and

- to promote civic engagement and community partnerships. In addition, an interdisciplinary team (Engineering, Humanities and Arts) developed a course called "Sustainable Development for the 21st Century-Making Our World" that has been offered every year since 2008. This course emphasizes the role of materials science and engineering (MSE) as a vehicle for addressing many of the societal issues related to sustainable development, rather than focusing solely on the study of the physical and chemical nature of solids. Specifically, students learn about society's burgeoning needs in the areas of energy resources, mobility/transportation, housing, food and water, resource recovery/recycling, and health care, not to mention climate change and environmental issues, and see how materials science is intertwined with each of these societal issues. The course thus provides a much larger and holistic context for MSE.

During the first part of each of the above courses (a sevenweek period), students form teams of three or four and study the basic facts, write essays, and participate in active discussions on the above-mentioned societal issues, from both technical and public-policy perspectives. During the second part of the course, the student teams work on a specific project addressing one of these topics. At the end of the course, the teams present their work in a public forum, write a final report, and make a poster that is judged externally.

Each course is designed to have the students grapple with real-world problems and develop skills of rigorous analysis, active engagement, and creative synthesis. They develop communication skills to pursue inquiry-based work, to make connections between disciplines, to explore current events and issues, and to consider the broader implications of science and technology. Specifically, the aim is for students to

- learn about the concepts of sustainable development, climate change, energy sources, food and water issues, health concerns, and housing and transportation needs at the start of the 21 st century in terms of both the MSE issues and the human/social aspects;

- approach these issues proactively with an eye toward ecologically sound solutions;

- experience the value of engaging different disciplinary perspectives - from materials science to statistics, environmental studies, history, and philosophy — in addressing real-life problems;

- learn to formulate researchable questions based on multiple sources; and

- participate in classroom debates and discussions on complex issues of sustainable development and contribute to teamwork. The students in these courses have learned that sustainable development in the 21 st century is attainable and that it will require innovation and the will to effect change. Some of the students have taken these lessons much further afield, with projects in Kenya on water systems and soap making, for example (Figure 1). 
In 2008, The National Academy of Engineering (NAE) commissioned a study titled Changing the Conversation: Messages for Improving Public Understanding of Engineering. ${ }^{6}$ The resulting report recommends that the engineering community begin immediately to plan and initiate a coordinated communications campaign to interest young people from all backgrounds in engineering careers by appealing to their desire to find hands-on solutions to problems that can make a difference in the world and improve people's lives. The courses at WPI are very much in line with the recommendations of this report.

\section{Teaching sustainable development at lowa State University}

The Materials Science and Engineering Department at Iowa State University has partnered with the Mechanical Engineering Department to develop a series of three interrelated courses on sustainable development that incorporate a systems-level view, rather than centering on specific disciplines. The focus of these courses is, in part, on the developing world, largely because the systems there tend to be somewhat less complex and more amenable to analysis. Care is taken, however, to emphasize how these ideas also apply to the developed world.

Taken as a whole, these courses consider a wide range of technical and societal issues, with the balance between "engineering" and "context" varying between the classes. Although the courses constitute an interconnected set, linking to and supplementing each other, they are independent and can thus serve the needs of a broad group of engineering students.
The course "Sustainable Engineering for International Development" is specifically geared toward presenting descriptions of society and communities as systems and providing a broad view of sustainable development and appropriate technology to develop a picture of water, energy, and materials issues in communities at all stages of development. Although predominantly technical, this course contains a significant focus on economics, anthropology, and other topics. Materials make up a large part of the class, with discussions on resource sustainability and how one chooses materials for specific sustainable technologies. Typically, around 30 students take this class.

The Mechanical Engineering course "Design for Appropriate Technology" offers a new take on the senior design course, with a focus on creating appropriate solutions for specific applications in the developing world. Students are asked to respond to defined needs of people in a poor village in Africa. They have access to both previous designs and assessments of how well those designs have worked in a practical application. Although this course is predominantly technical, its problems are motivated within a societal context.

The final class in the sequence, "Applied Methods in Sustainable Engineering for International Development," is a summer study-abroad class taught in a small village in Mali, in western sub-Saharan Africa. ${ }^{7}$ The same village is visited each year, so projects implemented in one year can be assessed and improved in following years. Students spend three weeks in the village, in which most, if not all, villagers live on well under US\$1.25/day (designated as extreme poverty by the World Bank). The students implement projects in the village, some of which originate in the senior design course discussed above. Owing to the complexities of travel to Mali, this course can accommodate only 10-12 students at a time.

In this class, the use of materials is a critical part of the experience. In an isolated village with few resources, the students must rely on local materials, generally mud (for bricks and stoves), iron from the village blacksmith, and wood from the carpenter, to complete their projects. As an example, we introduced new cook stoves into the community, with the aim of reducing smoke and associated health hazards, as well as improving efficiency compared to open fires. These stoves were of a simple design, made of local materials, so that the villagers could manufacture their own stoves, as purchasing stoves is generally beyond their financial means. Over the first three years of the class, we first assessed the cooking needs of the village, which determined what form of stove to create, and then assessed, within the context of a wider-ranging evaluation of village energy needs, the effectiveness of the stove design. For example, Figure 2 shows a
Figure 1. Worcester Polytechnic Institute student Anna Chase (second from left) introducing women in the village of Malewa, Kenya, to the Better Water Maker (foreground). This portable device purifies water with ultraviolet light generated using a hand crank. Photo by D. Apelian. 
student learning how to separate grain as part of this assessment of energy and cooking needs.

One outcome of this experience is a realization of how materials dominate our technology, as well as an appreciation of how much one can do with some basic materials understanding. Another part of the assignment is to create a report on some specific social, economic, or environmental aspect of the village, to supplement the systems-level description. Students create these reports through data gathered, in part, by interviewing people in the village. Among the goals for this class is the creation of an environment in which students can learn how to work effectively in a culture that is very different from their own. The major goal, however, is to change how students view the role of engineering in society, enabling them to have a first-hand understanding of how context informs engineering solutions. The net result is also a change in how they view themselves as engineers.

It is also important to extend the discussion of sustainable development beyond engineering. To that end, Engineering and Economics faculty have co-created a course called "Globalization and Sustainability" that teaches a systems-level view of sustainable development and is open to all undergraduates. Taught in the "Technology and Social Change" program in the College of Liberal Arts and Sciences, this course includes students from all six undergraduate colleges and from all stages of their undergraduate experience, with enrollment of approximately 100 students. Materials make up an appreciable portion of this class, with a focus on the ubiquity of materials in technology, as well as the scarcity of some resources and how that scarcity can have an impact on future technological solutions for sustainable energy

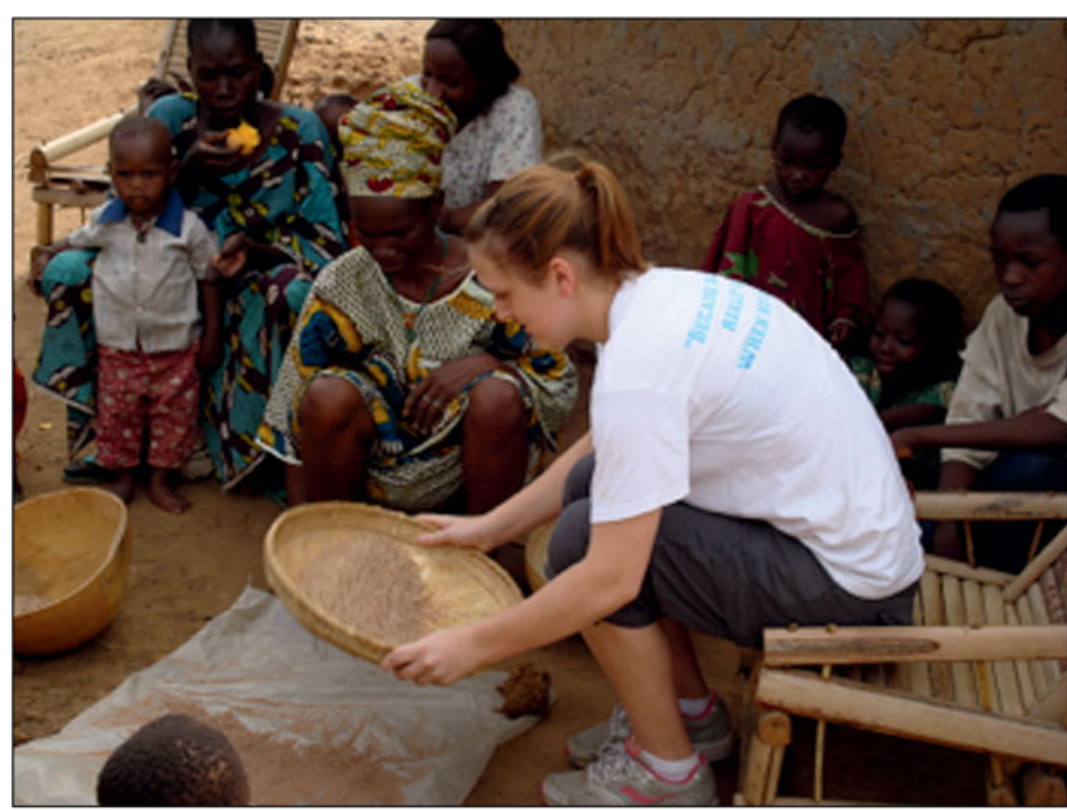

Figure 2. Student working with women in a village in Mali to help determine energy and cooking needs. Photo by R. LeSar. and products. This class is a core course in a new minor in sustainability.

\section{Teaching principles of sustainability at California Polytechnic State University}

The Materials Engineering department at the California Polytechnic State University ("Cal Poly”), San Luis Obispo, has taken the approach of infusing principles of sustainability throughout its entire curriculum. That is, awareness and considerations of the social and environmental impacts are interwoven within several courses and have a prominent place in the program's mission and culture. Through a National Science Foundation departmental-level reform grant awarded in 2006, the department collectively transformed its curriculum to embrace sustainability and project-based learning. ${ }^{8,9}$ Although basic principles of materials science and engineering are still at the core, there has been a shift in the approach - from scientific analysis to project-based engineering design with realistic constraints. Central tenets of the new curriculum include systems thinking and the role of engineers in society. Problems have been reframed to show interconnectedness and to give greater context (e.g., new alloy systems must be developed to replace toxic, lead-based solders yet still provide equal or better thermal and mechanical performance), in order to help develop engineers with the skills and mindset to effectively handle the complex, global issues of the future.

Sustainability themes are introduced in the freshmen year and continue throughout the students' program of study in different courses and from different perspectives. ${ }^{10}$ Firstyear students design, build, and test solar water heaters in the context of impoverished communities. They then perform a service-learning project with local community partners and learn about user needs, engineering design, communication, and project management. As an example, a team of students worked with a local charter elementary school that did not have any hot water for hand washing or science experiments. The Cal Poly students designed and installed a solar water system (Figure 3) and created associated learning materials about their design for the children. User-centered design places the focus on people and can be a great motivator for learning.

The second year includes the courses "Materials, Ethics \& Society" and "Materials Selection for the Life Cycle." CES Selector software with the Eco Audit tool ${ }^{11}$ is employed to quantitatively assess the choices of different materials during different parts of the product life cycle. Students learn about the "triple bottom line" (as mentioned in the Introduction) and how the cost of a product involves many different factors such as labor, embodied energy, transportation, supply and demand, and politics (e.g., wars, 


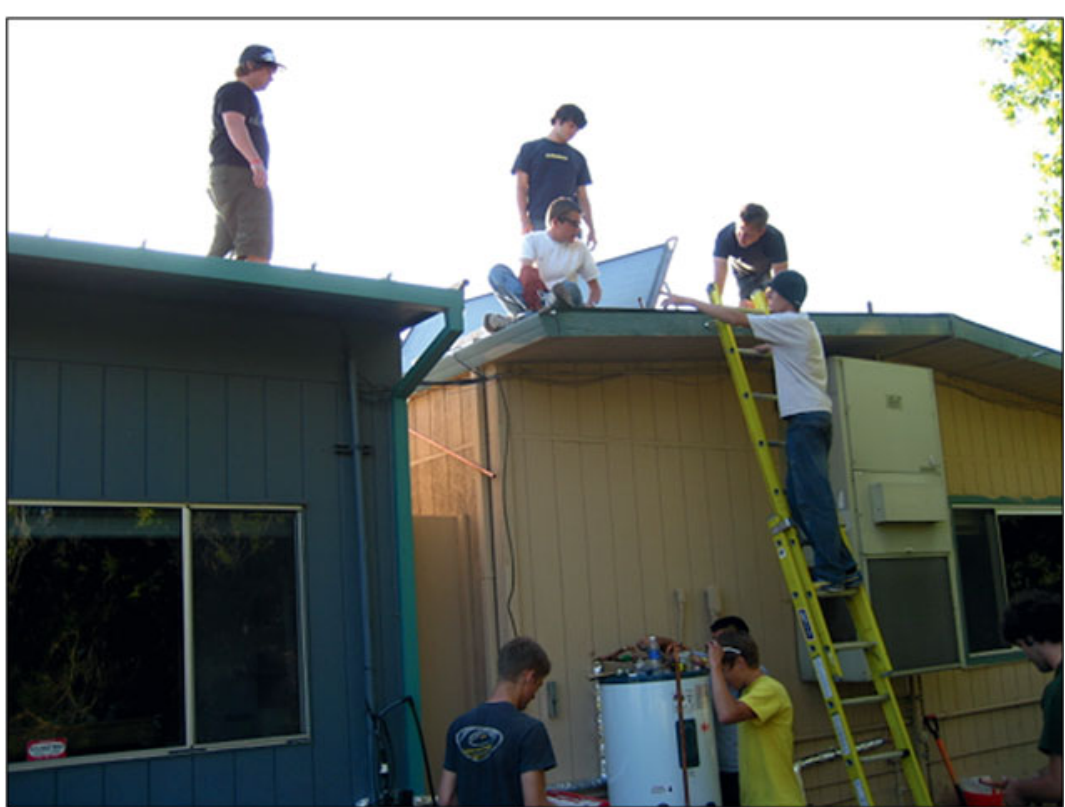

Figure 3. Freshman service learning project with a California K-6 charter school to install a solar water heater. Cal Poly students conducted a user needs assessment and identified the engineering design constraints and requirements to provide hot water to school children to wash their hands and for the science teacher to conduct experiments. They then installed the system and still maintain it. Photo by K. Chen. bioresins for surfboards, degradation of natural fiber composites, biochar as an energy source for developing countries), and several graduates have actively sought jobs in areas that pertain to sustainability (e.g., solar cells, electric vehicles).

\section{Where do we go from here?}

Thus far, this article has summarized our experiences in implementing educational programs in sustainable development at Worcester Polytechnic Institute, Iowa State University, and California Polytechnic State University. As we and others improve current courses and develop new learning opportunities in sustainable development, the central issue is how to provide the most meaningful and practical learning experiences for our students. Questions on the details of such programs remain, such as:

- How should specialization in the materials field be balanced with broader, multidisciplinary education?

- How can different universities share their experiences in teaching sustainable development?

strikes, and embargos). Current news articles are used to emphasize the topics' relevance, and directed reflection assignments and in-class discussions allow greater opportunity for thought on the impact of engineering on people and the planet. For example, an assignment that has a significant impact on students is a set of articles and photo gallery ${ }^{12}$ on the electronic wastes that end up in developing countries. Students make the connection between their latest cell phone and young children exposed to toxic materials in other parts of the world. Likewise, the connection between the demand for rare-earth metals for renewable energy technologies and the devastation of farmland in $\mathrm{China}^{13}$ requires broader views and systems thinking.

Processing, structure, and properties of materials find new context in appropriate technology. For example, discussion of the organization Potters for Peace (http://www.pottersforpeace. org/) provides great context for considering purposeful porosity in ceramics to filter water. Similarly, an introduction to the European RoHS regulations (Restriction of the Use of Certain Hazardous Substances in Electrical and Electronic Equipment) and the search for lead-free solders drives the need to understand eutectic alloy systems and phase diagrams. Real-world contexts and realistic design constraints that involve environmental and societal impacts provide rich learning experiences for students.

Experience at Cal Poly has shown that students become more invested in their learning when topics relate to the "real world" and when engineering offers solutions to global problems. More students in this program are also choosing senior projects that have a sustainability theme (e.g.,
- What types of data should be collected to assess the teaching of sustainable development? (e.g., How does one assess student ability to "systems think"?)

- How can these programs impact all materials science students and encourage all practitioners to embrace sustainable development as part of our profession?

We feel that a clearinghouse or forum for educators to share ideas and experiences around the teaching of sustainable development would be beneficial for our community. Perhaps the University Materials Council, an organization of U.S. and Canadian materials science educators that serves as a forum for sharing best practices and discussing issues such as curricular improvements (http://www.umatcon.org/), could take the lead in this domain.

\section{Summary and conclusions}

The educational system is still in the beginning stages of learning how to teach a broader view of sustainable engineering. In addition to the three institutions profiled, many other universities have also been developing new curricula and research based on these ideas, and indeed, a few have created centers focused on these issues. ${ }^{14-16}$ The key point for all materials scientists is that the solutions that are being proposed for sustainable development, including green designs, renewable energy, and a host of others, cannot meet our future challenges unless we find appropriate technologies and paths for our society and ourselves. Our job in the university is to ensure that we turn out scientists and engineers who are best prepared to do so. 


\section{References}

1. Report of the World Commission on Environment and Development: Our Common Future (Annex to Document A/42/427, Oxford University Press, Oxford, UK, 1987).

2. W.M. Adams, The Future of Sustainability: Re-thinking Environment and Development in the Twenty-first Century (International Union for Conservation of Nature, Gland, Switzerland, 2006).

3. S. Dodds, Ecol. Econ. 23, 95 (1997).

4. W.A. Wulf, in Issues in Science and Technology Online (University of Texas at Dallas, Richardson, TX, 1998), www.issues.org/15.2/wulf.htm (accessed November 2009).

5. Undergraduate Studies: Great Problems Seminars (GPS), http://www.wpi.edu/ academics/Undergraduate/FirstYear/gps.html.

6. Changing the Conversation: Messages for Improving Public Understanding of Engineering (National Academy of Engineering, Washington, DC, 2008).

7. R. LeSar, K.M. Bryden, "Study Abroad Experiences in the Developing World: Opportunities and Challenges," in Mater. Res. Soc. Symp. Proc. 1320 (Materials Research Society, Warrendale, PA, 2011).

8. L. Vanasupa, K.C. Chen, J. Stolk, R.N. Savage, T.S. Harding, B. London, W.L. Hughes, "Converting Traditional Materials Labs to Project-based Learning Experiences: Aiding Students' Development of Higher-order Cognitive Skills," in Mater. Res. Soc. Symp. Proc. 1046 (Materials Research Society, Warrendale, PA, 2007).
9. L. Vanasupa, K.C. Chen, F. Splitt, J. Mater. Educ. 28 (3-6), 171 (2006).

10. K.C. Chen, L. Vanasupa, B. London, R.N. Savage, "Infusing the Materials Engineering Curriculum with Sustainability Principles," in Proc. 2006 Am. Soc. Eng. Educ. Annu. Conf. (ASEE, Washington, DC, 2006), paper 2006-378.

11. Granta CES 2012 Selector (Granta Design Ltd., Cambridge, UK), www. grantadesign.com/products/.

12. "China's Electronic Waste Village," Time Magazine (7 January 2009), www. time.com/time/photogallery/0,29307,1870162,00.html.

13. "Earth-Friendly Elements, Mined Destructively," New York Times (26 December 2009), p. A1.

14. Center for Sustainable Engineering, a partnership among Syracuse University (lead institution), Arizona State University, Carnegie-Mellon University, Georgia Institute of Technology, and the University of Texas at Austin supported by the National Science Foundation and the Environmental Protection Agency, www.csengin.org (accessed November 2009).

15. International Sustainable Engineering Initiative, Civil and Environmental Engineering Department, Michigan Technical University, www.cee.mtu.edu/ sustainable_engineering (accessed November 2009).

16. School of Sustainable Engineering and the Built Environment, Arizona State University, http://engineering.asu.edu/sebe (accessed November 2009).

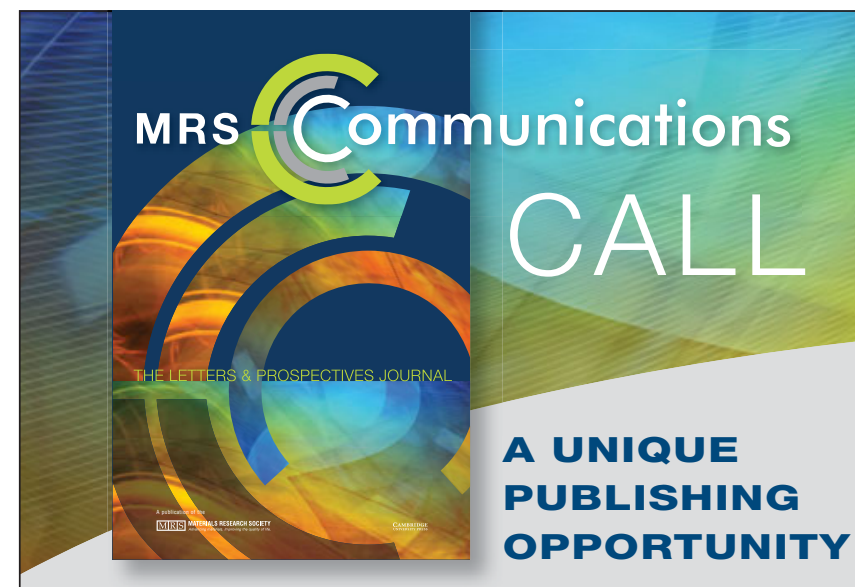

Manuscripts are being solicited for MRS Communications - a new full-color, high-impact journal focused on groundbreaking work across the broad spectrum of materials research.

Published jointly by the Materials Research Society (MRS) and Cambridge University Press, MRS Communications offers a rapid but rigorous peer-review process and time to publication. An aggressive production schedule will bring your article to online publication and a global audience within a target 14-day process from acceptance.

Hosted on the cutting-edge Cambridge Journals Online (CJO) platform, the journal features a robust suite of author and reader services, as well as an immediate reader/subscriber base including almost 16,000 MRS members and over 2,500 academic, industrial and government libraries worldwide.

Major article types for MRS Communications include:

\section{Research Letters \\ Ultra-Rapid Communications \\ Prospectives Articles \\ Editorials \\ Commentaries}

Correspondence

Prospectives Articles are a unique feature of this journal, offering succinct and forward-looking reviews of topics of interest to a broad materials research readership. For more information about the journal and/or these major article types, visit www.mrs.org/mrc or email mrc@mrs.org.
Manuscripts are solicited in the following topical areas, although submissions that succinctly describe groundbreaking work across the broad field of materials research are encouraged.

- Biomaterials and biomimetic materials

- Carbon-based materials

- Complex oxides and their interfaces

- Materials for energy storage, conversion and environmental remediation

- Materials for nanophotonics and plasmonic devices

- Theory and simulation of materials

- Mechanical behavior at the nanoscale

- Nanocrystal growth, structures and properties, including nanowires and nanotubes

- Nanoscale semiconductors for new electronic and photonic applications

- New materials synthesis, templating and assembly methods

- New topics in metals, alloys and transformations

- Novel and in-situ characterization methods

- Novel catalysts and sensor materials

- Organic and hybrid functional materials

- Quantum matter

- Surface, interface and length-scale effects on materials properties

For manuscript submission instructions, please visit www.mrs.org/mrc-instructions. 
PhD Student Positions

In-Situ Transmission Electron Microscopy (TEM)

Three PhD positions are available for graduate students to conduct a joint research program on in-situ TEM of energy materials at the University of Illinois at Chicago (UIC) and Michigan Technological University (MTU). The students will be admitted to the Department of Mechanical Engineering at Michigan Technological University and will have the opportunity to spend two or three years of their PhD research program at the University of Illinois at Chicago to use the new ARM 200CF STEM with CS Aberration Corrected and EELS/EDS capabilities.

Qualifications: Outstanding students with interests and background on transmission electron microscopy characterization of nanomaterials are encouraged to apply. Students who have previous research experience on electron microscopy of MetalInsulator Transition, Piezoelectric Energy Harvesting, Thermoelectrics, and Li-ion Batteries are also encouraged.

How to Apply: An interested student should send CV, sample publications, and contact information for three references to rsyassar@uic.edu and reza@mtu.edu. For submission, please merge all the files into a single PDF file.

Closing Dates: The positions are available starting summer 2012, fall 2012, or spring 2013. The applications will be reviewed in the order that they are received until the positions are filled.

EOE/AA Employer QTPCingentes C UNIVERSITY OF ILLINOIS
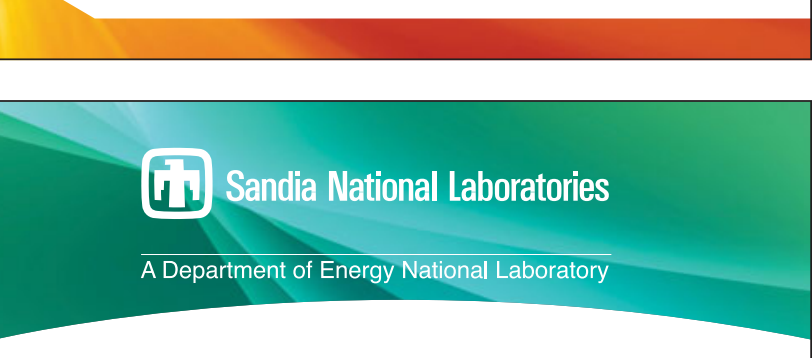

Postdoctoral Appointee Polymer Science/Soft Matter

Sandia National Laboratories is the nation's premier science and engineering lab for national security and technology innovation with major facilities in Albuquerque, New Mexico and Livermore, California. We are a world-class team of scientists, engineers, technologists, post docs, and visiting researchers all focused on cutting-edge technology, ranging from homeland defense, global security, biotechnology, and environmental preservation to energy and combustion research, computer security, and nuclear defense. To learn more, please visit our website at www.sandia.gov. We are searching for a Post Doc Appointee-Polymer Science/Soft Materials, for the Center for Integrated Nanotechnologies (CINT) Science Department for the Albuquerque facility. A benefit and relocation package is available.

The Center for Integrated Nanotechnologies (CINT) at Sandia National Laboratories is searching for a driven postdoctoral appointee to perform leadingedge research designing and synthesizing block copolymers for the development of novel materials. This work supports projects that explore the integration of functional molecules and nanoparticles into robust synthetic matrices to create complex hierarchical structures for responsive and reconfigurable materials. These multidisciplinary projects involve chemists, biologists, physicists, and encompass both experiment and modeling.

Please apply online at http://www.sandia.gov/careers/search-openings.html, click Search for Openings, and reference Job ID Number 640146. U.S. Citizenship normally required.

L O C K H E E D M A R TIN

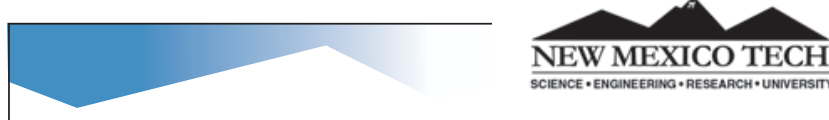

\section{FACULTY POSITIONS \\ Materials and Metallurgical Engineering Department}

The Materials and Metallurgical Engineering Department at New Mexico Tech has openings for two tenure-track faculty positions at the assistant or associate level beginning August, 2012. Exceptional candidates with leadership skills will also be considered for a full professor position. We invite applications from any field of materials science and engineering with emphasis on the following topics: (a) advanced processing of materials for structural and/or other multifunctional applications, and (b) materials in the area of bioengineering. Both topics may address structure and behavior at any length scale (nano to bulk or multiscale). Interdisciplinary research is particularly encouraged. The Materials Department offers bachelor's through doctoral degrees, and the selected candidates are expected to demonstrate excellence in both teaching and research that include graduate and undergraduate students.

Applications must include a cover letter, current resume including list of publications, a summary of research interests, and teaching interests/ philosophy, plus at least three references. This position will remain open until filled, but candidates are encouraged to apply by May 30, 2012 for full consideration. Apply to: New Mexico Institute of Mining and Technology, Human Resources, 801 Leroy Place, Brown Hall, Box 023, Socorro, NM 87801. Questions regarding this position may be directed to Dr. Nikolai Kalugin at nkalugin@nmt.edu. For further information about New Mexico Tech and Socorro, New Mexico, go to our website at www.nmt.edu.

New Mexico Tech is an Equal Opportunity/Affirmative Action Institution
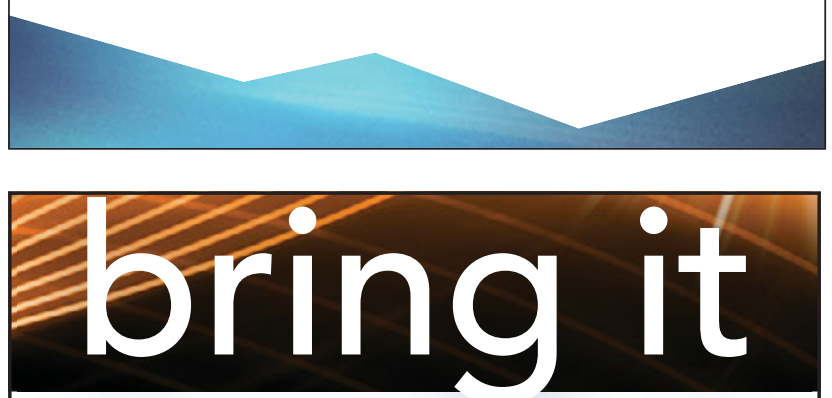

Your talent. Your knowledge. Your imagination. Your best.

At Automotive Fuel Cell Cooperation, our talented team is driven to be the best in our field, developing ground-breaking fuel cell technology that will make the world a better place to live.

Be part of our team, as a:

- Senior Research Catalyst Scientist/Engineer

- Senior Systems Engineer

- Unit Cell Engineer

Based in Vancouver, BC, we are gathered from around the world to create solutions for fuel cell and zero-emission automotive power trains. Our challenging, team-focused environment helps us to take our creativity and vision far, achieving excellence at every level.

This is the place to be for the zero-emission revolution-together we can tell the next generations: we were there.

To learn more and to apply online, please visit the Careers page on our website.

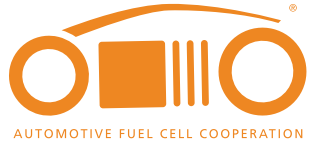




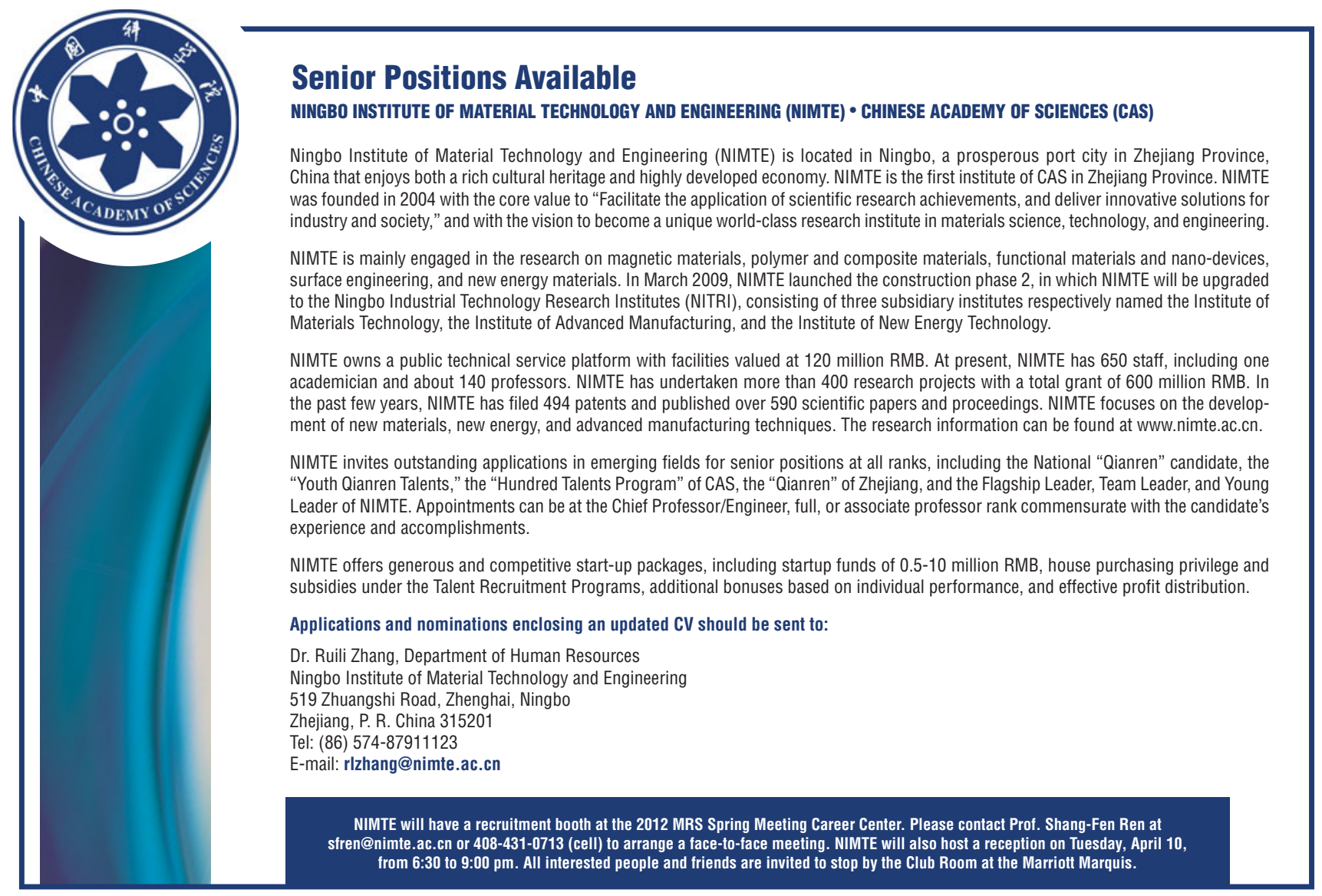

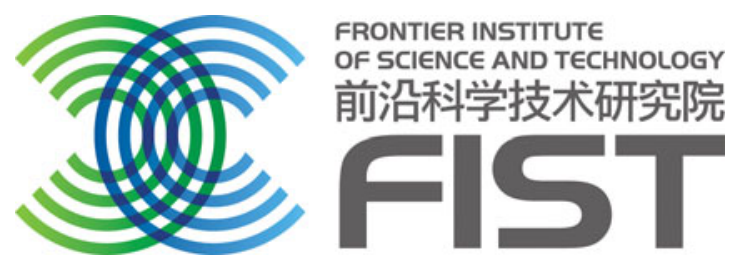

FIST is a large selective investment by XJTU in an effort to establish a world-class, multi-disciplinary research institute. To achieve this goal, FIST is setting up 14 research centers of excellence in Mathematics, Physics, Chemistry, Bio-Science/Life-Science/Basic-medical-Science, and Materials Science, and adopts a new management system similar to that of most U.S. universities. Seven out of the 14 planned centers have been established recently, and FIST is now recruiting the remaining seven Center Directors (either full-time or honorary). In addition, FIST invites applications to fill its multiple, full-time tenure-track faculty positions at all levels (from lab director to group leader), as well as postdoctoral positions. See our Chinese ad at http://fist.xjtu.edu. $\mathrm{cn} /$ show.php?id=40 for details.

An eligible candidate for the Center Director position should be an internationally renowned scientist and established leader in his/her field, with the ability and will to build his/her center into an internationally recognized center of excellence. Successful candidates will be provided with a sizable start-up package to establish a research center, together with a salary $(500 \mathrm{k}-800 \mathrm{k}$ RMB annually for full-time directors) or an honorarium commensurate with the working days (for honorary directors). See our Chinese ad at http://fist.xjtu.edu.cn/show.php?id=40 for details.

In addition to the Center Director positions, FIST also invites applications in the above-mentioned areas to fill its full-time, tenure-track faculty positions at all levels, from lab director to group

\section{CENTER DIRECTORSHIPS/TENURE-TRACK FACULTY POSITIONS/POSTDOCTORAL RESEARCH FELLOWS}

Frontier Institute of Science and Technology (FIST)

Xi'an Jiaotong University (XJTU)

Valid through June 30, 2012

leader. Applications for postdoctoral positions are also welcome. An eligible faculty candidate should have a track-record for excellence in research and the potential to lead a lab or a group to success. Successful candidates will be provided with a competitive start-up package including an annual salary of $100 \mathrm{k}-500 \mathrm{k}$ RMB, a $15-200 \mathrm{~m}^{2}$ lab space, and enough start-up funds, together with many other benefits. Position level and start-up package will vary with the candidate's qualification. See our Chinese ad at http://fist.xjtu.edu.cn/show.php?id=40 for details.

Interested individuals should set up their free ResearcherID webpage on http://www. researcherid.com. Please send your ResearcherID citation information along with a cover letter, $\mathrm{CV}$, and a list of ten representative publications to:

Dr. Xiangli Meng

Frontier Institute of Science and Technology (FIST)

Xi'an Jiaotong University

1 West Building, 99 Yanxiang Road

Yanta District, Xi'an, Shaanxi Province

P.R. China 710054

Tel/Fax: +862983395131

Email: fist@mail.xjtu.edu.cn 


\section{MRSBulletin}

EDITORIAL OFFICE 506 Keystone Drive, Warrendale, PA 15086-7573 USA

Bulletin@mrs.org tel 724.779.2747 fax724.779.8313 www.mrs.org

\section{Materials}

\section{for sustainable}

development

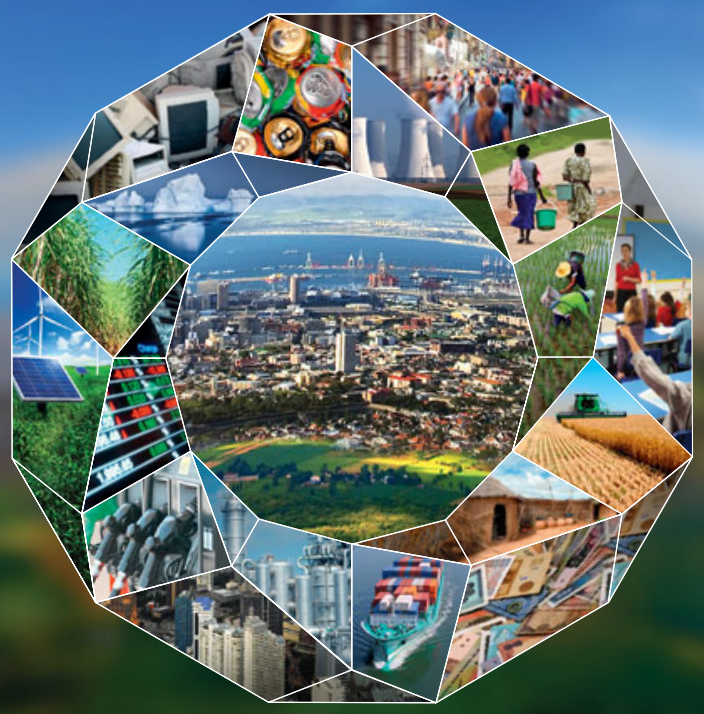

SPECIAL ISSUE

April 2012 Vol. 37 No. 4

www.mrs.org/bulletin

\section{SPECIAL THANKS}

This issue of MRS Bulletin, "Materials for sustainable development," was funded in part by:

\section{AALDFILCH}

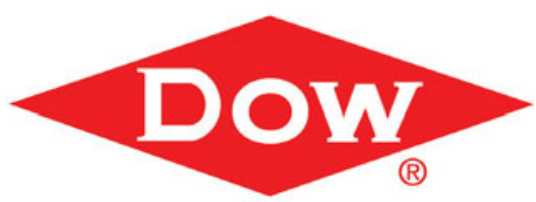

This special issue is the result of much intense work by a large international group of dedicated people, led by the MRS Bulletin Materials for Sustainable Development Organizing Committee and the MRS Bulletin Editorial Board.

\section{MATERIALS FOR SUSTAINABLE DEVELOPMENT ORGANIZING COMMITTEE}

Martin L. Green (Chair), National Institute of Standards and Technology, USA

Eric J. Amis, United Technologies Research Center, USA

Joseph J. Berry, National Renewable Energy Laboratory, USA

David Cahen, Weizmann Institute of Science, Israel

Laura Espinal, National Institute of Standards and Technology, USA

Rodney C. Ewing, University of Michigan, USA

Thomas E. Graedel, Yale University, USA

Igor Lubomirsky, Weizmann Institute of Science, Israel

Christina Meskers, Umicore Precious Metal Refining, Belgium

Enrico Traversa, Xi'an Jiaotong University, China; University of Rome, Italy

The Many Authors and Reviewers

The MRS Bulletin Editorial Board (Paul S. Drzaic, Chair) 


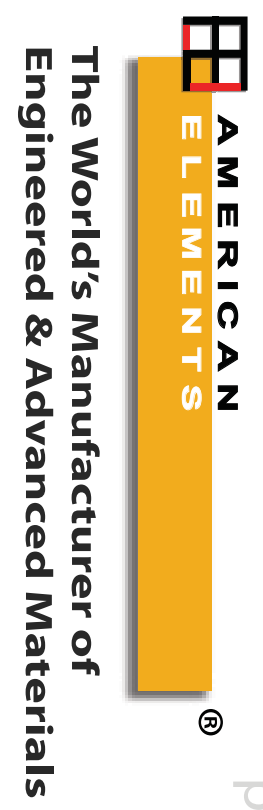

\begin{tabular}{|c|c|}
\hline 검 & ? \\
\hline $\mathbb{J}$ & ? \\
\hline c & $z$ \\
\hline$z$ & ${ }^{7}$ \\
\hline Ð & $\stackrel{\infty}{3}$ \\
\hline 3 & m \\
\hline$\stackrel{\Omega}{\beta}$ & 을 \\
\hline 宓 & 검 \\
\hline ? & \& \\
\hline 䍐 & I \\
\hline$\frac{T}{3}$ & m \\
\hline$\frac{3}{2}$ & $\bar{\beta}$ \\
\hline$z$ & $\delta$ \\
\hline 5 & E \\
\hline
\end{tabular}

\begin{tabular}{|c|c|c|c|c|c|c|}
\hline 국 & \& & $\frac{\partial}{\sigma}$ & $\pi$ & 2 & ㄷ. & $x$ \\
\hline קె & 罚 & $\mathscr{P}$ & 8 & 3 & $\underset{D}{\mathbb{D}}$ & \\
\hline
\end{tabular}

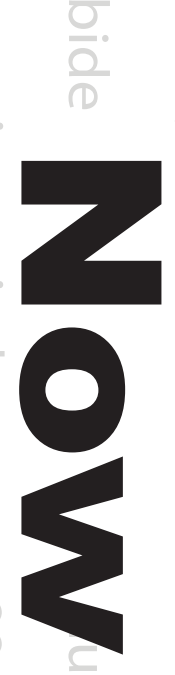

ค

忍 $\mathbf{7}$ 士

뭉 항

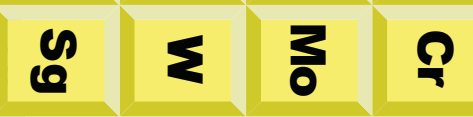

肎

采

3 ᄀ

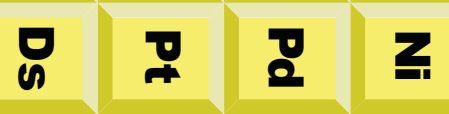

ह

$\stackrel{9}{\mathrm{~g}} \stackrel{\mathrm{N}}{\mathrm{g}}$

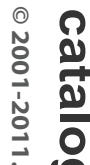

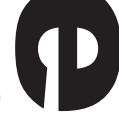

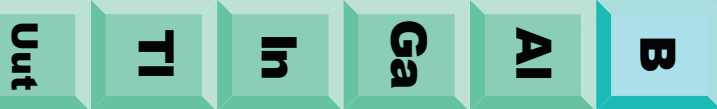

(은

空

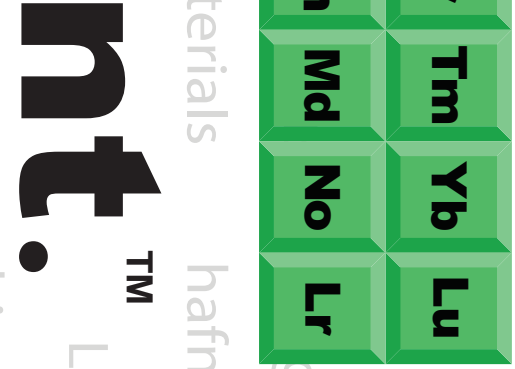

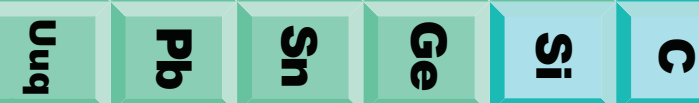

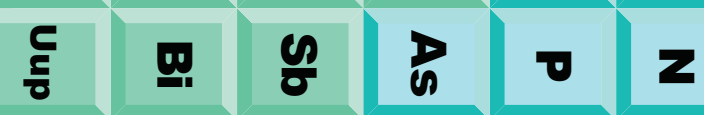

\begin{tabular}{ll|llll}
5 & 0 & $A$ & क & क & 0
\end{tabular}

\begin{tabular}{|c|c|c|c|c|}
\hline 喜 & - & 畀 & ㅇ & ד \\
\hline , & 爻 & 족 & $\stackrel{P}{2}$ & $\frac{z}{0}$ \\
\hline
\end{tabular}

